


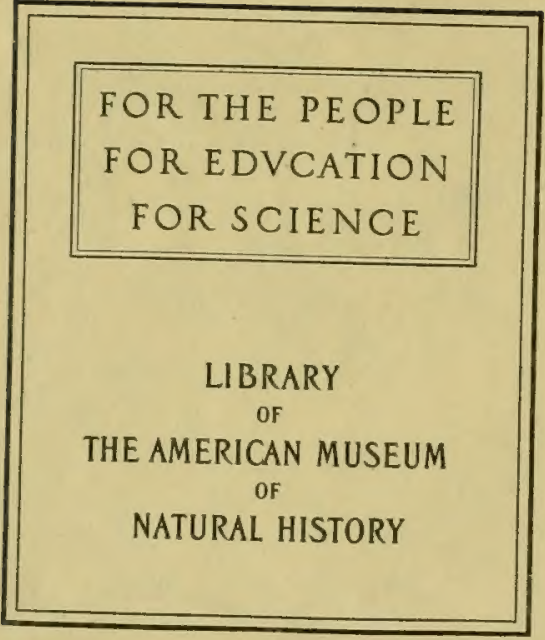




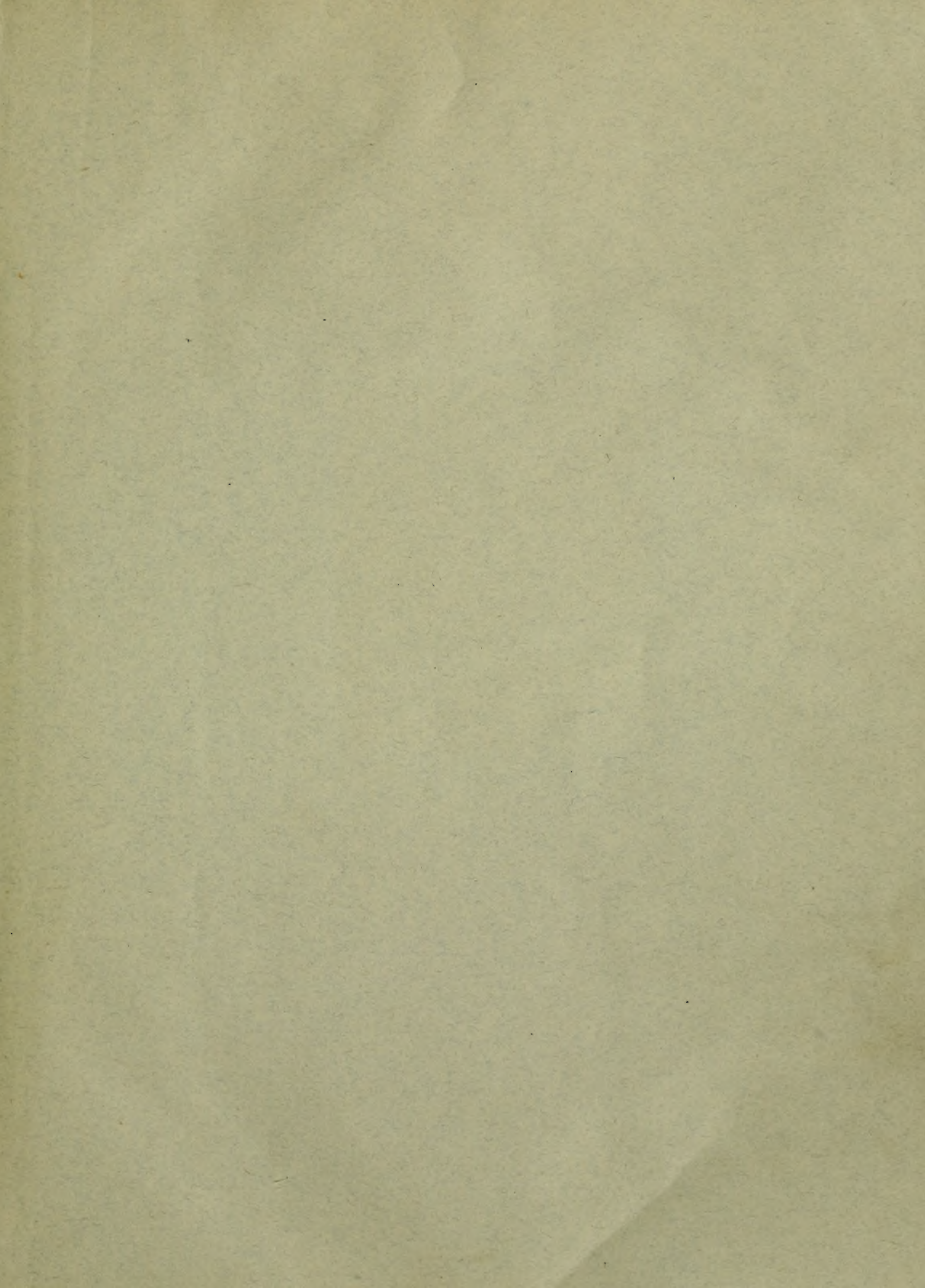






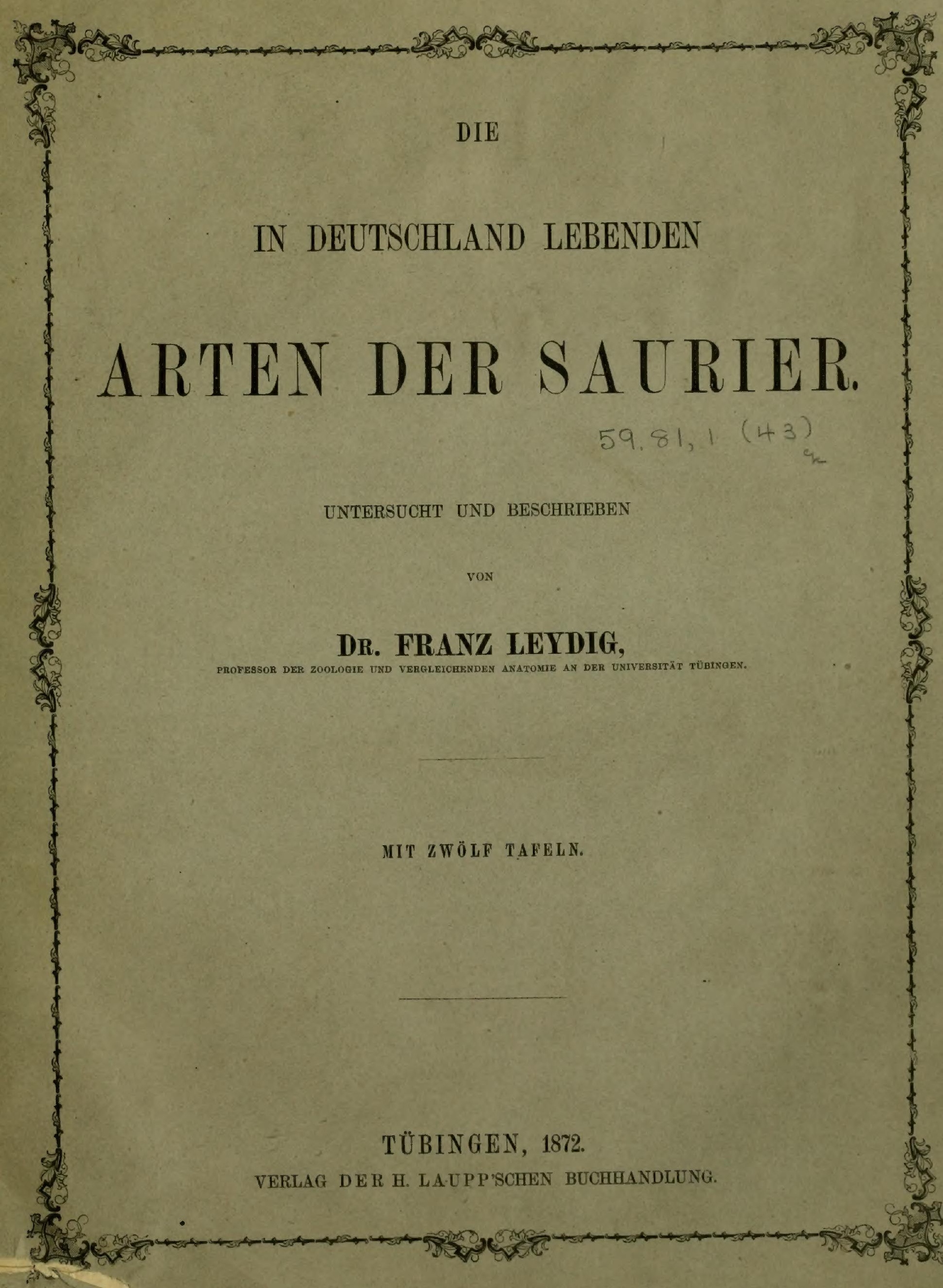


DIE

IN DEUTSCHLAND LEBENDEN ARTEN DER SAURIER. 

DIE

\section{IN DEUTSCHLAND LEBENDEN}

\section{ARTEN DER SAURIER. si, an: $(4,9)$}

UNTERSUCHT UND BESCHRIEBEN

VON

\section{DR. FRANZ LEYDIG,}

PROFESSOR DER ZOOLOGIE UND VERGLEICHENDEN ANATOMIE AN DER UYIVERSITÄT TÜBIXGEN.

MIT ZWÖLF TAFELN.

TÜBINGEN, 1872.

VERLAG DER H. LA UPP'SCHEN BUCHHANDLUNG. 
$21 \cdot 84476-2, \operatorname{rim} 5$

○)

MBUCK VUA II. IA A P P IN TL DINGEN. 


\section{Inhalts - Verzeichniss.}

Einleitung

Erster Abschnitt.

Zur Kenntniss des anatomischen Baues.

I. A eusere $\mathrm{Haut}$

Eidechsen

Oberhaut

Lederhaut

Blindschleiche

Oberhaut

Lederhaut

II. M u s kels y $\mathrm{t}$ e m

III. Skelet

Blindschleiche

Primordialschädel

Knochen des fertigen Schädels

Wirbelsiaule

IRippen

Brustboin

Schulterknochen

Beckenknochen

Eidechsen

Knochen des Schüdels

Verknöcherte Schädelhaut. •
Bleibende Theile des Primordialschädels

Virheltheoric des Schïdels

Wirbelsäule

Rippen

Brusthein

Schulterknochen

Vordergliedmassen

Becken

Hintergliedmassen

Anhan $\mathrm{ng}$. Brechbarkeit und Wiedererzeugung des Schwanzes _. . . . . . . 64

IV. Nervensystam

V. Sinnesorgane

Auge

Skleri

Kamm der Choroidea; Linse

Oln

Nebenorgane des Augapfels

bei der Eidechse

bei rler Blindschleiche 
Nase

Aeussere Nase oder Vorhöhle

Innere oder eigentliche Nase

Jacobson'sche Organe

Organe eines sechsten Sinnes

VI. Verdaung sorgane

Zähne

Eidechsen

Blindschleiche

Eizahn .

Speicheldrüsen

Eidechsen

Blindschleiche

Zunge

Eidechsen

Blindschleiche

Darmrohr

Eidechsen

Blindschleiche

Leber .

Bauchspeicheldrüse und $\mathrm{Milz}$

Eidechsen

Blindschleiche

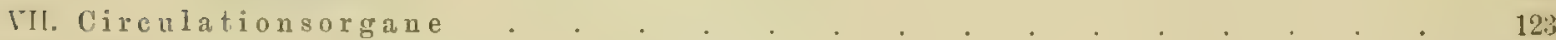

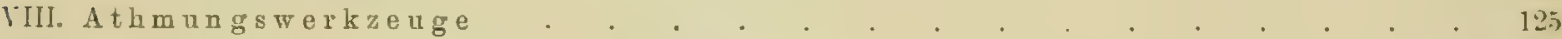

I. Harntwerkeuge . . . . . . . . . . . . . . . . . . . . . . . .

Eidechsen . . . . . . . . . . . . . . . . . . . . . .

Blindschleiche . . . . . . . . . . . . . . . . . . . . . . . . . . . . .

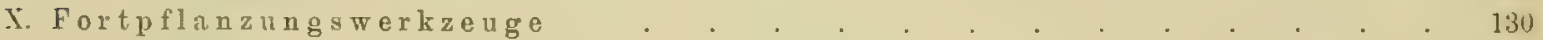

Eidechsen . . . . . . . . . . . . . . . . . . . . . . . . . .

Eierstock . . . . . . . . . . . . . . . . . . . . . . . . . . . . . . .

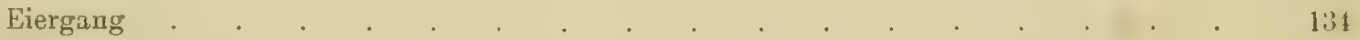

Eischale . . . . . . . . . . . . . . . . . . . . . . . .

Hoden- und Samengang . . . . . . . . . . . . . . . . . . . . . . . . .

Ruthen . . . . . . . . . . . . . 14.

Blindschleiche . . . . . . . . . . . . . . . . . . . . . . . 149

Weibliche Organe. . . . . . . . . . . . . . . . . . . . . . . . .

Mäunliche Organe . . . . . . . . . . . . . . . . . .

Zweiter Abschnitt.

Zur Kenntuiss der Lebenserscheinungen.

I. Nervenleben

Eidechsen

Bliudschleiche

II. B e weg un

III. Nahrung

Eidechsen

Bemerkung über Koprolithen

Blindschleiche 


\section{VII}

Art Lacerta viridis

Kennzeichen

Bemerkungen . . . . . . . . . . . . . . . . . . . . . . . . . . . . . .

1. Farbe . . . . . . . . . . . . 1 , ?

2. Schädel und Zähne . . . . . . . . . . . . . $1<1$

Vorkommen . . . . . . . . . . . . . . . . . . . . . . . . . . . . .

Geschichtliches und Kritisches . . . . . . . . . . . . 144

2. Art. Lacerta agilis . . . . . . . . . . . . . . . . . . . . . . . . . .

Kennzeichen . . . . . . . . . . . . . . . . 197

Bemerkungen . . . . . . . . . . . . . . . . . . . . . . . . . .

1. Farbe . . . . . . . . . . . . . . . . . . $19 x$

2. Schilder und Schuppen . . . . . . . . . . . . . 20:;

3. Schädel und Zähne . . . . . . . . . . . . . 201

Vorkonmen . . . . . . . . . . . . . . . . . . . . . 204

Geschichtliches und Kritisches . . . . . . . . . . . . . 111

3. Art. Lacerta vivipara . . . . . . . . . . . . . . 212

Kennzeichen . . . . . . . . . . . . . . . . . . . 218

Bemerkungen . . . . . . . . . . . . . . . . . . . 211

1. Grösse und Farbe . . . . . . . . . . . . . 211

2. Beschuppung . . . . . . . . . . . . . . 216

3. Schädel und Zähne . . . . . . . . . . . . . . . . . . . . . . . . . . .

Vorkommen . . . . . . . . . . . . . . . . . . . 11

Geschichtliches und Kritisches . . . . . . . . . . . . . 22.2

4. Art. Lacerta muralis . . . . . . . . . . . . . . 225

Kennzeichen . . . . . . . . . . . . . . . . 22\%

Bemerkungen . . . . . . . . . . . . . . . . . . . . . . . .

1. Farbe und Varietäten . . . . . . . . . . . . 2. . . .

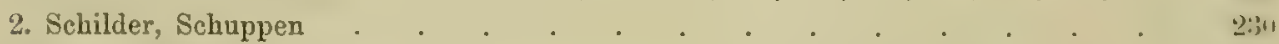

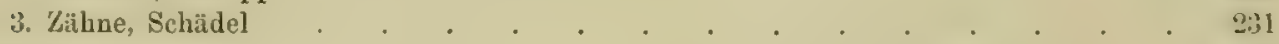

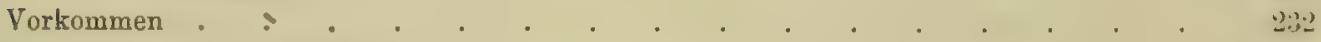

Geschichtliches und Kritisches . . . . . . . . . . . . . . . 2 2:"

Anhang. Die gegenseitige Verwandtschaft der einheimischen Arten . . . . . . . .

Familie der Scinke . . . . . . . . . . . . . . . . . . . . . . . . . . . . . . . . . . . .

Gattung: Anguis . . . . . . . . . . . . . . . 243

Art: Anguis fragilis . . . . . . . . . . . . . . . 21.2

Kennzeichen . . . . . . . . . . . . . . . . . . 313

Bemerkuugen . . . . . . . . . . . . . . . 241

1. Furbe . . . . . . . . . . . . 214

2. Kopfschilder . . . . . . . . . . . . . . . . 2410

3. Schädel und 7ähne . . . . . . . . . . . . 2 . . . . . . . . . .

Vorkonmen . . . . . . . . . . . . . . . . 217

Geschichtliches und Kritisches . . . . . . . . . . . . 219

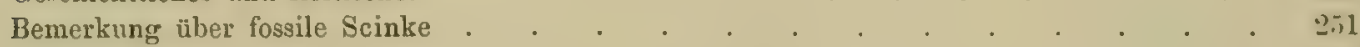

$\mathrm{Nachtrage} \mathrm{.} \mathrm{.} \mathrm{.} \mathrm{.} \mathrm{.} \mathrm{.} \mathrm{.} \mathrm{.} \mathrm{.} \mathrm{.} \mathrm{.} \mathrm{.} \mathrm{.} \mathrm{.} \mathrm{.} \mathrm{.} \mathrm{.} \mathrm{.} \mathrm{.} \mathrm{.} \mathrm{.} \mathrm{.} \mathrm{.} \mathrm{.} \mathrm{.} \mathrm{.} \mathrm{.} \mathrm{.}$

Erklärung der Abbilduggen. 
<smiles>C1CC1</smiles>

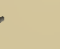




\section{Einleitung.}

Die Reptilien stellen nach ihrem Bau, Entwicklung und verwandtschaftlichen Verhältnissen, sowie in Anbetracht der Lebensäusserungen, der Verbreitung, endlich durch die Rolle, welche sie in frühern Weltaltern spielten, eine sehr eigenartige und merkwürdige Gruppe von Thieren dar; sie haben desshalb seit Langem eine besondere Anziehung auf die Naturforscher ausgeübt, wovon zahlreiche Schriften Zeugniss ablegen. LINNÉ zwar konnte noch sagen: Amphibiologi omnium paucissimi, aber im Augenblicke möchte es kaum mehr zulässig erscheinen, das an's Licht Treten einer neuen Arbeit mit der Bemerkung begründen zu wollen, dass die Reptilien weniger erforscht seien, als andere Abtheilungen der Thierwelt. Mir selbst gewährte schon zu wiederholten Malen die Beschäftigung mit dieser Classe Belehrung und Vergnügen; und wenn ich in den letztern Jahren von Neuem zum Studium der Reptilien zurückgekehrt bin, so hat mich einigermassen die Ansicht geleitet, welche DE CANDOLLE für die Botanik ausgesprochen hat, und welche in gleicher Weise für die Zoologie gilt: L'objet essentiel de la botanique est, et sera toujours, de connaitre les plantes. Hauptaufgabe des Zoologen bleibt die Bekanntschaft mit den Einzelheiten des Thatsüchlichen; von da mag er zu verknüpfenden, allgemeineren Betrachtungen übergehen.

Man kann aber jene wunderbaren Naturkörper, welche wir Organismen nennen, nicht genau genug kennen lemen und jeder derselben, sei er auch noch so oft untersucht, bietet dem Forscher, welcher mit einer neuen Frage herantritt, oder von einem neuen Gesichtspunkt das Auge darauf richtet, Stoff zum Nachdenken und kann seine Vorstellungen vom Zusammenhang und der Ausgangequelle der Erscheinungen - in so weit diess überhaupt möglich oder erreichbar ist - klären und befestigen. Und so sollen vorliegende Blätter die deutschen Arten der Saurier in eingehender Weise vorführen, nicht nur in Bezug auf die ansseren Charaktere und das Vorkommen, sondern auch mit Rücksicht des inneren, gröberen und feineren Baues.

Die Unterscheidung und Naturgeschichte der einheimischen Lacerten, jenes "genus elegantissimum" nach dem Ausdruck von PALLAS, wurde schon oftmals für eine 
dunkle Partie der Herpetologie erklärt, - hatte doch schon Linnḱ die Diagnose der Amphibien überhaupt "difficilis et ambigua“ genannt - und selbst Schriften von jüngster Zeit, Handbücher sowohl wie faunistische Aufzählungen, verrathen hin und wieder, dass eine richtige Kenntniss unserer Arten und ihrer Verbreitung viel weniger allgemein ist, als sich solches im Hinblick auf die übrigen Wirbelthiere der vaterländischen Fauna sagen lässt.

Die anatomischen und histologischen Studien erstrecken sich freilich nicht in gleichmässiger Weise über alle organischen Systeme. Denn obschon ich mehrere Jahre lang fast ausschliesslich alle meine freie Zeit diesen Untersuchungen gewidmet habe, so war es doch unmöglich den Stoff in dieser Frist zu bewältigen; noch auf lange Jahre hinaus würden die wenigen bei uns lebenden Thiere reichlichstes Material darbieten. Ich habe eines Tages mit Absicht und einfach abgebrochen; hoffe jedoch in späteren Arbeiten an Manches wieder anknüpfen und die Untersuchung weiter führen zu könnén.

Es wäre äberhaupt zu wünschen, dass alle unsere Wirbelthiere in ähnlicher Weise wissenschaftlich behandelt würden, wie solches seit Längerem bezüglich gewisser Abtheilungen der Wirbellosen gebräuchlich geworden ist. Anstatt einfacher Namensverzeichnisse mit kurzen Bemerkungen über Vorkommen und Lebensweise sollten sie Aufschlüsse über das ganze Thier zu geben sich bemühen.

Es ist eine herkömmliche Redensart von dieser und jener Wissenschaft, um sie herauszuheben, zu sagen, dass sie sich von einer anderen Disciplin abgelöst habe, und zu einem selbstständigen Zweig ausgewachsen sei, der jetzt für sich blühe. So sprach man früher von der vergleichenden Anatomie gegenüber der Anatomie des Menschen, ebenso von der Geweblehre. Man kann dieser Auffassung beipflichten, in so lange es sich um das Wachsen des Zweiges handelt, um dis Herbeischaffen des Rohmateriales; wenn aber der "selbststïndig gewordene" Wissenschaftszweig, um im Gleichniss zu bleiben, wirklich zum Blühen kommt, werden die Früchte nicht nur im Wesentlichen dieselben sein, wie an den anderen Zertheilungen des Baumes, sondem sie werden auch, indem sie reif zu Boden fallen, wieder zum Ausgangspunct, zur Wurzel, sich neigen.

Darum lässt sich von einem Fache des Wissens nur dann rühmen, dass es eine höhere Ausbildung erreicht habe, wenn es sich seiner Verwandtschaft und innigen Zusammenhanges mit anderen Disciplinen bewusst geworden ist. Und so haben Zootomie und Histologie in der T'hierkunde oder Zoologie aufzugehen; wals in der Haltung, welche fammistische Arbeiten der Neuzeit amnehmen, den entsprechenden Ausdruck finden mag. 
Anmerkung. Die Kenntniss über die einheimischen Reptilien lag noch im Anfang gegenwärtigen Jahrhunderts so in der Dämmerung, dass man in den deutschen Alpengegenden dazumal Eidechsen von der Grösse kleiner Alligatoren gesehen und geschossen haben will. Und wir finden solche Angaben in den Werken geachteter Naturforscher. Als ein Beispiel mag der Landshuter Botaniker ScnuLTes genannt sein, welcher in seinen ${ }_{n}$ Reisen durch Oberösterreich, 1809", gelegentlich der Bësteigung des Dachsteins (S. 109) anführt, dass in jenen Gegenden deș Salzkammergutes Bären noch vorbanden seien, auch Wülfe und Luchse, sowie Lümmergeier, „endlich Eidechsen von seltener Grösse, die kleine Alligators sind". In einer Anmerkung kommen genauere Aussagen hinsichtlich der Grösse, Dicke, Form, selbst von Skelettheilen! - Auch noch später spucken in wissenschaftlichen Schriften ähnliche Erzählungen. Der bekannte Zoolog Mrciauelles z. B. schreibt in die Isis 1830, (S. 190) sein Freund Dr. Scrinz theile ibm brieflich aus Zürich mit, dass man am Fusse des Jur: ein von Raubrögeln theilweise angefressenes, 2 Fuss langes, zweibeiniges, molchartiges Tbier gefunden und nach Solothurn gebracht habe." Mrchaueldes gibt sich der Hoffiung hin, dass wir hierin einen grossen Siren in Europa besitzen etc.

Wenn man sich nicht für berechtigt halten will, die obigen Angaben rom so späten Vorkommen riesiger Eidechsen in den Alpen kurzweg als leere Träumereien zu bezeichnen - und ich wäre freilich geneigt es zu thun -, so könnte man von zwei Seiten her eine Erklärung versuchen. Einmal liesse sich an die grossen Fische denken, welche in früheren, für die See'n und ihre Bewohner noch ruhigeren Zeiten, in diesem und jenem Alpeusee mitunter gefangen wurden, wie wir deren Porträte in Oelfarben, z. B. im Jagdschloss zu St. Bartholomiii des Königsee's beschauen können. Dieser Auffassung bringt gleich die Thatsache Einbusse, dass gewisse Lacerten nur im warmen Süden grüssere Maasse aunehmen, nicht aber in kalten Gegenden. Setzen wir anstatt Lacerta die Gattung Salamandra - und der Molch stimmt auch besser zu den fraglichen Oertlichkeiten nach seiner ganzen Natur — so könnte der Einwurf abgeschwächt werden; denn der gefleckte Salamander soll nach ScHREIBERs im nassen Lehm Jahre lang unterhalten zu Riesenexemplaren heranwachsen.

Ein zweiter Erklärungsversuch, der allerdings noch gewagter ist, könnte an die Toraussetzung anknüpfen, dass dic Geschlechter der grossen Saurier der Vorzeit doch wohl nicht alle auf einmal von der Erde weggefegt wurden, sondern walrscheinlich nach und nach erloschen. Die Menschen mochten so da und dort noch auf einzelne derselben gestossen sein und es hätte sich bei dem Eindruck, den solche Thiere auf den Naturmenschen machen mussten, das Andenken an diese alten Saurier „im Spiritus der Sage" beinahe bis zu unsern Tagen erhalten. Und anstatt daher die Erzählungen der Alpenbewohner und SchuLTes' mit Lïcheln abzuweisen, hätten wir mit geistigem Auge noch etwas Thatsächliches zu erblicken, welches in den Tiefen der Vorzeit sich schattenhaft bewegt. 


\section{Erster Absehnitt. \\ Zur Kenntniss des anatomischen Baues.}

\section{Aeussere Hant.}

\section{Eidechsen.}

Oberhaut.

Die Epidermis grenzt sich nach aussen durch ein homogenes Häutchen, Cuticula, ab, welches an der freien Fläche nicht einfach glatt, sondern im Anschluss und in Wiederholung der darunter liegenden Zellenlinien von welliger Sculptur erscheint. Auf den kleinen Hautwarzen bildet sie wegen der Anordnung der Elemente der Epidermis zierliche Kreise, woraus sich auch die gezähnelte Beschaffenheit an den Umschlagsstellen erklärt.

Die Zellen, welche die Epidermis zusammensetzen, sind in ihrer unteren Lage hell und meist von cylindrischer Form; in einer darüber folgenden Lage besitzen sie einen fettkörnigen Inhalt und diese Schicht zeigt sich als Ganzes eigenthümlich dunkel.

Die Epidermis ist, was ich bereits an einem anderen Ort mittheilte und weiter ausführte, da und dort pneumatisch oder lufthohl. An manchen Körperstellen, z. B. an den Lippen und der übrigen Gegend des Gesichts nur spurweise, deutlicher an den Rändern der Bauchschuppen, wo der Luftgehalt für die Betrachtung mit auffallendem Licht am Rand der Schuppe einen regelmässigen Silberstreifen erzeugt. ")

Wie auch sonst in der Thierreihe nimmt die Oberhant in ihrer Dicke nach gewissen Körpergegenden zu, so dass man von Hornplatten und Hornschuppen reden kann. Die dicksten und härtesten Hornbildungen sind die Scheiden für die Lúrallenglieder; sie entsprechen einem dachfürmig zusammengedrückten Nagel, ohne dass sich die Runder durchweg erreichen, wesshalb denn auch unten die Kralle eine Rinne behält. ${ }^{2}$ ) Ferner ist, was ein Längssschnitt durch den Kopf gut zeigt, die Epidermis

1) Ueber Organe eines sechsten Sinnes, Nov. Act. Acad. Leopold. Carol. 1868, z. B. S. 73.

`) Erste Tafel, Fig. 13. 
um das stumpfe Ende der Śchnauze herum ron besonderer Dicke, in Uebereinstimmung mit der darunter liegenden Lederhaut, welche gleichfalls dort an Stärke zugenommen hat.

Pigment kommt in der Epidermis nur sparsam vor und zwar nach Umständen entweder von der Form kugliger, dicht schwarzer Flecken, oder weit und zierlich verüstelter Pigmentfiguren; diese haben die Bedeutung beweglicher Farbzellen oder Chromatophoren.

Bei der Häutung, welche von Zeit zu Zeit insbesondere im Frühling eintritt, spaltet sich die Epidermis meistens hinter dem Kopf, in Nacken, und der Längsschlitz erstreckt sich über den Rücken abwärts. Doch reisst auch wohl ein andermal die Oberhaut von hinten nach vorn auf, und selbst nicht einmal immer am Rüeken, sondern der erste Schlitz kann am Bauche geschehen, ein Wechsel, welcher vielleicht von heftigen, zufälligen Bewegungen abhängt. Das in der Häutung begriffene Thier gewährt, indem es zwar noch in der alten, aber zu grossen Lappen aufgerissenen, Epidermis steckt, einen seltsamen, fast komischen Anblick.

Lederhaut.

Das Bindegew ebe der Lederhaut zerfällt auch hier in gleicher Weise, wie ich es vor Kurzem ${ }^{1}$ ) von der Haut der Amphibien nachwies, in drei Hauptschichten: in die Grundmasse und in zwei Grenzschichten. Die Grund- oder Hauptmasse besteht aus einer Anzahl derber, wagrechter Lagen. Die obere Grenzschicht, also diejenige, welche unter der Epidermis folgt und jene, welche die Haut nach unten abschliesst, sind weicher, lockerer und setzen sich in charakteristischer Weise, mitten durch die wagrechten Lagen, mittelst senkrecht aufsteigender Züge in Verbindung. Auch die Enden der Querlagen biegen in diese süulenartigen Bündel auf.

Doch ist zu bemerken, dass die Lederhaut ${ }^{2}$ ) der Eidechsen von jener der Amphibien in einem Puncte etwas abweicht. Es stehen nemlich die wagrechten Schichten, weil sie schmüler sind, dichter, und insbesondere sind die senkrechten Züge viel zahlreicher. Das mikroskopische Bild des senkrechten Schnittes erinnert durch die bogig wagrechten Linien, fortwährend unterbrochen durch die senkrechten Striche, lebhaft an den Durchschnitt gewisser Chitinpanzer, z. B. hartschaliger Käfer, welchem Gebilde ich denn auch vor vielen Jahren seine richtige Stelle beim Bindegewebe anwies.

Die obere Grenzschicht der Lederhant entwickelt einen bedeutenden Papillarkörper, ohne dass aber in der Zoologie dieser Name hiefür wäre bis jetzt ange-

8) Vergl. Siebente Tafel, Fig. 87, Fig. 88. 
wendet worden. Man spricht vielmehr von Körnern, Schuppen und Platten der Haut. Es erleidet aber wohl für Den, welcher die Dinge selbst geprüft hat, keinen Zweifel, dass alle diese Bildungen den Erhöhungen oder Würzchen zu vergleichen sind, in welche sich die Oberfläche der Lederhaut bei Säugethieren erhebt.

Man überzeugt sich hiervon, wenn man von Hautpartien ausgeht, allwo die Papillen noch klein sind, etwa von der Form niedriger rundlicher Warzchen, und eben das darstellen, was die systematische Zoologie „Körner" genannt hat. Dergleichen finden sich z. B. an den Augenlidern, sowie in der Fläche der Fusssohle; die einfache vergleichende Betrachtung findet, dass die Körner allmählig übergehen in das, was man Schuppen und Platten nennt, welche aber in der That die Eigenschaften grosser, niedergedrückter Papillen haben.

Die Richtigkeit dieser Auffassung kann auch einleuchten, wenn wir die Beschaffenheit der Oberfläche der Zunge berücksichtigen. Für die dort vorkommenden Erhöhungen hat der Sprachgebrauch immer das Wort: Papille, Zungenwärzchen, auch bezüglich der Eidechsen beibehalten. Indessen diese „Papillen“ kömnen bei manchen Arten so niedrig werden und zusammenrücken, dass der systematische Zoologe hin und wieder die Oberfläche der Zunge der Eidechsen als ,schuppig“ oder als "granulosa papillosa" bezeichnet.

Die Anordnung der "Schuppen" betreffend, 'so ist sie fast über den ganzen Körper weg, etwa den Kopf ausgenommen, eine ringförmige, was an Schwanze am meisten augenfällig und daher am gewöhnlichsten erwăhnt wird.

Dass der Ausdruck "Schuppe", wenn wir damit die Hautbelkleidung der Fische und dann wieder jene der Eidechsen und Schlangen im Auge haben, ganz verschiedene Dinge begreift, haben schon manche der älteren Naturforscher wohl gefühlt. Schrank z. B., indem er sich in seiner Fauna boica 1798, auf eine Zergliederung der Ringelnatter einlïsst, glaubt ausdrücklich daran erinnern zu müssen, dass die Schuppen bei einer Schlange "keine eingesetzten Schuppen" seien, wie bei den Fischen, sondern "Falten der zusammengelegten Haut", und führt dieses nach den damaligen Mitteln der Untersuchung weiter aus. Ich selbst erklärte mich schon vor Jahren (Histologie, 1857, S. 180) dahin, dass „die grösseren Höcker und Falten des Coriums bei Sauriern (Lacerta, Chamaeleo u. a.) in der Kategorie der Papillarbildungen unterzubringen seien." Achnliches findet sich bei Batrachiern, worauf ich auch noch jüngst in meiner Abhandlung über Organe eines sechsten Sinnes, 1868, S. 37 zurückgekommen bin, nachdem ich früher schon der Haut von Pipa dorsigera bezüglich dieses Punctes einige Aufmerksamkeit geschenkt batte.

Wie es für die Amphibien gesetzmässig ist, dass die Pigmente die derben, horizontal gehenden Lagen der Lederhaut frei lassen, um sich ansschliesslich in der oberen und unteren Grenzschichte, sowie in den beide verbindenden senkrechten Zügen, abzusetzen, so wiederholt sich Aehnliches bei den Reptilien: hier liegt ebenfalls die weitaus grösste Masse des Pigmentes in dem Papillarkörper. Man sieht dies schön und leicht an grösseren Hautstücken von Thieren, welche man etwa eine 
Woche lang in schwacher Kalilauge hat weichen lassen; und wiederum hesonders günstig sind diejenigen Hautstellen, wo die schuppigen Abgrenzungen nur in Form und Grösse rundlicher Papillen stehen. Das Bild gestaltet sich bei geringer-Vergrösserung so, dass auf dem ausgebreiteten Hautstück von einem hellen Grunde sich tief schwarze Höcker abheben.

Eigentlich ist gar nicht einmal das Mikroskop nöthig, um sich zu überzeugen, dass die Lederhant der Hauptsitz der Pigmente sei. Durch methodisches Maceriren wird hievon schon das freie Auge belehrt; denu bei allen unseren einheimischen Arten erscheint alsdann die Lederhant dunkel gefürbt, fast schwarz, während die Epidermis ein Häutchen von graulichem Ton bleibt.

Ueber die nähere Natur der Farlsstoffe, insoweit sie sich mit dem Mikroskop ermitteln lässt, habe ich bereits anderwärts berichtet, ${ }^{1}$ ) nachdem ich zuvor ausführlicher auf die Hautpigmente der Amphibien eingegangen war. ${ }^{2}$ )

Die Vertheilung der Nerven geschieht in ähnlicher Weise, wie es ron Batrachiern bekannt ist; und selbst in einem Puncte, auf den ich jüngst erst aufmerksam machte und welcher wohl von Bedeutung ist für das Zustandekommen der Farbenverinderungen, erblicke ich die gleichen Verhätnisse, - freilich unter besonderen Umstånden.

An einer Lacerta agilis nümlich, welche in sehr verdünnter Salpetersäure längere Zeit erweicht worden war, zerlegte sich die äussere Haut wie vou selbst in Epidermis, Pigmentschicht und eigentliche Lederhant. .In der gallertig anfgequollenen und durchsichtig gewordenen Lederhaut machte sich schon für die Lupe eiu schönes Nervennetz sichtbar, polygonale Maschen bildend. Aus den linotenpuncten erhoben sich grössere Büschel von Nervenfasern nach oben, feinere gingen noch da und dort ab. Indem die Fasern sich theilten und immer zarter wurden, entstand ein oberes Endnetz und aus diesem sah ich freie Ausläufer mit den Zacken der schwarzen Pigmentzellen oder ('hromatophoren sich verbiuden. ${ }^{3}$ ) In meiner zuletzt erwïhnten

1) Organe eines sechsten Sinnes. 1868, S. 74.

2) a. a. O. S. 30 .

s) Siebente Tafel, Fg. 97, B. 6. - Ich möchte nach der eben mir bekannt gewordenen Arbeit Scuöвl's (Die Flughaut der Fledermäuse, Archiv f. mikrosk. Anatomie, Octoberheft 1870.) beisetzen, dass die oben Endnetz genannte Maschenbildung der dritten Nervenschicht des genannten Beobachters entspricht. Ob auch hier bei Reptilien noch eine vierte und fünfte gleich denen der Fledermäuse hinzukomıt, wäre erst durch neue Nachforschungen zu ermitteln. Da übrigens Sçöв seine schönen Untersuchungen mit der Bemerkung einleitet, dass gegen meinen Ausspruch dio Flughaut der Chiropteren ausserordentlich reich an Nerren und Nervenendigungen sei, so lhat er damit den Gesichtspunet etwas verriickt. Cuvier glaubte ein bewunderaswerth reiches und feines Nerven-Netz im genannten Organ zu erblicken. Ich zeigte, dass dieses Netz nicht aus Nerven, sondern aus elastischen Fasern bestehe und im Hinblick hierauf durfte ich von den wirklichen Nerren sagen, dass dieselben *kaum zahlreicher seien 
Abhandlung spreche ich von zarten nervösen Endstreifen, welche mir in die Strahlen der Bindegewebskörper überzugehen scheinen; von der Richtigkeit dieses Verhaltens bin ich jetzt noch mehr überzeugt als früher.

Gegenüber den Verhältnissen, wie sie bei der Blindschleiche auftreten, verdient ausdrücklich bemerkt zu werden, dass die Lederhaut der Eidechsen im Allgemeinen wenige $\mathrm{Knochenbildungen} \mathrm{entwickelt.} \mathrm{Doch} \mathrm{kommen} \mathrm{am} \mathrm{Schädel} \mathrm{aller}$ Arten ächte Hautknochen vor, ganz abgesehen von jener den Scheitel des Kopfes deckenden Partie der Lederhaut, welche zu einer die dortigen Schädelknochen überziehenden Kruste verkalkt. Ueber beides wird unten beim Skelet nähere Auskunft gegeben werden.

Von besonderem Interesse ist es mir gewesen, eine Schicht welche die Natur der Lymphdrüsen an sich hat, unterhalb der Lederhaut aufzufinden. Ich bin zunächst damit bekannt geworden durch die Untersuchung einer stattlichen Lacerta ocellata, wo an der Innenseite der abgezogenen Haut eine Lage auffiel, welche weissgrau von Farbe, ein drüsiges Aussehen und eben solche Consistenz darbot. Die Schicht war über den grössten Theil der Haut verbreitet und stellenweise dicker als die Haut selber.

Bei der mikroskopischen Untersuchung ${ }^{1}$ ) zeigte es sich, dass das Bindegewebe, welches vorhin als untere Grenzschicht der Lederhaut bezeichnet wurde, mit einer feinkörnigen, zum Theil kleinzelligen Masse dicht erfüllt war. Ausserdem machten sich einzelne grössere Günge bemerklich; nach unten waren noch Lagen des Bindegewebes frei von der erfüllenden Körnermasse und dienten als Umhüllung.

Bei unserer Lacerta agilis erschien die drüsige Schicht sehr wenig entwickelt, ja war eigentlich nur in Spuren vorhanden, so z. B. am ehesten noch in der Haut hinter dem $\mathrm{Ohr}$ und wäre jedenfalls leicht zu übersehen, wenn man nicht eigens darnach zu suchen veranlasst sein sollte. Da das Thier, welches zur ersten Untersuchung gedient hatte, ein halbes Jahr im Zwinger lebte, so verglich ich damit ein frisch eingefangenes; aber es verhielt sich, abgesehen von einigen Fettstreifen, da und dort unter der Hant, im Wesentlichen nicht anders. Doch wäre es immerhin noch möglich, dass die Ausbildung der fraglichen lymphdrüsenartigen Schicht mit

als in der übrigen Hante, eine Ansicht, die ich jetzt noch für richtig halte. Denn die dichte Endausbreitung der Nerven in fünf übereininder liegenden Schichten, welche Scrünt nachweist, liess sich eben gerade an dieser IIautpartie, als an einer der Untersuchung günstigeren Gegend aufdecken; sic fehlt aber wahrscheinlich auch nicht in der übrigen Haut. Erst wenn sich diese Annahme nicht bestiitigen sollte, darf man betonen, dass die Flughaut der Chiropteren durch einen ausserordentlichen Nervenreichthum, gegenüber der Lederhaut der sonstigen Körporoberflïche, eine besondére Stelle einnehme.

1) Siebente Tafel, Fg. 87 , c; Fg. 88 , d. 
der Jahreszeit zusammenhüngt. Die Lacerta ocellata befind sich nach der Beschaffenheit der Hoden und der Schenkelporen ganz ausserhalb der Zeit der Fortpflanzung, Lacerta agilis hingegein stand gerade darin.

Bei den Fröschen und hiröten, nach meiner Beobachtung vielleicht auch beim Zitterrochen, verbreiten sich unter der Haut grosse Lymphräume, dereu Abgrenzmngen dem gleichen Bindegetvebe angehören, welches bei der Eidechse zur lymphdrüsigen Schicht sich umgestaltet und beides, die Lymphräume der Batrachier und die lymphdrüsige Schicht der Eidechsen, halte ich für gleichwerthig. Dies wird auch noch dadurch bestätigt, dass an gewissen Kürperstellen bei den Eidechsen, anstatt der köruig-drüsigen Lage, weite Lymphrïume sich zugegen zeigen. Es ist solches Verhalten in äusserst dentlicher Weise bei den Augenlidern wahrzunehmen, woron unten beim Sehorgan das Einzelne mitzutheilen sein wird; und es sei einstreilen nur bemerkt, dass man sich von dem Uebergang beider in einander oftmals in einem und demselben Präparat überzengen kamn; wie denn anch ohne Zweifel die bereits vorhin bei $L$. ocellata erwälnten einzelnen grösseren Weitungen, innerhalb der sonst wie gleichmässig körnigen Schicbt, Lymphräume vorstellen.

Ich habe bereits vor langer Zeit das gleiche lymphdrüsige Bindegewebe zuerst aufgefunden bei Selachiern ${ }^{1}$ ) und erlaube mir die Beobachtungen wörtlich zu wiederholen: „Merkwürdig ist mir eine weisse Substanz, welche man in ziemlich mïchtiger Lage zwischen der IIuskel- und Schleimhaut antrifft. Sie besteht ans einer Molecularmasse und $0,00675, \cdots$ grossen Körnchenzellen, beide umhüllt ron einem zarten Bindegewebe, welches eine nicht scharf ausgesprochene Läppchenbildung bedingt. Ich sehe diese Substanz bei Torpedo narke, Scyllium canicula, Scymmus lichia; sie beginnt und hört auf mit ganz bestimmter Grenze, nach oben, wo die Längsfalten des Schlundes anfangen und nach unten, wo der Schlund in den Magen übergeht. Es entspricht diese weisse, zwischen Muskel- und Schleimhant gelagerte Masse nach ihrer Structur der weisslichen Drüsensubstanz, welche ich bei Chinaera monstrosa in der Augenhöhle und unter der Rachenschleinhaut gefunden habe. (MÜLLER's Archiv 1851.)

Später wies ich dieser weissen Drüsenmasse ihre Stellung näher an, indem iclı sie ausdrücklich unter die Lymphidrïsen brachte. ${ }^{2}$ )

Wïhrend die Haut der Batrachier dureh grossen Reichthum an Drüsen sich anszcichnet, bildet die Haut der Eidechsen einen scharfen Gegensatz durch den fast vollstundigen Mangel der Hiatdrüsen. Bei den einheimischen Arten gehören einzigg und allein die Schenkeldrüsen hieher.

Linve ist es gewesen, welcher zuerst von den "puncta callosa: an den Schenkeln der Eidechsen reict. Ibann gedenken nach ihm riele Zoologen dieser Bildungen, wobei sie die verschiedensten bezeichnungen gebrauchen: sie hedienen sich auch wohl dicser Organe zum Zweck șstematischer 1 bgrenzungen, ohne aber

${ }^{1}$ ) Beitr. z. mikrosk. Anatomie d. Rochen u. Haie. 1852, S. 53.

2) Histologie, 1857. S. 422.

Leydig, Saurier. 
auf den Bau Rücksicht zu nelhmen. Vielleicht schwiegen sie auch über den letzteren mit Absicht, indem sie eben in der Erkenntniss desselben nicht weit kamen.

Duverxor ${ }^{2}$ ) weiss zuerst wenigstens zu sagen, dass den "puncta callosa" ebensoviele darunter liegende Drüsen entsprechen. Damit begnügte man sich lange Zeit, bis daun plötzlich gegen Ende der zwanziger und Aifang der dreissiger Jahre unseres Jahrhunderts die ${ }_{n}$ Schenkelporen" der Eidechsen Gegenstand genanerer Untersuchung wurden. Die Forscher, welche diess thaten, sind Brandt, Dugés (ANTon), JoH. MÜllere, Wagler, Meissner und OtTh.

BrasdT ${ }^{2}$ ) lässt zum erstenmal die Drüsen abbilden, sowie sie sich für's freie Auge und dann mit der Lupe vergrössert ausnehmen; doch möclıte ich hiebei die Bemerkung nicht unterdrücken, dass man schon mit der Lupe bei passender Behandlung una guter Beleuchtung mehr zu sehen im Stande ist, als die gedachten Abbildungen veranschaulichen. Da BRANot, wie es scheint, nicht die Absicht hatte, den Bau der Drüsen weiter zu verfolgen, 'so sind ihm auch bezüglich des Theiles, an dem gerade andere Beobachter strauchelten, keine Bedenken aufgestossen. Er sagt in gewissem Sinne ganz richtig: in der Höhle der Drüse finde sich oft "eine verhärtete Masse, ein walres, dem aus Hautdrüschen ausgedrückten ähnliches Secret."

Auch Joh, Müller, ${ }^{3}$ ) welcher die Organe von Polychrus (Lacerta) marmoratus L. unter geringer Vergrösserung abbildete, zeigt sich ganz unbefangen. Es seien ;Glandulae conglomeratae, ordine lineari aggregatae". Die dazu gehörige Zeichnung ist naturgetreu; sie giebt die Tracht der Urüsen richtig wieder, auch die streifigen Massen des "Secretes" sind entsprechend versinnlicht. Da JoH. MüLLER an der Form der Drüsen das deutlich nachweisen konnte, was ihm als Ziel seines grossen Werkes vorschwebte, so bekümmert er sich offenbar um das Weitere nicht.

Während das, was die beiden vorgenannten Forscher über die Drüsen auszusagen für gut fandell, richtige Angaben sind, so begegnen wir bei WAGLER, ${ }^{4}$ ) dem Herpetologen von Fach, einer seltsamen Mittheilung. Er lüsst die "wurmförmigen" Drüsen, deren Ausmündungen die Schenkelporen seien, vom Unterleibe liommen. Dem Genannten zufolge haben ferner diese Schenkelporen "gewiss mit der Seitenlinie der Fische, welche von kleinen Drüsenöffnungen gebildet wird, einerlei Bedeutung “. Einen besseren Blick verräth unser dutor, wemn er ausspricht, es möchten ,die Schenkelporen mit den Geschlechtsverrichtungen in einem gewissen Consensus stehen"; und dass iln die Theile doch besonders beschüftigt haben, geht auch daraus hervor, dass or die ans den Poren eines grossen Leguans gervonnene Substanz einem Chemiker (VoGEL in MItinchen) zur Analyse zuschickt, welcher ihm mittheilt: „Dic in den Schenkelporen dieser Eidechse vorkommende Substanz enthält keine Spur von Harnsäure, sondern nur Stearin mit thicrischer Faser."

Am einlässlichsten beschäftigt sich mit den fraglichen Organen die Schnift C. F. MEIssNer's, ${ }^{5}$ ) aus welcher sich ergiebt, dass der Bau nicht so ganz einfach sei, als es bisher den Anschein haben wollte. Man nahm stillschweigeml an oder sprach es auch, wie z. B. Cuvier ${ }^{6}$ ) es that, geradezu aus, dass die Drüsen cine ${ }_{n}$ schleimige Flüssiglieit‘ durch die Poren entleeren, während der Baseler Anatom ausdrücklich hervorhebt, dass er niemals, obschon er die rerschiedensten Arten von Eidechsen, darunter clie grösste der europäischcn Fauna: die Lacerta ocellata, Jahre lang lebend gehalten und beobachtet, eine Flüssigkeit (humorem viscosum) aus den Organen labe hervortreten sehen.

Am einzelnen Organe unterschcidet er drei Theile: die Schuppe (Squama papillaris), welche einen Auss hnitt oder Grübchen (Hilus s. foveula) an der gewölbten Filiche besitze; zweitens die unterhalb der. Schuppe

3) In ValsoNт DE Bosrake's Dictionuaire d'hist. natur. 1768-77.

2) Medicinische Zoologie, 1829, S. 160, Tab. XIX, t'g. 1, C, a, b, c, d.

i) De glandularum secern. struct. penit. 1830 , p. 36, TiL. I, Fg. 22.

1) Natüriches System der Amphybien, 1830, S. 235.

3) De Amphibiorum quorundam papillis glandulisque femoralibus. Basileae 1832. Alademisches Programm.

") s Dans les lézards, on voit sous chaque cuisse une rangéo très régulaire de petits pores, d'ou sort aussi une humeur visqueuse. \& thȩons d'anat. comp. 
liecrende Drise (Glandula); und endlich drittens cinen Kürper (Papilla), der aus dir Grube der Schulpe hervorrage. Aber was mochte der letztere bedeuten, und wie sich zur Drüse untelhalb der Schuppe verhalten? Oтти $\left.{ }^{2}\right)$ scheint nur den letztern Körper genauer gekannt, und von der cigenilichen Drüse blos einen Theil gesehen zu haben; was sich dadurch bemerhlich macht, dass er die Schenkelwarzen lediglich aus dem gewölbten, in der Nitte durchbohrten Schildchen und einem darunterliegenden drüsenübulichen, aber ziemlich festen, Kürperchen bestehen lässt. Dasselbe rage über das Schildchen als eiu stumpfer, hornartiger Kegel herror, und indem unser Autor nochmals auf die "hornartige Textur" zurückikmmt, theilt er weiter mit, dass kurz vor der Begattung das Gebilde als kegelförmige Klaue aus der Oeffnung des Schildes herrorrage und so die ganze Reihe mit einem liurzzalnigen Kamm verglichen werden könne.

Da auch genannter Beobachter weder die Absonderung einer Flüssigkeit sah, noch überhaupt eine Oefinung, durch welche eine solche ausgeleert werden konnte, so gelangt er zu dem Schlusse, dass die Organe keine Drüsen seien. "Ich müchte sie eher - sind seine Worte - mit dern erectilen und während der Begattungszeit turgescirenden Zellgewebe der Genitalien und Brustwarzen vergleichen". Mit dieser Annahme hat sich 0Tru, wie wir schen werden, selir geirrt.

Indem ich jetzt zur Darlegung der eigenen Beobachtungen übergehe, darf bemerkt werden, dass die in liede stehenden Organe histologisch alle Beachtung verdienen, indem ihre Secretmassen einerseits manches Besoudere an sich hahen, und andrerseits gerade hierdurch gewisse Bildungen, welche in weitem Abstand ron einander zu stehen scheinen, sich näher gerückt werden.

Nachdem man die Hant des Schenkels bei unseren einheimischen Eidechsen durch einen Längsschnitt, in einiger Entfernung von der Reihe der s'chenlielporen, grespalten und zurückgelegt hat, erblickt man leicht die Drüsen unter der Form plitter, linsenförmiger hörper von graner Farbe und dicht zusammengeschohen. Dal die Drüse unterhalh der Lederhant freiliegt und nicht etwa in die Vicke derselhen eingehettet, so stellt sich unter geeigneter Behandlung der Umrins und die ciliederung des Organs in solcher Schärfe und Schönheit dem Auge dar, wie man sonst nicht immer die Drüsen bei höheren Thieren zur Ansicht belommt; namentlich sind die Organe von Lacerta vivipara, frisch und bei geringer Vergrösserung, ganz besonders zur Demonstration geeignet. Daranf bezieht sich auch, wenn ich an einem anderen Orte die Schenkeldrüsen der Lacerta agilis als ,sehr zicrliche, scharf al)gesetzte“ Drüsengruppen bezeichnete.

Das einzelne Organ besteht aus linglichen, fächerig geordneten Schläuchen, wodurch es in Läppchen zerfällt; bei genatuerer Prüfung des Endstückes der Läppchen ergeben sich noch eimmal kurze Einschnitte, wesshalb eine Annäherung an die traubige Drüsenform zuwege kommt. ${ }^{2}$ ) Auf den Figuren bei BrandT sind die I)rüsen noch einfiche, ganzrandige Sückchen, bei MEISSNER ${ }^{3}$ ) werden bereits Längshinien als

\footnotetext{
1) Ueber die Schenkelwarzen der Eidechsen, Zeitschr. f. Physiol. 1831.

2) Siebente Tafel, Fg. 89.

3) a. a. O. Fg. 1, c, d.
} 
Abtheilungsstriche über die Drüse gezogen und finden ihre Erwähnung im Texte. ${ }^{1}$ ) Endlich die Abhildung bei JoH. MitLLeR zeigt nicht blos die Zusammensetzung ans deu Drüsenschläuchen, sondern anch an einzelnen derselben die wiederholte Gabelung. Dem standpuncte gemäss. auf welchem die Histologie ror etwa dreissig Jahren sich betand, beschreibt MeIssxer den feineren Ban so: ,intemia glandulae comprages tota nobis visa est conflatil e tela cellulosa subtilissima irregulari, pancisque vasis sanguiferis pertexta".

Wir können jetzt sagen: das bindegerrebige Gerüste ${ }^{2}$ ) der Drüse ist rerhältnissmässig zart. streifig und rou liernen unterbrochen; es enthält weder nach aussen noch etwa nach imnen aufgelagrert musculöse Elemente; hingegen trïgt es Blutgefässe, rrelche in ziemlich dichten Maschen die beerigen und schlinchförmigen Abtheilungen der Drüse umspinnen, und auch durch zarte scheidenartige Vorsprünge der Drüsenhant in: Innere geleitet werden. Den Hohlraum der Drüsenhant erfüllen die Epithel- oder secretzellen derart, dass keine Lichtung übrig bleibt, wesshalb auch schon der zuletzt genannte Autor ${ }^{\circ}$ ) zu sagen weiss, dass die Drüse nicht hohl sei und dass es nicht gelinge eine Borste in den Grund der Drüse einzuführen. Die Zellen haben in ihren Eigenschaften grosse dehulichkeit mit jenen, welche sich in der Tiefe der Talgdrüsen der Säugethiere befinden: sie sind ron zarter Cmgrenzung, und feimkürniger, mit ebenfalls feinkürnigem Fett untermischter substanz. Diese zelligen Elemente sind es, welche der Drüse die graue Farbe rerleihen.

Das Secret ${ }^{4}$ ) ist nun der Körper, welchen die Autoren Papille, Warze, hornartigen Kegel u. dergl. nennen.

Gehen wir von dem Fall aus, wo die Entwickelung eine starke ist, und nehmen hierzu die Lacertu agilis im Monat Mri. Lm liese Zeit ragt beim männlichen Thier ans der betroung der schuppe ein fester hörper ron gelber Farbe weit heraus, welcher nicht eigentlich legelförmig ist, sondern eher seitlich etwas zusinmengedrückt: Aer freie. hogige liand zeigt sich eingekerht und mit Furchen, welche mach unten sich fortsetzen. Das Gamze ihnelt im Kleinen dem Limriss des Hahnenkammes. Terfulgen wir den Körper unter die schuppe, in die Drüse hinein, so wirk klan, dass die Furchen der Ausdruck einer Entstehung aus walzenförmigen Missen sind, und

1) Es wird a. a. 0. p. 12 der verschmälerte Theil, welcher zur Oefinung der Schuppe geht, als Drüsenhals (Collum s. pedicellum) unterschieden und dann fortgefahren: sin ejus (colli) superficie autem lineas observarimus sulcosve 7-9 obsoletos haud procul a glandulae peripheria incipientes, sensim conrergentes et rersus pedicelli insertionem denique evanescentes.

)) Siebente Tafel, Fg. 91.

ग) a. a. 0. p. 13 .

i) Siebente 'T'afel, Fg. 9:. 
dass diese wieder den Grund ihrer Gestalt in den schlauchförmigen Abtheilungen der Drüse haben. Indem die gleich anfings etwas festen walzigen Secretmassen, in der 'Tiefe der Drüse büschelfürmig, mit getheilten Wurzeln gleichsam, ihren Anfang nehmen und dann gegen die Oefinung der Drüse aufsteigen, sich hierauf allmählig zusammenneigen und schliesslich an einander gekittet ans der Oeffnung der Schuppe frei hervorstehen, erzeugen sie zuletzt die unterdessen hartgewordene "Pipille". Im genamnten Monat, der Zeit der Fortpflanzung, hat demu auch die ganze Drüse -wegen der reichlich vor sich gehenden Abscheidung dieses Secretes eine durchaus gelbe Firlbe für's freie Auge, und erst unter dem Mikroskop lassen sich die grau gebliebenen Partieen der Secretzellen wahruehmen. Dabei ist um eben diese Zeit das die Drüse umspinnende Blutgefïssnetz sehr entwickelt.

Spaiter, und beim Weibchen ist es stets so, erscheint die Papille niedrig oder ragt gar nicht mehr zur Schuppenöflnung heraus. Doch sieht man mit dem Mikroskop immer, wie der gelben Masse, auch wenn sie dergestalt tief in die "Pore" sich zurückgezogen hat, dass diese als wirkliches Grübchen erscheint, eine Zusammensetzung aus Abtheilungen zukommt, welche, bedingt durch die platte Gestalt der Drüse, quergestellt sind. ${ }^{1}$ ) Diese Querlinien sind auch auf melureren der MEIssanerschen Figuren ${ }^{2}$ ) gut ausgedrückt.

Ehe ich in der Darlegung dessen, was ich selbst sah, fortfahre, ist jetzt DuGris zu gedenken, als des Einzigen, welcher schon vor langen Jahren das Verhältniss der Papille zur Drüse richtig erkannt hat. In seiner trefflichen Abhandlung: Mémoire sur les espèces indigènes du genre Lacerta, ${ }^{3}$ ) die so viel Neues bietet, sagt er mit ginz knrzen, aber deutlichen Worten: seine Landslente hätten bisher die Warzen in den Schenkeln der Eidechsen für wahre Hautpapillen gehalten; das seieu sie aber keineswegs, sondern vielmehr ein härtliches, röthliches Secret, welches trocken geworden und über die Oeffnung der Schuppe hervorragend, das Aussehen von Warzen annehme. ${ }^{4}$ )

Dieses Secret wird uns aber dadurch von Bedeutung, dass es nicht etwa eine homogene erhärtete Masse ist, sondern von einer zelligen Structur, welche mit jener der Oberhaut ühereinstimmt. Das Secret, die Warze, Papille oder wie man sonst den gelben Kö̈rper nennen will, ist eine Art Epidermis, welche in bestimmter lich-

1) Vergl. Hig. 90 .

3) a. ล. O. z. B. Fig. 4, a.

3) Annal. d. scienc. nat. T. XVI, 1829.

1) Ses cryptes sont formées d'une poche à parois épaisses: elles secretent une luumeur très-consistante, roussâtre, et qui, en se desséchant dans lo pore qui lui donne passage, pent prendre l'apparence de verrues qui ont quelquefois passé pour de véritables papilles cutanées. " 
tung umgewandelt erscheint. Die Zellen haben schon an den Anfängen der gelben Wülste imnerhalb der Drüse den epidermoidalen Charakter, weiter nach aussen besitzen sie ganz die Beschaffenheit echter Epidermiszellen, mit etwas Fettgehalt. ${ }^{1}$ ) Die gelbe Fürbung ist diffuser Art. Manches, besonder's die Zahl der Kerne deutet darauf hin, dass die Zellen rasch wuchern oder sich vermehren können.

An Thieren, welche einige Tage in äusserst verdünter Salpetersäure gelegen haben, lassen -sich die Papillen allesammt mit ihren Wurzeln, indem wir die Epidermis abziehen, zugleich mit dieser derart abheben, als wären sie nur Theile der Epidermis; noch besser ist es, die Thiere etwa eine Stunde lang zu liochen. Die Papillen treten jetzt mehr heraus, als sie selbst zur Brunstzeit es thun und lassen sich völlig als ein Ganzes hervorziehen; was sich Alles gut erklärt, wenn wir den histologischen Bau zuvor kennen gelernt haben. Da bei Merssner z. B. diess noch nicht der Fall ist, so müht er sich ${ }^{2}$ ) ab, eine Oeffinung an der "Papille" wahrzunehmen; und weil sich keine finden liess, sondern die Epidermis über die aus der Grube der Schuppe hervorstehende Masse ebenso weggieng, wie über die übrige Haut, so meint er, man könne diess Verhalten zur Bekräftigung der Ansicht verwenden, dass in der Haut der Thiere überhaupt keine „organischen Poren“ zugegen seien.

Die Anatomen einer früheren Zeit betrachteten bekanntermassen die Epidermis als ein „unorganisirtes Absonderungsproduct". Wir wissen jetzt, dass auch die Oberhaut eine lebendige und sehr zusammengesetzte Lage des thierischen Körpers sei. In gleicher Weise ist die bisherige Auffassung im Bau der Schenkelwarzen der Eidechsen abzuändern; auch hicr bestcht "das Secret" aus selbstständig bleibenden Epidermiszellen. Man könnte sogar so weit gehen, zu sagen: das "Secret" sei eine Uebergangsform zwischen Verdickungen oder Wucherungen der Epidermis gewöhnlicher Art und den Haaren. Eine solche Ausicht wäre nicht ganz ungereimt: denn die Papille wiederholt in höchster Entwicklung, zur Begattungszeit, einen auf niedriger Stufe stehen gebliebenen Haarbüschel, dessen Einzelhaare dicht neben einander verklebt wären, wobei man sich dann auch daran erinnern könnte, dass ich ${ }^{3}$ ) bei Süugethieren Büschel von Haaren in einem einzigen mehrfach ausgesackten Balg nachgewiesen; und obschon die Stachelborsten der Ringelwürmer nur in allgemein morphologischer Beziehung mit den Haaren der Säugethiere verglichen werden können, so darf man immerhin beachten, dass diese Gebilde in drüsenähnlichen Säckchen als Abscheidungsproduct und zwar hier als Cuticularbildung entstehen. ${ }^{4}$ ) Unter solchen Erwägungen würden wir auch dazu kommen, den Haarbalg der Säugethiere nicht mehr als eine Bildung besonderer Art, sondern wie einen Drüsensack anzusehen.

Bleiben wir jedoch bei dem zunächst Liegenden, so ist das Ergebniss für uns, dass die besagten Organe der Eidechsen T'algdrüsen sind, deren Secret nicht nur zellig ist, sondern in seinen Elementen bis zu einem gewissen (trade verhornt, dibei eine bestimmte Anordnung zu walzigen Partien einhält, und als ein alhgeändertes Stück Oberhaut aufzufassen ist.

${ }^{3}$ ) Vergl. Fg. 22. (Siebente Tafel.)

2) a. ล. 0. p. 11 .

3) Ueb. d. äusseren Bedeckungen d. Säugethiere, Arch. f. Anat. u. Physiol. 1859. S. 706.

j) Vergl. m. Auf'satz: über Plireoryctes Menkicanus, Archiv f. mikrosk. Anat. Bd. I. 


\section{Blindschleiche.}

Oberhaut.

Anf die mincherlei Eigenthümlichkeiten, welche die Epidermis slarbietet, insbesondere auf die so sehr entwickelte P'neumaticitat der Hornschupen soll hier nicht noch eimmal eingegangen werden, da ich darüher vor Kurzem ausführlich berichtet habe. $\left.{ }^{1}\right)$

Die Häutung geschieht auch hier, trotz der Verkalkung der Lederhaut, im Ganzen: die T'hiere streifen nach Art der Schlangen ein völliges "Natternhemd" ab; doch wird die Epidermis weniger oft als bei den Eidechsen gewechselt. ${ }^{2}$ )

Eine eigenthümliche Krankheit, welche die Ëpidermis mancher Individuen von Anguis fragilis auch im geriumigen Zwinger befallt, besteht darin, dass eiuzelne der Iornschuppen oder gleich mehrere zusammen den Glanz verlieren, trübe werden, wie wenn sich ein weisslicher Stoff darunter ansammelte; sie spreizen sich alsdann in die Höhe und sehen wie vertrocknet und schrundig aus. Man denkt hiebei wohl an Pilze, welche die lírankheit verursacht hätten. Allein ich sehe auch keine Spur von fremden Organismen. Die weisse Masse scheint vielmehr nur auf Wucherung der von mir (a. a. 0 .) beschriebenen fettigen Zellenschicht zu beruhen. Meist gingen die Thiere bald zu Grunde, doch haben sich manche der kranken Oberhaut nach und nach entledigt, obschon sie schwerer abging als die gesunden Partien.

Bei den Eidechsen scheint die Epidermis hin und wieder ebenfalls an solchen Entartungen zu leiden, wenigstens nach den Mittheilungen, welche GLitcrsilig ${ }^{3}$ ) darüber veröffentlicht hat.

Lederhaut.

Von diesem Körpertheil verdient unsere Beachtung ror allem Andern die (iegenwart der Knochentäfelchen ${ }^{4}$ ) oder Knochenschuppen, welche auf Kosten der Lederhunt entstanden, sich über den ganzen Körper verbreiten. Wer sie nicht mikroskopisch zu untersuchen vermag, kann sich von ihrer Anwesenheit leicht dadurch überzeugen, lass er die Hant lange fort im Wasser macerirt; nach Auflösuug des Bindegewebes lassen sich alsdamn die Knodienschuppen als zierliche weisse Kilktäfelchen in Menge sammeln.

Es gehören die Knochenplättchen zu den ganz besonders unterscheidenden Merkmalen der seincoiden gegenüber von den Lacerten, und man hatte immer bemerkt, dass die "Schuppen" der Eidechsen von jenen der Blindschleichen etwas abweichen. Ler Unterschied des lehenden Thieres, in guter schräger Belenchtung ist so gross, dass ex Niemanden entgehen kann: bei Eidechsen ist die Obertlïche der

1) a. a. 0. in den Schriften d. Acad. Leop. Carol.

2) Auch an P'seulopus Pallasii beobachte ich, dass die Knochentafeln der Lederhaut keinen Einfluss auf die Weise der Häutung ausüben; dabei erfolyte in der Gefangenschaft der Wechsel der Epidermis erst nach Verlauf von fünf Monaten.

$\left.{ }^{9}\right)$ Ueber d. Leben d. Eidechsen, 1863.

1) Siebente 'Tatel, Fg. 97, d, F'g. 97, c. 
Haut unter diesen Umständen verhältnissmässig matt, bei der Blindschleiche hingegen von spiegelndem glänzenden Aussehen, wesshalb auch die Bezeichnung "Glanzschleichen" eine recht passende ist.

Pallas, indem er den merkwürdigen, von ihm entdeckten Pseudopus näher untersuchte, weiss schon, dass die Haut mit Knochentafeln gepanzert sei. ${ }^{1}$ ) Der zweite, welcher „knochenartige Schüppchen, denen der Fische ähnlich in der Hant der Scinke" beobachtet hat, ist Hedsinger ${ }^{2}$ ) gewesen; spater wurden auch von Andern bei Scincus und den nahe stehenden Gattungen Ophisaurus, Cyclodus Knochenbildungen in der Haut wahrgenommen, sowie ich ${ }^{3}$ ) denn selbst schon vor geraumer Zeit nachwies, dass bei unserer Blindschleiche die Lederhaut wirkliche Hantknochen erzenge. Trotzdem wird dieser Charakter in den Handbüchern der Zoologie wenig oder gar nicht berührt; und wenn man dessen einmal gedenkt, so gesehieht es mit dem unrichtigen Beisatz, dass „die Knochentäfelchen in eigenen Taschen der Oberhaut stecken".

Dieser Irrthum fällt zusammen mit der Ansicht Heusingen's, welcher zufolge die "Schüppehen oberhalb der Lederhaut im Malpighi'schen Schleimuetz abgesondert werden, sohin nicht Verknöcherungen der Lederhant seien". Dass diese Ammahme ganz zu beseitigen sei, geht ans meinen ${ }^{4}$ ) vor Kinzem veröffentlichten Mittheilungen hervor, wo ich den histologischen Bau im Einzelnen dargelegt habe. Die Knochenschuppe ist in Wirklichkeit ein Stück verkalkter Lederhaut, wobei noch unverkalktes Bindegewebe eine Art weicher Rinde um den Knochen bildet.

Es darf vielleicht angenommen werden, dass die harte Unterlage der Knochentafeln den darüber folgenden Hornschuppen theilweise zu dem sie auszeichnenden Glanze verhilft.

Die Knochentafeln der Haut zeigen eine Anordnung in Querringen, was sich sehr deutlich zeigt, wenn wir von einem gekochten Thier die Haut abzuziehen versuchen: es gelingt alsdaun leicht in Querringeln, kaum aber in Längsstücken.

1) Totum cataphractum est squamis .... osseis, et supra osseam lameam epidermide corneola incrustatis. *

$\left.{ }^{2}\right)$ Vergl. dessen Histologie, 1822, S. 222.

3) Lebrb. d. Histologie, 1857 , S. 90.

1) Ueber Organe eines sechsten Sinnes, Nov. Act. Acad. Leop. Carol. 1868. Dort werden anch histologische Abbildungen der Schuppen von Anguis und Scincus gegeben, wesshalb ich anich diesmal auf vergleichende, mehr für den zoologischen Gebrauch bestimmte, Hantdurchschnitte von Anguis und Iacerta, sowie anf IViedergabe der Sculptur beschrinkt habe. - In genannter Abhandlung habe jch ferner auf Kalkablagerungen in der Haut der Kröte aufmerksam genacht und möchte hier gelegentlich bemerken, dass bereits, was mir damals unbekinnt war, zwei ältere auf den gleichen Punct bezügliche Angaben vorliegen. So führt Hrusinakr ( $\mathrm{n}$. a. 0.225 ) an, dass bei Yipa in der ligmentschicht der Haut, welche dazumal zur Epidermis gerechnet wurde, kreidenartige liörnchen sich finden. Dann hat zu gleicher Zeit DAvr (1'hil. 'I'rinsact. 1826) beobachtet, dass bei Kröten die Haut ihre besondere Festigkeit erhalte durch einen Ueberfluss von phosphorsiurem und kohlensaurem Kalk. 
Anch die Haut der Blindschleiche ist drüsenlos. Aber was im Hinblick auf die Verwandtschaftsverhältnisse, welche zwischen Lacerta und Anguis bestehen, von Bedeutung ist: es fehlen nach meiner Wahrnehmung den Schenkeldrüsen entsprechende Organe keineswegs völlig, sondern sie haben, bei dem Mangel von Gliedmassen, sich auf einen anderen Ort zurückgezogen. Es wird nümlich unten, wo über die Fortpflanzungswerkzenge die Rede ist, gezeigt werden, dass gewisse Drüsen der Begattungsorgane oder Ruthen die Stellvertreter der "Schenkelporen“ sind.

In der Epidermis der Blindschleiche, nicht minder bei Eidechsen und Nattern, habe ich Organe aufgefunden und beschrieben, welche man dem ersten Eindruck nach für Drüsen halten könnte, aber dies, wenigstens im gewöhnlichen Sinne, nicht sind. Vielmehr müssen sie in die Reihe der Sinnesorgane gerechnet werden, wesshalb ihrer unten noch einmal zu gedenken ist.

\section{Muskelsystem.}

Ueber die Muskeln des Stammes habe ich selbst keine zusammenhüugenden Studien angestellt, sondern nur gelegentlich, im Anschluss an die Betrachtung der Knochen mir Einzelnes bemerkt, wesshalb ich mich bei nachfolgenden Andeutungen auf andere Forscher stütze, und zwar zumeist auf die Angaben FtrRBrivgers, die mir den Eindruck grosser Genauigkeit machen.

Man hat auszugehen von den Seitenrumpfmuskeln. Die Rückenhälfte derselben, welche sich vom Kopf bis zum Schwanzende erstreckt, wird gebildet rom Spinalis (mit Splenius), Semispinalis, Mnltifidus, Longissimus dorsi, Sacrolumbalis und den Levatores costarum. Die Bauchhälfte setzen zusammen die Longi colli, Recti capitis, Retrahentes costarum der Hals- und vorderen Brustgegend und die unteren Schwanzmuskeln. Endlich die Seitenbanchmuskel umfassen die zwei Obliqui externi und interni und den Transversus. - Der Pyramidalis fehlt und die Recti abdominis gehören zu den Intercostalmuskeln.

An der Schwanzwirbelsäule behält die Museulatur nahezu den Charaliter des grossen Lateralmuskels der Fische. Man sieht daher von aussen nach Abzug der ïusseren Haut, namentlich gut bei der Blindschleiche, eine schöne zickzackförmige Zeichnung, bedingt durch die Anordnung der musculösen Elemente; und auch der Querschnitt erinnert an die Kegelstücke und Kegelmäntel der Fische. (Die ganze 
Schwanzmusculatur hat eine besondere von der Lederhant der äussern Bedeckung wohl verschiedene, bindegervebige, derbe Umhüllung.)

Für den Schulter- und Beckengürtel lösen sich ab vom Sacrolumbaris: der Depressor maxillae, der Cucullaris, der Latissimus dorsi, der Levator scapulae, der Serratus anticus major.

In der Brustgegend finden sich einige Muskeln als Fortsetzungen des Rectus abdominis. Auch den Pectoralis major der Brustgegend möchte der genannte Beobachter als eine abgelöste Partie des Obliquus abdominis externus ansehen, während er den Sterno-cleidomastoideus den Hautmuskeln zuzuzählen geneigt ist.

Am Beckengürtel stellt die tiefere Lage des Sacrolumbaris den Quadratus vor. Die untere Mnskelmasse des Schwanzes geht mit einzelnen Bäuchen ans Becken (Ileo-coccygeus und ischio-coccygeus.)

Am Schultergürtel fehlen mehrere Muskeln, welche sich beim Menschen finden, so z. B. der Subclavius, der Rhomboideus; während andere zugegen sind, welche beim Menschen nicht vorhanden sind, so z. B. ein Sterno-costoscapularis.

Der Deltoides des Oberarms ist ein kleiner schmaler Muskel. Ein Coracobrachialis, Teres major, Subscapularis, lassen sich ausser dem schon genannten Lirtissimus dorsi unterscheiden. Die Sehne des Triceps des Unterarms schliesst eine später noch zu erwähnende Ellenbogenscheibe ein.

Von den Muskeln des Oberschenkels sind Glutaeus medius und minimus, sehr verschieden von der menschlichen Bildung, lange schmale Muskeln; der Glutaeus maximus setzt sich an den Kopf des Wadenbeins. Der Adductor stellt nur einen kleinen Muskel vor. Andererseits treten wieder Muskeln auf, welche dem Menschen am Ober- und Unterschenkel fehlen.

Von Gesichtsmuskeln sehe ich keine Spur; selbst nicht einmal die kleinen IIuskeln, welche bei Fröschen an der Schnauze als Intermaxillaris und Lateralis narium unterschieden werden, sind vorhanden.

Die Kaumuskeln bestehen aus dem äusseren oder Masseter und Temporalis, und dem inneren orter Pterygoidens. Des Herabzieher's des Unterkiefers wurde schon gedacht.

In das Einzelne der anatomischen Beschreibung des IIuskelsystems ron Lacerta und Anguis geht vou äleren Autoren z. B. Meckel ein. Ganz besonders ist Heusingers Arbeit hervorzuheben, ${ }^{2}$ ) allwo nicht nur die Muskeln rom Iiticken und Banch, sondern auch des Schulter- und Beckengürtels der Blindschleiche im Näheren bebandelt werden, begleitet von bildichen sauberen Darstellungen. Nicht minder sind in der gleichen Abhandlung, wenigstens auf den Tafeln, lurch drei schöne Inskelprïparate Lacerta agilis und $L$.

1) Ueber die Extremitäten der Ophidier, Zeitschrift für organische Pbysik, 1828. 
viridis berücksichtigt. Eine in Geist der neueren vergleichenden Anatomie durchgeführte Arbeit über die MLuskeln von Anguis und anderer Scincoiden rerdanken wir Fürninger, ${ }^{3}$ ) welche, wie ich mir denke, alle die früheren, unseren Gegenstand berührenden Schriften überflüssig gemacht hat.

Noch mag auf die weite und allgemeine Verbreitung des Pigments in der Musculatur des Stammes hingewiesen sein. Nicht nur bei Eidechsen zeigt sich mir diese dunkle Besprenkelung der Muskeln, sondern auch bei der Blindschleiche. Und sucht man daruach wo das Pigment eigentlich untergebracht sei, so finden wir, dass es lediglich in den bindegewebigen Umhüllungen und Abgrenzungen der contractilen Substanz, niemạls in dieser selbst, liegt. Es hält sich vor Allem an die Blutgefïsse und hat seinen Hauptsitz in deren åusserer Hülle.

\section{Skelet.}

Es gliedert sich das Knochengerüste in das Kopfskelet und die Wirbelsänle nebst den Anhängen, sowie in den Brust- und Beckengürtel; daran schliessen sich bei Lacerta noch vordere und hintere Gliedmassen, während sie bei Angris fehlen.

\section{Blindschleiche.}

Primordialschädel.

Die Umstände lassen es nicht zu, den Primordialschädel von seinen ersten Anfüngen aus darzulegen, da mir nur Embryen von jener Reife, bis zu welcher sie in der Mitte Juli's gediehen sind, zu Gebote standen.

Man kaun den ursprünglichen knorpeligen Schädel in dieser Zeit bei einiger Sorgfalt ziemlich als ein Ganzes in der Art gewinnen, dass man nach vorausgegangener Einwirkung des Weingeistes auf das 'I'hier, das Präparat reinigt, hierauf mit verdümnter Kalilauge und endlich mit Glycerin behandelt. Das knorpelige Gerüste des Schiidels, gelbroth geworden, hebt sich jetzt von den weisslichen Deckknochen gut ab, so dass beide in einen die Uebersicht erleichteinden Gegensatz zu einander treten.

Ohne hiex schon auf die Frage, ob der Schädel aus Wirbeln sich zusammensetze, einzugehen, sei doch zum Voraus bemerkt, dass der Primordialschidel eigentlich nichts Wirbelähnliches an sich hat.

1) Die Knochen 11. Muskeln der Extremitäten bei den schlangenähnlichen Sauriern. Mit sieben Tafeln. Leipzig. 1870. 
Beginnen wir von hinten und unten, so zeigen sich zuerst zwei bogig nach aufwärts strebende Knorpelstreifen, welche später den Grund zu den Seitentheilen des Hinterhauptlueines geben. ${ }^{1}$ ) Hat man sie etwas abgebogen, so wird nahe ihrem unteren Ende eine grössere Oeffnung und weiter nach oben eine andere um vieles kleinere sichtbar. Vor diesen Occipitalia lateralia liegend bildet den Grund des Schädels eine Knorpelplatte ${ }^{2}$ ) von beilaufig dreiseitiger Form, in welcher man die Summe des späteren Körpers des Hinterhanptbeins, sowie den hintern Keilbeinkörper erblicken darf. Ihr hinterster, eigentlich plattenartiger Theil ist nach unten ausgewölbt, da auf ihm das verlängerte Mark rulht. Nach vorne zu wird die Platte zweimal von einer mittleren Oeffnung durchbrochen, wovon die hintere eine rundliche, die vordere eine beilüufig dreieckige Gestalt aufzeigt. Dann sind auch jederseits zwei längliche Spalten, unter sich von verschiedener aber immer beständiger Form, zugegen, welche Durchbrechungen sämmtlich einen häutig-bindegewebigeu Verschluss haben. In die vordere der mittleren Oeffnungen, genauer auf deren hăutigen_etwas vertieften Boden, kommt der Hirnanhang zu liegen.

Die Fortsetzung der Platte zieht als Knorpelstreifen nach der Mitte und Länge des Schädelgrundes hin bis zur Schnauzenspitze, allwo er sich gablig theilt. Auf diesem Wege entsendet er ummittelbar vor der Spitze der zweiten, den Hirnanhang bergenden, Durchbrechung einen Knorpelfaden nach rechts und links, und indem die beiden sich nach oben schliessen, entsteht ein Ring, dessen beide Hälften zum Durchtritt des Sehnerven dienen. ${ }^{3}$ )

Von beiden Seiten des Ringes geht ein Knorpelfaden nach rückwärts in die Gegend der knorpeligen Ohrkapsel. Unmittelbar vor dem Ring entwickelt der Basalknorpelstreifen einen Kamm, der ziemlich dick ist und aufsteigend zwischen die Augen zu liegen kommt.

Weiter nach vorne dient der Basallknorpelstreifen und seine kammförmige Erhebung, die jetzt wieder schmäler geworden, zur knorpeligen Nasenscheidewand; das knorpelige Ende, die Nasenhöhlen umgreifend, wird zur Nasenkapsel und die Einsprünge zu den Muscheln.

Endlich unterscheidet man noch einen Knorpelfaden, der am Seitenrand des häutigen Schädels hinziehend, hinter den Augen vorbei, in die knorpelige Nasenkapsel ansläuft, nachdem er sich zuvor durch eine kurze Querbrücke mit dem hinor-

1) $\mathrm{Fg} .28, \alpha, \mathrm{Fg} \cdot 29 \alpha$.

2) $\mathrm{Fg} \cdot 29, \boldsymbol{\beta}$.

3) Fg. $28 \mathrm{~d}, \mathrm{Fg} .29, \gamma$. 
pelkamm zwischen den Augen verbindet. Es hat mir mehrmals geschienen, als ob dieser seitliche lange Knorpelfaden hinten über die Ohrkapsel weggehend, in Verbindung stehe mit dem hintersten Knorpel des Primordialschädels d. h. mit dem Occipitale laterale.

Die Columella, ${ }^{1}$ ) ebenfalls ein Knorpelstab, setzt sich sowohl nach oben als auch nach unten, insoweit sie aus Knorpelsubstanz besteht, mit scharfer Grenze ab. Das Pterygoideum, dem er sich unten anfügt, ist nie knorpelig gewesen.

Einen sehr wesentlichen Theil des Primordialschädels bildet die knorpelige Ohrkapsel. ${ }^{2}$ ) Von innen her angesehen bemerkt man an ihr eine grössere Oeff̈nung zum Schädelraum, von länglicher Form. Von aussen macht sich ein grosses Foramen ovale auffällig, das wohl jetzt auch noch zugleich das Foramen rotundum mithegreift. Von den Gehörknöchelchen ist das Operculum ebenfalls knorpelig angelegt. Ferner unterscheidet man nicht blos deutlich die Umrisse für die Bogengänge und die stumpfkegelförmige Schnecke, sondern es schimmern auch zwei weissliche Haufen von otolithen hindurch, einer aus dem Vorhof, der andere aus der Schnecke.

Endlich stellen noch knorpelige Anhänge des Primordialschädels vor: das Quadratbein (Os tympanicum) und der Bogen für den Unterkiefer. Das erstere ist olsen etwas breiter als unten, aber sonst von noch ganz einfacher Form, ohne Aushöhlung für ein Trommelfell und ohne Muskelleisten.

Das Verhalten der Rückenseite (Chorda dorsalis) zum Primordialschädel ist gut wahrzunehmen. ${ }^{3}$ ) Die letzte Verdickung der Chorda liegt im Körper des zweiten Halswirbels (Epistropheus); dann zieht sie fadig verdünnt durch den ersten Halswirbel (Atlas) in die knorpelige Grundplatte des Schädels und erstreckt sich genau bis zum Rande der zweiten häutigen Durchbrechung jener Platte, auf welcher der Hirnanhang ruht. Ihre Spitze geht ummittelbar bis an den Hirnanhang heran, hört aber bestimmt für sich auf, ohme mit dem letzteren in Zusammenhang zu stehen. Auch lässt sich, bei Betrachtung des Schädels von innen klar sehen, dass die Chorda während ihres Verlaufs durch den Schädelknorpel von oben her nicht von Knorpelsubstanz bedeckt ist, sondern in einer Furche des Knorpels liegt, und ebenso jenseits der ersten grossen häntigen Lücke, in der Fortsetzung des Linorpels, jetzt geradezu auf' letzterem ruht.

Mit dem Studium des Primordialschädels beschäftigt vermied ich absichtlich Rature's bekannte

1) Fg. 29, e.

2) Fg. 28, e; Fg. 29, $\delta$.

3) Fg. 28, f; Fg. 29, f. 
Darstellung in der Entwicklungsgeschichte der Natter, ${ }^{1}$ ) deren Ergebnisse mir nur den allgemeinen Zügen nach im Gedächtniss waren, zur Hand zu nehmen. Erst nach Abschluss meiner Beobachtungen verglich ich die beiderseitigen Erfunde und lomnte mit Vergnügen die Uebereinstimmung in den Hauptsachen wahrnelimen. Die Unterschiede, welche sich herausstellen, beziehen sich offenbar darauf, dass die Blindschleiche zwar ein schlangenartiges Thier, aber doch keine echte Schlange ist.

Die knorpelige Grundplatte in ihrem hinteren Abschnitt nennt RAтикE den Körper des Hinterhauptbeins; die Knorpelquerbrücke zwischen der hinteren und vorderen häutigen Durchbrechung heisst bei ihm Kürper des hinteren Kieilbeins: die Ľnorpelstreifen, welche die seitlichen kleineren Durchbrechungen umfassen, sind die ${ }_{\eta}$ Fortsätze rom Körper des hinteren Keilbeins zum Felsenbein ${ }^{*}$. Die Knorpelstreifen, welche die vordere, hier bei der Natter viel länger ausgezogene, Oeffnung rechts und links begrenzen, heissen die " paarigen Balken der Hirnschale"; die Fortsetzung des Knorpels nach vorne ist "der verschmolzene Theil der Schädelbalken“; auch bildet RATukE einen Theil der knorpeligen Nasenkapsel ab, ebenso stimmen die Umrisse der Ohrkapsel gut mit dem was ich sah, nicht minder die Seitentheile des Hinterhฉuptbeins.

Verfolgen wir die weiteren Schicksale des knorpeligen Primordialschädels, so zeigt sich, dass der hintere Abschnitt, nämlich die Theile, welche dem Körper und den Seitentheilen des Hinterhauptbeins entsprechen, verkalken, ebenso die Ohrkapsel sammt dem Paukenknochen, der hintere Keilbeinkörper, ferner die Columella, das Tympanicum, sowie das Articulare des Unterkiefers. Der übrige Knorpel hingegen, welcher sich nach vorne erstreckt, also die sogenannten parigen Schädelbalken und ihre unparige Fortsetzung bis zur Schnauze, daun der auf letzterer sich erhebende Kamm, die Nasenkapseln und der lange Streifen nach oben, aussen und hinten bis in die Gegend des Schläfenbeins, bleiben zeitlebens bestehen und lassen sich an jedem rein präparirten Schädel wieder auffinden, nicht weniger der Meckel'sche Iñnorpel im Unterkiefer.

Einer ganzen Reihe von Krnochen geht keine knorpelige Bildung voraus; sie sind sogenannte Belegknochen. ${ }^{2}$ ) Dazu gehören: die Schuppe des Hinterhauptbeius, Scheitelbeine, Stirnbeine (sowohl die Haupt- als auch die vordern und hintern Nebenstimbeine), Thränenbein, Nasenbeine, Zwischenkiefer, Oberkiefer, Unterkiefer, PHugschatrbeine, Gammenbeine, Flügelbeine, endlich del Stachel an Keilbeinliörper. Diese herkömmlich gewordene Unterscheidung in Ínochen, welche knorpelig rorgebildet sind und in solche, welche das niemals waren, die Belegknochen, verschwindet zwar ror einer genaneren histologischen Untersuchung der Art und Weise wie Knochensubstanz entsteht, da GEGENBAUR ${ }^{3}$ ) ermittelt hat, dass auch diejeniggen Knochen, welche anscheinend dem Knorpel ihre Entstehung verdanken, aus dem umhüllenden

1) Tab. VII., Fg. 17. Schädel eines Embryo von der unteren Seite angeschen.

2) Fg. 28, F. 29.

3) Jenaische Zeitschrift I, II. Ich kann bei dieser Gelegenheit nicht unterlassen zu erwähnen, dass zu meinen Nachweisen uber die Verwandtschaft der Cuticularbildungen mit den Bindesubstanzen dnrch das, was Gegexsaur über die Entstehung des Knochengevebes d. h. über die Beziehung der Zelle zur Intercellularsubstanz aufgedeckt hat, neue und feste Stützen hinzugekommen sind. 
Bindegewebe, dem Periost, ihren Ursprung nelmen. Aber trotzdem wird Jedem, welcher den Schädel eines Wirbelthieres aus dieser frühen Zeit unter den Augen hat, die Bemerkung sich aufdringen, dass die einen Knochen eine năhere Beziehung zum knorpeligen Primordialschädel haben und die anderen nur eine entferntere und man wird zugestehen, dass die hergebrachte Unterscheidung eine wohl berechtigte ist.

Knochen des fertigen Schädels.

Das Hinterhautsbein besteht aus dem Körper, den zwei Seitentheilen und der Schuppe, welche nicht blos unter sich fest verschmolzen sind, sondern auch mit dem Kieilbein und Schliffenbein so imnig verbunden erscheinen, dass erst bei liungerem Maceriren das Keilbein sich löst; während auch damn noch Sulläfenbein und Hinterhauptsbein zu einem Ganzen verbunden bleiben.

Der unpaare Gelenkkopf, stark vorspringend, hat eine dreigelappte Beschaflenheit, $\left.{ }^{1}\right)$ die bei jüngeren Thieren sehr ansgeprägt ist, indem die drei $A$ btheilungen förmlich vorquellen; später verliert sich hin und wieder diese scharfe Ausprägung und bei längerer Lebensdaner kann sie wie verwischt sein. Die dreilappige Form des Cielenkhöckers rührt her von seiner Entstehung, indem der Kürper des Hinterhauptbeins den mittleren und die Occipitalia lateralia die seitlichen Lappen liefern. ${ }^{2}$ ) Die Seitenstücke des Hinterhauptloeins sind ursprünglich am Primordialschädel verhältnissmässig sehr schmal angelegt, und übertreffen die hinten sich auschliessenden Wirbelbogen wenig au Umfiug. Sie sind aber keineswegs die einzigen Elemente für die späteren Seitenstücke; diese haben sich vielmehr am fertigen Schüdel dadurch vergrössert, dass sich ein Knochenstück, welche's in seiner knorpeligen Grundlage der Ohrkapsel angehörte, mit ihm verbunden hat. Yon diesem hinochen wird beim Schläfenbein näher die Rede sein. - Die Occipitalia laterulia erhalten seitwärts bald eine bogige Leiste zum Ansatz von Muskeln.

Die unpaare Schuppe (Occipitale superius) ist ziemlich umfïnglich und hei reifen Embryen und ganz jungen Thieren sitzen an ihrem oberen und vorderen Rande zwei auffüllige Höcker, weisser von Farbe als die übrige Schupue. ") Im Inneren der Höcker sind die Enden der Kialksäckchen des Ohrlabyrinthes geborgen, wesshalb ich noch einmal bei Besprechung des Gehörorgans diuruuf zurückkommen werde. Beim fertigen Thier erhebt sich an dieser Stelle ein cylindrischer medianer Vorsprung, der nichts mit den vorerwähnten Höckern, wohl aber mit Theilen des Knorpelschädels zu thun hat.

\footnotetext{
') Zweite Tafel, Fg. 32, a.

3) Dritte Tiufel, F'. $38, a, b, b$.

3) Fig. 38, c.
} 
Ein cylindrisches aus echtem Knorpel bestehendes Stück von etwa einer Linie Lünge sitzt auf diesem Kinochenvorsprung der Hinterhauptsschuppe und erstreckt sich von da in eine mittlere Aushöhlung des Scheitelbeins. Am macerirten Schädel hat sich das Knnorpelstück vom Hinterhauptsbein gelöst und der walzige Vorsprung der Schuppe, dem er aufsass, zeigt auf der Verbindungsflïche eine strahlige Beschaffenheit. ${ }^{1}$ )

Ausser diesem unpaaren, ein Knorpelstück tragenden walzigen Knochenvorsprung gibt es einen paarigen Höcker am oberen Rande des Schläfenbeins, genauer Felsenbeins, welcher schon jetzt erwähnt sein soll, da er von gleicher Beschaffenheit ist und sich auf ihm die vorhin angezeigten nach rückwärts gekehrten Seitenstreifen des Primordialschädels anheften mögen. Diese drei Knochenzapfen erscheinen am frischmacerirten Schädel nicht blos eigenartig durch eine strahlige Endfliche, sondern auch durch ihre röthliche Farbe, welche von dem Weiss der Umgebung absticht; alle drei sind auch wohl erst nachträglich aus Knorpelfäden des Primordialschädels entstanden. Zwischen der Schuppe und dem Scheitelbein bleibt längere Zeit (an jungen Thieren) eine grössere Fontanelle, durch deren mittlere Verbreiterung der mediane Knorpelstreifen geht. ${ }^{2}$ )

Das Keilbein besteht aus dem Körper, der gross und breit ist, und nach vorne in eine mittlere Platte oder Schnabel vorspringt. Die hintere Grenze zwischen ihm und dem Körper des Hinterhauptbeins bleibt bei genanerem Zusehen fast immer als Nath bemerklich. Nach oben erhebt sich jederseits ein kurzer flügelartiger Theil, den ich als Andeutung einer knöchernen Ala superior nehmen möchte, womit freilich sehr gegen die Cuvier'sehe Deutung verstossen würde. ${ }^{3}$ ) Nach unten und aussen gehen starke untere Flügel oder Flügelfortsütze (Processus pterygoidei) ab, mit welchen dann die Flügelbeine oder Ossa pterygoidea articuliren. ${ }^{4}$ )

Betrachtet man das Keilbein von oben und innen, so zeigen sich vorne, wo der Schnabel in den sogenannten vorderen Keilbeinkörper übergeht, zwei rein walzige Vorsprünge, - man könnte anch sagen - kurze Stäbe, von demselben Aussehen, wie die bereits erwähnten drei Fortsätze in der Hinterhauptsgegend. Und offenbar sind sie auch desselben Ursprunges, indem sie nach Firbe und Form auf verknöcherte Partien jener Theile des Primordialschädels zurüclizuführen sind, welche RATHKE Schädelballien genannt hat. Diese letzteren erhalten sich im knorpeligen Zustande jenseits der zwei Kinochenstäbchen, wie schon bemerkt, durch's ganze Leben.

1) Zweite Tafel, Fg. 31, a; Fg. 32, b, c.

2) Fg. $32, d$,

3) Fg. 31, d.

4) Fg. 31, e. 
Ein deutlicher Türkensattel (Sella turcica) ist vorhanden, und vor ihm eine tiefe Aushöhhng' zur Aufnahme des Hirnanhanges. Unten und seitlich vom Türkensattel, in der Ecke, machen sich zwei Grübchen sehr bemerklich, welche fast für Oeffnungen genommen werden könnten. (S'ollten vielleicht Augemmuskeln hier entspringen?)

Der Erwähnung werth halte ich auch die Beobachtung, dass der eben bezeichnete Vorsprumg im Inneren des Schädels nur seinem kleineren Theile nach einen knorpeligen Vorläufer hat, seiner weitaus grösseren Masse nach aber aus Verknöcherung der harten Hirnhaut hervorgeht; wovon man sich an Durchschnitten des Schädels von Embryen aus der Mitte Juli überzengt. Mau sieht hier dentlich die bekimnte Knickung des Gehirns, aber der Vorsprung der Schüdelbasis in den Raum vor dem verlïngerten Mark erscheint nur eine Strecke weit als Fortsetzung der Knorpelbasis des Schädels; weiter nach einwärts und oben wird er von dem Bindegewebe der faltig zusammengeschobenen harten Hiruhaut gebildet.

Für das Keilbein des fertigen Schüdels liefert übrigens der Knorpel des Primordialschädels nur einen kleinen Crundstock. Am ursprünglichen Knorpelgerüste nümlich wird der hintere heilbeinkörper blos von der linorpeligen (Luerbrücke') vor dem häutigen Ausschnitt des Occipitale basilire vorgestellt; den grössten Zuwachs bezieht er offenbar von dem hinter ihm befindlichen Material des häntigen Schüdelverschlusses. ") Ferner bleibt der Raum zwischen dem Kéibein und dem Schläfenbein, mäher Petrosum, ebenfalls nur häutig geschlossen; ebenso weiter nach vorne im Bereich der Austrittsstelle des Sehnerven und Riechnerven. Es sind somit, um gleich weiter zu blicken, die hnochen, welche aus der Verknöcherung der Ohrkapsel entstehen. diejenigen, welche den Haupttheil der knöchernen seitenwand des Schädels bilden. Erwängt man diess, so können wir uns geneigt finden, anzunehmen, dass anstatt wohl entwickelter, knöchemer Alae magnae und parvale ein physiologiseher Ersatz gegeh)en sei, einmal in dem Vorhandenseiu der ('olumella, dem bekimnten senkrechten Stützknochen zwischen Flügelbein und Scheitelbein, und dium noch in spïter zu gedenkenden Verknöcherungen der allgemeinen Türüperbedeckung.

Was man den vorderen Keilbeinkörper nennt, ein Stachel, welcher vom vorderen Rande des Schmabels des hinteren Keilbeinkörpers unter scharfem seitlichem Absitz entspringt und fein anslaufend weit nach vorne sich elstreckt, so ist derselbe zu leiner Zeit knorpelig gewesen, sondern entsteht anf"s dentlichste in

\footnotetext{
1) Fg. $37, \mathrm{~b}$.

2) Fg. 37,

Loydig, Saurier.
} 
jenel Haut, welche die dreieckige Oeffnung zwischen den knorpeligen schädelbalken schliesst. Wie schon erwähnt, bleiben zeitlebens neben dem Stachel und seiner breiteren Wurzel die nach vorne ziehenden linorpeligen Schädelbalken bestehen.

Bei Untersuchung des Felsenbeins oder der Knochen, welche das Ohrlabyrinth umschliessen, wird man, was oben ebenfalls bereits herührt wurde, gewahr, dass in den Seitenstücken des Hinterhauptbeins ein guter Theil vom Vorhof, ferner rom hinteren Bogengang, sowie eine kleinere Partic des äusseren oder horizontalen liegt; der hintere und vordere Bogengang erstrecken sich auch in das Occipitale superius. Diese Anfuahme eines Theiles des Ohrlabyrinthes, welches doch am Primordials:hïdel von einer besonderen Lnorpelkapsel unschlossen erschieu, in die seitlichen Partieen und Schuppe des Hinterhauptbeins muss befremden und unverständlich bleiben, so lange man in den verhältnissmässig schmalen, die Wirbelbogen an Lunfang weng übertrettenden, knorpeligen Stücken der Occipitalia lateralia die - einzigen Elemente der späteren seitentheile des Hinterhanptbeins erblicken will. Allein das Unklare hellt sich befriedigend auf, weun man bei Embryen sieht, dass beim Verknöcherungsurocess der Ohrkapsel diese in drei Linochenstücke sich aus einander legt: in ein vorderes, hinteres und oberes: Prooticum, Opisthoticum und Epioticum, wenn wir die von HuxLEY eingeführte Bezeichnung anwenden wollen. Das hintere, mit dew Occipitale laterale des Primordialschädels zusammensehmelzend, bildet das spätere seitliche Hinterhautbein. Das obere (Epioticum), schon gyleich bei beginnender Verkalkung vom Occipitale superius weniger abgesetzt als vom Pro- und Opisthoticum, wird mit der Schuppe zu einem Ganzen; das vordere oder Prooticum den Hauptheil des Ohrlabyrinthes in sich bergend, gestaltet sich zum Us petrusum.

Schon Ratnke hat bei der Ringelnater einen Theil dieser Gliederung der Ohrliapsel und Verschmetzung mit dem Hinterhauptbein wahrgenommen. Eine der Figguren, welche ich ron, einem Embryo der Blindschleiche ${ }^{1}$ ) vorlege, ist bei durchfallendem Licht gezeichnet, so dass die Stellen mit den abgesetzten Kalksalzen dunkel erscheinen; und man sieht, dass während die hellen Theilungslinien zwischen den drei Theilstiicken der Ohrkapsel dentlich und rein durchgreifen, die Verkalkung des Occipitale Jaterale schon jetzt über die Grenzlinie herüber zum Epioticun greift. Auch ist um diese Zeit bequem zu sehen, welche Particen der Bogengänge des Labyrinthes auf die drei Theilstücke der Ohrkapsel kommen.

Das Foramen ovale ist gross, hat eine runde Form und anf ihm ruht das knorpelige Opereulum. Das fenster liegt zwischen den aus der Ohrliapsel hervorgegangenen Knochenstäcken und seht uhne Unterbrechme jetzt noch in eine fontanelle fort, welche nach unten zwischen Petrosum, ()ecipitale laterale und (Iceipitale basilare sich ausbreitet und wohl zum Foramen rotundum wird. Am fertigen sichälel nuterscheidet man deutlich das Foramen ovale, welches oben liegt, damn

1) Fg. 25 auf der zweiten Tafel; vergl. auch Fg. 36 auf der dritten Tatel. 
darunter das Foramen rotundum. Davor machen sich, ebenfalls übereinander, zwei kleine Löcher bemerklich, welche dem Austritt von Nerven dienen.

Auch - was gleich hier erwähnt sein mag - der starke Querfortsatz der beim fertigen Schädel den (ielenktheil ${ }^{1}$ ) für das Qnudratbein bildet und gewöhnlich dem occipitale laterale zugesprochen wird, gehört nath seiner Entwicklung ebenfalls der (Mhrkilpsel an. Min sieht an Embryen, deren (Quardrathein ${ }^{2}$ ) schon knöchern geworden, wie dassellse der Ohrkapsel unmittelhar angeheftet ist, eine Erfahrung, die ein weiteres Verständniss in diese Partie des Schädels eröftuet, und lie Homologie des Quadratheins mit dem Tympanicum der säuger anch von dieser seite her erkennen litsst.

Einen Schläfenflügel ('Temporale s. Syuamosum), wenn auch in schwächster Ausbildung, könnte man in der plattenartigen seitlichen Erhebung des Felsenbeins suchen wolleu, welche mit etwas zackigem Rande abschliesst. Doch möchte auf eine solche Dentung nichts zu geben sein; das Squmosum ist bei unsem Thieren von der Bildung der eigentlichen Schädelkapsel ausgeschlossen.

Was man Scheitelbein, Os parietale nennt, ist ein Knochen, der sich aus einem parigen und unpuarigen stück aufbant. Beim Embryo erhlickt man nimlich von der S'eite der Ohrkipsel heraufgreifende schmale Kinochen, welche nach vorne in bogige spangen anslaufen, und zusammen eine weite Oeffnung umgrenzen, welche zmnïchst nu hatutig geschlossen ist, also eine sehr grosse Fontanelle darstellt. ${ }^{3}$ ) Diese palarige erste Anlage, welche später die hinteren Bogenschenkel und einen Theil der seitlichen Particen des Scheitelbeines bildet, müsste man, indem man sich an die Dentung, welche Luvier vom Krokodilschädel gegeben hat, anschliesst, für die Zitzenbeine, Mastoidea halten. Indem später zwischen diesen Mastoidea diss hïutige schädeldach ossificirt, entstehen die Elemente des eigentlichen Scheitelbeines, zwischen denen einerseits und den Stimbeinen andrerseits liugere Zeit sich noch eine dreieckige Lücke erhält. Selbst an Thieren, welche schon einige Zeit geboren sind und deren Schitdel etwa drei Limien Länge hat, ist als Rest der Fontanelle ein kreisrundes Loch ${ }^{4}$ ) im jetzt einzigen Scheitelbein geblieben, zum Durchtritt von Blutgefïssen. Das fertige Scheitelhein ${ }^{5}$ ), welches eine grosse umpare Platte, vorne mit zalkigem liande, hinten mit zwei, zum Querfortsatz des Hinterhauptbeins herab-

\footnotetext{
1) Fig. $31, \mathrm{~g}$.

2) Vergl. zweite 'lafel, F'g. 26, bei durchgehendem Licht gezeichnet.

3) Zweite Tafel, Fg. $23, \mathrm{~h}$; Fg. 32, e; dritte Tafel, Fg. 38, d.

1) $\mathrm{Fg} .32, \mathrm{f}$.

3) $\mathrm{Fg} .34$.
} 
steigenden Schenkeln, die langer sind als bei Lacerta, dirrstellt, ist sonach eine Terschmelzung aus línochen, welche lange zuvor bestanden - den vorhin Mastoidea genannten Theilen - und Ossificationen, welche erst später hinzutraten. Diese Auffassung, wornach das Mastoideum gleich dem Temporale und den (Luadrato-jugale ein ausserhalb Der Begrenzung der eigentlichen Schädelkapsel befindlicher línochen wïre, wird aber der entschieden verlassen, welcher den embryoualen Schädel der Blindschleiche prüft. Denn hier springt klar in die Angen, dass das Opisthoticum oder hintere Stück der verknöchernden Ohrkapsel das Homologon des Hastoideum der Säugethiere ist, also ein Knochen, der bleibend eine nähere Beziehung zur Schädelwind, insbesondere zum Ohrlabyrinth behailt. Luten bei Lacerta wird auf diesen Punct noch einmal eingegangen werden.

Zwischen den Bogenschenkeln des fertigen Parietale findet sich ein Ansschnitt mit Vertiefung zur Aufnahme des früher beim Hinterhanptbein ervähnten linorpelstïckes. Ein medianes Loch, welches sich in der Platte des Scheitcheines bei Eidechsen zeitlebens erhält, ist hier bei der Blindschleiche nur in der Jugend di; später schliesst es sich und lïsst als Spur eine rundliche Vertiefung oder (irübchen an der Innenseite der Platte zurück. - Ein Theil deș Knochens erhält oben durch Verkalkung der daranfliegenden Lederhant eine Fínste, die von Furchungslinien so durchzogen ist, dass die Oberflüche dieser unpaaren Platte von anssen wie ans einem grösseren mittleren Stück von dreieckiger Form, sammt kleinem, ungeführ viereckigen Endstück und zwei seitlichen Theilen zu bestehen scheint. ${ }^{1}$ )

Die Stirnbeine, Frontalia, erhalten sich zeitlebens paarig; bei jüngeren Thieren ist selhst noch trotz der deckenden Hantinerustation die Tremnungsinie sichtbar; später schwindet letztere allerdings derart, daws dils Stirnhein von aussen wie ein einziges erscheint; am gut gereinigten linochen lïsst sich aber von imen her") das Gedoppeltsein sicher sehen. Zur Umgreifung des rorderen Theils des (irosshirns und des Riechkolben, dient ein mach unten absteigendes Blatt, welches breiter ist als bei Lncertu. Senkrechte Schnitte an dieser Stelle dureh den schiatel gelegt, helehren, dass der Abschluss nach unten durch zwei dem Primordialschädel angehörende Knorpelleisten geschieht, die durch ihre bindegewebige llülle oder Perichondrium mit dem linorpelseptum zusammenhängen, ohne ummittelbare Ausstrahlungen desselben zu sein. ${ }^{3}$ ) Ausser diesen Hauptstirnbeinen sind auch noch am rorderen und hinteren fiand der Augenhöhle Nebenstimbeine vorbanden, sog. Frontalia orbi-

1) $\mathrm{Fg} .32, \mathrm{~g}$.

3) Dritte Tafel, Fg. 45.

3) Fg. 46 . 
talia anteriora und posteriora. Das hintere ${ }^{1}$ ) erscheint, was schon Cuvien meldet, in zwei Stücke zerlegt, wovon das eine von langgezogener Form sich zwischen das Ende des Cuadrato-jugale und das Jugale schiebt, wïhrend dis vordere von ausgezogen dreieckiger Gestalt die Hanptrerbindung nit dem eigentlicheu stimbein, den hinteren Nebenstirubein und dem Jochbein hat. Auch das Frontale anterius zerlegt sich jederseits in zwei stüche, woron sich das vordere zwischen Nasenbein, Oberkicfer und Hauptstirubein einschiebt, während das hintere mit zwei lïmdern frei in die Augenhöhle vorspringt. Dieses letztere fällt am embryonalen Sichädel durch seine weissere Farbe bei auffallendem, und dunklere bei durchehendem Lichte, vor den andern aus Bindegewebe sich bildenden Tinochen anf; es erimert daturch mehr an die Knochen, welche eine knorpelige Grundlage haben.

Die Nasenbeine, Nasalia, bleiben ebeufalls paarig, wenn auch von oben her durch die Sculptur der Hantincrustation dieser (harakter sich verwischt. Zwischen den scharf begrenzten Nasenbeinen, dem Zwischenkiefer und Oberkiefer wölbt sich die knorpelig bleibende Nasenkapsel stark hervor.

Bei JoH. MÜLLER ${ }^{2}$ ) erhält das einzelne Nasenbein nach rückwärts eine unrichtige Gestalt, indem dort übersehen ist, dass anch das vordere stimbein jerlerseits in zwei stücke zerfälit. Anf rer betreffendeu Abbildung wird das eine derselhen zum Nasenbein gezogen und letzterem damit eine eigenthümlich bogenförmig verlängerte Gestalt gegeben.

Das 'I'hränenbein, Lacrimale, nennt JoH. MÜLLER „ausserordentlich klein“, alus welcher Angabe, sowie aus der Abbildung hervorzugehen scheint, dass unserem Forscher, diazmmal wenigstens, das eigentliche Latcimale gar nieht beliamnt war. Was er so nennt und zeichnet finde ich nicht an den Schädeln, welche mir vorliegen, so dass ich an einen Schalthnochen denke. Dis wirkliche Latcrimale ist, wie bei den Eidechsen, ein sehr ansehnlicher Knochen und von ganz ähnlicher Form wie dort, auch insofern, dass das, "Loch des Thräneubeins" durch einen Ausschnitt des Larcimale und der auschliessenden Knochen, als da sind Oherkiefer mod Jochbein, zu Stande kommt.

Der $\mathrm{L}$ wischenkieferknochen, Intermaxillare, wird parig ${ }^{3}$ ) angelegt; beicle Stücke schmelzen aber später imnig zu einem finochen zusimmen. ${ }^{1}$ ) Doch ist z. 13. in der Zeit wo dieser Kñnochen den Eizahn trägt, der anfsteigende Theil (Ajo-

1) Fg. 38, g, h. Die Veroindung mit den andern Knochen gibt Fg. 26 iuf der zweiten 'lafel.

2) Anatomie der Amplibien, (a. a. O.) Taf. XX, Fg. 4.

3) $\mathrm{Fg} .28, \mathrm{a} ; \mathrm{Fg} .29$, a.

4) Fg. 42 . 
physis internasalis ('uv.) noch deutlich parig, während der die Zühne tragende Bogen keine Trenumgshinie mehr wahruehmen lässt. Der fertige Knochen mit seinem Zahnbesatz hat Aehnlichkeit mit einem Handrechen, dessen Stiel der aufsteigeude spatelförmig verbreiterte 'Theil entspricht. An der hinteren Fläche des Fortsatzes (Processus frontalis) erhält sich eine Strecke weit eine mittlere tiefe Furche, als letzter Rest der Verschuelzungshinie. Der zahntragende Bogen (Processus maxillaris) entwickelt gegen die Mundhöhle zu eine zierliche, bogig ausgeschweifte Platte (Processus palatinus). Diese Gegend am Schädel weicht in den Linien merklich ab von der gleichen Stelle bei der Eidechse; insbesondere bleibt anch da, wo Zwischenkiefer, Oberkiefer und Pthugscharbein zusmmentreffen, jederseits eine Lücke am Boden des Nasemannes, die nu durch den Nasenknorpel uud die überziehenden Śchleimhäute zugedeckt wird.

Das Jochbein, Jugale, trägt zwar zur Bildung des Augenringes bei, aber es sendet lieine Kinochenbrücke weiter rückwärts zum Quadratbein, sondern wie bei den Eidechsen ist der entsprechende Theil ein Band geblieben. Am Oberkieferfortsatz des Jochbeins hat sich das Ende als ein besonderer Theil abgelöst. So fasse ich wenigstens das "kleine Knöchelchen“ auf, dessen .JоH. MÜLLER zuerst gedenlit und an gedachter Stelle liegt.

Das Quadratbein, Os tympanicum, ist kürzer, gerader und viel weniger ausgehöhlt als bei Lacerta, während die darüber liegenden Knochen, das kleine 'Temporale s. Squamosum und das grössere Quadrato-jugale, um vieles länger und grätenartiger sind als bei den Eidechsen. Das Temporale, näher besehen, erscheint nicht blos in Limriss sichelförmig, sondern ist auch platt, mit zugeschiarftem Ramd, und läuft sehr spitz aus. Auch das Quadrato-jugale ist gegen die Spitze hin platt und zugeschairft. ')

Vergleicht man noch die Vomera und Pterygoidea sammt Transversa mit den gleichen hinochen der Eidechsen, so zeigt sich zwar durchaus im Wesentlichen die gleiche Bildung, aber in Näheren besehen immerhin von einer dbänderumg, wie man sie bei zwei verschiedenen, wenn auch verwandten Gruppen erwarten darf. Insbesondere siud die Pflugscharbeine breiter als bei den Eidechsen, während Ganmen- und Flügelbeine sich wieder mehr ins Enge ziehen, so dass am skeletirten Schädel ein weiter hamm in der Mitte klaflt, der bei Eidechsen nur hinten besteht, nach vorne aber linienförmig schmal wird.

Wie bereits hin und wieder angedeutet, sind die Grenzlinien der Knochen

") Vergl. vierte Tafel, Fg. 48. 
des Schädeldaches, und etwas zur Seite herab, unkemutlich durch die Verkalkung der Lederhaut, welche den Konf überdeclit. Die Furchen, welche in diese linochenliruste eingreifen, folgen gewissen Bildungen in der Hatut und nicht den darunter liegenden Kinorhen, wovon nachher bei ren Eidechsen näher die Rede sein wird. Die Knochenkiaste erstreckt sich über den Bereich eines, zuteu 'Theils rom Scheitelbein, von den Haupt- und Febenstirnbeinen, Nasenbeinen, 'Thlünenbein, einem Stück vom Oberkiefer. Indem diese Verkalkung der Lederhant anch über die drenzen der eigentlichen Schädelknochen hinausgreift, entstehen Knochen die keine Grundlage in der embryonalen häutigen Schädelkapsel haben, sondern als reine Hautlinochen zu bezeichnen sind. Dazu gehört die Plättchenreihe der Lamina superciliaris.

Es darf an dieser Stelle wohl ausdrücklich daran erinnert werden, dass bereits vor beinahe vierzig Jahren JoH. MüLter, als es ihm darum zu thun war, die Verwandtschaft der Blindschleiche mit den Eidechsen auf anatomischem Wege noch ticfer zu begründen, als es den Vorgängern gelungen, eine sorgfïltige Zergliederung des Schüdels vornahm, mit welcher er selbst so zufrieden war, dass er nichit unterlässt zu sagen, er bezweitle, dass man diesen Schädel genauer untersuchen kömue, als es von ihm geschehen sei. ${ }^{2}$ )

Wirbels a ule.

Der erste Halswirbel, Atlas, ist ringförmig, dabei klein und niedrig und zerfällt beim Maceriren leicht in drei Stücke: in ein Mittelstück und zwei Bogentheile. Was Mittelstück besitzt einen nach unten gerichteten Fortsatz und entspricht wohl den unteren Bugen. Fon den oberen Bogentheilen, deren jeder eine rückwärts gerichtete Zarcke zeigt; dart besonders hervorgehoben werden, dass sie ohen sich nicht berühren, der Wirhel somit oben offen mol im Leben nu durch Bindegewebe geschlossen ist. - Das Mittelstück, früher Körper genannt, gilt seit den Untersuchmogen líthikes ${ }^{\prime}$ ) als unterer Bogen und der Zahntortsatz des närchsten Halswirbels als der zum Atlas gehörige Körper. Ohne an dieser Dentumg etwa rëtteh zu wollen, sei doch hemerkt, diss bei den Embryen unsrer Blindschleiche zur Zeit, wo nouh eine umunterbrochene litackenseite das Rückerat durchzieht, und zwar in der Weise, dass sie zorischen den Wirbeh verdünnt und innerhall der Wirbel verdicht elscheint, der Körver des Epistropheus eine solche Anschwellung der chorda in sich birgt, in dem Zahnfortsatz abeq die Chordar bereits den Gridd der Verjüngnng angenommen hat, den sie durch den Atlas und das Hinterhauptssegment beibehält.

Der zweite Halswirbel, Epistropheus, ${ }^{3}$ ) hat ausser seinem Zahufortsatz an der unteren fläche zwei hintereinander stehende Dornen, deren trenzlinien an hörler deutlich bleiben. ${ }^{4}$ ) Der (querfortsatz ist gering. Der Dornfortwatz des oberen Bogens

1) Beitrïge z. Anatomie u. Naturgescl. der Amphibien, in d. Zeitschr. für Physiol. Bd. 4, 1832.

2) Entwicklungrgreschichte der Natter, 1839, S. 119.

9) Vierte Tafel, Fg. 56.

†) An den Embryen sind es wohl gesonderte Stücke; vergl. zweite Tafel, Fg. «ủ. 
ist eine hohe starlie Leiste und an aufgehellten reifen Embryen, wobei alle Theile in ihrer Lage bleiben, ist ersichtlich, dass die beiden Bogen gleich deuen des Atlas oben noch unverbunden sind, ${ }^{1}$ ) während vom dritten Wirbel an dies geschehen ist. Später zeigt, wie erwähnt, nur der Atlas diese Besonderheit.

Am dritten und vierten Wirbel werden die Querfortsätze stårker und es tritt an dem des dritten Wirbels die erste Halsrippe auf. Sie ist noch um ein gutes Stück kürzer als die nächste, aber schon ganz rippen- das heisst spangenartig, lieineswegs breit, wie solches bei Lacerta der Fall ist; Anguis besitzt keine einzige derartige, so eigenthümlich geformte Halsrippe. - Die dritte und vierte erseheint stark winklich gebogen und an ihnen sitzt der Schultergürtel. - Die unteren Dornen der Halswirbel, welche noch am dritten und vierten vorhanden sind und wie fest verwachsen mit dem Körper, ${ }^{2}$ ) haben sich verloren.

Vergleicht man die Brustwirbel etwa einer Lacerta agilis mit jener der Anguis fragilis, so macht sich mancher Unterschied bemerklich. Diejeuigen der Blindschleiche sind stärker, sowohl was den Körper als anch die Fortsätze angeht; die vordere Gelenkfläche des Körpers ist in beiden bekanntlich ausgehöhlt, nach hinten springt ein Gelenkkopf vor. Letzterer erscheint hei Lacerta gewölbter, bei Anguis etwas Hacher; gereinigte Wirbel zeigen an der Wurzel des Gielenkkopfes eine Abgrenzungslinie, welche andeutet, his wie weit der Kopf in die Grube des nächstfolgeuden Wirbels greift. Die Querfortsätze sind bei Anguis kuí, aber dick und ihre Gelenkflüche ist nicht einfach gekrümmt, sondern wegen des ausitzenden Rippenendes durch eine mittlere Wölbung in zwei Rollen zerlegt. Alles dieses, sowie die noch hervorzuhehende Stairke der vorderen und hinteren Gelenkfortsätze del Wirbel ${ }^{3}$ ) lässt sich mit dem Umstand in Zusammenhang bringen und davon ableiten, dass im Körper der Blindschleiche, beim Nangel der Gliedmassen, der Wirhelsïule allein, unter Nachhülfe der Rippen, die Fortbewegungeu übertragen sind. - Die Gelenkfläche des Processus articularis steht schrïg und wie bei allen Reptilien decken die hintern Flächen die vordern des zunächst folgenden Wirbels.

Kreuzbeinwirbel sind zwei vorhanden und durch besondere Form leicht erkembar. Am ersten ${ }^{1}$ ) geht jederseits ein starker, in zwei Endhöcker auslaufender Querfortsatz weg; an ihn heftet sich der Beckenknochen. Der zweite") Wirbel hat

1) Fg.

2) $\mathrm{Fg} .57$, a.

$\left.{ }^{3}\right)$ Vergl. z. B. Fg. 58.

1) Fünfte Tafel, Fg. 69 .

5) $\mathrm{Fg} .70$ 
sehr breite Querfortsätze, mit einem Loch an der Wurzel und einem nach hinten gerichteten Fortsatz; leides deutet auf eine Zusammensetzung aus zwei Hälften von ungleicher Entwickelung. Uelnigens ist mir bei der Untersuchung einer gewissen Zahl von Thieren bemerkenswerth geworden, dass in der Dicke und Länge der Krenzbeinwirbel mancherlei individuelle Abweichungen vorkommen.

Auch die Schwanzwirbel haben ihre sie wohl unterscheidenden Eigenthümlichkeiten. Schon am ersten ${ }^{1}$ ) beginnen untere Bogenschenkel, welche sich zu einem C'anal vereinigen und sich leicht vom Wirbel lösen. (Bei Lacertı ist es der dritte Schwanzwirbel, allwo die untern Bogen anfingen.) Der erste Schwanzwirbel, sowie noch der zweite haben eineu derartig gegabelten (Uuerfortsatz, dass man von zwei Querfortsätzen, wovon der eine höher steht als der andere, sprechen liönnte. Diese zwei ersten Schwanzwirbel sind anch im Körper kürzer und breiter und ohne die Sonderung in zwei Stücke. Die nächsten Wirbel sind gestreckt, vorne gleich den übrigen Wirbeln ausgehöhlt, hinten mit Gelenkkopf, was ich kaum erwähnen würde, wemn nicht JoH. MÜlLer von den Schwanzwirbeln sagte: „eigenthümlich ist ihnen, dass sie nicht mehr durch Gelenkköpfe und entsprechende Aushöhlungen der Wirbelkörper, sondern durch blosse Facetten verbunden sind“. Diese Bemerkung darf um so mehr autlallen, als der Gelenkkopf sehr hervorsuringt. Bei den Eidechsen erscheint aber in der That das vordere und hintere Ende der letzten Schwanzwirbel so gebildet, wie JoH. MƯLLER angab, wovon unten.

Der Wirbelkörper besteht aus einem vorderen kleineren, die Concavität tragenden und einem hinteren längeren, in den Gelenkkopf auslaufenden Theil. ${ }^{2}$ ) Die Trennungslinie hleibt gut.sichtbar, anch lösen sich bei längerem Maceriren die Stücke vou einander al). Entsprechend diesen beiden Hälften entsteht auch der nach aussen zugespitzte Querfortsatz an seiner Wurzel aus zwei Stücken, welche je einer Hältte des Körpers zukommen, was sich anch durch eine grössere dreieckige Oeffuung an der Wurzel des Querfortsatzes ausdrückt. Die untern Bogen sind übrigens die längsten Fortsätze der noch vollständigen, nicht verkümmerten Schwanzwirbel. - Die Wirbel werden ringsum von Fett umgeben, welches in sehr regelmässigen Reilen sich folgende Kilümphen bildet. Auf einem Querschnitt durch den ganzen Schwanz umziehen siè den Wirbel so, dass nur die Spitzen der obern und untern Bogen hervorstehen. Erst jenseits dieser Fetthülle beginnt die Musculatur. ${ }^{3}$ )

Am Ende der Schwanzwirbelsäule ergeben sich einige Besonderheiten. Die

\footnotetext{
1) Vierte Tafel, Fg. 59.

2) Fig. $60, a, b$.

3) Sechste Tafel, Fg. 84.

Leydig, Saurier.
} 
letzten Wirbel sind sehr klein geworden und schieben sich nahe zusammen; doch haben sie Spuren der verschiedenen Fortsätze behalten. Die untern Bogen sind aber jetat nach unten nicht mehr verbunden, der Canal somit offen und die einzelnen Schenkel haben eine annähernd ankerförmige Gestalt angenommen. ${ }^{1}$ ) Der letzte eigentliche Wirbel ist nur noch ringförmig, daher der Canal zur Aufnahme des Rückenmarks hinten offen steht und sein Verschluss geschieht auf eigenthümliche Weise.

Bekanntlich geht der unverletzte Schwanz der Blindschleiche in eine Hornspitze, wie man sagt, aus. Bei näherer Betrachtung ist es aber eigentlich ein becherförmig ausgehöhltes Knöchelchen, das bei gewisser Ansicht den Schälchen unserer Flussnapfschnecke ähnelt. ${ }^{2}$ ) Seine Aussenfläche ist streifig-höckerig. Man kömnte, so lange man nur das fertige Thier vor sich hat, im Zweifel darüber sein, ob man das Knöchelchen als einen Hautknochen von umgebildeter Form ansehen, oder ob man es zum Wirbelskelet als Schlussstück zählen soll. Bei Besichtigung von reifen Früchten erhält man sofort die Belehrung, dass man es nur mit einem Hautknochen zu thun habe.

Am Schädel erhalten sich nach dem oben Vorgetragenen vom primordialen Gerüst zeitlebens viele Theile. Die Rückensaite (Chorda dorsalis) schwindet aber völlig; doch sieht man bei reifen, dem Geboren werden nahen Embryen in den Wirbelkörpern starke Ueberreste des Chordastranges, welche immer durch das Intervertebralgelenk unterbrochen werden.

Rip pen.

Die Rippen sind alle sogenannte falsche Rippen, beginnen am dritten ${ }^{3}$ ) Halswirbel und erstrecken sich bis zum ersten Kreuzbein- oder Beckenwirbel; jedoch mit individuellen Verschiedenheiten, indem bei dem einen Thier noch am Wirbel vor dem ersten Kreuzwirbel eine Rippe ansitzt, und dann der Querfortsatz des Wirbels nur kurz ist, oder die Rippe fehlt an diesem Wirbel, hingegen erscheint der Querfortsatz lang und rippenartig entwickelt.

Auch der Form der Halsrippen wurde bereits gedacht und an dieser Stelle verdient noch hervorgehoben zu werden, dass die Rippen der Brustwirbel bei der Blindschleiche merklich dicker als bei der Eidechse sind, dann auch stärker gekrümmt. Ebenso ist das Gelenkende dicker und zeigt neben der ansgehöhlten (relenktläche ein Tuberculum. ${ }^{4}$ )

1) Vierte T'ufel, lig. til, a.

2) Fünfte 'lafel, Fg. 63 .

3) Bei den Embryen war es bereits der dritte Wirbel, welcher eine kurze lippe besass; an erwachsenen Thieren sah ich die erste am vierten Wirbel. Vielleicht schwindet die des dritten Wirbels im weiteren Veriauf.

1) Fünfte 'lafel, Fg. 76 , a. 
Nach dem freien Ende gehen die meisten Rippen in eine schanfelförmige Knorpelplitte aus, deren Gewebe wegen fist völligen Hangels der Grundsubstanz zum Zellenknorpel zu stellen ist.

Brustbein.

Las Brustbein, mmittelbar ïber dem Herzen liegend, besteht ans dem eigentlichen oder hinteren Brustbein und dem vorderen oder Episternum.

Ersteres ${ }^{1}$ ) stellt eine in die Quere gezogene dunne, daher leicht eimreissbare Platte dar, mit mittlerer schwacher Ausbuchtung am unteren hand und tiner seitlichen, schrägen, parrigen Leiste auf der älsseren Fläche. Die Platte besteht aus Hyalinknorpel, ist aber unterhalb der erwähnten Leiste einem guten Theil nach rerkalkt; insoweit diess geschehen ist, sieht das Brustbein weisslich aus.

Das Episterum “) um vieles kleiner, und anf dem vorderen und mittleren Theil der Brustbeinplatte liegend, nimmt sich etwa wie eine Spindel ans, die quer liegt und deren mittlere Partic nach vorne in einen kleineren, nach hinten in einen grösseren rundlichen Höcker anschwillt; dieser Theil besteht aus echter Kunochensubstauz und gieng aus der Verknöcherung einer bindegervebigen Grundlage hervor. Ungefialn in der Mitte, doch mehr nach oben zeigt sich ein Markraum in seinem Inneren.

Bei Untersuchung einer ganzen Anzahl von 'Thieren machte ich die Bemerkmug, dass das Epistermm mancherlei individuelle Abweichungen darbietet: die geringste ist die, dass der eine Querschenkel sich gegen den andern asymmetrisch verkürzt zeigt, daun aber erscheint er auch in audern Fällen stark verkrümmt, wie demu überhaupt rudimentäre Organe - und ein solches ist ja anch das Episternum der Blindschleiche - gerne individuell abăndern.

Wegen der verschiedenen histologischen Beschaffenheit unterscheidet sich Brustbein und Episternum schon für die Lupe durch die Farbe: jenes sieht, was schon gesagt wurde, weisslich aus; dieses gelblich.

Ich habe ferner einen Embryo von zwei Zoll Länge und mit noch grossem Dottersack auf die Bildung des in Rede stehenden Theiles untersucht, wobei sich zeigte, dass um diese Zeit das Brustbein aus reinem Zellenknorpel bestand, während spitter Intercellularsubstanz, wenu anch nicht gerade reichlich, sich absetzt. liecht merkwürdig war das Episternum. ${ }^{3}$ ) Hier bot sich zunächst eine bindegewebige Grundlage von ziemlich regelmässig dreieckiger Form dar; ditun erschien diese bindegewebige Grundlage im Verhältuiss zur knorpeligeu wirklichen Brustbeinplatte grösser

1) Sechste Tafel, Fg. 79a a. Vergl. füntte Tafel, Fg. 65.

2) Fg. 79 is, b.

3) Vergl. Sechste Tafel, Fg. 80. 
als es der Knochen - das Episternum - ist, welcher daraus hervorgeht. Von diesem letzteren waren innerhalb des bindegewebigen Dreiecks die Anfünge in Form von vier sehx unregelmässigen Knochenstücken aufgetreten. Die zwei grösseren lagen gegen die Mitte zu, in die Quere und seitwärts wachsend; von den zwei kleineren befand sich der eine Knochenkern gegen das Ende der beiden Querbalken, der andere in dem medianen seitwärts gerichteten Balken.

Vergleicht man das Episternum der Blindschleiche mit dem der Eidechse, so gewahrt man leicht, dass es durchaus jenem schlanken, zierlichen, kreuzförmigen Knochen zwar entspricht, aber in's Plumpe oder Verkrüppelte gerathen ist.

In historischer Beziehung möchte ich nicht unerwähnt lassen, dass wohl HeLluann zuerst die Brustbeinplatte sicher gekannt und, wenn auch nicht ganz richtig, abgebildet hat. ${ }^{2}$ ) Von dieser Beobachtung scheinen weder der genaue HeUsisger, noch der umsichtige JoH. MüLler etwas gewusst zu haben, da sie beide das Brustbein bei Anguis fehlen lassen, was ich mir bei dem ersten Forscher damit erkläre, dass er nur ein einziges Exemplar untersucht hat. Da nun beim Abziehen der Haut das Brustbein gar leicht an dieser hängen bleibt, so mag es dadurch übersehen worden sein. JoH. MüLLER scheint nicht selbst geprüft, sondern sich auf Heusinger verlassen zu haben. Dann war es Cuvier, relcher vielleicht selbstständig ${ }^{\text {2) }}$ das Brustbein der Blindschleiche wieder auffand.

Das Episternum ist wohl zuerst von RATHKE ${ }^{3}$ ) gesehen und sehr genau beschrieben worden. Er nennt es das kleinere Stück, es habe eine Aebnlichkeit mit einem Kartenherzen, seine Masse sei eine feste, harte Knochensubstanz mit verzweigten Knochenkörperchen. - Der jüngste Beobachter, Fürbinger, hat offenbar die Theile des Brustbeins nicht so genau untersucht, wie RATHKE es gethan hat. Denu einmal lässt er das "knorpelige Sternum" biconvex sein; dann meint er zweitens, das Episternum sei „durch eine rauhe Knochenstelle am Vorderrand des knorpeligen Sternums repräsentirt", welche Augabe Jeder so deuten wird, als ob dieser Knochen nicht selbstständig wäre. Und dass unser Autor wirklich dieser Ansicht ist, verräth eine andere Stelle (a. a. 0. S. 61), wo er sagt, bei Anguis fragilis gehe das Episternum „ohne Grenzen in das Sternum" über. Es ist aber in der That nicht schwer, sich zu überzeugen, dass der Knochen, wenn auch verkümmert, doch ein selbstständiges Glied des Brustgürtels ist.

Sehulterknochen.

Das S'chultergerüst ) wird zusammengesetzt aus dem Schlüsselbein (Clavicula), dem Hackenschlüsselbein (Coracoideum) und dem Schulterblatt (Scapula).

Das Schlüsselbein stellt einen etwas winkelig gebogenen, sonst einfachen Stab dar, welcher aus der Verknöcherung von Bindegewebe hervorgegangen ist; er zeigt sich daher um vieles härter und weisser als die übrigen Gilieder des Schultergerüstes. Die Knochenkörperchen haben, entsprechend der Form des Kinochens in Ganzen, fast durchweg eine längliche Gestalt.

1) Ueber den Tastsinn der Schlangen. Göttingen 1817. „Das Sternum, welches die Form eines sphärischen Dreiecks hat, ist sehr dïnn, liegt auf der Mitte der Brust und ist durch Ligamente mit den Schulterblättern verbunden. .

") Ich vermag leider nicht die zweite Ausgabe seiner vergleichenden Anatomie, wo 'Tom. I. Pag. 253 die Angabe stehen soll, zu vergleichen.

$\left.{ }^{9}\right)$ Bau und Lntwicklung des Brustbeins der Saurier. 1853.

4) Fünfte Tafel, F'g. 65 u. Sechste Tafel, Fg. 79 … 
Das schulterblatt, nach oben und seitwarts gekehrt, verbreitert sich in dieser Richtung etwas, doch viel weniger als solches vom freien Endstück des Hackenschlüsselbeins zu melden ist, welches dadurch vor dem Herzen eine breite Platte erzengt, die mit jener der anderen Seite zusammenstüsst. Die Platte verbindet sich mit dem sichulterblatt ausser dem eigentlichen Coracoideum noch durch eine Knorpelspange oder Procoracoid, so dass zwischen dem Schulterblatt, der Spange und dem Hackenschlüsselbein sammt plattenartiger Endverbreiterung, ein grösseres länglich ovales Loch oder Fenster bleibt.

Alle die zuletzt genannten Theile bilden zusammen eine einzige Masse und stellen histologisch einen verkalkten Knorpel dar, von dem sich nur das eigentliche Coracoideum zu einem wirklichen Knochen fortentwickelt hat.

Will man die Stücke des Brustbeins und jene des Schultergürtels vom histologischen Gesichtspunct mit einander vergleichen, so entsprechen sich als ossificirte Bindegervebspartieen das Episternum und Clavicula einander; das eigentliche Sternum, das Schulterblatt sammt spangenartigem Ausläufer und Endplatte stellen verkalkte Knorpel dar; somit erhält das Coracoideum eine Sonderstellung dadurch, dass es zwar beim Embryo ebenfalls nur verkalkter Knorpel war, aber zuletzt nach Einschmelzung der verkalkten Partieen, und Neubildung wahrer Knochenlagen, wohl ron der Beinhaut her, zu echtem Knochen wurde.

Seit Schnerder zuerst auf Rudimente eines Brustgürtels bei Anguis fragilis aufmerksam machte, sind die Knochen ron Helcirann, Cuvier, Mecrel und Heusinger, welcher die Clavicula als "Gabel", das Coracoideum als "Schlïsselbein" bezeichnet, vielfach abgehandelt worden. Zuletzt hat sich GegexBaur ${ }^{1}$ ) darüber ausgesprochen: den vorderen Schenkel des Coracoides nennt er Procoracoid,' die beilförnige Yerbreiterung am Bauchende Epicoracoid.

Beckenknochen.

Das Becken der Blindschleiche ist bekanntlich sehr rudimentär und wird nur von einem einzigen Knochen jederseits dargestellt; beide stossen bauchwärts nahe aneinander, olme aber unter sich verwachsen zu sein. ${ }^{2}$ ) Man hat bisher gewöhnlich den Kunochen als Darmbein gedeutet; ich halte es aber für richtiger anzunehmen, dass auch die Anfänge der übrigen Theile eines vollständigen Beckens in dem Einen Knnochen enthalten seien. - Auf eine Widerlegung der von MAYER ${ }^{3}$ ) rorgebrachten, und wie er meinte ausser Zweifel stehenden Meinung, dass das „Beckenrudiment" nicht dem Becken, sondern der hintern Extremität entspreche, braucht min wohl sich nicht mehr einzulassen.

1) Untersuchungen z, vergleichenden Anatomie d. Wirbelthiere. 2. Heft. Schultergürtel der Wirbelthiere. Brustflosse der Fische. 1865.

3) Fünfte Tafel, Fg. 62.

3) Ueber die bintere Extremität der Ophidier. Nov. act. Acad. Leop. Carol. Vol. XII, p. 831. 
Was zunächst die Lage im Näheren betrifft, so findet man die Beckenknochen zur Seite der Kloake, und genaueres Zusehen ergibt, dass sie die vordere Lippe der Kloake umgreifend mit dem Bauchende gerade über dem Stiel der Harnblase stehen. Das obere oder Rückenende der Knochen ist dem ersten Kreuzbeinwirbel angeheftet und zwar so, dass wie es anch sonst bei entwickeltem Becken der Fall ist, das Ende über den Querfortsatz des Wirbels hinausragt.

Wenn man reife Embryen durch Reagentien aufhellt, so zeigen die beiden Beckenhälften eine ungemein starke Neigung nach vorne, wodurch ihr Bauchende der vierten Rippe, von hinten her gezählt, gegenüber liegt. Allein diess ist nicht das ganz natürliche Verhalten, sondern wie die jetzt weit offen stehende Kiloakenspalte lehrt, durch Aufquellung der Weichtheile und dadurch bewirkte Verschiebung der Knochen entstanden. ${ }^{1}$ )

Die Form des fertigen Lnochens ist in den beigegebenen Zeichmungen getreu dargestellt; wobei zu bemerken, dass am Bauchende bleibend ein kleines Knoryelstück sich erhält. ${ }^{2}$ ) Im Inneren des Knochens verbreiten sich Markräume. Interessant ist es, das Becken eines reifen Embryo nüher zu untersuchen: es tritt mis als ein Knorpel entgegen, der oben und unten zwar ein Stück weit ohne Kalkkrümeln ist, nach seiner grössten Ausdehnung aber verkalkt erscheint. Aus der verkalkten Partie hebt sich da, wo der Beckenknochen am breitesten ist, eine helle unverkalkte Stelle von querlänglicher Form scharf ab. Um den gimzen Knorpel zieht eine dicke bindegewebige Hülle, vou welcher wohl die eigentliche linochenentwicklung ausgeht, wenn der verkalkte Knorpel sich wieder gelöst hat.

Mir scheint nun bezüglich der Deutung des Knnochens wichtig, dass man gar wohl die helle abgegrenzte, nicht verkalkte Stelle, welche innerhialb des breitesten Theils sich bemerkbar macht, als den Ort ansehen kam, wo sich die Pfanne bilden würde, wenn ein vollkommenes becken zu entstehen und Extremititen sich anzuschliessen hätten. Und demzufolge betruchte ich den nach oben anslanfenden Theil als Darmbein, den nach unten gehenden kürzeren als Śchambein; das Sitzbein wäre in dem von der Pfannengegend nach hinten gerichteten Fortsatz zu erblicken. Das bleibende Kinorpelstück am Bauchende könnte an die medianen Linorpel bei Lacerta erinnern.

Die lier uber die Deutung des Beckenknochens der Blindschleiche niedergelegte Ansicht hege ich seit Langem. Um so angenehmer war es mir zu sehen, dass FurbrivgnR, dessen Studien ganz besonders auf diesen Punct gerichtet waren, lasselbe Ergebniss gewonnen hat. Während ich oben einfach vom Darm-

') Sechste Tafel, Fg. 86 .

") Fünfte Tafel, Fg. 67, d. 
Scham- und Sitzbein gesprochen habe, so bringt genannter Beobachter, im Anschluss an seine Deutung des entwickclten Beckens der Saurier, die Be\%cichnung Ileo-pectineum für Schambein (0. pubis) und Pubo-ischium furr Sitzbein (O. ischii) in Anwendung, cine Auffassung, fler ich nach dem was unten vom Becken der Eidechse zu sagen ist, beitrete. Derselbe Naturforscher bemerkt, dass, bar" seien zwisclien 0 . ilei, pubo-ischium und ileo-pectineum. Ich habe früher nichts von Näthen gesehen und möchte daher einstweilen, da ich seit der Zeit, als ich mit dessen Schrift bekannt geworden, die Theile nicht melrr untersucht labe, annehmen, dass die beim ganz jungen Thier unverkalkte Stelle, wo die Pfaune zu suchen wäre, eins und dasselbe mit diesen "Näthen" ist.

Das Becken ist selr beweglich. In früherer Zeit haben Mecker und Heusinger die ans Becken sich heftenden Muskel beschrieben; besser und mit richtigerer Deutung behandelt Fürbrixger diesen Gegenstand.

\section{Eidechsen.}

Als eine Bemerkung zum histologischen Verhalten des Skeletes möchte ich vorausschicken, dass in den Knochen das System der feineren Gefässränme, der sog. Havers'schen Canäle nicht vorhanden ist. Man sieht zwar grosse Markräume von unregelmässig buchtiger Form in den platten und in den dicken Knochen, sowie in den Röhrenknochen einen Längsraum; aber wie der Quersehnitt etwa des Humerus oder vom Femur darthun kann: ausser diesem mittleren Markraum durchbricht kein Canal- oder Lückensystem mehr die Knochenlamellen, welche daher alle einfach concentrisch verlaufen.

Nach DuGÉS wäre das Skelet der Eidechsen "presque toujours colorée en rouge", was ich nicht zu bestätigen vermag. Die Farbe hängt einigermassen von der Zubereitungsart des Skeletes ab; längere Zeit macerirt werden die Knnochen schön weiss. Lacerta vivipara, weil am meisten von dunkelm Pigment durchdrungen, hat ein schwarzliches Skelet, wobei das Pigment in der Beinhaut und ihren Fortsetzungen nach einwärts liegt; aher selbst bei $L$. viridis und agilis begleitet das Pigment wenigstens die bindegewebige Auskleidung des Markrammes der Röhrenknochen. Am entkalkten durchscheinenden Skelet wiederholen daher z. B. der Humerus, Radius, Ulna, für's freie Auge dasselbe, was man mikroskopisch an der Columella des Ohres wahrnimmt: wie dort, zieht hier ein schwarzer Pigmentstreifen durch die Lange des Knochens.

Knochen des Schảdels.

Beim erwachsenen Thier bleiben, mag auch der Schädel stark macerirt sein, so dass alle übrigen Knochen sich von einander gelöst haben, Hinterhauptbein, Felsenbein und Keilbein zu einem untrembaren ('anzen vereinigt. ${ }^{1}$ ) Ja selbst an Köpfen

1) $\approx 0$ s petrosum, cum osse sphenoideo et occipitis, in unum, os basilare conflatum, latera cranii formate bemerkt bereits richtig Ponr in seiner Expositio generalis anatomica organi auditus. 1818. 
jüngerer Thiere, allwo noch die Nähte sichtbar sind, haften sie bereits in dieser festen Weise aneinander.

Das Grundstück, Basilare, des Hinterhauptbeins zeigt an seiner unteren Fläche starke, bogige Leisten sowie Vertiefungen und Höcker für die Muskelansätze, namentlich der Beugemuskeln des Kopfes (Musculi recti). Die Seitenstücke, Lateralial, ursprünglich ganz unbedentend und wenig breiter als die rückwärts anschliessenden Wirbelbogen, verbreitern sich dureh Hinzutreten eines Knochenstückes, welches wie die Untersuchung des Embryo auch hier darthnt, ursprünglich der Ohrkapsel angehört. Es ist das Stück, welches dem Mastoideum der Säuger entspricht. Nicht minder gehört der starke Querbalken, welcher beim alten T'hier vom Occipitale laterale nach anssen geht und den Schädel am Hinterhauptbein in auffïlliger Weise verbreitert, seiner Entwicklung nach den das Ohrlabyrinth umschliessenden Knochen, und nicht dem Hinterhauptbein, an.

Der Gelenkkopf zur Verbindung mit der Wirbelsäule ist zwar ein einziger, aber bei genanerem Zusehen und namentlich an jüngeren Thieren besteht er dentlich ans drei Stücken: einem mittleren und zwei Seitentheilen. ${ }^{1}$ ) Mitunter sind freilich die ursprünglichen Trennungslinien bis auf Spuren verschwunden. Vor dem Gelenkkopf, unten und seitwärts, gerade wo der hintere Bogengaug des Ohrlabyrinthes herabbiegt, bemerkt man drei Oeffnungen, wovon wohl die eine dem Foramen jugulare zum Austritt des Nervus vagus und N. glossopharyngeus entspricht, die hinterste für den Durchgang des $\mathrm{N}$. hypoglossus dienen mag, und die dritte einem Canalis caroticus gleichliommt. Doch muss ich hierzu ausdrücklich bemerken, diss ich die Gefässe und Nerven dieser Gegend nicht näher studirt habe.

Die Schuppe des Hinterhauptbeins erhebt sich an ihrem oberen freien Rand in einen nach vorue geneigten Höcker, dem ein cylindrisehes hinorpelstück anfsitzt ${ }^{2}$ ) und sich ebenfalls schräg nach vorne gegen eine Aushöhlung des S'cheitelbeins neigt, um dort aufzuhören. ${ }^{3}$ ) Ich habe es so bei Lacerta viridis, L. agilis, L. viripara und L. muralis gesehen. Das Kinorpelstäbchen löst sich leicht ab, hört damn vorne und hinten aljgerundet anf und hat eine verkalkte Mitte. An $L$. viridis, einem jüngeren Exemplar, machte ich nach Entfermung der Kalksalze einen Schnitt durch das Scheitelbein, sammt Kinorpelstäbchen und Schuppe, wobei zum Vorschein kam, dass das vordere Ende des Tinorpelstabes sich unterhalb des Scheitelbeins in eine wabige Bildung aufïst; es schien sich der Hyalinknorpel des Stabes in Zellen umzusetzen, wie

\footnotetext{
3) Dritte Tafel, Fg. 33, a.

3) $\mathrm{Fg} .33, \mathrm{c}, \mathrm{d}$.

3) Vergl. hiezu dritte Tafel, Fg. 35.
} 
man sie als Substanz der Chorda dorsalis kennt. Uebrigens schied sich der Knorpelstab in Mark und Rinde.

Das hintere Keilbein ${ }^{1}$ ) zeigt einen breiten Körper, Basisphenoid; in einem beiderseits nach oben gerichteten schmalen Fortsatz möchte ich den Anfang des hinteren oder grossen Flügels, Alisphenoid, und in einer im Kinorpel der Augenscheidewand befindlichen, nach hinten vom Sehnerven liegenden kleinen Kinochen eine etwelche Vertretung des vorderen oder kleinen Flügels, Orbitosphenoid, erblicken.

Das vordere Keilbein, Praesphenoid, der Stachel oder nach Halumann Deichsel des Körpers vom hinteren Keilbein, erstreckt sich weit nach vorne: es übertriflt im unverletzten Zustande das Hinterhauptbein und den hinteren Keilbeinkörper zusammen an Länge, was man jedoch nur nach sorgfültigem Maceriren beurtheilen kamn. Dieses sogenannte Corpus ossis sphenoidei anterius ist anch hier bei len Eidechsen vom Körper des eigentlichen Keilbeins in der Art verschieden, dass es beim Embryo nicht knorpelig vorgebildet erscheint, sonderu aus Bindegewebe entsteht, also Belegknochen ist.

Die Columella oder jener Knochenstab, welcher von der oberen Fläche des Os pterygoideum nach oben zum Scheitelbein frei sich erhebt, ist so charakteristisch für den Schüdel der Eidechsen und Scinke, dass min wohl auch die ganze Gruppe danach zu benennen sich veranlasst glitubte. ${ }^{2}$ ) Wie man das Tinochenstück im strengeren sinne denten soll, ist schwer zu sagen; obschou man im Allgemeinen fühlt, diass es bei der Eigenthümlichkeit des Schädels, vorn und seitlich einem guten Theile nach linorpelig-hüutig zu bleiben, in physiologischen Sinne als Ersatz für festere Seitenwandungen dienen möge, welche Ausicht bereits oben, als vom gleichen Theil der Blindschleiche die Rede war, ausgesprochen wurde.

Das Felsenbein birgt den grössern Theil des Gehörlabyrinthes, doch ist eine Partie des letzteren in dem aus dem Opisthoticum, gleich IIastoideum, hervorgegangenen Seitenstücli des Hinterhauptbeins enthalten; ja selbst die Schuppe, insoweit sie sich aus dem Epioticum ergänzt hat, nimmt einen 'Theil der Bogengänge auf; die Umrisse der drei Bugeugänge, des vordern, hintern und äussern machen sich ron anssen gut bemerklich. Ein Foramen ovale und darmuter ein Formen rotundum sind deutlich; nach unten vom letzteren erhebt sich ein Torsprung, welcher zunitchst durch die Schnecke des Ohrlabyrinthes bedingt wirl, damn aber auch zu einer Leiste behufs Ansatz vou Muskeln sich vergrössert. Nach oben und rorne

2) Zweite Tafel, Fg. 30; dritte Tafel, Fg. 33.

$\left.{ }^{2}\right)$ Kinocrania von $x$ icu, columna.

Leydig, Saurier. 
erhebt sich das Felsenbein zu einer mit bogigem Rande ansgehenden Platte, wefche hier grösser ist als bei Anguis, und in welcher man abermals den Schuppentheil des Schläfenbeins vermuthen könnte; allein ich muss mich mit Ueberzeugung dem Gedankengang Cuvier's anschliessen, welcher bekanntlich zuerst aussprach, dass eine Schuppe des Schläfenbeins nur bei Sängethieren vorkomme, bei den Reptilien aber nicht mehr in die Znsammensetzung der eigentlichen Wand der Schüdelkapsel eingehe, sondern nach anssen liege, zwischen Quadratbein und Jochbein. Ich werde nachher auf dieses Temporale zurückkommen.

Bezüglich des Siebbeins, Ethmoideum, pflegt man anzunehmen, dass es ebenfalls in der senkrechten Knnorpelplatte des vorderen Schädelabschnittes mitbegriffen sei. Ich stimme dieser Auffassung zu, möchte aber zwei kleine Knochen ${ }^{1}$ ) vou stark gekrümmter Form und von unregelmässigen Ründern begrenzt, für knöcherne Seitentheile des Siebbeins halten. Sie werden sonst als Conchae oder knöcherne Muschehn aufgeführt; sitzen nach innen vom vorderen Ende des Oberkiefers. oberhalb der Vomera; einwärts stossen sie an's knorpelige Septum narium, von welchem sie etwas schwierig zu lösen sind. Sie stehen in Beziehnng zu dem darunter liegenden Jacobson'schen Organ.

Das Scheitelbein, Parietale, ist eine unpaare Platte, in der Mitte durchbohrt von einem grösseren rundlichen Loch und am hinteren Rande, welcher im degensatz zum vorderen zackigen, glatt ist, in der lichtung zu dem erwähnten Loch mit einer Aushöhlung versehen. ${ }^{2}$ ) In dieser liegt der Knochenstab, dessen hinteres Ende dem Vorsprung der Schuppe des Hinterhauptbeins ansitzt.

Auf der Innenseite des Knochens macht sich ein mittlerer Vförmiger Wulst bemerklich und es ist mir aufgefallen, wie selbst in der Bildung dieser Leisten kleine Speciesverschiedenheiten vorhanden sind. Bei L. agilis z. B. ist der Wulst entschieden stäker und auch etwas anders geformt als bei $L$. muralis, womit zusammenhängt, dass bei letzterer Art der hintere Ausschnitt, mit dem Knorpelstückichen darin, offener liegt, als dies bei $L$. agilis der Fall ist.

Nach rückwärts geht das Scheitelbein in zwei Bogenschenkel aus, welche herab) zum (Uuerbalken des Hinterhanptbeines steigen. Diese Schenkel sind, wie bei Anguis, im embryonalen schiadel linge schon zugegen, ehe das Mittelstück des Scheitelbeins anfgetreten ist. Ueber die Sculptur anf der Anssentiatche dieses und des folgenden Knochen wird noch unten im. Weiteren die Rede sein.

1) Elfte Tafel, Fg. 142, c.

2) Uritte I'afel, Fg. 35. 
Das Stirnbein, Frontale, ist parig zeitlebens. Beide Stücke biegen mit ihrem seitlichen Rande, von di an wo sie sich nach vorne verschmälern, abwärts; doch etwas weniger als bei Anguis. Es geht dieser Rand nach unten in einen scharfen Fortsatz aus, welcher weiter absteigend sich an das Thränenbein anlegt. Nach vorne, wo die Stirnbeine von den Nasenbeinen überdeckt werden, schärft sich der Rand zu und endigt in mehrere Spitzen.

Das vordere Nebenstirnbein, Frontale anterius Cuv., zwischen dem Hauntstimbein, Nasenbein, Thrinenbein und Oberkiefer gelegen, ist in seinen Grenzen durch die Knochenkruste der Hant meist verwischt; bei L. vivipara bleiben am ehesten noch die Linien erkennbar.

Das hintere Nebenstirnbein, Frontale posterius, ist entgegen von Anguis, allwo es wie schon Cuvier gesehen in zwei Stücke zerfällt, hier bei Lacerta von einem einzigen Knochen vorgestellt; wovon man sich überzeugt, wenn man von innen her das Schädeldach besieht. Von anssen aber erscheint es durch eine Furche der deckenden Knochenkruste ebenfalls wie in zwei hintereinanderliegende Abschnitte zertheilt.

Das Nasenbein, Nasale, ist nicht minder paarig angelegt und bleibt es auch, wie man bei Betrachtung des Knochens von seiner inneren Seite gut gewahrt. Von aussen freilich, durch die darüber gelagerte Incrustation und gewisse Furchen, ${ }^{1}$ ) erscheint es ganz anders zerlegt, wovon später.

Nach vorne umgreifen die Nasenbeine den aufsteigenden Ast des Z wischenkieferbeins. Dieses orler das Os intermaxillare ist zwar ursprünglich ebenfalls pararig angelegt, stellt aber später einen einzigen Kinochen vor, dessen Processus maxillaris die Zähne, etwa neun trägt. Der Gaumenfortsatz erscheint nach hinten in zwei dreieckige Blitter ${ }^{2}$ ) ausgezogen; in den dadurch entstehenden Raum treten die vorderen Enden der Vomera ein. Der anfsteigende Theil schien mir nach den Arten und Individuen insoferme zu wechselı, als er bald etwas breiter und kürzer, dann wieder schmäler und länger war.

Das 'I'hränenbein, Lacrimale, ist verhăltnissmässig sehr gross, nach aussen gewölbt, nach inneu stark schüsselförmig ausgehöhlt: oben und rückwärts in einen langen spitzen Fortsatz ausgezogen. ${ }^{3}$ ) Mit dem ausgehöhlten Theil bildet es jenen Abschnitt der Nasenhöhle, in welchem die lintere Partie der knorpeligen Nisenmuschel liegt. Ein rundlicher Ansschnitt an dem unteren hinteren hand des Thrünen-

\footnotetext{
1) Vergl. dritte Tafel, Fg. 44.

2) $\mathrm{Fg} .13$.

3) $\mathrm{Fg} .39, \mathrm{~b}$
} 
beines bildet, unter Beihülfe des Oberkiefers, dem sich hier der Oberkieferfortsatz des Jochbeins anlegt, ein Loch zum Durchgang der Thränenröhrchen. Es ist somit deì Ausdruck "durchbohrtes 'Thrănenbein" nieht ganz genau.

Der Oberkiefer, Maxillare, entwickelt eine senkrecht aufsteigende Platte, welche einen Theil der Seitenwand des Gesichtes bildet;' an ihr stehen in Längsreihen etwa sechs Löcher zum Durchtritt von Nerven. Der horizontale oder Gaumenfortsatz ist schmal, so dass die von beiden Seiten sich nicht erreichen, sich also anch nicht zur Schliessung des (iaumens und Bedeckung der Vomera verbinden liönnen.

Das Pflugscharbein, Vomer, ist paarig, ${ }^{1}$ ) und das einzelne stellt im Allgemeinen ein lïngliches linochenblatt dar, welches hinter dem Zwischenkieferbein und zwischen diesem und dem Oberliefer gelegen den Boden der Nasenhöhle und des Jacobson'schen Organes bildet. Im Nüheren besehen rollt sich der innere Rand etwas nach einwärts und aufwärts; nach vorne ist das Blatt in einer schwach gebogenen Linie aufgeschlitzt; anstatt der Durchbrechung bleibt bei manchen Individuen von Lacerta agilis nur eine tiefe Furche mit einer Oeffnung im Grunde. Nach hinten begrenzen die Vomera in Gemeinschaft mit dem Oberkiefer und Gaumenbein die Choanen.

Rückwärts und in enger Verbindung mit den Vomera folgen die Gaumenbeine, Palatina; durch einen starken Fortsatz nach aussen stossen sie an den Oberkiefer. - Die Grenze zwischen Vomer und Palatinum liegt in der (iegend der Choanen und stellt eine sehr ansgesprochene Bogenlinie vor, welche am deutlichsten bei $L$. ocellata bleibt.

An die Gaumenbeine nach hinten schliessen sich die F'lügelbeine, Pterygoidea, ${ }^{2}$ ) an, welche ähnlich wie die Gammenbeine durch einen kräftigen nach aussen und vorne gehendeu Balken, Os transversum, dem Oberkiefer und Jochbein sich verbinden; während der rückwärts und auswärts lenkende Bogen sich den Flügelfortsätzen des Kéilleinkörper's, dann schliesslich deın Paukenknochen anlegt. Die 'l'rennungslinie zwischen dem Pterygoideun und dem Transversum bleibt zwar zeitlebens deutlich sichthar, aber die Verbindung ist doch eine so innige, dass ein lïngeres Haceriren nothweudig wird, um beide linochen von einander zu lösen. Während die Verbindung dieses Knochens nach vorne mit dem Caumenbein, Jochbein und Oberkiefer eine feste ist, heftet sich der nach hinten gehende Schenkel dem Kéilbein und Paukenbein einigermassen beweglich an.

ग) Fg. 41
2) Fg. 40 
Das Quadratbein, 'Tympanicum, erinnert durch seine Form, wenn auch noch entfernt, an das Paukenbein der sänger, für dessen Homologon es auch zu halten ist; es zeigt sich übrigens um vieles stirrker und ausgehöhlter ${ }^{1}$ ) bei der Eidechse als bei der Blindschleiche. Sein oberes Ende sitzt am (unerbalken des Hinterhauptheins, welcher Theil aber eigentlich seiner Enstehung nach der Ohrkapsel angehört, wie bereits erörtert wurde.

An den gleichen Querbalken gelangt von oben her und zwar wenn wir von hinten nach rorne gehen, zuerst der Ĺnochen, wolchen man den hinteren sichenkel oder bogenfürmigen Auslïufer des Scheitelbeins nenut. Diese . hinteren Schenkel orler bogenförmigen Ausläufer" könnten, wie bei Anguis, wenn man sich nur an fertige Schädel und an die C'viver'sche Auslegung des Krokodilschädels hailt, den Ëndruck von Hastoidea machen. Sie entstehen als Spangen, welche den Schätlel von unten und hinten her umgreifen; später bekommen sie nach ohen und einwärts eine Verbindung, welche mit der verkalkenden allgemeinen Bedeckung verwächst, sich aber seitwilrts gar wohl von der eigentlichen Platte des Scheitelheines zeitlebens abgegrenzt erhalten kamn. Ith hahe wenigstens mehrere gutgereinigte ichädel ron $L$. ryilis, sowie von $L$. viridis vor mir, wo eine deutliche Lüngsuath ${ }^{2}$ ) vorhanden sich zeigt, welche heiderseits von der hinteren Grenze des Stirnbeins heginnend üher das "Scheitelhein" wegzieht, so dass letzteres eigentlich in ein Mittelstück und zwei seitentheile zerfăllt.

Wollte man das Mittelstück allein für das wahre Scheitelbein halten, die Seitenstücke aber für die oberen flachen Partien des Zitzenheins, so mürde, wie schon angedentet, diese Ansicht eine Belirïftigung erhalten durch den Schädel dess Krokodils. Dort gliedert sich ${ }^{3}$ ) der hintere, hreite und fiache Theil des schäleldaches noch schärfer in das mittlere und zwei Seitenstücke und CUviER hat die T'heile auch so gedentet, dass er dis Mittelstück Parietale neunt und die Seitenstücke Mastoidea. Allein, obschon ich gestehe, dass mir diese Dentung auch für die Ei-. dechse anwendbar schien, ich bin davon ganz zurückgekommen. Der embryonale Schädel lehrt zu deutlich, dass auch das Mastoideum mserer Laccerten der Schiadelkapsel sellber angehört und in näherer Beziehung zum Gehörlabyrinth steht. Es ist ein aus lnorpeliger Grumallage hervorgegangener Knochen, wie das Mastoidemu der Säuger und anch dadurch gamz verschieden von den aus bindegewebiger (irmundage entstandenen Spangentheilen des Parietale, des anschliessenden T'emporale und Qua-

\footnotetext{
1) Vierte 'lafel, Fg. 47, b.

7) Vergl. erste Thfel, Fg. 18.

3) Man blicke z. B. auf die in's Einzelne gehenden Abbildungen bei BвüuL: Skelet der Krokodilinen, 1862.
} 
drato-jugale. Das Mastoideum der Eidechse ist mit einem Wort im Opisthoticum der Gehörkapsel enthalten, und wird später durch Verschmelzung ein Theil des Occipitale.

Um nun weiter in der Aufzählung der Knochen fortzufahren, welche sich an den Querbalken des Hinterhauptbeins stützen, ist zu nennen: ein kleiner gekrümmter Knochen, der nach Cuvier Mastoideum wäre, nach HalLuANn aber Schläfenschuppe, Temporale. An der nach aussen gevendeten Fläche erscheint er einfach glatt, auf der entgegengesetzten Seite zeigt er einen 'schwachen Querwulst und Ausschnitt am Rande, wenigstens nach meiner Prüfung bei L. agitis. ${ }^{1}$ ) Eudlich schliesst sich noch ein $\mathrm{nm}$ vieles lüngerer, sichelförmig gekrümmter und zugeschärfter Ḱnochen an, welcher die Richtung gegen das Jochbein nimmt, nach CUVIER Temporale ist, nach HaLLmann ein Quadrato-jugale vorstellt. ${ }^{2}$ ) Er erreicht das Jochbein, d. h. den aufsteigenden Ast, welcher den hinteren Augenhöhlenrand bildet, nicht ganz, aber nahezu, so dass im Leben wohl die kleine Lücke durch Bandmasse ausgefüllt sein kann. Da das Mastoideum, nach voriger Erörterung, durchans nicht in diesen änsseren aus Bindegevebe entstandenen oder Beleglinochen gesucht werden kann, so ist Cuvien's Deutung gewiss irrig. Inden ich aber die Habluann'sche Bezeichmung angenommen labe, möchte ich noch bemerken, dass Temporale und Quadrato-jugale, wie schon in ihrer Form, so auch in ihrer Bedeutung noch näher verwandt sein mögen. Sie scheinen beide zusammen die Schuppe des Schläfenbeines der Sänger vorzustellen.

Die auf den Querbalken des hinteren Schädelabschnittes von oben her sich stützenden Enden der erwähnten Kinochen sind dicht zusammengeschoben, doch so, dass der Bogen des Parietale nur den oberen Raud des Querbalkens berührt, während das Temporale weiter herabgehend sich nur zwischen das Ende des Querbalkens und das Tympanicum hineinschiebt, so dass letzteres eigentlich, was abermals für die Deutung dieser Knochen nicht unwichtig ist, dem Ende des 'T'emporale verbunden erscheint.

Das Jochbein, Jugale, entwickelt zwar keinen wirklichen Jochbogen, sondern durch einen kurzen Fortsatz nach hinten nur den Anfang eines solchen und es wird der Mangel eines knöchernen Jochbogens durch ein queres fibröses Band ersetzt, welches von dem Fortsatz des Jochbeins rückwürts zum unteren Ende des Tympanicum zieht.

Der Unterkiefer besteht aus fünf Knochenstücken: einem. zahntragenden

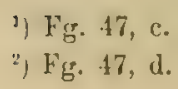


Theil oder Dentale ${ }^{1}$ ), einem Gelenkstück oder Articulare mit der Gelenkfläche zum Quadratbein, einem C'oronoideum zum Ansatz der grossen Sehne des Schläfenmuskels und endlich aus zwei Ausfüllungsstücken. Leicht überzeugt man sich, dass in seinem Inneren ein primordialer Theil, sog. Meckel'scher Kinorjel zeitlehens sich erhillt. $\left.{ }^{2}\right)$ Auf (Gnerschnitten sieht man letztern als cylindrischen Kinorpelstrang, umgeben von den Kinochenstücken, welche den Unterkiefer zusammensetzen und es mag bemerlit sein, dass dils Ausfüllungsgewehe, welches die einzelnen Knochenstücke zusammenhält sehr reich an schmalen, faserartig verlängerten Kernen ist.

Verknöcherte Schädelhaut.

Schon frühere Autoren sprechen von einer "Crusta calcarea", welche am Schïdel der Eidechsen vorkomme; später pflegte man sich darüber so auszudrücken: es habe eine imnige Verwachsung der Knochen der Schiddeloberflïche mit den soliden Schupenkörpern stattgefunden. Mir scheint es von mehrfachem Interesse, sowohl in Hinblick auf die Znsammensetzung des Schädels als auch hinsichtlich der sogenimnten Schilder, diesen Gegenstand etwas nüher in's Auge zu fassen, um so mehr als Anatomen wie Cuvier und Meckes sich von dem Verhalten der Haut und ihrer Schilder zu den wirklichen Schidelknochen keine Rechenschaft gegeben haberr.

Von der línochenkruste sind bei allen einheimischen Arten überdeckt: die Platte des Scheitelheins, Hanpt- und Nebenstirnbein, Nasenbeine, ein Stück vom Oberkiefir nebst einem kleinen Rind vom Thränenbein, endlich der wherflächlich gelegene Theil vom Jochbein.

Ferner' aber' gibt es, was bereits oben gelegentlich des Integuméntes angedentet wurde, echte für sich bleibende Hautknochen, welche nicht mit einem aus der häntigen, embryonalen Schädelwand entstandenen Kunochen verschmolzen sind. Dergleichen finden sich in der Angen- und in der Schläfengegend. Die Ĺnochentafeln, welche den oberen Rand der Angenhöhle bilden, die Bramenplatte „Lamina supereiliaris", wie sie WAgler nennt, sind solche reine Hautlinochen. Bei $L$. anjilis, L. muralis, L. vivipara beschränkt sich die Verknöcherung der Hant auf das Hinterhauptsegment bis zum seitlichen Riande des hinteren Nebenstimbeins: die Derke der schläfengegend bleibt lüutig. Bei $L$. viridis aber verknöchert hier die Haut weiter heral) zu vier bis fünf Tafeln, welche an die Kinochenkruste les .Jochbeins sich anschliessend, diesen hinochen bedecken, und sich bis zur hinteren cirenze des Oberkiefers ansdehnen. Noch weiter rückt die Verkalkung der Hant der schliafengegend hei Lacerta ocelluta vor, indem sie sich zwischen Ange und Ohr zu etwa

1) Sechste 'lafel, Fg. 81.

2) Siebente Tafel, Fg. 93, b. 
vierundzwanzig verschieden grossen Tinochentafeln umgestaltet hat, wovon die grösseren mehr gegen das Auge zu liegen, und die kleineren nach rückwärts.

Diese Knochentäfelchen der Schläfengegend scheinen bisher wenig beachtet worden zu sein. Vielleicht dass CaLorI, dessen Abhandlung über das Skelet der $L$. viridis mir nicht zugänglich ist, davon redet. In dem Werke Bibrox und Dumeril's, welches eine Darstellung des Skeletes gibt, ${ }^{2}$ ) ist keine Spur von den seitlichen línochenplatten zu sehen; wohl aber hat sie РонL, als er die grosse Perleidechse (L. ocellata) für seine Studien über das Gehörorgan wäblte, richtig abgebildet, ohne im Text daron zu handeln. ${ }^{2}$ ) Cuvier lässt später den Schädel derselben Eidechse ( La mienne est faite d'après le grand lézard ocellé d'Espagne ${ }^{4}$ ) zeichnen, aber auch dort ist lieine Andeutung dieser auffäligen und charalsteristischen Knochentafeln zu erblicken; der Rand hört mit jenen Hautknochen auf, welche nach CuvıER'scher Deutung hintere Stirnbeine sind. ${ }^{8}$ ) Doch scheint immerhin Cuvike nach einer Bemerkung zu schliessen, welche er über den Schädel der Eidechsen überhaupt macht, etwas von diesen Hantknochen gesehen zu haben. ${ }^{4}$ ) - Noch sei, bevor wir die Hautverknöcherung weiter betrachten, eine physiologische Bemerkung eingeschaltet.

Der Schädel der Eidechsen an sich ist schmal; er verbreitert sich aber schon in der Stirugegend durch die Tafeln der "Braunenplatte ${ }^{*}$ und noch mehr rückwärts dadurch, dass das Scheitelbein, und die Nebenstirnbeine die eigentliche Schädelkapsel dachig überwölben, woran endlich auch noch reine Hautlinochen sich anreihen können. Diese Umbildung erscheint bedingt von den Weichtheilen, durch die Nothwendiglieit den mächtigen liaumuskeln, besonders dem Schläfenmuskel, eine feste Ansatzfläche zu bereiten, da der eigentliche Schädel, wegen Kleinheit des Gehirns, dazu nicht ausreichte. Was daher bei gewissen Säugern, Raubthieren insbesondere, durch Entwicklung von Knochenkräten und Kämmen bezweclit wurde, geschah hier in der angedeuteten Weise.

Ueberall, wo es sich um Verknöcherung der Haut handelt, tritt an der freien Oberfläche eine eigenthümliche Sculptur auf, von körnig schrundigem Wesen. Die Verkalkung greift nicht durch die ganze Dicke der Lederhaut, sondern es zieht die Verknöcherung von unten herauf durch die derben wagrechten Lagen oder die eigentliche Grundmasse der Cutis; lisst daun aber die obere, weichere, umittelbar unter der Epidermis ruhende Schicht, welche zahlreiche Blutgefïsse und Nerven, sowie die Han,tmasse des Pigments trägt, theilweise oder vielleicht ganz frei. Hievon kamn mau sich nicht blos beim Maceriren des Schädels überzeugen, sondern anch mikroskopisch an senkrechten Schnitten.

Die Wahrnehmung, dass die obere Schicht der Lederhaut nicht oder wenigstens nicht völlig verknöchert, in Berücksichtigung ferner des Umstandes, dass hier eine reiche Ansbreitung von Blutgefïssen statt hat, gibt ms einen Fingerzeig, woher die senlptur oder eigenthümliche Körnelung an der Hautverknöcherung rührt.

Man sieht am gereinigten und getrockneten Schädeldach, z. B. von Lacerta agilis, eine Menge von schwarzen Grübshen oder Löchern, und von ihnen weg anch kürzere oder lïnger verzweigte Rimnen. Wer nun den Ban der Lederhint der liep-

1) a. a. O. H. V, Fg. 1. - Ich habe die Theile abgebildet auf Fg. 23 der zweiten Tafel.

2) Expositio generalis anatomica organi auditus, 1818, Tab. IV, Fg. V.

$\left.{ }^{3}\right)$ Kech. sur les ossemens fossiles, troisieme Edition, 1825, Taib. XVI, Fg. 4.

ग) a. a. 0. p. 264, sub Nro 3. 
tilien nïher liennt, wird nicht im Zweifel sein, dass die Löcher den Stellen entsprechen, wo die Blutgefüsse durch die senkrechten oder säulenartigen Bindegewebsstrünge von unten nach oben ihren Weg genommen haben, um sich in der pigmentirten Grenzschicht flïchenhaft zu verbreiten. Sie sind schwarz, indem, wie der Schnitt dureh die unverkalkte Haut lehrt, das Pigment die Gefässe sehon von der unteren weichen Grenzschicht her begleitet. Und man begreift sofort, dass die festgewordenen Bahnen für die Blutgefüsse es sind, welche der verknöchernden OberHäche der Hant eine Reliefbildung geben, welche an linocheu des inneren slieletes niemals vorkommt. ${ }^{1}$ )

Die Knochenkruste am Schädel erhält eine fernere Bedeutung für uns dadurch, dass sie es ist, welche durch ihre grösseren Gefässfurchen die Abgreuzung der sogenamnten Kopf'schilder bedingt, letztere sonach keineswegs gan\% unl überall mit dem Umriss der darunter liegenden Knochen zusummenfallen. Wemn wir diess erwägen, kann es auch weniger befremden, dass bein Durchmustern einer grösseren Anzahl von Thieren derselben Art die Kopfschilder nicht allzu selten $\Lambda$ biveichungen zeigen. Es genügt das Auftreten einer nenen Gefässfurche um ein Schild weiter zu gliedern oder umgekehrt es kann ein Schild, das sonst fül sich besteht, bei Mangel einer solchen Trennungsfurche in ein anderes aufgenommen sein.

Betrachten wir jetzt einige Knochen und ihr Verhältniss zu den sie deckenden Schildern nãher.

Das Scheitelbein glaubt man bei Besichtigung von aussen in zwei mittlere mparare kleine, und zwei seitliche oder parrige, grössere Platten zerlegt. Das hinterste oder mittlere gibt das sogenannte Occipitalschild, dias davorliegende dis Interparietalschild, die zwei seitlichen die Parietalschilder. Diese scheinbare Auflösung des unparen Scheitelbeines in genannte vier Platten geschieht durch tiefe Gefïssrimnen. Auch, nebenbei gesagt, die mitten auf dem Scheitelbein, in der Abgrenzung welche den Namen des Interparietalschildes trägt, hefindliche kreisrunde Oeffunng, dient ebenfalls dazu, Blutgefüsse vom Schädelraum nach aussen aut die Oherflitche zu leiten.

Am Stirnbein ist wieder eine mittlere, dann sich gabelnde und die Blutge-

1) Viel nuffallender, weil in's Grosse gezeichnet, ist diese Sculptur der Hautknochen z. B. an der Schildkröte Trionyx, dann besonders bei fossilen Sauriem; der Grund der Entstehung ist wohl immer derselbe, wie er oben von Lacerta dargethan wurde. Dasselbe gilt von der bekannten schrundigen Oberfliche des Hirschgeweihes. W. Süssmentive, wolchem wir lehrreiche Mittheilungen über den Wechsel und das Wachsthum des Geweihes beim Edelhirsch verdanken (Zool. Garten, 1866), bemerlst ohne dass er sich die Frage vorgelegt hätte, woher die Sculptur des Geweihes sich bilde, dass man an der abgeworfenen Stange wanfangs beim Wasshen sogar noch Spuren der getrockneten Blutgefïsse des Bastes, der in den Furchen festsass, erkanntex. 
fïsse leitende Furche die Lrsache, dass man den linochen nach aussen zusammengesetzt sein lisst ans einer paarigen hinteren Abtheilung, „Fronto-Parietalschilder" und einer vorderen unpaaren Platte, „Frontalschild“. Am skeletirten Schädel sieht man deutlich und abermals zum Beweis, dass die Schilder an frischen Thier keineswegs mit den Grenzen der Kopfknochen zusammenfallen, wie ein guter Theil der Fronto-Parietalschilder noch auf dem vorderen Abschnitt des Scheitelbeines ruht.

Endlich das Nasenbein, von aussen unpaar erscheinend, zeigt eine mittlere Gefässfurche mit Gabehng, somit eine Art Trennung in zwei hintere kleinere und in ein vorderes, grösseres unpaares Schild.

Bleibende Theile des Primordialschädels.

Embryen von Lacerta vivipara, welche fast reif waren und auf den Primoldialschädel geprüft wurden, zeigen im Wesentlichen ein gleiches aus Balken, Platten, und verästigten Stäben bestehendes Knorpelwerk, wie der Primordialschädel von Anguis; ich will daher nicht noch einmal auf eine Auseinandersetzung dieser Theile eingehen, sondern vielmehr jener Knorpelstücke gedenken, welche am fertigen Schädel vom Primordialskelet zeitlebens übrig bleiben.

Bei Betrachtung des Schädels von unten, ich habe es von Lacerta viridis abgebildet, ${ }^{1}$ ) sieht man zu beiden Seiten des langen Stachels des Keilbeins, genauer neben dem sog. vorderen Keilbeinkörper, einen Knorpelfaden nach vorn treten, welche beide sich in der Medianlinie des Schädels zu einer Knorpelplatte erheben. Zugleich gewahrt man aber noch in der bezeichneten Lage des Schädels einen Knorpelfaden, welcher rechts und links năher dem Schädeldache, im Bogen von vorne, aus der Gegend der Augenhöhle, nach hinten zur Ohrgegend zieht.

Ein gut macerirter Schädel lässt erkennen, dass wie bei Anguis die neben dem Stachel des Keilbeins verlaufenden Knorpelfäden von zwei cylindrischen Kno(chenstäben") ausgehen, die als ilıre verknöcherten Wurzelstücke anzusehen sind, und von welchen sie sich scharf ablösen lassen. Die Kinorpelfäden sind die ursprünglichen sog. Schädelbalken.

Das zweite erwähnte Paar der Knorpelstreifen geht vom Primordialschädel zwischen den Augen von der grossen knorpeligen Scheidewand ab und verliert sieh nach hinten in die knorpelige Ohrkapsel. Bei Anguis markirt sich noch am fertigen Schädel klar die Stelle, wo das Felsenbein den Streifen aufnimmt. ${ }^{3}$ ) Bei Lercerta,

1) $\mathrm{Fg} .19$ auf der ersten Tafel.

2) Vergl. die Figuren 30 u. 31 auf der zweiten Tafel; beide lassen die zwei Knochenstäbe von Lacerta und Anguis sehen.

3) $\mathrm{Fg}$. 31, b. 
wenigstens bei $I_{\text {. }}$ agilis und muralis, welche ich anf diesen Punct untersucht habe, wollte sich die gelenkartige Flïche nicht mehr zeigen; während sie doch an der Schuppe des Hinterhauptbeins für einen anderen medianen Knorpelstreifen so deutlich bleibt wie bei Anguis.

Den dritten und ausgedehntesten hinorpeltheil bildet die Platte, welche zwischen den Augen in die Höhe steigt und nach vorne in den vierten Abschnitt, in die knorpelige Nasenkapsel, zunächst S'cheidewand der Nase, ausgeht. Von unten her ist sie eine gute Strecke weit eine undurchlöcherte Wand; dann gegen oben, sowohl in der kichtung nach vorne als auch nach hinten zeigt sie sich von grösseren und kleineren Oeffnungen durchbrochen. Es scheint, dass in Form, Grösse und Zahl der Löcher, welche die Platte durchsetzen und beinahe wie in ein Gitter verwandeln, nach den einzelnen Arten Unterschiede vorhanden sind; wenigstens stimmen meine Skizzen, die ich hierüber von Lacerta vivipurn, L. ngilis, L. virillis und $L$. ocellata nahm, nicht ganz genau mit einander überein. ${ }^{1}$ )

Erwähnenswerth ist auch, dass sich in dem Knorpel an bestimmter Stelle, ganz inselartig, eine Knochenbildung vorfindet, nämlich dort, wo der Sehnerv vom Schädelraume heranstritt. Bei L. ocellata stellt sie einen halbmondförmig gekrümmten linochenstab vor, bei $L$. agilis und $L$. viridis hingegen ein Knochenstitl,chen von gerader Form. Mau kann fragen, ob der Knochen nicht wegen seiner Lage und Beziehung zum Sehnerven dem Anfang eines knöchernen Keilbeinflügels zn vergleichen wäre. - Verschieden davon sind Verkalkungen des Knorpels, welche ich bei $L$. viridis in der Platte zwischen den Augen antraf. Es befanden sich dort in die Intercellularsubstanz des ḱnorpels abgelagerte kalkkrümeln, welche für das freie Auge weissfitrbige Flecken erzeugten. - Histologisch ist der hinorpel von rein hyaliner Beschatfenheit: die Zellen, im Allgemeinen rundlich-eckig, sind so zahlreich, dass sie an Menge die Grundsubstanz überwiegen.

Dass die aufgeführten línorpeltheile des Schädels sich wirlilich zeitlebens in dieser Form erhalten und nicht etwa doch nur vorübergehend sind, lehrte mich besonders eine untersuchte Lacerta ocellata, welche eine bedentende Grösse und Dicke hatte, und auch ihr Alter durch den sehr abgenutzten Zustand der Zähne kundgab.

Wirbeltheorie des Schädels.

Jedem, welcher den Knochenbau des Schaidels eines Wirbelthier's zum Gegenstand seiner Untersuchung und Nachdenkens gemacht hat, tritt die Frage entgegen: besteht der Schădel aus umgewandelten Wirbeln?

1) Auf Figur 20 der ersten 'Tafel ist dieser Theil schematisch gehalten. 
Von einem ganz allgemeinen Gesichtspunct aus, welcher sich auf das Hervorgehen nener Bildungen durch das Sichverändern und Sichsondern schon bestandener, einfacherer Elemente richtet, wird man zu der Ansicht hingeleitet: der Schädel sei ein Stück ungebildeter Wirbelsäule. Diese Auffassung, in älterer wie neuerer Zeit wie oft schon ausgesprochen, erhält auch eine nähere thatsïchliche Unterlage durch die Betrachtung des Schädels gewisser Säugethiere, insbesondere der Wiederkäuer. Doch bereits gegenüber dem Schädel gar mancher anderer Gruppen muss der Beobachter sich gestehen, dass die "Wirbeltheorie des Schädels" schwer zu benützen ist und beim Versuch sie strenger durchzuführen, sich zu verflüchtigen droht.

Geht mau nun gar zurück zu dem embryonalen Schädel, der doch einem Stück Wirbelsäule noch mehr vergleichbar sein sollte, als der fertige, so schwebt die Theorie in der That in der Luft. Oder um bei unserem nächsten Gegenstande zu bleiben, was hat der von mir abgebildete Primordialschädel der Blindschleiche - und ebenso verhält es sich mit dem der Eidechse - Wirbelähnliches? Wollte man dieses aus Platten und Stäben bestehende Knorpelgerüst einer anderen bekaunten Bildung vergleichen, so hätte es jedenfalls mehr Aehnlichkeit mit dem Nervenskelet im Kopfraum mancher Arthropoden, - ich erinnere an gewisse Käfer - als mit Elementen der Wirbelsänle.

Dieses Knorpelskelet des embryonalen Kopfes dient, wie der unbefangene Beobachter sich sagen muss, zur Umhüllung und Stütze des Gehirus, des Ohrlabyrinthes, ferner der Nase und man könnte auch anführen des Auges; denn die knorpelige Sklera des Auges liesse sich in gemeintem Sinne gar wohl als ein dieses Sinnesorgan stützender Theil des Primordialschädels ansprechen.

Man hat nun zunächst schon in früherer Zeit - und selbst von Seite mancher entschiedener Anhünger der Wirbeltheorie des Schüdels ist diess geschehen in den hinorpeln und Linochen, welche zur Stütze des Geruchsorgans dienen, keinen ungebildeten Wirbel mehr erblickt und ebenso die Knochen, welche das Ohrlabyrinth umschliessen, für Schaltknochen zwischen den Wirbeln erklïrt, sonach ebenfalls ausser Spiel gelassen; vom Auge gar nicht zu reden, dessen Skleril man überhaupt nie zum Primordialcranium rechnete.

Auf diese Weise waren alle Knochen, welche den Sinnesorganen dienen, von vorneherein von den Wirbeln ausgeschlossen und die Theorie exschien jetzt eingeschränkt auf diejenigen Knochen welche das Gehirn umfassen.

Bleiben wir ebenfalls dabei stehen und prüfen junge Limbryonen auf das Verhalten des Gehirns und der umschliessenden hunorpelplintten und Spangen zu einander - und ich habe diss wiederholt an noch fiast fiublosen früehten der Eidechsen 
mit grossem Dottersack gethum, - so drängt sich uns die Wahrnehmung auf, dass die Dreitheilung des Gehirns in Vorderhirn, Mittelhirn und Hinterhirn zwar nicht eigentlich am Primordialschürdel, aber später beim Entstehen der knöchernen Tiapsel sich einigermassen nach aussen abzeichnet und zwar fast mehr an der Decke als am Sehädelgrund. Denn die Stirnbeine haben näheren Bezug zum Vorderhirn, das Scheitelbein zum Mittelhirn und die Schuppe des Hinterhanptbeins zu dem kleinen Gehirn und verlängerten Mark. Am S'chädelgrund würden als entsprechende Particen hieher zählen: vorderer und hinterer Keilbeinkörper sammt Anfüngen von Flügelfortsătzen, Hinterhauptsbein mit Seitenstücken.

Wir finden somit als Ergebniss, dass eine Theilung des Schädels in drei hintereinanderfolgend'e Abschnitte zunächst eine Wiederspiegelung der ursprünglichen Dreitheilung des Gehirns ist, aber in so lange es sich um den primordialen knorpeligen Zustand handelt nicht eigentlich auf Wirbel bezogen werden kann. Erst nach der Entstehung der Knochen tritt eine etwelche Aehnlichkeit mit Wirbehn zu Tage.

Wenn wir uns nun vergegenwärtigen, dass auch an dem ursprünglichen Knorpelskelete für das Rückenmark das Wirbelartige noch nicht vorhanden ist, sondern ebenfalls erst mit der Ausbildung der Knochen in die Erscheinung tritt, so müssen wir schliessen, dass die Abscheidung der Kalksalze das bedingende Moment sei; und in diesem Sime wäre auch für das Verständniss des Schädelbanes die Wirbeltheorie keineswegs ganz aufzugeben. Gleichwie das geistige Auge in der Bildung des Crehirns eine Unformung und höhere Ausbildung des vorderen Endes des Riückenmarkes erblicken darf, ebenso wird es auch immer in den unschliessenden Lnochen einen Wiederschein Dessen wahrnehmen, was an der Rückgratsüule geschah; wemn anch das Einzelne einer solchen Betrachtungsweise sich nicht meh" fügen will. Und es ist gewiss beherzigenswerth und gibt einen sichern Fingerzeig, dass die Hinterhauptgegend des Schädels noch an meisten wirbelähnlich ist, da ja anch das verlängerte Mark, welches in ihm liegt, den Charakter des Rückenmarkes noch am wenigsten eingebüsst hat. Je weiter nach vorne das Rückenmark zur "Blüthe“ des (iehirns sich entfaltet, um so mehr entfernen sich auch die umschliessenden Kinochen ron der Wirbelbildung.

\section{Wirbelsäule.}

An der Wirbelsăule lassen sich die verschiedenen Partieen unterscheiden, welehe mam für die Silugethiere anzunehmen pflegt. Halswirbel gehen voin Atlas bis zu dem Wirbel, dessen Rippen sich mit dem Brustbein in Verbindung setzen; dieser eröflnet die lieihe der Brustwirbel, an welche sich damn die Leudenwirbel 
amreihen, von denen diejenigen, welchen sich das Darmbein des Beckens anheftet, als Kreuzwirbel bezeichnet werden liönnen; jenseits der letzteren folgen die Schwanzwirbel. Die Verbindung der Wirbel untereinander ist gelenkartig, indem der Körper vorne zu einer Pfanne vertieft ist, während das lintere Ende sich zum Gelenkkopf wölbt.

Der Wirbelkörper und seine Fortsätze bestehen bei den Embryen aus hyalinem Kinorpel; später verkalkt derselbe und schmilzt als solcher wieder ein. Macht min daher vom fertigen Wirbel Querschnitte, so erscheint er von Markiummen durchsetzt, welche an die Stelle des geschwundenen Kalkknorpels getreten sind; die Markräume sind von echten línochenlamellen schalig umzogen, welche sich von ossificirendem Bindegervebe herleiten. Ebenso verhalten sich die Bugen und übrigen Fortsätze des Wirbels.

Der Atlas, ich habe ihn von L. agilis vor mir, zerfält durch Maceriren leicht wie bei der Blindschleiche in drei Stücke, in einen unteren oder mittleren 'Theil und zwei aufsteigende Bogen. ${ }^{1}$ ) Da das Mittelstück zwar einem hörper ïhnelt, der eigentliche Körper des Atlas aber, nach dem was die Entwicklung lehrt, vom Zahnfortsatz des Epistropheus vorgestellt wird, so wird man diesen mittleren, nach unten dornartig vorspringenden Theil den unteren Dornen zu vergleichen haben. Die beiden Bogen lassen oben eine Lücke frei und der Atlas ist hier so wenig als bei Anguis knöchern geschlossen; ich habe mich von diesem Verhalten an mehr als einem Exemplar üherzeugt. $\left.{ }^{2}\right)$ Ein Ligamentum transversum, welches den Zahnfortsatz des nächsten Wirbels überbrückt, ist vorhanden.

Der zweite Halswirbel, Epistropheus, hat einen besonders langen, kammförmigen Dornfortsatz; ebenso sitzt unten am hörper win Dornstück, welches seine Abgrenzungsimie so gुut behält wie der Zahnfortsatz. ${ }^{3}$ ) Der untere Dorn trifit nach hinten auf den gleichen untern Dorn des dritten Halswirbels, wie um mit diesem zu verwachsen (L. agilis).

Die Wirbelkörper der Hals - und Rumpfgegend bieten von vorne angesehen, einen grewissen herztörmigen Umiss dar und ihre Vorderfläche erscheint, nach hinten besonder's, etwas ausgetieft. Diejenigen ler Brustgegend sind dabei etwas schmäler,

1) Vierte 'Tafel, Fg. 49.

2) Bei Currer, Rech. B. les ossemens fossiles T. V, erscheint auf PI. XVII, Fg. I0 der Atlas von einem Monitor abgebildet, dessen Bogentheile cbenfalls oben sich nicht berübren. Wahrscheinlich sah dies der grosse Kenner des Skelets, welcher den Theil nicht selbst prïparirt baben mochte, für etwas Zufalliges an; denn der

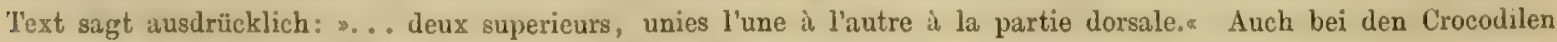
- ich kann es gut an einem grossen Skelet des Crocodilus biporcalus der hiesigen Sammlung sehen - endigen die Schenkel des Atlas für sich, aber die Lücke deckt ein selbststïndig bleibender dachtörmiger Knochen.

3) Vierte Tafel, kg. 50. 
daher lïnglicher als die des Halses, während die der Kreuzgegend wieder breiter werden und sich ins Kürzere ziehen. Die Wirbel der s̀chwanzgegend verschmälern sich abermals und bekommen äussere Vertiefungen, wie Fischwirbel; in ihnen liegen auch Ansammlungen von Fett, welche die ganze Schwanzwirbelsäule gleich der von Anguis wie perlschnurartig aneinander gereihte Klumpen begleiten.

In den schwanzwirbeln ${ }^{1}$ ) tritt wie hei der Blindschleiche die Eigenthümlichkeit auf, dass der einzelne Wirbel in zwei Hälften zerfält. Diese Trennung begimnt erst am siebenten Schwanzwirbel, wo der Körper auf eimnal doppelt so lang ist als vorher; es geschieht die Sonderung hinter dem Querfortsatz und oben bildet sich eine Art von secundärem Dornfortsatz.

Ueber die Entstehung dieser zuerst von Cuvier, dann später von Anderen zum zweitenmal „entdeckten“ Bildung klärt uns GEGENBaur dahin auf, dass in der Anlage der Wirbel nichts gegeben sei, was jene 'l'renung bedingen könne, sondern dass sie auf der Entstehung eines grossen Markrammes beruhe, der mit dem Verschwinden des Chordarestes einigen Zusammenhang hat.

Die Körper der letzten Schwanzwirbel sind sehr verschmächtigt und was besonders auffallig und erwähnenswerth ist: sie haben vorne und hinten eine Concavität, also keinen Gelenkkopf mehr. Dabei zerfallen sie immer noch deutlich in zwei Stücke.

Die oberen Bogen sämmtlicher Wirbel vom Epistropheus an, sind so verbreitert, diss sie den Rückgratscanal nach oben völlig schliessen. Der Dornfortsatz der Halswirbèl ist an seinem freien Ende deutlich, wenn auch schwach gegabelt: ${ }^{2}$ ) gegen den sechsten und siebenten Wirbel verliert sich diese Bildung und der Dorn geht mehr ins einfach Leistenförmige über, an den Schwanzwirbeln ins einfach Spitzige.

Die unteren Bogen ${ }^{3}$ ) beginnen in Form von Dornen nach dem oben Gesagten schon an Atlas, sind dam aber besonders entwickelt vom Epistropheus an: rückwärts nehmen sie an Grösse ab, am sechsten Halswirbel ist dis Tínochenstück schon sehr winzig und am siebenten zu einem parigen Knöchelchen geworden. das aber. nochmils in wieder schwächerer Ausbildung am achten Wirbel sich zugegen zeigt. Alle diese Kinochenstücke lösen sich bei der Maceration rom Wirbelkörper ebenso leicht al), als solches mit den unteren Bogen der Schwanzwirbel der Fall ist.

Diese Erscheinung, sowie die Thatsache, dass die unteren Dornen der Halswirbel in ihrer Entstehung paarig sind und wohl erst. inden sie sich rergrüssern,

\footnotetext{
") Vergl. vierte Tafel, Fg. 55.

2) F'g. 31.

g) $\mathrm{Fg} .53$, a.
} 
zusammenschmelzen, lässt mich in diesen Bildungen die Homologa der unteren Bogen der Schwanzwirbel erhlicken; wenn sie auch am Hals-Alschnitt der Wirhelsäule etwas anderes zu leisten haben, uls am Schwanz. GEGENBAUR andrerseits erklärt, dass er diese sogenamnten unteren Dornfortsätze auch bei Eidechsen für ganz selbstständige Fortsätze des Wirbelkörpers halte. ${ }^{1}$ ) Es ist diess eine natürliche Folge seiner Ammahme, dass hei den Reptilien die untern Bogen der Schwanzwirbelsïule den Rippen homolog seien. ${ }^{2}$ )

Die Rumpfgegend entbehrt der unteren Bogen; sie beginnen erst wieder am Schwanze und zwar am vorderen Rande des vierten Wirbels, da wo zwei Wirbel anteinanderstossen; wobei sie jedoch eigentlich den vorderen angehören. Sie fallen leicht ab und ihre Schenkel können noch durch eine Querbrücke verbunden sein.

Die schiefen oder Gelenkfortsatze treffen nach der ganzen Länge der Wirhelsätule immer derart aufeinander, dass die hinteren die vorderen des zunïchst folgenden Wirbels decken; die Gelenkflächen liegen mehr oder weniger schräg, nühern sich aber am Halse stark dem Wagrechten. Untersucht man die Gelenkflïchen geuau so überzengt man sich, dass sie von einer dünnen Knorpelschicht überzogen werden. - Von Processus mammillares und musculares an den Gelenkfortsätzen lässt sich nicht sprechen.

Die Querfortsatze erscheinen an den Hals- Brust- und Lendenwirbeln nur als geringe Höcker. Jene der Halswirbel sind noth etwas stärker, als die der Brustwirbel und springen, bei Betrachtung des Halses von vorne, wie gesimsartig vor. Entsprechend dem einfacheren Rippenende, das sich an den Querfortsatz heftet, ist dieser anch nur einfuch rundlich gewölbt. Stark sind diese Fortsitze an den Schwanzwirbehn; die stärksten aber finden sich an den heiden Krenzwirbeln; ${ }^{3}$ ) dabei übertrifft derjenige des zweiten Krenzwirlvels deu des ersteren noch an Dicke. Indem der erste etwals nach hinten neigt und der zweite nach vorn, treffen sie mit ihren freien Enden nahezu winklig zusammen und erzeugen damit die Ansatzfläche für das Darmbein.

An den letzten Schwanzwirbeln zeigen sich die Fortsätze, insbesondere die queren und die untern Bogen, sehr zuräckgebildet. Die untern Bogen sind nach ụten offen, bis sie zuletzt völlig schwinden.

Nach der gitnzen Austelmung der Wirbelsiatule lïuft vorne ein Längshand herah von weissem glänzenden Aussehen.

$\left.{ }^{1}\right)$ Grundzüge d. vergleichend. Anatomie. 'Lweite umgearbeitete Authge, 1870.

2) Jenaische Zeitschrift, Bd. III, S. 414.

3) $\mathrm{Fg} .54$ 
Rippen.

Die Halsrippen begimnen am ersten Wirhel hinter dem Epistropheus, also am dritten Halswirbel; die erste Rippe ist noch schwach, dann werden sie am vierten und fünften Wirbel stïrker. Es unterseheiden sich ${ }^{1}$ ) die Rippen der Halsgegend gar sehr von denen der Brust- und der Lendengegend durch breite ciestalt und einen platten grossen Endknorpel. Die sechste ist die breiteste und hat den grössten hnorpel; die siebente nimmt bereits, indem sie lang und schmal geworden, den Charakter gewöhnlicher Rippen an.

Von den Rippen der Brustgegend setzen sich an den Rand des Brustbeins unmittelbar drei Parare an, dann unten noch mittelst eines besonderen Knorpels zwei Paare, demnach jederseits fünf einzelne Rippen. - An ihrem olvern Ende sind sie einficher als bei der Blindschleiche: sie zeigen noch nicht die Zerlegrng in C'apitulum und 'Tuberculum, sondern nur eine schwache Anschwellung mit ansgehöhlter Gelenkfläche. $\left.{ }^{2}\right)$

Schon oben als von den Rippen der Blindschleiche die Rede war, wurde bemerkt, dass dort der letzte Wirbel vor dem ersten firenzwirbel bald eine Rippe noch trïigt, bei kurzem Querfortsatz, oder keine Rippe mehr hat, aber alsdamn einen. langen Querfortsatz besitze. Es lässt sich daraus folgern, dass die Rippen als lange alggegliederte (Querfortsiltze zu betrachten sind. Zu gleicher Auffassung liommen wir auch hezüglich der Eidechsen, wenn man die letzten Lenden-, damn wieder die zwei Krenzwirbel und die Schwanzwirhel vergleichend in's Auge fasst. Denn am letzten Lendenwirbel sind die Rippen nicht lïnger, als der Qnerfortsatz der Kreuzwirbel ist, und jene von den anstossenden Schwanzwirleln sind wieder wenig kürzer als die der Líretzwirbel; dann aber nehmen sie rasch an Länge ab.

Was man an den Rippen der Embryen bezüglich des histologischen Verhaltens gegenüber vom fertigen Theil sieht, spricht dentlich dafür, dass die knorpelige Anlage znerst wirklich ossificirt, aber das darans entstehende Gewebe wieder schwinden muss. Embryen von Lacertu viripara boten Rippen dar, deren Knorpelzellen von strahliger Form waren, derart, dass die von der Zellsubstauz ausgehenden strahlen imnerhalb der stark verdickten Knorpelkapseln oder Verdickungsschichten lagen. Knochenkürperchen von dieser Form bemerkt man aber nicht meln in der fertigen hippe; sie sind wieder eingegangen und der Knochen zeigt in seinem ciewebe die Merkmale des ossificirten Bindegewebes.

\footnotetext{
d) Vergl. F'g. 53, b.

2) Fünfte Tafel, Fg. 75.

Loydig, Saurier.
} 
Brust bein.

Man unterscheidet das eigentliche Sternum und das Episternum. Das Ster$n n \mathrm{~m}^{1}$ ) stellt eine ziemlich grosse, nach aussen gewölbte, einwärts ausgehöhlte. beiläufig rhomboidale Knorpelplatte dar, welche grossentheils verkalkt ist und die sternalen Enden der Rippen aufnimmt. S'eitwäts am Vorderrand zieht eine Leiste herah. woduch eine Art Rinne entsteht, gegen welche sich der hogig scharfe Rand des Coracoideum stemmt. Diese Leiste ist bei den grösseren Arten, wie bei $L$. viridis und selbst L. agilis, für's freie Auge deutlich, fehlt aber auch nicht den kleinern z. B. nicht der I. vivipuru. Am hinteren Ende zeigt sich in Knorpel ein läutig geschlossenes Loch, etwa vergleichbal der Oeftnung im Schwertfortsatz des Ilenschen. Uehrigens erscheint, ebenfalls wie heim Menschen. dieses Loch im Brusthein renuderlich nach Grösse und Vorkommen, sowohl was die Arten als die Individuen betrifft.

Das Episternum, ${ }^{2}$ ) von zierlicher schlank kreuzförmiger Gestalt, scheint nach den Arten ganz leise Unterschiede zu besitzen. Von L. vivipara z. B. habe ich mir angemerlit. diss die Linien nicht rein symmetrisch ziehen. namentlich nicht am unteren vder lingeren Theil, allwo sich eine lïngliche Anschwellung hemerktar macht; dann erst folgt das wieder verschmälerte Ende. - Das Mittelstück liegt eine ziemliche strecke weit auf der ventralen Fläche des sterum. Der querbalken triftit genau an den blattartigen Vorsprung des unteren Randes der Clavicula.

Das Episternum ist ein aus Bindegewebe entstandener Knochen und erhätet früh. Bei Embryen ron I. vivipror, welche nahe dem Geborenwerlen staulen, war es schon verknöchert; während in das Brusthein und die Riplen noch kein Kalli sich abgesetzt hatte.

Schulterknochen.

Das Schlüsselbein, Clavicula, ${ }^{3}$ ) erscheint stark gebogen, am hinteren oder Acromialende vershmälert, am vorderen oder sternalende verbreitert, aber von einem Fenster durchhrochen. Letzteres, am grössten bei $L$. riridis, ist aluch noch muliunglich, doch kleiner bei $L$. muratis und L. vivipara, am kleinsten bei L. agilis. Genauel' hezeichnet: der breitendurchnesser des l'ensters ist hier sehr gering geworden, was nicht der Fall ist nit dem Längendurchmesser. Dieser 'Theil der C'lavienda sieht aus wie ein Virlelöhr. Das Mittelstück unseres Knochens entwickelt an seiner Biewnge

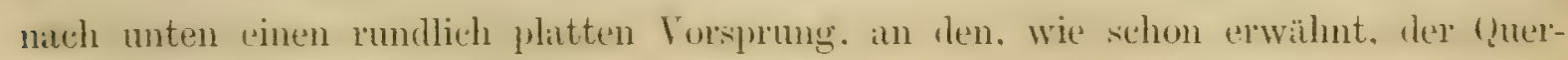
balken des Episternum stösst.

\footnotetext{
1) Sechste 'lafel, F'g. 78 , a.

2) $\mathrm{Fg} .78,7$.

3) $F$ gू, $78, \cdots$
} 


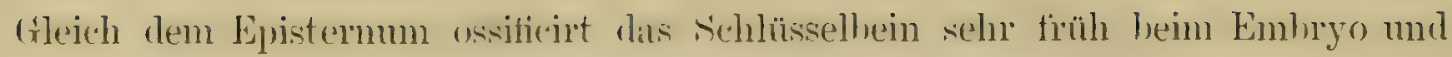
entsteht wie letzteres aus bindegewebiger Grundlage, nicht aus Knorpel.

Iats sehulterliatt ${ }^{1}$ ) zeight eine breite grösstentheils verkalkte hinorpelplatte oler das suprascapulare. Ier ohere Rand verlänft loggig. rler hintere ausgeschnitten, der vordere zieht sich in eine Spitze oder Art Acromion aus. Der Theil ist bei $L$. ayitis und $L$. vivipurn ziemlich lang; lei einer anf riesen Punct untersuchten $L_{\text {. }}$ riridis, waren statt dessen zwei kurze Vorsprünge zugegen.

Dann unterscheidet man zweitens ein Kinochenstück, ${ }^{2}$ ) welches die eigentliche Scalpulat vorstellt, die (ielenkfläche für den Oberarm trägt und ohne drenze in dass

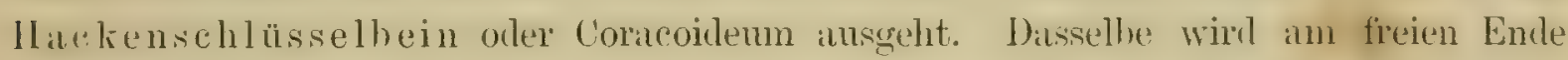
umsïunt von einer theilweise rerkilkten Kinorpelplatte, welche, wofür die V'rhäilt-

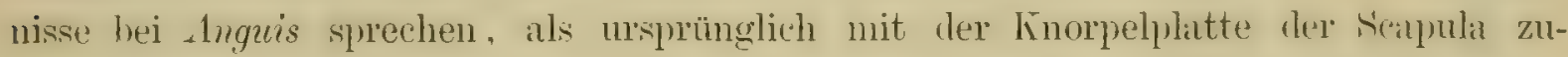
simmmenhängend zu denken ist. Jleses Knochenstück ist gleich dem anschliessenden (Theram zwar aus rerkillstem hnorpel hervorgegangen, dieser schmolz aber wieder ein. um einer aus Bindegewele hervorgehenden (Ossification Platz zu machen. - Zwei Fensterl, ein grösseres mul ein kleineres, das letzte der Gelenkhöhle näher, finden sich hei allen Arten; wie sind in frischem Zustande von einer straffen Memhram geschlossen.

Das ganze Gerüste, welches sich aus Sternum und Episternum, Scapula, Coracoiclemm, nebst clavicula zusammensetzt, elscheint in seinen verschiedenen Theilen sho heweglich gegen einander, namentlich was den hogigen Rand des coratcoidem betrifft, da wo er gegen, das Brustbein sich stemmt.

Vordergliedmassen.

Der Arm besteht aus dem Kinochen des Oberarms, Humerus, und den zwei Vorderarmknochen: Ulna und Radins. Das obere Ende ${ }^{3}$ ) des Oberarms ist breit, suitlich zusammengedrückt und auch der Gelenkkopt ist weniger halhkugelig als vielmehr ehenfialls seitlich zusimmengedrückt, länglich und schräg. Unter ihm öftinet sich ein grosses (iefïssloch. I) T'uherenlir stehen weit ansemander, das Mittelstürli ist platt. - Das untere Ende ${ }^{4}$ ) ist noch etwas breiter als das obere, zeigt einen änsseren und inneren Gelenkhöcker und den Gelenkfortsatz, der dentlich in Rotula mud 'Trochlęu zerfällt. Die Vertiefung über dem Gelenkfortsat» ist gut ausgebildet, die hintere hingegen fehlt.

Die von MECKEL vor langen Jahren an $L$. agilis und $L$. ocellata nachgewiesene

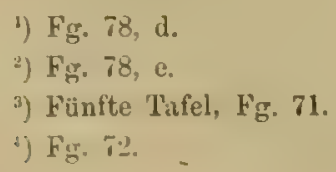


Ellenbogenscheibe lässt sich bei allen, anch den kleineren Arten in der Strecksehne (II. triceps) des Vorderarms unschwer auffinden.

Ulna und Radius ${ }^{1}$ ) sind leicht nach der Bildung ihres oberen und unteren Endes zu erkemnen. Erstere hat oben ein, wenu auch kleines Olecranon mit Cavitas sigmoidea; das Mittelstück ist ziemlich walzig; das untere Ende erscheint abgerundet und mit einem kaum angedeuteten Processus styloideus. - Das obere Ende des Radius hat eine Gelenkfläche für die Rotula; das untere Ende ist etwas breiter als das obere, und zeigt die Incisura semilunaris. - Beide Vorderarmknochen steheu ziemlich weit, namentlich in der Mitte, auseinander.

Der Carpus setzt sich nach GEGENBaUR ${ }^{2}$ ) aus acht Stücken, in zwei Reihen zusammen. Die erste Reihe, den zwei Knnochen des Vorderarms zunächst, bilden ein Radiale und ein Ulnare; dazwischen liegt ein dreieckiger hnochen, der nicht dem Intermedium, welches den Sauriern fehlt, entspricht, sondern dem Centrale. Den Mittelhandknochen näher liegt die zweite oder untergeordnete Reihe, welche aus fünf Carpalia besteht. Hinsichtlich der Textur gehören die Elemente des Carpus vorzugsweise zum verkalkten Knorpel, mit mehr oder minder zahlreichen Markräumen. In den Wandungen der letzteren sieht man häufig echte oder secundäre Knochenschichten.

Ich habe den Vorderfuss von Embryonen untersucht, welche noch unpigmentirt waren und die Anordnung der Carpalknochen schou durchaus so gefunden, wie GEuenbaur sie beschreibt, nur von dem Sesambein war noch nichts vorhanden. Die Zahl der Phalangen betrug in den drei kleineren Fingern zwei und das Nagelglied, also zusammen drei; die zwei längeren Finger hatten drei Phalangen und das Nagelglied, somit im Ganzen vier. Die Knorpelzellen der Phalangen lagen sehr dicht beisammen und in die Quere geordnet; da wo Gelenke sich bilden sollen, werden die Zellen grösser und rundlicher, und es scheint die Ablösung in Glieder auf einer Metamorphose der Zellen zu beruhen.

Die Nagelglieder, welche bereits an diesen zarten, farblosen Embryonen sich durch eine Sprur von Pigment und eine gewisse seitlich zusammengedrüclite Beschaffenheit auszeichnen, werden später mit scharfen Krallen ausgestattet. Bei den Arteu agilis, muralis, vivipara kömnen sie entsprechend der geringen lïrpergrösse, wenigstens nicht gegen unsere Haut als Waffe wirken; aber die grosse dalmatinische Art, kratzt die Hand blutig, olme sich anzustrengen. Schon Dugks bemerkt bezüglich der Krallen der $L$. ocellata: „... des griffes acćrées avec lesquelles ils peuvent faire (surtout celles des membres postéricurs) des egratignures assez profondes".

Von Interesse war mir bei näherem Vergleichen der Krallen unserer vier einheimischen Arten zu

\footnotetext{
2) Fig. 73 .

2) Untersuchungen zur vergleichenden Anatomie der Wirbelthiere. 1. Heft, 1864.
} 
bemerken, wie sich die engere Verwandtschaft zwischen $L$. viridis mit $L$, agilis, und auf del anderen Seite die ron $L$. vivipara zu $L$. muralis, auch in der Form und den Grössenverhältnissen dieser untergeordneten Theile noch ausspricht. Bei viridis und agitis sind die Krallen der Vorderfüsse kürzer als die der Hinter-

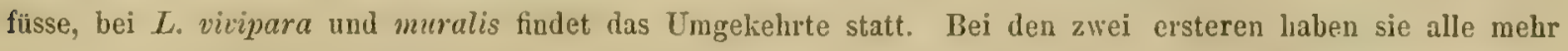
eine rein sichelförmige Gestalt, bei den zwei anderen hat die Höhe an der Basis beträchtlich zugenommen, ${ }^{2}$ ) Becken.

Die Eidechsen haben ein vollständiges Becken, indem die Elemente des HüftScham- und sitzbeins vorhanden siud und ausserdem noch ein Theil sich sehr entwickelt zeigt, der bei den meisten Säugernn einen einfachen Höcker darstellt. Schon in dieser Bemerkung liegt das Geständniss, dass ich den neueren Ausichten üher die Deutung der Beckenknochen beizustimmen mich veranlasst sehe.

Ueber das Darmbein, Os ilei, kann keine Meinungsverschiedenheit stattfinden. Es ist der schmale, schwach gekrümmte Knochen, mit welchem das Becken an die Querfortsätze der zwei Kreuzwirbel sich anheftet. Unten in der Nähe der Pfanne hat es einen höckerartigen Fortsatz, die Spina anterior.

Von der Pfanne nach vorne und etwas abwärts erstreckt sich ein Knochen, den ('uvisr und alle späteren Anatomen bis anf REICHeRT und Gorskr²) für das Schambein, Os pubis, hielten. Der Knochen ist lang, geht in seinem hinteren Drittel in einen starken nach unten gewendeten Fortsatz aus, und vereinigt sich mit dem der Gegenseite, wenn wir an der früheren Dentung festhalten wollten, zu der Symphysis ossinm pubis. Zwischen diese Symphyse, mehr nach vorne zu, schiebt sich ein verkalkter Knorpel von rundlicher Gestalt ein.

Ich stehe durchaus nicht an, in diesem Knochen mit GoRSKY nicht das Schambein, sondern ein $O_{s}$ ileo-pectinemm ${ }^{3}$ ) zu erblicken; der von den beiden linochen bei der Eidechse umschlossene Raum ist das Foramen cordiforme.

Ist das bisherige 0 s pubis nicht Schambein, so muss selbstverständlich das Os ischii zum Schambein werden, wie das vom genannten Autor in sorgfaltiger Weise nåher begründet wird. Indem er nun aber das Os ischii der Antoren in seiner Ganzheit dem Os pubis vergleicht, und die Reihe der Beckenknochen damit zu Ende ist, so wird er zu dem Schlusse gedrängt, dass den Eidechsen das Os ischii mangle und nur ein Band, das Ligamentum ischiadicum, eine Art Homologon des Sitzheins vorstelle.

In diesem Puncte hat nun offenbar FürbRINGER, ${ }^{4}$ ) welcher vor Kurzem den versinnlichen.

1) Vergl. hierzu die Figuren der ersten T'afel, welche die Krallen unserer Arten in getreuer Darstellung

$\left.{ }^{2}\right)$ Ueber das Becken der Saurier. Inauguraldiss. Dorpat, 1852. Unter dem Präsidium von Rerciert.

3) Vergl, fünfte Tafel, Fg. 65.

4) Die Knochen und Muskeln der Extremititen bei den schlangenähnlichen Sauriem. Leipzig, 1870. 
Gegenstand geprüft hat, das richtigere getroffen, wenn er annimmt, dass das Os pubis GORSKY auch das Os ischii mit enthält, und desshalb den Knochen Os puboischium nennt. Das Becken der Gattung Lacertı spricht sehr für diese Auffassung.

Das Schambein, Os pubis, ist kürzer als das Os ileo-pectineum und geht fast gerade nach abwärts. Nach vorne schiebt sich ein lanzettförmiger Knorpel zwischen die Symphyse ein, dessen Spitze sich in ein Band verlängert und, indem es his zur Symphyse des Os ileo-pectineum gelangt, den herzförmigen Ram in zwei Hiilften zerlegt.

Das eigentliche Sitzbein, Os ischii, nach unten und hinten in eine Art Knorren ansgehend, ist als hinterer schmälerer Abschnitt in dem von c'UviER Schambein genanntēn Knochen enthalten. Zwischen beiden bleibt ein Foramen obturatorium bestehen, so bei Lacerta muralis.

Auch in die Symphyse des Sitzbeins schiebt sich ein Knorpel, der ziemlich weit über das Becken hinaus nach hinten sich verlängernd, wie ein Stab aussieht, dessen Ende bei sorgfaltiger Behandlung gegabelt sich zeigt. Hier schliesst noch ein Band an, das weiter rückwärts zur Hant der Vorderliple der Kiloakenspalte verläuft. Dieser mediane Skelettheil wird auch als Os cloacale unterschieden.

Wie bei allen 'Theilen 'des Skeletes, so herrschen auch am Becken kleine Verschiedenheiten nach den einzelnen Arten. Bei $L$. viridis z. B. verlängert sich der Tnorpelstreifen zwischen der Symphyse der Schambeine selber his zur Symphyse des Os ileo-pectineum, so dass das Dazwischentreten eines Bandes, wie es bei agilis, viviprra und muralis gesthieht, muöthig ist. Hingegen ist der nach hinten abgehende Knorpelstreifen kiurzer"; auch fehlt das Foramen obturatorimu, welches bei L. muralis so deutlich ist, und an seiner Stelle zeigt sich bloss eine flache, dreieckige Grube. Und dars es sich hiehei nicht mm individuelle Abänderungen handelt, geht dauras luervor, dass bei einer ganzen Anzahl von Thieren, auch eines grossen dahmatinischen Exemplars, immer das gleiche Verhalten bestand. Bei der erwachsenen I. agilis erscheint ebenfalls die Oeffnung immer knöchern ausgefüllt.

Die oben dargelegte Ansicht, dass das sog. Schambein nicht dem wirlichell Schambein entspreche, sondern ein den eigentlichen Beckenknochen fremdes Knochenstück sei, bestätigt sich auch, wenn wir auf das Becken anderer Reptilien und Amphibien, sowie der Siugethiere blicken. Bei den Crocodilen wird das Schamund Sitzbein ron einem einzigen Knochenstück rorgestellt und der starke jederseits nach vorne gerichtete Knochen, welcher an der Bildung der Gelenlipfanme licinen Antheil nimmt, ist gleich dem Os ileo-pectineum der Fidechsen. Bei einem riesigen Zanclodon laevis ${ }^{1}$ ) der hiesigen palioutologischen Sammlung zeigt sich dieser knochen nach Form und Befestigung in wesentlich glcicher Weise. Wenn wir nun uberlegen, dass die Saurier die Vertreter und Vorganger der Sängethiere in fruheren Weltaltern waren und linwiederum

1) Gefunden im Keupermergel der Jächklinge bei I'frondorf, Oberamt Tübingen. 
dass die Beutclthiere als die ältesten Säugethiere bekannt, und auch rolı die Schmabelthiere ron hüctstem Alter sind, so wïrde es den Gedanken, welche man gegenwärtig über den Zusammenhang dè Thiere hegt, nur entgegen kommen, wenn wir sehen, dass gerade am Becken der Beutelthiere und Schnabelthiere diese knochen der genannten grossen Saurier am deutlichsten sich als sog. Beutelknochen erhalten haben. Bei den späteren Säugethieren ist als Irest des Knochens nur cir Dorn, z. 13. dic Eminentia ileo-pectinea am Becken der Fledermäuse, oder ein Höcker, 'Tuberculum ileo-pectineum, geblieben. Für gleichwerthig halte ich auch noch den breiten Fortsatz am Schambein des Pterodactylus und die Cartilago ypsiloidea der Salamander.

Die Abschnitte des Schultergürtels und Beckengürtels lassen sich, wenn man vielleicht von der Clavicula absicht, welche nach Gegenbaur ${ }^{3}$ ) kein Aequivalent am Beckengürtel hat, unschwer auf einander zurückführen. Wenn nun, wie gezeigt, am Becken ausser dem Darm- Sitz- und Schambein noch ein besonderer Skelettheil zugegen sein kann, so wird man fragen dürfen, welches sein Homologon am Brustgürtel ist. Ich meine, dass dieses im Episternum zi erblicken sei und freue mich hintendrein zu sehen, dass Brescuet ${ }^{2}$ ) schon vor Jahren daran gedacht hat, wenigstens die Beutelknochen, dann die Cartilago ypsiloidea der Salamander mit den ron ihm beschriebenen Episternalknochen zu rergleichen.

Hintergliedmassen.

Der Kopf des Oberschenkels, Femur, ist nicht kugelrund, sondern seitlich zusammengedrückt; der hollhügel ist vorhanden, von einem Hals hingegen kaum eine Spur; das untere- Ende geht in zwei Gelenkknorren aus.

Die T'ibia ist der stärkere Knochen des Unterschenkels und gegen das obere Ende von dreiseitigem Umris.. Die Gelenkifläche zum (h)ersehenkel zeigt eine mittlere runde Grube, gegen welche eine thalartige Einsenkung zwischen den Erhöhungen der Gelenkftäche zieht. Im Ganzen nimmt sich daher die letztere, von oben angesehen, wie dreilappig aus. ${ }^{3}$ )

In dem knorpeligen Meniscus des Gelenks sind mehrere Verkalkungen vorhanden, die sich in trockenem Zustande als weisse Kinochen leicht abheben; auch in der Strecksehne des I. rectus femoris liegt eine Verknöcherung oder Líniescheibe, eine andere gerade über der Gelenkfläche der Fibula, so dass man im Granzen fünf Knnochenstückchen am líniegelenk unterscheidet, wovon das letzterwähnte dias grösste ist.

Die Fibula ist der schwïchere Knochen des Unterschenkels, und die Gelenkfliche des oberen Endes spitzt sich etwas pyramidal zu. ${ }^{*}$ )

Der Tarsus, indem ich hiebei den Angaben GEGENBaUR's folge, gliedert sich wie der Carpus in zwei Reihen von Stücken. Die erste Reihe besteht aus einem einzigen grossen Knochen, der den Astragalus, Caleaneus und das Xaviculare vorstellt: bei jungen Thieren sind anch in dem gemeinsamen linorpelstück melnere hinochenkerne zu muterscheiden. Diese Neigung zur Verschmelzung zeigt sidh anch

\footnotetext{
1) Grundzüge d. vergl. Anatomie, 2. Aut. 1870.

$\left.{ }^{2}\right)$ Squelette des Vertébrés, Ann. d. scienc. nat. 1838.

ง) $\mathrm{Fg} .74, \mathrm{f}$.

1) Fy. $74, f$.
} 
für die zweite Reihe; anstatt fünf gesonderter Stücke sieht man nur zwei: ein Cuboideum, welches das vicrte und fünfte Tarsale umfasst und ein Cuneiforme tertium; die beiden fehlenden 'Tarsalien haben sich mit dem entsprechenden Metatarsus vereinigt. ${ }^{1}$ )

Wegen der straffen, festen Verbindung des Tarsus mit den beiden Knochen des Unterschenkels bewegt sich der Fuss der Eidechsen am Unterschenkel nicht an einem dem Sprunggelenke der Säugethiere homologen Orte, einem 'Tarsocruralgelenke, sondern in einem Tarso-Tarsalgelenke, wie GEGENBAUR ferner nachwies.

Was die Zehenglieder anbelangt, so zähle ich im aufgehellten Hinterfuss eines Embryo an der kleinsten Zehe zwei Phalangen, an den zwei långern drei, und in den zwei ganz langen Zehen vier. Bei Embryen, deren Extremitäten erst die Form einfacher stummeh haben, lassen sich noch keine Knochenanlagen imterscheiden.

Ein eigenthümliches Wechselverhältniss besteht im Aussehen und Bau von Hand und Fuss zwischen den Embryen der Eidechsen und gewissen fertigen Molchen einerseits und den Fingern und Zehen der Larven von Molchen und denen ausgebildeter Eidechsen andererseits. Die Gliedmassen ${ }^{2}$ ) nureifer Embryen der Eidechsen gehen in förmliche Flossenfüsse aus und erimneru damit an Wassermolche; umgekehrt besitzen gerade die Larven der Molche Finger und Zehen, welche durch Länge und Zartheit denen der fertigen Eidechsen vergleichbar sind. Mir scheint, dass sich anch hierin eine nähere und ursprüngliohere Verwandschaft der lieptilien zu den höheren Classen kundgibt, dil der Enıbyo von Vögeln und Säugethieren ebenfalls ähnliche Fussformen vorübergehend besitzt.

\section{A n h a n g.}

\section{Brechbarkeit nnd Wiedererzengung des Schwanzes.}

Eine allbekannte Erscheinung ist, dass der Schwanz der Eidechsen gar leicht, in geringerem Grade der von Blindschleichen, sich ablöst; doch ist schwerlich anzunehmen, dass es auf Beobachtung beruht, wenn Tschud versichert, der Schwanz breche oft entzwei, indem sich die 'Thiere spielend durch die Dorngebüsche herumtreiben, oder unter Steine sich verkriechen; obschon ich immerhin selbst sah, wie einer frisch eingefungenen und in tinen gerüumigen Gilakiasten gesetzten L. viridis der Schwanz dadurch abbrach, dass das Thier solehen als Anstemmungsmittel gebranchte,

ग) Eine gute Umrissfigur des Fussskeletes der Eidechse findet sich in den Grundzügen der vergl. Anatomie von Gevievisur, 2. Auflage. S. 699.

") Füinfte 'l'afel, Fg. G4. 
um möglichst hoch an der Wand hinaufzukommen. Aber bei den Kämpfen der Männchen zur Begattungszeit, bei den Angriffen, welchen die Thiere von Seiten der Raubvögel und gewisser Schlangen (Coronella laevis, Coluber Aesculapii) ausgesetzt sind, mag der 'Theil oft genug zu Verluste gehen.

Der Grund dieser leichten Brechbarkeit liegt wahrscheinlich zunächst in der Quertheilung der Schwanzwirbel, wofür vor Allem der bemerkenswerthe Umstand spricht, dass gerade in der Gegend des siebenten Wirbels, allwo die Quertheilung beginnt, am leichtesten der Schwanz abknickt. Immerhin möchte zu beachten sein, dass noch Anderes ausser der Theilung der Wirbelkörper mithilft; wozu ich rechne, dass die itussere Hautbedeckung zwischen den Wirteln der Schwanzschuppen um gar vieles dümner ist, als unterhalb der Wirteln selber, was sich beim Skeletiren des Schwanzes dadurch kund gibt, dass die Haut, indem wir sie abzustreifen versuchen, lieber in die Quere, zivischen den Wirteln durchreisst als nach der Länge. Dann mag endlich das viele lockere Fett um die Wirbel, sowie die Anordnung der Schwanzmusculatur etwas dazu beitragen, die Festigkeit des Zusammenhangs der Theile gegen Widerstände zu mindern.

Bekannt und von jeher ${ }^{1}$ ) bewundert ist auch die Erginzungskiraft, durch welche das verloren gegangene Organ leicht wieder erzengt wird. Nachdem sich die Wunde zusammengezogen und geschlossen hat, kann die Neubildung sofort beginnen, zumächst unter der Form einer grauschwärzlichen Warze, die sich kegelförmig verliingert. An Thieren, denen der Verlust des Schwanzes im Herbst zugestossen war und welche wïhrend des Winters im Zimmer gehalten wurden, wuchs in dieser ganzen Zeit der sich neu bildende Kegel kaum nemnenswerth. Mit dem Eintritt der warmen Jahreszeit, bei guter Fütterung, geht die Wiedererzengung rasch von statten. Der nene Zuwachs ist bei den meisten Arten, so bei viridis, agilis, vivipara, gleich anfangs stark dunkel pigmentirt; seltener, ich sah es so bei L. muralis, var. campestris, war er hell durchscheinend, wie fleisehfarben; erst nach und nach bekam er anf der liückenseite Pigmentirungen und zwar als Fortsetzung der dunkeln Bandstreifen des unversehrten Schwanzes. Die Haut, lïngere Zeit glatt, erhebt sich jetzt in Ringfalten oder Schuppen, welche mitunter nicht mehr so ganz regelmaissig gerathen, wie sie es am verloren gegangenen Organ waren.

Wemn man sich einige Rechenschaft üher den Grund der geweblichen sonderungen gehen und die Vorstellung nicht genügen will, dass das sich Nenzubildende

1) Lacertis et serpentibus amputatae caudae renascuntur, Arsstoteres et Prrsius. Auch gaben die Alten eine Art Erklärnng: Cardanus causam cur quibuscham animalibus partes quaedam praecisae excisaeve renascantur, in eo collocat, quod imperfecta sint; medici ob id quod humidiora sint, dicerunt. Vergl. Gessser, quadr. ovip. p. 30.

Leydig; Saurier. 
durch „die Idee des Organismus“ vorgezeichnet sei, so lässt sich nur denken, dass die Nachiarschaft der gebliebenen Gewebe auf die Sonderung der Neubildung bestimmend einwirke; obschon genau besehen, auch mit dieser Auffassung kaum etwas gewonnen ist.

Nicht allzuselten, was ich nach eigener Erfahrung bestätigen könnte, trifft man auch Eidechsen mit zwei Schwänzen. Schon Plinius weiss davon, dann GEssner, und Aldrovandi ${ }^{1}$ ) hat sie zuerst abgebildet; selbst solche mit drei Schwänzen wurden beobachtet, wovon ein Beispiel bereits REDI bekannt machte. ${ }^{2}$ ) In derartigen Fällen mag mitunter einer der Schwänze noch der ursprüngliche sein, da wenigstens LACÉPÈDE bezüglich einer doppelschwänzigen Eidechse angibt, dass in dem einen der beiden Organe vollständige Wirbel vorhanden gewesen. Häutiger scheint aber nach den bis jetzt darüber augestellten Untersuchungen das Vorkommniss zn sein, dass beide Organe neu ergänzte waren.

Wie zwei Schwänze entstehen können, ist in neuester Zeit von GLückselig ${ }^{8}$ ) an 'Thieren in Gefangenschaft beobachtet worden. Ein Mảnnchen biss einem anderen im Kampf den Schwanz so ab, dass nur ein Drittel seiner Länge übrig blieb und der Stumpf zwei Linien ober seinem Eude noch eine tief eindringende Wunde hatte. Es wuchs nun nicht blos der Stummel zu einem neuen Schwanz aus, sondern auch aus der Wunde am Rücken des Schweifes erhob sich eine Warze, die sich gleichfalls verlängerte und einen zweiten Schweif bildete.

Es begreift sich, dass die verschiedensten Beobachter den Bau des wiedererzeugten Schwanzes untersuchten; da aber Heinrich MüLler seine Verwumdermg aussprechen zu müssen glaubte, dass man den Bau der nachgewachsenen Schwänze der Eidechsen noch so wenig beachtet habe, so darf ganz besonders auf DuGis hingewiesen werden, welcher in seiner Abhandlung über die auf französischem Boden vorkommenden Eidechsen ${ }^{4}$ ) nicht nur das, was man äusserlich an dem nachwachsenclen Schwanz bemerkt, aufgezeichnet hat, sondern auch mit dem inneren Baue

1) De quadrupedibus oviparis, 1637. Isacertus viridis cauda bifurca auf $\$$. 635 und Lacertus viridis exsiccatus auf S. 636 .

*) Osservazioni intorno agli animali viventi etc., 1684, Tav, seconda, Lucertola con tre code. Bei Skßs Thesaur. 'T. II, Tab. CIII erscheint ebenfalls eine Lacerta (ocellata?), deren nachgewachsener Schwanz - dass er wieder erzeugt sei, sieht man deutlich an dem starken Absatz - zwei Seitensprossen hat ( Cauda alias saepe bifurcata rarissimo huic spectaculo plures quasi ramulos laterales emittit.\&) - Auch Eversman sah in einer Sammlung in Algier Eidechsen mit drei Schwiinzen. Erinnerungen aus einer Reise in's Ausland 1857-58. Bulletiu d. naturalistes de Moscou, 1858.

3) Ueber das Leben der Eidechsen, Verhandlungen d. zool. botanischen Vereins in Wien, 1863.

4) Ann. d. sc. natur. 1829, p. 360. „A l'interieur, quelle que soit l'ancienneté d'un bout reproduit, il ne contient point de vertèbres, mais un cartilage d'une seule pièce, blanc, flexible, fistuleux et reunpli d'un prolongement du cordon ou faisceau nerveux zachidien. - Zwei andere spätere Arbeiten über den gleichen Gegenstand kenne ich nur dem Titel nuch, nämlich: Gacır, Mém. sur la reproduction de la queue des reptiles sauriens, Actes d. l. soc. Linn. de Bordenux, 1833, und CaLorr, sullo scheletro della Lacorta viridis, sulla riproduzione della coda nelle Lucertole, Mem. Accad. di Bologna, $18 ; 5$. 
völlig vertraut war. Denn nicht blos sagt derselbe, dass im Inneren eines solchen Schwanzes keine Wirbel sich fänden, wohl aber ein weisses biegsames Knorpelstück, welches hohl sei; sondern man erfährt bereits durch den Genannten, dass das Kinorpelrohr erfüllt sei mit einer nervösen Verlängerung des Rückenmarkes.

In Deutschland kam man erst auf Umwegen zu dieser Erkenntniss. Allerdings wusste man auch lier seit langer Zeit, dass im Iuneren des nachgewachsenen Schwanzes, anstatt einer Wirbelsiule, ein kıorpeliger, und zwar hobler Cylinder zugegen sei. Was sollte derselbe aber morphologisch bedeuten?

Heinrich MüLLer gieng zuerst auf eine histologische Untersuchung ein, ') dessen Ergebniss war, dass das Knorpelrohr den Wirbelanlagen entspreche und die weiche Masse, welche das Rohr ausfülle, sci der Chorda zu vergleichen.

Ich selbst, als ich die regenerirte Schwanzspitze einer Eidechse prüfte, ${ }^{2}$ ) dachte bei dem Knorpelfaden zunächst an eine Chorda dorsalis; doch musste ich beisetzen, dass dieselbe daun mikroskopisch nicht wie die Substanz der Chorda bei Fischen und Batrachiern aussehe. Hierauf wies Gegenbaur ${ }^{3}$ ) überzeugend nach, dass es sich keineswegs um eine Regeneration der Chorda dorsalis handle, sondern dass dỉe Masse, welche man dafür genommen, mit dem Rückenmark im Zusammenhang stehe; es sei demnach die Lichtung des Knorpelrohrs eine Fortsetzung des Rücligrateanales. Mithin wäre das hnorpelrohr einer Summe von Wirbelkürpern und oberen Bogenstuicken gleichzusetzen; es sei ein neugebildetes, ungegliedertes Rückgrat.

Auch Heinrich Mülcer hatte die Sache wieder aufgenommen und indem er seinem Vorgänger beistimmen musste, erledigte er die strittigen Fragen mit einer schönen Arbeit, worin er namentlich zeigte, die Masse in dem Knorpelrolı sei wirklich Rückenmark, indem sie aus nervösen Elementen bestehe, ${ }^{4}$ ) ein Punct, itber den gerade GEGENBAUR noch Zweifel gehegt hatte.

Ich habe im Laufe vorliegender Studien aus dem nachgewachsenen Schwanz den línorpelfaden mehrmals ausgeschält und mikroskopirt. Seine Länge betrug z. B. bei einer L. viridis $2^{1 / 2}$ Zoll und war für's freie Auge ganz vom Aussehen einer Chorda: ohne alle Abgliederung der Wirbel, einfach walzig, nach hinten sich allmählig verschmälernd. Nur am Vorderende, da wo der Knorpelfaden den noch bestehenden Wirbeln insass, war er nicht rein walzig, sondern entsprechend den Kanten der Wirbel, erhoben sich als Fortsetzung derselben leistenartige Vorsprünge an der Neubildung welche sich erst nach und nach verloren.

In Scheiben geschnitten und unter dem Mikroskop, unterschied man zunächst um den, das Rückenmark bergenden, C'anal eine dümne Lage von Hyalinknorpel; dimn kam dir Hauptmasse des Stranges, welche sich als theilweise verkalkter Kinorpel darstellt; hiernuf schloss nach aussen eine dünne Lage rindenirtig ab und diese bestand aus ossificirtem Bindegewebe.

An einer Lacerta agilis, deren nachgervachsener Schwanz noch nicht völlig

1) Würzburger Verhandlungen 1852.

$\left.{ }^{2}\right)$ Histol. S. 62 .

3) a. a. O. S. 48.

j) Ueber die Regeneration der Wirbelsïule und des Rückenmarkes bei Tritonen und Eidechsen, Abhandlungen d. Senkenberg. Naturf. Ges. Bd. V. (1864-65.) 
die Länge von einem halben Zoll hatte, zeigte der Querschnitt ebeufalls zunächst um das Rückenmark herum eine Knorpelschicht mit rundlichen Zellen; dann kam nach aussen die Hauptknorpelmasse, wobei mir bemerkenswerth war, dass die Zellen durch Grösse und sonstige Beschaffenheit doch etwas an das Gewebe der Chordasubstanz erinnerten. Davon schied sich als Rinde eine Lage, deren zugespitzte Zellen ringförmig verliefen. ${ }^{1}$ )

Man darf selbst auf den Gedanken kommen, dass bei manchen Individuen die Schwanzwirbelsäule überhaupt nicht die vollständige Ausbildung erreicht, sondern ein solcher Knorpelstrang deren Stelle vertreten kann. Ich habe nemlich den Knnorpelfaden anch bei Exemplaren von $L$. viridis, $L$. muralis und $L$. vivipara getroffen, wo es sich nach der Länge des Schwanzes, sowie in Aubetracht der regelmässigen Beschuppung und der Farbe, nicht entfernt um einen wiedererzeugten Theil handeln kounte. Und doch war in Inneren ein gutes Stück Knorpelfaden zugegen und in einen Längscanal ausgehöhlt, welcher zur Aufnahme des Rückenmarkes diente. Bei grossen Exemplaren betrug ein solcher Knorpelfaden zwei bis drei Zoll Länge.

Und damit komme ich zum Schlusse wieder auf die Frage: als was soll der Knorpelfaden angesehen werden? Ich meine, dass, gleichwie er ausgeschält und für's freie Auge einer Chorda dorsalis etwa einer kleinen Lamprete oder eines kleinen Störes ähnlich ist, so auch nach seiner Bedentung; selbstrerständlich in einem gewissen beschrünkteren Sinne. Legen wir uns zu diesem Zweck die Mittheilungen vor, welche wir GEGENBAUR über die Entwicklung der Wirbelsäule der Lacerten verdanken. ${ }^{2}$ )

Die skeletbildende Schicht, welche die Chorda umgibt, besteht anfänglich aus indifferenten Zellen. Durch Ablagerung von Intercellularsubstanz wird diese Schicht zu linorpel ungewandelt und dieser bildet jetzt, gleich den vorher indifferenten Zellen, einen cylindrischen Beleg um die Chorda, zugleich anch die Bogenstücke abschickend. Die Anlage der Wirbelkörper erscheint dadurch, dass je ein dünner linorpelring, dem jedesmal die oberen Bogen seitlich ansitzen, verkalkt. Die zwischen je zwei Kalkringen lagernde Kinorpelmasse wird zum Interrertebralknorpel, welcher nach aussen sowohl als nach innen wächst, mit andern Worten sich wulstet und dadurch die in seinem Inneren liegende Chorda einschnürt; während die inner-

\footnotetext{
1) Die Durchschnitte belehrten auch, dass der sich wiedererzeugende Schwanz nicht bloss äusserlich schwarz gefiribt ist, sondern dass das liguent sich von der Haut nach innen fortsetzt.

$\left.{ }^{2}\right)$ Untersuchungen z. vergl. 'Anat. der Wirbelsäule b. Amphib. u. Reptil. 1862. Abgebildet ist auf 'Iaf. IV der senkrechte Längsschnitt durch einen Schwanzwirbelkörper eines reifen Embryo von Laceria agilis, sowie im Text S. 45 der horizontale Schnitt durch zwei Rumpfwirbel einer einjährigen Lacerta agilis; beidesmal in der gewohnten sicheren und leichten Art des Verfassers.
} 
halb der Kalkringe oder Wirbelkörper befindliche Partie der Chorda sich zuerst noch erhält. Bei weiterem Wachsthum trennt sich der Intervertebralknorpel in zwei Abschnitte, derartig, dass er sich in Pfanne und Gelenkkopf sondert. Bei Lacerta agilis erhält sich im Inneren der abgeschnürte Rest der Chorda durch das erste Lebensjahr; er schwindet erst nach dieser Zeit zufolge Veründerungen und Rückbildungen, welche der verkalkte Knorpel erleidet und die anf Entstehung von Markräumen hinauslaufen.

Der fertige Wirbel besteht nämlich aus wirklich ossificirten Lamellen. Diese kommen einerseits aus dem Periost her, durch Auflagerung von der Innenseite desselben auf die Aussenfläche des Wirbels; sie bilden das System der Lamellen, welches die Umrisse des Knochens im Grossen und Ganzen wiederholt. Andererseits entstehen die concentrisch geschichteten, die Markräume und Canäle umgebenden Knochenlamellen durch sklerosirende Schichten an den Wandungen der Markiäume; wobei der ursprüngliche Knorpelknochen nach und nach völlig aufgezehrt wird.

Vergleichen wir mit diesen Vorgängen den Knorpelfaden im regenerirten Schwanz, so ist hier allerdings die Chorda im engeren Sinne, oder in ihrem Axentheil, nicht vorhanden; aber zugegen sind die Rinden oder skeletbildenden Schichten, das heisst, ein verkalkender Knorpel und ossificirendes Bindegewebe als Grundlage für Wirbelkörper und obere Bogen. Die wirkliche Sonderung und Gliederung in Wirbel erscheint aber meist gehemmt oder nur auf eine Strecke des "Knorpelfadens" beschränkt, so dass der grösste 'Theil im sonst vorübergehenden Zustand sich erhält. Aber gleichwie man sagt, die Chorda sei bei Embryen ein Vorläufer, bei manchen Fischen dauernd ein Vertreter der Wirbelsäule, so lässt sich auch vom Knorpelfaden im Schwanze der Eidechse behaupten, dass er jene Schichten und Theile in sich begreift, welche sonst aus der Scheide der Chorda ihren Ursprung nehmen; das ganze Gebilde behalte sonach etwas Chordaähnliches und sei in gewissem Sinne auch Chorda. Und nach dieser Auffassung liegt kein Widerspruch darin, wemn man hinwiederum gelten lässt: der Knorpelfaden stelle ein unfertiges Rückgrat vor.

Auch bei der Blindschleiche findet Wiedererzeugung des Körperendes statt. Ich spaltete mehrmals den Schwanz von Thieren, wo sich in dessen Spitze anstatt der Wirbel ein Kinorpelstück vorfand, von 3-4 Linien Lünge, auch wohl kürzer und ohne Abgliederung. Es entsprach deutlich einer Anzahl ron Wirbehn, umschloss auch nach oben das Ende des Rückenmarkes.

Für andere 'l'heile des Körpers, z. B. der Extremitäten, wirkt die Erganzungskraft in schwächerem Grade. "Ein abgeschnittener Fuss wächst nie mehr nach, aber auch nicht ganz stumpf zu, sondern verlängert 
sich in eine Spitze (Tschudi). Jüngst zeigte ErBer ${ }^{2}$ ) eine lebende L. viridis vor, welcher kurz vorher von einem Bipes Paliasii ein Hinterfuss glatt abgebissen worden war. Es hatte sich jedoch in der Zeit von einigen Wochen ${ }_{n}$ ein bedeutender Nachwuchs" gebildet.

\section{Nervensystem.}

Das Gehirn der heimischen Eidechsen ${ }^{2}$ ) hat ein paariges, längliches Vorderhirn (Lobi hemisphaerici), das sich nach vorne in die Riechnerven auszieht; durchschnitten lassen die Lappen in ihrem Innenraum einen deutlichen Streifenhügel (Corpus striatum) erblicken, der von unten und seitlich sich hereinwölbend, den Binnenraum sehr verengt. Das mnpaare Zwischenhirn (Lobus ventriculi tertii) wird ziemlich bedeckt vom Vorderhirn; biegt man letzteres nach vorne, so zeigt sich die 0effnung, durch welche seine Höhle zu Tage tritt.

Es folgt jetzt das paarige Mittelhim (Corpora quadrigemina), welches zwei rundliche Massen darstellt; auf dem senkrechten schnitt erscheint eine Hölle, welche beiden Hügeln gemeinsam, jedoch klein ist, da der Boden der Höhle sorrohl sich verdickt, als auch von oben und seitlich die Wand massig geworden ist. Vor den Vierhügeln erheben sich die Stiele der verhältnissmässig sehr grossen Zirbel, welch letztere eine faltige Oberfläche darbietet; nach meinen früheren Untersuchungen besteht sie aber aus Schläuchen, welche auf's reichste von Blutgefässen umzogen werden..$^{3}$ )

Das unpaare, kleine, nach vorne und aufwärts gewendete Hinterhirn (Cerebellum) ist zwar wenig entwickelt; stellt aber doch nicht mehr wie bei den Amphibien ein einfach queres Iarkblittehen dar, sondern hat eine deutliche mittlere Wölbung. Enrlich das Nachhirn (Medulla oblongata) bietet noch eine weite offene Rautengruhe dar. Auf dem Längsschnitt gewahrt man die allen höheren Wirbelthieren zukommende, unter dem Mittelhirn befindliche Einknickung und deutlich die Lage des Hirnmhanges. Dieser, durch einen langen dünnen Stiel mit dem Gehirn in Verbindung, erscheint stark rückwärts gerichtet und zeigt gleich der Zirbeldrüse eine anscheinend faltige Oberfläche. Das verlängerte Mark ist nach unten, was schon frühere Beobachter erwähnten, bédeutend angeschwollen.

Spaltet man den Schädel eines frischen Thieres, so tritt sehr zu Tage, in

1) Verhandlungen d. zool, bot. Vereius in Wien, $180^{\circ}$ (ERвEn, Bericht einer Reise nach Rhodus).

$\left.{ }^{2}\right)$ Vergl. Zwölfte 'l'afel, Fgg. 152, 154, 155, 156 '.

5) Fische u. Reptilien, S. 94. 
welchem Gegensatz auch durch die Farbe das eigentliche Gehirn zum Rückenmark steht. Letzteres sowie das verlängerte Mark und die austretenden Himnerven sind lebhaft weiss; hingegen Vorder- Mittel- und Hinterhirn erscheinen von grauer Farbe, auf solche Weise schon ausdrückend, dass Nervenzellen und Punctsubstanz das vorherrschende Element dieser Theile ausmachen.

Ueber die äusseren Unrisse haben bereits vor Jahren KUHL ${ }^{1}$ ) und SERRES ${ }^{2}$ ) bildliche Darstellungen gegeben, wovon die des deutschen Naturforschers von grösserer Sorgfalt zeugen. Dennoch habe ich es nicht für überflüssig gehalten, noch einmal das Gehirn etwas mehr vergrössert vorzulegen, und zwar sowohl von $L a$ certa als auch von Anguis.

Am Gehirn der einzelnen Arten der Eidechsen fand ich keinen Unterschied: Lacerta agilis verhielt sich wie $L$. muralis und L. vivipara. Die Blindschleich $\mathrm{e}^{3}$ ) hingegen zeigt eine bestimmte Abweichung, welche in dem Grössenverhältniss des Vorderhirns zum Mittelhirn besteht. Hier sind nämlich die Corpora quadrigemina an und für sich kleiner als bei der Eidechse, und dann noch im Besonderen um vieles kleiner als die Lobi hemisphaerici; diese hinwiederum sind bei der Blindschleiche merklich grösser, als bei der Eidechse. Für mich war diese anatomische Thatsache insofern von einiger Bedeutung, als ich bei längerer Pflege der beiden Thierarten mich überzeugen musste, dass die Blindschleiche in ihrem Benehmen mehr Ueberlegung verräth, als die Eidechsen.

Es wäre wohl zu wünschen, dass eine dem jetzigen Standpunct der thierischen Morphologie entsprechende Zergliederung des Gehirnes gegeben würde; bis jetzt fehlt eine derartige Arbeit. Vor mehreren Jahren hat Fr. E. Schulze bei seinen Studien über das kleine Gehirn ') anch die Eidechsen berücksichtigt. Nach ihm besteht hier, wie auch bei Krröte und Frosch, das ganze kleine Gehirn nur ans einer einzigen Windung oder vielmehr nur aus der Rinde einer Windung; eine eigentliche weisse Substanz fehle vollständig. Auf senkrechten Schnitten durch die Randpartie erscheinen. Faserzüge, die sich zu einer unterhalb der Gefässhant liegenden Grenzhaut (Membrana limitans) verbinden.

Da DuGÉs den C'entralcanal des Rückenmarkes in Abrede stellt, sei erwähnt, dass man desselben an Querschnitten leicht ansichtig wird; selbst in dem wiedererzengten Rückenmirk nachgewachsener Schwänze zeigt er sich deutlich zugegen.

1) Beitrïge z. Zoologie u. vergl. Anatomie, 1820. S. 59, Taf. III, Fg. 10, 11 น. $111 \frac{1}{8}$.

2) Anatomie comparée du cerveau, 1824 .

3) Vergl. Zwölfte Tafel, Fg. 153, Fg. 157, Fg. 158.

") Ueber den feineren Bau der Rinde des kleinen Gehirns, 1863. 
Bezüglich der häutigen Umhüllungen mag bemerkt sein, dass bei allen unseren Lacerten die harte Haut des Gehirns dunkel pigmentirt ist; bald mehr, bald weniger, zum Theil tief schwarz.

Man kann diese Färbung in Zusammenhang bringen mit der Erscheinung, dass das schwarze Pigment eine selur weite Verbreitung bei diesen Thieren durch alle möglichen Organe hat. So ist ja nicht blos das Bauchfell von tief schwarzer Farbe, sondern auch die Sinnesorgane, wie z. B. die Nase, sind von vielem Pigment durchzogen, nicht minder die Schleimhaut der NIund- und Rachenhöhle, Zunge einbegriffen; dann die Gefässe, die Muskeln des Stammes etc.

Aber auf eine ganz besondere Bildung in oder an der harten Hirnhaut habe ich noch aufmerksam zu machen, die mir, da sie nicht an Bekanntes mit Sicherheit angereiht werden kann, unverständlich blieb. Wahrscheinlich hat sie einen näheren Bezug zum Gehirn; denn sie tritt an diesem schon zu einer Zeit auf, wo die Sonderung in harte Haut und Schädeldecke noch kaum eingetreten ist.

Wenn wir nämlich - ich that es bei Lacerta agilis, L. muralis, L. vivipara noch für's freie Auge ganz weisse Embryen aus dem Ei nehmen, von der Entwickelung, wie Figur 160 sie vorstellt, so sehen wir über dem Zwischenhirn oder der Gegend des dritten Ventrikels einen lebhaft schwarzen Punct, der gerade durch seine Farbe von dem sonst, mit Ausnahme des Augenschwarzes, ganz pigmentlosen, also hellen Kopf absticht. Greift man zu noch jüngeren Embryen, als der vorgestellte ist, so zeigt sich der Punct ebenfalls schon vorhanden; aber olme Pigmentzone, blos von Blutgefüssen umgeben.

Unter dem Mikroskop, bei starker Vergrösserung, besteht der Körper aus länglichen, einem Cylinderepithel ähnlichen Zellen, so geordnet, dass sie zusammen eine flache Grube von rundlichem Umriss bilden. Der Rand der Grube ist nach oben gewendet und hat einen dichten schwarzen Gürtel von Pigment; dieser ist es eben, welcher schon für's freie Auge das Organ sehr bemerklich macht. Etwas weniges, zerstreutes Pigment umspinnt auch sonst das ganze Gebilde; wie man auch jetzt sieht, dass in der Gehirnhülle bereits Pigment, wenn auch schwach, aufgetreten ist. Blutgefïsse umziehen in allen Füllen und reichlich das fragliche Organ. Ich finde auf den mir bekanut gewordenen Abbildungen von Embryonen der Eidechsen das Gebilde weder angedeutet, noch sonst in Worten erwähnt.

Das Organ ist keineswegs, woran man zunächst denken könnte, die embryonale Zirbel, denn diese folgt erst darmenter und ist von ganz anderer Beschaffenheit. Fragliches (iehilde entspricht ferner der Stelle, wo sich im skeletirten Schïdel des fertigen Thieres, im späteren Scheitelheine, das oben sthon erwïhnte kreisrunde Loch befindet; über welchem sich aber anch am frischen Thier nach aussen noch ein kleiner runder Fleck als etwas besonderes abhebt. 
Yan darf sich wundern, dass die schon dem freien Auge bemerkbare und bei guter Beleuchtung mit wallartiger Umfassung ( $L$. muralis, var. campestris) versehene Stelle, bis jetzt liaum beachtet wurde; denu der einzige Zoolog, der sie crwähnt, ist BRANDT, ${ }^{1}$ ) welcher von Lacerta agilis sagt, es fünde sich "meist mitten auf dem Hinterhauptschild eine runde, vertiefte Stelle" und in einer Anmerkung hinzufügt: "eine eigene Drüsenstelle bezeichnend." Mirne Evwards in seiner bekannten Abhandlung über die Eidechsen, ${ }^{2}$ ) obschon el die hopfschilder geuauer durchgelıt, schweigt davon; aber unter den zahlreichen Küpfen, welche dort abgebildet sind, hat der Zeichner die markirte Stelle doch nicht überall übersehen können, und trägt sie daher als ein Ringelchen bei Lézard piqueté, Lízard pomieté und Lézard d'Olivier auf das Interparietalschild ein. In einem Werke KEssLer's über die Reptilien und Amphibien des Gouvernements Kiew, allwo ebenfalls die liöpfe von Eidechsen in vergrôssertem Massstabe geźeichnet sind, ist nicht minder das Organ ganz unberücksichtigt gelassen; selbst bui Anfertigung der sonst so genauen Abbildungen in Bonaparte's Fauna ist nur hin und wieder das Auge des Zeichners an dem Punct haften geblieben und hat iln angebracht, so z. B. auf Acanthodactylus velox.

Ua mir sehr daran gelegen war, die Natur dieses "Ringes" näher kennen zu lernen, so habe ich an frischen Köpfen, nachdem sie in Säuren erweicht waren, Schnitte gemacht, von oben herein durch die markirte Stelle bis in den Schädelraum. ${ }^{3}$ ) Man gewinnt dadurch die Ueberzeugung, dass es sich um eine innerhalb der Epidermis besonders abgegrenzte Partie handelt; und zwar einer solchen, welche vou kngeligem Umriss und zelliger Zusammensetzung über der Oefinung im Scheitelbein ruht. Unmittelbar unter dem Knochen in der gleichen senkrechten Linie steht die Zirbeldrüse. Sollen etwa die Lagen des Schnittes genauer aufgezählt werden, so folgt von aussen nach innen zuerst die Hornschicht der Epidermis; dann die Schleimschicht und das kugelige, zellige Organ in ihr; darauf der nicht ossificirte, stark schwar\% pigmentirte Theil der Lederhaut; alsdann der Kinochen mit seinen Markräumen, welche gegen die Oberfläche geöffnet sind. Unterhalb des Kinochens kommt die wieder stark gefärbte harte Hirnhaut, und unter dieser, ihr angeheftet, die Zirbel; sie verbindet sich durch zwei nervöse Schenkel mit dem Gehirn.

Bei Anguis fragilis tindet sich das räthselhafte embryonale Organ ebenfalls vor. Schon bei noch sehr jungen Früchten ${ }^{*}$ ) mit grossem Dottersack hebt es sich als schwärzlicher Punct vor den Vierhügeln und einem grossen Blutsinus ab. Bei reiferen Embryen ${ }^{5}$ ) aus der Mitte August lässt sich mit der Lupe ausser dem schwarzen Punct sammt lichter Umgebung noch ein dahinter liegender schwarzer Strich, gleichfalls von hellerem Saum begrenzt, unterscheiden; endlich in gleicher Linie nach hinten macht sich, doch nicht mehr an allen Individuen, ein kleiner unpigmentirter Körper, wie ein winziger Hügel bemerkbar.

1) Medicinische Zoologie, S. 160.

2) Recherches zoologiques pour servir à l'histoire des Lézards, Ann. d. sc. nat. 1839.

3) Zwölite Tafel, Fg. 159.

t) Fig. 161 .

ग) $\mathrm{Fg} \cdot 162$.

Leydig, Saurier. 
Alles dieses zeigt sich deutlich und rein, nachdem wir die Haut des Kopfes abgezogen, und ohne dass das häutige Schädeldach verletzt wurde. Es gehören somit der schwarze Punct, der schwarze Strich und der helle Hügel, jener Partie der Haut an, welche zu den Deckknochen des Schädels wird. Darunter liegt erst, und ist verschieden von allen den drei aufgezählten Bildungen, die Zirbel.

Geht man an die Untersuchung mit dem Mikroskop, so findet sich, dass die Gebilde der imeren Flitche der Schädelhaut angehören, aber leicht davon sich abstreifen lassen. Ferner wird klar, dass der schwarze Punct und der schwarze Strich von gleicher Structur sind: die Wand beider besteht aus cylindrischen, ziemlich langen Zellen, welche am schwarzen strich so sich ordnen, dass dadurch eine Lichtung begrenzt wird; während sie am schwarzen Fleck eine Grube einschliessen, die vielleicht als Ansgang jener Lichtung zu deuten ist. Die Zellen sind an dem Ende, welches sich gegen die Lichtung und den Rand der Grube richtet, schwarz pigmentirt; an dem Punct stärker als an dem "Strich". Es ist kaum nöthig zu ererwähnen, dass für die Besichtigung mit der Lupe der pigmentfreie Theil der Zellen die helle Umgebung des schwarzen Punctes und Striches bedingt.

Der kleine, ebenfalls helle und dabei etwas unbeständige Hügel dahinter ist von ganz anderer Art. Er stellt ein deutliches inselartig abgegrenztes Knorpelstückcheu vor, welches mit jenem früher erwähnten Knorpelstreifen des Primordialschädels, zwischen Hinterhauptbein und Scheitelbein, in Beziehung zu stehen scheint.

Die Zirbel, deren Stiel aus zwei Schenkeln besteht, liegt muterhalb des "Punctes" und "Streifens"; und zeigt sich als etwas von beiden wohl verschiedenes. Thre Oberflitche hat das schon gedachte, faltige Aussehen, das ich auf eine Zusammensetzung aus gewundenen schländhen bezog. Doch erhielt ich auch den Eindruck, als ob es sich un eine hlasige Bildung mit Filtung der Oberfläche hamdle. Die Zirbel ist röllig unpigmentirt.

Noch mag bemerkt sein, dass der zierliche dunkle Rückenstreifen, welcher die jungen Thiere anszeichnet, am liopfe seinen Anfang gerade an der markirten Stelle nimmt, indem er den zelligen, theilweise pigmentirten liörper hogig umgreift.

Doch nicht blas bei Embryen und jungen, bis einjährigen Blindschleichen hebt sich am Interparietalschild nach aussen der merkwürdige Körper ah, sondern anch bei manchen ganz erwachsenen 'T'hieren ist er völlig deutlich geblieben. ${ }^{1}$ )

Wie das Organ zu denten sei, wird im Augenblick wohl Niemand zu sagen

2) Vergl. Erste 'T'afel, f'g. '25. 
sich im Stande fühlen. Doch kann ich nicht umhin, einstweilen an die "Stirndrüse“ der Batrachier zu denken und etwas dieser Bildung Verwandtes zu vermuthen. ')

Bekanntlich ist gewissen Labyrinthodonten (Trematosaurus) ebenfalls das Loch im Scheitelbein eigen und man lrann sonach für walrscheinlich halten, dass sie auch die eigenthümliche, in der Epidermis abgegrenzte, nach aussen hüglig vorragende Partic in der Epidernis besassen. Aber ich liann nicht unterlassen, bei dieser Gelegenheit noch eine andere Vermuthung zu äussern. Auf dem Schädel der genannten Amphibien aus del secundären Epoche macht sich jederseits zwischen Nasenloch und Iuge eine merkwürdige Furche bemerklich, die beide, als Ganzes genommen, bei den Paläontologen den Namen "Brille" tragen. Die Furche ist ohne jene Sculptur. welehe rings herum ïber die schiddelinochen wegzieht. Nach meinem Iafürhalten mochte in der Furche ein Ast des Nervus trigeminus verlaufen, welcher alsdann nach oben in der Haut ähnliche epidermoidale Endkörper trug, wie ich solche am liopf der Larven von Batrachiern auffand. Mit andern Worten, ich hege die Vermuthung, dass die sog. Brille zur Aufnahme von Organen diente, wie ich sie in den Figuren 25, 26 und 27 auf der vierten Tafel der unten angezogenen Abhandlung dargestellt habe.

Es ist mir unbekannt, ob das peripherische Nervensystem einer der einheimischen Arten in gleicher Vollständigkeit behandelt worden ist, wie wir dergleichen Arbeiten über die Schildkröte und den Froseh besitzen. Ich weiss nur von Studien über Kopfnerven, welche an der grössten in Europa lebenden Art, an Lacertu, occlluta, angestellt wurden; dahin gehören die Untersuchungen und der Nachweis BischofF's, ${ }^{2}$ ) dass anch bei Eidechsen der Nervus accessorius vorhanden sei, ferner die Darstellung F'ISCHER's über die Ursprünge sämmtlicher Gehirnnerven.

Erwähnung verdient vielleicht, dass ich in der Augenhöhle von Anguis ein deutliches Gauglion ciliare bemerlit habe. Dasselbe bestand aus drei Abtheilungen, wovon die grösste etwa fünfzig Ganglienkugeln zählen mochte; die kleineren bestanden aus etwa vierzig soleher Elemente. Die Ganglien liegen hinten und seitlich an der Sklera.

Den Stamm des sympathischen Nerven verlegt DUGÉs in den Rückgrathscanal, unterhalb der Pia mater des Rückenmarkes; wesshalb ich bemerken darf, dass man beim Herausheben des Harn- und Geschlechtsapparates bei jungen Thieren grössere Stücke des Nervus sympathicus, sowie seiner Geffechte und zahlreiche Ganglien zur Ansicht bekommt.

Histologisches über die spimalganglien der $L$. agilis hat vor Kurzem SCHWALBE veröffentlicht. ${ }^{3}$ )

1) Vergl. m. Abhandlung: Ueber Organe eines sechsten Sinnes. Nov. act. acad. Leop. Carol. 1868.

3) Commentatio de nervi accessorii Willisii anatomia et physiologia, 1832. Während fast alle Figuren zu dieser Schrift, auch in Nebendingen, treu und mit künstlerischem Geschick von Franz Wagner gezeichnet sind, darf es einigermassen verwundern, dass die Oberfläche des Schïdels etwas in Bausch und Bogen gehalten erscheint. Es werden nemlich die Superciliarknochen von beiden Seiten zusammengerückt, anstatt das Stirnbein dazwischen zu fïgen und es blieb so für letzteres, wenigstens nach hinten, kein rechter Raum.

3) Archiv für mikrosk. Anatomie, Bd. IV, 1868. 


\section{Sinnesorgane.}

\section{Auge.}

Der Augapfel der Eidechsen und ebenso jener der Blindschleiche ist wohl entwickelt, wenn er anch bei Anguis eine etwas geringere Grösse hat. Schon an gleichalterigen Embryen macht sich diese Verschiedenheit der beiden Gattungen sehr bemerkbar; es quellen alsdann die Augen bei der Eidechse äusserst stark hervor, was nicht der Fall ist bei der Blindschleiche.

Legen wir einen Horizontalschnitt durch das Organ, so zeigt sich der hintere oder Skleroticalabschnitt etwas in die Quere gezogen; die Wölbung der Hornhaut tritt bedeutend hervor, wozu auch wohl der Kranz von Knochenplättehen beitragen mag.

Sklera.

Die harte Haut ist in ihrer Grundlage hyalinknorpelig. An Thieren von $L$. agilis, welche in Weingeist gelegen, gewährt der Knorpel der Sklera bei geringer Vergrösserung ein etwas ungewöhnliches Bild; was sich bei starker Vergrösserung dahin aufklärt, dass die eigentliche Zelle klein ist, $m$ sie herum aber eine lichtgelbliche, dicke Kapsel geht, mit zahlreichen Schichtungshinien. 1) nun die Kapsel der Zelle nach aussen sich scharf abgrenzt und zwischen den Kapseln der einzelnen Zellen eine helle Zwischensubstanz sich hinzieht; so möchte man auf den ersten Blick meinen, die Kapseln, welche doch nur Abscheidungsproduct der Zellen sind, wären die Hauptmassen der Zellen und die eigentliche Zellsubstanz wäre blos der Kern.

Am Vorderrand treten bei Lacerta und Anguis die zu einem Ring verbundenen Knochenplättchen auf, welche der treffliche BoJANus' ${ }^{1}$ ) dazumal wenigstens noch nicht gekannt zu haben scheint, als er die Vermuthung äusserte, die Knochenstücke am oberen Rand der Augenhöhle (Squamae supraorbitales) bei Eidechsen seien dem Knochenring im Auge der Vögel zu vergleichen.

Es ist mir nicht bekannt, dass irgend Jemand bisher der eigenthümlichen Form dieser Knochen seine Aufmerksamkeit gewidmet hätte. Nan unterscheidet an dem einzelnen Plättchen ${ }^{2}$ ) den Vordertheil mit etwas buchtigem Rand und einen davon nach hinten abgehenden, wie stielartigen Abschnitt. Betrachtet man den Augapfel im Ganzen, ${ }^{2}$ ) so greifen die vorderen Partien der Kinochen dachziegelartig übereinander, wïhrend zwischen den rückwärts gerichteten Stielen grössere Lücken

2) Isis 1821 .

2) Elfte Tafel, Fg. 1351 und Fg. 135‥

3) E'g. 134. 
frei bleiben. Die Stiele reichen nach hinten bis dahin, wo die Augenmuskeln sich ansetzen. Doch nur bei der Eidechse findet sich diese Gestalt.

Bei der Blindschleiche bieten die Ǩnochenplatten eine einfachere Form dar, wie man nach der beigelegten Zeichnung ${ }^{1}$ ) beurtheilen kann.

Der Augapfel, gesämbert von Dem was an seine Aussenflache tritt, sieht, soweit die knorpelige Grundlage der Sklera geht, schwarz aus, da das Pigment der Choroidea durch den hyalinen Knorpel durchschimmern kann; weiter nach vorn, wo die Kinochenplättchen folgen, ändert sich das Schwarz in Bläulich um, da jetzt das Pigment der thoroidea durch das Grau des hnochenringes nud des bindegewebigen 'Theils der Sklera gedämpft erscheint. Denn es geht der Knorpel der Sklera, wie ich an L. viridis mich überzeugte, keineswegs bis zum Rande der Hornhaut, sondern hört viel früher auf. Der vordere Theil der Sklera ist bindegewebig und diesem Theil gehört der Knochenkranz an; jedoch so, dass die Stiele der Ḱnochenplattchen noch etwas den Knorpel bedecken.

Die Knnocheuplättchen, von dünner zarter Beschaffenheit, und leicht isolirbar, sind ihrer Entstehung nach Verknöcherungen des Bindegewebes; und wegen ihrer besondern Dünnheit verbreiten sich gegen das Ende des stielartigen Abschnittes die Kinochenkürperchen nur in einfacher Schicht, am vordern Theil, welcher etwas dicker ist, in mehreren Lagen. Ihr Kern ist in frischen Präparaten meist sichtbar. Auch ist mir anfgefallen, dass wenn man auf die Oberfläche des Knochens den Blick richtet, die Strahlen der Kinochenkörperchen mit verhältnissmässig grossen Oeffnungen dort ausgehen. Bei Embryen von L. vivipara, welche schon ganz schwarz gefürbt und anch sonst schon reif waren, zeigten sich die Inochentïfelchen bereits vorhanden.

Kamm der Choroidea; Linse.

Die Choroidea besitzt einen kleinen Fächer oder Kamm, welcher in Form eines schnalen schwarzen Keiles ins Innere des Auges vorspringt. ") Bei einem mässig grossen Thier von L. viridis war er etwa eine Linie lang.

Wer vom Kamm im Auge unserer Eidechsen zuerst wusste, ist mir unklar geblieben; vielleicht war es Tredemans, welcher in seiner Naturgeschichte der Amphibien (1817) sagt: Ein dem Kiamm des Vogelauges ähnliches Organ, welches wir im Auge des Leguans und einiger anderer Eidechsen fanden, besitzt das Crocodil nicht. Vom Leguan hatte übrigens bereits im Jahre 1814 Gustav Carus in seiner Darstellung des Nervensystems und Gehirns das Gebilde erwähnt. Fast alle Späteren, welche sich mit dem Auge der Eidechsen beschïfigen, kennen den Kamm, so Friker (1827), Brainville (1828) und Duges (1829); wïhrend ich ${ }^{3}$ ) vielleicht zuerst den näheren Bau desselben crörterte, indem ich zeigte, dass el einen grossen

3) Vergl. zwölfte Tafel, Hg. 146 ‥

2) Fg. 136.

3) Anat. hist. Untersuchungen über Fische u. Reptilien, 1853, S. 95. 
konischen Glomerulus ron Blutcapillaren vorstelle, zusammengehaiten ron zartem Bindegewebe und überdecht von schwarzem Pigment. Es verlalte sich sonit der Kamm nach seinem Bau wie ein Ciliarfortsatz der Choroidea.

Uebrigens steht anch bereits in der Abhandlung I'RIKER'S ${ }^{1}$ ) richtig: "Hujus pectinis structura eadem est, quae in oculi avium pectine invenitur; constat enim tunica rasculosa, sine ullo fibrarum irritabilium vestigio, sed distincta pigmento nigro". Ich rermuthe, dass diese Bemerkung aus Tredemann geschöpft ist.

Auch bei der Blindschleiche ist der Kamm zugegen, wenn er auch von geringerer (Hrösse ist als jener der Eidechse. ${ }^{2}$ ) Beim Durchschneiden des Auges bleibt er im Grunde sitzen und hebt sich als ein schwarzer Punct von der weissgewordenen Netzhaut ab. Unter dem Mikroskop ${ }^{3}$ ) erscheint er wie eine Art Papille die gegen das freie Ende hin dicht schwarz, nach der Wurzel zu aber nur gering netzförmig gefürbt ist. Von der spitze zieht eine Art Bindegewebe rein und ohne Pigment, weiter in den Glaskörper hinein, wahrscheinlich gegen die Linse hin.

Ein gleiches fibrilläres Bindegewebe, von der Art, wie es das Tapetum im Ange der Wiederkïuer bildet, sehe ich hier in Auge der Blindschleiche als dünne Lage über die Membrana choriocapillaris sich ansbreiten. Letztere die Blutcapillaren tragende Haut ist sehr stark dunkel pigmentirt. Hebt man die Retina aus dem Auge, so bleibt an ihrer hinteren Fläche die Lamina pignenti der Choroidea hangen, wie wenn sie zur Retina und nicht zur Choroidea gehörte. Dann erscheint eine zarte Lage - das tapetalartige Bindegewebe - und zeigt wegen des vielen durchscheinenden Pigrnentes der Membrana choriocapillaris eine bläuliche Farbe.

Im Gewebe der Iris sind die Muskelelemente, sowohl die, welche zunächst dem Pupillarrande einen geschlossenen Ring bilden, als anch die radiären Fasern dentlich erkennbar. Die radiären Züge, quergestreift wie die übrigen, stehen weiter anseinander, als die cirenaren. Die einzelne quergestreifte Muskelfaser ist sehr fein, worauf ich schon längst anderwärts ${ }^{4}$ ) aufmerksam machte. - Von der Iris der Blindschleiche ist hin und wieder zn lesen, dass sie schwar sei; in Wirklichlieit ist sie aber an Pupillarrand gelbroth und der färbende Stoff gehört wie auch sonst zum metallisch glänzenden Pigment.

Noch möchte ich bemerken, dass bei einigen Exemplaren von Lacerta viridis, welche ich frisch in starken Weingeist gesetzt hatte, beim Erölinen des Auges zwischen Sklera und Choroidea eine weissliche Masse, geronnener Lymphe ähnlich, sich vorfand, die wohl den Imhalt eines unterdessen von ScHwalße von Neuem entdeckten und im Naheren begründeten Lymphraumes darstellt. ${ }^{5}$ )

1) De oculo reptilium. Dissertatio inaug. (Praeside RArr) 'T'ubingae, 1827.

2) $\mathrm{Fg} .137$.

3) F'g. 138.

") Anat. histol. Untersuchungen üb. Fische u. Reptilien S. 9 b.

¿) Archiv f. mikrosk. Anat. 1870, Heft 1. 
Die Linse des Auges, wie ich wenigstens bei $L$. agilis sehe, ist nicht rein kugelig; am Horizontalschnitt litsst sich erkennen, dass die Krümmung vorne und hinten einen etwas verschiedenen Bogen beschreibt.

Der Retina der lieptilien und Amphibien habe ich seiner Zeit längere Aufmerksamkeit gewidmet und obschon meine Arbeiten durch die späteren verbesserten Methoden der Untersuchung und die gesteigerten optischen Hilfsmittel weit überholt worden sind - Jeder mit der Histologie Vertraute liennt die Leistungen von il. Schultze, Strinlin u. A. - so gestatte ich mir doch daran zu erinnern, dass ich bezüglich der Stäbchen, welche man dazumal noch fur rein homogen hielt, zuerst gewisse Zusammensetzungen nachwies, so insbesondere eine von der Substanz des Stäbchens sich abhebende Hülle, $\left.{ }^{1}\right)$ ferner eine feine Querstrichelung ihrer Substanz. $\left.{ }^{2}\right)$ Auch wüsste ich nicht, dass Jemand vor mir die Grundzüge im Bau der Retina, ich meine das Verhalten des stützenden Gewebes zu den Körnern und Stïben ausgesprochen hätte. Die Radialfasern und ihre Verbreitung galten noch für nervös. Meine Untersuchungen bestimmten mich aber zu der Erkklirang: „das radiilre Fasersystem dér Autoren scheine mir sammt der Membrana limitans gleichsam den Stützapparat oder liahmen abzugeben, in welchem die specifischen und nervösen Gebilde der Retina enthalten sind " ${ }^{\text {s }}$ )

Die Auffassung, dass die Elemente des Nervus opticus schliesslich mit den Stäbchen zusammenhängen, letztere demuach nervöser Natur seien, wird bekanntlich in neuerer Zeit abermals bestritten. Sie sollen vielmelrr in den bindegewebigen Stützapparat endigen, und somit ein katoptrisches System vorstellen; die eigentliche Endigung der Fasern des Nervus opticus wäre unbekannt.

Ich bekenne mich zu der Ansicht, dass die Stäbe Endorgane der Fasern des Selunerven sind: Denn mag auch die Hülle der Stäbchen in den bindegewebigen Stützapparat übergehen, was nach der eben veröffentlichten, wie mir dünkt, seln sorgfältigen Arbeit von LANDoL'T ${ }^{4}$ ) der Fall zu sein scheint, so kann dieselbe nach unten zu ebenso feinlöcherig durchbrochen scin und dadurch zum Durchtritt von verbindenden Elementen geeignet, wie es der gesammte bindegewebige Stützapparat ist. - Endlich bestimmt mich bei der bisherigen Anuahme zu bleiben die Aehnlichkeit der Dinge mit Dem, was in Auge der Arthropoden mit mehr Sicherheit wahrgenommen wird. Es möchte schwer fallen, darthun zu wollen, dass die von mir Nervenstäbe im Auge der Gliederthiere genannten Theile den Stäben im Auge der Wirbelthiere nicht entsprechen. Da erstere nun aber unzweifelhaft mit den Elementen des N. opticus zusammenhängen, so gibt dies einen Grund ab, das bisher im Auge der Wirbelthiere an den homologen Theilen Beobachtete in gleichem Sinne zu deuten.

Nebenorgane des A ugapfels.

Man unterscheidet bezüglich der A ugenlider ein oberes und unteres Lid und eine Nickhant. Das obere Lid wird durch Hautknochen gestützt (Lamina superciliaris), die wohl dem Kuorpel des oberen Lides beim Menschen einigermassen zu vergleichen sind.

Im unteren Lid kommt ein Knorpel ${ }^{5}$ ) vor, dessen zuerst DuaÉs gedenkt und den ich anch bei mehreren Arten untersuchte. Seine Gestalt im. Ganzen ist die eines Hachen Schüsselcheus, gleichsam un die Wölbung der Hornhant anfzunehmen, wie man wegen der Girösse an L. riridis am hequemsten sieht. Zur histologischen

\footnotetext{
1) Aunt. hist. Unters. ül). Fische u. Reptilien, 1853, S. 96.

2) Archiv f. Anut. u. Plays. 1855, \&. 428.

5) Histologie, 1857, S. 221.

1) Archiv fo" mikrosk. Anat. 1870, Octoberheft.

ग) Lwölite Tiafel, Fg. 145, e.
} 
Untersuchung empfiehlt sich dann durch Kileinheit L. vivipara, wo man den Linorpel leicht an Thieren, die in passenden Reagentien gelegen, isoliren kann.

Beim Abziehen des Lides bleibt er an der Conjunctiva sitzen. Die Knorpelzellen sind schmal, sehr zugespitzt, uähern sich mehr den Bindegewebskörpern; wie ich denn bereits längst von dem gleichen Gebilde, welches ich aus einigen grösseren fremden Sauriern mikroskopirte, meldete, dass dieser Lidknorpel Verwandtschaft habe mit dem Tinorpelrahmen in der Schnecke der Vögel. ${ }^{1}$ ) An seinen unteren Rand setzt sich ein quergestreifter Muskel, welcher das untere Lid herabzieht.

Wenn man erwägt, dass der Lidknorpel in seine Höhlung die Wölbung der Hornhaut aufnimmt, dann, dass über ihm nach aussen die Hant hell ist (L. muralis, L. vivipara, agilis) und ohne die Warzenbildung, welche sonst die Oberfläche des Lides überzieht, so kann man sich der Betrachtung nicht verschliessen, dass diese unpigmentirte Stelle den Uebergang zu der durehsichtigen, brillenähnlichen Partie im untern Lid mancher Scinke bildet.

Unter der äusseren Haut des oberen und unteren Lides, nicht minder der Conjunctiva verbreitet sich, wie ich an $L$. agilis und viridis verfolgte, dasselbe lymphdrüsenartige Gewebe, von dem oben bei der allgemeinen Hautbedeckung die Rede war. Dasselbe stellt sich der gewöhnlichen Besichtigung als weissgraue drüsige Masse dar, und man erhält am besten Anfklärung an Querschnitten durch das ganze Lid. ${ }^{2}$ ) Wăhlen wir z. B. das untere Lid von $L$. viridis, so haben wir von aussen nach innen: zuerst die Epidermis, dann die Lederhant von den Eigenschaften wie sie oben dargelegt wurde, nur alles etwas zart und dünn; darunter breiten sich weite Räume aus, so gross, dass sie schon mit freiem Auge unterscheidbar sind; die durchsetzenden bindegevebigen Balken zeigen an der Aussentlitche rundliche Kerne, welche wohl einer Art Epithel angehören. Schon dieses Verhalten deutet auf Lymphräume; man sieht aber bei weiterem Nachforschen, dass manche, selbst viele oder unter Umständen die meisten Räume, mit derselben fein-granuläreren Masse erfüllt sind, wie es oben von der ausseren Haut gesagt wurde. Dadureh erhält das freie Auge den Eindruck von einer weissgranen drüsigen Lage. ${ }^{3}$ ) Unter den Lymphrüumen schliesst das Bindegewebe wieder zu einer die hintere Fläche des Lidknorpels aufnehmenden Hant zusammen, von welcher sich die helle Substanz des letztern abhebt. Die freie

$\left.{ }^{2}\right)$ Histologie S. 243.

2) Fg. 145 .

$\left.{ }^{3}\right)$ Bekanntlich erscheint auch beim gesunden Menschen leicht das untere Lid wie sackartig geschwollen; man sagt dann, es sei » von seröser t'lüssigkeit infiltrirt*. Nach dem, was man bei Lacerta sieht, darf angenommen werden, dass auch beim Menschen in den Lidern grössere Lymphrïume zugegen sind, bei deren starker Füllung das untere Lid wie beutelartig anschwellen kann. 
Flïche des hnorpels ist bedeckt vom Epithel, welches unmittelbar auf dem Linorpel sitzt; jedoch so, dass sich vom Knorpel ein heller Saum abgrenzt, etwa in der Art, wie die Hornhaut auf ihrer Hinterflache die Descemet'sche Hant erzengt, und diesem Saum liegt erst das Epithel auf. Trifft das Messer gerade auf den unteren Rand des Knorpels, so bemerkt man anch wohl noch etwas fetthaltiges Bindegewebe und grosse Venen.

Bei diesen Schnitten macht man aber ferner auch die beachtenswerthe Erfahrung, dass in der Conjunctiva eine reiche glatte Musculatur sich ausbreitet. Sie durchzieht die ganze Bindehaut des Anges und scheint theilweise sogar in die erwähnten, die Lymphräume durchsetzenden Balken einzutreten. Weiteres Nachforschen belehrt, dass man es eigentlich mit einem grossen glatten Mnskel von hautartiger Ausbreitung zu thm habe, der rings um das Auge entspringend die Richtung gegen die Lider nimmt. Besonder's stark ist der Muskel am vorderen Augenwinkel; hier unterscheidet man leicht neben dem oberen schiefen Augenmuskel, schon an der Farbe, einen glatten Muskel, welcher von der knorpeligen Angenscheidewand kommt und sich vor dem M. obliquus superior gegen das obere Lid, die Nickhaut und Harder'sche Drüse verliert; auch von unteu her strebt eine stürkere Portion dieser glatten Musculatur gegen das dritte Lid. ${ }^{1}$ )

Dieser letztere Theil oder die Nickhaut bietet ebenfalls Verhältnisse dar, welche bis jetzt unbekannt waren. Was zunächst die Gestalt betrifft, so unterscheidet man auf der nach aussen gewendeten Fläche zwei halbmondförmige Leisten, - nicht etwa Falten, sondern bleibende Bildungen. Die erstere gehört dem Vorderrand des Lides an und ist ein starker, wie zweilipuiger Wulst, dabei etwas dunkel pigmentirt. Der andere weiter nach hinten gelegene, aber ebenfalls bogige Wulst, ist zarter und nicht minder etivas dunkel pigmentirt. Ginz verschieden davon sind eine Menge Fialtchen, welche an der hinteren Ausdehnung, wo das Lid in die Bindelant des Auges übergeht, im zurückgezogenen Zustande auftreten.

Die Nickhaut besitzt anch einen Knorpel, ${ }^{2}$ ) der aber sowohl in der Gestalt als auch histologisch sehr verschieden sich zeigt von jenem des unteren Lides; es ist cin spangenartiger Streifen, welcher wie eine Art Vorhangsstange das Lid stütıt; sein Gewebe ist eeliter Hyalinknorpel. Min erhailt den hinorpelstreifen leicht zur Ansicht, weun man Nickhaut und Harder'sche Drüse zusammen ansschneidet;

1) Obige glatte Musculatur hat aber wohl nichts mit der Bewegung der Lider zu thun; vielmehr spielen alle, oberes, unteres und drittes am lebenden Thier so rasch, wie es nur durch çuergestreifte Muskeln geschehen kam. Es seleeint die glatte Musculatur der Bindehaut des Anges hauptsächlich auf die Entleerung der Drüsensecrete berechnet zu sein.

2) Fg. 139, b.

Leydig, saurier. 
er zieht von der Nickhaut über die Drüse weg und ich will nicht verhehlen, dass es mir anfangs schien, als sei er nur ein Theil der bogigen Ĺnorpelstreifen, wie sie oben als Reste des Primordialschädels beschrieben wurden. Allein die Untersuchung ganz junger, noch ungeborener Thiere von $L$. vivipara liess sehen, dass der linorpelstreifen kein abgeschnittener Theil vom Gestell des Primordialschädels sei, sondern nach heiden Enden frei anslanfend, lediglich zur Nickhaut in Beziehung stehe. - IJas Epithel der inneren Fläche der Nickhaut besitzt viele Becherzellen. Die bindegewebige (irundlage erscheint sehr reich an elastischen Fasern feiner Art (L. agilis).

Die A ugenmuskeln zerfallen in die vier geraden und die zwei schiefen, welche alle im Unkreis des Sehnerven von der Knnorpelwand zwischen den Augen entspringen; aher es scheinen noch einige kleinere Muskeln an der hinteren Fläche des Angaptels vorzukommen, welche, ohne dass ich dies nüher studirte, dem Quiadrat- und Pyramidenmuskel am Auge der Vögel entsprechen mögen. Ich sehe nämlich wie eine lange dünne Sehne, für die Nickhant bestimmt, sich an der hinteren Wölbung des Augapfels in einem Bogen um den Sehnerven herumbiegt, damn gegen den unteren Rand der Nickhant sich verliert; und zwar so; dass sie da, wo sie in die Nickhaut überzugehen sich anschickt, die strangartige Beschaffenheit aufgibt und unter Verbreiterung zu einer Art Hohlkehle sich gestaltet. Diese letztere Form der Sehne scheint sich bereits auf die zwei bogigen Leisten der Nickhaut, wie sie oben beschrieben wurden, zu beziehen, indem sie die eigentlichen Puncte des Ansatzes der Sehnen abgeben mögen. Mit mehr Sicherheit sehe ich damn wieder, dass die lange dünne Sehne auf ihrem Wege um den Sehnerven herun vom freien Ende eines Muskels ${ }^{1}$ ) umfasst wird, welcher auf der Hinterfläche des Angalfels liegend, ganz so wie der (guadratmuskel am Vogelinge, einen Canal durch Umbiegung seiner Bündel erzeugt, in welchem alsdann die Sehne hinzieht.

Von den Drüsen der Augenhöhlen sind die beiden, eine 'Thränendrüse und eine Nickhautdrüse, vorhanden.

Die erstere liegt am äusseren oder hinteren Augenwinkel, und ist seln klein gegenüber von der Nickhantdrüse. Sie hesteht aus wenig langen, am Lnde gern schwach gegabelten Schläuchen, die sich nicht zu einem einzigen (rang sammeln, sondern sich "zu mehreren Mündungen zu gruppiren scheinen. Auch in der Nähe der Thränendrüse zeigt sich die Conjunctiva mit Lagen glatter Muskeln ansgestattet.

Die Nickhantdrüse oder Harder'sche Drüse befindet sich im vorderen oder inneren Angenwinkel und ist so entwickelt, dass sie wie schalen- oder halbringförmig

1) Vergl. Elfte 'Tafel, Fg. 140. 
den Auginfel von unten und hinten ungreift; wobei die Hauptpartie nach hinten und oben liegt. Die Drüse hat nur einen einzigen Ausführungsgang, welchen ich ziemlich weit gegen die Nasenhöhle verfolgt habe, ohne aber der eigentlichen Ausmündungsstelle mit Bestimmtheit ansichtig zu werden.

Thränenröhrchen sind am inneren Augenwinkel zugegen. Man wird ihrer am besten gewaln, indem man die Nickhant scharf ausschneidet; didurch wird die Lichtung der nahe beisammenstehenden Röhrchen offen gelegt und die nähere Prüfung ergibt, dass sie mit demselben an Becherzellen reichen Epithel ausgekleidet sind, wie es die Conjunctiva besitzt. Die Röhrchen werden von Blutgefïssen unzogen; eine Borste in das Lumen der T'hränencanäle eingeführt, gelangt in die Nasenhöhle.

Noch verdient Erwähnung, dass in der Angenhöhle der Eidechsen keineswegs der bei Säugethieren vorhandene Fettreichthum zugegen ist; man trifft hier blos einzelne spärliche Läppchen dieses Gewebes.

"War in Bisherigem fast ausschliesslich nur von Lacerto die Rede, so sei noch in vergleichendem Hinblick auf Anguis bemerkt, dass sich im unteren Lid die schüsselförmige Kinorpelplatte ebenfalls findet, nur entsprechend dem überhaupt kleineren Auge von geringerer und zarterer Entwicklung. Die glatte Musculatur der Bindehaut des Auges ist nicht minder zugegen. Der Bewegungsapparat für die Nickhaut, welche dieselben bogigen etwas pigmentirten Leisten und die Knorpelspange hat, ist wie bei Lacerta: ich sehe cine lange, dünne Sehne, welche durch die Schlinge eines Inskels geht, Die Thränendrüse am äusseren oberen Augenwinkel ist hier grösser als bei Lacerta; die Harder'sche Drüse unfasst wie dort im Halbbogen den Augapfel.

\section{ohr.}

Eidechse.

Das Gehörorgan unserer Eidechsen gliedert sich bekanntlich in ein frei liegendes Trommelfell, eine dahinter folgende von der Kette der Gichörknöchelchen dnrchsetzte Paukenhöhle, mit einer weițen Oeffumng oder Eustachischen Röhre zur Riwhenhöhle; das innere Ohr oder Labyrinth besteht aus Vorhof, hallkreisförmigen Canälen und der Schnecke.

Schon Geofrrox, ${ }^{1}$ ) welcher vor nahezu hundert Jahreu die Eidechsen seines Landes - nach der Abbildung zn schliessen wahrscheinlich $L$. agilis und $L$. muralis - untersuchte, hat bereits vieles richtig

1) Abhandlungen von dem Gehörwerkzeuge des Menschen, der Amphibien und Fische. Leipzig 1780. Das Original erschien 1778. 
gesehen und bildlich dargestellt. Er beschreibt das Trommelfell genauer, namentlich seine Zusammensetzung aus „Zwo Platten, einer äusseren und einer inneren“. Auch scheint er schon ganz gut eingesehen zu haben, dass die äussere Platte eine Fortsetzung der allgemeinen Hautbedeckung ist, während die innere zu der die Paukenhöble auskleidenden Schleimhaut als Abschnitt gehört. Die Trommelhöhle selber sei nicht ganz aus Knochen gebildet, sonilorn nur ihr vorderer Theil durch einen sattsam breiten, in einem lalben Kreise cndigenden Knochen - was wir jefzt das Tympanicum s. Os quadratum nennen -; der Rest der Höhle sei lhäutig, oder wie er sich ausdrückt, werde nur aus Bändern zusammengesetzt. Die Kette der Gehörknöchelchen: den nagelähnlichen, am Trommelfell befestigten IIammer sammt seinem Muskel (?), den stabförmigen Ambos und den tellerförmigen das eirunde Fenster verschliessenden Steigbügel ${ }^{1}$ ) beschreibt und zeichnet er gut. Selbst die Zusammensetzung des am schwierigsten zu behandeInden Theils, des Labyrinthes, wusste er bereits der Hauptsache nach aufzulellen; indem er das "Gewölbe des Vorhofs" kennt und darin "drei kleine Oeffnungen, welche ihrer Lage nach die Enden einer Triangel bilden"; darin lägen die halbkreisförmigen Canäle. Seine Worte sowohl wie die Zeichnung thun dar, dass er die Lage und Richtung derselben gut aufgefasst hat. Das Verdienst Geoffroy's ist um so höher anzuschlagen, als er alle diese nausnehmend feinen 'Theile die leicht dem blosen Auge entwischen", nur mit freiem Auge und der Lupe untersuchte. Dass er noch nichts von der Schnecke weiss und dem runden Fenster, wird ihm Niemand verargen.

SCARPa hat von Reptilien das Ohr der Schildkröte und des Crocodils nicht blos genauer studirt, sondern auch durch sehr gelungene Abbildungen von Künstlerhand versinnlichen lassen; aber auf die Eidechsen geht er nicht näher cin. Ich finde wenigstens in seinem mit liecht hoch berülımten Worke ${ }^{2}$ ) lkeine Angabe, welche über das, was GEOFFror bereits gesehen, hinausgienge. Die Tafeln enthalten den etwas oberflächlich behandelten Kopf und Vorderkörper von „Lacerta agilis“, ${ }^{9}$ ) um das Trommelfell zu zeigen und dann noch den Umriss dieser Haut, sowie die anschliessende Kette der Gehürknöchelchen sammt dem Muskel des Hammerknorpels. Es scheint dem Anatomen von Pavia bezüglich unserer Eidechsen überhaupt zumeist um das mittlere Ohr zu thun gewesen zu sein; er wollte zeigen, dass bei Reptilien, welche länger und lieber auf dem Lande und im Trockenen leben, noch Werkzeuge zur Aufnahme des Luftschalls dem inneren Ohre zugetheilt wären. Und ein besonderes Beispiel sei hiefür auch die "Kupfereidechse", welche dürre und ron der Mittagssonne fast verbrannte Stellen aufsucht und bewohnt; desswegen sei bei diesem Thier das Trommelfell ausserordentlich dünn, ganz frei und fast wie unbedeckit.

Im Jahr 1818 gab PouL , ${ }^{4}$ ) welcher noch in gutem Glauben und Willen die vergleichende Anatomie des Ohrs zu Heil und Frommen der Physiologie und P'athologie betrieb, eine Darstellung der Theile bei der Eidechse, nund wählte wegen der Grösse $L_{\text {. }}$ ocellata. Ex bespricht das Vestibulum und die Bogengänge und ihre Ampullen; er weiss von den Otolithen ("materia cretacea sacculi inclusa"); das "rudimentum cochleae", scheint er nicht anerkennen zu wollen, denn er will finden, dass dieser Processus nicht hohl sei. Bezüglich der Paukenhöhle, der Eustachi'schen Röhre, der Hörknöchelchen, des Nervus,facialis, welcher die Columelia begleitet, sind die Angaben richtig. Als Art eines äusseren Olres möchte er die Hautfalte am vorderen Rande des Paukenfells betrachten.

Duabs (1829) hat wie aus seiner Arbeit über die Eidechsen der französischen Fauna hervorgeht, das Gehörorgan ebenfalls zergliedert. Er hebt hervor, dass die Eustachi'sche Röhre sehr weit sei („la caisse communique asec le pharynx par une ouverture large"); daun beschreibt er die Gchörknöchelchen, worin er

1) 》Stegreif $\ll$ sagt dex Uebersctzer.

2) Mir liegt nux die Uebersetzung vor: Anatomische Untersuchungen des Gehörs und Geruchs. Nürnberg, 1800.

3) Mit dieser Bezeichnung ist wohl $L$. muralis gemeint, denn unsere $L$. agilis kommt in rler Lombardei, sowie iberbaupt jenseits der Alpen nicht mehr vor; worüber unten bei dieser Art das Nähere gesagt wird.

1) Expositio generalis anatomica organi auditus. Vindobonae 1818. Wer sich fur naturhistorische Abbildungen interessirt, wird die 'T'afeln in's Auge fassen; zur Zeit der eben erst aufkommenden Lithographie entstauden, sind sie in einer Manier unsgeführt, welche nicht für den Steindruck pisst, und daher wohl auch allgemein verlassen wurde. 
von dem Herkömmlichen etwas abweicht, namentlich will er auch ein dein Linsenbeincher (0s lenticulare) entsprechendes Stück unterscheiden. Endlich, was besonders wichtig ist, Dugbis spricht zum erstenmale ron einer Schnecke: "rudiment probable du limacon"; nachdem allerdings zuvor durch Cuvier das Vorkommen einer kleinen Schnecke beim Crocodil und Leguan angezeigt worden war.

Einige Jahre später erschien die treftliche Arbeit Windischimans's äber das Gehörorgan der Amphibien überhaupt; er wählt zum Studium dieses Sinneswerkzeuges ${ }^{3}$ ) bei Eideclısen im engeren Sinne nicht die kleineren einheimischen Arten, sondern wie PomL die grüsste der europäischen Fauna, die Lacerta ocellata. Auch er hebt, wie solches Cuvier ${ }^{2}$ ) in seiner bekannten klaren Weise bereits gethan hatte, bezüglich der Eustachi'schen Röhre die grosse Weite derseiben hervor, wesshalb die Gehörknöchelchen wie in einer Ausbuchtung (recessus) der Mundhöhle lügen. Von einem Muskel des Hammers findet er nichts. Die Schnecke wird jetzt zum erstenmal an ciner echten Lacertı nach ihrem Knorpelrahmen, Lagena und Nerven beschrieben; auch das Dasein eines Schncckenfensters (Foramen rotundum) betont. Eine beigegebene Abbildung - ebenfalls die erste über die Schnecke einer Lacerta - versinnlicht in geringer Vergrösserung, damals freilich als "multum magnitudine aucta" bezeichnet, den Knorpelring, die. Flasche, den Schneckennerven sammt dessen Așt zum Vorhof. ${ }^{3}$ )

Als ich seiner 'Leit das Gehörorgan der Lacerta agilis auf den feineren Bau untersuchte, fand ich bezüglich der Paukenhöhle erwähnenswerth, dass diesen Raum cin Flimmerepithel auskleidet; aber mit der Einschränkung, dass der zellige Ueberzug an der Innenseite des Trommelfells, sowie das Epithel der Gehörknöchelchen cilienlos seien. ${ }^{4}$ ) Und wie Pigment sehr allgemein bei diesen Thieren die Blutgefässe begleitet, so seien auch die im Inneren der Columella verlaufenden Blutgefüsse pigmentirt. Dann gab ich ferner eine bildliche Darstellung nebst Erörterung über den histologischen Bau der Schnecke.

Die genaueste $A r b e i t$, welche bisher die Wissenschaft über die Schnecke der Eidechse mit gelegentlicher Vergleichung jener der Blindschleiche besitzt, verdanken wir dem leider zu früh verstorbenen DeITERs in Bonn. ${ }^{5}$ )

Das innere ()hr oder Labyrinth liess ich bei memen letzten studien ziemlich ausser Acht; nur mag bemerkt sein, class die knöcherne Höhle zux Anfnahme des läutigen Labyrinthes in Verhältniss zum Schïdelraume sehr gross genamnt werden muss, ${ }^{6}$ ) was besonders Querschnitte durch den ganzen Schüdel darthun. Dann sind namentlich die Bogengänge des häutigen Labyrinthes noch immer im Hinblick auf die Grösse des Kopfes sehr umfïnglich und hehen sich alle drei nach aussen am gereinigten Schädel, selbst ganz alter Thiere, in ihrer knöchernen Umgrenzung derart ah, dass sie nach ihrer Lage gut zu überblicken sind. ${ }^{7}$ )

Am rein präparirten Schüdel lässt sich auch hei guter Belenchtung sehen, dass die Umgehung des Foramen ovale in Form eines ählichen Wulstes vorspringt. wie bei den Salamandrinen, weun auch viel weniger stark.

1) De penitiori auris in ąuphibiis structura. 1831.

$\left.{ }^{2}\right)$ Rech. sur les ossimeus fossiles, 3. edit. 1825. Tom. V, p. 253.

3) a. a. O. Tab. II, Fg. 11.

4) Histologie S. 267. Nach PArтexhers hingegen trägt das Trommelfell an seiner Innentliche ebenfalls ein Flimmerepithel und Varesris will es bestätigen. Repertorium f. Anat. u. Physiologie 18\$1, S. 95.

$\left.{ }^{5}\right)$ Archiv f. Anat. u. Phys. 1862.

$\left.{ }^{0}\right)$ Vergl. 'Kwölfte Tafel, Fg. 146, b.

7) Vergl. z. B. Dritte Tafel, Fg. 33. 
Am meisten habe ich diesmal auf das mittlere Ohr oder die Paukenhöhle Rücksicht genommen. Hier bleibt es immer von Bedeutung sich leicht überzengen zu köunen, dass der Paukenraum nur eine Ausbuchtung der Rachenhöhle, um den dickbauchigen Musculus pterygoideus externus hermm, nach hinten und oben vorstellt. Ganz besonders eignen sich zum Nachweis dieses Verhältnisses Thiere, welchen der Kalk des Skeletes entzogen wurde, und die daher nicht blos in jeder Richtung ohne Hinderniss durchschnitten werden können, sondern anch in allen Theilen biegsam sind. An Längsschnitten ${ }^{1}$ ) des Kopfes kaun man von der Rachenhöhle her das Trommelfell in ganzem Umfang sehen. Ja bei der L. muralis, var. campestris BETTA, vermag man sogar, da hier das Trommelfell eine überaus zarte und helle Beschaffenheit hat, am unverletzten lebenden Thier, welches man mur gegen das Licht zu halten braucht, von dem einen Trommelfell quer hindurch zum anderen zu selsen; was eben nur dadurch möglich wird, dass die Paukenhöhle einfich ein Nebenraum der Rachenhöhle ist. Und desshalb kann man aber auch nicht in strengerem Siune von einer Enstachischen „Röhre“ sprechen, da es sich un eine weite Communication zwischen der Rachenhöhle und ihrer zur Paukenhöhle gewordenen Ausbiegung handelt.

Im Trommelfell sehe ich die früher von mir am gleichen Organe beim Frosche aufgefundenen glatten Muskeln.

Auch über die Gehörknöchelchen ist einiges zu erwähnen. Die Membran, welche das Operculum zur Befestigung auf dem Foramen ovale umzieht und wohl der Fensterhaut entspricht, ist sehr reich an elastischen Fasern. Das Operculum ist zwar verkalkt, aber es behält für immer (L. agilis) einen rein knorpeligen, ziemlich breiten Saum. Nach unten ist das Knöchelchen offen, stellt also nicht eigentlich eine Scheibe, sondern einen Trichter dar. Dieser innere liam führt, sich verschmälernd, in die Markhöhle der Columella, mit welcher äberhaupt das Opereulum ein Ganzes bildet. Jetzt folgt das linorpelstück, welches rein präparirt ein schaufelförmig verbreitertes Ende hat, und sich damit an's Trommelfell anheftet. Der stamm des linorpels erfährt nach Abgabe des erwähnten Fortsatzes immer eine leichte Knickung, um hierauf in zwei Fortsätze auszulaufen, welche stärker sind als der Stamm. Der eine geht etwas spitz zu, der andere - es ist der kürzere - verbreitert sich gegen dats Lude hin ebenfalls schaufelartig. Durch diese beiden Fortsätze geschieht die zweite Verbindung des linorpels mit dem Trommelfell. Bei Besichtigung mit der Lupe will es bedünken, als ob der Knorpel mit einer Scheibe sich am Trommelfell befestige; die bezeichnete form erkemnt man erst bei näherer Prüfung. 
Es hat mir einigemale geschienen, als ob an der Kinickung des Knorpels eine wirkliche Abgliederung stattfinde, aber in inderen Fällen sah ich wieder nichts davon. Jedenfalls ist bemerkenswerth, dass das linorpelstürk jenseits der Knickung - also gegen das Trommelfell hin - verkallit ist, wähend das andere Stück rein knorpelig hleibt. - Einen Muskel, der sich an die Kette der Gehörknöchelchen etwa ansetzte, habe ich niemals gesehen. Wo sich der hrnorpel dem Trommelfell anfügt, sieht man sehr viele feine elastische Fasern, dlie wohl offenbar zm. Verknüpfung des linorpels mit der gedachten Haut dienen. -- Gleichwie die Schleimhant der Trommelhöhle überhaupt viel dunkles Pigment hat, das sich auch über die :̈ussere Fläche des Hammerknorpels hinzieht, so erstreckt es sich anch von der Oeffnung des Operculum aus in den Markraum der Columella und erzengt in deren Innerem ofters einen ganz schwarzen Achsenstrich.

Die Gehörknöchelchen liegen in gewissem Simne wie ausserhalb der Paukenhöhle und springen nur in dieselbe vor. Denn sie ziehen nicht blos nahe an der Wand der Paukenhöhle her, sondern sind anch völlig überdeckt und umhüllt von der Schleimhant der Pankenhöhle. Im Hinblick anf die Fälle, wo das mittlere Ohr sich zurück zu bilden beginnt, scheint mir dieses Verhalten beachtenswerth.

Zugleich mit den Gehörknöchelchen hebt man immer anch einen Nerven heraus, welcher wohl der Stamm des die Paukenhöhle durchsetzenden Nervus facialis ist. Derselbe liegt jedoch ebenfalls nicht frei, sondern wird von einer Falte der Schleimhaut rings umgeben, was man sich dadurch zur Ansicht bringt, dass wir mit scharfem Schnitt das ganze Trommelfell abtragen: im obersten Ende der Trommelhöhle, hinter der Paukenmembran, erblickt man jetzt den Durchschnitt des Gehörknöchelchens, ${ }^{1}$ ) umgeben von der Falte der Schleimhant; damn noch eine andere Falte, von welcher der Durchschnitt des Facialnerven umzogen wird. Diese Lagerung von Theilen, von welchen man zu sagen pflegt, dass sie den Paukenraum "durchsetzen", begreift sich gut aus der Entstehung der Pankenhöhle von der ersten Visceralspalte her, indessen die Gehörknöchelchen aus der Substinz des ersten Visceralbogen ihren Lrsprung nehmen.

Das vordere Horn des Zungenbeines sehe ich bei $L$. agilis in seiner Biegung sich gegen den knorpeligen Gehörknochen (Hammer) wenden und demselhen so nahe kommen, dass heide, der Hammerknorpel und das Ende des lnorpeligen Zungenbeinbogen, sich fast berühren.

Es erklört sich dieses aus der ursprünglichen Zusammengehörigkeit beider Bildungen, und es mag an dieser Stelle eine Beobachtung Heusinger's an Pseudopus aus der Zeit, in welcher man noch nicht tiber

2) Zwölfte Tafel, Fg. 149b. 
die Herkunft gewisser Gehörlnöchelchen von den urspringlichen Kiemen- oder Visceralbogen unterrichtet war, in Erimnerung gebracht werden. $^{1}$ ) Derselbe sagt: ${ }_{n}$ Noch etwas ist mir bei der Untersuchung des jungen Thieres aufgefallen, was die grösste Aufmerlisamkeit verdient. Als ich nämlich die Muskeln an der linken Seite des Kopfes untersuchte und mit dem Zungenbein etwas nachlässigg umgegangen war, schien es mir, als habe sich das vordere Horn des Zungenbeins in die Trommelhöhle fortgesetzt; ich war nun auf der rechten Seite vorsichtiger und salı in der That, dass sich dieses Horn immer mehr verfeinerte und längs des Trommelfells durch die 'Trommelhöhle bis zum Gehörknochen fortsetzt! Im erwachsenen Thier fand ich nichts Aehnliches." - Weun andere Beobachter von einer "Verbindung der vorderen Hörner des Zungenbeins mit Schädelquerfortsätzen in der Gegend der Trommelhöhle" sprechen, so bezieht sich dies wohl auf das gleiche Verhalten.

Bei den Embryonen der Eidechsen tinden sich oben auf dem Hinterhaupt zwei Anhäufungen von Kilkmassen, welche mich längere Zeit beschäftigt haben. Die Bildungen könmen nicht übersehen werden, und so gedenken ihrer auch bereits EMmert und HochstetTen, ${ }^{2}$ ) wenigstens insoweit, als sie sich dem freien Auge darstellen. Sie sagen, dass die Embryonen am Hinterhaupt auf jeder seite ein zugespitztes, cylindrisches, kreicleweisses Körperchen besässen, das durch eine leichte Verletzung in eine kreideweisse Flüssigkeit zerfloss; anch vom reiferen Fötus gedenken sie der „kreideweissen Zäpfchen am Hinterhaupt".

Gerade dreissig Jahre später handelt von denselben Gebilden Gustav CARus, welchem sie an Schlangenembryonen aufgefallen varen, ohne dass er die Wahrnehmungen der zwei vorgenannten Beobachter zu kennen scheint. ${ }^{3}$ ) Lr sieht „am Hinterhaupt zwei weisse Tiörperchen von kreideartigem Ansehen, die starki von der ührigen zart röthlichen substanz des Kopfes abstachen“. Unser Forscher geht nähel auf die Untersuchung ein und findet, dass unter dem Mikroskop die Substanz der Körperchen aus unzïhligen Krystallen bestehe, die er näher beschreibt und abbildet. Ferner im Hinblick anf die Frage, wo demn eigentlich die Stelle sei für diess ,merkvürdige Anhäufung von Krystallen“, überzengt er sich, dass dieselben „an der inneren Fläche der werdenden schädelwandungen liegen, olne mit dem dehirn einen näleren Bezug zu haben".

Bezüglich der Deutung äussern EMmert und HochstetTer nur gauz obenhin, es möchten die Körperchen „vielleicht die Anfänge des Labyrinthes sein"; CARUS erkliart als Lrgebniss einer lieihe von Untersuchungen, dass die hiystallbildung am Hinterhaupt mit der Krystahlhilhung des (Ohres nichts gemein habe, vielmehr sei vie als cine selbstständige, der hnochenhildung vorausschneitende krschemung anzusehen.

t) Zeitschrift f. organische Physik. Bd. III, 183:3, S. 483.

") Untersuchungen über die Entwichlung der Eidechsen in ihren Eiern. Archiv für L'hysiologie, 1811.

3) Archiv für Anat. u. Physiol. 1811. 
Die Krystallhaufen scheinen eine Art von Depot des entstehenden Kalkes zu sein, der später wieder aufgesaugt und anderwärts verwendet werde.

Mich hatten wohl gelegentlich auch schon diese kreideweissen Pünctchen am Hinterhauptsbein der Eidechsen angezogen, ohne dass es inir damals gelungen wäre, über die Mittheilungen von dem zuletztgenannten Beobachter hinauszuliommen. Jetzt aber bei Anwendung anderer Methoden ist mir kilar geworden, dass die Klümpchen von Kalkkrystallen doch mit dem Labyrinth des Ohrs im Zusammenhang stehen; aber weder mit dem Vorhof oder der Schnecke, noch weniger mit den halbkreisförmigen Canälen, sondern mit einem besonderen langgestielten Anhang des Labyrinthes, welcher vom Vorhof sich aussackend nach oben in die Hinterhauptsgegend sich wendet. In dem blinden erweiterten Ende desselben liegt jederseits die weisse Kalkmasse. ${ }^{1}$ )

Eine Belehrung, welche übrigens früher und leichtel zu erwerben gewesen wäre, wenn ich RATHis's Entwicklungsgeschichte der Natter über diesen Punct befragt hätte. Demn dort ist vom Embryo der Ringelnatter das Labyrinth anf Taf. VI. abgebildet und gibt getreu den birnfürmigen Anhang wieder. Ratuke nenut ihn aus der Periode des Fruchtlebens, welche er als zweite bezeichnet das "keulenförmige Säckchen“, später in der dritten Periode wegen seines'Inhaltes „das Kalksäckchen"; er theilt in einer Anmerkung mit, dass er auch bei der erwachsenen Natter das Kalksäckchen, wenn schon mit einiger Abänderung gefunden habe. Auffallend bleibt mir, dass der genane Beobachter, soviel ich wenigstens bemerke, mit keinem Worte sagt, wie sich diese Bildungen am unverletzten Embryo dem freien Auge darstellen.

Das keulenfürmige Sïckchen verdient unsere Beachtung in hohem Grade, denn es wirft ein Licht auf einen seltsamen, lange morphologisch ganz unverstandenen Canal an Ohrlabyrinth der Selachier. Dort kennt man seit GEofFror einen vom Vorhof ausgehenden, nach oben zur Hinterhauptgegend strebenden, an seinem Ende mit Kalk gefüllten Canal, dessen Homologon offenbar das keulenförmige Säckchen im Ohx der Reptilien ist. Und die Bedentung beider lässt sich an der Hand dessen, was die Entwicklungsgeschichte des Ohrlabyrinthes gelehrt hat, dahin fassen, dass sie Reste und Unbildungen des Ganges sind, durch welchen das Ohrbläschen in früher Embryonalzeit mit der äussern Hautoberfläche im Zusammenhange war.

Blindschleiche.

F'ast länger noch habe ich dem mittleren Ohr der Blindschleiche Aufmerksamkeit gewidmet und zwar im Hinblick auf die An- oder Abwesenheit eines 'Trommelfells.

Vor BiBRon und Duméril sagen alle Zoologen, welche das Ohr der Blindschleiche näher betrachteten, dass hier von aussen nichts vom Gehörorgan sichtbar sei: das Trommelfell liege versteckt unter der Haut. Anders sprechen sich die genannten

1) Zwölfte Tafel, Fg. 148, c. 
französischen Herpetologen aus, indem sie behaupten, es sei eine feine Ohrspalte vorhanden, zwar etwas versteckt, aber doch deutlich genug. ${ }^{1}$ )

Ich habe, nachdem ich mit dieser Angabe bekannt geworden war, von neuem alte und junge Thiere auf das Vorhandensein der Ohröffnung untersucht, bin aber auf kein Thier gestossen, bei welchem ein von der äusseren Haut vorgestelltes Trommelfell mit Sicherheit zu erkennen gewesen wäre. Nur einmal schien es mir an einem grossen weiblichen Thier mit kurzem gedrungenen Kopf, als ob ein ganz feines Ohrspältchen zugegen sei; aber bei näherer Prüfung wollte es sich doch nicht bestätigen: die aussere Haut, abgezogen und von innen angesehen, liess nichts von einer Oeffnung wahrnehmen; die Stelle, wo das Trommelfell sein sollte, war erfüllt von einem weichen lockeren Bindegewebe, welches der Schleimhaut der Paukenhöhle zugehörte.

Das Ergebniss meiner Studien könnte ich so zusammenfassen: bei geringer Grösse des Os tympanicum ist anch der liecessus der Rachenhöhle, welcher zur Paukenhöhle wird, viel kleiner als bei Lacerta und darum rücken die Muskeln, welche aussen um das Os tympanicum liegen, so nahe aneinander, dass über der Schleimhaut kein Theil del äusseren Haut sich als deckender Ueberzug unter der Form eines Trommelfells abgrenzt, und es geht die ganze Beschuppung ununterbrochen darüber weg.

Immerhin muss es aber doch Thiere geben, wo das $\mathrm{Ohr}$ von aussen durch ein winziges Spältchen bezeichnet wird. Deun abgesehen von BIBRon und DuméRIL finde ich bei JeitTeles, $\left.{ }^{2}\right)$ dessen Angaben ich Vertrauen schenken möchte, von der Anguis frrailis der Kirschauer Gegend gesagt: „Ohröffnung ist sehr deutlich". Damit steht aber im Widerspruch, wenn ein anderer ungarischer Zoolog FrivaldszkY, ${ }^{3}$ ) von den Blindschleichen desselben Landes sagt: „aures sub cute latentes".

Bezüglich der Hörknöchelchen, $\left.{ }^{4}\right)$ welche im Ganzen kürzer sind als bei $L a$ certa, erwähne ich, dass das trichterartige Operculum, welches mit der Columella zusammen den einzigen knöchernen Theil bildet, ebenfalls einen bleibenden, aber schmalen Knorpelsaum hat. Sein knöcherner Boden ist durchbrochen und setzt sich in den Markraum der Columella fort, zur Ueberleitung der Blutgefässe. Der dem Hammer entsprechende Knorpel zeigt einen Stiel, welcher geknickt ist, wodureh die Stelle auch wohl den Eindruck machen kam, als ob eine wirkliche Abgliederung hier statt fünde; damn endigt er in einen selı kurzen und in einen längeren Fort-

1) Eirpétologie générale, T. V, p. 79\%.

3) Prodromus faunae Hungariae superioris.

3) Monographia serpentum Hungariae. Pestini 1823.

4) Zwölfte Tafel, Fg. 150 . 
satz. An den Knorpel tritt ein Band, das ich auch bei Lacerta agilis sehe, wo es entsprechend breiter und stärker ist. Ueber dem Hammer erblickt man den Stamm des Nervins facialis. Um das Ende des Hammerknorpels herum ziehen feine elastische Fasern, welche auch in dem Ueberzug der Gehörknöchelchen nicht fehlen. Das Epithel auf den Hörknöchelchen zeigt viele Schleim- oder Becherzellen.

Die Bogengänge des Gehörlabyrinths schimmern am gereinigten Schädel dentlich nach aussen hindurch, was bereits SCHNEIDER hervorhob, ${ }^{1}$ ) gegenüber von GEOFFROY, welcher bei der Blindschleiche diese 'Theile nicht zu finden vermochte. Noch klarer ist das Bild am Schädel ganz junger Thiere, welche etwa Mitte Angust aus der Mutter genommen werden; und hiebei muss man sich abermals sagen, dass doch diese Theile im Verhältniss zur Grösse des Thieres ungemein gross sind!

Es fehlen auch nicht die bei den Eidechsen erwähnten Kalksäckchen, welche in Form zweier gestielter Beutel ${ }^{2}$ ) nach oben zur Hinterhauptgegend streben und dort durch ihren Inhalt zwei lebhaft weiss gefärbte, dicht beisammenliegende Flecken erzeugen. Der Knochen springt über jeden der beiden Flecken etwas gewölbt hervor, so dass zwei deutliche höckerähnliche Partien an der Schuppe ${ }^{3}$ ) des Hinterhauptbeins sich abheben. Der Flächenschnitt belehrt, dass die Höhle im Inneren der Höcker zur Aufnahme des Kálkbentels bestimmt ist. Hat man den Inhalt des letztern frei vor sich, so lässt sich bemerken, dass die Kalkkrystalle durch eine klebrige Bindemasse zusammengehalten werden: denn sie fliessen beim Einreissen des Săckchens keineswegs auseinander.

\section{Nase.}

Den Geruchsapparat der Reptilien lassen manche Zootomen in eine, der äusseren Nasenöffnung entsprechende, eigentliche Nasenhöhle und in einen davon durch Vorsprünge geschiedenen hinteren Nasengang zerfallen. Daran ist nun zwar, wie mich meine Untersuchungen gelehrt haben, soviel richtig, dass wirklich zwei von einander wohl verschiedene Rüume zugegen sind, aber die bisherige Deutung ist irrig; denn der Raum, welcher die eigentliche Nasenhöhle vorstellen soll, ist der iusseren Nase der Säuger zu vergleichen und der sogenannte hintere Nasengang stellt die wirkliche Nasenhöhle vor, wie das jetzt im Näheren gezeigt werden soll.

1) Hist. natur. et litteraria Amphibiorun, p. 313.

2) Zwölfte Tafel, Fg. 148; Zweite Tafel, Fg. 25.

3) Vergl. Dritte Tafel, Fg. 38. 
Aeussere Nasen-oder Vorhöhle.

Dies ist eine geräumige Höhle, ${ }^{1}$ ) in welche die äussere Nasenöffnung führt und im weiteren Sinn vom Oberkiefer, Zwischenkiefer, der sog. Concha und den Nasenbeinen umfasst wird. Enger hegrenzt wird sie von einer hyalinknorpeligen Trapsel, welche in sehr früher Zeit am Primordialcranium auftritt und von den genannten Knochen nach und nach überlagert wird. .

Schon bei Betrachtung des knöchernen Skeletes ${ }^{2}$ ) dieses Nasenraumes lässt sich am oberen freien Rand der sog. Concha ein Vorsprung bemerken und die Untersuchung der Weichtheile zeigt, dass die auskleidende Hant der Nasenhöhle von dieser Knochenecke weg nach vorn und aussen eine Falte bildet, welche den Raum unvollkommen halbirt. Diese, einspringende Falte ist auch die Ursache, dass, nachdem man durch wagrechte Schnitte das Dach der Höhle abgetragen, es den Anschein gewinnen kanu, als ob mau, anstatt mit einer rundlichen, halbgetheilten Höhle, es mit einem Gang zu thun habe, welcher mit der äusseren Nasenöffnung beginnend, zuerst quereinwärts gehe, dann sich hinterwärț umbiege.

Die Schleimhaut, welche die Vorhöhle auskleidet und mit der äusseren Hant zusammenhängt, ist umpigmentirt. Ihre bindegewebige Grundlage besitzt, wie Querschnitte am besten zeigen können, eine gewisse Dicke und Derbheit; sie weicht auch in der feineren Zusammensetzung vom Corium der äusseren Haut merklich ab. Zunächst nämlich ist nichts von der eigenthümlichen Gliederung in wagrechte und senkrecht aufsteigende Bindegewebslagen wahrzunehmen, sondern die Hauptsubstanz sind feine elastische Fasern, von denen auch die weissliche derbere Beschaffenheit der Haut herrührt. Die elastischen Fasemetze weichen auseinander um Blutgefässe durchzulassen, ungrenzen aber auch wie es scheint einfache Blutrüume in fast athnlicher Weise, wie am erectilen Gewebe der Ruthe. Wenigstens wurde ich wiederholt, durch den Blutreichthum und dieses doppelte Vorhandensein von wirklichen Arterien und Venen, sowie von wandungslosen Bluträumen an den Schwellkörper derselhen Thiere erinnert. Auch Nervenstümpfen begegnet man anf Querschmitten, die wohl vom Trigeminus abstammend, an der Schnauzenspitze enden mögen. Dageggen fehlen, abgesehen von der Riuglage der Arterien, musculöse Elemente völlig. Auch sind keine Drüsen in dieser Schleimhant der Nasenhöhle vorhanden, was ich ausdrücklich bemerken will, da es mir zuerst selbst, namentlich an Glycerinprälparaten scheinen wollte, als ob drüsige Bildungen zugegen seien; wiederholte Prüfungen hahen mich aber vom Gegentheil überzengt. Auch das Epithel sieht, frisch unter-

¡) Elfte Tafel, $\mathbf{F g} .141$, a.

2) Fg. 142. 
sucht, charakteristisch aus. Es hesteht aus Plattenzellen, welche dicht mit punctförmiger Masse und Klümpchen verschiedener (trösse, dem Ansehen nach fettartiger Natur, erfüllt sind; die Epithellage im Ganzen erhält dadurch ein gewisses trübes Aussehen. Einige Fetzen des Epithels sackten sich in kuze hohle Zapfen aus, von denen ich nicht mehr bestimmen komnte, ols sie zum Ueberzug von Papillen oder umgekehrt zur Auskleidung von crypten bestimmt waren. An Schnitten, welche in Glycerin anflowaht werden, zeigt das Epithel durch seine scharfe Scheidung in eine untere weichere Lage und obere festere, sowie durch die Art wie sich letztere abblätert, endlich durch die Conturen der Zellen selber eine gewisse nähere Verwandtschaft mit der Epidermis der äusseren Haut.

In diese Vorhöhle der Nase mündet anch die naçher zn erwälmende I)rüse aus, und zwar geschieht es nahe der Uehergangsstelle in die eigentliche Nasenhöhle.

Dass num diese Höhle nicht „eigentliche Nasenhöhle“ sei, sondern dem Raume der änsseren Nase bei Säugethieren zu vergleichen, dafür spricht auch Alles. Die Tinorpelstücke in der äusseren Nase höherer Wirbelthiere, welche ja auch selbst beim Menschen zum 'Theil unter' sich und mit dem Nasenscheidewandknorpel innig' zusammenhängen, werden hier in ter noch ursprünglicheren Weise von einer zusammenhängenden Knorpelkapsel vorgestellt. Die innere Wand derselben ist das senkrechte Kinorpelblatt, welches nach rückwärts zwischen den beiden Augen in die Höhe steigt; von ihm wölhen sich seitliche Theile zu einer Kapsel zusammen, welche in frischen 'Zustancle, nach Abzug' der äusseren Haut, am Seitentheil der Schnauze etwas bauchig vorquillt. Die Natur des Epithels, welches wie erörtert der Epidermis der äusseren Haut sich verwandter zeigt, sowie endlich der Mangel von Endisten des N. olfactorius machen es gewiss, dass man es keineswegs mit der "eigentlichen Nasenhöhle* zu thun habe.

Niemand kamn einen Anstoss daran nehmen, dass diese „äussere Nase“ nicht über die Schnauze vorspringt, demn bei vielen, ja den meisten Säugethieren ist es auch nicht anders; vielmehr sind der Umriss der Schnauze einer Eidechse und jener mancher Säugethiere sich so ahnlich, dass wie riele Abbildungen lehren können, der Zeichner geradezu den Schnauzentheil des Kopfes der Eidechsen vollkommen wie bei einem Sïugethier ausfiuthrte.

Innere Nasenhöhle.

Man könnte diesen Abschnitt auch die eigentliche Nasenhöhle nennen, weil in ihr die Entfiltung und Endausbreitung von Aesten des Riechnerven statt hat. Es ist der Raum, welchen Andere den hinteren Nasengang heissen.

Die eigentliche Nasenhöhle ist um mehr als das Dreifache länger und gerïu- 
miger als die änssere Nasenhöhle. Sie beginnt mit ganz bestimmter Grenze hinter dem Knochen, welchen man gewöhnlich "Concha" nennt und wird ausserdem von den Nasenbeinen, dem Oberkiefer- und Thränenbein umgeben und ihren knöchernen Boden bilden insbesondere die Pflugscharbeine. Die Oeffnung, durch welche äussere und innere Naseuhöhle mit einauder zusammenhängen, ist von rundlicher Form, während die Iründung der inneren Nasenhöhle in den Raum des Rachens - die Choane länglich ist, mit rundlicher Ausweitung am Ende. Am Boden der Nasenhöhle unterscheidet man ansser dem Eingang zur Choane, nach einwirrts von dieser, gegen die Nasenscheidewand zu, eine starke Längsrinne, wozu der Vomer die Grundlage bildet. ${ }^{1}$ )

In dieser Höhle befindet sich dann ferner eine grosse Muschel. Sie entspringt gegenüber der Nasenscheidewand von der Nasenkapsel und besteht wie diese aus Hyalinknorpel. Sie erstreckt sich durch die ganze Länge der Nasenhöhle und stellt, was ihre Form betrifft, ein einwärts gerolltes Blatt vor, mit oberem und unterem umgekrempten Rand, wovon der untere in die vorhin erwähnte Rinne am Boden der Nasenhöhle sich legt, der hintere etwas verjüngt über dem Eingang zur Choane steht und sich selbst in den Anfang der Oeffnung hineindrückt. Die Hauptbefestigung oder der Abgang der Muschel von der Nasenkapsel geschieht seitwärts von oben her; aber wie man namentlich an Längsschnitten durch den ganzen Apparat leicht erfahren kamn, es ist noch eine zweite Verbindung mit der Nasenkapsel vorhanden und zwar in Form einer schmäleren Brücke, nach hinten und unten seitwärts von den Choanen.

Die Beschaffenheit der Haut, welche diesen eigentlichen Nasenraum auskleidet und die Muschel überzieht, ist wesentlich verschieden von jener der äusseren Nasenhöhle. In ihr verbreitet sich der Riechnerv, und dadurch, dass die Zweige und Aeste dieses Nerven sowie auch die Blutgefüsse reichlich von Pigment umsponnen sind, erhält das Bindegewebe der Schleimhant einen schwärzlichen, ziemlich plötzlich auftretenden Anflug. Das Epithel ist ferner sehr verschieden von dem der Vorhöhle, indem man unterscheidet

1) Cylinderzellen mit Flimmern an den Stellen, wo keine Endausbreitung des Riechnerven statt hat. An gleichen Orten finden sich auch (flimmerlose) Becherzellen in grosser Menge.

2) Da wo Endausliufer des Nervus olfactorius im bindegewebigen Theil der Schleimhant ausstrahlen, stehen hohe faserähnliche Zellen, wie wir sie bekanntlich durch MAX SChULTZE ${ }^{2}$ ) von allen Wirbelthieren kennen gelernt haben. An ihrem

1) Vergl. Fg. 141.

2) Bau der Nasenschleimbaut bei dem Menschen und den Wirbelthieren, 1862. 
freien Ende tragen sie starre Härchen, welche die Wimpercilien an Länge weit übertreffen und von ganz anderer Natur als die letzteren sind. Ich kaun nur bestätigen, was der genannte Forscher über die ansserordentliche Empfindlichkeit der Härchen gegen die Einwirkung des Wasser's angibt; sie schmelzen derart rasch ein, dass man ihre Anwesenheit an einem aus dem frischen Thier genommenen Stück Schleimhaut geradezu läugnen würde. Auch dass die Zellenlage nicht den Cuticularsaum besitzt, ist ginnz richtig. Es ist wohl unzweifelhaft, dass diese eigenartigen Zellen mit den Enden der faserigen Elemente des Riechnerven in Beziehung stehen, obschon ich keinen unmittelbaren Zusammenhaug vor die Augen bekam.

Weiterhin besitzt die Gegend der Muschel reichliche Drüsen in Form kurzer cylindrischer, von Zellen mehr erfüllter als ansgekleideter Schlïnche, welche dicht beisammen stehen und ebenfalls meist von Pigmentnetzen umzogen sind. Dass auch dieses Pigment eigentlich in der Wand der die Drüsen begleitenden Blutgefässe liege, ist mir nach der ganzen Art der Ausbreitung wahrscheinlich. Hat man die Schleimhaut von Köpfen vor sich, welche in doppelt chromsaurem liali gelegen waren, so machen sich in Epithel eigenthümliche Zelleneinheiten beinerklich von einer gewissen trichterförmigen Gestalt und mit einer ammöhernd schuppigen Giruppirung der Zellen anı weiteren Ende des Trichters. Es mögen diese Zellengruppen die Ausmündungen der Drüsen im Epithel sein.

Ich bin im Zweifel darüber geblieben, ob nicht neben diesen auf der Schleimhaut der Muschel ausmündenden Drüsensäckchen anch Drüsenelemente noch anderswo, und in anderer Weise ausmünden. Zu dieser Annahme bestimmt mich zweierlei. Einmal ist mit Sicherheit zu sehen, dass in die Vorhöhle oder äussere Nase ein Drüsengang mündet, und zwar am äusseren Unfang, nahe der Grenze zwischen Vorhöhle und eigentlicher Nasenhöhle. Bei $L$. agilis, wo ich näher darauf achtete, entsteht das Ende des Ganges ans der Vereinigung von drei Gängen, die leicht kenntlich dadurch werden, dass ihr Inhalt oder das auszuführende Secret, eine sattgelbe F'arbe an sich hat. Dann ist zweitens, recht deutlich für's freie Auge schon an grossen Exemplaren von $L$. viridis, eine Drüse zu beobachten, welche aussen an der Knnorpelkapsel der Nase liegt, gerade über der Bucht, welche von Seite der hinorpelkapsel durch die nach einwärts vortretende Muschel sich bildet; wobei es mir allerdings anch wieder vorkam, als ob diese Drüse und die Haufen der Drüsensäckchen, welche der Muschel angehören, zusammenhiengen und als ein Ganzes zu hetrarhten seien. Wenn aber letzteres nicht der Fall sein sollte, so möchte ich die obigen Ausführungsginnge mit bezeichneter Drüse in Verbindung bringen und annehmen, dass es sich um ein der Nasendrüse der Vügel gleichwerthiges Organ handelt, dessen 
Ausführungsgang nach den Beobachtungen von NiTzscH ebenfalls ziemlich weit nach vorne in die Nasenhöhle sich öffnet. Doch würde der Unterschied bestehen, dass bei Lacerta drei Gänge ans der Drüse kommen, die erst kurz vor der Ausmündung zu Einem zusammentreten. - Was man an Querschnitten der Nase von Anguis sieht, spricht gleichfalls dafür, dass die Drüsen der Muschel und die Drüse anssen an der Nasenkapsel von einander völlig geschieden sind. ${ }^{1}$ )

Jacobson'sche Organe.

Diese merkwürdigen Organe, welche den gleichen Bildungen bei Săngerm entsprechen, kommen hier von Lacerto und Anguis zun erstenmal zur siprache. Entdeckt wurden sie bei Varanus, Porlinema, Iguana, Pseudopus, Chamaeleo durch den Verfasser der Zootomie der Amphibien. „Paarige, enge, vor den Choanen in den Gaumen mündende Oeffnungen sind die Ausgänge von Höhlen, die gewöhulich durch

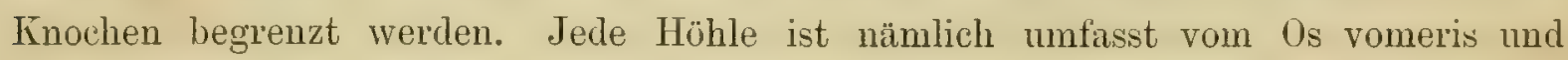
der Concha ihrer Seite; sie liegt unmittelbar unter dem knöchernen Boden der Nasenkapsel. Die Höhle besitzt eine häutige Auskleidung; sie enthălt z. B. bei Varanus ein eigenthümliche̊s, ziemlich weiches, scharfbegrenztes Organ, das wie ein Pilz auf einem sehr kurzen Stiel sitzt."

Ich habe mich an Lacerta vor Allem darüber vergewissert, dass die Höhlen zwar unterhalb des Bodens des Nasenraumes liegen, jedoch mit letzterem keineswegs in offener Verbindung stehen; vielmehr sind sie nach dieser Seite hin völlig geschlossen, was um so beachtenswerther ist, als ein Haupttheil des Nervus olfactorius in dieser Höhle seine Endausbreitung hat. Jede der beiden Höhlen mündet für sich durch einen feinen Gang in die Rachenhöhle und zwar in den Anfang der Furche, welche weiter rückwärts mit der Oeffnung der Choane abschliesst.

Will man die Lage der Höhlen näher bezeichmen, so ist es die Stelle, wo unmittelbar darüber die äussere und die innere Nasenhöhle in einander übergehen; doch wieder so, dass der grössere Theil des Organs unterhalb des Beginns der eigentlichen oder inneren Nasenhöhle sich hin erstreckt. ${ }^{2}$ )

Die von oben her geöffnete Höhle ${ }^{3}$ ) zeigt einen querovalen, annähernd nierenförmigen Umriss. Der Gang zur Rachenhöhle geht von dem hinteren, inneren Eck - wenn man dieser Bezeichnung sich bedienen kann - ab.

Nach dem grössten Theil ihres Umfanges hat die Höhle eine hyalinknorpelige

1) Vergl. Elfte Tafel, F'g. 144 .

$\left.{ }^{2}\right)$ Achte Tafel, Fg. 108.

3) Fg. 110. 
Grundlage, welche mit der Nasenkapsel zusammenhängt; die Knochen, welche sich darüber legen sind der Oberkiefer, die sog. Concha und das Pflugscharbein. ${ }^{1}$ )

In den Raum springt, ähnlich wie die Muschel in die Nasenhöhle, ein papillenartiger Querwulst vor nit eingeschnürter Basis, und verengt die Lichtung der Höhle um ein Bedentendes. Der papillenartige Wulst besteht aus linorpel und ist .eine Fortsetzung der Knorpelwand; er wird weder von Blutgefüssen noch von Nerven durchbohrt. In histologischer Beziehung ist aber erwähnenswerth, dass die Zellen dieses Hyalinknorpels, da wo sie gegen den Rand des Wulstes zu liegen kommen, gleich dem darüber wegziehenden pigmentirten Gewebe, selbst einiges dunkle Pigment besitzen. Ich sah es so bei L. agilis und viridis. Pigmenthaltige Krnorpelzellen sind aber etwas Seltenes, für mich wenigstens wäre es erst das zweite Beispiel, welches ich kennen gelernt. ${ }^{2}$ )

Die häutige Auskleidung der Höhle besteht aus einer bindegewebigen Schicht und dem Epithel. Erstere ist stark pigmentirt, am meisten da, wo die Mehrzahl der Nervenbündel liegt. Vergleichungsweise wird dadurch der Raum tiefer schwarz für das freie Auge gefürbt als die eigentliche Nasenhöhle es ist. Dass in der bindegewebigen Schicht der auskleidenden Haut Blutgefüsse sich verbreiten ist selbstverständlich und ich habe sie nach oben auf dem papillenartigen Wulst gesehen.

Von besonderer Wichtigkeit sind die Nerven. An je eine Höhle geht ein starker Zug von Bündeln des Riechnerven, welche an das Dach der Höhle herangetreten, dasselbe förmlich umfassen und nach einwïrts enden. Alle Bündel sind reichlich von dunkelm Pigment umsponnen, was theilweise, namentlich gegen das Ende zı, die Verfolgung der feineren Bündel erschwert. Doch habe ich so viel gesehen, dass die knorpelige Wand von zahlreichen zum Hohlraum radiär stehenden Canälen durchbrochen ist, in welchen die durch Zertheilung feiner gewordenen Endbündel des Nervus olfactorius vordringen und in die bindegewebige dunkle Lage der die Höhle anskleidenden Schicht gelangen. ${ }^{3}$ ) Man gewahrt somit an feinen Schnitten zu äusserst die dickeren Büudel des Riechnerven, welche die Höhle umgreifen und reich von dunkelm Pigment umsponnen sind; dann die Fortsetzungen in den Kunorpelcanälen, immer noch ringsum schwarz von Pigment; hierauf ihr Auslanfen in die ebenfalls schwarze Hant der Höhle. Die Hauptmasse der Nerven liegt am Umfang des Daches, welches einwärts nach der Nasenscheidewand steht; der Boden der Höhle und jedenfalls der papillenartige Querwulst gehen leer aus. Damit hängt denn auch

\footnotetext{
1) Elfte Tatel, Fg. 143.

2) Bau d. thierisch. Körpers. S. 54.

s) Achte Tafel, Fg. 111.

Leydig, Saurier.
} 
wieder zusammen, dass das Epithel der Höhle nicht allerorts das gleiche ist, sondern einen ähnlichen Unterschied zeigt, wie in der eigentlichen Nasenhöhle zwischen den Stellen, wo Nerven enden, und wo dies nicht der Fall ist. So wird der knorpelige in die Höhle vorspringende Wulst von einem Flimmerepithel überzogen, dessen Zellen nach Gestalt, Cuticularsaum, Länge der Cilien mit den gleichen Bildungen in der Nasenhöhle ühereinstimmen. Hingegen am Dach oder der Wölbung der Höhle stehen dicht zusammengeschlossen sehr lange Zellen mit den starren, aber leicht zerstörbaren Härchen und bilden als Ganzes eine dicke in Weingeist weisslichtrübe Schicht, die noch etwas massiger ist, als die entsprechenden Lagen des Epithels des Nasenraumes. - Dass auch Zweige vom N. trigeminus an die Höhle gehen, ist wahrscheinlich, doch bin ich keinen begegnet.

Gleichwie an den Choanen, wenn man ihren Eingang von der Nasenhöhle her betrachtet, das Pigment der Schleimhaut mit ganz bestimmter Grenze plötzlich aufhört, so geschieht dies iuch an dem Gang des Jacobson'schen Organs, welcher an bereits bezeichneter Stelle in den Rachen führt.

Da ich bezüglich der Ausmündung des in Rede stehenden Hohlraumes einige Zeit auf falscher Führte mich befand, will ich nicht unterlassen, diese hier anzudeuten.

Legen wir nämlich einen Schnitt durch die Schnauze etwa in der Höhe der Nasenlöcher, so erscheint in der Schleimhaut der Mundhöhle, unterhalb der verschmolzenen und hier einen Längswulst erzeugenden Vomera die Lichtung eines in der Mittellinie gelagerten Canales. ${ }^{1}$ ) Seine Wand wird von der Bindegewebsschicht der Schleimhaut gebildet und zu beiden Seiten, gewissermassen in der Wand des Canals, erblickt man den Durchschnitt eines stärkeren Nerven, der auch wohl wie halblugelig in die Lichtung des Ganges vorspringt. Fertigt man eine grössere Anzahl von Schnitten, so zeigen sich gewisse Veründerungen. Die Lichtung des Canals ist in dem einen von scharfer Begrenzung und scheint selbst wie von Epithel ausgekleidet; in anderen Schnitten hat der Canal kein reines Lumen, es fehlt nicht blos das Épithel, sondern der laum ist von einem Bindegewebsnetz durchspannt. Nur die beiden Nerven erhalten sich. Schneidet man aber immer weiter nach rückwärts, so ist der Gaug nach und nach verschwunden und an seiner Stelle sieht man lediglich einen dunkeln Fleck, der ein Rest der Nerven zu sein scheint; endlich nach dem Ende des Gaumenwulstes zu ist auch diese Spur verschwunden. Verschaffi man sich umgekehrt Schnitte weiter nach vorne, als die im Bisherigen gemeinten, so hat man anstatt eines, zwei Canäle, jeden mit seinem Nerv zur Seite, welch ${ }^{9}$ letzterer wohl dem $\mathrm{N}$. nasopalatinus Scarpae entspricht.

Diesen Canal war ich geneigt mit den Jacobson'schen Höhlen in Verbindung zu bringen, allein es ist wahrscheinlich nur ein bloser medianer Lymph- oder Blutraum, ahnlich wie sich weiter nach aussen an den gleichen Schnitten je seitwärts ein grösserer Blutraum zeigt.

Schon der skeletirte Schädel der Eidechsen von unten her angesehen, lässt die Vermuthung aufkommen, dass den Jacobson'schen Organen der Säuger verwandte Bildungen zugegen sein mügen. Man sieht nămlich voru, linter dem Zwischenkiefer, zwei Oeffnungen von etwas wulstigem Rande umgeben und den Vomera zugehörig. Sie erinnern an die Foramina incisiva der Säugethiere und sind denselben auch wohl zu vergleichen, trotzdem dass sie nach rückwärts mit den Choanen zusammenfliessen. Um sich davon zu überzeugen, halte man den Sclüdel eines Wiederkäuers, mir liegt gerade der des Hirsches vor, gegenüber dem 
der Fidechse und es wird klar, dass der scheinbar grosse Unterschied zwischen beiden am vorderen 'l'heil des Rachens dadurch entsteht, dass bei den Süugethieren der Oberkiefer durch Entwickelung des Processus palatinus die Nasenhöhle und Mundhüble trennt und dadurch das Foramen incisivum so gut wie die Choanen für sich abschliesst, der Vomer selbst aber jetzt nicht mehr der Ihachen- sondern lediglich der Nasenhöhle angehört. Denken wir uns den Gaumenfortsatz des Oberkiefers bei Säugethieren weg, so werden die Verhältnisse lenen des Eidechsenschädels nicht wenig ähnlich. Diese Foramina incisiva stehen uun in Bezieluung zur Ausmündung der oben abgehandelten, einen Theil des Riechnerven aufnehmenden Höhlen. Doch muss erwähnt werden, dass auch Blutgefässe und Nerven in nächster Nähe hier in die Raclıculühle übertreten. L's zeigt sich ein grosses venöses Gefäss, das sich rückwärts in einen Blutraum fortsetzt und in einer längs des Oberkicters herziebenden äLnlichen seitenfalte der schleimbut ausgegraben, sich gegen die weite Oeffnung erstreckt, welche beiderseits hinten im Rachengewölbe vom Oberkiefer, den Gaumen- und Flügelbeinen gebildet wird. Der Blutraum führt in die Nähe des Auges, und zwar linter dieses Organ. Der Nery lässt sich ebenfalls schon ohne Hilfe der Lupe am Rachen des lebenden Thieres, wo alsdann die Schleimhaut woch durchsichtig ist, ermitteln.

Was den (ieruchsapparat ${ }^{1}$ ) der Blindschleiche anbetrifft, so habe ich wich wenigstens davon überzeugt, dass im Wesentlichen dieselben Verhältnisse bestehen. Insbesondere gliedert sich auch hier das Organ in eine der ausseren Nasenöffnung entsprechende Vorhöhle, auf welche erst rückwärts die eigentliche Nasenhöhle folgt. In diese springt die knorpelige Muschel herein, deren Epithel viele Becherzellen eingestrent enthält. Die aus kurzen Schläuchen bestehende Drüse an der concaven Flïche der Muschel ist ebenfalls vorhauden, sowie eine zweite aussen an der Nasenkapsel gelegene. Damn ist auch das Jacobson'sche Organ unterhalb des Bodens des Nasenraumes zugegen, mit dem gleichen Nervenreichthum und jenem Knorpelwulst, welcher auf dem Längsschnitt pilzartig in die Höhle vorspringt.

Die physiologische Bedeutung der Jacobson'schen Organe der Süuger will bekanntlich noch nicht ganz klar werden. Der Bau des Organs hier bei Lacerta und Anguis möchte aber geeignet sein, auf die richtige Spur zu leiten. Wir sehen nämlich einen Hohlraum, der zur Aufnahme eines Endabschnittes vom Riechnerven dient, ohne dass dieser Hohhaum mit der Nasenhöhle in Verbindung steht. Auf die Endigung des Riechnerven vermögen nur Stoffe zu wirken, welche von der Rachenhöhle in den nach oben geschlossenen Raum gelangen. Daraus können wir einstreilen kaum etwas anderes folgern, als dass die in den vorderen Theil der Mundhöhle bereits aufgenommene Nahrung durch besagtes Organ vom Geruchsinu geprüft werden kann.

1) Acbte Tafel, Fg. 109; Elfte Tafel, Fg. 144; Zwölfte Tafel, Fg. 158. 


\section{Organe eines „sechsten Sinnes“.}

In einer bereits mehrfach angezogenen Abhandlung ${ }^{1}$ ) habe ich bei Sauriern und Ophidiern Bildungen nachgewiesen, welche mit den becherförmigen Organen der Fische in eine Reihe gehören. Wie bei letztgenannten Thieren können sie über die ganze Körperoberfläche ${ }^{2}$ ) vertheilt sein; ich fand es z. B. so bei der Blindschleiche. Und gerade mit Rücksicht auf die Gattung Anguis möchte ich jetat noch zusetzen, dass man die Verbreitung über die ganze Haut am leichtesten bei reifen Embryonen sehen kann. Am gehäuftesten stehen sie jedoch am Kopf, besonders an den Lippen.

Zu Folge weiterer Untersuchungen, welche ich an Eidechsen - diesmal an $L$. agilis und L. vivipara - anstellte, vermag ich jetzt anzugeben, dass bezüglich der Verbreitung der Organe die Saurier noch in einem anderen Puncte mit den Fischen übereinstimmen. Ich zeigte vor Jahren, dass bei den Süsswasserfischen und beim Stör die Gebilde nicht blos an der äusseren Haut vorkommen, sondern sich von den Lippen nach einwärts über die Schleimhaut der ganzen Mund- und Rachenhöhle weg erstrecken, und am Ġaumen so gut, wie am Zungenrudimente vorhanden seien. Aehnliches sehe ich jetzt auch bei den Eidechsen.

Die Organe, um welche es sich handelt, verbreiten sich von den Lippen über die s'chleimhant der Mund- und Rachenhöhle. Ich begegnete denselben an den verschiedensten stellen, besonders zahlreich standen sie am Gaumen, und zwar an jenem Höcker (T'uberculum palatinum), welcher zwischen den Choanen liegt. Dort bilden die Vomera einen leistenartigen Vorsprung und die schleimhint gestaltet sich zu einer wulst- oder plattenartigen Verdickung, welche beinahe einem "Zäpfchen" vergleichbar wäre. ${ }^{3}$ ) Ausser diesem mittleren Gaumenvorsprung sah ich die Organe noch recht zahlreich anf zwei seitlichen Gaumenfalten. Aber ihr Vorkommen erstreckt sich rückwärts nicht über die Rachenhöhle hinaus; im Anfang des Schlundes finde ich wenigstens keine mehr. Auch an der Zunge. sowohl oben wie unten, vermisse ich sie.

1) Ueber Organe eines sechsten Sinnes, Nov. Act. Acad. Leop. Curol. Vol. XXXIV, 1868. Zu den dort über die Gallertröhren zusammengestellten Mittheilungen fiüherer Autoren finde ich nachtråğlich noch des P’hysiologen Rudolpur zu erwähnen, welcher in seinem Grundriss der Pliysiologie erzihlt, dass er im Jahr 1817 bei Friour in Rimini sebr hübsche Priparate äber die sSchleimgänge sah. Der genannte Italiener halte dieselben, wie $\mathbf{J}_{\Delta c o n s o N}$ und 'I'reviasus, für eigene Sinnesorgane; ihn selber sei diess unwahrscheinlich, weil man eine schleimige Flïssigkeit aus den Poren durch Druck auf die Schnanze des l'hieres hervorpressen könne. Was der Berliner Gelehrte sonst noch gegen diese Annahme sagt, zeigt nur, dass er mit dem Bau der Organe unbekannt was.

$\left.{ }^{3}\right)$ Ich höre, dass P'rof. RernusRox in Kopenhagen eigenthïmliche auf den Schuppen der Schlangen befindliche Grübchen beschrieben hat, welche er für die Systematik verwendet. Mir ist nicht unwahrscheinlich, dass damit die Stellen der Haut gemeint sind, wo die becherförmigen Organe liegen.

3) Vergl. Achte 'Tafel, F'g. 10:. 
Man unterscheidet in dem Bindegewebe, besonders gut nach Aufhellung durch Reagentien, zahlreiche Blutgefïsse und Nerven. welch' letztere von Auslïufern des Nervus nasopalatinus herrühren und durch Austausch der Fasern Geflechte erzengen. Die bindegewebige Hantlage erhebt sich in kurze Papillen und auf ihnen sitzen die Organe, welche im Allgemeinen kleiner sind, als jene der äusseren Haut des Kopfes, aber von demselhen Ban. ${ }^{1}$ ) Die Becher bestehen aus einer von länglichen Zellen zusammengesetzten Wand, die an der Mündung einen streifigen Saum zeigt, bedingt durch feine Spitzen der Zellen. Die Oeffnung des Bechers trifft man bald sehr erweitert, bald sehr verengt. Im Grunde des Bechers ruht ein zelliger Innenkörper; an die Organe heran treten die Nerven.

Die Gebilde, von denen hier die Rede ist, sind zwar selbst an Thieren, welche in Weingeist lagen, gut sichtbar, werden aber doch am besten an frischen Exemplaren untersucht; empfehlenswerth ist es lebende Thiere in äusserst verdünnte Sialpetersäure zu werfen, wodurch die Theile sehr dentlich sich abhehen. Von der Höhlung im Imeren des Bechers überzengt man sich auch gut durch Betrachtung von unten.

Der besondere Geruch, welchen die Batrachier von sich geben, kommt bekamntlich aus den Hautdrüsen. Auch die Eidechsen und Blindschleichen verbreiten, wenn man sie in frischem Zustande zergliedert, einen eigenthümlichen Geruch, ohne dass wirkliche Hautdrüsen, mit Ausnahme der hier nicht in Betracht kommenden Schenkeldrüsen, zngegen wären. Der Geruch scheint hier von den becherförmigen Organen auszugehen; was mir dadurch-höchst wahrscheinlich, um nicht zu sagen, sicher geworden ist, diss frisch abgekochte Blindschleichen zunächst nichts von dem Geruch verspüren lassen. sondern etwa wie gekochte Fische duften. Sobald man aber die Epidermis abreiht. lassen sich sofort noch die Spuren des in frischem Zustand so stark hervortretenden eigenthümlichen Geruches wahrnehmen.

Die becherförmigen (Irgane clürfen unser Interesse um so mehr in Anspruch nehmen, als in nenester Zeit Schwalbe in Bom und Chr. Loven in stockholm bei Säugethieren und dem Ienschen entsprechende Bildungen anf den unwallten und schwammförmigen Papillen der Zunge aufgefunden haben. ") Die Organe werden mit (ieniluigkeit beschrieben und als "Schmeckbecher" oler "(keschmacksknospen" angesprochen; und bezüglich dieser Dentung könne nach ihrer Ansicht gar kein Zweifel herrschen. Ich halte diesen s'chluss für ähereilt und ungerechtfertigt, olsschon auch f'kAN\% ÉILHARD ScuULZE dieselbe Mleinung schon früher geäussert hat und noch vertritt. ${ }^{3}$ )

1) Zwölfte Tafel, Fg. 151.

$\left.{ }^{3}\right)$ Archir fo mikrosk. Anatomie, Bd. 4.

3) Ueber die Sinnesorgane der Seitenlinie bei Fischen und Amphibien. Arehiv fo mikrosk. Anat. Bd. VI, 187 . 
Wenn ich mir herausnehme dieses Urtheil zu füllen, so liegt die Begründung zwar schon ausführlich in meiner oben angezogenen Abhandlung; es mögen aber im besonderen Hinblick auf die gegentheilige Auffassung noch einige Puncte zusammengestellt werden.

1) Die becherförmigen Organe der Fische erstrecken sich über die ganze äussere Haut, stehen gedräugt an den Lippenrändern und verbreiten sich von da über die Schleimhaut der Mundhöhle. Wollte man sie einfach dem Geschmackssinne dienen lassen, so müsste man auch sagen, der Fisch schmecke nicht blos mit der Schleimhaut des Mundes, sondern auch mit seiner ganzen äusseren Haut. Es wäre dies ein nener Satz, welcher in die vergleichende Physiologie noch nicht aufgenommen ist. Obgleich ich schon seiner Zeit auf diese weite Verbreitung der Gebilde aufmerksam machte, so glaubt man der Darstellung SCHWALBE'S entuehmen zu müssen, als of sie nux am Gaumen vorkämen, was dann freilich leicht zu dem Schlusse, dass es Geschmacksorgane seien, hinführt. ${ }^{1}$ )

2) Bei den Reptilien finden sich die homologen Körper zwar wieder in der Rachenhöhle und man könnte abermals, wenn sie nur in diesem Raum vorkämen, sie für Geschmacksbecher gar wohl ansprechen; allein auch bei diesen sind sie über die äussere Haut verbreitet und stehen besonders gedrängt an den Lippenränderm.

3) Nach der gegenwärtig in der vergleichenden Anatomie und Physiologie herrschenden Ansicht würde man schliessen, dass Organe, welche als Endapparate den Nerven aufsitzen und über die ganze äussere Haut zerstreut vorkommen, dabei an (len Stellen, wo erfahrungsgemäss eine geschärfte Empfindung ihren sitz hat, sich anhäufen, in das Bereich der Tastorgane gehören. Bei dieser Deutung kann man sich aber nicht beruhigen, weil der Bau ein solcher ist, dass wir uns gar heine Vorstellung abzuleiten vermögen, wie sie als "Iastorgane" wirken sollten.

4) Wir sehen, dass hei den Amphibien im Larvenzustande die hecherförmigen Körper den Seitennerven aufsitzen und daher die Classe der in noch höherem Grade eigenartigen nervösen Bildungen der Seitenlinie der Fische vertreten, anders zu sagen, mit den Organen der Seitenlinie der Fische in eine Reihe zusammen gehören. Die letzteren Organe aber schlechthin als dem Geschmackssinn dienend ansprechen zu wollen, liegt noch weniger ein Grund vor.

j) Wenn wir daher nach der gegenwärtigen Sachlage nicht behaupten kömmen,

J) Ieh will keinen bezonderen Werth darauf legen, dass bereits Jo11. MüLLen in seinem Handbuch der Physiologie (Bu. I. S. 798) nach Reirungsversuchen sich dahin erkliirte, dass das Gaumenorgan kein Geschunacksorgan sei, sondern ein eigenthümlicher Schlingapparat; wofür sich auch Davase (Compt. rend. de la Societ. de Biologie, 1850) ausgesprochen hat. Doch mag immerhin hier an die Auftissung dieser Beobachter erinnert sein. 
die Becher der Fische, Amphibien und Reptilien seien T'astorgane sehlechthin. und noch viel weniger, dass es Geschmacksorgane seien; so ahnen wir, da Auge und Ohr nicht in Betracht kommen können, dass sie einer Empfindungsform dienen. welche die Plyysiologie noch nicht kennt und eben desshalb habe ich für sie die Bezeichnung "Organe eines sechsten Sinnes“ gewählt.

\section{Verdauungsorgane.}

\section{Zähne.}

Eidechsen.

Die Zähne unserer Eidechsen verdienen eine genauere Berücksichtigung als ihnen bisher zu 'Theil geworden ist. Dass in den Kinnladeu, in der oberen so gut als in der unteren, Zähne sich finden, konnte wohl von keinem Beobachter übersehen werden, und wir finden sie daher z. B. schon auf dem "Lacertae sceleton" bei ALDRovandr ${ }^{1}$ ) angedeutet. Die Gaumenzähne blieben wegen ihrer Lage und Kileinheit noch lange verborgen; insoweit wenigstens meine historische Kenntniss geht, werden sie erst bei (Uvier, ${ }^{2}$ ) danu bei MLCcKet ${ }^{3}$ ) erwähnt. Und trotzdem hat noch später gar Nancher, obschon er sich näher mit unseren Thieren abgab, ich nenne z. B. KocH, von den Zühnen des Gaumens nichts gewusst.

Am genauesten hat offenbar WAGLER ${ }^{4}$ ) die Zähne unserer Eidechsen nach Vorkommen, Form und Bau studirt; insbesondere anch zuerst bemerlit, dass die Gaumeuzihne keineswegs den sümmtlichen einheimischen Arten zukommen, sondern nur einzelnen: immerhin finde ich seine Angaben mehrmals zu verbessern und zu erweitern.

Nicht alle Zähne dur Kimnladen haben gleiche Grösse: die kleinsten sind jene des Zwischenkiefers, die längsten diejenigen, welche im Oher- und Unterkiefer die Mitte einnehmen, während sie dann nach leiden Seiten hin, nach vorne und nach rückwärts, sich verkürzen. Aehnliches sieht man an den Gaumenzähnen: die mittleren sind die grösseren, nach vorne und hinten schliessen sich kleinere an.

2) De quadrupedibus oviparis, 1657, p. 628. Diese Figur war offenbar das stark benutzte Vorbild der Zeichuung des Skelets bei Corter; erscheint auch aufgenommen in das Sammelwerk des Bussus: Anatome animalium, 1681, 'Tub. LIV.

$\left.{ }^{2}\right)$ Le règne animal, $181 \%$.

3) Systen der vergleichenden Anatomie, 1829.

1) System der Amphibien, 1830; besonders in dem Abschnitt: iescriptio dentium crocodilorum et lacertarum. 
Was die Form betrifft, so lautet die gewöhnliche Angabe dahin, dass die Zähne vou Lacerta stumpf-kegelförmig seien; so heisst es bei MECKEL und vielen Anderen. Covier jedoch gab bereits früher an, die Zähne der gewöhnlichen Eidechse, wenigstens die grösseren, besässen einen Einschnitt, während die vorderen ohne Einkerbung wären. Vergleicht man noch die späteren Angaben ('Uvien's, ${ }^{1}$ ) so merkt man, dass er zwar die ,dentelure“ der Zähne kennt, aber über die Zahl der Zacken immer im Unkluren geblieben ist. DUGÉs erklärt, dass er deutlich zwei Zinken, ${ }^{2}$ ) einen kleineren vorderen und einen grösseren hinteren, bei allen einheimischen Arteu beobachtet habe, ansgenommen $L$. ocellat $\iota$, bei welcher der Zahn in drei Zacken endige. Dann hat wohl um dieselbe Zeit auch WAGLER die Form des Zahnes näher in's Auge gefasst; nach ihm wäre die s̀pitze der langgeren Zähne in dem Uber- und Unterkiefer zwei- bis dreilappig, ${ }^{3}$ ) welche Lappen bei alten Thieren sich verwischen könnten, so dass die Schneide gauz einfach erscheine. Aber wirklich sollten diese Lappen fehlen an den Zähnen des Zwischenkiefers. ${ }^{4}$ ) Endlich beschreibt MLENGE die Kieferzähne von $L$. agilis und $L$. croce als cylindrisch, an der stumpf legelförmigen Spitze eingekerbt, so dass sich ein grösserer und ein kleinerer Höcker zeige. ${ }^{5}$ )

Ich habe die Zähne von sämmtlichen unten aufzuführenden Eidechsen untersucht und mich überzengt, dass sie alle, auch die des Zwischenkiefers, zweispitzig sind; ebenso bestimmt habe ich aber auch gesehen, dass kein Zahn in Wirklichkeit dreispitzig ist, was Alles besonders hervorgehoben zu werden verdient, da noch Bibron und Dumerul. als einen allgemeinen charakter oben an stellen: dents maxillaires un peu comprimées, droites; les premières simples, les suivintes obtusément tricuspides.

Wer sich indessen selbst damit abgibt die eigentliche Form des Ziahnes heriuszufinden, wird bald gewahr, woher der Irrthum WAGLER's und der Anderen rührt. Man kann in der That bei Einstellung des Mikroskops auf die Krone der grösseren Zähne glauben, als ob neben den zwei Spitzen noch eine kleine dritte vorhanden sei; allein diess ist Schein, hervorgerufen von der Wendung, welche die Hanptspitze nach innen macht, wozu die Unmöglichkeit kommt die ganze Zahnkrone auf einmal in den F'ocus zu bringen. Der Eindruck des „Dreilappigen" entsteht am leichtesten bei

1) Kech. sur les ossemens fossiles. 3. edit. 1825. 'T. V, p. 277.

3) a. a. 0 . wne grande dentelure posterieure, et une anterieure plus petite«.

${ }^{3}$ ) a. a. O. maxillares apice plus minusve distincti bi-sive trilobi, mandibulares scalpro fere simplici aut obsolete lobato.

4) $\gg$ Apice obtusiusculo-acuminato $\%$

5) Neueste Schriften d. naturf. Gesellschaft in Danzig, Bd. 4, 1850. 
Anwendung geringer Vergrösserung; nicht aber an der Hand stärkerer Linseu, da man hier den Linien besser nachgehen und sich eher zurecht finden kann.

Von den zwei wirklich vorhandenen Spitzen ${ }^{1}$ ) steht die eine, es ist die kleinere, tiefer, nach vorne und aussen und ist gerude; die andere oder grössere erscheint nach hinten gerichtet und krümmt sich nach einwäts; von innen angesehen erinnert sie an eine umgebogene Blattspitze in der Ornamentik. An den Zuhnen des Zwischenkiefers ist diese Spitze in höherem Grade hackig einwärts gekrümmt.

Genau genommen vermag man schon bei Besichtigung des trockenen Schädels einer grösseren Eidechse, der L. viridis z. B., mit der Lupe die zweispitzige Form der Zahnkrone deutlich zu erkennen. Aber um die weiteren Einzelheiten der Oberfläche ansichtig zu werden, muss man für starke Vergrösserung und gute Belenchtung sorgen, auch die Beleuchtung manchfach wechseln. Dann kommen ferner Bildungen zum Vorschein, welche uns darthun, dass der kleine Zahn unserer Eidechsen mit den grossen Zähnen ansgestorbener Saurier manches gemein hat. Man sieht, dass die Spitzen nicht einfach glatt sind, sondern durch herablaufende Leisten kantig werden. Auch heben sich zarte Lüngsstreifen, richtiger Furchen ab, welche genaner besehen, wieder durch schräge Linien verbunden sind; dadurch erhält die Krrone bei scharfer Einstellung ein eigenthümlich unebenes Wesen und im Profil können verschiedene Eckchen und Spitzchen - Alles natürich sehr schwach - vorspringen.

Hat man den Zahn in Säuren erweichen lassen, so büsst er nicht blos durch Quellung von seiner Gestalt überhaupt ein, sondern es verschwindet die feine Sculptur der Oberfläche oder die streifige, rinnige, dann wieder höckerige Beschaffenheit; nur die Huuptleiste der zwei Zacken erhält sich auch jetzt noch. Hingegen ist ein Zahn, welcher nach der zuletzt angedenteten Weise behandelt wurde, recht geeignet zum Studium des feineren Baues.

Auf die histologische Beschaffenheit des Zahmbeins und seiner Grenzschicht nach aussen, welche man auch wohl Schmelz genannt hat, gehe ich hier nicht mehr ein, sondern verweise auf meine frühern hierüber veröffentlichten Mittheilungen. ${ }^{2}$ )

Die Höhle des Zahnes hängt zusammen mit den Markräumen jener Knochen, welchen sie an-oder aufsitzen. Dies lässt sich sehr deutlich sehen, sowohl am Os pterygoidemm, wenn es „Gaumenzähne" hat, - welchen Knochen man aufgehellt, ganz wie er ist unter dis Mikroskop legen kann - als auch an Durchschnitten in sehr verdünnter Sümre erweichter Kiefern. Und so hängt auch die sogenannte Zahn-

3) Sechste Tafel, Fg. 83.

2) Histologie, und Molche der württ. Fauna. S. 84. 
pulpe mit dem Inhalt der Markraume unmittelbar zusammen. Die Substinz der Zahnpulpe ist ein feinstreifiges Bindegewebe, in welchem etwas veränderte Fettkugeln beinahe wie einzelne grössere, kernartige Gebilde sich ausnehmen können. Die Pulpa enthiilt ferner zahlreiche Blutgefässe; man unterscheidet schon bei natürlicher Injection ein paar stärkere Gefässe und dazwischen ein dichtes Netz feinerer. [Vass die Gefässe mit jenen der Markräume des Knochens zusammenhängen, ist selbstrerständlich. Beim Salamander ${ }^{1}$ ) war nichts von Blutgefüssen in der Zahmpulpe wahrzunehmen; dass sie hier bei Eidechsen vorhanden sind, erklärt sich gut durch eine Abweichung im Entstehen der Zähne, wovon gleich nachher.

Nach Nerven habe ich mich oft vergeblich umgesehen; selbst an quer durchschnittenen Zähnen, allwo doch die Lichtungen der einzelnen Blutgefüsse sich deutlich unterscheiden lassen, will es nicht gelingen, nervöse Elemente zu erblicken. Da jedoch die Verhältnisse der Nervenstämme in den Kiefern denjenigen der Sängethiere ähnlich sind, indem man innerhalb des Hauptcanals nicht blos Arterien, Venen, Capillaren und Marktheile, sondern auch Nervenstämme klar vor Augen hat, so nahm ich den Gegenstand immer wieder vor und endlich gelang es an Lacerta vi ridis Nerven zu sehen, welche wenigstens die Richtung zur Zahnpulpe einschlugen. Das Präparat war ein senkrechter Schnitt durch den Oberkiefer, an dem man innerhalb des Haupteanales wie immer die quergetroffenen Blutgefässe, Arterieu sowohl wie Venen, Mark und Pigment, sowie endlich den Nervenstamm beisammen hatte. Von diesem Hauptcanal zogen sich Markräume herüber zum Zahn und in diesen, auss'r den Blutgefässen, anch mehrere Nerven in geffechtartiger Verbreitung und ihn Eude musste nach der Richtung, insoweit man sie verfolgen konnte, in der Zahnpulpe liegen. Doch waren sie schon ausserhalb des Zahns blass und nur hei starker Vergrösserung und gehöriger, diurauf gerichteter Anfmerksamkeit zu erkemnen.

Von Interesse ist es die Entwickelung des Zahnes zu verfolgen, besonders im vergleichenden Hinblick zu den salamandern. Dort gehört, wie ich gezeigt habe, die Zahnsubstanz nach ihrer Entstehung lediglich dem Epithel der Schleimhant an. Dasselbe ist der Fall bei den Zähnen unserer Eidechsen, indem in gleicher Weise wie dort das Zahnsäckchen eine Partic des Epithels vorstellt; und in diesem entstehen das Zahnbein simmt der sogenannten Schmelzschicht, beide als C'nticularbildung. ")

1) a. a. 0.5 .85 .

4) Achte 'lafel, $\mathrm{kg}$. 10:\% 
Aber - und hierin zeigt sich der Unterschied gegenüber vom Salamander in die zellige, ursprüngliche Pulpe hinein erhebt sich vom bindegewebigen Stratum der Schleimhaut ein Kinopf, welcher zugleich Ausbiegungen der Blutcapillaren enthält. Der Knopf bildet durch Wachsthum und Vermehrung seiner Blutgefässe die spätere Zahnpulpe. Der ursprüngliche, vom Epithel der Schleimhaut herrührende Theil der Zahnpapille, welcher im früheren Stadium den von unten her in die Höhe wuchernden Kinopf als dicke, zellige Zone völlig unzieht, verdünnt sich, bleibt aber für das ganze Leben des Zahns fortbestehen; demn er wird zu dem zelligen Beleg, welchen man das Epithel der Zahnpapille nennen könnte; obschon diese zellige Lage der Innenfläche des Zahnbeines allezeit inniger angeheftet bleibt, als der Oberfläche der Zahnpapille.

Von dem letzteren Verhalten überzeugt man sich dadureh, dass man Zähne, auf welche längere Zeit Essigsŭure und Glycerin eingewirkt haben, zur Untersuchung auswïhlt. Man sieht alsdann zwischen der Papille und dem Zahnbein einen oftmals geradezu weiten Raum klaffen, wobei das Zahnbein, also die Innenfläche der Zahnhöhle, noch eine zellige oder epitheliale Lage trägt, die offenbar dem Zahnbein - es war ja die Substanz desselben aus solchen Zellen abgeschieden worden inniger angehört als der Zahnpulpe.

Vergleicht man die Zähne der Salamander und jene der Eidechsen bezüglich ihrer Befestigung, so ist der Unterschied ein nicht geringer, und wie mir scheint der bleihende Ausdruck dessen, was die Abweichungen in der Entwicklung zeigen. Dort bei den Salamandern ist anch der fertige Zahn durch eine scharfe cirenze bleihend ron dem knöchernen Sockel geschieden; hier hei den Eidechsen findet eine engere Verwachsung der Basis mit den Kieferm statt.

Nehmen wir anch Rücksicht auf die Art und Weise wie bei den Eidechsen die Zähne mit den Kiefern verwachsen sind, so wirft ein näheres Stndium noch den diewinn ab, diss ein anscheinend schroffer Unterschied zwischen den Crocodilen und Eidechsen verstanndlich wird und an Schärfe verliert.

Die (rocodile allein unter den jetzt lebenden sauriern haben eingekeilte Zähne, oder solche, welche in Löchern des Kieferrandes stecken, und der einzelne Zahn shliesst in seiner Höhlung einen jungen Zahn ein; dieser kann den andern ersetzen, wenn er rerloren gegangen wäre. Bei unseren Eidechsen ${ }^{1}$ ) sind die Zähne der Innentlaiche der hiefer ,angeheftet, gleichsam angeleint"; an ihren Grunde, nach der 
Mundhöhle zu steht ein junger Zahn - Glied einer zweiten Zahnreihe -, der wohl ebenfalls zum Ersatz des ersten dienen kann.

Man macerire die Kiefer - ich that es mit Lacerta vivipara - bis zu dem Grade, dass sie nicht blos in ihre einzelnen Stücke rein auseinander gehen, sondern anch die jungen Zähne abgefallen sind, ebenso ein Theil der alten. Prüfen wir jetzt die zahntragenden Theile mit dem Mikroskop, so zeigt sich, dass die Lücken, allwo die alten Zähne „angeleimt" waren und welche die Form einer Mulde haben, eine Art unvollkommener Alveole vorstellen oder den Anfang zu einer knöchernen Umfassung des Zahnes. Man könnte die Bildung derjenigen einer senkrecht halbirten Alveole vergleichen; denn würde sie nicht an den Seitenrändern des Zahnes aufhören, sondern rings herum greifen. so würde eine wirkliche oder ganze Alveole damit gegeben sein und in gleichem Maass auch das Verhältniss des jungen Zahnes zum alten sich ïndern. Denn anstatt dass der junge Zahn jetzt nach unten und vorn einigermassen frei von dem alten Zahn steht, müsste er wohl bei vollständiger knöcherner Hülse oder Alveole in den alten hineinwachsen.

Immerhin erinnert auch das, was man schon jetzt sieht, nicht wenig an die Verhältnisse beim Crocodil. Der alte Zahn bekommt an seiner „Wurzel“, an der Seite nach der Mumdhöhle hin, zuerst eine längliche Oeffnung; letztere vergrössert sich zu einer bedeutenden Lücke, welche auf Kosten eines guten Theils des Zalnrandes inmer mehr zunimmt. In diese Lücke hinein wächst der junge Zahn. Wer diese Verhältnisse berücksichtigt, wird sich wohl geneigt finden zuzugestehen, dass von hier bis zu den Crocodilen nur einige Schritte seien.

Oeffnen wir die Mundhöhle einer frischen Eidechse, so erheben sich bekanntlich nur die Spitzen der Zähne als eine Reihe glünzender Körper ans dèn „Zahnfleisch". Der Durchschnitt, den ich vom Unterkiefer der Lacertu muralis vorlege, ${ }^{1}$ ) versinnlicht die nähere Beziehung der Weichtheile zum Zahn. Wir sehen, dass das Epithel der Mundschleimhant den Zahn bis auf die Spitze umgreift; daun legt sich anch nach innen vor den Zähnen eine Falte derselben Schleimhaut über die Zahnreihe her, welche an Schïdeh, die sammt den Weichtheilen getrocknet wurden, wie ein wirkliches "Zahntleisch" weit herauf die Zahmreihen unmittelbar bedeckt. Im frischen Zustande aber, wie der schnitt belehrt, zieht eine tiefe Furche zwischen den Zahnen und der Falte hin. 
Blindschleiche.

Vorans sei bemerkt, dass an der Innenseite des Oberkiefers, wie bei den Eidechsen, eine hohe Lüngsfalte besteht, in der ein weites venöses Blutgefäss liegt. Für das Uebrige empfiehlt es sich als Untersuchungsmethode ganz junge Thiere in verdünnter Kililange zu erweichen, wo alsdann der Schädel leicht zu behandeln ist. Denn beim Skeletiren, mag man sich auch noch so sehr in Acht nehmen, gehen doch immer einzelne Zähne verloren.

Das Gebiss hat hier mehrere Eigenthümlichkeiten, wodurch es nicht wenig von jenem der Eidechsen abweicht. ${ }^{1}$ ) Zunächst lïsst sich nicht von einer eigentlichen Rinne der Kinnladen sprechen, in welcher die Zühne stehen, höchstens von einer schwachen, und überdies nach vorne sich verflachenden Andeutung einer solchen. Ferner ist die Anzahl der Zähne bei jungen Thieren grösser als später, was damit zusammenhängt, dass die Zühne der hinteren Reihe, welche an sich kleiner sind, nur in der Schleimhaut haften. In frischem Zustande sind desshalh auch die Zähne der zweiten Reihe beweglich und an getrockneten Kiefern zeigen sie nach unten eine weit offene Mündung. Dass sie auf solche Weise leicht ausfallen, ist begreiflich; aber anch von denen der vorderen Reihe geht gern ein oder der andere verloren. Ueber die Zahlenverhältnisse gibt unten die Artbeschreibung Auskunft.

Der einzelue Zahn ist hackenförmig gekrümmt und einspitzig. Bei auffallendem Licht erscheint die Lirone glänzend weiss, wie polirt, an der Spitze gelblich, dabei von hartem Gefüge; die Wurzel ist mattweiss, streifig und grubig, auch minder hart. Unten sitzt der Zahn anf einer A Sockel von lockerer Ḱnochensubstanz, wahrscheinlich gebildet durch Verkalkung der bindegewebigen Schicht der Schleimhaut. An dem sockelartigen Wulst zeigt sich gewöhnlich eine Oeffunng, die stelle andeutend, wo ein kleiner Zahn der zweiten Reihe sass. Löst mau den Zahn vom Sockel ab, so findeu wir ihn nach unteu weit offen und überhaupt lockerer befestigt als solches hei Eidechsen der Fall ist. Noch lässt sich bei schärferem Zusehen und anffallendem Licht ermitteln, dass die Krone oder Spitze nicht rein oral im Querschnitt ist, sondern vielmehr nach unten zu etwis ansgehöhlt. Wan bemerkt nämlich eine scharfe Leiste, welche an der Spitze von beiden Seiten zusammenstossend, und rückwärts auseinander weichend, eine Art Furche erzeugt; in dieser ziehen damn selbst wieder als sculptur des Zahnes zarte schräge Furchenlinien herab, um weiter unten in die schwatch grubigen Bildungen der Ziahnobertläche überzugehen.

Die Zähne des Zwischenkiefer’s sind am kleinsten und am weuigsten gekitümmt;

\footnotetext{
1) Sechste Tafel, Fg. 82, Fg. 84.
} 
im Oberkiefer und Unterkiefer stehen die ersten und hintersten an Grösse zurück, wăhrend jene, welche die Mitte der Kinnlade besetzen, die längsten sind.

Der Umstand, dass man früher die Verwandtschaft del Blindschleiche mit den Schlangen besonders in's Auge gefasst hatte, war wohl Ursache, dass man auch Gaumenzähne der Anguis zuschrieb. Doch schon WoLF ${ }^{8}$ ) erklärt, dass er, olne und mit Vergrösserungsglas, keine Gaumenzähne habe eutdecken können. Cuvier hingegen scheint eine Zeit lang in der Meinung gestanden zu laben, dass die Blindschleiche Gaumenzähne besitze; wenigstens lauten die Angaben in seinen verschiedenen Schriften hierüber nicht gleich, ${ }^{2}$ ) und die Haltung Cuvier's mag nuch auf manchen andern Zoologen eingewirkt haben. Metaxa z. B. in seiner Beschreibung der Schlangen der Gegend um Rom ${ }^{5}$ ) theilt an einer Stelle den "Angues" im Allgemeinen die Gaumenzälune zu, an einer andern Stelle aber schweigt er von Gaumenzähnen und spricht blos von nmascelle dentate. Am genauesten hat wohl unter den Späteren WAGLER ${ }^{\star}$ ) die Zähne der Blindschleiche untersucht, doch jedenfalls nur mit der Lupe. Was sich bezüglich der Form noch mit dem Mikroskop laran sehen lässt, fand sclion oben Erwähnung.

Eizahn.

Die Embryen der Eidechsen, der Blindschleichen und Nattern besitzen bekanntermassen einen merkwürdigen Zahn, ${ }^{5}$ ) der ihnen zur Erötthung der Eischale dient.

Ich habe denselben zunächst von reifen Früchten der Lacerta vivipara näher angesehen und gebe davon eine Abbildung. ") Der Zahn ist um vieles grösser als die zunächst stehenden Zühne des Zwischenkiefers und ragt weit hervor; er sitzt genau in der Mittellinie mit einer wulstigen Abgrenzung anf einer besonderen Wölbung des Kiefers, und zwar ziemlich locker. Es scheint auch, dass er sofort ausfällt, wenn der mit ihm zu erreichende Zweck vorüber ist; denn an ganz jungen 'I'hierchen, die frei eingefangen, kurz zuvor geboren sein mussten, war er nicht mehr vorhanden. Was seine Form angeht, so nimmt er im Allgemeinen eine wagrechte Stellung zur Schnamze ein und ist dabei stark gekrümmt, die concave Flache nach uben gewendet; er hat eine breit schaufelförmige, glänzende, zugeschärfte spitze. In seinem Inneren sieht man eine weite Pulpahöhle und in der Wand die feinen Zahncanälchen.

Der Eizahn von Anguis fragilis ${ }^{7}$ ) ist kleiner als bei der Eidechse. Er ragt

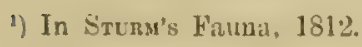

\#) Vorlesungen über vergleichende Anatomio, MEckeL'sche Uebers. 1810: »die Blindschleichen haben ausser den konischen, etwas gebogenen Zähnen in den beiden Kiefern in der hinteren Halfte des Gaumenbogens sebr kleine und kurze, in zwei Reihen zusammengestellte Zühne.* Man seho ferner Regne animal, 1817.

") Monografia de' Serpenti di lioma e suoi contorni. 18:3.

i) System d. Amphibien, 1830; in dem Abschnitt: descriptio dentium crocodilorum et lacertarum.

5) Nachdem Joll. Miruex den Zahn im /wischenkiefer bei Lmbryen exotischer Schlangen und Eidechsen entdeckt hatte, Arch. f. Anat. u. Phys. 1841, wies Wvisı ANw das Gebilde, welches er sizahn nannte, bei den einheimischen Arten ron Laccrta und Anguis fragilis, sowie von der Viper und der glatten Natter nach. (Württemb. Jahreshefte des Vereins $\mathrm{f}$. vaterlindische Naturkunde, 1856.)

$\left.{ }^{6}\right)$ Siebente 'Lafel, l'g. 94.

i) Siebente 'lafel, F'g. 95. 
am unverletaten 'Thier nicht aus der Mundhöhle heraus; weder mit freiem Auge noch mit der Lupe sieht man bei geschlossener Mundspalte etwas von ihm; ja selbst an der abgeschnittenen Kinnlade ist er noch durch bedeckende Weichtheile unsichtbar; wobei freilich erwähnt werden muss. dass die untersuchten Embryen noch nicht zum Auskriechen reif waren. Der Zahn steht ziemlich weit nach hinten und der \%wischenkiefer bildet für ihn eine Art Seharte, aus welcher er so hervorkommt, dass er sich zuerst stark nach abwärts, dann nach oben krümmt.

\section{Speicheldrüsen.}

Eidechsen.

Die Speicheldrüsen scheinen bisher niemals genaner untersucht worden zu sein, insoweit man dies nach den vorliegenden zum Theil unvollständigen, zun Theil unrichtigen Angaben schliessen darf. Ich habe sie von Lacerta viridis, $L$. agilis, $L$. vivipara und $L$. muralis geprüft, ohne einen wesentlichen Unterschied, abgesehen von dem Umfang welcher sich nach der Grösse der Thiere richtet, zu bemerken.

Man überzeugt sich leicht vom Vorhandensein einer Drüse, welche längs der Lnterlippe unterhalb der üusseren Haut liegt, und einer ituderen oder der Unterzungendrüse. Vou der Oberkieferdrüse, welche der Giattung Lacertu auch zugeschrieben wird, ${ }^{1}$ ) sehe ich keine Spur und muss sie in Abrede stellen.

Die Unterzungendrüse ${ }^{2}$ ) ist die grössere und bildet für's freie Auge jederseits einen starken Wulst zwischen der Innenseite der Unterkinulade und der Zunge. Ueber das weitere Verhalten unterrichtet man sich am besten an Querschnitten durch die Gegend der unteren Kimnlade. Mim sieht jetzt, dilss die Drüsenschlänche quer gelagert sind; die eingehendere Betrachtung lehrt, dass, ähnlich wie bei den sichenkeldrüsen, immer eine Anzahl von Śchlïuchen sich za einer Irüse verbinden; der Ausführungsgang, ebenfalls quer gerichtet, mündet in die tiefe f'urche, welche zwischen dem ganzen drüsigen Wulst und der Zunge hinzieht. Ilan erblickt an einem Quersehnitt eine ganze Menge von Ausführungsgingen, welehe hald uher und bald neben einander liegen.

Mehrmals, namentlich an $L$. muralis, hat es mir geschienen, als ob nach der 
Beschaftenheit des die Schlïuche auskleidenden Epithels zu urtheilen, die Drüse aus zwei etwas verschiedenen Partieen bestehe: aus einer grösseren, oberen Masse, deren Epithelzellen hell sind und einer hinteren, welche sich gegen den unteren Rand des Unterkiefers hinkrümmt und deren Zellen einen dunkeln Inhalt haben. Dabei liesse sich im Hinblick auf andere Wirbelthiere denken, dass in der Unterzungendrüse das zusaumengefasst sei, was anderwärts sich in Unterzungen- und Lnterkieferdrüse gesondert hat.

Für unsere bisherigen Anschaungen über das Vorkommen und Fehlen der Speicheldrüsen bei Amphibien und Reptilien scheint es mir ferner ron Bedeutung zu sein, dass, wie Jeder durch Vergleichung bemessen kann, die Drüsen im Boden der Mundhöhle von Lacerta nach Umriss und histologischem Bau jenen Drüsen rollkommen gleichen, welche sich bei den Früschen in der Substanz der Zunge finden. Man sagt gegenwärtig allgemein: den Batrachiern fehlen die Speicheldrüsen. Es ist rielleicht naclı dem Vorgebrachten richtiger, auch den Fröschen Speicheldrüsen zuzuschreiben, die zwar nicht frei für sich bestehen, sondern in die Substanz der Zunge aufgenommen sind; was man sich hinwiederum durch die breite, den ganzen Boden der Mundhöhle einnehmende Form der Zunge bedingt denken könnte. Bei Lacerta im Gegentheil ist die Zunge sehr schmal, in ihrer Substanz liegen keine Drüsen, wohl aber treten sie neben der Zunge als selbstständige Massen auf.

Die Lippendrüse, ${ }^{1}$ ) welche sich an der äusseren Seite des Unterkiefers herzieht, ist weniger massig als die Unterzungendrüse; sie kann aber democh schon mit freiem Auge unterschieden werden. Bequemer wird sie abermals an Querschnitten untersucht; hiebei zeigt sich, dass sie so wenig, wie die Unterzungendrüse eine einzige mit einem gremeinsamen Ansführungsgang rersehene Drüse ist, soudern rielmehr die Zusammenhäufung einer grossen Anzahl kleiner Drisen vorstellt, jede mit ihrem hesonderen in einer feinen Rinne an der Innenfläche der Lippen mündenden Ausführung:gang. Obschon auch hier die einzelne Drüse aus einer Auzahl zusammenhängender Blindschlänche, sammt Epithel besteht, so erhält das Organ doch eine eigenartige, ron jener der Unterzungendrüschen verschiedenen Tracht dadurch, dass die Schläuche gewunden und zusammengeschoben sind; das Bild erinuert damit im Ganzen mehr an traubige Drüsen.

Gelegentlich sei auch erwähnt, dass man nach einwärts von den Drüsen im Bindegewebe der Unterlippe allezeit den Durchschnitt ${ }^{2}$ ) eines derberen cbenfalls bindegewebigen Stranges bemerlit, welcher, oftenbar wie zur Stüze der inneren Partie der Unterlippe, nach der gauzen Länge derselben sich sclarf abhebt. In der Anordnung seiner bindegewebigen Elemente gemahnt er an den Durchschnitt einer festen Seline.

Blindschle iche.

Es stimmt Anguis fragilis mit den Eidechsen darin überein, dass eine Lippendrüse an Oherkiefer fehlt, was schon MECKEL ${ }^{3}$ ) richtig bemerkt hat; diejenige des

1) $\mathrm{Fg} \cdot 93, \mathrm{~d}$.

2) Siebente Tafel, Fg. 93, f.

3) System der vergl. Anat. 4. Theil, S. 360. 
Lnterkiefers ist nicht nur wohl entwickelt, sondern entschieden stirker als bei den Eidechsen. Für das freie Augre erscheint sie beim Abhäuten der Kinnlade in Form eines platten, weissgranen Lüngswulstes, an welchem man alsdann mittelst der Lupe die Drüsenbälge gut unterscheidet. Hat man ein in verdünnter Kalilauge erweichtes Thier vor sich, so lassen sich die vielen Oeffinungen der Lippendrüse nach ibrer ganzen Länge bequem sehen.

Ferner ist, gleichwie bei den Eidechsen, eine grosse Drüse vorhanden, deren die früheren Antoren nicht gedenken und welche ich oben Unterzungendrüse naunte. Sie bildet für die Besichtigung mit freiem Auge einen länglichen Wulst, welcher am Boden der Mundhöhle zwischen der Zunge und dem Unterkiefer scharf rorsteht. Ueber die gegenseitige Lage und Grösse der Lippendrüse sowohl wie dieser Lnterzungendrüse bekommt man an Guerschnitten, welche durch alle Theile am Boden der Mundhöhle grehen, gute Bilder. Die letzt genaunte Drüse hatte ich schon früher untersucht und erwähnt. ${ }^{1}$ )

Endlich finde ich noch eine Drüsengruppe in der Mundhöhle, welche der Eidechse mangelt. Dieselbe liegt paarig am Gaumen unterhalb der die Vomera überziehenden Schleimhaut; sie besteht aus kurzen, dicht zusammengeschobeneu Bälgen.")

\section{Zunge.}

Eidechsen.

Am skelet der Zunge - liest und Umbildung der ursprünglichen Kiemenoder Visceralbogen - unterscheiden wir zunächst das mittlere Stück oder Zungenbeinkörper, weleher nach rorne mit langer Spitze weit in die Zunge hinein sich erstreckt. ") Man kamn diesen lingen Kinorpelfaden dem Os entoglossum der Fische vergleichen. Nach hinten zieht sich die Platte des Zungenbeinkörpers in zwei lange etwats einwärts gekrümmte Fortsitze ans; vor letzteren, also an der Seite des Körpers, gehen die eigentlichen Hörner ab und zwar jederseits ein Paar. Sie sind zweigliederigg, wobei am vorderen Horn dils Wurzelstück das kïrrere ist und am hinteren Horn umgekehrt diss Wurzelstück den Endtheil weit an Lünge übertriftt; das Endglied am vorderen Horn verbreitert sich zuletzt zu einem wahren Knorpelflügel. Schon gewiesen.

1) Histologie, S. 312. Dort wird auch auf eine wahrscheinlich ähnliche Bildung beim Chamäleon hin-

3) Elfte Tafel, Fg. 144, c.

3) Achte Tafel, Fg. 100.

Leydig, Saurier. 
für's freie Ange ist die F'arbe des vorderen und hinteren Hornes verschieden, was sich unter dem Mikroskop, dahin aufklärt, dass der Kïrper und die vorderen Hörner in ihren festen Abschnitten nicht wirkliche Knochen sind, sondern nur verkalkte Tinorpel: das linge Basalglied des zweiten Knochens hingegen besteht ans echter Kunochensubstanz mit mittlerem Markiram, gleich einem Röhrenknochen. Wie Cuviti drei Paar von Hörnern dem Zungenbein der echten Eidechsen zuschrieb, so thun diess auch die späteren Beobachter, z. B. Wiegmann. ${ }^{1}$ ) In diesem Fall werden die zwei langen spitzen am Hinterrande des Körpers mit den wirklich abgegliederten Hörnern für ein und dasselbe gehalten, was wohl schon im Hiublich auf das Zungenbein der Blindschleiche unstatthaft ist.

Bekannt ist die Theilung der Zunge an ihrem Vorderende. Diese Bildung hat ein neues Interesse für den Morphologen gewonnen, seitdem man weiss, dass auch die Zunge höherer Wirhelthiere aths einer dentlich paarigen Anlage, wie Kow MANY ${ }^{2}$ ) znerst am IIenschen dargethan hat, hervorgeht. Die Zunge erscheint hinten zur Anfnahme des liehllkopfes wie ansgeschnitten; an ihrem seitenrand ist wie mit einer schwachen Einbuchtung versehen; die zwei Endspitzen haben in Näheren den Unriss einer Zitze; an der Zungengahelung geht die Theilungsfurche weiter nach hinten als die wirkliche Trennung reicht. Ich glaube mich (an L. vivipara) überzeugt zu haben, dass diess die eigentliche Form der ruhenden Zunge ist.

Ueber die Musculatur. ${ }^{3}$ ) suchte ich mich an L. agilis ${ }^{4}$ ) zu unterrichten, und zwar an (bner- und Längsschnitten durch das ganze Urgan. Man sieht auf diese Weise erstens Muskelzüge, welche nach der Lünge der Zunge verlaufen, wozu gehören:

a) eine zusammenhängende Schicht gegen die Schleimhant hin, welche oben nur ron den in die Papillen aufsteigenden MLuskelbündeln durchbrochen wird. Diese Schicht erstreckt sich auch seitwärts gegen den unteren Rand der Zunge.

b) Zwei grosse, wohl abgegrenzte Muskeln, welche an der Unterseite der Zunge von hinten nach vorn verlaufen und für's freie Auge als zwei starke Wülste sich

3) In der Herpetologia mexicana: $\nsim 0$ s hyoideum cornibus tribus ntrinque instructum Losasa's über Abgliederung dieser sog. hinteren Hörner vom Körper des Zungenbeins in dessen Abhandlung: Essai sur l'os hyoide de quelques reptiles. Mem. d. Accad. d. sc. li Torino, 1834, stimmen meine Beobachtungen nicht ïberein.

") Zeitsclurift 1. Biologie, 1868 .

$\left.{ }^{3}\right)$ \%u vergleichen wïre, obschon dort nicht anf die Muskeln der Eidechsen cingegaugen wird: Duversor, de la langue, considerée comme organe de préhension des aliuens, ou recherches anatomiqnues sur les mouvemens de la langue dans quelques animaux, particulierement de le classe des mammiféres et de celles des reptiles; Memoires de la socicté d'histoire nat. de Strasshourg, 18:30.

4) Vergl. F'g. 104. 
diurstellen; sie sind die Hauptzurütkzieher der Zunge (M. hyoglossus). Der Hauptnerv der Zunge liegt oben und seitwärts von diesen Muskel.

1.) Endlich verbreiten sich Lüngszüge zerstreut durch die ganze Zunge und schieben sich zwischen die queren und senkrechten Bündel ein.

Han unterscheidet zweitens senkrechte Bündel oder die Ausstrahlungen des M. genioglossus. Sie bilden zum Theil Bogen, welche von unten her die M. M. hyoglossi umgreifen, dann nach oben anseinander tretend bis in die Papillen anfsteigen und zwar bis unter das Epithel derselben.

Endlich sind drittens noch quere Fiserzüge zu unterscheiden, und zwar nach oben gegen die schleimhant hin. Näheres Zusehen lässt bemerken, dass alle die aufgezählten Bündel minchfach sich durchlireuzen und durchflechten, woraus zuletzt für die Thätigkeit des Organs die ungemeine Beweglichkeit erwächst.

Die Obertläche der Zunge ist keineswegs nach der ganzen Ausdehnung von gleicher Beschaffenheit, vielmehr lässt sie sich zum mindesten in drei Zonen zerlegen. Zu hinterst, vor dem Kiehlkopf, erscheint ein dreieckiges unpigmentirtes Feld, glatt und nur in der Mitte mit einigen queren Schleimhantfalten. Zn beiden Seiten von dieser Partie dehnt sich von hinten nach vorne die Zone der Querleisten ans, welche am liande der Zunge auch etwas nach unten biegen. Eingeschlossen ron diesen beiden Gegenden der Querleisten nimmt die eigentliche Mitte und Vorderhälfte der Zunge, die Zone der Papillen ein; unter sich von ungleieher (irösse sind alle Papillen dachziegelförmig rütckiürts gekehrt. Anf den beiden 'Mungenspitzen bilden sich die Papillen wieder mehr zu Längsleisten oder blattartigen Erhöhungen um.

Was den Bau ') der Papillen betrifft, so ist ihr freier Hinterrand ausgezackt und zwar, indem wir eine grössere Anzahl durchmustern, von einer einzigen Einkerbung aus bis zur manchfaltigsten Zackenbildung. Wer damit noch unbekannt ist, wird anf Schnitten Bildern hegegnen, die nicht sofort verstïndlich sind; es ist daher gut die Pallillen erst von der Fliche zu besehen und sich zu überzengen, dass nur der rückwärts gerichtete Rand gezähnelt ist. Diese Zatcken, welche zunächst lediglich dem Epithel anzugehören scheinen, werden herrorgerufen durch die Anwesenheit kleiner höckeriger Vorsprünge oder Wärzchen zweiter Ordnung, in welche die bindegewebige Grundlage der Hauptpapillen ausgeht.

Der zellige Beleg ist über die ganze Zunge weg ein geschichtetes Plattenepithel, das besonders dick gegen die zwei (ribelspitzen wird und diesen theilen etwas steifes, hornartiges verleiht. Anch auf jeder Papille scheidet sich die epitheliale Lage deutlich in eine Horn- und Schleimschicht.

1) Achte 'Tafel, Fg. 105, Fg. 106. 
Im Tmneren der Panjillen steigen, wie schon angedentet, quergestreifte Inskeln in die Höhe; anf Querschnitten bemerkt man, dass, namentlich in den grösseren Papillen, eine ganze Menge von sogenannten Primitivbündeln vorhanden sind. Ueber die Art und Weise wie die Nerven enden, habe ich nichts in Erfahrung bringen können, nur wiederholt mich davon überzengt, dass anf den Papillen sich keine becherförmigen Organe vorfinden. Dass anch Blutcapillaren in den Papillen zugegen sind, braucht wohl kaum hervorgehoben zu werden.

Was ich im Bisherigen mittheilte wurde im Wesentlichen bei L.agilis, L. viridis, $L_{\text {. }}$ rivipara und $L_{0}$ muralis in gleicher Weise gessehen, nur dass selbstverstinndlich bei den kleineren Arten alle Bildungen mehr ins F'einere ziehen. Am ehesten noch zeigt sich etwelcher Unterschied in der Ausbreitung der schwärzlichen Farbe. Bei L. arjitis erstreckt sich meist das dunkle Pigment über die ganze Zungenoberfliche weg, mit Ausnahme der an der Wurzel befindlichen und mit Querleisten versehenen Partie; bei L. vivipara war sie weniger pigmentirt, und nur etwas vorne, sowie nach hinten, da, wo sie sich für die Umgreifung des Kehlkopfes gabelt. Doch selhst diess wechselt nach den Individuen ab. Immer liegt das Pigment im Bindegewebe der Zunge, nicht im Epithel, welches daher als heller Saum über den dunkeln Rand wegzieht.

Endlich sei, obschon bereits oben die Rede davon war, und seine Erklärung gefunden hat, noch einmal daran erimnert, dass die Zunge drüsiger Bildungen in ihrer Substanz entbehrt.

Blindschleiche.

Die Zunge dieses Thieres ${ }^{1}$ ) zeigt nicht blos für die Besichtigung mit freiem Auge mancherlei Cuterschiede gegenüber von jener der Eidechsen, sondern auch wenn wir auf den feineren Bau eingehen.

Bekanntlich ist sie nicht blos kürzer, etwas dicker und die Spitze kurz gabelförmig getheilt, sondern ich sehe, diass weun die Zungenspitze völlig trschlatft ist, sich zwischen den zwei Hauptspitzen noch eine ganz kleine mittlere ahhebt. Bei Thieren, welche in Weingeist gelegen haben, können die zwei Endspitzen wie abgeschnürt anssehen, indem dahinter wieder eine in die Quere gehende Absonderung folgt und da nur diese Partieen stark dunkel prigmentirt auftreten, der äbrige Theil der Zamge aber hell bleibt, so kömnte man meinen, etwas sehr Charakteristisches vor Augen zu haleen; allein das Vergleichen mit andern Individuen thut dar, dass 
nur eine bestimmte Form der Inskelzusinmenziehung im Torle durch den erhärtenden Einfluss des Weingeistes festgehalten wurde.

Die Zungenoberfläche erscheint hier schon für's freie Auge von mehr weicher, zottiger Beschaffenheit, was sich anch hesonders schön zeigt an Thieren deren Epithel weg macerirt wurde.

Die Form der Papillen geht mehr ins Blattartige und da und dort erheben sich von ihren Rïndern secundäre Papillen in Gestalt kurzer Vorsprünge. Wie überhaunt die Papillen der nicht pigmentirten Partie der Zunge eher an blattfömmige Darmzotten erinnern, so ist auch ihr Epithel weicher und vom Charakter der Cylinderzellen. Erst imnerhalb des pigmentirten vorderen Abschnittes überdeckit ein deutliches Plattenepithel. mit Scheidung in Horn- und S'chleimschicht, die Papillen; aber selbst hier ist es noch immer weicher als bei den Eidechsen, erst an den zwei Endspitzen wird es dicker und etwas härtlich.

Einige durch die sanze Zunge gelegte Querschnitte scheinen mir anzuzeigen, dass anch die Musculatur gewisse Abänderungen habe. Eine Scheibe, z. B. aus der Mitte der hintereu umpigmentirten Partie genommen, liess zwar die M. M. hyoglossi erkemnen und neben ihnen den stark gewundenen Zungemerven, ebenso die Elemente des M. geniuglossus und seine Ausstrahlung in die bei dieser Ansicht ganz darmzottenïhnlich sich darstellenden Papillen, nicht minder die starke Lage der queren Fasern; alber jene bei der Eidechse in der Schleimhaut noch über den Zügen des II. transversus verlaufenden Lüngsfasern düncken mir zu fehlen.

Das Pigment, namentlich der sehr stark dunkelgefarbten Zungenspitze, liegt wieder nur im Bindegewebe.

Der Körper des Zungenbeins geht wie bei der Eidechse nach vorn in einen langen Faden aus, der tief in die Zunge dringt; hingegen ist ex hinten einfach hogig geschweift, ohne sich in zwei lange Fortsïte zu gabehn, wie solche's bei Lacerta der F'all ist. Hörner finden sich jederseits zwei; ein vorderes kïrzeres, welches sich gegen das freie Ende hin verbreitert; ein hinteres, lingeres, welches aus mehreren Stücken zusamnengesetzt ist und verjüngt ausgeht. Derr Körper und dits vordere Horn bestehen ans einem theilweise verkalkten hnorpel; vom hintern Horn bleibt nur das Endstück knorpelig, der übrige Theil besteht aus echtem Kinochen, hervorgegangen ans ossificirtem Bindegewebe. Imnen erhält sich ein Ifarkiam. Schon beim reifen Embryo ist dieser. Knochen gebildet, während der winze übrige Zungenbeinapparat noch rein knorpelig bleibt.

Das Zungenbein hat wohl IIELLans in sciner Schrift über den Tastsinn der Schlangen (1817) zuerst abgebildet, später ist diess z. B. von Jolt. MUtuer in seiner Anatomie der Amplibien (1832), bald darauf von 
Losana (1834) geschehen. Eines Fehlers, lessen ich mich früher schuldig gemacht, habe ich zu berichtigen Gelegenheit gefundev. ${ }^{1}$ )

\section{Darmrohr.}

Eidechsen.

Die Gliederung des Nahrungsrohres in einen sehr weiten Pharynx, einen stark gefalteteu schlund und daran schliessenden länglichen, etwas birnförmigen Magsen, sowie in einen mehrmals gewundenen Dünndarm und betrïchtlich weiten, mit Blindsatk versehenen Dickdarm, zeigt sich bei einficher Eröffnung des Thieres; auch wurde bereits die grosse Weite des Munddarms, sowie die Ausdehnungsfähigkeit des Schlundes mit der Weise der Eidechsen, ihre Beute ganz zu verschlingen, von den älteren Beobachtern in Zusammenhang gebracht.

Was mir aber besonders beachtenswerth erscheint, ist der Umstand, dass da, wo der Darm in die Kloake mündet, der abschliessende Iruskel (Sphincter) die Schleimhaut zu einer Ringfalte erhebt, welche soweit nach einwärts und nach vorne sich wendet, dass sie bei seitlicher Eröffnung des Enddarmes wie eine weite, faltige, (quer abgestutzte Papille sich ausnimmt." ) Sie mag etwas versehieden hoch bei den einzelnen Arten sein: bei Lacerta vivipara ist sie wenigstens niedriger als bei L. agilis. - Diese auffällige Mastdarmklappe ist von zwei Beobachtern, MarTiN SAINT-ANGE und LEREBodldet in Arbeiten, welche unten noch vielmals zur Sprache kommen werden, richtig gesehen und gezeichnet worden.

Den feineren Bau des Tractus intestinalis habe ich bereits früher an Lacerta agitis dargelegt, ${ }^{3}$ ) und führe hier blos an, dass am Schlund die Muskelhant, grermle wie am Jagen und Darm, nur ans glatten Elementen besteht; und dass lie Schleimhant des Schlmiles olme Drüsenbildung ist. Das Epithel besteht ans geschichteten Wimperzellen. Ich möchte Dem jetzt vielleicht noch beisetzen, dass im hachen sowohl gegen die Chomen zu, als auch am Boden, im Unfang des beginnenden Schlundes, Schleimzellen in grosser Verbreitung sich finden. Bei Betrachtung vou der Fliche gewalnt man ihre Geffnungen sehr deutlich, und von der Seite angesehen zeigen sie eine sunderung in eine Art Secretblasschen, den bauchigen Theil der Zelle einnehmend, uml in einen hinteren stielirtig verdümnten Theil. In letzterem befindet sich die eigentliche Zellsulstanz, welche nur in einem streifen, wie becherförmig dats Secretblüschen ungibt; in dem Stiel der Zelle liegt auch der Kern.

4) Organe eines sechsten Sinnes. Nov. Act. acad. Leopold. Carol. 1868. S. 67.

${ }^{2}$ ) Vergl. 'Lehnte Tafel, f'g. 124, Fig. 129.

$\left.{ }^{3}\right)$ Anat. histol. Unters. üb. Fische und Reptilien, 1853. 
Die sichleimhant des Magens. dessen Epithel aus nicht flimmeruden Cylinderzellen zusimmengesetzt ist, hesitzt brüsen in Form kurzer säckchen und mit einer gewissen gruppenweisen Anordnung.

Bezüglich der Inmentläche des Darmés möchte ich auf die angezogene Abhandlung zurückweisen. - Das Epithel des Darmes ist wie am Magen ein nicht Himmerndes Cylinderepithel.

Die Faltenbildung der sichleimlaunt geht im ganzen Nahrungsschlaum in die Länge. Schon zur Seite des Kehllkopfes begimnen leistenartige, regehnässig längsgestellte l'alten des S'chlundes; hei ganz jungen 'Thieren, wo die Leisten der schleimhaut aus dem Dünn- und Dickdarm durehschimmern, sieht man, dass sie in der erstern Abtheilung zickzackförmig nach der Länge verlanten, wänrend sie sich im Dickdarm zu einfachen Längsfalten umbilden.

Im Gekröse des ganzen Darmes, den MIagen mit einbegritten, fand ich deutliche Züge glatter Muskeln, die im Mesorectum am stärksten auftreten.

Das Bauchfell, da wo es die Leibeswandungen überkleidet, zeigt sich bei allen einheimischen Arten und bei beiden Geschlechtern tief schwarz gefärbt. Doch beschränkt sich diese Schwärze auf die eigentliche Bauchhöhle; jene Partie des Leibesraumes, welche von den Rippen umschlossen der Brust entspricht, hat eine helle Serosa. Das Sehwar\% hört ganz scharf auf, so dass bei geöffnetem, auf dem liücken liegenden Thier, der Leibesram nach der Farhe sich scheidet in einen vorderen hellen Abschnitt von dreieckigem Unriss, dessen spitze weit nach hinten dringt, mn in einen hinteren tiefschwarzen 'Theil, der, die Seiten des hellen Dreiecks umgreifend, seitwärts nach rorne bis dahin sich erstreckt, wo z. B. beim Weibchen das freie Ende ler Eileiter sich anheftet. S'chon Dugks's gedenkt dieses hemerkenswerthen Unterschiedes des "péritonée" von der ,plevre".

Dals Pigment des Banchfells liegt in der bindegewebigen schicht; dis Epithel geht davon unberührt zart und blass darüber weg.

Blindschleiche.

Schlangenähnlich ist hier die grosse Länge der Śpeiseröhre; auch steht der Magen ganz gerade. Der eigentliche Darm in seinen Windungen entfernt sich aher entschieden ron der l'orm bei den Shchlengen; denn während dort eine grosse Menge kurzer, zusammengeschobener, jia hei der liürze des Gekröses eng zusammengehefteter Windungen zngegen sind, zeigen sich die Darmwindumgen bei Anguis frompilis eidechisenartig: dals (iekröse ist breit und die Windungen nicht \%nsammengelöthet, ein Lnterschied, welcher schon von MEckfL ${ }^{1}$ ) bemerkt wurde.

1) System d. vergl. Anat. 4. Bis. 
Ebenso spricht der genannte Anatom bereits von einer starken „Pförtnerklappe", die in der That etwas Auffallendes hat. ${ }^{1}$ ) Sie erseheint als eine hohe ringförmige Falte, welche in den Anfang des Zwölffingerdarmes vorspringt und einer hohen offenen Papille ähnlich sieht. Die Andeutung eines Blinddarmes an der Grenze zwischen Dünndarm und Dickdarm fehlt.

Der Mastlarm schliesst von der Kloake mit einer ebenfalls derart grossen Papille ab, dass man bei erster Besichtigung fast etwas in die Irre geführt werden kiann. Nachdem nämlich die Schleimhant des Darms nach unten zu ihre sammetartige Beschaffenheit verloren, treten Längsfilten auf, dann folgen starke Ringsfalten, alles sehr musculös; hieran schliesst ein glatter Endabschnitt des Mastdarıns und in diesem ragt einwärts - nicht abwärts in die Ḱloake - die Afterpapille, welche 3 bis 4 Millimeter hoch and immer sehr faltig ist. ${ }^{2}$ ) Mikroskopisch untersucht, zeigt sie eine dichte glatte Musculatur, deren Elemente hauptsächlich in Lüngszügen, zum Theil aber auch in Ringzügen geordnet sind. Bei der Kothentleerung stüpt sie sich wahrscheinlich gegen die Kloake um.

Man nennt herkömmlich die Kloake den untersten, erweiterten Abschnitt des Nahrungsrohrs; allein dieser liaum zeigt doch gerade bei der Blindschleiche und den Eidechsen eine grosse Selbstständigkeit. Es ist cine Bildung für sich, in welche oben und vorne der Mastdarm mit besonderer verengter Oeffnung einmündet, worauf sich dann der Raum tief nach hinten und oben ausbuchtet, um die Papillae urogenitales aufzunehmen.

Nach meinen früheren Untersuchungen über den feineren Bau des Nahrungsrohrs ist die IIusculatur der Schleinhaut glatt, die Schleimhaut selbst ohne Drüsen. Im Gekröse des Darms zeigen sich Züge glatter Muskeln.

Das Banchfell ist bekanntermassen tief schwarz. Die Pigmentirung ist nicht auf die Seitenwände des Leibesraumes beschränkt, sondern geht auch auf die verschiedenen Gekröse über, und von diesen selbst zum Theil anf die Eingeweide, welche von ihnen gehalten werden. So kann das Mesorectum ganz schwarz sein, theilweise die Serosa des Darms, des Hodens, der Ueberzug der Nieren und Anderes.

\section{Leber.}

(Mnne bezüglich dieses Organes Untersuchungen angestellt zu haben, welche etwa die Prüfung nenerer histologischer Angaben sich zur Aufgabe setzen, glaube ich doch einige andere Puncte berühren zu können.

Von der Leber der Eidechsen berichtet schon MaLpigur ${ }^{8}$ ) dass sic zusammengesetzt sei aus vielen

1) Achte Tafel, Fg. 98, a.

3) Vergl. Neunte Tafel, Fg. 118.

3) De hepate, p. 252 . 
lănglichen, mu theilweise zarten Lappen (lobi), dic wieder in Läppchen getheilt seien, ohne Mlikroskop noch sichtbar, und diese seien abermals zerlegbar in Drüsenkörner (acini). Dugḱs ') kennzeichnet Form- und Lappenbildung gut und richtig, sowie das Verhalten der hinteren Hohlvene und auch der Gallenblase zur Lebersubstanz. Sphiter gaben über den Umriss, Grösse und Gewicht der Leber bei den verschiedenen einheimischen und fremden Arten Brotz und WagenuasN genamere Angaben. ${ }^{2}$ )

Was die Gallenblase betrifft, so würde sich nach den darüber vorliegenden Mittheilungen die Art I. viripara merkwürdig verhalten. Die Gallenblase soll beim Weibchen bald felien, bald da sein. Die letztgenannten Autoren nämlich vermissten sie in drei weiblichen Exemplaren; drei männliche Thiere hatten das Organ, einem Männchen mangelte es wieder, wie den Weibchen. BRand ${ }^{8}$ ) lässt die Gallenblase bei $L$. agilis fehlen. Hierzu bemerlit bereits R. WAGNER, ${ }^{4}$ ) es sei diess wohl cin Irrthum, die Gallenblase finde sich lier bestimmt, sei aber zuweilen stark in der Leber verborgen.

Unter zahlreichen von mix zergliederten Thieren glaubte ich einmal ebenfalls bei einem Männchen der $L$. rgitis die Gallenblase zu vermissen. Allein nachdem die Leber herausgeschnitten und unter Wasser untersucht wurde, tauchte dis Organ doch auf, nur war es ginz in die Lebersubstanz eingesenkt gewesen. Vielleicht liesse sich noch bezüglich der BRANoT'schen Angabe eime andere Erklärung geben. Vergleicht man nämlich die Synonymie, welche genanuter Forscher zusammenstellt, so bemerkt man, dass el die Lacerta vivipara für gleich hält mit L. agilis; es wäre denkbar, dass ein so genamer Zergliederer ein Exemplar von L. viripara zur Hand gehabt habe, welchem die Gallenblase wirklich fehlte und sein Irrthum wäre dann, dass er $L$. vivipara für einexlei mit $L$. agilis gehalten hätte.

Diess angenommen würde man folgern können, dass bei der genannten Art von Eidechsen im Vorkommen der Gallenblase sich Aehnliches wiederhole, was man auch sonst bezüglich des Daseins oder Fehlens des fraglichen Organes bei Virbelthieren überhaupt beobachtet: dieser oder jener Art von H'isch, Vogel oder Sängethier mangelt die Gallenblase, während nächst verwandte Arten sie besitzen.

Allein meine eigenen weiteren Beobachtmgen lassen eine solche Annahme nichit zu, da ich bei keiner Art unserer Eidechsen die Gallenblase wirklich vermisst habe, auch nicht bei Lacerta vivipara. Ich habe eine ganze Auzahl von Exemplaren eigens auf diesen Punct geprüt, und obschon die Thiere aus verschiedenen Gegenden stammten - von hier, dann aus dem Schwarzwald, ein Exemplar auch aus den Hochalpen, die einen Männchen, die anderen Weibchen waren - alle zeigten sich mit der Gallenblase versehen; so dass ich die Richtigkeit der obigen Angaben zu bezweifeln Grund habe, um so mehr als die Blase mitunter recht klein war und in die Lebersubstanz eingebettet. Bei ganz juugen 'Thieren von L. vivipara war die

\footnotetext{
1) a. a. 0. p. 363 .

2) De amphibiorum hepate, liene ac pancrente observ. zootom. 1838.

s) Medicinische Zoologie. S. 164.

*) Vergleichende Anatomie. S. 133. Leydig, Saurier.
} 
Leber noch sehr fetthaltig, daher von mehr weisslicher Farbe und die Gallenblase hob sich dann sofort dentlich ab, wenn sie auch ziemlich in der Masse der Leber steckt.

Die Gallengänge sind fein und ich überzengte mich an L. agilis, dass ausser dem (iallenblasengang (Ductus cysticus) noch mehrere Lebergallengänge (D. hepatici) innerhalh des Pancreas herah zum Darm gehen; ferner dass nm den Stiel der Gallenblase herum ein von der Leber kommendes Netz von Gallengängen vorhanden ist.

Da RATHKE nach seiner Aussage auch bei reifen Embryen der Ringelnatter die Mündungsstelle der fraglichen Günge nicht erblicken konnte, so möchte ich bezüglich der $L$. agilis hervorheben, dass man hier im Anfang des Darmes - gleich hinter dem Magen - eine dentliche, ${ }^{1 / 2}$ bis ${ }^{3 / 4}{ }^{1 / 1}$ lange Papille ${ }^{1}$ ) sieht, mit welcher die Gallen- mnd Pancreasgänge ausmünden. Diese verhältnissmässig sehr stattliche Papille, richtiger ihr Hohlram, kann vielleicht jener Lrweiterung oder dem Behälter verglichen werden, zu dem sich bei manchen Säugethieren, der Fischotter z. B., der Ductus choledochus und Ductus pancreaticus in der Darmwand vereinigen.

Meine Nachforschungen giengen auch auf das Verhältniss der Gallenblase zu den Gallengängen, wobei ich mich nicht der Injection, sondern jener einfachen Methode bediente, welche ich seiner Zeit zum Studium der Gallengangsnetze bei der Ringelnatter anwandte. ") Man sieht auf die dort angegebene Weise, dass wie bereits vorhin bemerkt, nicht ein, sondern mehrere Giüge herab zum Darme treten, die sich nach oben gegen die Gallenblase gabelig theilen, worauf sie, indem die Theilung zahlreicher wird und die Aeste sich verbinden, ein Netz von Gallengängen erzengen. Hat man die ansgeschnittenen Theile durch Essigsäure aufgehellt, so wird diess Alles sehr dentlich, weil die Gallengänge mit ihrer epithelialen Auskleidung sich von der Umgebung gut abheben. Die Gallenblase schien mir einfach eine grosse Ausstülpung dieses Netzes zu sein, und zugleich wie wenn sie an mehreren Stellen mit dem Netz zusammenhienge. - Das Epithel der Giallenblase bot einen hohen ćnticularsaum dar, der von dem gelblichen \%ellinhalt sich schon durch seine lichte Farbe klar unterschied und nuverkenmbare Porenstreifung zeigte.

\section{Bauchspeicheldrüse; Milz.}

Eidechsen.

Die Bauchspeicheldrüse weist bei allen einheimischen Arten eine so eigenthümliche form auf, dass man sich wundern darf, warum sowohl Braviot als

1) Vergl. achte T'afel, F'g. 99 , a.

") Vergl. m. Histologie S. 418, Anmerkung. 
anch Brotz und Wagenmans sie einfiach als linglich und schmal bezeichnen. Der Haupttheil allerdings stellt ein lingliches Band vor, das sich weit nach vorne erstreckt, bis unmittelbirr an den Hals der (xallenblase; aber im unteren Viertel der Länge geht ein dünner, nicht kurzer balken ab, dex quer gerichtet zuletzt kugelig anschwillt. ${ }^{1}$ ) Diesem rundlich verdickten Ende ist die Milz angelöthet, Was in so fern von Interesse ist, als es an das bekannte Verhältniss der Milz zun Pancreas bei den Nattem erimnert. ${ }^{2}$ ) Die II ilz der Eidechse ist länglich oval mit seitlichen Einkerbungen; durch röthliche Farbe hebt sie sich, wie immer, von dem ciranweiss der Banchspeicheldrüse ab.

Das Bindegewebe, welches die Bauchspeicheldrüse und trallengünge unfasst, theilt mit dem übrigen Bauchfell die Eigenschaft, dass in ihm Züge glatter Muskeh verlanten.

Blindsehleiche.

Die Bauchspeicheldrüse ${ }^{3}$ ). ist hier massiger, glätter und dichter im Gefüge als bei den Eidechsen; sie besitzt eine tiefe Furche, aus welcher eine starke Vene kommt.

Die längliche Milz hăngt nicht mit der Bauchspeicheldrüse zusammen.

\section{Circulationsorgane.}

Zum Studium der Cireulationsorgane im Näheren bin ich nicht gekommen und beschränke mich auf einige Bemerkungen.

Jedem Beobachter muss auffallen, dass das Herz der Blindschleiche nach dem Gesanmtumriss beträchtlich von jenem der Eidechsen abweicht. Die letzteren haben ein mehr konisches, an der Basis in's Breite gehendes, damn stark zugespitztes Herz; jenes der Blindschleiche zieht in's Längliche, was sich namentlich an den Vorhöfen zeigt, die Spitze endet stumpf. Mit einem Wort: das Organ ist hier von der Form des Herzens der Schlangen und entsprechend der Aehnlichkeit nach dieser Seite hin erscheint es auch etwas weiter nach rückwärts gelagert, als solches bei Eidechsen der Fall ist.

1) Fg. 99, c.

") Losaxa, dessen Abhandlung über die Milz der Schlangen (Memorie della accademia di Torino, T. XXXI, 1827) ich nur aus OKEx's Isis kenne, da diese früheren Bände der Akndemieschriften in hiesiger Bibliothek fehlen, scheint die wahre Gestalt obigen Organs bei Eidechsen und der Blindschleiche bemerkt zu haben.

s) Achite Tafel, Fg. 98, b. 
Sowohl bei der Eidechse als bei der Blindschleiche gehen von der Herzspitze herüber zum Herzbentel einige bindegewebige Füden, welche Blutgefüsse zum Ueberzug des Herzens leiten. Der Herzbeutel befestigt sich ( $L$. vivipara) nach unten und hinten durch einen Faden ans Brusthein. - Die sinusartig erweiterte, in den rechten Torhof führende Hohlvene hat bei beiden (iattungen in der Wand eine quergestreifte Musculatur.

Ueber das Herz hatte BrưckE ${ }^{1}$ ) nach Untersuchungen an $L$. viridis zu dem schon Bekannten anzufügen, dass die Scheidervand zwischen dem Carum renosum und den Carum arteriosum wenig ausgebildet sei, indem sie ähnlich wie bei Schildkröten und Nattern in einzelne Stücke und Blätter aufgelöst ist.

Von hohem Interesse sind aucl Ratwise's Untersuchungen über die Aortenwurzeln der Saurier, ${ }^{2}$ ) wo vielfach auf Lacerta agitis, in Wort und Bild, Bezug genommen wird und dieser nicht leichte Gegenstand äusserst klar dargelegt erscheint.

Die Arbeit, welche jüngst über den Bau des Herzens und der Gefüsssfämme G. Fritscr ${ }^{3}$ ) geliefert hat und von sehr schönen Figuren ( $L$. ocellata) begleitet ist, macht den Eindruck grosser Zuverlässigkeit. Ob Verfasser immer in seinen Berichtigungen der Angaben namentlich der beiden genannten Vorgänger im Rechte ist, wird nur Der sagen können, welcher in gleich genauer Methode nachzuprüfen sich entschliesst.

Die Blutkügelchen der Eidechsen (L. agilis) sind zuerst von R. WAGNER ${ }^{4}$ ) nach ihrer Grösse und Form bein Embryo und erwachsenen Thiere, sowie in ihrem Verhalten gegen Eiweis und Wasser beschrieben worden. Jene der Blindschleiche lat GULLIVER ${ }^{5}$ ) gemessen. - An mehreren Blindschleichen, welche einen Sommer und Winter in Giefangenschaft zugebracht hatten und deren Blut ich ansah, fiel mir auf, dass bei allen die Zahl der farblosen Blutkörperchen in jedem untersuchten Blutstropfen eine ungemein grosse war, wie mir schien eine grössere als bei Thieren, welche im Freien lebten.

Das Lymphgefässsystem der Eidechsen, wie der Reptilien und Amphibien üherhaupt, ist schon mehr als einmal Gegenstand der Untersuchung gervesen, so von Seite JoH. Mürcers, welcher dabei die Lymphherzen entdeckte (1832), und an den Eidechsen wenigstens die hinteren aufzufinden vermochte; ebenso haben sich damit Panizza, Rosconi, Merer, ") beschäftigt. Der letztere zeigt sich in seiner Arbeit als Geguer des erstgenannteu Anatomen von Pavia, und obschon er den, mir freilich nur theilweise bekannten Prachtfiguren PANizzA's sehr einfache, fist roh

j) Beitrïge z. vergl. Anat. u. Physiol. des Gefässsystems, Denkschriften der Wiener Akad. 1852.

3) Denkschriften d. Akad. d. Wisg. in Wien 1857. - Eine ältere figürliche Darstellung der Hauptgefïsse der grünen Eidechse, wohl aus französischer Quelle stammend, findet sich in verschiedenen deutschen Schrifteu wiederholt.

s) Zur vergleichenden Anatomie der Amphibienherzen. Archiv f. Anat. u. Phys. 1867.

4) Zur vergleichenden Physiologie des Blutes, 1833.

5) Varentin, Repertorium zur Physiol. 1843, S. 180.

$\left.{ }^{6}\right)$ Systema amphibiorum lymphaticum. Diss. inaug. 1845. Die Untersuchungen des Verfassers erstrecken sich neben Lacerta viridis anch auf $L$. agilis. 
gehaltene und nath Lacerta niridis entworfene 'Jeichnungen gegenüberstellt, so ist immerhin diesen Fïguren nuthzurühmen, dass sie das natürliche Verhalten gut in's Auge fassen. Meine eigenen Beobachtungen über das Lymphgefässsystem, anch dẹr Reptilien, gaben mir die (irundlage zu einer kritischen Belenchtung ${ }^{1}$ ) der Arbeiten vorgenannter dutoren, deren Richtigkeit durch die neneren und nenesten F'orschungen nur bestätigt wird.

Als eine besondere Bereicherung unserer Kemntnisse nach dieser lichtung hin sind die Mittheilungen S'CHWEIGGER-SEIDEL'S ${ }^{2}$ ) anzusehen. Er fand Veffnungen im Bauchfell, welche bei Eidechsen (auch Blindschleichen und Fröschen) in's Innere der Lymphräume führen, und als Lücken im Epithel des Peritoneums beginnen.

Ich darf wohl hiebei erinnern, was dem genannten Beobachter unbekannt zu sein scheint, diss indem ich schon früher die serösen Höhlen der Wirhelthiere unter die Lymphrüume brachte, diess durch vergleichend anatomische 'I'hatsatchen begründete ${ }^{3}$ ) dam habe ich längst an (yclas ${ }^{1}$ ) offene Wege oder Lücken - ich nannte sie C'anäle - zwischen den Epithelzellen besphrieben, welche in's Innere der Lacunen zwischen die IIskeln leiten. Es ist mir kein Zweifel, dass die Lücken zwischen dem Epithel mit den Oeffnungen im Bauchfell der Amphibien und Reptilien, endlich anch am Banchfellüberzug bei Säugern ${ }^{5}$ ) in eine Reihe gehören.

\section{Athmungswerkzenge.}

Zur bequemen Untersuchung des Kehlkopfes eignen sich besonders ganz junge Thiere und es haben mir solche von $L$. vivipara gedient.

Die Cartilago thyreoidea und C. cricoidea bilden einen einzigen Ring, Cartilago laryngea, dessen vorderer Theil eine höhere Wand hildet als der hintere; ${ }^{6}$ ) auf der ersteren sitzen die Giesshannenknorpel, unter der Form ein- und rückwärts gerichteter Spitzen. Sie sind ursprünglich 'wirkliche Fortsätze oder Hörner des Hauptknorpels, wovon man sich durch gehörige Einstellung des Mikroskops üherzeugen kann; demn es geht in der Tiefe die Knorpelsubstanz ohne Lnterbrechung von beiden Stücken in einander über. Später aber hat sich diess geändert, denn

2) Histologie, S. 419 .

3) Ueber die Peritonealhöhle bei Fröschen und ihren Zusammenhang mit dem Lymphgefässsystem. Berichte der siichs. Ges. d. Wiss. 1866.

3) Vom Bau des thierischen Körpers, 1864. S. 106.

4) Arch. f. Anat. u. Phys. 1 \$S55.

5) (Schwergaer-Seider) Ueber das Centrun tendineum d. Zwerchfells. Ber. d. sächs. Ges. d. Wiss. 1866.

6) Neunte Tafel, Fg. 121. 
am erwathenen Thier ist die Cartilago arytaenoidea selbstständig gewurden, indem sie sich von der Cartilago laryngea abgelöst hat.

Dieses aus. schönem Hyalinknorpel bestehende Skelet des Kehlkopifes ist an sich nicht breiter als die Luftröhre selber, aber es erscheint der Kehlkopf als Ganzes un vieles dicker durch das Muskelpolster, welches sich um die Ḱnorpelstücke legt. ${ }^{1}$ ) Ian nnterscheidet einen äusseren Muskel, dessen Bündel nach der Länge verlaufen; durch ihn werden die Giesskannenknorpel von einander entfernt. Darmter liegt ein fist noch dickerer Quermuskel, durch dessen Thätigkeit die genannten Knorpel einander genähert werden.

Die Schleimhaut zwischen den Giesskannenknorpeln zeigt sich sehr reich an feinen elastischen Fasern; und auch das Band, welches gegen die Zunge geht, besteht fast nur aus eben solchen elastischen Elementen.

Eine eigentliche Epiglottis ist nicht vorhanden; aber betrachtet man erwachsene Thiere, ich that diess an $L$. agilis, so scheint doch eine Falte der Schleimhaut die Stelle eines Kehldeckels zu vertreten.

Die Blutgefässe, welche die Musculatur des Kehlkoptes versorgen, sind in ihrer Wand pigmentirt und zwar bei den Eidechsen mehr als bei der Blindschleiche, was auf die Farbe des ganzen Organes natürlich Einfluss hat.

Bezüglich der Luftröhre möchte ich erwåhmen, dass ihre Knorpelringe sich gerne gabeln; daun dass der zweite, dritte und vierte Ring durch Ausläufer sich untereinander in Verbindung setzen. ") Da ich dieses Verhalten bei mehreren Thieren immer in gleicher Weise gesehen habe, so kanu es sich nicht wohl um eine individuelle Bildumg handeln. Neben der Luftröhre liegt auf der einen Seite eine grosse Jugulinvene, welche auch die Venen der anderen Seite aufuimmt. Eng an die beiden Seiteu der Luftröhre angeheftet erscheinen die Nervi recurrentes, und am Kiehlkopt angekommen dringen sie von hinten her in dessen Muskeln ein.

Die Lungen stellen bekanntlich ein paar längliche Säcke dar, welche beide ziemlich von gleicher Grösse sind. Ich habe früher ${ }^{3}$ ) den histologischen Bau an L. agitis durch eine Zeichung versinnlicht: die Innenfiache wimpert, die $W$ and ist mit Muskeln ausgestattet, nimentlich bestehen die Septen bis zur Spitze der Lungen aus glatten Muskeln. Die Knorpelstreifen, welche bei anderen Reptilien (Crocodilus, Monitor, Testudo) als Ansläufer der Bronchialringe in die Lmngensïcke verfolgbar sind und die Eing:̈nge in das Maschennetz ausgespannt erhalten, sind bei L. agilis nur an

1) $\mathrm{Fg}, 12 \mathrm{2}$

2) Vergl. Fg. 121.

3) Histol. S. 375 . 
der Ifurel dex Lunge noch rorhanden. Mim sieht bei geeigneter Behandlung wit an dieser Stelle streifen hyalinen hnorpels ron cinfacher oder astiger form in die Lungenbalken ausstrahlen und zuletzt als Ḱnorpelinseln aufhören.

Die Schilddrüe (Glandula thyreoidea) fand ich bei genannter Eidechse ron zweihörniger Gestalt, in der Mitte am dicksten. Ihre von zahlreichen bilutgefüssen umsponnenen Blasen, an deren Innenflüche ein schönes Epithel liegt, sehliessen entweder eine wasserklare Flüssigkeit ein oder auch Colloidmassen. ${ }^{1}$ )

\section{Harnwerkzeuge.}

Eidechsen.

Die verhältnissmässig kurzen Nieren, wovon die linke etwas weiter nach vorne als die rechte geht, liegen in der Leibeshöhle stark nach hinten, tief im Becken; mit ihrem spitzen, zusammengeflossenen Ende erstrecken sie sich eigentlich über das Becken hinaus und in die Schwanzwurzel hinein. Mehrmals habe ich mir auch angemerkt, dass bei der männlichen Lac. ayjilis die Nieren grösstr seien als beim Weibchen.

Jede Niere zerfällt durch scharfe Einschnitte in mehrere Lappen, welche jedoch ron rechts und links sich nicht ganz entsprechen. Auf den frischen Nieren (L. agilis) benerkt man mit der Lupe, zum 'Theil schon mit freiem Auge, eine schön blattartige ") Zeichmung von gelblicher Farbe auf rothgranem Grunde. Nähere Untersuchumg belehrt, dass dis Aschgrane sich auf die Masse del eigentlichen Harncanäle bezieht, während die gelblichen Figuren von den mit Harn gefüllten simmmelgängen herrühen. Das dianze erscheint als Ausdruck einer bestimmten Gruppirung der Harncanälchen. wie Aehnliches auch von der Niere der Crocodile und sichildkröten bekannt ist. - Bei Lacerta vivipara findet sich ebenfalls die von 'L. agilis angeführte Ungleichheit der beiden Nieren, nicht minder neigen nach hinten beide gegeneinander und spitzen sich stark zu; doch sah ich nicht, dass sie am Ende eigentlich mit einander verwachsen.

Mit Rücksicht auf die Frage, woher die bleibenden Nieren stammen, habe ich einige Untersuclungen an Embryen von $L$. agilis und $L$. vivipara angestellt. Beim noch ganz unpigmentirten Foetus ron $I_{\text {s. agilis }}$ sieht man, wie am hinteren Ende des Austührungsganges vom Wolf'schen Körper, nachdem die cigentlichen Quercanäle der Urnicren unter \%uspitzung des ganzen Drüsenkörpers aufgehört, neue ('unälchen sprossen und damit die Anlage der bleibenden Xieren bilden. Letztere sind um diese Zeit noch winzig gegenüber von der

1) a. a. 0. S. 376 .

") Zehnte Tatel, Fg. 124, at. 
Masse der Urnieren, und die Canälchen verlaufen noch ziemlich gerade. Wie sich das ändert, kamn die Figur 107, ${ }^{2}$ ) welche Urnieren und bleibende Nieren von einem neugeborenen Thierchen der $L$. vivipara darstellt, lehren. Obschon der Wolff'sche Körper in fast noch völliger Ausdehnung zugegen sich zeigt, ist durch Wucherung der Canälchen ein Drüsenkörper aufgetreten, der ganz sehon den Unriss und die Einschnitte der bleibenden Niere an sich hat.

Der Harnleiter, nachdem ei aus den Sammelgängen entstanden, mündet beim mamnlichen 'Thier zusammen mit dem samengang auf der Geschlechtspapille seiner Seite, innerhalb der Koloake. Beim Weibchen besteht chenfalls diese parrige, gefïssreiche md mit glatten Muskeln versehene Papille; mo ist sie, cla sie jetzt lediglich zux Papille des Harnleiters geworden, viel kleiner als beim Männchen. Insofern die Mündung des Uterus einen ziemlichen Umfing hat, und die Papille gewissermassen innerhalb der Uterusmündung zu liegen kommt, so ergibt sich daraus auch beim Weibchen deren nahe Beziehung zum Geschlechtscanal.

Was hier mit kurzen Worten gesagt ist, kann aber nicht ebenso schnell gesehen werden, sondern bedarf mancherlei wiederholter Untersuchungen. Und wer die Schwierigkeiten, mit welchen man zu kimpfen hat, nicht as eigener Erfahrung kennt, mag sich eine Vorstellung davon machen, wenn er eine Schrift des Zoologen ScHreiber's, welcher Jahre lang sich mit dem Studium der lieptilien beschättigte, über diesen Punct nachlesen will. ${ }^{2}$ )

Den weissbreiigen Harn sah ich öfters in dem Mastdarm über der Kloake angesimmelt, während in der Harnblase nichts davon vorhanden war. In anderen Fälen enthielt nur die Harublase einen kreideweissen Harn, der milroskopisch aus rundlichen, radiär streitigen Harnsteinchen des verschiedensten Unfanges, die kleinsten von Moleculargrösse, und daher von entsprechender Bewegung, besteht.

Die Harnblase ist länglichrund, zarthäutig, und entspringt mit einem ganz schmalen Stiel von der vorderen Wand der Kloake, gerade da, wo der Darm in die Kiloake übergeht. In natürlicher Lage des lebenden Thieres scheint der Stiel der Harnblase gerade über den Ausmündungsstellen der Harnleiter zu stehen. - Die Harnblase ist nur an der gegen die Banchhöhle gewendeten seite vom Bauchfell überzogen.

Von Emmert und Hochstetter wurde zuerst im Jahre 1811 die Harnblase unserer Eidechsen nachgewiesen; entgegen Cuvier, Hecket, Budmenbach u. A., welche sie diesen Thieren bestimmt abgesprochen hatten.

Blindschleiche.

Die $\mathrm{Nieren}{ }^{3}$ ) erinnern hier schon stark an diejenigen der schlangen; nicht nur sind sie weit länger als bei den Eidechsen, sondern zeigen anch ein entschiedenes

1) Auf der achten Tafel.

$\left.{ }^{2}\right)$ In der Arbeit: Ueber den Harn der Eidechsen, Griserq's Annalen der Physik, 43. Bd. (1813).

3) Vergl. Neunte 'Tafel, Fg. 118. 
Zerfallen in Lappen, etwa bis zu fünf Hauptlappen. Auch die Art und Weise wie die Sammelgänge ans den Lappen zum Harnleiter heran treten, - was man bei Betrachtung der unteren Seite der Nieren gut sieht - gemahnt an die Verhältnisse bei den Schlangen. Und ähnlich wie dort bemerlite ich an Thieren, welche längere Zeit in Gefangenschaft gehalten wurden, dass gauze Partien der Harncauälchen kreideweiss aussahen, zufolge der in ihnen angeschoppten Harnconcremente.

Was das Ende des Harnleiters in der Kloake betrifft, so verhalten sich wieder. die beiden Geschlechter etwas verschieden. ${ }^{1}$ ) Beim Männchen neigen gegen die Iñloake zu der Harnleiter - weit hinab von kleineren Partieu der Nierencauälchen begleitet - und der Samenleiter zwar gegeneinander, aber es bleibt doch jeder Gang für sich. Zuletzt münden beide zusammen am grübchenförmigen Eude eiues kleinen, für's freie Auge, besser für die Lupe unterscheidbaren Längenwulstes; aber immer noch so, dass ich im Grunde des Grübchens zivei Veffnungen zu unterscheiden glaube.

Beim Weibchen bestehen die Mündungen der Eileiter in der Kloake, sowie diejenigen der Harnleiter, nicht blos für sich, sondern sind weiter aus einander gerückt. Die Eileiter öffnen sich stark nach vorne und aussen; die Harnleiter mehr nach hinten und gegen die Mitte der Kloake. Man unterscheidet dort zwei längliche, nahe zusammenliegende niedrige Wülste, wovon jeder am hinteren Ende die Oeffnung der Harnleiter zeigt. Den Hauptbestandtheil der Wülste bilden bei mikroskopischer Untersuchung glatte, in verschiedener Richtung verlaufende Muskeln, wozu sich Blutgefässe und zahlreiche Nerven gesellen.

Die Harnblase ist grösser als bei den Eidechsen, namentlich länger; das Bauchfell fasst sie nur seitlich, die Dorsalfäche umhüllend, während die ventrale Seite, von dieser Haut unbedeckt, den Bauchmuskeln sich zukehrt.

Das Organ ist sehr zarthäutig, aber bei näherer Prüfung doch mit glatten Muskeln von geflechtartiger Anordnung ausgestattet. Gleichwie die Harnblase an sich mehr das Aussehen einer Allantois beibehält, so sammelt sich auch der kreideweise Harn in der Kloake an; allerdings da, wo der Stiel der Harnblase abgeht.

1) Vergl. Neunte Tafel, Fg. 114, Weibchen, u. Fg. 118, Männchen. 


\section{Fortpflanzungswerkzeuge.}

\section{Eidechsen.}

Ei erstock.

Lage und Form dieses Organs sind bekannt grenug, so dass ich darüber hinweggehen und andere Puncte erörtern will. An ausgewachsenen 'Thieren ist es schwierig, sich über den Bau des Eierstockes zu unterrichten, obschon man bald dazu liommt, einzusehen, dass die herkömmliche Angabe: der Eierstock sei ein Sack, unrichtig ist. Man findet, dass zwischen den Eifollikeln ein Balkenwerk von Bindegewebe sich hinspannt und in den Balken Blutgefässe verlauten. Die Anwesenheit glatter Muskeln lässt sich in den Zügen des Bindegewebes bemerken. Man wird nach diesen Befunden annehmen: der Eierstock bestehe einfach atus dem spürlichen Keimlager oder Stroma und den grossen Follikeln, die aber wegen der geringen Mächtigkeit des Stroma's dem Eierstock ein traubiges Aussehen verleihen.

Eine überraschende Belehrung gewährt der Eierstock ganz junger 'T'hiere, die noch nicht über das erste Lebensjahr hinaus sind. Wegen Kleinheit und Durchsichtigkeit kimn man das ganze Organ, wie es ist, unter das Vikroskop loringen, und min sieht jetzt, disss es alls zwei wesentlich verschiedenen Partien zusammenyesetzt ist: aus der Keimstätte der Eier, und zweitens ans einem, weite Lymphräume umschliessenden und Blutgefässe tragenden Theil.

Beginnen wir mit dem letzteren, welcher abwärts nach dem Darm geliehrt ist. Dass die grösseren und kleineren hellen Räume, welche man überblickt, Ly mp l- $^{-}$ räume sind, ergibt sich unwiderleglich nicht blos durch ihren wasserklaren, sie prall machenden Inhalt, sondern auch dadurch, dass ihre Wände - ein Blätterund Balkenwerk von Bindegewebe - von einem hellen zarten Epithel ïberkleidet sich zeigen. Innerhalb der Balken des Gerüstes, welche nach aussen zur Hülle des Eierstockes zusammentliessen, verlaten Blutgefässe; anch sind glatte Muskeh dem Bindegewelse eingeflochten. Die Lymphräunte stehen wohl in nächster lerbindung mit jenen Lymphrïumen, welche zum Theil vou besonderer Grösse auch in anderen Partien des Banchfells vorhanden sind, und in denen, ganz ähnlich wie hiel'im Eierstuck, awishen dru beden ans cinander weichenden Bhattern des Banchfells ein Balkenwerk sich ausspannt. - Hat man bei jüngeren 'Thieren diese Lymphräume erkannt, so findet man sich atrch an ausgewachsenen zurecht, indem man inne wird,

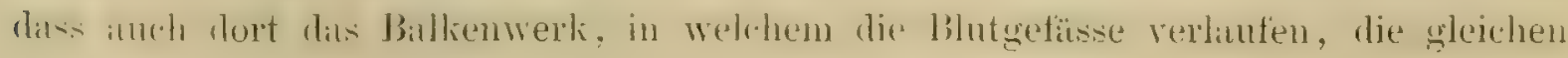


Lymphraume umgrenzt; nicht minder liisst sich die epitheliale Ueberkleidung der Balken erkennen. Zwischen den Lymphränmen liegen die grösseren und die kleineren Follikel, welche aber alle ihren Ursprung an einer anderen stelle genommen haben und erst zwischen die Lymphräume sich vor- und eingedrängt haben.

Dieser Theil ist die Keimstäte. Sie liegt nach imnen und auswärts gegen den Wolff"schen Körper gekehrt und hat im Ganzen die form eines nahezu spindelförmigen Doppelwulstes. Näher besehen zeigt ein solcher Wulst einen kleinzelligen $\mathrm{Bau}$, in der Art, dass ein bindegewebiges, wenn auch noch zartes, Fachwerk zur Grundlage dient, dessen Räume mit Zellen angefüllt sind. Ueber die Oberfläehe dieser Keimstätte der Eier geht das Hachzellige Epithel des Bauchfells weg.

Es entsteht die Frage, von woher kommt diese Keimstätte der Eier? Ist sie vom Wolff"schen Förper abzuleiten und als eine umgewandelte Partie desselben anzusehen; oder nimmt sie ihren Ursprung auf andere Weise.

Ich gestehe, dass es mir anfänglich geschienen hat, als ob die Keimstätte ihren Ausgangspunct von einem Canalstück des Wolff"schen Körpers nähme. Ein Cimal erweitere sich banchig in der Mitte, während er sich nach den beiden Enden verjünge und abschnüre; die Epithelzellen vermehrten sich, vertheilten sich in Gruppen und erzeugten durch Abscheidung ein bindegewebiges F'achwerk um sich herum. Zu dieser Auffassung durfte man sich besonders bei Untersuchung frischer Präparate von neugeborenen Jungen der Lacerta viripara himneigen; die schon jetzt eintretende fettige Metimorphose eines Theils des Wolff'schen Kiörper's, zunächst un den kaum angelegten Eierstock herum, schien dazu bestimmt, die Treunung zwischen Eierstock und Wolff'schen Körper hervorzurufen.

Allein bei geänderter Methode der Untersuchung stellte sich heraus, dass um diese Zeit die Anlage des Eierstockes dem Wolff'schen Körper keineswegs mehr unmittelbar ansitzt, vielmehr schon ziemlich von ihm entfernt ist.

Alles vou mir wiederholt an dergleichen jungen Thieren beobachtete Thatsilchliche liess sich zuletzt nur unter folgenden Gesichtspunct bringen. Der Eierstock bildet sich ans zwei 'Theilen her, die, weil von verschiedenen Keimblittern abstammend, ursprünglich verschiedener Natur sind, aber unter einander zu einem Ganzen verwachsen. Die massigere, der Lage nach untere Partie - das 'I'hier in natürlicher Stellung gedacht - ist eine oval-spindelförmige Anschwellung des bindegewebigen Stratums des Bauchfells; ihre Auftreibung geschieht durch das Wachsen der jetzt noch kleinen, zum Theil wie mit wasserklaren Zellen erfülten Lymphräume. An dieser spindelförmigen Verdickung des Bauchfells lagem die beiden dichten zelligen Kímwülste. Letøtere nun, somit anch die primitiven Eier vom Epithel abzu- 


\section{2}

leiten, wie WALIEYER ${ }^{1}$ ) für andere Wirbelthiere jüngst aufgestellt hat, gelang mir auf keine Weise, so sehr ich mich von vorneherein für die Darlegung des genannten Beobachters angezogen fühlte. Das eigenartige Epithel des Bauchfells geht, um nu’ diess noch einmal zu bemerken, von den dünnen Theilen der spindelförmigen Anschwellung üher die Keimwülste weg. Das Kieimlager ist sonach, wann es als Organ sich-gesondert hat, ein aus Zellen bestehender Wulst, dessen Elemente nicht vom Epithel der Batuchhöhle herrühren können, sondern von einem anderen höher gelegenen lieimblatt abstammen müssen. Das bindegewebige Fachwerk zwischen den Zellen ist wohl einerseits Abscheidung der letzteren, andererseits mögen manche der Zellen geradezı sich zu Bindegewehskörpern gestalten. Es kimn nicht ein Wachsen ler Keimzellen in die Räume des bindegewebigen Fachwerks stattfinden, sonderu dies (xerüste ist spätern Datums, und erst durch sein Auftreten geschieht die Zerlegung der zelligen Uranlage in die Follikel. Ein Follikel ist daher eine von Bindesubstanz umzogene Gruppe ursprünglich gleicher Zellen, von denen eine der mittleren durch stärkeres Wachsen und Umwandhung ihrer Substanz zum Dotter des Eies wird, während die andern das Epithel des Eifollikels liefern; ganz ähnlich den Verhültnissen der Eibildung, wie sie noch jüngst von den Insecten bekannt geworden sind. ${ }^{2}$ ) Bei der Weiterentwickelung des Ei's war für mich die Wahrnehmung befremdend, dass eine Dotterhant in dem Sinne einer Membran, welche von dem Protoplasma des Eies selbst, durch Erhärtung der Rinde entsteht, nicht erliennbar ist. Vielmehr ist hiel die erste im Eierstock sich bildende Hülle der Zona pellucida an die Seite zu stellen; sie hat die Beschaffenheit einer weichen Hant, wixd rom Epithel des Follikels abgeschieden und erscheint bei einiger Dicke von feinen streifen radiar durchsetzt.

Ich kann nicht umhin, gleich an dieser Stelle zu bemerken, dass, was ich an ebenso jungen männlichen Eidechsen als die waren, welche zum Studium des Eierstockes dienten, bezüglich der Entwickelung des Hodens salı, in Uebereinstimmung sich bringen lässt mit der Eifollikelbildung. Auch beim Hoden handelt es sich um einen ursprünglich gleichmässig zelligen Körper; die Sonderung in die späteren Samencanäle geschieht durch Abscheidung von Bindesubstanz in der $\Lambda$ rt, dass der ursprünglich gleichmässige Zellenkörper in C'ylinder zerfällt, die von Anfang einen geschläugelten Verlauf haben. Dort beim Eierstock zerlegt das Bindegewebe den Zellenkörper in rundliche Ballen oder die spätern Follikel; hier in geschlängelte Cylinder oder die späteren Samencanäle. Beides verläuft in der gleichen geheimnissvollen weiterer

1) Eierstock und Ei. Ein Beitrag zur Anatomie und Entwicklungsgeschichte der Sexualorgane. 1870.

$\left.{ }^{2}\right)$ Vergl. meine Abhandlung: Eierstock u. Samentasche der Insecten. Nov. Act. Acad. Leopold. Carol. 1867. 


\section{3}

Forschung unzugänglichen Weise, wie die sämmtlichen organischen Sonder'ungsprocesse: von der Furchung an lösen sich alle Organe ans dem allgemeinen Zellemmaterial nicht anders, als wie die Hand eines Bildhaners in den Marmor ilne Linien zieht.

Bei weiblichen Thieren von Lacerta agilis, welche im Januar aus ihren Winterverstecken ansgegraben, im warmen 'Zimmer bald Nahrung zu sich nahmen, und gegen Ende Februar untersucht wurden, waren Eierstöcke und Eileiter noch in rölliger Ruhe, ohne alle Anschwellung. Im April zeigten sich'die äber Erbsen gross gewordenen gelben und zum Austreten reifen Eier dicht von Blutgefässen umsponnen; doch so, dass eine rundliche. Stelle frei von den Gefässen blieb, wie diess auch bereits LEREBoulLET ${ }^{1}$ ) bemerkt hat und abbilden liess. An dieser gefiisslosen stelle wird wohl das Platzen des Follikels stattfinden.

Noch später, nachdem die reifen Eier vom Eierstock bereits ausgetreten sind und im Uterus verweilen, heben sich die geborstenen Follikel als "gelbe Körper" sehr schön durch ihre Farbe von den granen, noch unreifen, Eiern ab. Die gelbe Substanz rührt her von einer fettigen Metamorphose, welcher das Epithel des Eierstockes verfüllt. Die einzelnen Zellen, meist von cylindrischer oder fadig verlängerter ciestalt, zeigen sich dicht erfült mit Fettpuncten und Tropfen. - Das Gekröse des Eierstockes ist von einem reichen Geflecht glatter Muskeln durchzogen. Die Arterien erscheinen theilweise sehr klar von Lymphscheiden umgeben, wie denn bereits gesagt wurde, dass man die an jungen Thieren näher bezeichneten Lymphrïume des Eierstockes auch bei ganz ausgéwachsenen Thieren nachweisen könne.

Neben dem Eierstock zwischen ihm und dem Eileiter liegen noch - beim erwachsenen Thiere - zwei beachtenswerthe Reste vom Wolff'schen Körper. Der eine, von stark goldgelber Farbe und länglicher Form, ist das Gebilde, welches frühere Autoren Nebennieren naunten. Es besteht aus gewundenen, durcheinander geschlungenen Canïlen, deren Zellen fettig umgebildet sind; der Theil entspricht, wie WaLdeYer zuerst dargelegt hat, dem Parovarium (HIS) der Vögel. ${ }^{2}$ ) Die Verödung dieser Stelle des Wolft"schen Körper's beginnt, wie ich oben zeigte, in sehr früher Zeit, zusammenfallend mit der ersten Anlage des Eierstocks. Der andere Rest ${ }^{3}$ ) des Wolff'schen Körpers erscheint dem freien Auge von Farbe grau und ist weiter hinterwirts gelegen. Von mir zuerst aufgefunden, wurde el jüngst auch von WaLDEYER

1) Anatomie des organes genitaux des animaux vertebrés. Nov. Act. Acad. Leopold. Carol. 1851.

2) Zehnte Tafel, Fg. 129, e.

3) Fg. 129, d. 


\section{4}

mntersucht, der überdiess das Innere der Canälchen flimmern sah. Das Gebilde eutspricht dem Nebenhoden des Männchens, ist also Nebeneierstock.

Beim einjährigen 'Thiere ${ }^{1}$ ) von Lac. agilis, der sog. Lacerta argus, ist dieser Theil des Wolff"schen Körpers noch in bedeutender Ausdehmung erhalten, demn er erstreckt sich, wie in Fg. 132 dargestellt ist, bis zur Niere herab. (In der Blindschleiche wie wir sehen werden, ist er selbst noch beim ansgewachsenen, geschlechtsreifen 'Thier, ein langer Streifen.)

Eiergang.

Obschon selbst nenere Autoren, wie MARTIN SAINT $\triangle \mathrm{NGE}^{2}$ ) den Eiergang von seinem Anfang bis zum Ende von gleicher Beschaftenheit sein lassen, so ist doch bei näherer Prüfung ganz dentlich, dass er sich in mehrere Abschnitte gliedert, die durchaus an die gleichen Theile der Vögel erinnern: nemlich in Trichter, Eileiter und Uterus. Auch dieses Verhalten hat LEREBOULLET zuerst erkannt und richtig hervorgehoben.

Der Trichter ist von heller dünner Beschaffenheit, hat eine sehr weite, änssere Vefinumg und in seinem Grunde befindet sich erst der verhältnissmässig enge Eingang zum Eileiter. Die geräumige Oeffuung des Trichters liegt nahe an den Rippen, da wo das Bauchfell aufhört schwarz zu sein und zeigt sich für's freie Auge wie einfach abgeschnitten. Unter dem Mikroskop ${ }^{3}$ ) aber erscheint (L. vivipara, $L$. agilis) ein gar zierlich gefilteter und umgelirempter Mündungsrand, gewissermassen die Enden der inneren Schleimhautfalten. Das Epithel ist ein flimmerndes; trotz der Dünne der Wand sind doch glatte Ring- und Längsmuskeln, unter sich in geHechtartiger Verbindung, zugegen; die zahlreichen Blutgefässe sind in charakteristischer Weise stark gewunden.

Vom Eileiter, der etwas dickwandig, doch noch immer hell und durchscheinend ist, setzt sich dann wieder sehr bestimmt der weisshichere, und viel dickwandigere Uterus ab, welcher überdiess den Eileiter nicht blos im Durchmesser, sondern auch in der Länge weit äbertrifft. Die Mündung des Uterus in der Kloake liegt hinter der Einmündung des Darmes; die Oeffnungen beider Uteri sind nahe beisammen. - MARTIN SAINT ANGE lässt, nach Untersuchungen an $L$. viridis, die beiden Eileiter am Ende zusimmenfliessen und bildet es auch so ab. ${ }^{4}$ ) Bei agilis

\footnotetext{
1) Neunte Tafel, Fg. 132, d.

4) L'appareil reproducteur dans les cinq classes d'animaux vertebres. Ifén. d. l'Inst. d. Fiance. Savants étranges's. 1856.

3) Neunte Tafel, Fg. 116.

) a. a. O. Pl. IX, Fg. 7.
} 
und vivipara ist diess gewiss nicht der Fall. Oefthen wir den Uterns natch der Längeve, so erscheint die Innentlache der schleimhant ron sehr filtiger Art, worlurch eine Menge von Vertiefungen oder drüsenähnlicher Grübchen entstehen.

Dann aber überzengte ich mich bei $L$. agilis u. a. von dem Vorkommen echter Drüsen an trächtigen 'Thieren, und auch schon an solchen, deren Eier reif waren, um ans dem Eierstock in den Uterns überzutreten. Die Schleimhaut des Uterus erhelst sich bei trächtigen 'Thieren in rosettenartige Falten, die zum Vittelpunct eine Drüse haben. Die Drüse selbst ist ein rundliches Säckchen mit enger Mündung; dats Epithel der rusettenartigen Erhehungen ist dunkler als das der Zwischemränme, allwo es hell bleibt. Auch schon im unteren 'Theil des Eileiters treten Drüschen auf. Ausserhalb der f'ortpflanzmyszeit, nachdem der ganze eileitende Apparat zusammengefallen und ron gelbweisser larbe ist, haben die Ejpithelzellen einen stark fettigen Inhalt.

Dass nach aussen von der Sehleimhaut Muskellagen kommen, braucht wohl kaum hervorgehoben zu werden, sowie es anch an Bekanntes anschliesst, wenn ich bemerke, diss am Uterns die Mnskelwand dicker ist als am Eileiter. Hingegen ist besonders erwahnenswerth, dass die Fortsatze des Bauchfells, welche als Halthand de's Lileiters und Uterus dienen, und nicht wie das Bauchfell schwarz gefärbt sind, reichliche, sich verflechtende Züge glatter Muskeln besitzen. Noch grenzt sich am freien liand les Utertus ein feiner schnurartiger 'Theil ab, "cordon ligamenteux" bei LEREBOULLET, der mikroskopisch sich ebenfalls als ein Längsmuskel ausweist.

Zwischen den beiden Blattern des Bauchfells, welche das Gekröse des Uterus und Eileiters bilden, lässt sich beim Inurchschneiden eine grössene Höhle wahrnehmen. welche wahrscheinlich die Bedeutung eines Lymphraumes hat.

In der Kloake auch des Weibchens, wie ich bereits lingst angegeben, ${ }^{1}$ ) finden sich Drüsen und was ich jetzt beizusetzen habe: von zweierlei Art. Beide Paare liegen in der Rückenwand der Kloake, hinter den Mündungen des Uterus. Jede der grösseren erscheint schon für's freie Auge als eine rundlich dreieckige Masse ron weissgraner Farbe, und bestelit aus Säckchen mit grösseren und kleineren einspringenden Scheidewänden. Ueber die einzelne Drüse wölbt sich die Schleimhant der liloake zu einer vorspringenden Falte, so ditss jederseits eine Art kleiner Tasche am vorderen üusseren Eck der Drüsen entsteht. In der Substanz der Falte, welche die

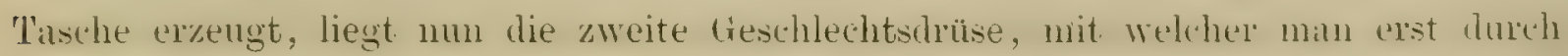
nihlere Untersuchung bekannt wird. Sie ist kleiner mul nath form ihrer lïnglidhen 
Säckchen mehr von der Tracht der Talgdrüsen der Sängethiere, in so fern sie nämlich sich dem Aussehen von traubigen Drüsen nähert.

Da Lacerta vivipara ${ }^{1}$ ) gegenüber von den andern einheimischen Arten lebendig gebarrend ist, so habe ich den eileitenden Apparat besonder's untersucht; ohne aber gerade auf wesentliche Unterschiede zu stossen. Des zierlichen Randsaumes vom Trichter wurde bereits gedacht. Im Uterus erhebt sich bei trächtigen Thieren die Schleimhant ebenso in rosettenartige Platten, ${ }^{2}$ ) mit je einer Drüse in der Mitte, wie es vorhin von $L$. agilis erwähnt wurde. Und das Epithel dieser zahlreichen Erhebungen, welche man in gewissem Sinne den Cotyledonen rergleichen könnte, ist ebenfalls trüber als jenes der Zwischenräume. Wenn ich die rosettenförmigen Erhebungen der Schleimhant den Cotyledonen verglich, so muss doch gesagt werden, dass sie mir an Blutgefässen nicht reicher zu sein schienen als die übrige Schleimhaut es ist. - Vom Ende des Uterus trennt sich deutlich eine Art Scheide ab. Biegt man nemlich die "Eileiter“ stark von den Nieren weg, so dass diese bis zu ihrem hinteren spitzen Ende frei liegen, so zeigt sich ein vom übrigen Uterus dureh Farbe, Dickung der Wand und Ringfurche scharf abgeschiedener Theil, mit welchem der Uterus in die Kiloake mündet. Dazu kommt noch, dass gerade an der Grenze zwischen Uterus und Vagina, ganz inselartig, ein schwarzer Pigmentfleck sich zeigt. (Von diesem Fleck habe ich bei einer grossen weiblichen L. agilis mit zusammengefallenem Eierstock und „Eileiter“" nichts wahrgenommen. Ob er sich erst bei der 'Thätigkeit der Organe entwickelt?)

Innerhalb der Scheide macht sich, entsprechend der änsseren Ringfurche, eine lingfalte, wie eine Art Muttermund bemerklich. - Hat man gerade ein trächtiges Thier vor sich, so findet sich im geöffneten Uterus, dass jedes Ei wie abgekammert vom anderen liegt, und je eine Kammer mit der andern durch eine verhältnissmăssig nur kleine Oeffnung im Zusammenhang steht. Die Wand des Eileiters ist hiebei merkwürdig dünn durch die Ausdehnung geworden; doch lassen sich, namentlich nach Einwirkung von Weingeist, immer noch die Muskeln erkennen. ${ }^{3}$ )

Aussen zieht, wie bei $L$. agilis, nach der ganzen Länge des Uterus und Eileiter's der musculöse Längsstreifen hin, der den Längsmuskeln am Dickdarm der Süugethiere zn vergleichen ist. Am „Eileiter“ ausserhalb der Zeit der Geschlechts-

j) Vergl. Zehnte Tafel, Fig. 130.

2) Neunte Tafel, Fg. 117.

3) Im neuesten Hefte der Zeitschr. f. wiss. Zoologio (Bd. XXI, Heft 1) tritt in einer Abhandlung wüber die Schale des Ringelnattereies etc. der Uterus als eine \#Hüllbaut des Eies, welche der "Schleimhülle der $B_{a-}$ trachiereier entspreche, auf! 


\section{7}

thätigkeit lässt sich wahrnehmen, dass der Streifen eigentlich der freie Rand des Gekröses ist, welches den eileitenden Apparat in der Lage erhält. - Von den Kloakendrüsen erscheinen die grösseren als zwei weisse Streifen von hackig gebogener Form.

Eischale.

Eine besondere Erwähnung verdienen die Hüllen, welche sich um das Ei auf seinem Wege durch den Eileiter und Uterus bilden.

Ich glaube mich an Weibchen von Lacerta agilis, deren Eierstock über Erbsengrosse, zum Austreten reife Eier enthielt, überzengt zu haben, dass auch solche umfüngliche Eier nur die bereits oben erwähnte vom Follikelepithel gelieferte Haut besitzen und sonst keine andere Hülle im Eierstock haben.

In den Leitungsröhren erwerben sie sich aber eine weissliche, derbe Haut oder S'chale. Das Element derselben sind Fasem, welche ich bereits früher ${ }^{1}$ ) elastischen Fasern verglich; was ich auch jetzt noch für richtig halte. Sie sind unverästelt, von der Tracht der geschwungenen Bindegewebszüge, haben aber gegen Reagentien die starke Widerstandskraft elastischer Fasern. Schon für das Messer lässt sich die Schalenhaut in mehrere Lagen spalten, am ehesten in drei, und unter dem Mikroskop gewahrt man ein so dichtes Verwebtsein der Fasern in den äusseren Lagen, dass die Schichten wie körnig aussehen können. Die mehr inneren Lagen sind lockerer gewebt, und der wellige oder lockige Verlauf der nach innen zu inmer feiner werdendeu Fasern tritt dentlicher hervor. Da und dort sehe ich das Ende einer Faser und zwar kolbig angeschwollen und hackig gekrümmt.

Nach der Weise wie diese Fasern entstehen mögen, hat zuerst WeInLAND ${ }^{2}$ ) geforscht, dam Lereboulitet. ${ }^{3}$ ) Nach dem Ersteren sollen sie sich ans Zellen derart hervorbilden, dass eine Zelle nach einer Seite hin in eine sehr lange Faser sich fortsetzt. In soweit ich dem Gegenstande nachgegangen bin, kann von einer solchen Entstehmngsweise nicht die Rede sein; was der genannte Beobachter als gelblichen ovalen Körper, oder als Zwiebeln der F'asern bezeichnet, und für „Bildungszellen“ ansprechen möchte, sind die vorhin erwähnten kolbigen Enden der Fasern. Aehnlich linsst LeReboullet das gedachte Gewebe aus "nucleoles primitifes“ entstehen.

Nach dem, was ich sehe, gehören die Fasern in die Gruppe der Zellenabscheidungen. Das Epithel der Leitungsröhren sondert sie ab, und sie gehen von einem weicheren Zustand bald in den des harten oder chitinisirten über; wodurch sie die

1) Histol. S. 515.

2) Ueber d. Eizahn der Ringelnatter. Württemb. naturwiss. Jahreshefte. 1856.

9) Rech. sur l'eaveloppement du Lezard, Ann. d. sc. nat. 1862. 
scharfen Linien und ihre Widerstandskraft gegen Reagentien erhalten. Nähere Angaben über die Weise der Entstehung folgen unten bei der Blindschleiche.

Vorstehendes bezieht sich zunächst auf die Eischale der Lacerta agilis. Bei der lebendig gebärenden Eidechse (L. vivipara) finden sich die gleichen Faserlagen, nur sind nicht nur die Schichten dünner, sondern auch die Fasern feiner; man erhält auch Bilder, wie wemn die Faserzüge von gewissen Knotenpuncten ausgiengen. Zu innerst von den faserigen Lagen schliesst ein homogenes Hüutchen âb, das sich gern in F'alten legt, welche den Schein von Faserzügen bewirken können. Hat man daher den optischen Querschnitt der Uteruswand und des Randes des Eies vor sich, so folgt auf das Epithel des Uterus nach einwärts: zuerst ein Lager geschwungener, dunkelrandiger Fasern, dann die dünne homogene Haut, hieranf die ebenfills homogene, die Dottersubstanz unmittelbar umschliessende Hülle.

Bei Lacerta agilis kommt zu dem faserigen Theil der Eischale noch ein $\mathrm{kal}$ kiger. Ueberzug, dessen soviel ich finde, RATHkE zuerst gedenkt: „zu c̈usserst (an der Schalenhaut) befand sich eine dichte Schichte von Kalk, die äusserlich und innerlich eine sehr grosse Menge kleiner Höckerchen bemerken liess." Dann erwähnt des Kalkes LEREBoulLET: „.... la couche la plus extérieur se charge d'une certaine quantité de molécules calcaires; mais celles-ci ne sont jamais assez nombreuses pour donner is l'enveloppe la consistance d'une veritable coque." Letzteres möchte ich dahin verbessern, dass sich allerdings ein vollstïndiger kalkiger Ueberzug bildet; die Talktäfelchen, aus denen er sich zusammensetzt, schliessen wie unregelmässige Pflastersteine an einander.

Betrachtet man ferner ein grösseres Stück der Kalkschichte von aussen, im unverletzten Zustande, so macht sich schon für die Lupe auf der Oberfläche eine ahnliche grubige und netzförmige Zeichnung von Höhen und Thälerzügen bemerklich, wie eine gleiche an der Innenfläche des Uterus besteht; und hegreiflich ist dieses Aussehen der Schale der Abdruck der den Kalk absondernden Schleimhantfliche.

Hinsichtlich der Lacerta vivipara ist hervorzuheben, dass, wie ich bestimmt sehe, bei dieser Art die an sich schon dünnere Eischale auch des Kalküherzuges ermangelt.

Hoden und Samengang.

Die Hoden sind von länglich rundlicher Gestalt; der von rechts liegt etwas weiter nach vorne in der Bauchhöhle als jener der linken Seite. Das Organ besteht aus den vielfach gewundenen und sich theilenden Samencaülchen; es schien mir als ob, verglichen mit den Süngern, die schlingenförmigeu Windungen sich weniger dicht folgten, so dilss die Canäle ofters einen mehr gestreckten Verlauf amnehmen; 


\section{9}

sie sind verknüpft durch Bindegewebe, in welchem die Blutgefässe und Nerven ihren Weg gehen.

Ausserdem enthalt aber dieses Bindegewebe, wie ich wenigstens an Lacerta agilis früher und jetzt wieder beobachte, eine zellenartige Masse, welche ich noch früher vom Hoden der Säugethiere ${ }^{1}$ ) nachwies: reichliche Zellenhanfen nämlich breiten sich zwischen den Samencanälchen aus und fühıren einen aus scharf' conturirten gelbbraunen Körnchen bestehenden Inhalt. ${ }^{2}$ ) In Kalilauge entfärben sich die Kügelchen und sehen dann wie Fettpünctchen aus.

Die Tunica albuginea enthält nach EBERTH ${ }^{3}$ ) eine stark entwickelte glatte Musculatur. - Im Frühjahr erscheinen die Hoden geschwollen und von einem Gefüssnetz übersponnen, das sich von der um diese Zeit lebhaft gelblichen Farbe des Hodens schön abhebt. - Von den Samenelementen der Lacertı agilis hat vièlleicht R. Whaner die erste Abbildung gegeben. ${ }^{\text {a }}$ ) Ich habe die Zoospermien von derselben Art angesehen, wo sie einen cylindrischen, gekrümmten uìd verjüngt zulaufendeu Körper zeigen, der in einen sehr langen Schwanzfaden ausläuft. Sie haben die meiste Verwandtschaft mit jenen der Vögel.

Auch beim Männchen erhalten sich Reste der ursprünglich beiden Geschlechtern gemeinsamen Anlage des Harn- und Geschlechtssystems.

An :usseren Rand des Hoden, zwischen ihm und dem Nebenhoden, liegt derselbe lingliche goldgelbe Körper, ${ }^{5}$ ) der ans gewundenen, stark fetthaltigen Canälchen besteht; er ist die am frühesten verödete und der fettigen Metamorphose verfallene Partie des Wolff'schen Körpers.

Dann ist zweitens noch der Rest ${ }^{6}$ ) eines weiblichen 'Theiles, des Müller'schen Ganges, vorhanden. Man bemerkt nemlich mit freiem Auge, wie von dem vorderen

1) v. la Vallette S'r. George in seiner Arbeit ïber den Hoden schreibt die erste Beobachtung dieser zelligen Masse um die Sameneanälchen irrthümlich KöLríer zu, was sich daraus erklärt, dass er nur meine Angaben in dem Lehrbuch der Histologie, 1857, berücksichtigt. Allein ich habe die Zellen in m. Autsatze über d. mïnnlichen Geschlechtsorg. d. Säugethiere, Zeitschr. f. wiss. Zool. Bd. II, 1850, zuerst besprochen. KöLliker's Bemerkungen sind aus dem Jahre, 1854.

") Histologie S. 495. Zeitschrift f. wiss. Zoologie, Bd. II.

3) Zur Kenntniss der Verbreitung glatter Muskeln, Zeitschr. f. wiss. Zool. Bd. XII

1) In den Fragmenten zur Physiologie d. Zeıgung. Doch ist der Körper zu dick und der Schwazfaden zu kurz gehalten. In dieser Abhandlung WAGNer's sind auch bereits, wie ich nachträglich finde, die eigentluinlichen Zellen des Hodens exwähnt, von welchen vorhin die Rede war. Es kamen, sagt er, einzelne, ganz goldgelbe, sehr dunkelkörnige Körper vor, die auch zuweilen haufenförmig verbunden seien und die man um ersten den gelben Fett- oder Oelbälgen in der Iris der Ohreulen vergleichen möchte. Ueber die eigentliche Lage dieser Zellen ist aber WAGser im Irrthum, wenn er sie zwischen die Samen erzeugenden Zellen, also ins Innere der Hodencanälchen verlegt, während sie in Wirklichkeit 2 wischen den Hodencanälchen sich binziehen.

$\left.{ }^{5}\right)$ Zehnte Tafel, Fg. 124, e.

$\left.{ }^{6}\right) \mathrm{Fg} .124, \mathrm{~g}$. 
spitzen Ende des Nebenhoden ein grauer Faden, ziemlich weit nach vorne geht und zwar am Rande des Gekröses hin. Mikroskopisch untersucht besteht er aus Bindegewebe, welches stellenweise ziemlich durchbrochen erscheint, Blutgefässe und etwas Pigment enthält; am eigentlichen Rande zieht ein Längsstrang glatter Muskeln hin. Das ganze wird selbstverständlich vom zarten Epithel der Bauchhöhle überdeckt. Am oberen Ende des Fadens liegt der fragliche Rest, genau dort, wo die Grenze des schwarzen Bauchfells ist. Fürs blosse Auge ein punctförmiger Körper erscheint er unter dem Mikroskop, nach Aufhellung des Banchfells durch Essigsäure, entweder als Knüuel eines derbwandigen, von Epithel ansgekleideten Canales, oder, wie alle rudimentüren Organe gerne individuelle Verschiedenheiten zeigen, es kann nur noch das blinde Ende eines unten spitz zulaufenden Canals zugegen sein. Selbst in einem und demselben 'Thier bietet dieser Rest von rechts und links Verschiedenheiten dar. Bei einer einjährigen Lacerta agilis sah ich den Canal sich noch eine ziemliche Strecke nach unten fortsetzen, ehe er verkümmernd mit spitzem Ende auslief.

Aus dem Hoden führen nahe der Mitte des etwas eingebogenen äusseren Randes, doch mehr dem oberen Ende zn, Quercanïle herüber zum Nebenhoden. Man zählt vier oder fünf, welche so nahe beisammen liegen, dass sie fürs freie Auge den Eindruck eines einzigen Streifen machen.

Der Nebenhoden hat Anfangs April eine graue Farbe, weil seine Canäle noch ohne Samen sind; später, wenn letztere damit gefüllt werden, erscheint er weiss und geschwollen. An seinen vielfach gewundenen Canälchen, welche schon fürs freie Auge sichtbar sind, habe ich vor langer Zeit Haschenartige Erweiterungen beobachtet; ${ }^{1}$ ) ebenso sah ich die Epithelzellen der Canäle flimmern. Gleichwie der Wolff"sche Körper nach der Grösse der Lichtung zweierlei Canäle besitzt, so erhält sich diess auch im Nebenhoden erwachsener Thiere. Man kann sich hievon schön und sicher dadurch überzeugen, dass man an Thieren, die eben ihre Winterverstecke verlassen und daher noch leere Nebenhoden haben, die Theile in Weingeist erhärtet und Längsschnitte macht. Da zeigt sich, dass im oberen freien Ende oder Kopf des Nebenhoden, neben den weiten Canälen, namentlich gegen den Umfing zu, so enge Camäle sich schlängeln, dass ihr Durchmesser nur den dritten Theil der Lichtung der andem aufzeigt. ${ }^{2}$ ) Uebrigens glaube ich bemerkt zu haben, sowohl am Wolfl"schen Körper als am Nebenhoden, dass nicht sowohl wirklich zweierlei c'analle

') Anat. histol. Untersuchungen üb. d. Fische w. Reptil. S. 87, od. Hist. S. 495, Fg. 241.

$\left.{ }^{2}\right)$ Zehnte 'Tafel, Fg. $128 \underline{2}$. 


\section{1}

vorhanden sind, sondern die engen und weiten Gänge als verschiedene Abschnitte eines und desselben Canales zusammengehören. In der dicken Wand der Canäle des Nebenhoden sind bereits glatte Muskeln zugegen, welche sich dann über den Samengang fort erstrecken. Auch die Umhüllung des ganzen Nebenhoden besitzt die gleichen Elemente.

Die Fortsetzung des Nebenhoden oder der Samengang bildet bis an sein Ende kurze, dicht zusammengeschobene Windungen, und mündet zuletzt auf der paarigen Papille in die Kloake aus. Wie das letztere geschieht, erfährt man dadurch, dass wir den Samengang sammt Papille ausschneiden und etwa mit Kalilauge aufhellen. Man sieht alsdamn, dass das Vas deferens, nachdem es sich mit dem Harnleiter verbunden, an seinem Ende innerhalb der Papille sich zu einer kleinen Blase erweitert, die bei frischen brünstigen Thieren wegen des Sameninhaltes sich lebhaft weiss abhebt. Die Oeffnung auf der Papille ist klein und rund.

Bereits Martin SaInT-ANGE ${ }^{1}$ ) hàt richtig erkannt und es schön und rein dargestellt, dass Harn- und Samenleiter unten zusammenfliessen, und mit Einer Oeffnung iuf der entsprechenden Papille münden. LEREBOULLET hingegen zeichnet auf der Papille zwei Oeffnungen, wie wenn Harn- und Samenleiter getrennt blieben und sagt sogar noch ansdrücklich, dass die unteren den Harnleitern, die oberen den Samenleitern angehören. ${ }^{2}$ )

Der Körper der Papille, obschon er in die Kloake vorragt, liegt doch eigentlich hinter der Wand der Kloake. Er besteht der Hauptmasse nach ans glatten Muskeln und Nerven; wie demu die ganze Stelle der Schleimhaut der Kloake, wo die Papillen sich erheben, nach Aufhellung sich üusserst reich mit Nerven versehen zeigt, wobei in die Endgeflechte auch Ganglienkugeln sich einlagern.

Hinter den Papillen folgt in der Kloake eine Drüse, welche man der Prostata vergleichen darf. Der einzelne Drüsenkörper erscheint beim Auseinanderlegen wie ein hornartig gekrummter Wulst, und beide Drüsen sind mit dem convexen Rand gegen einander gekehrt. Die Farbe ist in frischen Zustande grau, später wird sie weisslich. Bei zurückgezogenem Penis umgreift jede der Drüsen durch ihre Kirümmung eine Oeffnung, aus welcher die Rnthe sich hervorstülpt. Die Schleimhaut, welche die Drüsen deckt, hat zahlreiche und starke Nerven.

Es findet sich aber auch noch eine zweite Drüse. Während die erste nicht blos viel grösser ist, sondern anch der Rückenwand der Kloake angehört, ist diese

1) a. a. O. Pl. IX.

3) Auf den Figuren zeigt sich aber ein Schwanken. Denn auf Fg. 81 (Taf. 7) sind die Papillen mit je zwei Ueffinungen versehen, wïhrend auf Fg. 105 (Taf. 16) denselben Gebilden nur eine grössere Veffnung gegeben ist. 
zweite kleiner, von Gestalt schmal bandförmig und liegt, einen Bogen bildend, in der Bauchwand der Kloake, innerhalb des Sammes, welcher die Oeffnung der KKloake begrenzt. Von Farbe ist sie in frischem Zustande weiss.

Wie diese beiden Drüsen schon fürs freie Auge in Grösse, Gestalt und Farbe sich verschieden zeigen, so anch bei mikroskopischer Betrachtung. Die Drüsenschlüuche der ersteren, obschon ebenfalls mit zahlreichen Scheidewänden im Innern, wodurch sie wie aus länglich gruppirten Follikeln zu bestehen scheinen, sehen doch geschlossener ans; auch ist der Inhalt der Epithelzellen ein mehr heller, und daher die graue Farbe im Ganzen. Die Drüsenelemente hingegen der zweiten sind wirklich mehr von tranbiger Anordnung, auch durch Bindegewebe entschiedener von einander abgesetzt, gervissermassen selbstständiger; der Inhalt der Epithelzellen ist ein dem Dunkelkörnigen sich nähernder, wesswegen die Drüse weiss fürs freie Auge erseheint.

Mran hat somit auch von dieser Seite her eine gewisse Berechtigung die grosse Drüse einer Prostata zu vergleichen und die kleinere einer Art Talgdrüse.

Dass beim Weibchen dieselben Drüsen in der Kloake vorkommen, nur weniger entwickelt, ergibt sich aus dem, was oben darüber gesagt wurde.

Die Gegenwart dieser Drüsen scheint MlARTIN SAINT-ANGE gar nicht bemerkt zu haben, wenigstens finde ich keine hieranf bezügliche Augabe. LEREBoulLet kennt und beschreibt sie wach seiner Art, unter dem Namen Glandes vestibuliemnes näher.

Ruthen.

Die Begattungsorgane sind bekanntlich doppelt und liegen ausserhalb der Thätigkeit zurückgerollt unter der Haut der Schwinzwurzel. Beim Männchen ist daher diese Gegend merklich anders geformt als beim Weibchen, und kamn, was unten im systematischen Abschnitt geschieht, zur Erkennung und Bestimmung der Geschlechter wesentlich beitragen; wie dies von Anatomen schon hin und wieder hervorgehoben wurde, von den reinen Systematikern aber, wie es scheint, noch kaum benützt worden ist.

Diese Lagerung der Ruthen unter der Hant ist im Hinblick anf die Lintwickelung der Organe ein späterer Zustaud. Denn an frühen Embryen der Eidechsen sehe ich, wie RatHke solches von der Ringehnatter gezeichnet hat, die heiden Rnthen als vorstehende rundliche Warzen mit eingeschnürter Basis.

Will man sich eine Kenntmiss ihres Baues verschaffen, so empfichlt sich, sie zunïchst im ausgestülpten Zustande zu untersuchen, und spaiter erst bei ihrem umgekehrten Verlalten. Beginnt man damit Querschnitte ron den eingezogenen Theilen zu machen, so wird man vicl linger brauchen sich zurecht zu finden, als wenu mau die andere Präparationsweise hat vorausgehen lassen. MAR'TiN SAINT-ANgE sagt über den Bau de"

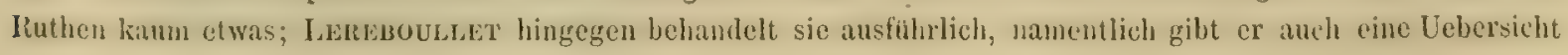


der verschiedenen, beim Ein- und Ausrollen des Organs, in Betracht kommenden Muskeln, welche ich nicht näher studirt habe. Andrerseits glaube ich, dass meine Mittheilungen eine genauere Vorstellung vom Bau dieser Organe zu gewähren vermögen, als diess bisher geschehen konnte.

Jede der ausgestülpten Ruthen ${ }^{1}$ ) stellt einen walzigen Körper dar, dessen’ freies Ende oder Eichel in zwei stumpfe Spitzen ausgeht; die Furche zwischen ihnen zieht an der inneren Seite der liuthe eine Strecke weit abwärts bis zu einem länglich runden Wulst. An der nach aussen gevendeten Fläche verläuft ferner eine Rinne mit lippigen Rändern von der Wurzel der Rühe im schrägen Bogen, wie spiralig herauf bis dahin, wo die Gabelung der Eichel beginnt; es ist bekanntlich der Weg zum AbHuss des Sameus. Da wo diese Rinne beginnt, wird sie nur gegen den Penis hin gleich von einem Hantsaum oder Lippe begrenzt, während die gegenüberstehende Begrenzung anfänglich keine eigene Haut ist, sondern von dem Rande der Prostata gebildet wird, und erst wenn die Drüse mit gekrümmtem Ende aufhört, beginnt der andere Lippensaum.

Die hervorgerollten Begattungsorgane haben im frischen Zustande eine grauröthliche Farbe, besonders roth aber zeigen sich die Lippen der Samenrinne, und der erwähnte Wulst, welcher an der Wurzel des Penis, nach einwärts zu, sich abhebt.

Bei vielen Individuen, nicht bei allen, bemerkt man nach dem Auseinanderlegen der Lippenrinder einen schwarzen Pigmentfleck am Anfang der Samenrinne, genauer an den beiden Enden der weissen accessorischen bogenförmigen oder T'algdrüse; in dieser Stelle quillt das Secret der Prostata hervor. Noch sieht man auch am frischen Copnlationsorgan die Oberfläche von scharf hervortretenden Querlinien überzogen.

Hat Weingeist auf die erigint gewesene Ruthe eingewirkt, so bekommt sie das Aussehien wie es in Fig. 126 dargestellt wurde. Man könnte jetzt an dem Organ einen kurzen Stiel und den eigentlichen Ruthenkörper unterscheiden; am freien Ende elzeugt die zurückgezogene Eichel eine eigene wulstförmige Figur, nmgeben von den zwei zipfelartigen, wie Kilappen sich herüberlegenden, Rändern der Samenrinue.

Wenden wir die Aufmerksamkeit auf den feineren Bau, so verdienen unsere Beachtung besonders das Epithel und die Schwellkörper.

Ich habe schon in meiner Histologie ${ }^{2}$ ) auf dieses merkwürdige Epithel, welches als abgezogenes Häntchen ein weissliches Aussehen hat, hingewiesen: es gehe jede Zelle an der freien Seite in eine abgesetzte knopfö̈rmige Verdickung ülser,

1) Vergl. Zehnte 'lafel, F'g. 125 u. Fg. 126.

2) S. 505, Fg. 246. Auch Lenenoulcet gedenkt bereits vor mir, wenu auch nicht nach den Einzelheiten, dieses ¿Epithelium hérissé d'épines*. 
welche selbst wieder eine Anzahl kleiner Höckerchen habe; die Ľnöpfe seien schärfer conturirt als die Zellen und hielten sich in Kalilange. Meine neueren Untersuchungen setzen mich in den Stand über die Form und das Vorkommen dieses Epithels - ich will es kurzweg stachliges nennen - noch einige Mittheilungen zu machen.

Die Stachelzellen überkleiden nur die Eichel, weiter nach abwärts verlieren sich nicht nur die Knöpfchen, sondern auch die Spitzen stumpfen sich ab, und es breitet sich ein gewöhnliches Epithel aus; anch auf dem oben erwähnten Wulst an der Wurzel des Organs bleibt es von dieser Art; ebenso ist das Epithel der Samenrinne nach ihrem ganzen Umfange ein gewöhnliches stachelloses. Meine Abbildung von früher stellt die Stachelzellen von $L$. agilis nach ihrer höchsten Entwicklung dar und zwar genommen von der Spitze der Eichel. Bei jüngeren Individuen und entfernter vom Ende der Eichel gehen die Zellen in nur einfache, kürzere oder lïngere, Stacheln aus, ohne dass sich die Spitze noch mit dem höckerigen Knopf krönt.

Was mir anch erwähnenswerth vorkommt, besonders in systematischer Hinsicht ist die Beobachtung, dass das freie Ende der Stacheln nach den Species bestimmte Verschiedenheiten darzubieten scheint. Der Form bei $L$. agilis wurde bereits gedacht; bei $L$. vivipara ${ }^{1}$ ) ist der Stachel mehrfach spitzig, wie gezähnt; dies jedoch wieder nur auf der Höhe der Ringfalten der Eichel; nach abwärts in die Thäler zwischen den Erhabenheiten verlieren sich zuerst die Endzähnchen, dann der Stachel selbst, und in der Tiefe der Falten sind diese Cuticularbildungen ganz geschwunden. Leider waren die Exemplare von $L$. viridis und $L$. muralis, welche ich mit Rücksicht auf diese Frage untersuchte, zufällig nicht geeignet klare Bilder zu geben, so dass ich einstweilen nicht sagen kann, ob anch hier die Speciesverschiedenheit am Epithel der Eichel sich ausprăgt.

Gleichwie die Epidermis der übrigen Körperoberfläche bei der Häutung auf einmal im Zusammenhang abgeworfen wird, so geschieht dies in ähnlicher Weise mit dem Oberhüutchen der Ruthen. Man bemerkt, dass zu diesem Behuf das Thier ungefähr die Stellung annimmt wie zur Kothentleerung, wobei die. Ruthen etwas aus der Kloake hervortreten. Es setzt aber nicht den Kothballen ab, sondern zwei weissgraue, weiche Massen von etwa birnförmiger Gestalt; mikroskopisch untersucht erweisen sie sich als das so eigenartige Epithel der Ruthen.

Das cavernöse Gewebe konnte ich mir früher nicht recht zur Ansicht bringen, wie denn auch Martin SAint-ANGE und Lerebodlitet übereinstimmend melden, dass von einem erectilen Gewebe eigentlich nichts dir sei. Diese Ansicht ist irrig: das Gewebe ist nicht nur vorhanden, sondern ich bin jetzt auch im Stande, darüber năhere Auskunft zu geben.

i) Zehnte Tafel, Fg. 1272 . 
Vor Allem sei bemerkt, dass das Schwellgewebe in seinem Bau grosse Aehnlichkeit mit dem Hahnenkamm, wie ich denselben früher beschrieben ${ }^{1}$ ) aufzeigt. Man sieht nemlich zahlreiche Bluträume") als Lücken in der Sulsstanz eines festen Bindegewebes; entweder als reine Lücken oder da und dort mit sicherer Umgrenzung, und man darf im Hinblick auf den Hahnenkamm annehmen, dass dies gerade solche Stellen sind, welche den zum Corpus cavernosum herantretenden Gefässstämmen zunächst liegen. Die scharfe Abgrenzmng ist die Linie der auskleidenden Tunica intima. ${ }^{3}$ )

Die Bluträume können sich in gefïlltem Zustande auch wohl als ein Capillarnetz von weitem Caliber darstellen, besonders wemn wir die Endzipfel der Samenrinne unter das Mikrosk bringen. Das Bild z. B. von Lacerta agilis ist so, dass unterhalb dem stachellosen Epithel das feste Bindegewebe folgt, am Saum mit etwas schwarzem Pigment versehen, und durchsetzt von engmaschigen Capillargängen.

Dazu kann aber noch eine beachtenswerthe Structur kommen. Gewisse Partien des Schwellkörpers - es wird nachher der Ort näher bezeichnet werden sind in ihrem Bindegewebe nach der Länge durchzogen von walzigen, verschiedenen dicken Strïngen, welche um vieles fester als das übrige Bindegewebe, ja hart sind, und auf dem Querschnitt rein homogen sich ausnehmen. ${ }^{4}$ ) Diese Stränge oder Balken haben offenbar bei der Füllung der Blutrüume als Stützapparat zu dienen.

Endlich gibt es noch ein System von Hohlräumen, von welchen mir nicht klar wurde, ob sie sich ebenfalls mit Bhut füllen können, oder nur zur Aufnahme lymphatischer Flüssigkeiten bestimmt sind, was mir wahrscheinlicher ist, da ich niemals Blut in ihnen angetroffen. Die Hohlräume sind um vieles grösser als die Lacunen fürs Blut und erscheinen durchsetzt von weichen bindegewebigen Balken; auf Querschnitten erscheinen sie immer leer.

Ausser dem Epithel und dem Schwellkörper bildet einen mächtigen Bestandtheil der Copulationsorgane eine Anzahl quergestreifter Muskeln. Auch Nerven fehlen selbstverstündlich nicht und ich sehe z. B. einen, welcher unterhalb der Samenrinne bis zur Eichel aufsteigt um dort zu enden. ${ }^{5}$ )

Nachdem wir uns diese Kenntniss über den Ban des Organes erworben haben, wird es gelingen Querschnitte der eigentlichen Ruthe zu deuten. Der nach Spaltung

\footnotetext{
I) Histologie S. 81 u. S. 82.

$\left.{ }^{2}\right)$ Zehnte Tafel, Fg. 128ㅁ, a.

3) $\mathrm{Fg} .128 \stackrel{1}{\mathrm{~b}} \mathrm{~b}$.

4) Fg. $128 \underline{\text {, c. }}$.

5) $\mathrm{Fg} .127 \mathrm{i}, \mathrm{d}$.

Leydig, Saurier.
} 
der Hant herausgeschälte Penis hat (L. vivipara) eine spindelförmige Gestalt, indem er sowohl nach vorne als nach hinten sich stark verjüngt. Aeusserlich macht sich an der Verdickung eine Längsfurche bemerklich, welche wohl Bezug hat zur Gabelung der Eichel. Querschnitte belehren, dass das mehrere Linien lange verjüngte Ende lediglich aus quergestreifter Längsmusculatur besteht, mit bindegewebiger Abgrenzung nach aussen. Die Muskeln mögen besonders die Umstülpung des Organs besorgen, und erstrecken sich als schalige Umhüllung weiter nach vorne; auch nachdem der Dickendurchmesser der Ruthe sich vergrössert hat. Haben die Querschnitte die Stelle erreicht, wo äusserlich die Längsfurche beginnt, so ändert sich das Bild wesentlich. Ein guter Theil ist noch reine Muskelmasse in paariger Anordnung; in der anderen Hälfte des Schnittes aber ist ein paariger Hohlraum aufgetreten mit welligen Rändern. Die Wand des Hohlraumes geht gegen die Muskelmasse hin in ein Corpus cavernosum aus, mit zahlreichen Bluträumen und den hellen festen Stützbalken im Bindegewebe. Der Hohlraum bezeichnet die Gegend der eiugestülpten Eichel; bei der gabeligen Form der Eichel in ausgestülptem Zustande können Querschnitte des eingestülpten Organs mitunter das Ansehen geben, als ob der Penis innerlich aberınals in zwei Hälften zerfalle, wie im Ganzen die Ruthe paarig ist.

Die beste Uebersicht gewähren Schnitte, etwa aus der Mitte des Organes. ${ }^{1}$ ) Hier sieht man zunächst eine äussere bindegervebige feste Umgrenzung; von ihr umschlossen ist die Längsmusculatur, welche auf vier, weit aus einander gerückte aber im Ebenmaass stehende, Bündel sich vertheilt hat. Es zeigt sich jetzt auch das Corpus cavernosum von grosser Ausdehnung und zwar so, dass ein zweihörniger Theil zwischen den zwei Lichtungen der Eichel steht, und ihm gegenüber ein anderer die Wand der Samenrinne bildender Abschnitt, welche letztere durch die jeweilige Verschiebung der Lippenränder in verschiedener Form gesehen werden kann. Wenn man die Vertheilung des Corpus cavernosum auf diesem und anderen Schnitten zusammenstellt, so lässt sich sagen, dass vergleichbar den Verhältnissen bei Süugern, ein Schwellkörper der Ruthe und der Samenrinne, dort Harnröhre, zugegen sei. In dem Bindegewebe zwischen den Schwellkörpern, den Hohlräumen der Eichel und den Muskeln sieht man noch die Durchschnitte von Nerven, Arterien und Venen.

Bei Lacerta viridis schien es mir, als ob die Schwellkörper der Samenrinne gewissermassen in mehrere Schichten zertheilt wären, welche durch ein lockeres Balkenwerk, desseu liüume ich nie mit Blut erfüllt sah, sich wieder verbanden. Gibt es etwa Vorrichtungen durch welche bei dem Organ, wenn es in Thätigkeit

1) Zehnte Tafel, Fg. 1281. 
tritt, auch diese vorhin als Lymphräume gedeuteten Höhlungen sich zu füllen vermögen?

Auch die weiblichen Eidechsen besitzen verkümmerte Copulationsorgane, an gleicher Stelle und ebenfalls paarig. Ich sah sie z. B. auf dem Durchschnitt der Schwanzwurzel einer weiblichen $L$. viridis sehr deutlich, ohne sie weiter zu untersuchen; nur muss die Eichel wie beim Nännchen gegabelt sein, denn hier im Querschnitt und im eingestülpten Zustande nahm sich die einzelne Clitoris so aus, wie weǹn sie aus zwei Röhren bestünde.

Eine gewisse Beziehung zur Geschlechtsthätigkeit, sich durch Vor- und Zurückbildung änssernd, haben zwei Fettmassen, welche bei der Eröffunng der Leibeshöhle in der Gegend des Beckens zum Vorschein kommen. Aehnlich wie die Fische vor dem Eintritt der Laichzeit am fettesten sind und nachher abmagern, so sind diese Fettkörper der Eidechse im Frühling bei beiden Geschlechtern am grössten, von Farbe grauweiss oder gelb, und da sie eigentlich ausserhalb des Bauchfelles liegen, so werden sie nur nach einer Seite hin von dieser schwarzen Haut überzogen. Ende Juni sind sie zurückgegangen, aber eben desshalb jetzt leichter zu untersuchen. Fürs freie Auge dümne weiche grauröthliche Lappen darstellend, erscheinen sie mikroskopisch als ein sehr gefïssreiches Bindegewebe von zelligem ('harakter, welches Blutgefüssen aufsitzt. Man unterscheidet deutlich eine Arterie, die ins Läppchen hinein, und eine grössere Vene welche herausführt; dazwischen liegt ein abgeschlossenes capillares Netz. Sind die Zellen des Bindegewebes mit Fett gefüllt, so sitzen sie, Fettträubchen vergleichbar und ron Capillaren umsponnen, den Blutgefüssen auf. Es unterliegt wohl keinem Zweifel, dass diese Fettmassen am Eingange desं Beckens. bei Eidechsen jenen band- oder fingerförmigen Fettlappen entsprechen, welche bei Salnmandrinen, Fröschen und Firöten weiter vorne in der Leibeshöhle, zunächst den Hoden oder Ovarien, sitzen.

Nachdem die verschiedenen Organe, welche in die Kloake münden oder in ihr liegen, beschrieben wurden, soll nochmals dieser Bildung selber mit einigen Worten gedacht werdeu.

Schon oben (S. 120) wứde bemerkt, dass man die Kloake nicht eigentlich als Endabschmitt des Darmes deuten könne, sondern dass sie eine gewisse Selbststinndigkeit habe. Vielleicht richtiger noch liesse sich mit MarTin SAINT-ANGE sagen, dass die Kloake den Harn- und Geschlechtsorganen angehört. Anch kann man füglich, 


\section{8}

wie diess ausser dem Genannten auch LEREBOdLLET thut, einen vorderen und hinteren Abschnitt unterscheiden. Wie bereits erörtert wurde, so mündet am meisten nach oben und vorn der After ein; aber nicht mit vorspringender Papille, sondern diese ist umgekehrt in die Lichtung des Mastdarms einwärts gerichtet. ${ }^{1}$ ) Dann folgen beim Männchen die Urogenitalpapillen; beim Weibchen die Mündungen des Uterus, zugleich mit den Harnpapillen, welche noch innerhalb der Oeffnungen des Uterus liegen. Gegenüber von den Harn-Geschlechtsöffnungen entspringt von der vorderen Wand der Kloake die langgestielte Harnblase. Zunächst der Mündung der Kloake finden sich die Drüsen, die grössere oder Prostata an der hinteren Wand, die kleinere oder Talgdrüse im vorderen Saum.

Die Gesammtöffnung der Kloake, von Ringmuskeln umgeben, ist bei eingezogenen Copulationsorganen rund, und es ist nicht ganz genau, wenn man in herkömmlicher Weise als Merkmal der Eidechsen aufführt: "After oder Kiloake eine Querspalte." Kосн ${ }^{2}$ ) scheint der einzige zu sein, der sich die Theile ebenfalls ansah und den Widerspruch fühlend, der zwischen der gebräuchlichen Angabe und der wirklichen Bildung herrscht, richtiger sich so fasst: "der After ist unter einem etwas breiten Querschild verborgen." Die rundliche Oeffnung der Kloake zieht sich auch wohl, was man an frischen eben getödteten Thieren leicht sehen kann, in eine länglich runde Spalte aus. Jedenfalls ist klar, dass die Anwesenheit der beiden Begattungsorgane, die zur Seite der Afteröffnung aus der Kiloake sich hervorrollen, den grossen breiten Sclild bedingen, ferner die Kloakenöffinung sehr ausweiten und in die Breite ziehen. Die Crocodile, welchen nicht zwei sondern nur eine Ruthe zukommt, haben bekanntlich auch keine Quer- sondern eine Längsspalte.

An der Kloake der L. ocellata, eines grossen männlichen Thieres aus Südfrankreich, stiess mir eine in histologischer Beziehung merkwürdige Thatsache auf, nemlich die Anwesenheit von verhorntem oder chitinisirtem Bindegewebe.

Die hintere Lippe der Kloake bot ein gewisses dunkles Aussehen dar, nicht etwa durch eingelagertes Pigment, sondern bedingt von einer hornig durehschimmernden Substanz. Die mikroskopische Untersuchung belehrte, dass um die hintere Lippe der Kloake herum eine Art von Cavernensystem zieht, dessen bindegewebiges Balkenwerk in seiner gegen die Epidermis gekehrten Partie, also in der Lederhaut, von besonderer Härte und hornbrauner Farbe sei. Wie mit dem freien Auge, so auch unter dem Mikroskop sieht man, dass die Verhornung oder Chitinisirung des Bindegewebes nur in bestimmter Ausdehnung sich verbreitet. Die stärksten und lärtesten, daher tiefbraunen Bündel ziehen kreisförmig und dienen offenbar zur Gegenwirkung, wenn bei der geschlechtlichen Erregung die Theile sich ausdehnen. An der vorderen Kloakenlippe war das Bindegewebe nicht verhornt, sondern von gewöhnlicher grauer Farbe und herkömmlicher Consisfenz. Noch mag bemerkt sein,

1) Vergl. Zehnte 'Tafel, Fg. 124; Fg. 129.

$\left.{ }^{2}\right)$ In Sтовн's Fauna Deutschlands 5, u. 6. Heft 1828, S. 6. 
dass das Thier olme Zweifel ausserhalb der Brunstzeit getöltet worden war; denn die Hoden waren itusserst klein und das Secret der Schenkelporen stand nicht kammförmig vor.

Dieser Fall von verhornter oder chitinisirter Bindesubstanz reiht sich an das an, was ich über die „Hornfäden“ in den Flossen der Fische und ähnlich erhärteter Züge aus der Lederhaut der Pachydermen bekannt gemacht habe. ${ }^{1}$ )

\section{Blindschleiche.}

Weibliche Organe.

Nach der vorausgegangenen, die Fortpflanzungsorgane der Eidechsen im Einzelnen behandelnden Darlegung wird es genügen bei der Blindschleiche nur auf gewisse Puncte năheren Bezug zu nehmen.

Die Eierstöcke, abermals länger als bei den Eidechsen, stehen sich so wenig in gleicher Höhe gegenüber, dass, wenn mit reifen Eiern gefüllt, das untere Ende des einen, dem oberen Ende des anderen gegenüber liegt. Es liesse sich denken, dass auf solche Weise die Anschwellung der beiden Organe nach der Länge des Leibes vertheilt werden soll.

Im Bau des Eierstockes, welcher auch mehr oder weniger von Pigment umsponnen sein kann, herrschen dieselben Verhältnisse, wie bei Lacerta; insbesondere sind ebenfalls die weiten Lymphrüume zugegen. Die Eier zeigen die einer Zona pellucida vergleichbare, dann noch weiche, von radiären Strichen durchsetzte Haut.

Recht bemerkenswerth ist mir geworden, dass hier noch stärkere Reste des Wolff'schen Körpers²) erhalten bleiben als bei der Eidechse. Zunächst ist der goldgelbe Streifen am Innenrande des Eierstocks bei manchen Individuen so lang, dass er über dieses Organ nach unten hinausgeht, und selbst noch weiter abwărts ein inselförmiges Stück entwickelt. Diese gelbe Partie lässt deutlich wieder eine Zusammensetzung aus gewundenen Canälen, mit fettigem Inhalte, erkennen. Dann ist aber zweitens auch das Homologon des Nebeneierstockes zugegen in Form eines langen graugelblichen Streifens, nach anssen von dem so eben erwähnten goldgelben Reste. Die mikroskopische Untersuchung ergab, dass man es mit einem Canal zu thun habe, an dem noch in der Gegend seines oberen Endes, welches so ziemlich auf gleicher Höhe mit dem oberen Ende des goldgelben Körpers stand,

1) Vom Bau des thierischen Körpers S. 48.

2) Neunte Tafel, Fg. $112 \underline{1}, \mathrm{Fg} .112 \underline{2}$. 
Reste von gewundenen Canälen sitzen, ja selbst noch mit dentlichen Malpighischen Gefässknäueln; sein oberstes Ende war zu einer runden Cyste erweitert. Das untere Ende des Ganges habe ich nicht gesehen, obschon ich ihn weit nach hinten verfolgen konnte; was nicht schwer ist, da er sich schon seiner epithelialen Auskleidungen wegen von den Blutgefässen, Arterien und Venen dieser Gegend, bestimmt unterscheidet. Walnsscheinlich tritt das untere Ende, wenn es nicht verkümmert sein sollte, in den Harnleiter. Der Canal ist dem Gartner'schen Canal der Säuger zu vergleichen. Ich bemerke ausdrücklich, dass die Blindschleiche, nach welcher diese Beschreibung genommen ist, kein junges Thier war, sondern ein ganz ausgewachsenes, welches, schon längere Zeit in Gefangenschaft, im Spätsommer eine Anzahl Junge geboren hatte und im darauffolgenden Mårz zergliedert wurde.

Die Eiergänge scheiden sich auch hier deutlich in Trichter, Eileiter und Fruchthälter. Der Trichter, auf halber Leibeshöhe an die Rückenseite der Bauchhöhle geheftet, öffnet sich mit einem sehr weit geschlitzten Spalt. ${ }^{1}$ )

Am trächtigen Uterus, in dessen mit glatten Muskelzügen versehenem Gekröse man zahlreiche quer und schräge herübergehende Arterien und Venen unterscheidet, besteht die Wand, ausser dem serösen Ueberzug, aus einer Muskelhaut, deren Elemente ringförmig verlaufen, und zweitens der Schleimhant. Letztere erhebt sich in zarte Leisten zu Trägern einer capillaren Gefässentfaltung; die von den Leistehen, welche sich netzförmig verbinden, gebildeten Vertiefungen stellen kugelige Drüsensăckchen vor.

Das Gekröse für den Uterus lässt wie bei der Eidechse einen freien Rand üher den Fruchthälter hinaus entstehen und ist hier musculös verdickt. Es dient wahrscheinlich dieser Heischige Randfaden dazu dem Organ mehr Richtung und Haltung zu geben.

Da die Blindschleiche gleich der Lacerta vivipara lebendig gebärend ist, so stimmt auch die Beschaffenheit der Eischale mit jener der genannten Eidechse überein. Für das freie Auge eine durchsichtige dünne Hant, entbehrt sie unter dem Mikroskop jeder Spur von Verkalkung; sie zeigt sich lediglich zusammengesetzt aus Fasern, welche der Tracht nach geschwungenen Bindegewebsfisern ämlich sehen, gegen Reagentien aber sich wie elastische Fasern verhalten. Man unterscheidet feinere und breitere Züge, und da und dort bemerkt man wie die Enden der Fasern kolbige, hellere Anschwellungen, öfters noch von hackiger firümmung erzengen.

Alles was ich bisher über die Entstehung dieser Fasern beobachtet, spricht

1) L'g. 113. 
dafür, dass sie unter den Begriff der Cuticularabscheidungen gehören; sie sind zuerst weicher und heller als nachher und zwischen den Fasern liegen viele F'ettpünctchen. Im Näheren scheint mir die Art und Weise der Entstehung die zu sein: zuerst entwickeln die Epithelzellen einen zusammenhängenden Cuticularsaum; dann bilden sich auf diesem die Fasern wie Verdickungen, man kömnte sagen wie fadige Sculpturen, alnnlich dem Spiralfaden der Tracheen. ') Dass die Schale ein Secret der Wand des Uterus sei, wird man anch beim Abziehen vom Uterus gewahr, indem die Schale der Wand recht innig anhaftet.

In der Kloake, nahe dem Ausgang, zeigt sich ein seitlicher Wulst, der nach Aufhellung mit Reagentien aus traubig gruppirten Drüsen besteht. Es scheint als ob hier bei der weiblichen Blindschleiche der Drüseuwulst die zweierlei, bei dem männlichen Thier und den Eidechsen getrennten, Formen der Prostata zugleich vorstelle. Theilweise nämlich erimnern die Drüsen an Talgdrüsen, nicht blos durch die Anordnung der Follikel, sondern anch durch weissliches Drüsensecret; ein andermal aber ist der Inhalt nicht eigentlich fettiger Natur, sondern ziemlich hell und für's freie Auge mit kaum gelblichem Anflug.

Die den männlichen Ruthen entsprechenden Theile sind deutlich vorhanden. Jede Clitoris hat etwa 8 Millimeter Länge und ein zweispitziges Ende der Eichel, woran sich nach hinten ein mehr als doppelt so langer Muskel, Musculus retractor, ansetzt. Aufgeschnitten erscheint die Clitoris faltig mit niedrigen Papillen und den Spuren der nachher zu erwähnenden Drüsen des Mănnchen.

Männliche Organe.

Beim Männchen liegen abermals die Hoden, welche länger und walziger sind als bei den Eidechsen, in ungleicher Höhe und ihr Ueberzug besitzt gerne vorn und hinten eine Pigmentirung, mit Freilassung einer hellen mittleren Zone. - Die Zoospermien sind von der Tracht jener der Eidechsen, nur etwas feiner; anch schien mir das Kopfende etwas mehr zugespitzt.

Auch beim männlichen Geschlecht fehlen nicht Reste ${ }^{2}$ ) des Wolff'schen Körpers und des weiblichen Ganges. Zwischen dem Hoden und Nebenhoden liegt nemlich wieder als linglicher Streifen von stark gelber Farbe die fettig verödete Partie des Wolff'scheu Körpers. Dann geht zweitens vom Kiopf des Nebenhoden ein Faden aufwarts, der in so fern etwas schwierig zu untersuchen ist, als viel dunkles Pigment das Bauchfell überzieht; doch lässt sich wahrnehmen, dass in dem Faden Reste eines C'anales stecken, die einige cystenartige Erweiter'ungen bilden

1) Neunte Tafel, Fg. 115.

') F'g. 118. 
können, und deren Epithel an frischen Thieren ich deutlich wimpern sah. Man hat offenbar rückgebildete Theile des Müller'schen Ganges vor sich. Wie bei der Eidechse sind an einem und demselben Individuum die Reste von rechts und links sich keineswegs gleich.

Der Nebenhoden, dessen Canäle deutlich wimpern, ist sehr entwickelt, in die Länge gezogen und geht nach hinten in den Samenleiter aus, der dann, wie schon erörtert, in der Kloake zugleich mit dem Harnleiter auf einem Längswulst mündet.

Die beiden Ruthen, gleich denen der Eidechsen in der Schwanzwurzel hinter der Kloake untergebracht, sind verhältnissmässig kleiner (wenigstens im Monat Juli) als bei den Eidechsen. In hervorgerolltem, ausgestülpten Zustande zeigt sich deutlich, wie vou der Wurzel zur Eichel schräg die Sameminne geht; ferner dass an dem doppelköpfigen Eichelende ein Schwellkörper als blutreiche Partie durchschimmert; nicht minder macht sich etwas schwarzes Pigment in der Grube der Eichel bemerklich. Endlich sieht man nach rückwärts von der Eichel quere Streifen, welche von weicheren, weisslichen Papillen und Ringwülsten herrühren.

Bei näherer Prüfung erblickt man in dem Schwellkörper der Eichel grosse Bluträume, welche von Bindegewebsbalken durchspannt sind; auch werden in dem Eichelende Nerven sichtbar, ohne dass über die Endigungsweise etwas zu beobachten gewesen wäre.

Eine merkwürdige Beschaffenheit bieten die erwähnten Papillen dar. Jede ist eine vorstehende Drüse von einfucher Flaschen- oder Sackform. ${ }^{1}$ ) In der bindegewebigen Wand liegen zahlreiche längliche, wem auch etwas zarte Kerne, die vielleicht auf die Anwesenheit glatter Mnskeln zu deuten wären. Das Secret, wenn man es so nennen will, wird von den Zellen der gewöhnlichen Oberhaut der Eichel vorgestellt; doch sind sie nicht wie an den Schenkeldrüsen der Eidechsen von gelber, sondern von grauer Farbe. Denn den letztgenannten Organen der Eidechsen halte ich, wie schon oben bemerkt wurde, die hier gemeinten Bildungen für gleichwerthig.

Es haben diese Organe bereits früher meine Aufmerksamkeit erregt, und mich veranlasst eine Beschreibung und Abbildung davon zu veröffentlichen. ${ }^{2}$ ) Legt man

1) Fg. 120 .

2) Histologie, S. 504, Fg. 245. - Während des Druckes erhalte ich die Schrift: Ueber die Bursa Fabricii, von Garźs, Dorpat 1871, welche unter der Anleitung Prof. Streda's erschienen ist und offenbar das Organ genauer kennen lehrt, als es bisher geschehen war. Es wird gezeigt, dass die von mir zuerst nachgewiesene lymphdrüsenartige Substanz zwar der Wand der Follikel angehört, diese indessen der Hauptsache nach >kug-

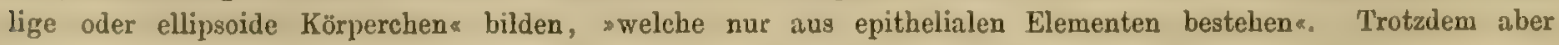
dass der anatomische Bau nun festgestellt erscheint und obschon der Verfasser alle bisherigen Deutungen sammt 
bei Thieren welche in Weingeist getödtet wurden, Querschnitte durch die Schwanzwurzel, so heben sich die Ruthen im Ganzen nicht blos deutlich als weissliche Körper von der Musculatur ab, sonderm es lassen sich schon die 1)rüsenpapillen mit der Lupe erkennen. Und nüheres Zuseheu findet auch schon jetzt, dass die Drüsen in Querreihen um den Penis stehen.

Die Prostatadrüse der Kloake ist kleiner als bei Eidechsen; doch im eingestülpten Zustande der Ruthe von ähnlich dreieckiger Gestalt. Die einzelnen Drüsenfollikel scheinen mir aber grösser zu sein als bei Lacerta agilis; sie haben lange Cylinderzellen und sind von glatten Muskelelementen umgeben und durchflochten.

Die etwas auffällige Lage der Ruthe unter der Hant der Schwanzwurzel kommt auch hier spöter zu Stande. Bei noch ungefürbten Embryen ${ }^{1}$ ) aus dem Monat Juli und mit noch grossem Dottersack, stehen die beiden Ruthen als kolbige oder pilzförmige Bildungen frei hervor und die nähere Untersuchung lehrt, dass sie durch Wucherung von der Haut und der MIusculatur des Stammes ihren Ursprung nehmen. Erst nachträglich werden sie durch die lebendig gewordene Thätigkeit der Muskeln eingestülpt.

Bei der Blindschleiche springt die After, richtiger Kloakenklappe weiter dachartig vor als bei den Eidechsen.

Zum Schlusse dieses Capitels sei noch eine Uebersicht über die Homologien der Hauptabschnitte der Fortpflanzungswerkzeuge der beiden Geschlechter gregeben.

und sonders zurückweist, muss er sich doch dahin erklären, dass es noch cine offene Frigge sei, welche physiologische Bedeutung die Bursa Fabricii habe. Ich meine, dass durch die Thatsachen, welche ich über die drüsigen Papillen an der Ruthe der Blindschleiche dargelegt, eine Verknüpfung und damit der Anfang einer Erklärung sich ermöglicht. Denn es liegt auf der Hand, dass der von Streda und Galuḱx erkannte Baı der Follikel bis jetzt einzig und allein nur Dem verglichen werden kann, was oben über die Zusammensetzung der Penisdriisen ausgesagt wurde. Da aber die eigenartigen Drüsen bezeichneter Reptilien jedenfalls mit der Geschlechtsverrichtung in Beziehung stehen, so darf man sebliessen, dass auch die Follikel der Bursa Fabricii in den Kreis dieser Organe zu bringen sind. Bedenkt man ferner, dass im Bereich der Begattungswerkzeuge der Saurier weite Lymphräume zugegen sind und dass bei diesen Thieren anstatt der letatern lymphdrüsenartiges Bindegewebe vorkommen kann, so verliert auch die lymphoide Substanz, welche die Follikel der Bursa umgibt, einen Theil des fremdartigen Wesens. Und ist es nicht auch sonst beachtenswerth, dass dieses sräthselhafte Organ « der Vögel bis jetzt nur einer Bildung verglichen werden kann, welche sich bei Reptilien, also den nächsten Verwandten der Vögel, vorfindet? Die Orgine bei den Eidechsen an der Innenfläche der Oberschenkel gelagert, stehen bei der Blindschleiche an den Ruthen und bei den Vögeln sind sie in eine Aussackung der Kloake verlegt. Darnach ist auch die Natur der zelligen Innensubstanz abgeändert: in der Bursa weich, vom Charakter des Epithels der Schleimbäute, hingegen an der Ruthe härtliclz und nahezu ron den Eigenschaften der Epidermiszelleu.

1) Neunte 'lafel, Fg. 119.

Leydig, Saurier. 
Männchen.

Hode,

Epididymis (Nebenhodentheil des WoLfF'schen Körpers),

Paradidymis, GIRALDE'sches Organ, gelber

Rest des WoLfF'schen Körpers,

Vas deferens (WoLfF'scher Gang),

MỨLIER'scher Gang (Eidechse, Blind-
Weibchen.

Eierstock.

Epoophoron (WaLdeYER) Nebeneierstock, (Eidechse, Blindschleiche).

Paroophoron (Waldeyer), Parovarium (His).

GARTNER'scher Canal, (Blindschleiche).

Eileiter.

schleiche),

Die beiden mehrmals genannten französischen Beobachter, welche mit ihren Arbeiten eine von der Pariser Alkademie 1845 gestellte, und auf die Erforschung der Reproductionsolgane der Wirbelthiere gerichtete Preisfrage zu lösen suchten, haben von den Umbildungen des Wolff'schen Körpers und seinen bleibenden Resten bei der Eidechse, welches Thier doch beide zergliederten, nichts gewusst, und daher sind ihre Deutungen, wenn sie sich auf dieses Gebiet begeben, ganz verfehlt. Was uns aber nicht abhalten darf anzuerliennen, dass ihre Schriften in den übrigen Einzelheiten viel Neues und Richtiges bieten. Die zahlreichen Abbildungen bei LEREBoullet haben, trotzdem dass sie offenbar vou sehr geschickten Zeichnern geliefert sind, meinen Beifall desshalb nicht ganz, weil sie häufig nur ein bestimmtes Präparat porträtiren; mit Ausführung von allem Nebensächlichen, so dass viele Figuren einen sehr unruhigen Clarakter haben und erst wieder studirt sein wollen. Den Zeichnungen bei MarTIN SAINT-ANGE gebe ich wegen ihrel reinen scharfen Weise den Vorzug. ${ }^{1}$ )

1) Von ganz dürftiger Art ist die Darstellung der weiblichen Fortpflanzungswerkzeuge einer Eidechse in dem Artikel Reptilia der Cyclopaedia of anatomy and physiology, 1852. Ob die Zeichnung entlehnt oder Original, ist mir unbekannt. 


\section{Zweiter Abselnitt. \\ Zur Kenntniss der Lebenserscheinungen.}

\section{Nervenleben.}

Eidechsen.

Dem aufmerksamen Beobachter unserer Thiere kann es vor Allem nicht entgehen, dass sich in den seelischen Aeusserungen ganz ähnliche individuelle Verschiedenheiten zeigen, wie solches von höheren Wirbelthieren, so namentlich von mnseren Hausthieren, eine allbekamnte Sache ist, und eben wohl Hand in Hand gehen mag mit besonderen, uns unbekannten Abänderungen im Bau. Daher lässt sich das eine Thier in der Gefangensehaft bald dahin bringen, die dargebotene Nahrung anzunehmen, ein anderes versteht sich niemals hiezu; manche Thiere entledigen sich im Zwinger ihrer Excremente an einer bestimmten Stelle, während andere sich nicht um solche Kleinigkeiten bekümmern.

Jedes wohl ausgebildete thierische Wesen ist eigentlich intelligent innerhalb des Fireises, ler seiner Natur gemäss ist. Es beurkundet ein angeborenes oder ererbotes Wissen - herkömmlich Instinct genamnt - bezüglich der Nahrung, Wohnumg, Fortpflanzung, Brutpflege, Schntz vor Feinden; und es gibt wohl keinen Naturforscher, welcher die Lehensweise irgend eines Thieres ins Ange fassend, nicht von einem Erstaunen ins andere über das ganz besondere Wissen, welches hiebei sich geltend macht, gerathen wäre.

Bei einem näheren Zusehen und Abwägen solcher Erscheinungen gelangen wir aber doch zu der Annahme, dass was jetzt als ein angeborenes Wissen und Kömen - als Instinct - sich diustellt, für die früheren Generationen des Thieres cin individnell erworbenes war und sich allmählig in den Abkömmlingen zn einem Niturtriebe festsetzte. Individuelle Zustinde und Erfahrungen der Vorfahren, oftmals wiederkehrend, hewirkten leibliche Veränderungen und erscheinen in der Nachliommenschaft als vererbte Vorsicht, Neigung, Fertigkeiten, kurz als Naturaulage. In dieser Weise sind auch viele Thätigkeitsainsserungen der Reptilien aufu- 
fassen und werden nur so verständlich. Oder wäre es sonst nicht höchst merkwürdig, dass die grosse grüne Eidechse anf den ersten Blick den Carabus auratus von Cetonia aurata unterscheidet, den ersten, wenn auch wiederholt dargeboten, verschmäht, den andern aber sofort ergreift; während doch beide Käfer als "Goldkäfer “ selbst von gebildeten Leuten nicht jedesmal sicher auseinander gehalten werden. ${ }^{1}$ ) Ebenso scheint das Benehmen der Eidechsen gegen die ihnen so feindliche glatte Natter (Coronella laevis) von individuellen Erfahrungen der Voreltern herzurühren, welche jetzt zum bewusstlos wirkenden Instinct durch Vererben geworden sind. Setzt man in einen Zwinger in welchem bisher eine Anzahl Eidechsen ungestört hauste, genannte Schlange, so erfolgt sofort die grösste Aufregung der Bewohner. In Sprüngen, welche sie in der Weise sonst nie ausführen, suchen sie dem Behälter zu entkommen, starren dann, da der Fluchtversuch nicht gelingt, unter den lebhaftesten Athembewegungen die Natter an, wie in Erwartung dasitzend. Nach einer Stunde, als die Schlange, ohne einer Eidechse ein Leid zugefügt zu Laben, sich unter die Steine verkrochen, blieben die Eidechsen, welche sonst immer um die Zeit des Wegganges der Sonne sich zurïckizuziehen pflegten, oben auf den Steinen sitzen. Erst nach Tagen legte sich, da die Schlange sich harmlos aufführte, die Unruhe; doch nahmen die Eidechsen ihre Stellung gerne so, dass sie die Feindin im Auge hatten und fuhren lieftig auseinander, wenn es der ersteren beliebte eine ihnen bedenlilich scheinende Bewegung zu machen. - Dass wirklich von Seite der Eidechsen die glatte Natter als Feindin erkanñt und gefürchtet wurde, bestätigte sich mir auch dadurch, dass eine lebende Würfelnatter (Coluber tessellatus), welche ich ron jenseits der Alpen mitgebracht, und zu einer anderen Gesellschaft von Eidechsen gesetzt hatte, die letztern nicht im mindesten erregte. Bekanntlich lebt aber auch die Würfelnatter nicht von Eidechsen, sondern ibre Nahrungsquelle sind die Fische!

Hat man ein altes, meist für sich einsam lebendes Männchen ron Lacerta viridis mehrmals bintereinander aufgesucht, ohne seiner babhaft werden zu können, so lenkt das sich sonnende Thier immer früher zu seinem Schlupfwinkcl un, je öfter man in seine Nähe kommt. Und was dabei das Beachtenswerthe ist und schon an "Intelligenz" streift: die Eidechse unterscheidet und beurtheilt gar woll einen schwer belasteten Landmann, den sie in geringer Entfernung an sich vorübergehen lässt, ohne die Lage zu ändern, wälırend sie sich bei Ansichtigwerden des ihm nachstellenden Städters schon aus weiter Ferne zurückzieht. - Wemn ein Markstein an einem Platze steht, wo Lacerta agilis sich findet, so wird dieser mit Vorliebe zum Wohnplatz errwählt. Das Thier sonnt sich auf demselben bei friedlicher Ungebung und scheint, indem es unter ihn sich flüchtet, eine Alnung zu haben, dass dieser Stein in seiner Lage zu den bleibenden gehört.

Wollen wix den Ansdruck Intelligenz auf das Vermögen beschränken, eine gevisse Steigerung des ursprünglichen Denkens und 'Thuns dureh Anpassung' an nene Zustände sich zu erwerben, so ist das Mass dieser Intelligenz bei unseren I'hieren gering und steht. weit hinter dem von allen Vögeln zurück. Insoweit meine Beobachtungen gehen, erstreckt sich diese Fähigleit nicht weiter, als dass sie in der Gefingenschaft bei guter Pflege eine gewisse Zutraulichlieit amnehmen und zu begreifen scheinen, dass man ihnen wohl will. Auch lässt sich bemerken, dass. sie den Pflerger kemnen, so lange er in der ihnen gewohnten Kleidung erscheint. Nähert

1) Dieses Unterscheidnngsvermögen der grünen Eidechse wird freilich weit übertrofteu von dem entomologischen Scharfblick der Neuntödter unter den Voggeln. Nach J. Sturs (Deutschlands Käfer, erstes Bändchen, 1805) spiessen Lanius collurio nnd L. excubitor nur den Geotrupes vernalis an die Stacheln des Schlehendorns, niemals aber den an den nämlichen Orten gleich häufigen G. stercorarius! 


\section{7}

man sich aber einmal etwa im Mantel, so stieben sie scharf auseinander; doch lässt sich dieses Benehmen nicht gerade zur Verkleinerung ihrer Intelligenz auslegen, da bekanntlich bis zu den gescheidesten Thieren, selbst bis zum Hund hinauf und aus leicht begreiflichen Gründen der gleiche Umstand immer einen Tumult in ihrem Denken erzeugt.

Die Eidechsen sind von sehr erregbarem Wesen und geben ihre Unruhe und Spanumg, auch wenn sie sonst sich zu fassen wissen, durch Züngeln kund. Sie gerathen leicht in Zorn, besonders die Münnchen und beissen nach Kíräften zu, was bei den Mümuchen wegen stärkerer Kiefer und Muskeln ansgiebiger ist als bei den Weibchen. Wie es ein allgemeiner durch die Thierwelt ziehender Charaliter ist, dass die Jungen und die Weibchen milderer Simnesart sind, als die IJunnchen, so auch hier in auffulliger. Weise. Die Jungeu, noch ohne Erfahrung und noch nicht gewitzigt, sind wenig scheu und leicht zu fangen. $\left.{ }^{1}\right)$ Auch die Weibchen von $L$. agilis sowohl als ron viridis lassen sich noch eher überlisten als die wachsameren und vorsichtigeren Mänuchen. Das 'Temperament zeigt übrigens nach den einzelnen Arten Abstufungen: während L. viridis ${ }^{2}$ ) unter den mir bekannten Arten die leidenschaftlichste ist, zeigt sich $L$. vivipara, nach ihrem ganzen Körperban zarter als die andern, am sanftesteu, so dass sie schon mehrmals geradezu als ein ,gutmüthiges Thier" bezeichnet wurde.

Sollte nicht die grosse Erregbarkeit, sowie das geringe Widerstandvermögen gegen Gifte, end̊lich die Abhängigkeit der Kraft der Bewegungen von der Sonnenwärme auf einen gewissen reränderlichen und bestimmbaren 'Zustand des Organismus deuten, der uns die Mittheilungen über das "Bezaubertwerden “ dieser" Thiere nicht von verne herein ganz verwerfen lässt? Mehrere ornsthafte Naturforscher, z. B. EvERsmanN ${ }^{3}$ ) sagen aus, dass Prof. JAN in Mailand vor ihren Augen Eidechsen in magnetische Eirstarrung zu bringen rermochte. Es nahm der Genannte aus dem Kasten, in welchem er lebende Eidechsen hielt, sehr grosse Exemplare ron Laccrta ocellata und viridis heraus, hielt sie hinter dem Kopfe fest und sah sie einige Secunden starr an; alsbald wurde das Thier ruhig und lag ganz gelilimt auf der Hand; auch konnte man es auf den Iiücken legen, es blieb liegen und rührte sich nicht, und wenn er mit dem. Zeigefinger eine Secunde lang in einer Entfernung ron einem Zoll zwei oder drei magnetische Striche machte, so schloss das Thier auch die Augen. - Soll man die Erscheinungen einfach von dem auf die Medulla oblongata ausgeubten Druclie ableiten? Mir scheint diese Frlärung nicht ganz zu genügen.

Schon die Alten behaupteten, dass die Eidechsen die Nähe der Meuschen

1) IdAurextı sagt daher von seinen Seps argus, welcher bekanntlich das Junge von Lacerta agilis ist: mansuetus, ut non mordeat, quomodocunque irritatus; licet agilissimus, manu tamen facillime se capi patitur.

2) Nach den Angiben Derer, welche die $L$. occllata im Freien beobachten konnten, übertrift diese noch wie an Körperstärke so auch an Nuth die L. viridis. W VALT (Reise nach Südspanien, 1835) welcher mehrere dieser Thiere auf den Haiden Andalusiens einfing, theilt mit, dass die Mannchen, wenn sie ausgewachsen oder in der Brunstzeit sind, sich mitten im Laufe umkehren und mit aufgespertem Kachen sich zur Wehre setzen. Aehnliches erfihrt man auch bei Dursis.

$\left.{ }^{3}\right)$ Bulletin de la Société impériale des naturalistes de Noscou, 1858, 2. S. 270. 


\section{8}

lieben; Latreille ${ }^{1}$ ) nennt die L. muralis (bei ihm heisst sie Lézard gris, L. agilis) geradezu „un animal presque domestique“. Jedenfalls bemerkt man leicht beim achtsamen Herumwandern, wie ich solches z. B. in Italien that, dass die Zahl der L. muralis an Mauern und Felsen in der Nähe menschlicher Wohnungen, wenn die Uertlichkeit sonst günstig ist, ganz besonders zunimmt. Immerhin möchte ich die Erscheinung nur in Verhältnissen begründet sehen, welche auch gewisse Pflanzen, wie das Schöllkrant und den schwarzen Hollunder, vorzngsweise die Nähe menschlicher Wohnungen aufsuchen lassen.

Eidechsen sollen auch für Musik empfänglich sein; worüber ich selber keine Erfiahrungen habe, um so lieber aber einen sehr zuverlässigen Beobachter reden lassen möchte. Es ist DE SELYs-Longchamps, welcher seiner Zeit mit dem Fange der Eidechsen in der Umgegend von Turin beschäftigt, aussagt: „elle se laisse approcher facilement lorsqu' on siftle un air, tandis que la notre (die belgische $L$. muralis) n'est nullement sensible à la musique“.

Zu den erwähnenswerthen Eigenthümlichkeiten gehört auch, dass unsere Thiere nicht selten in ruhigem Dasitzen recht dentlich gähnen, wie wenn sie Langeweile hätten; was meines Wissens weder bei anderen Reptilien oder Amphibien, noch bei den Vögeln beobachtet wird. Auch eine weitere Eigenschaft erinnert an die höchsten Wirbelthieré: L. viridis aus Dalmatien niesst zuweilen - an kühlen Maitagen ganz vernehmlich.

Junge Thiere halten sich, wie mir diess namentlich bei L. viridis auffiel, aber auch bei $L$. agilis und $L$. viripara vorkommt, noch gesellschiftlich oder truppweise zusammen. Später leben sie vereinzelt und wie schon angedeutet, die illteren Männchen, namentlich von viridis gerne zurückgezogen; eine Erscheinumg, die bekamntlich auch weit durch die Reihen der höheren Thiere sich erstreckt. Am ehesten liesse sich der L. muralis ein geselliger Sinn fürs ganze Leben zuschreiben, da sie passende Stellen in Menge bevölkert. Eine Sitte, welche die Eidechsen ebenfialls mit sehr vielen niederen und höheren 'I'hieren gemein haben, ist ihr zähes Festhalten an dem Fleck Erde, wo sie zur Welt kamen. Man wird in Gegenden, die uns durch viele streifereien genau bekannt sind, bemerken, dass sich die Eidechsen, Jahr ans Jahr ein, an gewisse Bezirke halten, ohne sich über andere Oertlichkeiten, die soviel sich beurtheilen lissst, gleich pissend wären, anszubreiten. Das Wandern scheint elen anch hier erst damn und als Nothwendigkeit einzntreten, wemn der Plat\% überfuillt ist.

\footnotetext{
1) Histoire natur. d. reptiles, 1826.
} 
Wie nicht leicht bei einem anderen Geschöpf macht sich der Einfluss der Wärme, namentlich der Sonnenwärme, auf die Eutfaltung des Nerven- und Muskellebens so bemerklich, wie bei den Eidechsen. Welch' seltsamen Anblick gewähren Thiere, die man F'rülujahrs, eben erst hervorgekrochen aus ihren Erdlöchern und im Zustande grosser Ungelenkigkeit, überraseht! Auch büssen sie im Zimmer gehalten, bei herabgehender Temperatur ihre Behendigkeit sofort ein und setzen bei den jetzt trägen, schleppenden Bewegungen ganz bedächtig einen Fuss vor den anderen; während im sonnenschein, namentlich bei $L$. muralis, die Bewegungen eine federnde Leichtigkeit annehmen, wie ohne alle Körperschwere. Bei $+16^{\circ} \mathrm{R}$. im Zimmer und ohne Sonne fühlen sich die südlichen grünen Eidechsen nicht blos ganz kalt an, sondern bekommen auch ein eingefallenes, mageres Aussehen; in den strahlen der Somne hebt sich der Herzschlag und die Athunung, und gerade durch den letzteren Umstand, durch Ausdehnung der Lungen und Füllung mit Luft, ändert sich ihr Aussehen wieder in's Vollere um.

Alle unsere Arten nehmen, während sie sich sonnen, eime ganz besondere Stellung an, um den Sonnenstrahlen eine grösstmögliche Fläche des Körpers entgegenzubringen. Durch Hebung der Rippen und Spannung der Hant verbreitern sie den Körper und platten sich ab, was man an Thieren in Gefangenschaft, so oft die Sonne den Käig bescheint, sehen kann; und dabei führen sie nicht selten eigenthümlich zappelnde Bewegungen mit den Beinen aus. Schon die Griechen bezeich-

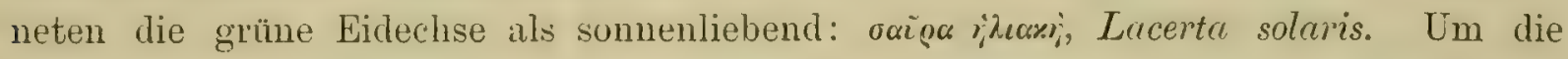
Wärme ihrer Umgebung ganz auszunützen und damit gar nichts verloren geht, schleifen meine im Zimmer gehaltenen grossen dalmatinischen 'Thiere mit Behagen ihren Bauch am sonnig durchwärmten Boden hin.

Aber trotz alle dem sind sie anch der Fenchtigkeit sehr bedürftig, was sich bei simmtlichen Arten nicht blos daraus zu erkennen gibt, dass sie gerne und viel trinken, sondern Lacerta viridis lebt mit Vorliebe an Plätzen, wo sie nicht allein die Sonne geniessen kamn, sondern welche auch Fenchtigkeit hinreichend darbieten; Waher sie sich bei Jerun z. B., was schon MILDE richtig bemerkt, gern neben den Wisserleitungen finden lasst. Lacerta vivipara trifft man sogar an wirklich nassen Orten an und Fitzinger neunt sie nicht ganz mit Unrecht: Sumpfeidecbse; auch badet sie sich in Gefangenschaft gerne im Wasserbehälter des Kastens.

Dieses Bedürfniss nach einem gewissen Grad von Feuchtigkeit, welcher in der Gefangenschatt so schwel lerzustellen ist, scheint mir auch der Grund zu sein, warum man die aus trockenen südlichen Gegenden mitgenommenen Eidechsen leichter und länger am Leben erhaiten kann, als die unserigen. Mir hat sich wenigstens immer gezeigt, dass $L$. muralis und $L$. viridis aus solchen Orten härter sind und sich besser der Zimmerluft anbequemen als $L$. agilis und $L$. vivipara; wie man denn auch tilnliche Erfahrungen zwischen 
den Ablepharus aus Ungarn und jenen von der Insel Syra gemacht hat: letzterer ist nach ERBER ebenfalls ron dauerhafterer Beschaffenheit als der erstere.

Die Tageszeit in welcher die Eidechsen - ich beobachtete es zunächst an L. viridis, L. agilis und L. muralis - dem Genuss der Wärme und des Sonnenscheins vorzugsweise sich hingeben, sind die Vormittagsstunden von 9-12 Uhr. Man wird einzelne zwar bei gutem Wetter so lange die Sonne am Himmel steht, antreffen; aber um genannte Zeit sind sie am zahlreichsten und lebendigsten. In der Gefangenschaft kommen sie selbst an trüben Tagen gerne gegen 11 Uhr zum Vorschein. Kündigt sich Südwind an, so sind sie schon alle in frühester Morgenstunde munter; wenn Regen droht, halten sie sich versteckt, während bekanntlich gerade diese Luftheschaffeuheit unsere Schlnugen hervorlockt. Wirklich kalte Witterung scheint ihnen sehr nachtheilig werden zu können: so beọbachtete schon Pallas, dass in Chersones bei drei hintereinander folgenden nasskalten sommern, die früher äusserst zahlreiche Lacerta taurica fast ver'schwunden war. ${ }^{1}$ ) V. ('HARPENTIER theilt mit, dass Lacerta viridis vor dem strengen Winter 1829 auf 1830 bei Bex hïutig war, nachher aber auf einige Jahre hinaus selten; es mochte eine grosse Anzahl dieser Thiere in ihren Löchern, weun sie nicht tief genug waren, erfroren sein. ${ }^{2}$ )

Die der Wärme so sehr bedürftigen Eidechsen ziehen sich vor der rauher werdenden Luft des Herbstes in Verstecke zurück, um dort in einer Art Erstarrung den Winter hinzubringen. Die Zeit dieses Rückzugs ist wohl nach den wärmeren oder kälteren Gegenden etwas rerschieden; aber sie ist auch verschieden für die einzelneu Arten, selbst Altersstufen und wie es scheint auch bezüglich des Geschlechts. Hier bei Tü̈bingen, wo es sich nur um Lacerta agilis und L. vivipara handelt, beobachtet man, dass in der Regel Anfangs Octoher die alten Thiere verschwunden sind und nach meinen Aufzeichnungen ziehen sich die Männchen früher zurück als die Weibchen. Die ganz jungen Thiere (Seps argus LAUR.) treffe ich an sonniger Stelle noch zahl-

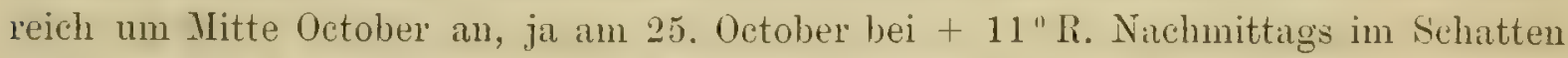
und Ostwind liessen sie sich in Menge an warmen Hängen noch sehen, während kein einziges erwachsenes Exemplar mehr aufzutreiben war. Dasselhe hegegnete mir mit Lacerta vivipara. Im Wald von Bebenhausen, an Puncten, wo man im Sommer erwachsene 'Thiere fist sicher trifft, konnte ich im Oetober kein altes Thier. mehr, leicht aber eine Anzahl gauz junger, in der Nïhe von Baumstumpen gewaln werden.

3) .... Lacerta taurica in Cherśoneso taurica olim frequentissima, post insecutos tres annos (1803-180J) admodum pluviosos et continua intemperie infames ita nunc periit, ut vix unam vel siteram per plures annos hine inde offendere daretur. Zoographia rossica.

2) 'Т'scuud, Schweizerische Echsen, 1837, S. 13. Anmerkg. 
Auch von Rana esculenta sind die ganz jungen diessjührigen Fröschehen um eben dieselbe Zeit noch an den Rändern der Gewässer lebendig, während die Alten schon sich zur Ruhe begeben haben. Diess stimmt Alles gut überein mit dem, was an Säugethieren, welche dem Winterschlaf unterworfen sind, beobachtet wurde. Beim Igel und Ziesel sind es nach BARKow ${ }^{1}$ ) die jüngeren l'hiere, welche eines kürzeren Winterschlafes bedïrfen, als die alten; ebenso verhält es sich bei der Haselmaus nach BErTHoLd. Selbst bei niederen Thieren bat man Aehnliches beobachtet; ich finde wenigstens die Angabe, dass nach Scurenk die Jungen der Landschnecken (Helix pomatia, H. hortensis u. a.) den Winterschlaf später als die Erwacbsenen antreten. ${ }^{2}$ ) Soll man diese Erscheinung einfach mit der Unerfahrenheit der Jungen erliaren wollen, die im Sommer ans Licht der Welt gekommen, noch nicht wissen, was der Winter ist? Der Grund mag doch wohl tiefer liegen.

Wann sich in deutschen Gegenden die Lacerta viridis zurückzieht, darüber kenne ich keine Angaben. Wohl aher hat MILDE in seiner interessanten Abhaudlung: Wissenschaftliche Ergebnisse meines Aufenthaltes bei Meran ${ }^{3}$ ) sich aufgezeichnet: ,3. November. Die letzte Lacerta viridis ist sichtbar."

Was die Lacerta muralis betrifft, so ist sicher, dass sie am längsten ausdanert und daher am spätesten verschwindet. Hier im Württembergischen, im Gebiet der Zaber tummelt sich die Eidechse, wie ich einer brietlichen Mittheilung ${ }^{4}$ ) entnehme, noch Mitte Novembers an warmen T'agen in .ganzen Gesellschaften herum. In Südtyrol bleibt sie noch einen Monat weiter wach; nicht blos MILDE hat sich von Meran angemerkt: „15. Decbr. die letzte Podarcis muralis ist sichtbar“", sondern es wurde mir von verschiedener Seite gesagt, dass wich noch um die Weihnachtszeit einzehe Thierchen durch den warmen Sonnenschein hervorlocken tusseu. In Südeuropa selber hält das 'Thier gar lieinen eigentlichen Winterschlaf mehr, sondern kommt den ganzen Winter hindurch an heiteren 'I'agen zum Vorschein, wie schon CETT von der Insel Sardinien, dann Dugés von Südfrankreich melden und ich selbst bei Cagliari erfahren habe. ${ }^{5}$ )

Wenn die Eidechsen die Winterquartiere beziehen, so ist ibnen daran gelegeu, sich in Gesellschaft, wenigstens zu zwei zusammenzuthun. In allen den mir zur Keuntniss gekommenen Fällen, wo man in hiesiger Gegend, gelegentlich von Erdarbeiten, auf Winterschlaf haltende Eidechsen stiess, waren sie immer, wohl der Erwitrmung halber, zu mehreren beisammen. Selhst im Zwinger der in geheiztem Zimmer steht, legen sich 2 grüne Eidechsen, als im December die 'Temperatur draussen

1) Der Winterschlaf nach seinen Erscheinungen im Thierreich. 1816.

2) Siche E. v. MAntens Verbreitung d. europ. Land- u. Süsswissergasteropoden, 1855. - In dem mir eben zugehenden Decemberheft des zoologischen Gartens", 1869, finde ich eine gleichfalls hieher gehörige Benerkumg les Pfurrers SxiLl, dem zufolge unter den Vandervögeln die jungen Vögel es sind, welche zuletzt aufbrechen.

9) Botanische Zeitung Nr. 50, 1862.

1) Des Hrn. Forstissistenten Karrer.

5) Molche der wïrttemb. Fauna. Arch. f. Naturgesch. 1867. (Separatabdruck S. 6. Anuerkg.) Ley lig, Sauricr. 
auf $-S^{0}$ and $9^{0} \mathrm{R}$. stand, hübsch dicht der Länge nach aneinander, während sie sonst sich ans dem Wege gehen. - Thiere, welche im ungeheizten Raum in Winterschlaf fielen, lagen mit gesthlossenen Angen da und ohne Athembewegungen, manche aber mit geöffnetem Mund. Sie waren wie todt, aber nicht starr; in die Hand genommen zeigten sie bald einige Regung der Gliedmassen, öffneten die Angen und die Athembewegungen stellten sich ein.

Wie in Abtreten vom Schauplatz, so anch im Wiedererscheinen beim beginnenden Frühling zeigen sich Abstufungen nach den Arten, dem Alter und selbst dem Gieschlecht. Den Anfang macht Lacerta muralis; MILDE sah bei Meran die erste am 14. Febr. Wann sie diesseits der Alpen ihr Versteck verlässt, ist mir bis jetzt nicht bekamnt. Die L. viridis zeigte sich bei Meran nach dem mehrmals genannten Beobachter etwa einen Monat später als die Manereidechse, am 10. März; in Desterreich nach F'RITSCH am 8. April. Für Lacerta agilis ist wohl in Deutschland die erste Woche des April die Zeit, wo sie wieder hervorkriecht. Ich sah es so im ILainthat; nach früheren Aufzeichnungen glaubte ich für Tübingen, welches viel höher liegt etwa $1200^{\prime}$ w. F. üb. d. Mr. Mitte April annehmen zu müssen; allein sie ist auch hier unterdessen schon in der ersten Aprilwoche gefangen worden. Natürlich wird die Wittermng die Zeit etwas vor oder zurüchrücken. Im Vorarlbergischen sah BruHıN ${ }^{1}$ ) im Jahr 1866, am 5. April die erste Eidechse, 1867 aber schon am 27. März. In Kischinews, welches mit Vorarlberg so ziemlich unter gleichem Breitegrade liegt, erscheint das 'Thier Mitte April. ${ }^{2}$ ) - Mit Sicherheit habe ich beobachtet, dass die ganz jungen 'l'hiere, nachdem die 'Temperatur Mittags auf $13-14^{\circ} \mathrm{R}$. im Schatten sich gehoben, zuerst aus ihren Löchern an die Sonne kommen. Dann folgen die Männchen und zuletzt die Weibehen, welche etwa eine Woche später erscheinen, was an bekannte Verhältnisse anderer 'Thiere, z. B. der Zugvögel, anschliesst. $L$. vivipara scheint früher als $L$. agilis die Winterverstecke zu verlassen: es ist mir nemlich bemerkeuswerth geworden, dass ich bei meinen Excursionen in den Schönbuch hier bei 'l'übingen $L$. vivipara, Alt und Jung, schon antreffe, wemn sich von $L$. agilis am gleichen Orte nur erst die ganz jungen (L.argus) zeigen und zwar an Stellen, wo später auch die Alten in Menge springen. Es würde dies im Einklang

1) \%oologischer Garten. 1868. Miir heit.

$\left.{ }^{2}\right)$ Bull. d. 1. soc. des natur. d. Moseou, 1859, 1. S. 424. Wie sehr loch gewisse Umstände das friuhere oder spütere Hervorkommen bedingen, erfuhr ich in diesem frühjahr (1870), wo ich bereits an 16. März hier bei 'Tübingen die erste $L$ agilis zu Gesicht bekan. Nachts stand noch der Thermometer auf $-4^{0} \mathbf{R}$. und Mittags blos auf $+6^{\circ} \mathrm{R}$; aber die Stelle, wo das Thierchen sich bereits sonnte, lag ganz mittïgig und durchus geschützt gegen den Norl- und Ostwind. 


\section{3}

sein mit der weit nach Norden und in die Alpenhöhen gehenden Verlureitung dieser Art, wovon unten.

Uebrigens halten die Thiere dic Zeitabschnitte des periodischen Erscheinens in Grossen und Ganzen ziemlich regelmässig ein, und lassen sich nicht durch etwaige Wärme in Februar herrorlocken. Es gab Jahre, wo wir hier im Februar Mittags im Schatten $+12{ }^{\circ} \mathrm{R}$. eine ganze Woche lang lnatten, so dass die Grillen als Puppen mit Flügelstummeln vor ilıren Löchern sich sonnten, und selbst Carabus auratus uiber den Weg licf, aber trotzdem licss sich keine Eidechse an den Stellen, wo ich sie jihrlich zuerst zn sehen gewohnt bin, erblicken. Wahrscheinlich wirkte doch noch nicht die Wärme tief genü durch den erkälteten Boden.

Auffallend könnte es scheinen, dass die eben hervorgekrochenen 'l'hiere keinesweys ein abgezehrtes Aussehen haben, viehnehr ein wohlgenährtes, man könnte fast sagen, feistes. Joch wäre es irrig annehmen zu wollen, als ob sich erst während des Winterschlates der l'ettkörper in der Becken- und Hinterleilssgegend entwiclielt habe. Es geschieht solches vor dem Winterschlaf, wie der Anblick und die Zergliederung vou 'Thieren, die dieser Zeit entgegen gehen, beweist, und wie das ja anch in Uebereinstimmung mit der dicken und fetten Körperbeschafínheit anderer Geschöpfe vor dem abzuhaltenden Winterschlaf steht.

Blindschleiche.

Anguis fragilis zeigt dem Beobachter ein in vielen Puncten anderes 'I'emperament als dasjenige der Eidechsen ist. Vor Allem ist cie Blindschleiche um vieles ruhiger und nachdenklicher in ihrem ganzen Wesen und es mag desshilb daran elinnert werden, dass die Lappen des grossen Gehirns bei unserem Thier, in Anbetracht des Mittelhirns, entschieden grösser sind als bei den Eidechsen.

Es war mir interessant zu sehen, dass drei andere europaische Scinke: der Ablepharus pannonicus, der Gongylus ocellatus und Pseudopus Pallasii, welche sümmtlich bei mir längere Zeit in Gefangenschaft lebten, in granzen Behaben mehr an dic Blindschleiche als an die Eidechsen erinnerten. Ablepharus, obschon un vieles lebhafter als unsere Blindschleiche, stimute zum Beispiel doch darin ganz mit genanntem Thiere uhbercin, dass er gewöhnlich ling und andanernd, wie starr anfhorchte, ehe er sich zum filtiehten anschickte. ") Psendopus Pallasii in einem geräumigen Küfig z.ısammen mit grossen grünen Lidechscn aus Dalmatícn gelalten zcigt sich, gegenüber dem ungestümen, gern kopflosen Bonehnen der Mitgefangenen, geradezu verständig.

Auch die Blindschleichen sind, obschon sie sich gerne sonnen, doch der Feuch-

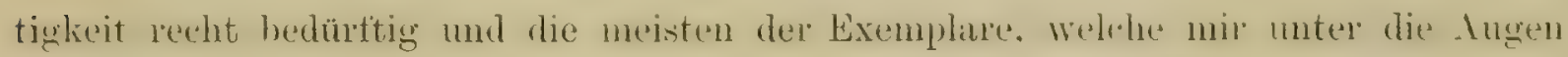
kamen, habe ich unter etwas fenchtliegenden Steinen angetroflen; anch mir beim

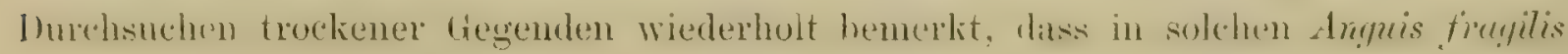

1) Von diesem niedlichen 'Thier siud mir zwei furbige Abbildungen bekannt. Die eine findet sich in dem. l'richtwerke von Bony de Sr. Vrscrsx's Expedition scientifique de Motée, Zoologie, 1833, und die andere in Coctraty's Eitules sur les Seincoides, 1836, beide und nanentlich die letztere in Zeichnung und Stich, sehr rein und richtig; iber das Colorit ist oftenbar nicht nach lebenden, sondern nach Weingeistexemplaren angelegt. Mein Ablepharus, von rler Insel Syra, stimmeud, hatte nicht blos clen Glauz, sondern auch dis schöne Bronzebraun der Blindschleiche. 
selten war. Selbst an Thieren in Gefangenschaft lässt sich beobachten, dass sie keineswegs wem die sonne ihren Behälter bescheint, hervorkommen, wie dies die Eidechsen thun, sondern sie bleihen verborgen; hingegen an Tagen, welche die Eidechsen zum Sichzurügkiehen bestimmen, so z. B. wenu Regenwetter im Anzuge ist, kriechen die Blindschleichen ans dem Versteck an die Obertläche. Wenn unsere Thiere schon in aller Frühe herumkriechen, deutet es entschieden auf eine Veränderung der Atmosphäre zum Regen.

Die Winterquartiere bezieht sie etwas später als die alten Thiere von Lacerta agilis und Lacerta vivipara. Noch Mitte Octobers fund ich Blindschleichen hier bei T'übingen theils frei, theils unter Steinen. Im Winter stossen die Feldleute öfters auf die wohlverwahrten Erdhöhlen, in welchen die Thiere die rauhe Jahreszeit hinbringen. In den mir bekannt gewordeneu Fällen war die Lage dieser Winterquartiere immer eine, sorgfältig gewählte in der Art, dass sie nicht blos genau gegen Süden sich richteten, sondern auch vor Nord- und Ostwind geschützt waren; dabei Latte sich immer eine grössere Gesellschaft von 'Thieren, Alt und Jung zusammengefunden, denen sich auch einmal eine Coronella laevis angeschlossen hatte. Die Höhlen oder ,s Stollen“ wählen sie sich durch Bohrbewegungen ihrer stumpfen Schnauze aus, was Frivaloszk zuerst beobachtet zu haben scheint. ${ }^{1}$ ) Tschud, welcher selbst einen solchen Stollen im Februar ausgrub, komnte nähere Angaben über die Läuge, Form und Krrünmugen des Winterquartier's mittheileu, auch genaueres über die Art und die Folge wie die Thiere - es waren 23 Individuen - darin liegen.

Im Frühling kommt die Blindschleiche etwas früher zum Vorschein als die gemeine und die lebendiggebärende Eidechse. Ich habe in hiesiger. Gegend schon Mitte März, mitunter bei noch recht rauher Witterung, die ersten wachen Thiere unter Steinen gesehen und wăre geneigt dieses, gegenüber von dẻn Eidechsen, wetterfeste Wesen mit den so dichten schützenden Kalkschuppen der Haut in Verbiudung zu bringen. Nach LENz, auf dessen Beobachtungen sich BARKow ${ }^{2}$ ) stützt, wäre die Blindschleiche ngegen Wind und Kälte am empfindlichsten". Ich habe immer das Gegentheil wahrgenommen.

Ieine Ansicht dass die Beschaftenheit der Lederhaut hicbei von Kinfluss sein möge, liisst sich auch durch das unterstützen, was ich am lehenden Pseudopus Pallasii zu beobachten Gelegenheit hatte. Diese Thiere zeigten deutlich, dass sie ron der Kälte viel weniger ausstanden als die Lidechsen. Wiihrend $L$. viridis, bei den Stand des Thermometers auf $+14^{\circ} \mathrm{R}$. im Freien, vor Frost zitterte und ganz eingefallen war, liess Pseudopus Pallasii bei seiner dicken verkalkten Haut nichts von Unbehagen bemerken.

tere soleta.

1) Mouographia serpentum Hungariac, Pestini 1823. „.... civitates terrae quas ipse rostro folicat pe-

") Her Wintersehlaf wach seinen Erscheinungen im Thiereich, Berlin 1816. 


\section{Bewegung.}

Die Bewegungen der von der Sonne durchwårmten Eidechsen sind zwar bekanntermassen bei allen Arten iusscrst schnell, aber doch wieder in merklich verschiedenem Grade nach den species. Oben an steht Lacertu viridis, deren Bewegungen schon DANTE naturgetren bezeichnet: "folgore par, se la via attraversa"; und. wer dieses noch nicht als etwas selbst Erprobtes kennt, mag sich vou GERMAR ${ }^{1}$ ) aus seiner Dalmatinisthen lieise erzählen lassen: „ich suchte ihrer (der grossen Lacerta viridis) auf verschiedene Art habhaft zu werden, um diese in mancher Hinsicht mir noch dunkle Art urtersuchen zu kömmen, abel vergebens, sie war mir zu schnell." — Beim Sprung schiessen sie, mit gestrecktem Schwanz, pfeilähulich über ganze klächen weg. in geradester hichtung und oft anch über ihr Ziel hinaus. Welche Wichtigkeit fï̈ diese Art Bewegung ler lange Schvamz hat, kamn uns klir werden, wemn wir zufïllig 'I'hieren begegnen, die am Schwanz verstümmelt sind. Solche, obgleich sich in die Flucht stüuzend. können nicht die pfeilschnellen Bewegungen gewinueu, soudern suchen durch einfachen Lauf unter zahlieichen. l'aschen Schlïngelungen des Leibes zu entkommen und werden desshall leicht zur Beute. ${ }^{2}$ )

Auch die Lacerta muralis ist ausserst behend; doch lässt sie sich bei einiger Uehmug an passenden Orten. z. B. an Planken viel hesuchter Wege. leichter als $L$. virịclis fangen. ${ }^{3}$ )

Unsere Lacerta agilis trägt ihren Namen, gegenüber von diesen südlichen Springern und Läufern. beinahe nicht mehr mit rollem Recht; und man begreitt, wie die italienischen Zoologen früher so allgemein in den Fehler fallen komnten. die Linmeische Bezeichnung agitis auf die Mauereidechse zu denten.

Alle genannten Arten sind auch gute Kletterer. Man sieht nicht nur $L$. viridis gelegentlich Biume ersteigen, sondern auch L. agilis lässt sich belanschen, wie sie Hecken und Buschwerk duchklettert; selhst $I$. viripara sah ich öters einigge Fuss weit über dem Boden an Föhrenstämmen sich somnen. Doch wahrhatt bewundernswerth geschickt klettert $L$. muralis an senkrechten Wänden empor, an Häusern mehrere storkwerke hoch. Ilese (nanz hesondere Fähigkeit im Emporklimmen längt wohl

i) Reise uach Dalmatien 1817.

") Eiue verfolgte Katze oder ein springendes Eichhorn lassen deutlich bemerken, dass auch den Säıgern die lauge Schwanzwirbelsiiule in gleicher Weise als Stener dient.

y) Ich habe vielleicht ein halbes Hundert mit Händen gehascht; was desshalb hier stehen mag, weil ein gewiss nicht ungeübter Naturforscher, Hr. Mur. cr, crklït, das Thier mit Hïnden zu fangen gelinge blos bisweilen und nur dann, wenn es an senkrechten Mamern hoch hinauflaufe. 
mit einer Beschatfenheit del Zehen zusammen, welche bei dieser Art mehr als bei den andern ansgeprïgt sich zeigt. Die schuppen an der Unterseite der Zehen bilden nemlich scharf hervorspringende Querwïlste, dicht hintereinander gestellt und von schwärzlicher Farbe. Dadurch wird die sohlenseite der Zehen rauh und höckerig und kann leichter in die Unebenheiten der zu erkletternden Fläche eingreifen.

Im Gegensatz zur Neigung in die Höhe zu klimmen traf ich die ganz jungen 'Thierchen von L. viridis am öftesten auf ebener Erde und zwar im Grase an.

Bei ganzen Gruppen iusläudischer Eidechsen ändert bekanntlich das lebende Thier in der Erregung seine Farbe. Auch bei unseren Arten lassen sich hievon wenigstens Spuren beobachten: ein und dasselbe Individum kamn nach Umstäurlen etwas heller oder dunkler sein.

Am meisten fiel mir diese Erscheinung auf an der L. muralis, var. campestris BETTA, wovon ich mir eine Anzahl auf dem Lido von Venedig eingefangen hatte. Die Thiere boten im Freien auf dem heissen Sande ein sehr helles Aussehen dar; einige Wochen im Dunkel einer Schachtel gehalten waren sie beim Herausnehmen, obschon frisch und lebendig, doch merklich dunkler geworden; dem Tageslicht andanerud wieder ausgesetzt hellten sie sich zu dem früheren Farbenton anf. Geringer, aber an manchen Individuen für Den der daratuf achten gelemt hat murerkemnbar, ist die Veränderung des Grüns bei L. agilis. Wenn in Mai die Temperatur plötzlich rasch herabgeht, oder auch bei Regenwetter nimmt das schöne Grün der Seite an 'Thieren in Gefangenschaft einen etwas gelblichen Ton an.

lch möchte aber hier noch auf eine Beobachtung von VALLISNIERI ${ }^{1}$ ) aufmerksam machen, aus welcher hervorzugehen scheint, dass hei Lacerta riridis der Farbenwechsel durch starke Aufregung des 'Thieres in ungleich grellerer WVeise ertolgen könne.

Der genannte Naturforscher von Padua, zuror beschäftigt mit Studien am lebenden Chamïleon, traf im Mai zwei cliesel Lidechsen, welche in einander verschlungen, und, wie er meinte, im Kample begriffen waren, an. Beide wurden erfisst und in ein Gefäșs von Glas gesetzt. Die eine war grösser, ron Farbe goldgrün, mit schwarzen Puncten besprengt; der Kopf dunkelgrün, mit gelben Flecken getüpfelt. Die kicinere sehr abweichend vou der grösseren besass ganz wenig Grün, mit kaffeebraunen Längsstreifell. Diese Angaben über die verschiedene Grösse und Farbe Her beiden Thiere sowohl, als anch die weitere Mittheilung, dass beim Einfangën die grössere Eidechse sich rasch auf einen in der Nälte stehenden Baum zu retten suchte, während die kleinere sich leicht fassen liess, machen es mir höchst wahrscheinlich, um nicht zu sagen gewiss, dass Valdisnieri in dem grösseren Thier das Männchen und in dem kleineren das Weibchen vor sich hatte und zwar im Begattungsacte, der nach den Berichten späterer Beobachter an cinen Kampf crinnern mag, da das Männchen mit den Zähnen das Weibehen prachit und festhält; auch der italienische Forscher noch aus-

1) Opere diverse. Venezia, 1715. (Istoria del Camaleonte altricino o di vari animali d'ltulia, pag. 103.) Ein Werk, anch bezüglich der Lacerten wichtig, das ich leider zu spät genauer kennen lornte. 
drücklich beifügt, dass Blutflecken, welehe an der kleineren Eidechse zn sehen waren, nicht aus Hautwunden kamen, sondern aus dem Munde der grüsseren. Dies Alles glaubte ich noch auseinandersetzen zu müssen, um das folgende zu verstehen und einzureilhen. Yaldssierı erzühlt nembich weiter, dass l'ags darauf das kleinere Thicr seine Farbe in hohem Grade geändert latte. Lis war jetzt selır schön grün geworden, besprengt mit regelmissig gestellten schwarzen Flecken; eine Reihe anderer, theils gelblicher Flecken zog an der Seite des Leibes hin und erstreckte sich fein auslaufend bis fast zur Schwanzspitze. Der Schwanz allein hatte noch in seiner Grundfarbe das frühere Kaffeebraun, das jedoch auch antieng in Grün, besprenkelt mit Schwarz, sich umznsetzen. Die Farbe der Vorderbeine war in reines Smaragdgrün nbergegangen, wibrend die Hinterbeine zum Theil noch braun, zum 'Theil gelbgrün wareı.

Wenn man nun bedenkt, dass die Verfärbung auch bei anderen Amphibien und Reptilien unter dem Einflusse des Nervensystems steht und von dessen Stimmung abhängt, wozu ich bereits 'Thatsachen an einem anderen Orte ${ }^{1}$ ) vorbrachte, so wird sich obiger Fall dahin erklaren, dass die versehiedenen Zustande des Nervensystems bei dem Begattmugact, der Unterhrechung desselben durch die Gefangennahme, und nachfolgender Ruhe in dem Glasgetäss, ingen Ausdruck in rem Spiel der beweglichen Farbzellen der äusseren Hant gefunden haben.

„Ecco - schliesst Vabisnier seine Mittheiluug - ne' nostri lucertoloui, o ramarri un segnale molto considerabile simile a quello de Camaleonti Affricani, ciò̀ la mutazione de' colori, onde possiamo chiamargli i Camaleonti d'Italia, ornandosi anche i nostri l'estate del più vago, loro colore ch' è il verde. Non lo cangiano cosi frequentemente, si perchè sono privi di. quelle intralciatissime piegoline, o solchi che osservammo nella cute di quelli.“

Nicht unter den Begriff des Farbenwechsels gehört die bekannte Erscheinung, dass mmittelbar nach dem Abwerfen der Epidermis bei der Häutung alle Farbentöne grosse Frische und thlanz zeigen. Wie sehr überhaupt die Oherbant die Farben der Lederhant abdampft, macht sich anch dann sehr anffällig, wenn wir eine frische Lacertu agilis einige 'lage in sehr verdünnte Salzsïure legen und dimn die Epidermis abziehen. Alle Farben treten jetzt ungleich schärfer und satter zu lage.

Die Bewegrngen der Blindschleiche, obschon wegen Mangels der Gliedmassen im Allgemeinen schlangentörmig, weichen doch nisht wenig von jenen der Schlangen ah. Da nemlich die Haut der Blindschleiche duroh wirkliche lialktafeln gevanzert ist, so geschehen ihre Krümmungen nicht in kurzen Wellenlinien, wie solches bei den Schlangen in hohem Mass eintreten kamn, sondern, unter gewöhnlichen Umständen auf ebenem Boden, in grösseren Curven. Nur wemn sie sich im Steingeröll und Pflanzengewirr durchzudrücken haben, vermögen sie anch engere

1) Molche der Württemb. Faun:l, Arch. f. Naturgesch. 1867. 
Krümmungen anzunehmen, die jedoch wie alle sonstigen Bewegungen des Thieres, wegen der rerkalkten Lederhaut, etwas starres an sich haben; recht im Gegensatz zu den höchst geschmeidigen Windungen der echten Schlangen, die durch keine Verkalkung der Lederhaut behindert sind.

Wie bereits bemerkt, habe ich zwei andere Scincoiden, den Gangylus occllatus und den Ablepharus pannonicus längere Zeit im Zimmer gehalten und hier denselben Unterschied gegenüber von den Eidechsen, denen die beiden Gattungen durch Besitz von Gliedmassen näher stehen, beobachtet. Trotz aller Behendigkeit, die namentlich dem Ablepharus eigen ist, geht den Körperkrümmungen, offenbar wegen der linöchernen Hauttifelchen, etwas an del Geschmeidigkeit, woulurch sich die cchten Eidechsen auszeichnen, ab. Noch auffälliger ist wegen Grösse des Körpers diescr Unterschied bei Pseudopus Pallasii; die Bewegungen sind ungefüge und weit entfernt von der Leichtigkeit der Weise, wie Schlangen sich wiuden und drehen.

Der auf lebendiger Zusammenziehung von Chromatophoren beruhende Farbenwechsel ist anch bei der Blindschleiche deutlich wahrzunehmen.

Ich lıatte ein junges, wohl im zweiten Jahre stehendes 'Thier getangen, dessen Rückenseite das schönste Kastanienbrann zeigte, in der Mitte mit schwarzen Längsstreif; des anderen Tages war das Kastanienbraun in ein ganz leichtes Gelbbraun übergegangen, auf dem sich jederseits neben dem schwarzen Längsstreif jetzt ein paar andere, weun auch nur schwach bräunliche Lingsbinden abhoben.

Bald darauf kamen mir mehrere einjährige Thiere in die Hände, welche noch die bekanıte weisse Rückenfärbung der Jungen hatten. Ueber Nacht waren auf dem vorher mit Ausnahme der dunkeln Rückenlinie ganz weissen Rücken zwei zarte Längstreifen erschienen.

Unten werde ich von einer schönen hellstreifigen Varietait zu berichteu haben, welche ich hinter Schloss Planta bei Meran fieng und wegen ihrer ungewöhnlichen Färbung mit mir lebend nach Tübingen nahm. Als ich aber dort angekommen das Kästchen öfnete, war die Schönheit verschwunden, das Thier sab, iudem es einen gleichmässig dunkeln Ton angenommen hatte, so ziemlich aus wie cine gewöhnliche Bhindschleiche. Aber ins Terrarium gesetzt hellte sie sich, namentlich beim Eintritt somiger warmer Tage, wieder auf und zeigte über den Rücken und die Seiten bis zur Mitte des Bauches, auf schönem grauweissen Grunde, dicht gestellte feine Längsstreifen; nux die Mitte des Bauches nalm eine etwas breitere Binde ein. - Ein Thier, welches ich an einem rauhen Apriltage gefangen, war schön braun in der Grundfarbe; im gehcizten Zimmer hatte sich nach einigen Tagen das Braun in ein sehr helles Mäusegrau umgesetzt.

Die Beispiele mögen genügen, auch andere Beobachter auf einen Vorgang aufmerksam zu machen, der bisher an diesem Saurier noch nicht angezeigt wurde.

\section{Nahrung.}

Eidechsen.

Unsere Thiere sind was die Stoffe anbelangt, welche sie zu sich nehmen, bekanntlich Fleischfresser und zwar in ausgeprägtester Weise. Ich kiun z. B. bestätigen, was schon wiederholt von Andern beobachtet wurde, dass frisch gelorene zarte Jungen von den Alten verschlungen werden, obschon es keineswegs an Nahrung fehlte. Auch die Brut im Zuvinger zur Welt gekommener Blindschlei- 
chen wurde mit Gier von den Eidechsen verspeist. Nach DUGÉs sollen sie auch die Eier der eigenen Art gerne auffressen, worüber ich keine Beobachtung habe.

Ihre gewöhnlichste Nahrung holen sie indessen aus dem Reich der Gliederthiere, ${ }^{1}$ ) und zeigen sich im Freien viel weniger wählerisch als in der Gefangenschaft. Dranssen sind, wie die unmittelbare Beobachtung und anatomische Untersuchungen lehren, die verschiedensten Käfer nach ihrem Geschnnack; während sie im Zwinger z. B. Laufkäfer, Bockkïfer, Chrysomelinen nicht anrühren, eher noch Cetonien (C. aurata, Hoplia squamosa, Valgus hemipterus), anch wohl kleinere Melolonthiden, z. B. Arten von Rhizotrogus. Das Lieblingsfutter bilden Larven, Raupen, Heuschrecken, Grillen (Lacerta viridis frisst selbst Maulwurfsgrillen mit grossem Behagen), überhaupt weichere Insecten; dabei sind insbesondere Laubheuschrecken Leckerbissen; wenn $L$. agilis die Auswahl hat zwischen der zarten Phaneroptera falcata und dem Acridium coerulescens wird sie immer die ersteren vorziehen. Auch Regenwürmer nehmen sie, doch nicht mit sonderlicher Vorliebe. Nur Lacerta viripara verhielt sich hierin auders. Da diese Eidechse vorzugsweise im Fenchten lebt scheint sie mit Regenwürmern vertrauter zu sein, als die anderu Arten es sind. Mit Ueberraschung sieht man, wie das kleine Thier sich auf ganz grosse Würmer stürzt und mit ihnen fertig zu werden weiss.

Grössere, weiche Insecten wie Heuschrecken und Grillen, werden von den Eidechsen gerne in der Quere gepackt; anch die Regenwürmer fassen sie auf diese Weise, und in Gesellschaft zerstücken sie leicht und rasch einen langen derartigen Amneliden. Im Frühling und Sommer ist der Eifer im Fressen so gross, dass sie sich gegenseitig den Bissen aus dem Maul reissen; wie aber die Temperatur herabgeht, verringert sich der Appetit. Vor dem Niederschlingen des Bissens machen sie, wenn er nicht von vorne herein ganz weicher Natur ist, imancherlei, zum Theil heftige Káabewegungen; sie lassen übrigens den Bissen, sobald sie nux etwas gestört werden, leicht fillen. Nach. gehaltener Mahlzeit schlecken sie oft lange mit vorgestreckter Zunge die Schnanze und Wangengegend ab. - Honigstüekchen ron Zeit zu Zeit in den Käfig gebracht, und mit etwas Wasser besprengt, werden mit

1) Nach Purxivs (Lib. VIII) sollen die Eidechsen besonders den Schnecken nachstellen: lacerta inimicissimum genus cochleis, welche Ansicht jetzt noch im Süden Geltung zu haben scheint. Einigen Eidechsen, welche wir von der Insel Sardinien lebend zugeschickt wurden, war die dickschalige Helix candidissima, zu meiner Verwunderung, als Nahrung in grosser Anzahl beigegeben. (E. v. MArtens in seinen Reisebemerkungen aus Italien, Malak. Bl. 1857, aussert sich über die Weichtheile dieser Schnecke sehr richtig dahin, dass sie eben so massiv seien, wie die Schale. Indewn er sie nüher beschreibt, sagt er auch, er habe die Weichtheile nicht von. schwarzer Farbe gesehen, swie man sie aus Sardinien beobachtet haben will.. Es mag desshalb erwälnt sein, dass alle meine Exemplare aus genannter Insel in der That ganz schwarz waren, wodurch das Thier zu seiner kreideweissen Schale einen seltsamen Gegensatz. bildete.)

Loydig, Saurier. 
dem ausgesprochensten Behagen beleckt; auch sah ich, ${ }^{1}$ ) wie Lacerta muralis um reife abgefallene Feigen in Menge sich sammelte, um gierig an dem blossgelegten Inneren der Früchte zu lecken, und der Trupp immer wieder bald zu dem Schmausse zurückkehrte, wenn er davon verscheucht worden war.

Dass die einen Individuen sich leicht zur Annahme von Futter in der Gefangenschaft verstehen, die anderen gar nicht, endlich dass besondere Neigungen in der Auswahl der Nahrung vorkommen, wird Jeder, welcher sich mit dem Halten und der Pflege der Eidechsen abgibt, erfahren. Mir war z. B. auffallend, wie mehrere Individuen von $L$. agitis, und ebenso solche von $L$. muralis var. campestris, auf Regenwürmer lebhaft stiessen und sich darum rissen, während $L$. muralis (die Stammform), obschon ebenfalls durch den Eifer der anderen herbeigezogen, die Würmer immer verschmähte, hingegen sich sehr erpicht auf die grossen Fleischfliegen zejgte, und sie geschickt zu fangen wusste.

Wie nützlich sich die Eidechsen durch Wegfangen zahlreicher Insecten dem Landwirth machen können, geht schlagend aus den Erfahrungen ERBER's in Wien hervor.

„Eine Lacerta viridis - diese Art scheint besonders gefrässig -zu sein - verzehrte vom Februar bis November nicht weniger als 2040 Mehlwürmer, 112 grosse Heuschrecken, 58 Cetonia aurata, über 200 Regenwürmer und 408 grosse Fliegen, wozu noch zwei Separatmablzeiten mit je 18-20 Stück Mantis religiosa $\subsetneq$ und mehrere hundert kleinere Käfer zu reclnen sind, so dass dieses Thier, ein mittelgrosses Männchen, während dieser Zeit mehr als 3000 Stück Insecten sämmtlich grösserer Gattung verzehrte." Aber es ist wohl mit ERBER anzunehmen, dass das Thier im Freien noch ganz anders aufräumen mag, wo ihm nicht jeder Bissen vorgezäblt wird und es seinen starken Appetit genügend befriedigen kann. Trotzdem wird nach wie vor der unverständige Mensch diese und andere nützliche Thiere verfolgen und tödten, so oft sich die Gelegenheit bietet.

Die Eidechsen sind auch des Wassers sehr bedürftig. Im Freien lecken sie den Thau; ein aufmerksamer Beobachter kann die Mauereidechsen, welche in den späteren Stunden des Vormittags auf Planken und Mauern sich sonnen, immer in der Frühe am Boden treffen, damit beschäftigt, den Thau von Gras und Kräutern einzusaugen. In der Gefangenschaft trinken sie gierig das Wasser, womit man das Moos und die Pflanzen des Terrarimms besprengt, oder ihnen auch in einem Gefäss vorsetzt. Mangelt ihnen das Wasser, so legt sich ihre Haut bald in Falten, was sich zusehends wieder ändert, wem sie nach Beliehen dieses nothwendige Element aufnehmen können.

Das Trinken geschieht, was schon die alten Beobachter wissen, nach Art der Hunde; doch mit dem Unterschiede, dass nur die untere Fläche der hervorgestreckten und verbreiterten Zunge auf das Flüssige gebracht und dann zurückgezogen wird, ohne dass ein eigentliches Auflöffeln, durch Hohlmachen der Zunge, stattfindet. Die Art des 'Trinkens liess sich besonders gut an der grossen L. viridis aus Dalmatien beobachten, indem man ihr einen Kaffeelöffel voll Honigwasser darreichte, welcher innerhalb einer Minute völlig geleert wird. Hiebei schlägt zunächst das Thier die

1) Am Strande einer stillen, einsamen Bucht des Gardasees. 
verlüngerte, röthliche und an der Spitze etwas schwärzliche Zunge herans, welchem Herausschlagen dann ein Eintunken in die Flüssigkeit folgt, mit einiger Ausbreitung der beiden Zungenspitzen. Ich denke mir, dass jetzt die Lücken zwischen den Papillen an der Zungenoberfliche sich mit Flüssigkeit füllen, wornuf dann das so beladene Organ zurückgezogen wird, um den Vorgang von Neuem rasch zu wiederholen.

Hält man Eidechsen bei guter Nahrung in Gefangenschaft, so lässt sich beobachten, dass jeder Excrementballen aus zwei scharf geschiedenen Theilen besteht: aus einer grösseren länglichen, in frischem Zustande dunkelkaffeebraunen Masse, oder dem eigentlichen Kothballen, ${ }^{1}$ ) welcher die nicht einverleibbaren Speisereste, namentlich das Chitinskelet von Insecten, enthält, und zweitens ans einer daran hängenden Partie vom Aussehen eines kreideweissen Kalkbreies; dieser stellt den Harn vor. Alle Arten unserer Eidechsen verhalten sich darin im Wesentlichen gleich, nur dass in der Form und Grösse der beiden Massen theilweise noch die Speciesverschiedenheit sich kund gibt. Bei L. muralis ist z. B. der Kothballen von einfach länglicher Gestalt und der Harn von halbkugeliger, Brodlaibartiger Form; bei $L$. agilis hingegen ziehen beide Theile mehr ins Längliche und sind gekrümmt; bei den ganz grossen dalmatinischen Thieren ist es eim zollanger schwach birnförmiger Körper. Dieser Harnstein, wenn wir ihn so nemnen wollen, ist nach hinten, da wo er an den Excrementballeu anstösst, etwas gelblich gefärbt; während er im Uebrigen lebhaft weiss aussieht. Das Ganze ist dem gegenüber, was man bei Amphibien sieht, so auffallig, dass bereits vor vielen Jahren SchreIber's ${ }^{2}$ ) in Wien, welcher ebenfalls naturhistorischer Beobachtungen halber Eidechsen in Behältnissen pflegte, einen noch im Augenblick lesenswerthen Aufsatz darüber veröffentlichte. Es nähern sich bekanntlich auch in diesem Puncte die Reptilien den Vögeln, nur dass bei letzteren das Prodnct, man könnte beinahe sagen, nicht die zierliche Ausprägung wie hier bei den Eidechsen hat.

In grösserer Anzahl und von derselben Art in einem Terrarium gehalten, setzen einzelne Thiere ziemlich regelmässig die Excremente an einen bestimmten einmal hiefür gewählten Ort ab. Bei der Entleerung nehmen sie durch Aufwïrtskrümmen des Schwanzes und Niederdrücken des Hinterleibes eine Stellung an, wie manche Säugethiere bei gleicher Verrichtung; und wie schon nach dem Bau der

1) Dieselben enthalten im frischen Zustande regelmässig dichte Massen ron Vibrionen.

2) Grumerts Annalen der Physik 43. Bd. (1813). - Vergl, auch Varzisyreri a. a. O. Seite 73. 
Theile sich schliessen lässt, das Harnconcrement geht dem Kothballen immer voraus. - Die besondere Form und Verbindung der Harnconcremente mit dem Kothballen macht, dass man die Excremente der Eidechsen im Freien leicht erkennt und auf das zahlreiche Vorkommen, z. B. an Manern, wo man etwa bei bedecktem Himmel kein einziges Thier sieht, schliessen kann. - Während die Eidechsen an sich keine unangenehme Ausdünstung haben, und nur im frischen Zustande zergliedert, einen eigenartigen, nach méiner Ausicht aus den drüsenähnlichen „Organen des sechsten Sinnes" stammenden Geruch ${ }^{1}$ ) verbreiten, so riechen ilne Ausleerungen etwas ähnlich wie bei Vögeln und sie können dadurch, bei guter Fütterung, im Zimmer ebenso lästig werden wie die Stubenvögel. Es will mir vorkommen, als ob L. muralis noch am ehesten eine besondere Ausdünstung habe. Wenigstens fällt auf, dass eine Anzahl beisammen in einer Schachtel oder Glas einen sehr starken unangenehmen Geruch entwickeln, der nicht allein von den Excrementen herzurühren scheint.

Bemerkung über Koprolithen. Ich habe: den Harnklumpen von Pseudopus Pallasii auf der neunten Tafel, Fg. 123 unter der Lupe abgebildet, um vielleicht die Aufmerksamkeit der Paläontologen auf diesen Körper lenken zu können. Es ist mir nämlich sehr wahrscheinlich, um nicht zu sagen, gewiss geworden, dass manche der Bildungen, welche man herkömmlich als Koprolithen der Saurier anspricht, nicht eigentlich Excrementballen sind, sondern solche Harnconcremente. Wer die wirklichen Kothlaufen der Saurier und die Harnmassen in frischem Zustande ansieht, wird sich gestehen müssen, dass die letzteren bei ihrer von vorge herein steinigen Natur sich eher erhalten werden, als die weichen, leicht zerfallenden Excremente. Dazu kommt, dass beim Absetzen des Harneylinders ins Wasser, was im Zwinger gern geschieht, uer Harnklumpen keineswegs zerfliesst, sondern seine Gestalt noch viel reiner behält, als im Trocknen. Ferner, und desshalb lege ich besonders eine getreue Abbildung vor, der Harnklumpen zeigt auf der Oberfläche zierliche Ringfurchen, von denen wieder feincre verästigte Seitenfurchen abgehen, alles offenbar Abdrücke von Falten der Schleimhaut der Kloake! Durch die Güte meines Collegen r. QuenstedT hatte ich Gelegenheit, diese meine Ansicht an Koprolithen der hiesigen paläontologischen Sammlung, sowie an solchen, welche Dr. ENDLICII $^{2}$ ) in grösserer Menge aus dem von ihm näher studirten Bonebed bei Bebenhausen gesammelt, zu prüfen. Es ergab sich hiebei, dass allerdings die Koprolithen aus dem Bonebed eine ganz überraschende Aehnlichkeit mit den Harnmassen des Pseudopus darboten; insbesondere auch, was die Art der Furchenbildung auf der Obertläche betrifft. Dann musste ich aber hinwieder meinem Collegen r. Quenstedt zustimmen, wenn er Koprolithen von Fischen der hicsigen Sammlung, z. B. von Macropoina, in hergebrachter Weise als wirkliche Excrementballen ansah und ihre, in der That durchaus spiralige Furchenbildung von der Spiralklappe des Darms nach wie vor ableitete. Es scheint somit, dass man bisher unter dem Namen Koprolithen verschiedene Bildungen zusammen geworfen hat und zwar

1) wirkliche Kothballen der Fische, mit Spiraltouren versehen und auch von einer Grösse, dass sie ganz wolll als Abdruck eines mit Spiralklappe ausgestatteten Darmes gelten liönnen.

2) Harnklumpen oder Harnconcremente, welche lediglich den Sauriern angehören und auf der OberAäche nicht eigentliche Spiralgänge, sondern nur Ringfurchen mit seitlichen Auslaufern zeigen.

1) Vergl. oben den anatomischen Theil (S. 101.)

2) Freperac Mriten-Exduci, das Bonebed Württembergs. Inauguraldissertation, Tübingen 1870. 
Auf Grund der Beobachtung, wie sie im Voranstehenden dargelegt wurde, müssen auch Bedenken über die Anwesenheit einer bisher vorausgesetzten Spiralklappe im Darm der Ichthyosauren aufsteigen: jedenfalls möchte ich die Frage weiterer Forschung empfehlen.

Blindschleiche.

Die Nahrung unserer Blindschleiche besteht vorzüglich in Regenwürmern; es ist nichts allzuseltenes, dass man im freien, beim Aufheben von Steinen, auf Thiere stösst, welche gerade einen Regenwurm im Mund halten. In der Gefangenschaft packen sie vor den Angen des Beobachter's die Regenwürmer, und öfters bietet sich der Anblick dar, dass zwei Blindschleichen zugleich an einem und demselben Wurm zerren. Ich habe bis jetzt nicht gesehen, dass sie den Wurm jemals in der Quere, wie Eidechsen es thun, gefasst hätten, sondern immer packten sie ilm von vorue oder von hinten. Sieht man näher zu, so lässt sich gewahren, dass die Zühne der Blindschleichen wegen der feinen spitze und Rückwärtskrümmung sich fester in die Bente einhacken, als solches bei den Eidechsen der Fall ist. Es soll damit den Blindschleichen wie' den Schlangen gewissermassen das ersetzt werden, was die Eidechsen durch den Besitz von Gliedmassen voraus haben. Iehrere Schriftsteller theileu mit, dass unsere Thiere in der Gefangenschaft niemals Nahrung zu sich nehmen, welche irrige Angabe darauf beruhen mag, dass die Thiere unter sehr unnatürlichen Verhältnissen zu leben hatten.

Gleich den Eidechsen trinken sie das in den Behälter gespritzte Wasser ebenso eifrig und wie diese schlappend, nach Art der Hunde. Die Zunge, weil kürzer, wird weniger weit dabei vorgestreckt als bei den Eidechsen.

An dieser 'Stelle möchte vielleicht mitzutheilen sein, wie lange überhaupt Eidechsen und Blindschleichen bei mir die Gefaugenschaft ertrugen. Keines dieser Thiere, obschon mit Nahrung und Wasser immer versorgt und unter möglichst naturgemässe Verhältnisse gesetzt, konnte ieh zwei volle Jahre am Lehen erhalten. Die meisten, insbesondere $L$. vivipara giengen früher ein; diejenigen. welche am längsten ausdauerten, starben gegen Ende des zweiten Winters.

\section{Athmung; Stimme.}

Im Hinblick auf die Athmungsbewegungen nehmen die Eidechsen eine Mittelstellung zwischen den Batrachiem und den Tögeln ein. Mit den ersteren 


\section{4}

haben sie noch bei Mangel eines eigentlichen Zwerchfells gemein, dass unter Mithülfe des sich zusammenziehenden Schlundkopfes die Luft in die Lungen gelangt, welche Bewegungen aussen an der Kehle deutlich sichtbar sind. Andererseits, im Besitz eigentlicher Rippen, athmen sie wie die Vögel durch Erweiterung und Verengerung des Brustkorbes. Das scheinbar feiste Aussehen, welches die Thiere oft wie plötzlich, namentlich in der Sonnenwärme annehmen können, rührt, wie schon oben erwähnt, von der starken Füllung der Lungen mit Luft her.

Die Blindschleiche steht, wie in so vielem Anderen den Schlangen näher; es fehlen die Bewegungen der Kéhle und die Athmung geschieht lediglich durch Heben und Senken der Rippen. Dasselbe sieht man am Pseudopus.

Keine unserer einheimischen Eidechsen verräth anch nur die Spur einer Stimme; sie sind so gut wie die Blindschleichen völlig stimmlos. Die den Küsten des Mittelmeeres eigenthümliche kleine Lacerta Edwardsii gibt nach DuGÉs unter Umständen einen Laut von sich, der an das Knarren der Bocklkäfer erimnere; und die grosse südliche $L$. ocellata blase im Zorne die Luft so heftig von sich, dass eine Art Stimme dadurch erzengt werde.

\section{Fortpflanzung.}

Eidechsen.

Der (ieschlechtstrieb scheint bei diesen Thieren, wie bei allen Amphibien und Reptilien „trotz des kalten Blutes“ sehr heftig zu sein. (GESSNER ${ }^{1}$ ), nachdem er das, was ARistoteles und Plinids über die Begattungsweise der Eidechsen sagen, mitgetheilt, bemerkt: Audio eas vere circa exitum Martii (passt, weil zu frähe, nicht auf die deutschen Eidechsen) inter se complicatas coire, non supervenientes, sed incumbentes lateribus et ventribus junctis se amplectentes, caudis et reliquo corpore intortis." OтTH") hat Lacerta ocellata, und GLUCKSELIG ${ }^{3}$ ) Lacerta viridis bei der Begattung überrascht. Das Männchen der ersteren Art hielt das Weibchen ungefihlı während einer Stunde mit den Hinterfüssen fest umklammert, wie diess die Krö̈ten und Frösche mit den Vorderfüssen zu thun pflegen. ${ }^{4}$ ) Die Stellung war, wie Oтти .

1) De quadrup. ovip. p. 31.

$\left.{ }^{2}\right)$ Zeitschr. f. Physiologie, 1831.

3) Zool. bot. Verein in Wien, 1863.

1) Daraus begreift sich, warum bei allen Eidechsen die Männchen dickere Hinterbeine haben, als die Weibchen; welchen Punct ich unter die sehr brauchbaren Kennzeichen der Geschlechter aufgenommen habc. Отти sncht auch die physiologische Bedeutung der schenkelwarzen aus dem Beobachteten festzustellen. Schon Maissxer 
sagt, höchst sonderbar und gezwungen: beide Thiere sassen nebeneinander, mit den Zähnen hielt das Münnchen das Weibchen am Vorderleib fest, den After hatte es unter den des Weibchens gedreht und beide Schenkel waren fest um die Weichen desselben geschlungen, so dass von den Genitalien nichts sichtbar war. Als sie sich endlich losliessen, lagen sie noch einige Minuten mit anfgespertem Rachen nebeneinander und verkrochen sich dann, wie plötzlich aus ihrem Taumel erwachend, eilig unter die Steine! Weiter ins Einzelne hat GLC̈ckselig seine Beobachtungen ausdehnen können; er beschreibt eigenthümliche Bewegungen von Seite des Männchen und Weibchen bei der Annäherung, dann den Vollzug der Begattung und dass dieselbe mehrmals des T'ages erfolge.

Das Wenige, was ich bisher an Lacerta agilis beobachten konnte, stimmt mit den Angaben des letzt Genannten überein; ich sah, wie das Männchen mit eigenthümlich gekrümmtem, seitlich zusammengedrückten, daher kantigem Rücken (Katzenbuckel) und bogig gehobenem Schwanz sich dem Weibchen nüherte, um es zart am Kopfe mit den Zähnen zu fassen. Das Weibchen gilbt seine Geneigtheit namentlich durch zitternde, wellige Bewegungen des Hinterleibes und der Schwanzwurzel zu erkenuen. Auch pflegt wohl das Weibchen, während der Hinterleib einladende Bewegungen ausführt, den Mund weit gegen das Männchen aufzusperren, wie wenn es diesem etwas zu sagen hätte, was ihm aber offenbar in der Kehle stecken bleibt.

Die Entwickelung und Reife der Samenelemente geht bei $L$. agilis gleichen Schritt mit der Ausbildung der Farbe des Hochzeitskleides. Thiere, welche schon mit dem „frendig Grün“ geschmückt sind, zeigen den Nebenhoden und den Samengang prall erfüllt mit lebhaft sich bewegenden Zoospermien. Mănnchen hingegen aus der ersten Hälfte des Mai, deren Seiten erst einen grünlichen Ton angenommen haben, bieten auch innerlich noch jüngere Zustände dar. Im Hoden hat zwar die Samenbildung begomen, aber die Nasse der Zoospermien liegt noch zusammengekrümmt in den Zellen und wenn frei geworden, ist sie ohne Bewegung. Einzelne Zoospermien sind-bereits in den Nebenhoden gelangt und diese bewegen sich. Die C'anäle des Nebenhoden sind um die angegebene Zeit mit einer. Masse erfült, welche

hatte bereits vermuthet, dass die Warzen eine ähnliche Bestimmung haben, wie die Daumenschwiele des mämnlichen Frosches: sie mögen zum Festbalten des Weibchens dienen. Oxrm hält diese Ansicht für erwiesen. Ich selber bin hiervon nicht so ganz überzeugt, ohne darauf Werth legen zu wollen, dass die Papillen der Daumendrüse des Erosches und die Schenkelwarzen der Eidechse von vorne herein morphologisch ganz verschiedene Dinge sind; denn man kennt mehr als ein Beispiel, dass morphologisch einander ungleiche Theile doch ähnliche Leistungen ausführen können. Aber eines mag nicht unerwähnt bleiben. Man kann auf Querschnitten der Ruthenkörper, in der Lichtung des eingestülpten Organes auf gelbliche Massen stossen, welche in der Farbe und Zusammensetzung mit der Substanz der Schenkelwirzen übereinstimmen, so dass matu eler an Secrete, die abgeschieden werden solleu, denken möchte, als an Haltappunte. - Vgl. üb. die Schenkeldrüsen auch VArıssrer (a. ̊. O. pag. 107). 
sich, als Secret der Epithelwand, wahrscheinlich dem Samen beizumischen hat. Sie besteht aus Förnchen, welche nahezu die Beschattung von Fett haben, aber doch wohl aus Eiweiss bestehen. Die Epithelzellen, bei Thieren aus noch früherer Zeit ziemlich niedrig, haben sich jetzt zu hohen Cylinderzellen entwickelt, welche im hinteren Theil hell, im vorderen trüb körnig sind. Dieser Abschnitt der Zelle verwandelt sich in das erwähnte Secret.

Alle unsere Eidechsenarten, mit Ausnahme der darnach benannten Lacerta vivipara, legen Eier und es ist ganz irrig, wenn hin und wieder gesagt wird, z. B. von GLOGER, dass auch Lacerta muralis lebendige Junge gebäre. Die Weibchen der L. viridis legen nach der Beobachtung GLÜCKSELIG'S genau vier Wochen nach der ersten Begattung sechs bis acht Eier, von gelber Farbe und der Grösse einer kleinen Bohne. Mauereidechsen, welche Ende Mai eingefangen wurden, setzten in der Nacht des 4. Juni in die Erde und das Moos meines Terrariums eine Anzahl Eier. Auch L. agilis scheint die Nacht zu wählen zum Ablegen der Eier; wenigstens war es so bei allen Thieren die ich im Zimmer hielt.

Gegen Ende Mai ist die Haut des trächtigen Weibchens unserer L. agilis so gespannt, dass man die Umrisse der einzelnen im Eileiter befindlichen Eier durch die Hautbedeckung deutlich sehen kann; wovon alsdann die natürliche Folge ist, dass nach dem Leggeschäfte die Bauchhaut sehr faltig und runzelig erscheint.

Bekanntlich leuchten die Eier der Lacerta agitis, wenn auch nur vorübergehend, mit hellweiss grünlichem Licht, wie die Johanniskäfer. Der Entdecker dieser merkwürdigen Erscheinung, welche weiter verfolgt zu werden verdient, ist GRTNDLER in Halle gewesen, Maler und Kupferstecher seinem Beruf nach. ${ }^{1}$ ) schrank ${ }^{2}$ ) wollte dieses phosphorische Leuchten einfach von der Füulniss, in welche die Eier übergegangen sein sollten, herleiten, was gewiss unstatthaft ist. Deun mir brachte Dr. MEINERT aus liopenhagen während seines Aufenthaltes hier in 'Tübingen eimmal frisch gefundene Eier der L. agilis, mit der Nachricht, dass sie im Dunkeln geleuchtet haben; diese Eier, etwas feucht anfhewahrt, entwickelten im Zimmer ihre Embryonen weiter, waren also keineswegs abgestorben.

Ich selber finde mich in der fraglichen Angelegenheit übrigens in glcicher Lage, wie EMMERT und Hocustister ${ }^{8}$ ) bei ihren Studien über die Lintwicklung der Eidechsen. "Phosphoresciren salien wir weder die Eicr der Eidechsen, noch die der Coluber natrix, ob wir sie gleich in dieser Absicht mehreremale im Dunkeln betrachteten: indessen will Hr. I. Aufseher am Naturaliencabinet in Bern bemerkt haben, dass La-

\footnotetext{
1) Der Naturforscher, Stück 3, 1774.

$\left.{ }^{2}\right)$ Ebendaselbst, Stück 23, 1788.

3) Archiv f. Physiologie, 1811.
} 
certeneier an dem Abend, wo er sie unter Sand fand, leuchteten, aber nicht mehr an den folgenden." Diess letztere stimmt genau nicht nur mit dem, was Grundeer angibt, sondern auch die mir ubergebenen Eier batten nach Angabe MEINERT's nur an dem Abend des Tages, an dem sie gefunden wurden, geleuchtet; später, obsehon ich sie Wochen hindurch unter den Augen hatte, nicht mehr. Es scheint beinahe, dass die Bewegung durch's Heimtragen mitbedingend gewirkt habe, da GruxdeEr zwei Eier, welche nicht lenchtend, zwischen drei phosphorescirenden auf seinem Tisch lagen, llurch Schütteh zu cinem solchen Grad des Lenchtens bringen konnte, dass er in der dunkeln Kammer seine Hand deutlich zn erkennen vermochte. - TrevrRAxus ${ }^{1}$ ) scheint das Leuchten der Eidechseneier überhaupt anzweifeln zu wollen, was nach Voranstehendem ungerechtfertigt wäre.

Der reife Embryo der lebendig gebärenden Eidechse, wenn er zur Welt kommt, wird noch von der Eihant umgeben, sowie das bei allen lebendig gebärenden Amphibien und Reptilien der Fall zu sein scheint. ${ }^{2}$ ) ReichenBaCH ${ }^{3}$ ) hat wohl zuerst gesehen, dass die Jungen der Lacerta vivipara noch innerhalb ihrer Eihaut geboren werden, oder wie unser Autor sich ansdrückt, dass ein kurzer Zustand vom Eileben dem Lebendiggeborenwerden vorausgeht. ${ }^{4}$ )

Den Vorgang des Gebärens, welcher immer, sowie das Eierlegen der anderen Arten, zur Nachtzeit stattzufinden scheint, haben unterdessen wohl verschiedene Beobachter gesehen. Am genauesten und mit meinen Erfahrungen durchaus zusammenstimmend hat A. MEJAKOFF das Benehmen des trïchtigen 'l'hieres vor der Geburt, während und nach derselben, sowie auch die Jungen beschrieben. ${ }^{5}$ )

In trïchtigen Thieren hiesiger Gegend wareu Mitte Juni die Jungen schon wohl ausgebildet; doch mit Ausnahme der Augen und des oben erwähnten räthselhaften schwarzen Stirnfleckes, noch ganz hell und farblos; die weissen Kallsä̈ckchen heben sich am Hinterhaupt aus der gallertartig grauen Umgebung scharf ab. Im Zwinger gehaltene Thiere gebaren gegen Ende Juli, immer Nachts. Die Jungen hatten keine Spur eines iusseren Dottersacks mehr; aber am Bauch eine dentliche kleine Lüngsspalte der Haut, welche etwa der Länge von drei querreihen der Banchplatten entsprach; ans dem Grunde der Spalte schimmert das Grau der Banchmuskeln; die Spalte blieb einige Tage offen. Ich ernährte die allerliebsten, äusserst

1) Erscheinungen und Gesetze des organischen Lebens, 1831, S. 437.

2) Man vergleiche hiezu z. B. Rusconr's Werk über den Landsalamander.

s) Isis ron OKeN, 1837, S. 511.

4) Diese Mitheilung wird leider durch eine andere beigeschlossene Angabe entstellt, dn sie entschieden falsch ist. Rexcmexaci erklärt sich nemlich bei dieser Gelegenheit dahin, dass Lacerta crocea in allen ihren Ständen günzlich verschieden sei von Laceria vivipara, JAce. oder Lacerta montana, Mick. Vergl. hierüber unten den Abschnitt über dic einzelnen Arten.

3) Quelques observations sur les Reptiles du Gouvernement do Wologila. Société des naturalistes de Moscou. Bulletin, 1857. II. 
behenden Thierchen, deren Kopf noch etwas embryonal gross war, einige Zeit mit Blattläusen, welche sie eifrig verspeisten.

Die Eihaut kann aber schon innerhalb des Uterus gesprengt und abgestreift werden; ich habe mehrmals gesehen, dass sie neben den reifen Früchten in Form eines horngelblichen, zerknitterten Häutchens lag. In diesem Falle stellt sich natürlich ein reines Lebendiggeborenwerden ein.

Die Zahl der Embryen wechselt. Die geringste Zahl, welche ich beobachtete, war acht und zwar zu gleicher Hälfte auf die beiden Fruchthälter vertheilt; die höchste Zahl zehen. Sieht man die aus der Mutter herausgenommenen Jungen beisammen, so begreift man kaum, wie eine solche Anzahl wohl entwickelter Eidechsen in dem zarten kleinen Weibchen Platz finden konnte.

In welchem Verhältniss die Zahlen der beiden Geschlechter bei den verschiedenen Arten der Eidechsen zu einander stehen, ist mir noch unbekannt. Von $L$. viridis sah ich im. Herbst mehr Weibchen als Hännchen, aber von L. agilis begegnete ich im ersten Frühjahr entschieden mehr Männchen als Weibchen. Auf diese Beziehung der Geschlechter zu einander komme ich hier desshalb, weil das Nachforschen nach dem Zahlenverhältniss, in welchem die Männchen zu den Weibchen bei den verschiedenen Arten stehen, uns vielleicht einen Fingerzeig zur Beantwortung der Frage geben könnte, was die Differencirung des Geschlechts bedingen mag!

Wenn bei unserer Lacertc agilis die Fortpflanzungszeit vorüber ist, so scheinen sich die Thiere in Verstecke zurückzuziehen, oder zu vergraben, um vielleicht in ähnlicher Weise, wie es bei Wassermolchen vorkommt, eine Art Sommerschlaf zu halten. Es ist eine Thatsache, die Jeder leicht bemerken wird, dass im Frühjahr an einem bestimmten Orte die Eidechsen sehr häufig sein können und später, etwa gegen Ende Juli him, geradezu selten geworden sind, namentlich wenn starke Hitze sich eingestellt hat. DUGÉS hat dies auch längst wahrgenommen und ebenfalls dahin ausgelegt, dass die Thiere entweder in eine Art Erstarrung, Sommerschlaf, verfallen oder sich in kühle, feuchte Verstecke zurückziehen. $\left.{ }^{1}\right)$

Hiebei will ich nicht unterlassen zu gestelien, dass ich einige Zeit die Vermuthung hegte, als handle es sich um ein normales Erlüschen des Lebens, nachdem das Fortptlanzungsgeschüt vorüber sei. Es war mir immer merkwürdig gewesen, dass ich bei keiner weiblichen Eidechse, welche ich in den Monaten Mai

1) "Au printemps Lacerta muralis est le premier à paraitre; wais, des que l'été commence à brûler les campagnes, on ne le voit presque plus, soit qu'il tombe alors dans un engourdissement comparable à celui que la chaleur fait éprouver is certains animaux, soit qu'il se retire volontairement dans des lieux ombragés et humides ou il puisse aisement réparer par absorption les pertes que la transpiration lui fait faire.e 
und Juni zergliederte, Spuren früherer gelber Kürper, das lieisst, inı vorigen Jah geborstener Eifollikel antraf. Inmer waren es lie frischen diesjährigen Follikel und gerade so viele als Eier im Uterus sich befanden. Allein spätere Untersuchungen an einer Blindschleiche lassen anuehmen, dass die gelben Körper des Vorjahres sich völlig auflösen, und im Mai und Juni des nächsten Jahres keine Spur mehr von ilınen übrig geblieben ist. Eine Blindschleiche nämlich, welche während des Sommers im Zwinger Junge zur Welt gebracht, zeigte, als sie in darauf folgenden Monat März getödtet und untersucht wurde, un diese Zeit in Eierstock deutliche Spuren der gelben Körper und es begriff sich, dass sie, jetzt schon sehr kleiı, bis zu der angegebenen Zeit völlig geschwunden sein lionnten.

Noch einer andern Beobachtung, die in dem vermeintlichen Sinn gedeutet werden konnte, sei gedacht. Ich hielt in einem wohl eingerichteten Behälter cine ganze Anzahl von Lacerta agilis, welche sich bei reichlicher Füterung und immer vorhandenem Wasser gut hielten und namentlich die Weilchen verzehrten vor meinen Augen erstaunlich viele lRegenwürmer und Insecten. Nachdem aber die Eier abgesetzt waren es geschah im Juni - anderte sich die Scene in auffälliger Weise. Am Leib der Weibchen erloben sich die schon erwähnten zwei hohen Längsfalten als Folge der vorher durch die Eier bedingt gewesenen Ausdehıung der Haut; der Appetit verfiel gänzlich; die Thiere verkrochen sich und starben in Kurzem alle weg. Dasselbe Schicksal erfuhren viele del gleichalterigen Männchen. Jüngere Männchen und Weibchen hingegen, noch nicht geschlechtsreif, blieben am Leben, munter und frisch! Musste man biebei nicht unwillkürlich die Fälle sich ins Gedächtniss rufen, dass unter gleichen Umständen viele niedere Thiere, und auch einzelne Wirbelthiere, z. B. Neunaugen, nach Beendigung des Laichgeschäftes linsiecheu? Allein es ist doch wohl richtiger, die Erscheinung so zu erklären, dass die Thiere das Bedüfuiss empfanden, sich dauernd in passende kühle Verstecke zurück zu ziehen, welche der Behälter ihnen nicht, wenigstens nicltt in dem nothwendigen Maasse, gewähren konnte. Auch begeguete ich mehrmals Ende August, wenn nach längerer nasskalter Witterung wieder ein milder sonniger Tag erschien, an den gewohnten Plätzen, erwachsenen Thieren in grösserer Zahl, die ich als solche ansehen möchte, welche sich erholt hatten. Auch was $L$. muralis anhetrifit, so tummelt sich im Herbste cine Menge zweifellos alter Thiere, zum Theil schon mit lebbaft braunrothen Bauch gesclmückt, an Mauern und Felsen herum, obschon allerdings die Hauptmasse der oft in ungemeiner Zahl einen Fleck besetzt haltenden Thiere um diese Zeit aus ganz jungen und halberwachsenen bestelit.

Blindschleiche.

Die Art und Weise der Begattung konnte ich bis jetzt nicht wahrnehmen. Nach Tschupl geschieht sie im Mai und Juni an sonnigen Stellen, unter inniger Umschlingung, wie bei den Nattern, und danert einige Stunden. - Bekanntlich gehört die Blindschleiche zu den lebendig gebărenden Thieren, ') und die Reife der Jungen fallt gegen Ende August oder in den Anfang des September.

Hochtrïchtige Weibchen unter Wasser geöffnet, gewähren einen merkwürdigen Anblick: der Uterus ist so dünnwandig, dass das schön gefärbte Junge und sein Dottersack vollkommen durchschimmert; der Embryo ist um den Dottersack spiralig gerollt und zwar so, dass bei allen Eimbryen der Dottersack nach unten, d. h. gegen

1) Manche Autorer, selbst solche, welche viel mit der freien Natur verkebrten, wie z. B. Gisxi (Isis 1829) lassen unsere Blindschleiche Eier legen. Noch im Jahre 1862 wird von Sracck (Arch. d. Vereins d. Freunde d. Naturgesch. in Mecklenburg) dasselbe wiederholt. 
die Bauchseite der Mutter steht. Das Ei, anfänglich von mehr walzenförmiger Gestalt, wird spater beim Schwinden des Dottersacks scheibenförmig.

Die Zahl der Eier im Fruchthälter wechselt auch hier, und scheint auf beiden Seiten immer verschieden zu sein, z. B. neun Embryen rechts und elf links, oder sieben auf der einen, neun auf der anderen Seite. Und gleich den übrigen paarigen Organen der Leibeshöhle, welche wie Nieren, Hoden, Ovarien nicht die gleiche Höhe in ihrer Lage einhalten, so erstrecken sich auch die Leibesfrüchte auf der einen Seite höher hinauf, als auf der anderen und hören nach unten auch ebenso verschieden tief auf. 


\section{Dritter Abschitt. \\ Die einzelnen Arten.}

Ordnung der Echsen, Sauria.

Kaltblütige Wirbelthiere olne Netamorphose; Émbryo mit Amnion und $\mathrm{Al}$ lantois; Eierlegend mit Uebergang zum, Lebendiggebären. Leib gestreckt und mit langem Schwanz, meist mit vier verhältnissmässig kurzen aber wohl ausgebildeten Füssen, deren ungleichlange Zehen scharfe Krallen haben: dann im Allgemeinen von der Gestalt der Crocodile; manchmal mit Stummelfüssen; in anderen Făllen ohne äussere Gliedmassen: dann von Schlangenform. Kiefern bezahnt, selten Zithne am Gaumen. Kiefer-Gaumengerüst nicht verschiebbar. Meist mit beweglichen Augenlidern.

\section{Unterordnung der Schuppenechsen, Squamata.}

Die Hant meist mit schuppenartigen Abgrenzungen. Das Paukenfell frei oder unter der Haut. Zunge verschieden gestaltet, aber immer vorstreckbar. Zwei Ruthen. After eine Querspalte.

Familie der eigentlichen Eidechsen, Lacertina.

Körper walzig gestreckt, Kopf wohl abgesetzt vom Halse, Schwanz selı lang und dünn anslanfend; vier fünfzehige F'üsse; Zehen an den Hinterfüssen sehr ungleich lang. Haut, mit Ausnahme der Schenkelporen, drüsenlos; Oberhant zu Schuppen und Schildern verhornt. Lederhaut ohne Kalktafeln. Zähne in einer Rinne der Ober- und Unterkinnlade und deren innerer Seite angewachsen (seitenzähnig); mit oder ohne Gaumenzähne; lorm des Zahnes kegelförmig, gerade, am freien Ende etwats gebogen, ohne eigentliche Wurzel, zweispitzig, eine zweite Reihe lileinerer oder Ersatzzähne am Grunde der Hauptzähne. Oberer Rand der Augenhöhle mit Knochenplatten; freie Augenlider; Ohr (Paukenfell) äusserlich sichtbar. Zunge lang, platt, vorn tief gespalten, selur ansstreckbar, am Grunde ohne Scheide. 
Gattung. Lacerta, LiNn, Cuv.

Kopf und Banch mit Schildern; Rücken schuppig, Schuppen um den Rumpf in Ringen gestellt, was am Schwanze zum rein Quirlförmigen wird; ein Halskragen von grösseren Schuppen. Krallen seitlich zusammengedrückt, sichelförmig, unten mit Rinne.

1. Art. Lacerta viridis. GEssn, Grosse oder grüne Eidechse. Seps viridis. LaURENTI, Synopsis reptilium, 1768.

Grüne Eidechse. Schrank, Fauna boica, 1798.

Grüne Eidechse. Bechstein, Uebers. von de la Cepede's Naturgesch. der Amphibien, 1800. Lacerta viridis. WOLF in Sturm's Deutschlands Fauna, 1805.

Lacerta viridis. Fitzinger Fauna des Erzherzogthums Oesterreich, in der Landeskunde von Oesterreich unter der Ens, 1832.

Lacerta viridis. WALTL, Beschreibung d. eisenhaltigen Mineralquelle und Badeanstalt Kellberg năchst Passau. 1839.

Lacerta viridis. HeInrich, Mährens und k. k. Schlesiens Fische, Reptilien und Vögel 1856.

Lacerta viridis. FAHRER. Thierwelt von Niederbayern: Bavaria, Landes- und Volkeskunde von Bayern, 1863.

Lacerta viridis. Kinschbaum, Reptilien und Fische des Herzogthums Nassan 1865. Lacerta viridis. Mebreus, die Thierwelt der Rheinpfalz. Bavaria, Landes- und Volkeskunde von Bayern 1867.

\section{Kennzeichen. ${ }^{1}$ )}

Lünge bis 15 Zoll. Kopf kräftig, dick, doch im Verhältniss zur folgenden und nächst verwandten Art etwas gestreckter und weniger stumpfschnauzig. S'chwanz, wenn vollständig, am längsten unter den einheimischen Arten, zweimal so lang als der übrige Körper. Zähne am tiaumen. Von den vier Zügelschildern die zwei vorderen grade übereinander. Occipitalschild dreieckig und sehr klein. Schläfengegend mit unregelmässigen Schildern und Schuppen. Unterschied zwischen den Schuppen des Rückens und der Seiten gering. Von den Schuppenringen des Rumpfes gehen zwei auf eine Reihe der Bauchschilder. Letztere in acht Längsreihen, die am Rande jederseits sehr schnal sind. Krallen der Vorderfüsse bis viermal linger als breit;

1) Vergl. Erste Tafel, Fg. 3, Fg. 8, Fg. 12. 
Krallen der Hinterfüsse bis dreimal lünger als breit. Grundfarbe der Rückenseite ein Grün oder Braun, ohne oder mit Flecken und Streifenbildung. Die hintere Hälfte des Schwanzes grau oder braun. Banchseite immer gelblich (gelbgrün oder gelbweiss) und ohne Flecken. Schenkelporen 16-20.

Männchen. Kopf länger, höher und gedrungener; Schwanzwurzel an der Unterseite (wegen der Lage der Begattungsorgane) gewölbter; Extremitäten überhaupt, besonders aber die Hinterbeine kräftiger. Inguinalwarzen stärker. Farbe des Rückens ein lebhaftes Grün, in verschiedenen Abstufungen von Smaragdgrün und Bläulichgrün, meist mit perlweissen Puncten besprenkelt, welche sich am Kopf in grössere Perlflecken umsetzen. Kehle und Seiten des Kopfes zur Begattungszeit schön blau angelaufen.

Weibchen. Kopf kürzer, niedriger und feiner; Schwanzwurzel weniger gewölbt, dünner; Hinterbeine schwächer, Inguinalwarzen schwächer. Farbe des Rückens entweder dem des Männchens sich nähernd, d. h. schön grün mit dunkeleren Flecken oder das Grün setzt sich in's Bräunliche und ganz Braune um mit Lüngsstreifenbildung, welche aus weisslichen, schwarz gesäumten Flecken bestehen können.

\section{Bemerkungen.}

\section{Farbe.}

Nach der Analogie mit Lacerta agilis, wo man seit Langem sich überzengt hat, dass die Graubraunen die Weibchen seien und jene mit den grünen Seiten die Männchen, sprach ich auch sofort, als ich die L. viridis näher ins Auge fasste, die vom noch ziernlich Grünen ins Brăunliche bis Braune ziehenden Thiere, welche zudem meist mit zwei Reihen weisslicher, schwarz gesäunter Flecken geziert waren, als die Weibchen an. Und da bei der Zergliederung die Exemplare von letzterer Fürbung ohne Ausnahme den Eierstock besassen, so stand ich lingere Zeit in der Meinung, die Farbe reiche, wie bei L. agilis, allein hin, Mämnchen und Weibchen zu erkennen. Da hatte ich aber Gelegenheit ') ein lebendiges Thier, das nach seiner schön hellgrünen Farbe von gleichmässigem Ton, sich als Männchen darstellte, zu sehen, bezüglich dessen ich hören musste, dass es Eier gelegt; ebenso ward mir

1) Bei Hrn. Prof, Greder in Bozen. 
eine grüne Eidechse, selbst mit Tupfen auf dem Kopf, gezeigt ${ }^{1}$ ) die geöflnet ebenfalls als Weibchen sich ausweist. Zufolge dieser Erfahrungen schien es geboten in die Leibeshöhle aller theils von mir selbst gesammelter 'Ihiere, theils solcher, welche aus Frankreich, Italien, Dilmatien, Griechenland, Ungarn und Deutschland stammend, in hiesiger Sammlung aufbewahrt werden, einen Blick zu werfen; was bei einiger Sorgfalt und einem sehr scharfen Messer ohne Schaden ausführbar ist.

Hiebei fand sich denn, dass allerdings das Weibchen auch grün sein kann wie ein Männchen, ähnlich wie anch bei den Wassermolchen ${ }^{2}$ ) das Weibchen ausserlich gewisse Merkmale des Mämnchen annehmen kann; aber die typische Grundfarbe der weiblichen Lacerta viridis ist eben doch das grünlich Braun oder ein reines Braun. Ich fing weibliche Thiere, die abgesehen von den weisslichen Fleckenreihen der Seite, so braun waren wie eine weibliche Lacerta agilis. Uebrigens wäre auch noch zu bemerken, dass das Grün solcher Weibchen, welche man nach der Farbe für Männchen halten möchte, doch bei weiterem Vergleich von dem Grün der Männchen alıweicht: insofern es nümlich lichter erscheint, dabei zwar von dunkleren Flecken unterbrochen sein kaun, aber doch nicht in der dichten Weise mit Schwarz und Weiss besprenkelt, wie man solches bei den Männchen sieht. ${ }^{3}$ ) Dann habe ich bis jetzt kein reifes Männchen in Händen gehabt, bei welchem sich die Längsstreifenbildung gezeigt hätte.

Somit lässt sich die Farbe immerhin zur Unterscheidung des Geschlechtes benützen, besonders wenn man das, was ich oben über Kopf, Schwanzwurzel und Hinterbeine sagte, zugleich mit berücksichtigt. Hat man zwei grüne und zwar gleich grosse Exemplare vor sich liegen, von denen das eine männlichen, das andere weiblichen (Geschlechtes ist, so wird man nicht einen Augenblick zweifelhaft sein können, beide von einander weg zu kennen. ${ }^{4}$ )

(b) die Männchen allerorts während der Geschlechtsthätigkeit als Hochzeitskleid eine blane Kehle bekommen, scheint zweifelhaft. In südtyrol wird wie man

1) In der reichen Amphibiensammlung des Hrn. de BeTra in Verona.

2) Vergl. m. Abhandlg: die Molche der Württemb. Fauna, Arehiv f. Naturgesch. 1867.

$\left.{ }^{3}\right)$ Bei einem lebend eingefangenen mittelgrossen Mïunchen der Meraner Gegend war die Besprenkelung mit Schwarz und Weiss so über das Grün herrschend geworden, dass man ebenso gut sagen kounte, das 'Thier sei auf schwärzlicher Grundfarbe mit Weiss und Grün gesprenkelt.

i) Uebrigens scheint nir dieses Hinüberspielen der Farbe des einen Geschlechts in die des anderen noch ron allgemeinerer Bedeutung $\mathrm{zu}$ sein. Es bezcichnet eine nicht durchgreifende Sonderung des Geschlechts nach aussen, wozu auch einzelne Arten niederer Thiere Beispiele liefern. Man denle z. B. an die gefurchten Flïgeldecken bei Arten von Dylicus, wo sie eigentlich nur dem Weibchen angehören, hin und wieder aber und zwar nicht sebr selten auch beim Männchen vorkommen. Meiner hieher gehörigen Beobachtungen an Tritonen habe ich bereits gedacht. Aber auch bei noch höheren Thieren, obschon ungleich seltener, wiederholt sich Aehnliches: es sind z. B. Eier legende Hennen vom Gefieder des Hahns schon mehr als einmal beobachtet worden. 
mir sagte, die Kehle und ein guter T'heil des Kopfes im-Frühjahr blau. Nach ERBER ${ }^{1}$ ) und GLt'cKSELIG ${ }^{2}$ ) „kommen bei Wien und Mehadia Nännchen mit blauen Kehlen vor“. Auch der böhmischen grünen Eidechse legt der letztere ein „mentum et collare collumque laete coerulea" bei; die Männchen, welche JeITTELes in Oberungarn erhielt, hatten „eine tiefblane Keble“; hingegen will ERBER an Thieren aus Dalmatien dies nie bemerkt haben. Exemplare der Tübinger Sammlung aus Italien und Frankreich besitzen diesen Schmuck, während die Exemplare aus Griechenland allerdings eine einfach weissliche Kehle zeigen. Nach Allem ist es eben wahrscheinlich, class nur das erwachsene brünstige Hämnchen in gewissen Gegenden diese Auszeichumg erwirbt. Man hat auch wohl eine besondere Abart daraus gemacht: BONAPARTE stellt sie als Lacerta viridis mento-coemlea auf, GLÜCKSELIG als L. cyanolnema.

Das Blauwerden der Kehlgegend reiht sich an die mancherlei Auszeichnungen, welche die Hals- und Kehlgegend wïhrend der Geschlechtsthätigkeit selbst bei noch höheren Wirbelthieren erhält: nicht blos in der Farbe, sondern auch durch Entwickelung von Federn und Haaren, oder durch Anschwellung des Theiles. Und dass vorzugsweise die männlichen Thiere es sind, welchen solches zukommt, lehrt unter den Amphibien anch der Laubfiosch und die Kreuzkröte.

Min wird begreiflich finden, dass in früherer Zeit die tJpische Färbung des Teibchens Gruud zur Aufstellung einel besonderen Art wurde, so bei Daudn, welcher diarus eine $L$. bilineata machte; bei Schinz wird das Weibchen als L. bistriata aufgeführt. DUGES, welcher bereits in der DAUDIN'schen L. bilineata nur Abäuderungen der $L$. viridis erhlickte, hat auch das Verdienst zuerst bemerkt zu haben, dass die, streifige Fürbung nur bei Weibchen vorkomme.

Andere Systematiker haben die alten Mäunchen, dann die jüngeren Männchen, nicht melir zu reden von den Weibchen, zu besonderen Species erhoben. ${ }^{3}$ )

Es wäre zu wünschen, dass ein Beobachter in Gegenden, wo L. viridis häufig ist, die Umänderungen der Farbe vom jüngsten, eben ausgeschlüpften Thierchen bis

1) Die Amphibien d. österreichischen Monarchie. Verhandlgn d. zool. bot. Vereins in Wien, 1864.

2) Ueb. d. Leben d. Eidechsen, ebendas. 1863: - Synopsis rept. et amphib. Bohemiae, 1832.

s) Ich babe wiederholt die Erfahrung gemacht, dass Naturfreunde, auf welche die grüne Eidechse eine besondere Anziehungskraft ausübt, die gestreifte Form hurtnäckig für eine selbstständige Art erklären wollen, und zwar aus folgenden Gründen. Einnal so!le sich die grüne Eidechse und die streilge nie beisammenfinden, sondern immer an rerschiedener Oertlichkeit. Wenn dieses auch wahr wäre, obschon es meinen Erfahrungen durchaus widerspricht, so ist die Bemerkung ohne Gewicht; wie bei manchen anderen Thieren nämlich leben die alten Männchen gerne etwas für sich und streifen während der Beguttungszeit herum. Dann sei ferner doch die Kopfbildung eine ganz andere; dies ist wahr, beruht aber einzig auf der Geschlechtsverschiedenheit. Endlich und das wurde namentlich betont, das Betragen der beiderlei Thiere sei in vielen Stücken ein anderes: die grünen seien viel scheuer, zorniger und bissiger, auch vorsichtiger und schwerer zu fungen, die streifigen viel weniger scheu, leichter zu haschen und zähmbarer. Alles dies stimmt mit meinen Beobachtungen überein; aber auch diese Unterschiede vertheilen sich, wie bei vielen anderen Thieren in ihnlicher Weise, auf das rerschiedene Geschlecht.

Leyuig, Saurier. 
zum Hochzeitskleide in beiden Geschlechtern verfolgen würde. Ehe dies geschehen ist, mögen meine Beobachtungen hier eine Stelle finden.

Ich habe zu Ende August eine Anzahl ganz junger 'Thiere gefangen, die nach ihrer Ǩleinheit, dem verhältnissmässig grossen dicken Kopf und den grossen, einen beinahe treuherzigen Blick ansdrückenden Augeu, erst vor Kurzem aus dem Ei greschlüpft sein konnten. Bei allen war die Farbe des Rückens, des Kopfes, des Schranzes, auch die Beine einbegriffen, ein gleichmïssiges, lichtes Lederbraun; Bauchseite weisslich, an der Kiehle und Wangengegend etwas ins Grünliche ziehend. An wenig grösseren Exemplaren zeigten sich anf dem Lederbraun des Rückens Andeutungen seitlicher Flecken. Thiere, welche doppelt so gross als die vorhergehenden waren, hatten immer noch einen lichtbriunen Rücken; aber die zwei Reihen heller kleiner Flecken hoben sich jetzt deutlich ab; Bauch schwach gelbgrün, der kand der Kinnladen und der unteren Ohrgegend mit stärkerem Gelbgrün. Haben die Thiere jene cirösse erreicht, welche die unserer L. agilis etwas übertrifft, so setzt sich beim Männchen das Braun in das Dunkelgrün der Rückentläche un, das nach dem Kopf hin durch ein Uebergewicht dunkler Flecken zu einem unreinen Schwarz werden kann; die Rückenseite der hinteren Extremitaten bleibt ein unreines Braun. Eine dichte weissliche Besprenkelung namentlich an der Hals- und Kopfgegend gesellt sich hinzu. An der Wurzel des Schwanzes, Rückenseite, ordnen sich die weisslichen Flecken eine Strecke weit zu zwei Seitenlinien, was an die Fürbung des Weibchens erimnert. Die Bauchseite ist grünlich weiss, in der Kiefergegend mit Anflug von Blaugrau.

Gleichwie bei Lacerta vivipara ganz schwarze Individuen vorkommen, und die Varietăt L. atra bilden, so scheinen auch, obschon gewiss sehr selten, bei $L$. viridis schwarze Thiere aufzutreten. Ich schliesse dies wenigstens aus dem Titel eines Aufsatzes, den ich mir nieht zugänglich machen kimu: Gachet, Variété noir du Lézard vert, in den Actes de la soc. Lin. de Bordeaux, 1833. Weder Prinz Bonaparte, noch de Beтta, welchen Beiden eine grasse Erfahrung zu Gebot stand, gedenken eines ganz schwarzen Thieres; wohl aber stellt der letztgenannte Beobachter eine Varietas cinereo-nigrescens auf, die vielleicht mit ihrer Finbe eine schwache Neigung zeigt, der Variété noir GACHET's ähnlich zu werden.

\section{Schilder und Schuppen.}

Unter die Kennzeichen habe ich oben aufgenommen: "Occipitalschild klein". Es passt dies zwar auf sehr viele Thiere, aber keineswegs anf alle, vielmelnr zeight sich nuancher Wechsel. So habe ich ein Mitmnchen aus Italien vor mir, bei welchem 
das Occipitalschild gross ist; sehr gross sogar ist es bei zwei 20 Zoll langen Exemplaren aus Griechenland. Andererseits sieht man wieder das reine Gegentheil hievon: es kann das fragliche Schild auch ganz fehlen. Das Interparietale fand ich öfters durch eine Querfurche getheilt. Ueber das Internasale zieht nicht selten eine schwache, über das Frontale eine tiefe Längsfurche weg; doch wechselt das abermals nach den Individuen. - Auf die Beschilderung des Unterkiefers bin ich weder bei dieser noch den andern Arten eingegangen, da sie mir in den Verschiedenheiten viel zu schwankend erscheint, als dass man sie unter die Kennzeichen aufnehmen sollte.

Die Schuppen auf dem Rücken und an den Seiten zeigen sich wenig von einander unterschieden; 'die Rückenschuppen sind etwas schmäler und lünglich, stumpfgekielt, die Seitenschuppen mehr rundlich, die Spur des schrăgen Kiels ist mit der Lupe und guter Beleuchtung fast bis dorthin sichtbar, wo die Banchschilder anstossen. (Die Schuppen der Seiten sind im Gauzen etwas kleiner als bei der nächstfolgenden $L$ 。 agilis.)

Die Schilder des Banches, deren Lüngsreihen oben zu acht gezählt sind, werden von LATREILLE, ${ }^{1}$ ) später noch von GLC̈CKSELIG ${ }^{2}$ ) nur als in sechs Reihen vorhanden angegeben, wobei jedoch die zwei äussersten Reihen wenigstens von LaTrEILLE besonders erwähnt werden.

\section{Schädel ${ }^{3}$ ) und Zähne.}

Der Schädel der Lacerta viridis und jener von L. agilis zeigen sich nahe verwandt, sind aber doch auf den ersten Blick von einander zu unterscheiden: nicht blos durch die bedeutendere Grösse und die etwas gestrecktere Schnauze, sondern bei Betrachtung des Schädels von der Seite durch eine Anzahl von Knochentafeln hinter dem Augenjochbogen. Während bei $L$. agilis zwischen dem Os tympanicum und dem Augenjochbogen Alles frei und unbedeckt ist, daher die Columella und was weiter einwärts folgt, sichthar bleibt, decken bei $L$. viridis mehrere Hantknochen, vom Augenbogen und dem oberen Rand des Schädels her, diese Stelle zu; so dass die Columella in der Seitenansicht nur eine Strecke weit, von unten anf, gesehen wird.

Was man sonst vielleicht als specifische Unterschiede geltend mitchen wollte, wie z. B. die Länge und Breite des Stachels am vorderen hande des heilbeins viler die sehr dentliche dreilappige Beschaffenheit des trelenkiopfes des Hinterhauptbeines,

1) Hist. nat. des Salimandres de France, 1800.

2) Synopsis reptilium et amphibiorum Bohemiae, 1832: \&ectus, et abdomen teguntur sex scntellorum seriebus."

9) Verigl. Erste Tafel, Fg. 19, Fg. 20; Zweite Tafel, Fg. 23. 
oder die starke Gefässrinne auf dem Stirnbein, so bemerkt man beim Vergleichen zahlreicherer Schädel, dass in solchen Dingen viele individuelle Verschiedenheiten, Vor- und Zurückbildungen, herrschen. Ebenso sind bei $L$, agitis gleichwie bei $L$. viridis die Superciliarknochen in doppelter Reihe vorhanden, wovon die untere aus sehr schmalen Knochen besteht.

Was die Zähne anbetrifft, so zälle ich

im Zwischenkiefer $9-10$,

im Oberkiefer, eine Seite, 19-20,

im Unterkiefer, eine Seite, 23-24,

am Gaumen, eine Seite, 8 grössere und einige kleinere, alle nach rückwärts und einwärts gekehrt.

\section{Vorkommen.}

Die grüne Eidechse gehört den Ländern der Mittelmeerküste an, und erstreckt sich von da nordwärts ziemlich weit nach Mittel- und Osteuropa, sorvie nach Westasien hinein.

Was die Länder am südlichen Rande des Mittelmeeres betrifft, so ist es beinahe zweifelhaft geworden, ob sich die Art in Algier vorfindet. STrauch ${ }^{1}$ ) wenigstens sah daselbst nicht Ein Inäividum und bemerkt hierzu, dass ScHLEGEL die Angaben französischer Zoologen, zufolge derer das Thier dort vorkomme, anf eine Verwechslung mit der grünen Varietät der L. ocellata beziehe.

Dass sich $L$. viridis in Portugal tinde, erwähnt z. B. Barbosa de BocAGE in seinem Verzejchniss der lieptilien dieses Laudes. ${ }^{2}$ ) In Südrankreich scheint sie sich

1) Essai d'une Erpetologie de l'Algérie, Mém. de l'acad. imp. d. sc. de St. Petersbourg, 1862. Nebenbei sei erinnert, dass Sтravcr die $L$. ocellata durch das ganze südliche Europa verbreitet sein lässt ("repandue dans toute l'Europe meridionale ), ein Irrthum, den der Petersburger Zoolog unterdessen wohl selbst bemerkt haben wird. Nur in Portugal, Spanien, Südfrankreich bis in die Gegend von Nizza wuide bisher diese Art beobachtet; keineswegs aber weiter ostwärts, nicht in Italien, nicht in Griechenland und seinen Inseln. Vergleiche hicrüber besonders de Betra, Rettili ed anfibi del regno della Graecia. Venezia, 1868. Wenn es bei Erser in seinem Aufsatze: die Amphibien der österreich. Monarchie (Zool, bot. Verein in Wien 1864) heisst, es käme die Varietät ocellata in Dalmatien vor, so liegt wie ich vermuthe ein Schreibfehler zu Grunde, nicht sowohl weil $L$. ocellata eine gute Species ist, als weil einige Seiten vorher bei Aufzahlung der Synonyma und der Varictäten die Bezeichnung ocellata, wie billig, fehlt. Dense in dem Verzeichniss der Reptilien, welche Raßenuorst im Jahr 1817 in Italien gefunden (Allgem. deutsche naturhist. Zeitung II), spricht sich zwar auch dahin aus, dass $L$. ocellata »schon in Oberitalien ziemlich häufig® sei: allein der Genannte hat so geringe Proben seines Unterscheidungsvermögens gegeben - er hat z. B. den allbekannten Pelobates fuscus als neue Gattung und Art aufgestellt, liisst die Sandotter, V. ammodytes, schon bei Nürnberg vorkommen, und Anderes - dass man scinen Angabeu kaum eine Bedeutung beilegen darf.

2) Revue de Zoologie, 1863. 
von der Provence und Langnedoc weit über das Land nordwäts zu verbreiten; sie ist noch läufig bei Lyon, wird aber bei Paris selten nach DUGÉs; schon Latreille gedenkt ihrer auch aus dex. Umgebung von Paris. Andere erwähnen sie aus Gegenden der Loire, unsere Sammlung besitzt ein mässig grosses, aber schön blangrün gefiribtes Exemplar aus der Bretagne. (Unterseite des Banches, sowie die Handfläche und Fusssohlen auffallend hell und weiss.) Ob sie sich anch über das nordwestliche Frankreich ausdehnt, ist mir nicht bekannt geworden. Jedenfalls mangelt sie nach SELrs-Longchamps ${ }^{1}$ ) in dem anstossenden Belgien. Im Gebirgsstock des Montblanc, an dessen südlichen Lagen sie ebenfalls sich findet, steigt sie nach Venance Payot ${ }^{2}$ ) selten über 600 Mètres.

Von Frankreich geht der Zug des Thieres in die Westschweiz, wo es sich im Canton Wallis und Waadt vorfindet. In der übrigen Schweiz, nördlich vom Gotthardt, ist sie nach TSCHUDI noch nicht angetroffen worden; südlich vom Gotthardt, im Canton Tessin ist sie vorhanden, wie eben wohl am ganzen Südabhang der Alpen. Nach genanntem Beobachter erhebt sie sich bis zu einer Höhe von 4000 Fuss an den Bergen hinauf.

In Italien ist $L$. viridis sehr zahlreich und hat von jeher. ${ }_{-}^{3}$ ) durch die Schönheit der Fürbung, ebenso wie durch die pfeilschnellen, reissenden Bewegungen die Aufmerksamkeit auf sich gelenkt; und auch jetzt erinnert sich wohl mancher Naturforscher, besonders aus nördlicheren Gegenden, gerne an den Anblick, welchen eine grosse grüne Eidechse etwa auf einem beleuchteten Baumstamm behaglich ausgestreckt, dem Beschaner gewährt. Schon der Däne JacoBäus z. B. liann in seinem Werke über die Frösche und Eidechsen nicht umhin, dieses Reiseeindruckis zu gedenken. ${ }^{4}$ ) Sie scheint sich durch ganz Italien und seine Inseln zu erstrecken; um so anffallender ist, dass sie nach GENĖ der Insel Sardinien fehlt. ${ }^{5}$ ) Nordwärts steigt sie in die Thäler der südlichen Schweiz, des südlichen 'Tyrols und der venetianischen Alpen. In Südtyrol ist sie z. B. sehr häufig bei Meran, bei Bozen schien sie mir etwas weniger verbreitet; ich traf sie namentlich thalwärts vom Schloss Kühbach an; recht häufig und gross kam sie mir wieder am Kalterner See vor die Augen,

1) Finue Belge, 1842. Bei dieser Gelegenheit möchte ich nachtragen, dass der Verfasser dieses sorgfultig genrbeiteten Werkes, welches ich mir jetzt erst beschaffen kounte, zu den wenigen Autoren gehört, welche den Triton palmatus und Triton taeniatus richtig unterscheiden. Er bildet beide ab und in Text steht unter Anderem: "..... il est impossible de les confondre."

2) Erpétologie etc. des environs du Mont Blane. Ann. d. sc. phys. et natur. de Lyon. 1864.

s) Nunc virides etiam occultant spineta lacertos. Virgil.

1) De ranis et lacertis observationes. Hafniae, 1686: "Longitudine autem et elegantia coloris, viridis Bononiensis qualem saepius in Italia conspexi, caeteris praecellit.*

3) Syuopsis reptilium Sardinine indigenorum, 1838: "praeclara haec insula caret Lacerta viridi.* 
und es scheint, dass die Fenchtigkeit des See's, welche an den Felsen des Mittelgebirges einen. ungemein üppigen Pflanzenwuchs hervorruft, anch die Entwicklung dieser Eidechse befördert. Unser Thier hat in Südtyrol den Namen „Groanzen“, die bereits oben gedachte grauschwärzliche Abänderung wird nach GREDLER ${ }^{1}$ ) bei Bozen als "Holzgroanzen" unterschieden.

Es sind mir keine Mittheilungen darüber bekannt, wie weit sich die Art nordwärts in die Thäler hinein ausdehnt; bei Brixen habe ich sie noch gefaugen, mündlichen Angaben zu Folge kommt sie auch noch im Pusterthal vor.

Von lange her ist die grüne Eidechse aus ganz Dalmatien bekannt, ferner ans Griechenland, vom Festlande sowohl wie von deu Inseln. In beiden Ländern erreicht das Thier hin und wieder eine erstaunliche Grösse, wie schon BrBron und DUMÉRIL hervorheben. DE BETTA gedenkt ebenfalls solcher Riesenexemplare aus Griechenland. (Rettili ed anfibi della Graecia, 1868.) Ich halte in diesem Sommer (1869) zwei lebende Thiere aus Dilmatien, ${ }^{2}$ ) wovon das eine Exemplar reichlich zwei Fuss Länge hat. Beide sind am Rücken, mit Ausnahme des Endtheils vom Schwanz, über und über grün; die Kehle hat keine Spur von Blan, sondern ist, wie die Bauchseite überhaupt, von schönem reinem Gelb. Die hiesige Sammlung besitzt ebenfalls schon seit langem zwei Exemplare aus Griechenland, welche das Mass der Lacerta ocellata übertreffen, so dass man bei flüchtigem Ansehen sie für letztere zu halten geneigt wäre; doch weisen sie sich durch die Farbe und ganze Tracht, sowie durch die Einzelheiten (Form des Occipitalschildes, Zahıl der Längsreihen der Bauch-

1) In de BETTA's Erpetologia delle provincie venete etc. 1857. Bei einem Besuche im Herbst 1869 war Prof. GredLer so freundlich mir ein Exemplar dieser "Holzgroanzen" aus seiner Sammlung sehen zu lassen. Ich musste das Thier, soweit meine Erfahrung geht, für ein Weibehen halten, an dem die schwarzen Tupfen - vielleicht durch die Wirkung des Weingeistes - sich stark hervorhoben.

$\left.{ }^{2}\right)$ Mit Rücksicht auf die Grösse, welche $L$. viridis (oder vielleicht $L$. ocellata) erreichen kann, bleibt immer eine Angabe bei Purvius (Lib. VI. Cap. 37) beachtenswerth, wornach eine der canarischen Inseln, nach v. BucrI wahrscheinlich das heutige Ferro, durch das Vorkommen grosser Eidechsen ansgezeichnet sei, (wlacertis grandibus referta๔). Gegenwärtig weiss man freilich davon nichts mehr und der letzte Besucher der canarischen Inseln $\mathrm{K}$. †. Fritzsch, in Petermanns Mittheilungen 1868, sagt ausdrücklich, dass die gewöhnliche grüne Eidechse dort nur 30 Centim. Länge habe. Allein man erwäge, dass es sich bei PLrsus in seiner kurzen Beschreibung der glückseligen Inseln um unmittelbare Berichte handelt; ferner ist es wie v. Bucr (Physikalische Beschreibung der cannrischen Inseln, Berlin 1825) bemerkt, doch auffallend, dass BoutiER, der Beichtvater des ersten Eroberers dieser Insel, bei dem keine Spur zu finden ist, dass er die Beschreibung des Prisus gekannt, am wenigsten sie in seinen Berichten vor Angen gehabt hat, wenn er von F'erro redet, wo er sich selbst befand, sagt, dass man dort fände sdes lézards gros comme des chats et bien hideux ì regarder. "Sonach möchte es sich immerhin cmpfehlen, diesen 'Thieren weiter nachzuforschen. - In der mit Humor geschriebenen Reise WaLri's nach Südspanien (Passiu, 1835) erfihhrt man, dass auch $L$. ocellata, welche sich dort besonders gern unter den steifen Blattstengeln und stachlichten Blittern der Zwergpalme (Chamaerops humilis) aufhält, drei Fuss lang wird; ihr Kopf erreiche die Grösse eines Marderkopfes.

j) Von Hrn. ERrer mir überlassen. 
schilder) als $L$. viridis aus: 'T'rotzdem möchte ich nicht ganz unerwähnt lassen, dass diese grosse grüne Eidechse aus Osteuropa nicht blos in der Stärke ihres. Körpers von den Thieren z. B. aus Tyrol abweicht, sondern auch noch in andern Puncten, so z. B. durch den grossen stark gestreckten Kopf; damn auch durch die Krallen: während nämlich bei den Thieren ans Tyrol alle Krrallen schlank und sichelförmig sind, haben sie bei diesen eine grössere Höhe an der Wurzel. Auch weichen die Thiere durch lebhaft braun gefärbte Schenkelwarzen, welche weit hervorstehen, von der gewöhnlichen viridis ab. Auf den Cykladen hat ErHARD ${ }^{1}$ ) die grüne Eidechse. nur auf Mykenos und Syra gefunden. ERBER ${ }^{2}$ ) traf sie auf der Insel Tinos; bei einer nenen Reise ${ }^{3}$ ) fieng der Genannte das Thier auch auf der Insel Rhodus.

In Ungarn scheint unsere Eidechse ebenfalls weit verbreitet zu sein, wenn auch nicht überall vorzukommen. JEITTELES ${ }^{4}$ ) beobachtete sie in Oberungarn "aus den kalkigen Bergen von Torna", während sie bei Kaschan ganz fehlt. Im südlichen Ungarn, bei Mehadia, dann auch bei Orsova fimd sie ERBER "sehr häufig", doch nie so gross als in Dalmatien. Auch in Galizien und in der Bukowina ist sie nach Zawadzki ${ }^{5}$ ) nicht selten. In Siebenbürgen, in den östlichen Theilen Slavoniens, in der Nähe der Theissmündungen, und nächst den Mündungen der Donau, bei Tuldscha wurde sie gesammelt von Ferrari und ZeLebor. ") Sie geht danu um das schwarze Meer herum weiter östlich; so erwähnen sie PaLLas und RathkE ${ }^{7}$ ) ans der Kirym, EICHWALD ${ }^{8}$ ) aus dem Kaukasus und Chersones; sie erstreckt sich weiter ins südliche asiatische Russlind nach Paldas, doch nur da, wo Gebirge sich erheben. In den Steppen östlich vom caspischen Ieer kommt sie nach Eversmanr nicht mehr vor. $\left.{ }^{9}\right)$ Südlich rom schwarzen Meer, in Kleinasien, ist das Thier noch zu Hause: Steindachner erwähnt es von Brussa.

Kann man nach dem Voranstehenden sagen, dass das südliche, sowie südöstliche Europa, ${ }^{10}$ ) damn das westliche Asien, Wuhnplatz der $L$. ciricis sei, so hat es für uns ein besonderes Interesse die Ausläufer dieser Verbreitung auf deutschem Boden zu verfolgen, was offenbar von zwei Seiten her geschieht.

$\left.{ }^{1}\right)$ Fauna der Cykladen, 1858.

$\left.{ }^{2}\right)$ Bemerkungen zu m. Reise nach d. griech. Inseln. Zool. bot. Verein in IVien, 1867.

3) Bericht üb. eine Reise nach Rhodus (ebendas. 1868).

4) Prodromus faunae vertebratorum Hungariae superioris (ebendas. 1862).

5) Fauna d. galizisch-bukowinischen Wirbelthiere, 1840.

c) Vergl. Stemdacuneir, Verzeichniss von gesammelten Fischen u. Reptilien, Zool. bot. Verein in Wien, 1863.

7) Fauna der Krym. (Mir nicht weiter bekannt.)

s) Fauna caspio-caucasica.

9) Reise von Orenburg nach Buchara, 1823.

10) Merrem im Tentamen systematis amphibiorum, 1820 sugt noch blos shabitat in Europa meridionalix. 
Einmal ans dem westlichen Frankreich und der Westschweiz ins Rheinthal. Wenn es wahr ist, was man mir sagt, dass am Isteiner Klotz unsere Eidechse vorkomme, so wäre diess als die erste Station zu bezeichnen; die zweite bildet weiter abwärts die Rheinpfalz, wo sie unzweifelhaft lebt, wenn auch nach MEdicus ${ }^{1}$ ) als die „seltenste" unter den dort einheimischen Arten. Auch für das Vorkommen im Rheingau haben wir bestimmte Nachweise: Fresenius fand sie auf dem Niederwald bei Rüdesheim, LEX bei (aub. ${ }^{2}$ ) Wie weit sie rheinabwärts geht, ist unbekannt. Dass sie der holländischen Ebene mangelt, lässt die Schrift SCHLEGEL's ${ }^{3}$ ) errathen, welche für die Niederlande nur $L$. agilis, $L$. vivipara und $L$. muralis aufführt.

Daun geschah zweitens die Einwanderung von Südeuropa her die Donau aufwărts und in die Gegend von Wien. Für die Umgebung Wiens führt sie zuerst Ladrenti, dann Fitzinger als „ziemlich selten“ auf: von der Türkensehanze, sowie vom Kahlenberge, in der Brühl, bei Baden, vormals auch im Wiener Stadtgraben; ERBER bezeichnet sie jüngst aus dieser Gegend als nicht selten, was auch dadurch belräftigt zu werden scheint, weil das Thier einen volksthümlichen Namen hat. Schon Ladrenti sagt: "Krauthuhn Viennensibus". Wie weit sie sich im eigentlichen Oésterreich verbreitet, ist mir unbekannt, denn leider nennt Fitzinger von der Donau aufwärts nur noch ansdrücklich die Gegend bei Krems; doch erstreckt sie sich nordwestlich bis zur bairischen Grenze, bis in die Gegend von Passau. Es sagt wenigstens der verstorbene Botaniker SendtNer:4) „die dem südlichen Europa angehörige grüne Eidechse sonnt sich auf den warmen Felsen um Passau ebenso behaglich, wie an den heimathlichen Gartenmauern um Botzen;“ welche Angabe eine nähere Begrenzung erhält dureh WALTL und FAHRER, denen zu Folge das Thier ,am linken Donaunfer etwas unterhalb der genannten Stadt, bis nach Oberzell hin" vorkommt.") Wahrscheinlich meint anch ScHRAN ${ }^{6}$ ) die Passauergegend, wenn er die Lacerta viridis als Glied der bairischen Fauna aufführt. (Dass er wirklich $L$. viridis im Auge hat, geht deutlich aus seinen Worten hervor: "Sie unterscheidet sich von der grünen Spielart der kleinäugigen Eidechse, L. agilis, leicht durch ihre ansehnliche Grösse und die durchaus grüne Farbe.") Von Oesterreich geht $L$. viridis nordwirts nach Böhmen: „Lacerta viridis habitat . . per totam Bohemiam" sagt GLücKselit, 7 )

1) Thiere der Theinpfalz. In der Bavaria, 1867.

2) Vergl. Kurscubaus, Reptilien und Fische d. Herzogthums Nassan, 1865.

3) De Dieren van Nederland. Kruipende Dieren. 1862.

4) Bavaria. Landes- u. Volkeskunde von Bayern, II. 1. 1863. S. 80.

${ }^{5)}$ Ebendaselbst S. 122.

$\left.{ }^{6}\right)$ Fauna boica. Bd. J, 1798. Schraxk hatte, wie aus anderen seiner Schriften hervorgeht, die Passauergegend auf Thiere und Pflanzen näher untersucht.

7) Synopsis reptilium Boheniae, 1832. 


\section{3}

und von da aus müssen wir den Weg suchen, der das Thier weiter nordwärts in die Mark und in die Gegend, "der Kalkberge bei Udersberg zwischen Berlin und Frankfurt und in die Rüdersdorfer Kalkberge bei Berlin“ geführt hat. Die Wanderung gieng wohl durch Mfihren und Schlesien. Nach Henvich findet sie sich im Flach- und Hügellande von Mähren häufig; ${ }^{1}$ ) (iLOGER "vermuthet“ sie für die Ebenen Schlesiens. ") Eine nicht viel festere Angabe liest man in einem Verzeichniss der Wirbelthiere der Oberlausitz, ${ }^{3}$ ) wo es heisst: "Lacerta viridis DAUD. soll nach dem Verzeichnisse von Fechner im Steingerölle bei Königsheyn beobachtet worden sein.“

Unzweifelhaft wurde unser Thier im Anfange dieses Jahrhunderts von BECHSTEIN „in den brandenburgischen Kieferwaldungen" aufgefunden. Hier weiss man bestimmt, dass nicht eine Verwechslung untergelaufen ist; denn der Genannte kennt Männchen und Weibchen der $L$. agilis, welche er in Thüringen beobachtete, genau; auch hebt er überdies vou der grünen Art hervor: die bedeutende Grösse, die grössere Anzahl der Schenkelwarzen und den ebenfills grünen Rücken. In den Kalkbergen bei Rüdersdorf der Berliner Gegend ist das Thier wiederholt gefangen worden und anch die hiesige Sammlung besitzt von $\left(\right.$ daher $^{4}$ ) ein schönes, nicht sehr grosses Männchen mit blauer Kehle.

Es scheint beinahe, als ob noch an anderen Puncten in Norddentschland die grüne Eidechse auftrete; so gibt STrucK ${ }^{5}$ ) im Verzeichniss der Reptilien bei Dargun in Mecklenburg an: ,die grüne Varietät der Lacerta agilis kommt bei Finkenthal auf kalkhaltigem Boden vor." Nach der Fassung dieser Angabe sollte man auf L. viridis schliessen dürfen; auch der Herausgeber der unten erwähnten Zeitschrift glaubt das Thier bei Neubrundenburg gesehen zu haben. ${ }^{6}$ ) Selbst bezüglich Ostpreussen's könnte sich die Vermuthmig regen, ob nicht dort noch die echte grüne Eidechse zu Hause sei. Es ist nemlich auffallend, dass WULfF, ${ }^{7}$ ) mit Linné zu Lacertu riridis den Namen A Ldrovandi setzt, was auf die echte viridis hindentet; andererseits füllt aber freilich wieder die Vermuthung zusimmen durch die Berufung auf die Fauna suecica LinNE's. Denn in Schweden kommt, wie mir Dr. Collin in Copenhagen gütigst mittheilte, die L. viridis so wenig als in Dïnentirk vor. Rathke's mir leider unzugingliche Arbeit: die in Ust- und Westyrenssen rorkommenden

\footnotetext{
1) Mlïhrens u. k. k. Schlesiens Fische, Reptilien u. Vögel. 1856.

$\left.{ }^{2}\right)$ Schlesiens Wirbelthier-Fauna, 1833.

3) Abhandlungen d. naturf. Gesellsch. in Görlitz, 1862.

1) Durch Hrn. Dr. Gëxtier.

5) Archir d. Vereins d. Freunde d. Naturgesch. in Mecklenburg, 1862.

o) Jahrg. 1804 , S. 188.

7) Ichthyologia cum amphibiis Regni bornssici. Regiomonti, 1705. Leyuig, Saurier.
} 
Wirbelthiere ${ }^{1}$ ) mag wohl über die WulfF'sche $L$. viridis Aufschluss geben. Einstweilen ist mir wahrscheinlich, um nicht zu sagen gewiss, dass seine drei aufgeführten Landeidechsen sämmtlich zu agilis gehören. - Das inselırtige Vorkommeu der grünen Eidechse in Norddeutschland verdiente wohl nach allen Einzelnheiten genauer bekannt zu werden. ${ }^{2}$ )

\section{Geschichtliches und Kritisches.}

Ich habe nicht wie es gewöhnlich geschieht, DAUDiN als Autornamen hinter die Species gesetzt, sondern mit Absicht Gessser, ${ }^{3}$ ) da dieser Naturforscher vor mehr als drei Jahrhunderten unsere Eidechse richtig gekannt und von den verwandten Arten unterschieden hat. Wer sich die Mühe nimmt die Folioseiten des Züricber Zoologen zu durchlesen, wird, vorausgesetzt dass man selbst mit der Sache vertraut ist, die Ueberzeugung schöpfen, dass derselbe von drei Arten mitteleuropäischer Eidechsen weiss: von der jetzigen $L$. agilis, L.viridis und $L$. ocellata; die beiden ersten aus eigener Anschauung, die letztere vom Hörensagen kenut. Erstere heisst bei ihm Lacerta communis und er erklärt ${ }^{4}$ ) sich ausdrücklich dagegen, wenn man diess im Deutschen mit "grün Adex" geben wolle: denn obschon die gemeine auch grün sein lionne, so sei doch die eigentlich grüne eine andere Art und grösser. Nach fremden und eigenen Beobachtungen beschreibt er dann die Lacerta communis s. parva, und stellt sie auf Seite 29 bildlich dar, worauf ich nachher, wenn von der $L$. agilis die Rede ist, zurückkonmen werde. Die echte grüne Eidechse ist ihm Lacerta major et viridis oder grüner Heydox, welche ihm sowohl aus der Westschweiz als auch aus Italien bekannt sein mochte; er handelt eigens von ilur und lässt sie auf Seite 36 abbilden. Die Figur ist nach der Grösse nur auf ein jüngeres Thier zu beziehen; in der Stellung, als ob es ruhe und sich vielleicht sonne, nicht übel aufgefasst, aber im Einzelnen ungenau. Der Kopf ist nicht der Kopf einer Eidechse, sondern nach Wölbung und Umriss der eines Säugethiers (Nager), die Handwurzel erscheint so lang wie der Vorderarm, die Linien des Schuppenkleides sind unberücksichtigt geblieben unci dergl.

Auf die Lacerta ocellata beziehen sich offenbar einige Mittheilungen in dem Abschnitt de lacertis diversis. Er spricht dort von ungehener dicken Eidechsen, welche in der Provence vorkämen: von der Dicke des menschlichen Unterschenkels, wie man ihm sagte, doch dabei nicht sehr lang. ${ }^{5}$ ) Der Ort des Vorkommens, die wenn auch übertriebene Dicke bei mässig langem Schwanz passt Alles uur auf die in der Provence, sowie im Süden von Spanien lebende $L$. ocellata. Wenn man überdiess sich erinnert, dass GESSNER in Montpellier den Doctorhut nahm, so mag er wohl an Ort und Stelle über diese jedenfalls dickste der in Europa verbreiteten Eidechsen unterrichtet worlen sein.

Dass der in Italien lebende ALdrovand ${ }^{6}$ ) die echte grüne Eidechse gut liennt ist begreiflich. Er

1) Preuss. Provincialblatter. 1846.

2) Auf den Titel der Fauna marchica von J. H. Scrucz, Berlin 1845, aufmerksam geworden, glaubte ich in dieser Schrift Andeutungen in dem oben gewünschten Sinne finden zu können; allein die Kenntnisse des Autors gehen nicht über die liudersdorfer Kalkberge, welche als alleiniger Fundort angegeben werden, hinaus.

s) Liber de quadrupedibus oviparis. Tiguri. 1554.

4) a. a. O. p. 29: \$Non probo illum, qui lacertam germanice interpretatur grüne Adex, id est viridem lacertam. Quanquam enim communis etiam lacerta, de qua hic scribo, viridis aliquando reperiatur, sed raro, proprie tamen alterum genus majus et semper viride, de quo infra agetur, sic appellari solet .....

8) Quidam ex amicis nostris fide dignis, narravit mihi visas sibi in Provincia (regione Galliae) et Hispania aliquando Lacertas ea crassitudine, qua crus humanum sub genu est, aon admodum longas......

$\left.{ }^{\circ}\right)$ Quadrup. digit. ovip. 1637, p. 633. 
bezeichnet sic als Lacerta viridis Liguoro Bononiensibus. Da für Alorovandi die Lacerta vulgaris nur durch die jetzige $L$. muralis vorgestellt wird - denn es fehlt ja in Italien dic $L$. agilis - so verfällt er in den, eben desshalb leicht entschuldbaren Irrthum, dass er die Angabe Gessner's, in Deutschland seien die grünen Eidechsen selten, auf die eclıte viridis deutet, während GESSNER dabei nur die $L$. communis $s$. parva, das heisst unsere jetzige agilis dabei im Auge hatte. Die Abbildungen der -Lacertae viridis per excellentiam*, wie sich die Alten auch wohl ausdrückten, sind bei ALdrovand rohe Holzschnitte, deren Zeichnung wenig auf die MassverhäItnisse und sonstigen Einzelıheiten Bezug nimmt.

Eine illtere Schrift von dem englischen Naturforscher. PETIVER, ${ }^{1}$ ) in der vielleicht ebenfalls schon die Lacerta viridis neben der $L$. ocellata unterschieden wird, kann ich nicht einsehen.

In späterer Zeit ist oftmals, und es geschieht eigentlich bis zur Stunde noch hin und wieder, das grüne Männchen der $L$. agilis für $L$. viridis gehalten worden. Oder wenn nicht das, so hat man viridis wenigstens als Varietät zu agilis gestellt; selbst bei dem gründlichen PaLLas ${ }^{2}$ ) bilden $L$. viridis, agilis und muralis nur Varietäten seiner Lacerta europaea. - In älnnlicher Weise steht bei LATREILLE das Männehen sowohl wie das Weibchen der jetzigen $L$. agilis als Var."c. (९) und Var. e (†) unter $L$. viridis, worauf ich später zurückkommen werde.

LAURENTI ${ }^{8}$ ) in Wien lebend, allwo sich neben $L$. viridis auch $L$. agilis und $L$. muralis findet, hat die Geschlechtsverschiedenheiten und Altersstufen unsrer Art als besondere Species ausgegeben. So ist sein Seps viridis ein fast rein grünes Männchen mit blauer Kehle, wohl im Hochzeitskleid und daher , in sole omnibus smaragdis, chrysolitis et beryllis elegantior". Unser Herpetolog citirt zu seinem Seps viridis die Figur 4 auf Tab. CIII, Tom. II der Icones bei SEBA. Doch scheint mir diese Figur nicht recht passen zu wollen; man könnte-eher noch an $L$. ocellata denlen. WAGLer in seiner Deutung der Skba'schen Tafeln (in der Isis 1833) erklärt die fraglichen Abbildungen für "durchaus unbestimmbare Figuren“. Der Seps varius bei LAUrentr ist ebenfalls ein Männchen der $L$. viridis, dessen Grün durch Beimisclung dunkler Puncte unrein geworden. BIBron und Dumérı rechnen den $S$. varius zu Lo agilis (stirpium) was gewiss irrig ist. Dass das Thier zu viridis gehört, ergibt sich schon abgesehen von allem anderen aus der Angabe; "abdomen Havum absque punctis", und dass es ein Männchen sei wird bekräftigt durch die Abbildung (Tab. III, Fig. 2): der dicke Kopf, die fleischigen Beine sprechen es laut aus. Obendrein steht auf der Tafel gleich uber dem Seps varius der Seps terrestris, der ebenso unzweifellıft zu $L$. viridis gehört, aber das Weibchen vorstellt: "Corpore fusco, utrinque serie macularum obsoletarum; Caput teretius, oblongius etc." Auf der Figur sind die Unterschiede in der Kopfbildung und den Beinen zwischen diesem Seps terrestris und dem Seps varius so deutlich ausgedrückt, als habe der Zeichner absichtlich damit die Sellbstständigkeit der beiden Arten darthun wollen. Bezüglich des "Seps sericeus" hingegen bin ich nicht ganz sicher, ob er ebenfalls zu $L$. viridis gehört. Ohne Zweifel ist es ein junges Thier, entweder von der letztgenanuten Art, oder - und diess ist idas wahrscheinlichere - von $L$. muralis. Dafür spricht in der Zeichnung der fein geschuppte oder gekürnelte lücken, was auch in Text ausdrücklich bestätigt wird: cute subsquamulata; dann das Caput ovale, da junge virides von dieser Grösse einen sehr dicklichen, alggestumpften Kopf haben. Auch de BETTA, ohne seine Gründe anzugeben, seluliesst den S. sericens LaUR. von $L$. viridis aus und rechnete ihn zu $L$. muralis.

Zu den früheren und zwar besseren Abbildungen der $L$. viridis gehören die Figuren bei DaudiN. Das Weibchen, Lézard verd à deux raies ist besonders gut ausgefallen, sowohl was die Stellung im Ganzen betrifft, als auch hinsichtlich der Einzelnheiten. Dem Schwanz ist die gehörige Lünge gegeben. Beim Männchen lingegen sind die Massverhältnisse zwischen Leib und Schwanz ganz verfehlt: ersterer ist zu lang,

1). Gazophylacii naturae et axtis decades, 1702.

$\left.{ }^{2}\right)$ Zoographia rosso-asiatica. Gedruckt 1811, herausgegeben 1831.

$\left.{ }^{3}\right)$ Synopsis reptilium, 1768. Sebr überraschend und neu ist mir eine Mittheilung Frtzraer's in der susarbeitung einer Fauna des Erzherzogthuras Oesterreiche in den Beitrïgen zur Landeskunde Oesterreichs unter der Ens, 1832, welches Werk ich erst jetzt lrennen lernte, der zufolge Luunexr seine Dissertation nicht selbst geschrieben hat, sondern der eigentliche Verfusser sei sder bekannte Ohemiker Professor WrNicr zu Pesth gewesen. 
letzterer viel zu liurz gehalten. Der Unterschied in der Dicke der Hinterschenkel erscheint auf beiden gut veranschaulicht; nur ist beim Münnchen die Einpflanzung des Schenkels zu hoch an das Rückgrath hinaufgerückt.

Eine das Thier recht kenntlich vorstellende Abbildung ist jene in Stury's Fauna. WoLF, welcher hierzu den Text lieferte, hatte früher ebenfalls den Fehler begangen, die $L$. viridis für einerlei mit $L$. agilis zu halten. Er wurde aber sofort anderer Meinung als er ein Weingeistexemplar aus der Schweiz zugeschickt erhielt. Auch an die STurM'sche Figur darf man nicht den Anspruch machen, dass sie die feineren Einzelnheiten, z. B. die Beschilderung des Kopfes, wiedergeben soll. Eine geradezu falsche, obschon sehr hervortretende, Abtheilungslinie am linken Hinterfusse stört den Beschauer. In das Colorit hat sich der Fehler eingeschlichen, dass offenbar zu Folge eines Missverständnisses des Lichtfleckes, welchen der Ansatz des Hammerknorpels bedingt, dem Trommelfell in seinem mittleren Theil ebenfalls das Grün des Leibes zuertheilt wurde.

Unter den mil bekannt gewordenen Abbildungen steben ohne Widerrede oben an die Figuren in dem Werke des Prinzen Bonaparte, ${ }^{1}$ ) allwo der $I_{\text {. }}$ viridis zwei Tafeln gewidmet sind. Der Zeichner ist Peter QüTtrocch, zu dessen Lieblingen die Lacerten müssen gehört haben. Wer selber diesen Thieren im Freien einige Aufmerksamkeit geschenkt hat und ihre Stellungen kennt, sowohl im Lauern auf Beute als wenn sie anfangen in Erregung zu kommen, wird die Quatroccn'schen Eidechsen, nicht ohne das lebhafteste Vergnügen betrachten. Auch das Colorit ist recht gut. Einen wahren Glanzpunct des Werkes bildet das zornig vorschreitende Männchen mit blauer Keule und Wangen, als L. viridis Var. mento-coerulea aus Sicilien bezeichnet. Das andere Thier auf derselben Tafel Fg. 3, L. viridis Var. maculata künnte ebenfalls ein Männchen sein, ausser der Begattungszeit. Hingegen Fg. 1 und Fg. 3 der vorhergehenden Tafel (ohne Nummer) stellen Weibchen dar, die eine (bilineata) ist schon nach der Farbe, die andere (adulta) nach der Bildung des Kopfes, der Hinterbeine, und der Schwanzwurzel zu bestimmen. Man werfe einen vergleichenden Blick auf alle diese Theile bei dem Männchen (mento-coerulea) und man wird nicht im Zweifel über diese Deutung sein könneu.

Beror ler Band der Fauna italica, welcher die Reptilien enthält, erschien, musste die Figur in dem Prachtwerke: Expedition scientifique de Morée, Tom. III, Zoologie 1836, als die beste gelten, welche die Wissenschaft über die $L$. viridis bis dahin besass. Auch erklärt BoRY de ST. Vincent, der geistreiche und vielseitige Chef der Gelehrtencommission, welche den Peloponnes zu durchforschen hatte, dass es besondere Absicht sei, cinc Abbildung des Thieres zu liefern, "qui ne laisse rien ì desirer". Die Figur ron Oudart gemalt, steht aber schon insofern der QUATTRoccu'schen nach, als sie nach einem todten Exemplar gefertigt wurde, wie das geschlossene Auge und die schlaff heraushängende, wohl ctwas zu blau colorirte Zunge dar'thun. Auch wäe der Winkel, den die Kopflinie über dem Auge bildet, wegzuwünschen; sowie gewisse Schuppenpartien an den Gliedmassen nicht naturgetreu sind. Von solchen Kleinigkeiten aber abgesehen, erscheint die Abbildung des Werkes würdig, zu dessen Schmuck sie beitragen soll.

Ein besonderes Interesse darf vielleicht auch die fünffach gestreifte $L$. strigata, welche EICII ALD ${ }^{2}$ ) aufstellt, beanspruchen, welche wie bisher alle Herpetologen annehmen, zu $L$. viridis gehören soll. Die so ausgeprägtc streifige Färbung möchte ich mit dem Aufenthaltsorte des Thieres in Bezichung bringen, nach der Analogie der T. muralis, var. campestris, BETTA. Letztere, wovon unten, lebt am sandigen Strande des Meeres bei Venedig, hat dort ihre Schlupfwinkel zwischen dem Wurzelwerk der Strandptlanzen und zeichnet sich ebenfalls in auffäliger Weise durch ihre streifige Färbung aus. Von der $L$. strigata sagt nun EicuwaLD ausdrücklich: habitat in orientali et australi ora caspia, in insula Oretas, telo velocior ideoque captu difficillima, latebras ut plurimum in soluta arena arundinetorum patens. - Ich wire geneigt in dieser $L$. strigata EICIWALD's eine grosse und nach dem Wohnorte abgeinderte Form der L. muralis zu erblicken.

1) Fauna italica, 1836. In der Güte des Colorits weichen, was ich nachträglich zu bemerken finde, die cinzelnen Exemplare des Werkes sehr von einander ab.

2) Fauna caspio-causasica, 1841, Tab. X, Fgg. 4, 5. 6. 
2. Art. Lacerta agilis, (LinN.) Wolf. Gemeine Eidechse. Seps coerulescens, S. argus. LaURentr, Synopsis reptilium, 1768.

Kleinaugige Eidechse. Schrank, Fauna boica, 1798.

Lacerta agilis. Wolf bei Sturm, Deutschlands Fauna, 1799.

Grauc Eidechse. BEchstern, Ueberset\%ung von de la Cepede's Naturgesch. d. Amphibien, 1800 .

Lacerta ayjlis. Römer-Büchner, Verzeichniss der Steine und Thiere, welche in dem Gebiete der freien Stadt Frankfurt gefunden worden. 1827.

Lacerta agilis. ScHÜBLER, Thierreich in Memminger's Beschreibung von Württemberg, 1829.

Lacerta agilis. HaHN (und ReIDER), Fauna boica, 1832.

Lacerta agilis. Giü̈cKSELIG, Synopsis reptilium et anphibiorum Bohemiae, 1832.

Lacerta agilis. GLOGER, Schlesiens Wirbelthierfauna, 1833.

Lacerta stirpium. Martens, Thierreich in Memminger's Beschreibung von Württemberg, 1840 .

Lacerta stirpium. Plieninger, Verzeichniss d. Reptilien Württembergs in den Jahresheften für vaterländische Naturkunde, 1847.

Lacerta agilis. HeinRich, Mährens u. k. k. Schlesiens Fische, Reptilien u. Vögel, 1856. Lacerta agilis. FAHRER, Thierwelt von Ober- und Niederbayern, Bavaria, Landesu. Volkeskunde von Bayern, 1860.

Lacerta stirpium. Kinschbaum, Reptilien u. Fische des Herzogthums Nassau, 1865. Lacerta agilis. Medicus, Thierwelt der Rheinpfalz, Bavaria, Landes u. Volkeskunde von Bayern, 1867.

Lacerta agilis. LEYDIG, Thierreich in der Beschreibung des Oberamts Tübingen, herausgegeben vom statistisch topogr. Bureau, 1867.

Varietat. Seps ruber, LAUdenti a. a. O.

Seps stellatus, (Schrank) Koch, Sturm's Fauna, 1828.

Lacerta erythronotus, FITZINGER a. a. 0.

Lacerta stellata, GiÜCKSELIG'a. a. O.

\section{Kennzeichen. ${ }^{1}$ )}

Länge bis 8 Zoll; gewöhnlich nur 5-6 Zoll. Kiopf ron besonders dicklichem, gedrungenem, stumpfschnauzigem Wesen. Schwanz, weun vollstindig, ein und ein

1) Vergl. Erste Tafel, Fg. 4, F'g. 5, Fg. 14, F'g. 9. 
halb so lang als der übrige Körper. Zăhne am Gaumen. Von den vier Zügelschildern die drei vorderen im Dreieck stehend. Occipitalschild klein, trapezförmig. Schläfengegend mit unregelnässigen Schildern; mitunter ein grösseres in der Mitte. Unterschied zwischen den Schuppen des Rückens und der Seiten gross. Von den Schuppengürteln des Rumpfes gehen zwei auf eine Reihe der Bauchschilder; letztere in acht Längsreihen. Krallen der Vorderfüsse dreimal lünger als breit an der Wurzel; Krrallen der Hinterfüsse etwas über zweimal so lang als breit. Grundfarbe der Rückenseite ein Graubraun oder ein Grün. Der Scheitel, ein Streifen mitten auf dem Rückeu, der Schwanz immer braun. Nit gewöhnlichen oder Augenflecken (weiss mit dunkelm bis schwarzem Saum); Flecken gern in Längszügen, bis nahe an die Schwanzspitze. Bauchseite gelblich oder grünlich mit kleinen schwarzen Flecken oder Puncten. Schenkelporen 11 bis 14.

Männchen. Tracht gedrängter, kürzer, Kopf dicklicher, Kehle aufgetriebener, Wurzel des Schwanzes verdickt. Schenkelporen sehr hervortretend. An den Seiten des Kopfes und des Leibes herrscht das Grün vor, das in ein "schönes blühendes" Grün übergehen kann. Kehle und Bauch grünlich, dicht mit kleinen Flecken besprenkelt.

Weibchen. F'einer gebaut, wenn auch (im Frühling) dickbauchiger. Schwanzwurzel nicht verdickt. Schenkelporen weniger hervortretend. Anch an den Seiten herrscht das Braun vor; die Augenflecken der Seite, beiläutig in zwei Reihen stehend, kommen durch grosse dentliche weissliche Mitte mit schwarzem Raud zu besonderer Ausbildung; die der oberen Reihe sind mehr rundlich, die der zweiten länglich. Bauch gelblich oder weisslich, die kleinen dunkeln Flecken darauf bald zahlreich bald weniger dicht.

\section{Bemerkungen.}

\section{Farbe.}

Von allen Beobachtern wird angeführt, dass unser Thier in Zeichnung und Furrbung die "manchfaltigsten Varietïten“ darbiete, ein Ausspruch, welchem ich nicht ganz zustimmen möchte. Wem man nemlich im Auge behảlt, diss die beiden Geschlechter verschiedene Farbenkleider annehmen und ablegen, und dass ferner die Altersstufen ihre Besonderheiten haben, so ist eigentlich doch die Namnigfaltigkeit der Färbung nicht grösser als solches bei vielen anderen Thieren nach Alter, Geschlecht und Jahreszeit, sowie der Gegend ihres Vorkommens, der Fall ist. 
Das ganz junge Thier, "pulchria haec bestiola“, hat bekanntlich LAORENTr als Seps argus aufgeführt, doch nur fragweise: „statura omnium minima, si adulta?" Den Namen gab er wegen der vielen zierlichen, etwa in vier Reihen auf gelbbraunem Grunde stehenden Augenflecken. Die reine Argusform besteht, was ich aus wiederholter Beobachtung kenne, eigentlich nur für den sommer und Herbst des Jahres, in welchem die Thiere aus dem Ei gekrochen. Schon im nächsten Frühling hat sich die Grundfarbe nicht nur mehr ins Braume umgesetzt, sondern sich auch in einen etwas dunkeln Rückenstreifen und zwei Seitenstreifen geschieden; darüber weg vertheilen sich die verhältnissmässig kleiner gewordenen Augenflecken.

Die weitere Sonderung in der Grundfarbe bestelit alsdann darin, dass das dunklere Rückenfeld von den Seitenfeldern sich durch eine schmalere lichtere Zone jederseits absetzt; was sich, wenn auch um vieles schwächer, noch einmal gegen den unteren Rand der Seitenfelder wiederholt. An der vorderen Hälfte des Schwauzes, wo wegen Schmalheit dieses Körpertheiles Rücken- wie seitenfelder nebst ihren lichten Grenzen alle den Charakter von Streifen erhalten, heben sich daher, wenn die Farbentöne schärfer sind, ein dunklerer mittlerer Rückenstreif, damn jederseits zwei weissliche Streifen und zwischen ihnen wieder ein dunkler Streifen, gewissermassen wie ins Enge gefasste Fortsetzungen der Farben des Rumpfes, ab. Am Rücken und auf den Seiten des Leibes stehen Augenflecken in einer oder zwei Reihen, entweder so, dass das Weiss wirklich ins Innere vom Schwarz zu liegen kommt, oder das Weiss ist nicht umsäumt vom Schwarz, sondern steht am Rande der schwarzen Flecken. Nicht selten, namentlich am Rücken, ist das Weiss des Augenfleckes kein Punct, sondern ein Strich. Die Banchseite bleibt durchweg gelblich oder grünlich mit dunkeln Sprenkeln.

Es kommt vor, dass alle und jede Bildung von einfachen und Augenflecken ausbleibt, am Rücken wie am Bauche; doch scheint diess seltener zu sein. In der hiesigen Sammlung wird ein solches Exemplar, nach der Ueberschrift ans der Tübinger Gegend stammend, aufbewahrt; es ist ein Männchen. Ich hielt einen sommer lang ein weibliches Thier im Zwinger, welches ich bei Weinheim an der Bergstrasse gefangen und das sich ebenso gefürbt zeigt. Der Rücken ist von schönem lichtbramen Ton, olme alle Fleckenbildung; die Abstufung des Braun zwischen dem Rücken und den Seiten des Leibes durch lichtere Zonen fehlt nicht.

Wemn die Geschlechtsverschiedenheit anfingt sich in der Fürbung kund zu geben, so geht die früher brame Grundfarbe der Seiten beim Männchen in Grün über. Es geschieht das schon zeitig; soviel ich ermitteln lionnte im zweiten Jahr. Demn man trifft noch recht kleine ganz geschlechtsumreife Hännchen, welche bereits 
schön grün sind. Zur Zeit der FortpHanzung - als Hochzeitskleid - erreicht das Grün den höchsten Grad der Sättigung. Auch das Braun hebt sich um diese Zeit, bei guter Nahrung und sonstiger Pflege, in eiu angenehmes Graubraun. Bei geschlechtsreifen Mänuchen liann sich das Grün der Flanken weit ansbreiten und dadurch die braune Grundfarbe verdrängen. Nicht blos die Vorderbeine überziehen sich mit Grün, sondern auch die Seiten des Kopfes, die Kehle und der Bauch; ja selbst der für unsere Art so charakteristische Rückenstreifen kann theilweise, vielleicht gamz übergrünt werden. Ich habe lebende Thiere vor mir, wo der sonst weissliche Grenzstreifen zrvischen dem Rücken und den Seitenfeldern bereits gelbgrün geworden ist und auch das Braun des Rückenstreifens selber durch Aufnahme von einem gelblichen Ton abgeschwächt ist. Ferner kam mir in einer grösseren Anzahl von Thieren, welche behufs zootomischer Uebungen eingesimmelt wareu, ein Männchen zu Gesicht, bei dem der Rücken so grün war, wie die Seiten; erst über der Schwauzwurzel begann und zwar schwach der brame Rückenstreifen. Schon GISTL ${ }^{1}$ ) erzählt, dass er „in einem Wassergraben in der Gegend um Freising eine ganz grüne L. agilis gefangen habe." Sollten für diesen Fall die Worte: "ganz grün" buchstäblich zu nehmen sein oder in der Einschränkung, wie ich sie eben bezeichnet? Auch die hinteren Gliedmassen behielten immer, wenigstens an der Rückenfläche, das Braun.

Ich habe bis jetzt niemals ein lebendes oder frisches Männchen gesehen, welches ausser dem Grün auch noch Blau in Flecken oder Streifen gehabt hätte; denu selbstverständlich gehört nicht hieher, dass im Weingeist das Grün in Blau sich gerne umändert. Mir ist desshalb von jeher die Figur bei Rösel ") merkwürdig gewesen, welche blaue Flecken und Längsstreifen zeigt. Es scheint beinahe, als ob der ('olorist zu SchlEGEL's „Dieren van Nederland“ angewiesen worden wäre, Rössel sich zum Vorbild zu nehmen. Denn auch dort $^{3}$ ) erblicken wir die Lacerta agilis mit stark blauem Strich über den Rücken und eben solchen seitlichen Flecken.

Ganz besonders verdient hervorgehoben zu werden, dass die Münnchen nicht mit den grünen Fleid die Winterquartiere verlassen, sondern diesen farbenschmuck erst allmählig unter wiederholten Häutungen erhalten. Ieh hithe mich hievon bestimnt über\%engt. Im Mainthal bei Wertheim an dem somnigen Kaflelstein erwartete ich im Irühjahre das Hervorkriechen unsers Thieres, was am 5. April bei $+14^{\circ} \mathrm{R}$. geschah. An diesem Tage zeigte sich eine ganze Anzahl anf eimmal molle waren

1) Zeitschrift Isis, 1829.

2) Hist. nat. ranarum nostr. Titelkupfer.

i) II. I, Fig. 1. 
Männchen; aber keines derselben grün, sondern ohne Ausnahme an den Seiten von gelblich schwärzlicher Farbe. In der Gefangenschaft gehalten waren ihre Flanken Ende April noch nicht rein grün geworden, sondern blos schmutzig grün, welche Verzögerung aber gewiss ihren Grund in dem Aufenthalt im Zwinger hatte. Denn die im Freien lebenden Thiere, welche ich um diese Zeit gut ins Auge fasste, waren schon am 23. April prächtig grün, und mochten es wohl schon früher geworden sein.

Das Vorgebrachte schliesst an Verhältnisse an, wie man sie von Vögeln, Molchen und anderen Thieren kennt; aber es scheint bisher nur ein einziger Zoolog etwas davon gewusst zu haben. Es ist Schrank, welcher in der Fauma boica von

- unserer Art sagt: „im Sommer verwandelt sich die erdgrane Grundfarbe die das Thier im Frühling hat in ein schön blühendes Grün, aber alles übrige bleibt." Der Termin ist hier offenbar zu suät gesetzt, auch hat Schrank noch uicht die beiden Geschlechter untersehieden. - Nach der Begattungszeit, etwa um Mitte Juni, verliert das Grün von seinem Glanze, ist nicht mehr "laete viridis“, sondern nimmt einen Ton ins Dunkelgrüne, ein andermal ins Gelbgrüne an und verliert sich nach und nach völlig. Die Männchen wenigstens, welche ich im Spätsommer, Ende August, noch antraf, hatten bereits wieder das dunkle Kleid angelegt, mit welchem sie in Frühjahr aus ihren Löchern kommen.

Dass die Gegend des Vorkommens die Färbung zu beeinflussen vermag, wird nicht auffillen können. Hiebei handelt es sich besonders nun die helleren oder dunkleren Tinten der Grundfarben und nm die Ausbreitung der Fleckenbildung, was mit der Bodenbeschaffenheit zum Theil zusammenzuhängen scheint. Als ich z. B. im August 1866 von dem durch seine fossile Fauna und Flora berühmten Steinbruch bei Öhningen nach Stein am Rhein ging, fiel mir an den warmen sandigen Abhängen nicht blos die Menge der Eidechsen auf, sondern auch bei allen die ich haschen komnte, waren beide Geschlechter in der Grundfarbe, gleichsimn in Anpassung an den hellen Boden der Molassenhügel, äusserst licht. Bei den Weibchen war die Girundfirbe hellbraun, bei den Männchen grüngell). Didurch hoben sich die Angenflecken mit rein weisser Mitte auf's schürfste ab. Selbst auf der Rückentläche des hopfes trat die Fleckenbildung deutlich hervor. Und diss es sich wirlich um eine Anpassung an die Färbung des Molassensandsteins handle, bestätigte sich mir, als ich im Jilhr dariuf, Mitte Septemhers, an der Südseite des Gebhardsberges bei Bregenz die Lacertu agilis von der gleichen lichtgrauen Färbung traf. Von demselben ciesichtspuncte war mir eine Anzahl männlicher Thiere merkwürdig, welche ich im April 1869 an den sonnigen Bergen bei Weinheim an der Bergstrasse gefungen hatte. Hier steigerte sich das Grün wälnend des Mlonates Mai zu einem wahrhaft lenchtenden Grün; 
es zog sich selbst von den Seiten des Kopfès in das Braun der Kopfschilder. Die Mitte der Augenflecken, sonst weisslich, war selbstverständlich auch grün. Dazu kam, dass die dunkeln Flecken grösser waren als gewöhnlich, von buchtiger Form und indem sie von Stelle zu Stelle zusammenflossen in hübscher Vertheilung das Grün durchzogen.

Zu den grössten und schönsten Exemplaren, die mir je vorkamen, gehört ein Männchen, welches ich im Juni hier bei l'übingen im Ammerthal fieng. Das Grün der Seite, obschon mit einem Stich ins Gelbliche, war doch sehr lebhaft und fast ganz rein, indem von einer schwarzen Besprenkelung nur winzige Spuren eingemischt waren. Die weissliche Mitte der Augenflecken, von Form eines Striches, stiess zu Streifen zusammen und bildete so in der Mittellinie des braunen Rückenfeldes sowohl, als auch zu dessen Seiten je eine weissliche Längslinie.

Ferner habe ich mir von Thieren aus dem Mainthal bei Wertheim angemerkt, dass hei manchen Männchen die schwarze Besprenkelung des Bauches äusserst dicht sein kann, wodurch stellenweis, wie z. B. in der Gegend der Afterspalte und Wurzel des Schwanzes das Grün ganz zurückgetreten ist. Es entsprechen solche Thiere ungefähr der Abänderung nigriventris bei $L$. muralis.

Noch kann ein Farbenton auftreten, welcher unser 'Thier so auszeichnet, dass schon von dem ersten Beobachter diese Abänderung als besondere Art aufgestellt und auch von Manchem als solche festgehalten wurde. Es ist die rotbrückige Eidechse. Sie wurde zuerst durch LaURENTI bekinnt als Seps mubr, eine Bezeichnung, für welche später Fitzinger L. crythronotus setzte. Die Thiere, welche ich in Häuden hatte, waren alle, sowie LAURENTI schon bezeichnet, grösser und kräftiger als sonst $L$. agilis zu sein pflegt; eine Bemerkung, die auch bei Koch vorkommt. ${ }^{1}$ ) Der Rücken vom liopf bis zur Schwanzspitze ist von braunrother (kupferrother) Fürbung, ohne Flecken. Die Seiten sind grünlich oder bräunlich mit weisslichen, schwarz eingefassten Flecken; Banchseite hellgrün, mit schwarzen Puncten besprengt.

Eine von mir noch nie gesehene schöne Varietät hat 'T'schUDI ${ }^{2}$ ) beobachtet. Ueber den liücken läuft ein tiefschwarzes Band, das von zwei weisslich grauen Streifen eingeschlossen wird. Seiten schwarz, am Bauche ins 'l'iefgrüne übergehend, darauf weisse Puncte und Ringe. Kehle und Bauch schmutzig weiss.

1) a. a. O. „Ich fand sie wenigstens grösser als Seps agilis. "

2) Monographie der schweizerischen Echsen. 


\section{Schilder und Schuppen.}

Die Schilder des Kopfes können abermals nicht für sich allein zur Abgrenzung der species gebraucht werden, indem sie, wenn minn viele Individuen prüft, da und dort Abweichungen darbieten. So z. B. kamn die Zahnl der kleinen zunächst der Nasenöflnung in Dreieck stehenden Zügelschilder, auf welche man doch zuerst zu blicken ptlegt, vermehrt und vermindert sein. Ich habe Thiere vor mir, wo auf der einen Seite des Koptes die regelrechte Zahl sich findet, auf der anderen seite aber ist das oberste durch eine Querfurche in zwei zerfallen, so dass man vier hat. Umgekehrt zeigt ein anderes Thier nur zwei Zügelschilder, die aber, da sie den gleichen Raum zu überdecken haben, grösser sind. Aehmliches wiederholt sich bezüglich des Vecipitalschildchens. liegel ist, dass es dentlich vorhanden ist und Trapezform hat. Aber es kann auch ganz fehlen, oder es ist, wozu mir ebenfalls ein Beispiel vorliegt, gewissermassen unter die Rückenschuppen gerathen. Die Parietalschilder, hinten zusammenstossend, schliessen die Grenzlinien des Kiopfes ab und dahinter liegt in der ersteu Reihe der kleinen Rückenschuppen das Occipitalschildchen. Dergleichen Abänderungen - Zusammenschmelzen der Schilder, dann' wieder 'Theilungen, Auftreten von Nebenschildern - sind keineswegs allzuselten: unter zwölf Exemplitren befanden sich z. B. drei mit Abweichungen. Am meisten scheint die Hinterhauptsgegend zu störungen geneigt zu seiu und wemn es auch nicht immer zur Abgrenzung nener Schilder kommt, so zeigen sich doch oft Eindrücke und Furchen, die bei anderen Individuen zu T'heilungen führen. T'schud besass gar ein Mïmnchen, bei welchen der ganze hintere Theil des liopfes statt mit Schildern mit Schuppen bedeckt war.

Der Unterschied zwischen den Schuppen des Rä̈ckens und der Seiten ist gross. Denn die Rü̈ckenschuppen sind schmal, linglich, nicht eigentlich eckig oder polygonal, mit deutlichem Kïl; hingegen die Seitenschuppen, indem sie lïnger und breiter werden, verhieren den hiel und verflachen sich; doch erhält sich bei vielen eine gewisse Buckelbildung, unter schräg anffallendem Licht gut sichtbar. Dass zwischen den schuppen der suite noch kleinere Höcker (oder schüppchen) zugegen sind, wird besonders deutlich bei abgehobener Epidermis und bei Spannung des Bauches.

Die Schilder am Banche bilden, wenn man nur die grossen im Ange hat, sechs Lüugsreihen; jederseits nach ansseu schliesst noch eine Reihe kleinerer an, die mitunter sich wenig durch ihren Umfing von den anstossenden Schuppen der Seite abheben, an andereu Individuen aber, namentlich illteren Miunnchen, allerdings merklich grösser sind als die nächst anschliessenden Schuppen der Seite. Solche 
Verschiedenheiten sind Veranlassung, dass die einen Zoologen sechs, die anderen acht Reihen von Bauchschildern dem Thier zuertheilen.

\section{Schädel und Zähne.}

Die erste Abbildung des Schädels sammt übrigem Skelet gab der Nürmberger Miniaturmaler MEYeR ${ }^{1}$ ) und dieselbe ist für den Stand der osteologischen Kenntniss von dazumal als eine sehr gelungene zu bezeichnen.

In der Zeit wie man anfieng sich um die Deutung der Kopfknochen zu bemühen, gab BoJanus ${ }^{2}$ ) Zeichnungen von dem doppelt vergrösserten Schädel der Lacerta agitis, wie er sagt, weil ihm dieses "einheimische Diminutiv-Crocodil" bei Mangel eines wirklichen Crocodilschädels zur Nachweisung und Verständigung dienen muss. Dass ich übrigens seinen Deutungen nicht durchweg zustimmen kann, geht aus dem oben Dargelegten hervor, wie denn auch schon CuviER mancherlei daran auszusetzen wusste. ${ }^{3}$ )

Inwiefern sich der Schädel ${ }^{4}$ ) von agilis von dem der nächstverwandten viridis unterscheidet, wurde bei der letzteren Art erörtert.

Die Zahl der Zälıne beträgt

im Zwischenkiefer 9;

im Oberkiefer, eine Seite, 16;

im Unterkiefer, eine Seite, bis 20;

am Gaumen, eine Seite, die kleinen mit inbegriffen 12.

Alle sind rückwärts und einwärts gerichtet. Die Gaumenzähne sind weder auf den Abbildungen MEYER's zu bemerken, noch scheint sie BoJANus beobachtet zu haben. -BRANDT ${ }^{5}$ ) gibt ihre Zahl zu gering an, wenn er sagt, es seien nur fünf.

\section{Vorkommen.}

Man war früher der Meinung, dass Lacerta agitis nicht nur über ganz Europa verbreitet sei, sondern auch noch weit darüber hinausgehe und in „beiden Indien, sowie auf den Inseln der Süudsee " lebe. Wenn ein so streng sichtender Zoolog, als MerreaI ${ }^{6}$ ) war, sagt: der Aufenthalt ist Europa, Levante, nördliches Afrika; so wird

1) Angenehmer und nützlicher Zeitvertreib in Betrachtung allerhand Thiere. 1748. Tab. LVI.

2) Isis, 1821, S. 1162, Taf. 8, Fgg. 6, 7, 8, 9.

3) Rech. s. les ossemens foss. 1825 .

4) Vergl. Zweite 'Tafel, Fg. 23, Fg. 24.

5) Medicinische Zoologie.

e) System der Amphibien. 


\section{5}

begreiflich, wie weniger genane und zuverlässige Schriftsteller ${ }^{1}$ ) lurzweg vortragen konnten: "ihr Vaterland ist die ganze bewohnte Erde."

Das Ergebniss einer sorgfältigeren Prüfung lautet aber anders; denn wir erfahren dadurch, dass $L$. agilis eine beschränktere Verbreitung habe, als die Arten $L$. viridis, vivipara und $L$. muralis.

Beginnen wir mit dem nördlichen Afrika. Dass $L$. agilis dort einheimisch sei, stützt sich auf die Angabe PoIreT's, ${ }^{2}$ ) welcher an der Hand LINNÉ's, dessen Kennzeichnung unserer Eidechse hekanntlich, weil auf mehrere Arten gleich gut passend, unbrauchbar ist, das Thier zu erkennen glaubte. Die späteren Erforscher dieser Gegenden fauden die Art dort nirgends, worüber man z. B. die neueste Arbeit von STRAUCH $^{3}$ ) vergleichen möge, welcher der Ansicht ist, dass PoIrets L. agilis zu $L$. ocellata gehört.

Unter den vielen Reisenden, welche Syrien und Palästina besuchen, gibt es nur wenige, welche anch der Thierwelt des Landes ihre Aufmerksamkeit zuwenden. Ein solcher war der kenntnissreiche, scharf beobachtende SEETzEn, welcher im Anfang dieses Jahrhunderts die bezeichneten Länder durchforschend, auch ganz besonders auf die Eidechsen Acht hat und eine nicht geringe Anzahl so genau beschreibt, dass Lichtenstein und Wigganans, welche die zoologischen Fragmente durchgingen, sie noch bestimmen konnten. ${ }^{4}$ ) Es ist aber keine Art darunter, welche unserer $L$. agilis entspricht. Und damit steht in Uebereinstimmung, wenn einige Jahrzehnte später Ehrenberg erklärte, dass er auf seiner ostafrikanischen Reise nur der L. muralis verwandte Formen gefunden habe.

Da es selbst noch in dem grossen Werke BIBron's und DuMÉril's heisst: "cette espèce se trouve dans toute l'Europe, excepté tout à fait au nord," so lohnt es sich die verschiedenen Länder hierauf etwas năher zu besehen.

In dem neuesten Verzeichniss über die Reptilien Portugal's von BARBosa de BOCAGE ${ }^{5}$ ) ist $L$. agilis nicht aufgeführt, sondern lediglich ocellata, viridis und muralis.

Dass die Art in Frankreich zu Hause sei, ist aus den Mittheilungen der dortigen Zoologen bekannt; aber sowohl LATreilue, dessen Lézard vert var. c. und e unsere $L$. agilis ist, sowie DAUDIN geben als Wohnort nur die Ungebung von Paris

1) Z. B. der Verfasser einer Naturgesch. der Schlesisch-Lausitz'schen Amphibien. Görlitz 1831.

") Voyage en Barbarie etc., avec un essai sur l'histoire naturelle de ce pays, Paris 1789:

3) Essai d'une Erpétologie de l'Algerie, Mém. d. l'acad. d. St. Petersbourg, 1862.

4) Urrici Jasper Seetzex's Reisen durch Syrien, Palistina etc, heriusgegeben von Fr. Kruse. 1859.

5) Revue de Zoologie, 1863. (Mir leider nur bekannt aus Troscuen's Jabresbericht für 1864.) 
an; ob die Art, was besonders interessant wäre, auch im warmen Südfrankreich vorkomme, finde ich nicht erwähnt.

In Belgien ist sie nach Selys-Longchamps ${ }^{1}$ ) "assez rare", und wurde von Genanntem nu in der Umgebung von Arlon beobachtet.

In Italien fehlt $L$. agilis. Von der Insel Sardinien hob schon GENÉ hervor: „caret Lacerta agili“; bei BONAPARTE heisst es: „è raramente in Italia, ove sembra esser confinata ad alemi distretti superiori." Als mir Zweifel aufgestiegen waren über das Vorkommen der gegenwärtigen species in Italien habe ich anf mehreren Ferienreisen, so im Herbst 1867, 1868 und 1869 schärfer als früher auf diesen Punct geachtet; wobei es sich zeigte, dass diesseits des Brenners, z. B. in der Gegend von Kufstein, sowie bei Insbruck noch die L. agitis zugegen sei, jenseits des Brenners aber kam mir trotz aller Aufmerksamkeit die Art nicht mehr zu Gesicht. Um so lieber schenkte ich daher in Verona dem treftlichen Kenner der Reptilien seiner Heimath Herru de BEтTA Glauben, als ich von ihm hörte, dass diese Art nicht als Glied der italienischen Fauna zu betrachten sei, wie er denn auch bereits bezüglich Südtyrols und der venetianischen Provinzen diess in seiner "Erpetologia" angegrben. ") Aussagen verschiedener italienischer Faunisten ïber das Vorkommen von $L$. agilis in Italien beziehen sich, wie Prinz BonAPARTE und de BETTA gezeigt, nicht auf diese Art, sondern auf $L$. muralis. Wenn für die Ligurische Küste von SASSI ${ }^{3}$ ) neben Podurcis muralis WAGL. anch Lacerta agilis DAUD, aufgeführt wird, su liegt hierin ein offenbarer Fehler vor, denn DAUdiN's $L$. agitis ist bekanntlich $L$. muralis. Und da der Genueser Zoolog hingegen nichts von der L. viridis sagt, so wird diese wohl, da doch die beiden Eidechsenarten durch volksthümliche Bezeichnungen (Grigua und Lagheu) unterschieden werden, unter der einen oder der andern zu vermuthen sein. - Ueber Sicilien, welche Insel die Lacerta agilis besitzen soll, wird man neuere Aufklärungen abwarten müssen. Miın darf argööhnen, dass der Angabe abermals eine Verwechșlung zu Grunde liegt.

L. agilis fehlt feruer bestimmt noch audern wärmeren Ländern von Europa. Schon GErmar ${ }^{4}$ ) bemerkt von Dalmatien, dass obschon die Eidechsen in Menge vorhanden seien, so bei 'Triest, ${ }^{5}$ ) liume, Zara, er doch unsere eigentliche Lacerta ayjlis

1) Faune Belge, $184 \%$.

2) \$.... non venne mai fino ad ora incontrata nelle nostre provincie.

3) Saggio sopra i pesci rettili e mammiferi della Liguria, Genora 1856.

i) Reise mach Dalmatien, 1817.

j) Bezüglich der Gegend von 'Triest könnte man nach dem Buche Grune's: Ein Ausflug nach Triest und dem Quarnero 1861, wieder irre werden, da dort gesagt wird, dass in dem Boschetto bei 'Iriest $\bowtie$ Lacerta agilis zablreich unter den Gebüschen hervorschlüpft: Allein mir scheint diese Angabe nur anzudeuten, dass unser Beobachter die Reptilien nicht gleich gut kennt wie die Anneliden. 
nicht gefunden habe. Ehenso gibt Erber, ${ }^{1}$ ) welcher mit dem sammeln von Reptilien sich ganz eigens befasst, ausdrücklich an: "in Dalmatien find ich sie nicht". Nach demselben Beobachter kommt sie im südlichen Ungarn, bei Orsowat, nur selten" vor; duch sammelte sie noch Graf FErRari in der Sandwïste bei Basiasch; sie mangelt aber, wie ans BorY de ST. VINcext's bereits angeführtem Prachtwerk, sowie aus der neuesten Schrift de BETTA") hervorgeht, in Griechenland, auf dem Festland so gut wie auf den Inseln. - Ije Länder, für welche dị Vorkommen unsrer Art festgestellt ist, sind ausser dem schon genannten Frankreich folgende.

Die Schweiz, wo sie nach T'schud in dem nördlichen, mittleren und selbst südlichen (!) Theil die Ehenen und das Hügelland bewohnt. In Appenzell ist sie nach schläPfER (Versuch einer naturhist. Beschreibung ron Appenzell, Trogen 1829) nicht häufig. Dann zieht sie sich durch ganz Deutschland, wo sie z. B. LAcrextI und Fitzinger für Oesterreich, GLëckselta für Böhmen, SchrıNk für Altbaiern, Enrhand (Physisch-medicinische Topographie von Memmingen) für bairisch Schwaben, Wolf für die fräukischen Gegenden, BEchstein für Thüringen, Kalcza und Giloger für Schlesien, Heinlich für Mühren, Kirschbac̀r für das Nassauische etc. angezeigt haben. Da die Art gerne in Erdlöchern lebt, so kann ihr nicht jede Gegend gleich lieb sein und man wird sie auf weite Strecken hin, namentlich wo harter Boden ist, vermissen. Nach meiner Erfahrung ist sie z. B. bei Bamberg laüufiger als bei Würzburg; im eigentlichen Taubergrund bei Rothenburg, auf Kalk, ist sie geradezu selten und nur in den Hecken um die Stadt hin und wieder zu treffen; an der unteren Tauber aher, auf buntem Sandstein, sehr häufig. Bei Tübingen ${ }^{3}$ ) in soweit lieuperhoden sich ausdehnt, ist sie noch recht zahlreich, während man auf dem Gebiet des IInsehelkalkes stundeuweit gehen kann, ohne auch an den somnigsten Stellen des Thieres insichtig zu werden. Ebenso rerhält es sich mit unserer All): ich habe neben der dort häufigen $L$. viripara zwar auch $L$. ayilis beohachtet, aber verhïltuissmässig doch sehr vereinzelt. Am liebsten hält sie sich im sonnigen Rianen, am Girunde von Weinbergsmauern, au Berghalden auf. Doch kommt sie anch im Walde vor; hier bei Tübingen ist sie z. B. im Bebenhauser 'Thale, was

1) Amphibien der österreichischeu Monarchie.

") Rettili ed anfibi del regno della Grecia, 1868.

y) In hiesiger Gegend sah ich sonst nux $L$. vivipara von der Zecke (Ixodes lacertae) geplagt. Aber im Mai 1868 erhielt ich drei Exemplare von $L$. agilis auf denen dieser Parasit ebenfalls zahlreich schmarotzte und zwar in allen Aitersstufen. An dem einen Thier sassen 5, beim anderen 8 und beim dritten sogar 17, meist hinter dem Vorderfuss, einige auch weiter nach vorne, selbst auf dem Trommelfell. Ebenso waren Exemplare von $L$. agitis, welche ich im Frühjahr 1869 bei Wertheim und Weinheim fieng mit Ixodes besetzt. Am hiufigsten scheint L. muralis von diesen Parasiten geplagt zu werden; ich hatte ganz juuge Thierchen in Händen, welche bereits damit besetzt waren. 
doch einen entschiedenen Waldcharakter hat, geradezu häufig; selbst im dichten Laubrald habe ich sie da und dort in Hünden gehabt und mich so überzeugt, dass es nicht die gemeinhin als Waldeidechse bezeichnete $L$. vivipara sei.

Die schöne rothrückige Eidechse ( $L$. erythronotus FrTz., ruber LaUr.) wird nur hin und wieder gesehen. Bechstein (1800) meldet, dass sie in Thüringen nicht selten sei; Daudix fieng sie "une seul fois au Bois de Bologne“; Kocir, welcher" sie unter dem Namen $S$. stellatus Schrank, genau beschreibt und abbildet, fund sie (1828) in der Oberpfalz etwas selten; GISTL bei JIünchen (1829) ebenfalls "seltener" TscuUd, der doch den Eidechsen der Schweiz sehr eifrig nachging, sah, nach einer Anmerkung zu schliessen, nur ein Sammlungsexemplar in Neuchatel. Ich selber fing das Thicr in Laufe vieler Jahre wie ich schon anderwärts mittheilte erst dreimal: bei München, dann im bairischen Hochland, endlich noch im Herbst 1865 in der Ramsau, Gebirg ron Berchtesgaden; dieses letzte Exemplar, von besonderer Grüsse und Schönheit latte ich längere Zeit am Leben erhalten. Ostwärts wird aber vielleicht die rothrückige Eidechse häufiger. So ist mir bemerienswerth, dass Gứckselig kurzweg sagt: Habitat (in Bohemia) in stratis lapidosis prope aquam; auch muss er zu Folge seiner Angaben über die Abschattungen der Farbe zahlreiche Exemplare vor Augen gehabt laben. Endlich für Oberungarn heisst es bei JeıTteles: „die rothrückige Varietät (der L. agilis), ist bei Kaschau nicht selten." Nach MENGE findet sich unser Thier auch bei Königsberg, doch habe ich nach dem, was er über die Farbe sagt, einige Zweifel, ob er die wirklich rothrückige Eidechse vor sich hatte.

Dass Lacerta agitis in der gewöhnlichen Färbung im Norden von Dentschland, sowie in Dänemark nicht mangelt, darüber liegen bereits aus alter Zeit ${ }^{1}$ ) sichere Angaben vor, zuletzt noch von BoJE (Isis 1841); bezüglich der Niederlande kann SCHLEGEL als Gewährsmann genannt werden; sie findet sich in England nach dem Zeugniss älterer und neuerer Naturforscher. (THomas BelL, British Reptiles, 1849.) Dass unser 'Thier in Schweden vorkommt, geht aus NiLson's Shandinavisk Fauna (18.2) hervor; ob es aber wie BRANDT meldet, nördlich hinauf bis zu beiden Seiten des Bothnischen Meerbusens sich erstreckt, ist mir zweifelhat't geworden. Denu der. letzt Genaunte hat die $L$. vivipara, welche, wie wir sehen werden, am nördlichsten geht, und auch am höchsten vertical sich erhebt, noch mit $L$. agilis fälschlicherweise zusammengeworfen.

Hingegen verbreitet sie sich noch weiter ostwärts, z. B. nach Ostpreussen, was WulfF, JENGE u. A. bezengen; nach Oberungarn (Kaschau), wie wir durch JeITTELES wissen. Aus Russland kennt man sie z. B. durch Pallas, nach dessen Angabe sie sellust über das ganze asiatische Russland sich erstreclit; im Gebiet des Kaukisus fand sie EICHWALD; von seiner Reise nach Buchara brachte EversuANN Exemplare von besonderer Grösse und Fürbung aus der Gegend des Aralsee's zurück, in der Nähe der russischen Grenze. „Manche darunter waren fast ganz grün, die man aber dennoch nie mit der $L$. viridis verwechseln kann, andere bei denen nur der Iïcken bis zum Schwanz von dieser tief grünen Farbe ist, noch andere bei

1) Schon JAcoвäus sagt im Jahre 1686: sLacertus communis, coloris varii in patria nostra oberrat, fre-. quentius tamea sut viridis aut grisei coloris conspicitur.* 
denen die Seitenstreifen des Rückens höchst regelmässige braune und schwarze Querbinden haben u. s. W."

Ich habe diese Stelle ausgezogen, weil mir aus der Gegend von Sarepta ${ }^{1}$ ) an der untern Wolga eine ganze Anzahl von Lacerten vorliegt, welche höchst merkwürdig sind. Die kleineren Exemplare, von der Mittelgrüsse der dentschen $L$. agilis, scheinen jüngere 'Thiere zu sein; bei ihnen ist die Fleckenbildung schärferr und die dunkeln Flecken des Rückenfeldes sind umfünglicher als bei den unsrigen; sonst aber weichen sie nicht sonderlich von letztern ab. Anders verhält es sich mit den grossen geschlechtsreifen Thieren: sie haben eine Lünge bis zu zehn und einem halben Zoll, dadurch, sowie durch die Farbe, welche bei den Männchen auch über den Rücken weg grün ist und zwar so satt, dass die dunkeln Flecken nur noch schwach hervortreten können, erinnern sie lebhaft an L. viridis und bei flüchtiger Besichtigung würde man sie auch dafür erliläen. ${ }^{2}$ ) Allein die nähere Untersuchung lässt nicht den mindesten Zweifel übrig, dass man es nach der Tracht und den Einzelheiten mit der echten L. agilis zu thun habe, und zwar mit jener Form, welche Eversmans zuerst gefunden.

Schon Prinz Bonaparte sprach die Ansicht ans, dass L. agilis eine nördliche Art sei; aus den Angaben wie sie in Voraugehenden zusammengestellt sind, wird im Näheren ersichtlich, dass sie sich über Mittelemropa und Ostemopa verbreitet; wie weit sie nach Asien vordringt, bleibt noch zu erforschen.

Was ihre verticale Verbreitung betrifft, so soll sie nach der gewöhnlichen Angabe nur die Ebenen und die Hügelregion bewohuen; "jamais les montagues" sagen BIBRoN und DuMÉrIL. Doch fimd ich sie im Hochgebirge immerhin bis etwa 2000 Fuss Höhe, so an somnigen Stellen der Salzburger Alpen, wo sie allerdings. auch schon in der ersten Hälfte-des September da und dort erstarnt unter den Steinen lag. In ähnlicher Höhe traf ich sie auch auf dem Wege zum „wilden Kaiser" bei Kufstein. Es stimmt das ziemlich mit len Mittheilungen, welche TENance Parot über dis Vorkommen der Reptilien im Stock des Mont-Blanc veröltentlicht hat; dort sind 800 bis 900 Metres Höhenverbreitung angegeben. ${ }^{3}$ )

1) Durch die Güte des Herm Cosstantrn Gritsci, Verfassers der *Beitrïge zur Naturgeschichte der Antilope saiga Pstu, Moskau 1865, »sowie mehrerer Aufsätze über Vögel der Umgegend von Sarepta in der Naumannia, 1853 .

$\left.{ }^{2}\right)$ In der That sprach Herr Staatsiath EicuwaLd bei einem Besuch der hiesigen Sammlung dieselben für seine $L$. strigata, welche nach Andern gleich $L$. viridis wiire, an.

3) Leider werden in der Abhandlung des Genannteu die Arten.der Eidechsen in bedenklicher Weise durch einander gewürfelt: $L$. agitis und stirpium sind dort etwas Verschiedenes, argus und ruber gehören bei dem Verf. zu viridis, etc. 


\section{Geschichtliches und Kritisches.}

Obschon Gessner unsere Art kennt, ${ }_{\text {- }}$ und die Farbe der grünen und braunen richtig angibt, ${ }^{1}$ ) auch sein Zeichner ein gar nicht schlechtes Bild von ihr liefert, ${ }^{2}$ ) so habe ich doch die Bezeichnung "Lacerta communis", unter weicher er sie bespricht nicht aufgenommen, weil mir aus einer Stelle seiner Mittheilungen hervorzugehen scheint, dass mit Lacerta communis nicht ausschliesslich $L$. agilis gemeint sei, sondern auch L. muralis darunter stecke. „Amat Lacertus vetera aedificia, muros et moenia, fuscus praesertim lacertus; virides rero (in quoque parvi, nec nisi colore differentes, non enim de majoribus viridibus loquitur) in campis potius sunt." In diesem Satz unterscheidet Gessner die grosse oder echte viridis; dann die kleine, unsere agilis, welche das freie Feld licbt; endlich eine dritte kleine braune, welche alte Gebäude und Mauern vorzieht, - uni diess passt nur auf $L$. muralis.

Nach dem zu schliessen, was $\operatorname{SEBA}^{3}$ ) über seine „Lacertulae indigenae virides“ sagt, ist ihm der Unterschied der Geschlechter nach der Farbe schon bekannt gewesen. Die Abbildungen sind in einer rauhen, steifen, dabei fluchtigen Art gehalten; der Figur, welche das Münnchen vorstellen soll, hat der Zeichner eine Ringelung des Schwanzes gegeben, wie die alte Kunst sie wohl herkömmlich dem Lindwurm zuertheilt, wie sie aber nicht bei unseren Eidechsen beobachtet wird.

Die erste wirklich gute Abbildung und zwar eine colorirte, gab der Nürnberger Miniaturmaler MEYER (1748); das Thier, ein Weibchen, ist von unten und oben dargestellt; daneben das Ei, sowie das Skelet, wahrscheinlich von dem bekannten Arzt und Anatomen TrEu angefertigt, ebenfalls in zwei Ansichten. Gering ist hingegen die gleichfalls colorirte Abbildung, welche von dem englischen Maler EDwards unter dem Namen Lacerta ex insula Sarnia herrührt und mir aus der SeĹigmans'schen Nachbildung (Nürnberg, 1770) bekannt ist. Das Thier ist, wie auch der Text besagt, ein Männchen; wer an dem wie trächtig angeschwollenem Bauch bei dieser Deutung Anstoss nimmt, kann sich durch Vergleichung der andern Eidechse auf Taf. II, welche ich für $L$. vivipara halte, sowie des Wassermolches auf Taf. XXXXIX überzeugen, dass es Eigenthümlichlkeit des Malers war, die Bogenlinie des Bauches in übertriebener Weise zu wölben.

Am bekanntesten ist die Rösel'sche Figur auf dem Titelkupfer des Werkes über die Frösche (1758) und legt abermals von dem 'Talente des Meisters Zeugniss ab, obschon sie die Kopfsclilder im Einzelnen nicht getreu darstellt und auch den Fehlcr hat, dass die Rückenseite des Schwanzes wie eine Hohllkehle gezeichnet ist; Iängel, welche wohl auf Rechnung des gleichen Umstandes kommen, dessen ich sclion anderwärts ${ }^{4}$ ) gedachte. Die Copie in den Supplementen zu OKEN's Naturgesch. Taf. 21 ist in Hinsicht des Schwanzes verbessert, sowie auch die blauen Flecken des Colorites richtiger hier weggelassen sind. Nicht der Natur entsprechend ist auch die in der Zeichnung dem 'Thiere beigelegte Fähigkeit mit dem Schwanz einen Baumast spiralig zu umziehen, eine Willkür, welche auch bereits DuGḱs gerügt Lat. Die Originalblätter des Rösel'schen Werkes, in Wasserfarben gemalt und zwar mit bewundernswerther Sorgfalt, finden sich in der Hof- und Staatsbibliothek za Müncben. Durch die grosse Güte des Herrn Directors Halm wurde mir jüngst die Gelegenheit zu Theil, dieselben zu durchsehen und mit dem Stich vergleichen zu kömen. „Das Titelblatt, welches uns hier wegen der darauf angebrachten $L_{\text {. }}$ agilis allein berührt, hat der Künstler offenbar mehrmals abgeändert, denn das uns im Kupferstich vorliegende weicht in vielen Puncten von jenem Aquarellblatt $a b$, welches in München die IIandzeichnungen eröfhet. Die Grundzüge des ersten Entwurfes hatte der Kunstler zivar auch beim Blatte für den Sticlı beibehaiten, aber das Münchner Bild zeigt sich nicht nur in der Anordnung und Ausführung der zum Schmuck verwendeten Pflanzen manchfach verschicdeu von der

1) ล. ล. $0 \cdot \mathrm{p}, 30$.

2) ล. a. O. p. 29

8) Thesa urus, Tom. II, Tab. 4. Fg. 4, F'g. 5.

") Molche der württ. Fauna, 1867. Anmerkgn zu Salamandra maculata. 
Kupferplatte, sondern an den Thieren ist nicbt minder vielfach ge:̈ndert worden. So ist zwar auch auf dem Aquarell der Laubfrosch, der Grasfrosch, der Wasserfroseh, die gemeine liröte, der Landsalamander und die Eidechse zugegen; aber an allen hat die Hand des Küntlers, wenu man von dem Aqquarell hinweg auf die Kupferplatte blickt, zu besscrn gewusst, so namentlich, was die.Stellung, oder die Weise wie die Beine angezogen werden, betrifft $u$. dergl. Insbesondere die Eillechse hat er ganz ungearbeitet. Sie erscheint auf dem Aquarellblatt einfacher, sie züngelt zwar auch, aber der Schmetterling nach dem es geschieht, fehlt; ilre Gesammthaltung ist noch weniger lebendig, als auf ier liupferplatte. Das Colorit ist kium naturgetreu zu nennen, fast gänzlich grün, und ohne das spätere Blau; dem Schwanz erscheint noch nicht die IIolılkelıle aufgesetzt. Auf dem Aquarellblatt befindet sich auch unten rechts ein Thier, welches Rösec s̀päter ganz wegliess, ein Wassermolch nemlich und zwar das Männchen von Triton taeniatus, mit hohem gezacktem Kanm. Dieser Molch ist nicht sonderlich ausgefallen und da er aus dem Wasser kriechend eben ans Land kommt, so war es geradezu falsch, den Kamm hoch entfaltet zu zeichnen, denn dazu gehört, dass das Thier unter Wasser ist. Diess und anderes mag der treffliche Künstler wohl selbst erwogen und ibn zu dem Entschlusse gebracht haben, die Figur einfach zu streichen. Im Allgemeinen hat das Titelblatt, wie es uns im Stiche vorliegt, durch die Veränderung gewonnen, was z. B. bei der Vergleichung des Laubfrosches in die Augen springt; doch erscheint wieder Manches, wenigstens nach meinem Geschmack, in der Originalzeichnung gefäliger als auf dem Stich. Dem Aquarell dieses Titelblattes sieht man in Ganzen auch an, dass es weniger rein und sorgfältig gemalt ist, als die folgenden, welche die eigentliche Darstellung der Frösche und Kröten enthalten.

Gegen das Ende des vorigen und Anfang dieses Jahrhunderts hatte sich die Kenntniss von dem Unterschied der Geschlechter verloren und beide erscheinen daher als besondere Varietäten oder Arten; so hat selbst Latreille (1 800 ), was uns an diesem scharfen Diagnostiker inmer auffallen muss, das Weibchen als Var. c seiner Lezard vert unverkennbar beschrieben, und das Männchen ebenso treffend als Var. e. Sein

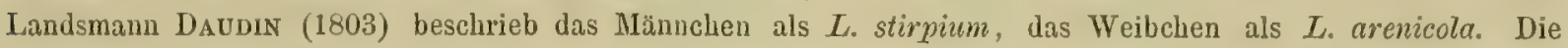
Figuren vou beiden Thieren gehören zu den besseren Abbildungen des Werkes.

Zum erstenmale wird unsere Eidechse nach den Geschlechtern scharf und sicher unterschieden von Wolf (in Sturm's Fauna, 1799). Er erzählt, dass er im Jahn zuvor alle Eidechsen, die ihm nim Nürnbergischen" unter die Hände kramen, untersucht habe, wobei sich fand: "Alle Eidechsen hatten entweder grüne Seitell und einen braunen Scheitel, Rücken und Schwanz, und diess waren allemal, wenn ich sie zergliederte, Männchen; oder sie waren röthlichgraubraun mit einen grüngelben Unterleibe, diese enthielten allemal den Eierstock und waren also Weibchen." Da er nun noch weiter ausführlich beide Geschlechter beschreibt und die Art agilis nennt, so hat man hier nebenbei zum erstenmale für diese Bezeichnung eine sichere Grundlage. Die Abbildungen sind gut, verlieren aber etwas durch die Verkleinerung, welche das einmal gewähite Format des Werkes den Figuren aufnöthigte.

Wohl gleichzeitig hat BECHsTeIs die beiden Geschlechter nach ihrer Farbe unterschieden. Da übrigens der Genannte lediglich die Eidechsen des Thüringer Landes und von Brandenburg aus eigener Auschauung kenut, so fällt er in den Irrthum, dass er bei Uebersetzung des LACÈPEDE'schen Buches den Lezard gris für die Eidechse hält, welche er in Thüringen täglich vor Augen habe, während der LAcLipeDE'sche Lezard gris die $L$. muralis ist.

Unter den spãteren Arbeiten verdient eine besondere Auszeichnung der monographische, auch die Anatomie beruclisichtigende Artikel ron Brandr und RATZeburg in der medicinischen Zoologie 1829; nur thut es etwas Eintrag, dass die Verfasser unter Lacerta agilis auch die sehr davon verschiedene L. vivipara begriffen' haben, was man im Gedächtniss behalten muss, wenn gar Manches auf $L$ o agilis nicht passen will. Der Abbildung, ein Mitnnehen vorstellend, sieht man wohl an, diss ein anfmerksamer und geschieliter Künstler sie gefertigt hat. Nur die Zehen der Hinterbeine sind etwas steif gehalten, namentlich sind sie alle zu gleichmässig nach vorne gerichtet, während in Wirklichkeit das lebende Thier sie gerne, wenigstens die äusserste Zehe, abgerückt hält, ein Punct, den z. B. die Zeichner der Eidechsen im Werke Bovaparte's nicht ausser 
Acht gelassen haben. Die Fauna italica (1836) entlualt ausser der Abbildung der gewöhnlichen $L$. agilis ron OKEN in den Atlas seiner Naturgeschichte aufgenommen - auch eine sehr gelungene von der rothrückigen Varietät.

Was in der englischen Ausgabe des Thierreichs von Cuvien ${ }^{1}$ ) als "Green Lézard, Lacerta agilis" abgebildet wird, ist ein grösseres Exemplar von L. muralis. Hingegen zeigt sich TnoMas BeLL als ein guter Kenner der auf englischem Boden heimischen Eidechsen, in einer Schrift, die nicht früher schon eingesehen zu haben ich sehr bedaure. ${ }^{2}$ ) Dabei sind die Abbildungen der $L$. agilis, Holzschnitte, in Zeichnung und Ausführung vortrefflich und das ganze Buch in seiner schönen Ausstattung, geschmückt mit heiteren Vignetten, erinnert an manches naturhistorische Werk der zweiten Hälfte des vorigen Jahrhunderts.

Auf eine Sichtung der Synonymie in dem Werke Brbron und DumḱRIL's im Einzelnen einzugehen halte ich nicht für angezeigt, obschon arge Verstösse vorkommen. Die unverkennbar abgebildete und beschriebene $L$. agilis bei Becurstern bringen genannte Autoren unter $L$ ocellata Daudrn! Doch wird sich Jeder, welclıer das treffliche Werk der franzüsischen Herpetologen benützt, geneigt fülılen, dergleichen Fehler zu entschuldigen. Bei der Masse des zu verarbeitenden Materials war es den Verfassern unmöglich, jeder einzelnen Art, auch in literarischer Beziehung, die wünschenswerthe Sorgfalt zu widmen.

3. Art. Lacerta vivipara JACQ. Berg-oder Waldeidechse. Lacerta vivipara. JACQUIN, Nov. act. Helvet. Vol. I, 1787.

Lacerta crocea. WolF in Sturse's Deutschlands Fauna, 1805.

Lacerta pyrrhogaster. MerReM, System der Amphibien, 1820.

Lacerta pyrrhogaster. KöMER-BüchNER, Verzeichniss der Steine und Thiere, welche in dem Gebiete der freien Stadt Frankfurt gefunden worden, 1827.

Lacerta crocea. GISTL, Bemerkungen über einige Lurche, Isis, 1829.

Lacerta crocea. HAHN (u. REIDER) Fauna boica, 1832.

Lacerta crocea. GLOGER. Schlesiens Wirbelthierfauna, 1832.

Lacerta vivipara. Plieninger, Verzeichniss der Reptilien Württembergs. Jahreshefte d. naturwiss. Vereins, 1847.

Lacerta vivipara. Heinrich, Mährens und Schlesiens Fische, Reptilien und Vögel, 1856.

Lacerta crocea. FAHRER, Thierwelt von Ober- und Niederbayern. Bavaria, Landesund Volkeskunde von Bayern, 1860; dann auch „Oberpfalz" 1863.

Lacerta vivipara. Kinschbaum, Reptilien und Fische des Herzogthums Nassau 1865. Lacerta crncea. MEDicus, Thierwelt d. Rheinpfalz. Bavaria, Landes- u. Volkeskunde von Bayern, 1867.

Lacerta vivipara. LEYDIG, Thierreich in der Beschreibung des Oberamts Tübingen, herausgegeben vom statistisch-topogr. Bureau, 1867.

1) The animal kingdom by Cuvier with additional descriptions by Edward GrifrTri, 1831.

$\left.{ }^{2}\right)$ A bistory of British Reptiles. Second edition, 1849. Hier ist nïmlich auch der Triton helveticus RAz. als Lissotriton palmipes gut alogehandelt, nachdem der Autor, wie er offen eingesteht, in der ersten Ausgabe des Buches diesen palmatus nur für eine Form des $T$. punctatus gehalten hatte. Er sah aber seinen Irrthum rasch ein, als er den wirklichen ppalmipes vor die Augen bekam. 
Varietat. a. Lacerta nigra. Wolf in STurM's Deutschlands Fauna, 1805. Das Inhaltsverzeichniss führt sie als $L$. atra auf.

- b. Lacerta montana. MiKan, ebendaselbst, 1805.

\section{Kennzeichen. ${ }^{1}$ )}

Lünge bis 6 Zoll. Steht in der Tracht zwischen L. agilis und L. muralis. In der Bildung des Kiopfes, des Leibes, der Zehen feiner und zarter als $L$. agilis. Schwanz meist wenig linger als Kopf und Rumpf und dabei in seiner ganzen ersten Hälfte von ziemlich gleicher Dicke (nicht wie bei den anderen Arten gleich von der Wurzel im Querdurchmesser stetig verringert). Meistens ohne Zähne am Gaumen. Zügelschilder, in der Zahl drei, stehen einfach hintereinander. Occipitalschild klein, länglich, trapezförmig. Schläfengegend mit unregelmässigen Schildern, aus deren Mitte nicht selten ein grösseres sich abhebt. Unterschied zwischen den Schuppen des Rückens und der Seiten gering. Von den Schuppengürteln des Rumpfes gehen immer noch zwei auf eine Reihe der Banchschilder. Letztere in acht Längsreihen, aber die zwei äusseren ganz wenig vou den anstossenden Seitenschuppen verschieden. Zahl der Schenkelporen neun bis zwölf. Krallen der Vorderfüsse über einmal länger als breit an der Wurzel; Krallen der Hinterfüsse nahezu zweimal so lang als breit an der Basis. Grundfarbe der Rückenseite ein Holzbraun oder Nussbraun, so abgestuft, dass eine Rücken- und zwei Seitenzonen entstehen; darin entweder einfach dunkle Flecken oder auch Augenflecken, ein andermal weissliche oder gelbliche Flecken oder kurze Streifen in Längsreihe. Nicht selten zieht ein scharfer dunkler Streifen in der Mittellinie des Rückens herab, oder es fliessen auch die schwarzen Fleckenreihen der Seite zu einen oberen oder unteren, von lichtem Saum begrenzten Lüngsband zusammen, das hinter oder schon vor dem Auge beginnend sich bis über die Schwanzwurzel erstreckt und von da sich wieder in Flecken auflöst.

II ĭ n n e hen. Von schlinkerer Tracht, dünnbanchiger, Kiopf abgeflachter, Schwanzwurzel geschwollen. Furbung gern von lebhafterer Zeichnung. Bauchseite safrangelb und schwarz gesprenkelt.

Weibchen. Kopf etwas dicklicher, Bauch gewölbter, Schwanzwurzel nicht verdickt. Farbung hăufig matter, Bauch weisslich, nicht gesprenkelt.

1) Vergl, erste Tafel, Fg. 1, Fg. 6, Fg. 10. 


\section{Bemerkungen.}

\section{Grösse und Farbe.}

Die meisten Exemplare sind merklich kleiner als L. agilis, doch habe ich auch Thiere verglichen, welche in der Körperlänge hinter der genannten Art nicht zurückstanden; dabei bleiben sie aber durchaus schmäler, zarter, und namentlich der Kopf erscheint gegenüber von $L$. agilis klein. ${ }^{1}$ )

In der Färbung kommen mancherlei Abänderungen vor. Auf dem Grünten im Allgäu sammelte ich eine ganze Anzahl von Thieren, welche alle eine tief dunkelbraune Grundfarbe des Rückens darboten, ohne dass aber die Reihen gelblichweisser Flecken der Seiten gefehlt hätten. Dann traf ich hinwieder an feuchten, aber doch durchwärmten Waldgräben bergiger Gegenden in Franken nur Exemplare, auf deren schön entwickeltem Nussbraun sehr wenige Flecken sich zeigten. Ein andermal ist die Fleckenbildung äusserst lebhaft, so namentlich bei Thieren aus dem Hochgebirg: die Grundfarbe zieht dabei mehr ins Helle, und die Flecken und Striche können sich schärfer abheben. Bei Reutte in Nordtyrol, dann auf der Insel Herrenwörth im Chiemsee habe ich die schönsten Thiere dieser Art beobachtet. Während eines längeren Anfenthaltes in Ratzes (Südtyrol) erhielt ich ${ }^{2}$ ) eine $L$. vivipara, welche an L. muralis stark erinuerte. Das Rückenfeld besass auf lichtem Grunde drei Reihen grösserer dunkler Flecken, dann kam ein breites dunkles Seitenband, welchem sich, abermals auf hellem Grund dunkle und weisse Flecken anschlossen und sich von dir über die Extremitäten und den Schwanz verbreiteten.

Das Safrangelb der Männchen kann sich auch in Ledergelb aufhellen, und bei Thieren des nördlichen Russlands scheint das Safrumgell sich sogar selten zu entwickeln. Es ist wenigstens sehr auffallend, dass MEJaKofF unter einer sehr grossen Anzahl von Individuen aus dem Gouvernement Wologda nur zwei „à ventre jauneorangé ${ }^{\prime}$ gefunden zu haben angibt. ${ }^{3}$ )

Bei den Weibchen, welche ich in den südtyrolischen Bergen fieng, war anch die Banchseite - bei den unserigen ist sie einfach weisslich - mit einem röthlichen Anflug geziert, der aber nicht ins sifrunfurbige, sondern ins carmoisinrothe gieng.

Im Weingeist aufbewahrt, nimmt die Rückenseite unserer Eidechse gern eine bluliche Färbung an

1) Dass $L$. vivipara die zärteste unserer Eidechsen sei, ergibt sich auch beim Maceriren des Thieres. Mit $L$ - agilis und $L$. muralis unter gleichen Umstïnden und gleich lang dieser Behandlung ausgesetzt, fälit bei $L$. vivipara schon Alles auseinander, während dio übrigen noch in ihren Knochen zusammenhalten.

3) Durch Hrn. Dr. Mersert aus Kopenhagen.

3) Bulletin, Sociét. d. naturalistes de Moscou 1857, II. 584. 


\section{5}

und das Orangeroth des Bauches, weil aus einer Art Fett bestehend, blasst in Grauweiss ab. Streift man die bräunliche Oberhaut ganz ab, so erscheint die Lederhaut äusserst lebhaft gefärbt: bei Männchen ein Blaugrau oder Weissgrau mit den hellen und dunkeln Flecken. Noch prächtiger ist die Farbe, wenn man ein frisches Männchen einige Tage in schr verdünte Salpetersüure gelegt und darauf die Lidermis abgehoben hat. Auf der weisslichen Grundfarbe des Rückens zeigen sich Spuren von Grüı und Blau, die Seiten sind bläulich mit Augentlecken, das Safran des Bauches ist ganz satt und die Besprenkelung darauf sehr scharf. Es ist beinahe Schide, dass man die Thiere in dieser Art niclit in den Sammlungen aufbewahren kam.

Blos auf Farbenabänderung beruhen die oben angeführten zwei Varietäten L. nigra und L. montana.

L. nigra ist, was die Tracht des Körpers im Allgemeinen betrifft, sowie auch ferner bezüglich der Form des Kopfes, der zarten Finger, der Zügelschilder, der Beschuppung am Rücken, Seiten und am Bauch eine echte L. vivipura. An einem zuletzt von mir nüher untersuchten Exemplar war der Schwanz nicht lïnger als Kopf und Leib zusammen, aber etwas dicklich; worin das "ihier von der Abbildung bei Strrar sowohl, wie bei Tschod abwich. Die Farbe ist durchweg schwarz; im Weingreist und bei noch vorhandener Epidermis erhalten sich längs der Mittellinie des Rüekens und an den Seiten Spuren ron Flecken; auch mildert überhaupt die Gegenwart der Epidermis das Schwarz der Lederhaut. Ist aber die Oberhaut entfernt worden, so zeigt sich die Eidechse anch im Weingeist schwarz wie Ebenholz; nur die Banchseite bleibt etwas heller. Eine L. nigra geöffnet gab sich als Weibchen zu erkennen und was noch bemerkt zu werden verdient: die Eingeweide waren keineswegs in höherem Grad pigmentirt als bei $L$. vivipara von der gewöhnlichen Färbung.

Auch bei der letztern sind bekanntlich die eben aus dem Ei gekrochenen Jungen immer schwarz; JACQUiN schon, der erste Beobachter, theilt ja mit, dass sie "atro colore" seien. Gistl nennt die Jungen kohlschwarz; die bei Reichenbach über Nacht ausgeschlüpften Lacertchen waren schwarz mit ockergelben Punctreihen für die beiden späteren Rüclienstreifen. Die Thierchen, welche in meinem Terrarium zur Welt kamen, waren am Kopf und Vorderrücken dunkel erzfarben mit schönem Bronzeschiller bei günstigem Licht; der Schwanz, die hinteren Extremitäten, der Hinterrücken schwarz; Banch nur schwärzlich, nach vorne lichter. Bei greller Beleuchtung war schon die Spur eines Rückenstreifens zu sehen, und ebenso zwei Reihen kleiner lichterer Pünetchen mit etwas Dunkel eingefasst; man wurde so trotz aller Verschiedenheit doch durch die Zeichnung einigermassen an das ansgekrochene Junge der L. agilis erinnert.

Bei zahlreichen Individuen, doppelt so gross als das nengeborene Thierchen, 


\section{6}

welche ich hier und anderwärts sammelte, war meist schon die spätere Färbung fast am ganzen Körper, wenn auch nur schwach angelegt, selbst der Bauch schon etwas safrangelb oder bloss hell, je nach dem Geschlecht; nur der Schwanz war zur Hälfte noch sehwarz.

Darnach liesse sich vielleicht sagen, die ausgewachsene $L$. nigra habe einfach ihr Jugendkleid beibehalten, und sich nicht etwa erst ans dem Bunten ins einfach Schwarze verfärbt. Doch könnte man auch die andere Ansicht vertheidigen, dass die schwarze Eidechse eine melanotische Rückbildung sei, etwa so, wie Stubenvögel, der Gimpel z. B., gleichmässig schwarz werden können.

Ich muss anf Grund verschiedener Beobachtungen annehmen, dass die schwarze Färbung in nähcrem Zusammenhang mit der Feuchtigkeit der Plätze steht, an welchen $L$.nigra gefunden zu werden pflegt, wozu einige Belege nachher folgen sollen. Ich werde in dieser Annahme bestärkt, seitdem ich sah, dass melrere Exempläre von $L$. agilis, die als sie gefangen wurden, von der gewöhnlichen braunen Farbe waren, stark dunkelten, nachdem sie längere Zeit in einem zu feuchten Zwinger zu leben hatten. Namentlich das Braun des Rückens und Schwanzes hatte sich allmälig in eine Art Schwarz umgeändert. Auch sind mir vou $L$. vivipara, der helleren Form, melirmals Thicre vorgekommen, deren Braun sebr stark ins Dunkle gieng und immer hatte ich solche Thiere an recht feuchten Oertlichkeiten, unter Steinen, angetroffen. ${ }^{1}$ )

Das Gegenstück der L. nigra bildet, was die Firbe betrifit, L. montana, MiKan; ihre Fürbung zieht durchaus ins Lichte: die Exemplare, welche ich frisch erbeutet hatte, besassen auf der Rückenseite einen grünlichbraunen Grundton, daranf ausser schwarzen Tupfen eine Menge weisslicher Flecken. Die Unterseite war perlfirrb bläulich, selbst, wie die anatomische Untersuchung auswies, bei Männchen.

\section{Beschuppung.}

Im Allgemeinen verhalten sich die Schuppen wie bei L。 agilis; nur die Rückenschuppen, schwach gekielt, sind nicht so stark verschieden vou deu Seitenschuppen; auf letzteren verliert sich der hiel sehr bald. In der Schläfengegend hebt sich ein grösseres Schild ab; doch fehlt es auch häufig, oder es sind zugleich mit ilmm noch einige ebenso grosse Schilder seitwärts zugegen; wieder in anderen Fiallen sind alle von so ziemlich gleicher Grösse. Sogar an einem und demselben Individuum können die Schilder von rechts und links verschieden sein.

An den Lăngsreihen der Bauchschilder sind öfters die üussersten so klein, dass es ganz gezwungen wäre, von acht Reihen zu sprechen, wesshalb auch viele

1) Ich wöchte, da ich einen Zusammenbang zwischen feuchtem Aufenthalt und schwarzer Hautfärbung anzunehmen geneigt bin, auch aufmerksam machen, dass bei jeder $L$. agilis in Folge des Macerirens im IVasser, nach Abzug der Epidermis, die Lederhaut ibr Pignent gleichmissig ins Schwarze umgesetzt hat. 


\section{7}

Autoren nur sechs gelten lassen. An manchen Thieren alser, bei Weibchen namentlich und wohl wegen des umfänglicheren Bauches, lïsst es sich rechtfertigen acht Reihen anzunehmen.

\section{Schädel ${ }^{1}$ ) und Zähne.}

Da die Haut über dem Schädeldach hier nicht verkalkt ist, so lässt sie sich durch Haceriren abheben; der Schädel zeigt sich alsdann ohne die runzelige Sculptur, welche durch die Hautknochen sonst hervorgerufen wird. Das Loch im sicheitel ist verhïltnissmässig sehr gross, insbesondere bei jüngeren Thieren von einem Wulst umgehen und nach der Schädelhöhle hin geschlossen durch die schwarze Hirnhaut. Eine tiefe Gefüssrimne, nach vorne gegabelt, bedingt eine scheinbare Zerfüllung des Stirubeins. Die '/ahl der Superciliarknochen kamn wechselu, indem bald eine grössere Platte in mehrere sich zerlegt zeigt, bald umgeliehrt eine Verschmelzung eingetreten ist. Es bilden die Supereiliarknochen nur Eine Reihe, doch springt der freie Rand dergestalt vor, dass es nicht viel bedarf, um denselbeu als eine zweite, abgegliederte Reihe anzusehen. Der Gelenkkopf des Hinterhauptbeins ist bei jüngeren Thieren sehr deutlich dreilappig. An der Basis des Schädels glaubt man, gegenüber von den voransgegangenen Arten, mancherlei kleine Unterschiede zn bemerken, z. B. wie wenn der Körper des hinteren lieilbeins breiter wäre als sonst, der vordere oder der Stachel hingegen länger; allein beim Vergleichen mehrerer Schädel wird klar, dass all dieses, sowie mancherlei kleine Eintiefungen und Vorsprünge nur individuelle Bildungen sind.

Obschon somit keine eigentlich wesentlichen Unterschiede sich kund geben, wird man doch, Alles zusanmenfassend, ohne Schwierigkeit den Schädel gegeuwärtiger Art zu erkennen vermögen.

Die Zahl der Zähne ist:

im Zwischenkiefer 7;

im Oberkiefer, eine Seite, 16 ;

im Unterkiefer; eine Seite, 16-21.

Alle Zühne, anch diejenigen des Zwischenkiefers, welche nach WAGLER nur einspitzig sein sollen, sind zweispitzig, was allerdings etwas schwieriger zu sehen ist. Am Gaumen mangeln meist die Zühne. Ich habe eigentlich unter vielen Exemplaren nur eimmal ein Thier getroffen, an dessen skeletirtem Schädel jederseits am Gaumen ein par Zähne sassen und Lücken andenteten, dass noch einige früher zu-

1) Vergl. Erste Tafel Fg. 15, Fg. 16.

Leydig, Saurier. 
gegen waren. In manchen Landstrichen scheint die Art immer mit Gaumenzähnen versehen zu sein. Denn MENGE, ${ }^{1}$ ) welcher die Species gegenüber von $L$. agilis gut kennt, theilt ihr ganz einfach vier Gaumenzähne jederseits zu; seine Angahe darf um so weniger in Zweifel gezogen werden, als er sich über die Form der Zähne näher àuspricht.

\section{Vorkommen.}

Lacerta vivipara ist uns hinsichtlich der Verbreitung dadurch interessant, dass sie nicht blos, horizontal sich weiter erstreckt als $L$. agilis, inshesondere am weitesten nach Norden geht, sondern auch unter allen Arten die höchste verticale Verbreitung hat.

Zunächst fehlt sie nicht, wie es mit $L$. agilis der Fall ist, dem südlichen Europa. Man findet wenigstens ihren Namen in Catalogen, welche Thiere aus dem nördlichen Spanien, vielleicht ans den spanischen Pyrenäen, ausbieten. ${ }^{2}$ ) In Frankreich ist sie aus verschiedenen liegenden, namentlich gebirgigen, durch BrBRoN und DUMÉRIL bekannt. Ganz besonders verdient erwähnt zu werden, dass sie nach den Beobachtungen NördLINGER's in ziemlicher Menge noch ganz nahe am Neer, z. B. auf den Sanddünen der Umgebung von Boulogue vorkommt. ${ }^{3}$ ) Die gleiche Erscheinung wiederholt sich für Belgien nach SELYS-LONGCHAMPs: auch dort ist sie zunächst Bewohnerin waldiger, bergiger Gegenden, besonders der Ardennen; aber das Thierchen findet sich auch auf den Sanddünen bei Ostende unter Büschen von Hippophae. ${ }^{4}$ )

Bonaparte besass die Art aus den Bergen von Piemont. In der Schweiz ist nach Tschud der eigentliche Verbreitmashezirk dieser Eidechse die montine Region, daher sie im Herzen der Schweiz, in den Cantonen Unterwalden, Schwyz, einem 'Theil von Uri, ziemlich häufig vorkommt.

Im bairischen Hochland, sowie in den tyroler Bergen findet man sie nicht selten. So gedenlit, derselben schon vor Jihren Gistu aus den fiebirgen bei T'egernsee

1) Ueber Lacerta agilis und crocea. Neueste Schriften d. naturf. Gesellschaft in 1)anzig. 4. Bd. 1850.

2) Aus den Abruzzen wird von Deuse (a. a. O.) eine Lacerta porphyrca erwähnt, welche in sallen körperlichen Verbältnissen am meisten mit $L$. crocea ibereinkomme, nur reichlich noch einmal so gross sei.* Wer mit der Reptilienfauna dieser Gebirgsgegend bekannt ist, wird uns vielleicht angeben können, ob wirklich $L$. vivipara darunter zu verstehen sei.

3) Württemb. naturwiss. Jahreshefte, 1851, S. 128.

!) Faune Belge, 1842 . 
mond bei Schäftlarn. Ich selbst fieng das Thier atuf der Insel Herrenwörth im c'hiemsee, ferner bei Rentte; aber auch auf der Südseite der Alpen, so z. B. bei Ratzes, wo sie zuerst von (iREDLER ${ }^{1}$ ) als Lac. montana angezeigt wurde. Auch MILDE ${ }^{2}$ ) führt sie von gennmtem drte unter diesin Namen anf, mit der beigeschlosisenen Bezeichnung zootoca. Aus andern Bergen Südtyrols - z. B. Val di Non, Irient - hat de Betra dits Thier natchgewiesen. Wals aber merkwärdig ist und unerwartet kommt gegenüher der Thatsalche, dass L. viripura voruggsweise die Berge lieht: genaunter Beobachter fand unsere Eidechse in den tiefen und feuchten Ebenen bei Verona auf den Dïmmen der Reisgräiben. ${ }^{3}$ )

Die lombardische Ebene ist bis jetzt der südlichste Punkt ihrer Verbreitung. Diesseits der Alpen geht sie durch ganz Deutschland, wo sie wieder vorzugsweise in waldigen berggegenden zu Hause ist. Hier hei 'Tübingen leht die Eidechlse im Schönbuch, damı in den Waldungen üher Derendingen; doch hat sie s'crübuer in seiner Aufzïhlung der 'Thiere. von Württemberg ${ }^{4}$ ) ans dem .Jahr 1820 noch nicht gekannt. Selbst zwanzig Jahre später weiss G. v. Martens noch nichts vom Vorkommen der $L$. vivipara in Württemberg. ${ }^{5}$ ) Bald daranf aber lernte man die Art unterscheiden und zwar scheint dem Prof. Nürding(ser ${ }^{6}$ ) das Verdienst hievon zuzukommen, welcher sie häufig auf der ganzen Alb, von 'T'uttlingen bis Crailsheim, chenso im Hohenheimer Revier, endlich im Schönbuch, anf ghasigen Lichtungen im Walde fand. - Sehr lange schon, seit dem Jahre 1805, ist sie durch Wouf und Stuka ans den grörseren Nadelwaldmgen der (iegend von Nümberg bekimnt. ${ }^{7}$ ) Ich kenne sie ebenfalls aus verschiedenen Strichen Frankens; so ist sie z. B. geradezu häutig in dem waldigen Höhenzng, welcher die Wasserscheide zwischen der 'Taulser, Wörnitz und Altmühl bildet; auch in dem rauhen und wenig wirthlichen Rhöngebirge habe ich sie angetroffen.

\section{Fauna. Bozen, 1863.}

1) Vierzehn Tage im Bad Ratzes. Eine naturgeschichtliche Localskizze, mit nüherer Berücksichtigung der

2) Lin Sommer in Südtyrol. Beil. z. botanisch. Zeitung 1864. Beide Naturforscher haben dabei offenbar den Namen $L$. montana fỉ ganz gleichbedeutend mit viripara genommen. Wenn man aber dic Charakteristik, wie sie Mrax für die von ihm aufgestellte montuna gibt, im Auge behält, so habe ich bei Ratzes nicht die Form oder Varietät montann gesehen, sondern immer nur an ganz gleicher Stelle - den hölzernen Wasserleitungen und dem aufgeschichteten Holz hinter dem Badhause - die Stammform vivipara oder nach der Farbe: $L$. crocea $(p y r-$ rhogaster).

3) Materiali per una Fauna Veronese, 1863, und früher schon in der Erpetologia delle provincie Venete, 1867.

i) In der Beschreibung Württembergs von MEмminger, 1820.

5) Dassclbe Werk, 3. Auflage, 1841.

5) Vergl. P'tunisara, Verzeichniss der Reptilien Württembergs. Naturwiss. Jahreshefte, 1817, uad ebendaselbst 1850.

7) Vergl. anch Haun, Fauna boica, 1832. 
Die Varietät $L$. montana wurde ron mir in schönen Exemplaren im Schwarzwald, in der Gegend von Rippoldsau gefangen, ganz von der Farbe, wie sie Mras beschrieben und Sturm abgebildet hat. ${ }^{1}$ ) Die Varietät $L$. nigra habe ich bis jetzt viermal lebend in Händen gehabt. Das erśte Individuum fieng ich vor vielen Jahren im botanischen Garten zu München, wohin es wohl durch Erde, Holz oder Laub verschleppt worden sein mag, cin anderes im Rhöngebirg, ein drittes auf dem fränkischen Bergrucken ( Frankenlöhe" ${ }^{6}$ ), und ein viertes hier bei Tübingen im Bebenhäusel Thal; die drei letzteren unter so gleichen Umständen, dass ich, wovon schon die Rede war, die schwarze Färbung mit der Fundstelle in Verbindung bringen möchte. Die L. nigra der Rhön nämlich hatte ihren Schlupfwinkel — ich beobachtete sie mehrere Tage lang, ehe ich ihrer habhaft wurde - unter den, über eine sumpfige Wiese auf dem Wege zum Dreistelz gelegten Schrittsteinen; die Exemplare vom Bebenhäuser Thal und der Franlienhöhe hatten ebenfalls ihre Wolmstätte unuittelbar am Wasser, unter einem Wurzelstumpen, aufgeschlagen, also sämmtlich an sehr durchfeuclıteten Plätzen. Noch jüngst erhielt ich ${ }^{2}$ ) ein schönes Exemplar in Weingeist, welches im August 1867 am Achensee, im Bletzachthal, ebenfalls an Rande eines Baches, in der Nähe einer Alphütte erbeutet worden war; wie denn auch das Wolf-STura'sche Exemplar als nauf der Wengeralp im Canton Bern" gefunden bezeichnet wird.

JÄckel sah die schwarze Abart einmal am Dorfe Weissenkirchberg in der Brunst bei LeutersLausen. ${ }^{9}$ ) Unter einer Anzahl von Lacerta vivipara aus Dänemark ${ }^{4}$ ) befand sich auch eine $L$. nigra von besonderer Grösse. Im Weingeist und noch mit der Epidermis bedeckt heben sich fleckige Zeichungen ab; ausserhalb der Flüssigkeit und gar bei abgelöster Epidermis ist das Thier rein schwarz am Rüclien, etwas lichter am Bauch. Wie man schon nach den Schenkeln und der Schwanzwurzel schliessen konnte, war es ein Männchen, was sich denn auch durch die Anwesenheit des Hodens beim Hineinblicken in die Leibesuöhle bestätigte.

Um die Aufzählung der Fundorte der L. vivipara von gewöhnlicher Färbung zu vervollständigen, so bezeichnet sie GLoGER für die schlesischen Gegenden, z. B. Schneeberg der Grafschaft Glatz; für die Gebirgswaldungen Mährens führt sie HeiNRICH auf. Im Fichtelgebirge würde sie, nach dem Werke ${ }^{5}$ ) von GoLdFuss und BischoF zu schliessen, fehlen; denn es wird dort nur $L$. agilis namhaft gemacht; allein mir ist wahrscheinlich, dass der Bearbeiter der Fauna die Art noch so wenig zu unterscheiden wusste, als viele andere Zoologen jener Zeit. Auch in der Mark Brandenburg würde die Art, wenn man sich auf den Verfasser der Fauna marchica, ScHuLz,

1) An diese Beiden hat man sich auch immer bei Bestimmung der $L$. montana zu halten und nicht an spätere Autoren, wie z. B. an Bonapante, was gegenüber der Methode einiger Faunisten in Erinnerung zu bringen, nicht unpassend sein dürfte.

$\left.{ }^{2}\right)$ Durch Hrn. Studiosus Herbr. Krauss.

3) Doch kenut dieser Autor offenbar die Eidechsen nicht genauer, denn er zieht sie zur gemeinen Eidechse und nicht zur »safranbauchigen». (Thierwelt von Franken. Bavaria, Landes- u. Volkeskunde von Bayern 1864.) Ein Jahr zuvor (1863) hatte anch FAmke in der Aufzählung der Thiere der Oberpfalz und Niederbayern's den Fehler begangen die $L$. nigra zu $L$. agilis zu rechnen. Derselbe Irrthum findet sich in Hermricu's Reptilien Mährens, und noch bei Andern. Da ich vor Knrzem auch auf eine Mittheilung Mrov's in den Verhandlungen d. zool.-bot. Vereins in Wien, 1868; stiess, der zufolge er zwei kollschwarze $L$. agilis angetroffen habe, so erlaubte ich mir bei diesem sorgfialtigen Beobachter brieflich anzufragen, ob wirklich $L$ agitis es gewesen sei; denn der Fundort, se uchte Wiesen«, liessen mich abermals $L$. vivipara vermuthen. Hr. Prof. Mride schrieb mir zurück, dass die schwarzen Eidechsen in der That nicht zu agilis, sondern zu vivipara gehörten, wie er dieses bereits selbst in den -Nachtrigen und Berichtigungene zu dem 46. Jahresbericht der Schlesischen Gesellschaft, Breslau, 1869, verbessert habe.

1) Ich verdanke dieselben der Güte des Hrn. Dr. Concrs in Kopenhagen.

3) Physikalisch-statistische Beschreibung des Fichtelgebirges, Nürnberg, 1817. 
ohne weiteres verlassen wollte, nicht zugegen sein; aber die nühere Durchsicht dessen, was er über $L$. agilis sagt, zu der auch $L$. crocea als synonym gezogen wird, zeigt, dass der Autor über die Eidechsen nicht recht im Klaren sich befindet. Im Rheingan kommt sie ebenfalls vor, scheint aber nach deu Mittheilungen KrinschBadms dort selten zu sein; aus waldigen und steinigen Gegenden des 'Taunus hat sie übrigens RöMER-BÜCHNER schon vor langen Jahren (1S27) angezeigt. Sie erstreckt sich uach Holland hinein, wenigstens führt sie SCHLEGEL ${ }^{1}$ ) unter den niederländischen Reptilien anf, mit der näheren Angabe, dass sie bei Nimwegen, Arnheim und Leiden walngenommen worden sei. In Dänemark erkannte sie zuerst BoJE; ${ }^{2}$ ) in Ostpreussen wiesen sie v. BAER und Menge nach; in Englaud ist sie die gewöhnlichste Eidechse; sie findet sich endlich auch in Schweden.

Ostwärts ist sie beobachtet worden im nördlichen Böhmen durch GLÜCKSELiG, in Oberungarn an der Seite des Tatragebirges von Honvath; in Bergen nordwestlich von Kaschau hat sie JeITTELES in ziemlich grosser Anzahl gesammelt.

Bei Thieren der Ietztern Gegend scheint sich das Gelbroth (Orange) der Bauchseite des Mänuchens auch nicht über das Strohgelb zu steigern. Jerr reles sagt wenigstens ausdrücklich: der Bauch sei entweder strohgelb mit einzelnen schwarzen Punkten, oder röthlich gelb (weinrüthlich), oder grünlich. Nur die letzteren spricht er als Weibchen an; aber nach meiner Erfahrung an den südtyrolischen möchte ich die mit weinröthlichem Bauch ebenfalls für Weibchen balten und nur die strohgelben mit den schwarzen Punkten für die Männchen.

Die kleine Eidechse, welche der Ornitholog SEIDENSACHER ${ }^{3}$ ) auf seinen Streifereien durch die Wälder Croatiens hie und da in ein bergendes Versteck eilen sah und $L$. agitis nennt, war wohl ebenfalls $L$. vivipara.

In der näheren Umgebung Wiens scheint die Art nicht vorzukommen, wenigstens steht sie nicht unter den Eidechsen, welche LAURENTI aufführt. ScHrEibERs schickte sie vor Jahren von Wien nach Paris und ILLnE EDwards machte daraus die L. Schreibersiana; wahrscheinlich stammte das Thier aus den sich gegen Wien erstreckenden Ausläufern der Aipen. Denn Frtzinger bezeichnet ausdrücklich nur die Voralpen des Schneeberges als Ort des Vorkommens; eben dort hatte ja auch JACQUIN das Thierchen entdeckt.

Ueber ihre weite Verbreitung nach Osten liegen noch fernere bestimmte Angaben vor. KEsSLER verzeichnet sie unter den Sauriern des Gourernements Kiew; sie ist die einzige Eidechse im Gouvernement Wologda nach den Mitheilungen von

\footnotetext{
1) De Dieren vau Nederland, 1862.

8) Isis, 1841, S. 698.

s) Zool. bot. Verein in Wien, 1863.
} 
A. MEJAKOFF; ${ }^{1}$ ) ebenso begegnet man ihr in dem Gouvernement von Nowgorod und Viatka, sie ist gemein in denen von Archangel und Olonetz, sie findet sich in der Umgebung vom Ural, und genannter Gewährsmann äussert sich: „il n'est pas impossible su'il ne s'etende jusqu' ì la mer blanche“. Die kleine Eidechse, welche schon Paldas ${ }^{2}$ ) ans dem nördlichen Russland und sibirien erwïhnt, ist zweifelsohne L. vivipara. Eversmann und Eichivald beschrieben sie aus dem Chersones, aus Gegenden der Wolga, aus Wäldern vom Ural und Kaukasus ${ }^{3}$ ) und anderen russischen Landstrichen. Endlich hat, was mir aber nur aús zweiter Hand ${ }^{4}$ ) bekannt ist, MAAK auf einer Reise nach dein Amur unsere Eidechse dort noch gefunden, sowie später auch im Thale des Flusses Usura. ( $L$. agilis findet sich wicht unter den aus diesen Gegenden aufgezăhlten Reptilien!)

Entsprechend der Verbreitung weit nach Norden, steigt L. vivipara auch hoch im Gebirge hinauf. Wenn ich mit meiner eigenen Erfahrung beginnen darf, so sammelte ich dis 'Thierchen am Rande der Schlernklamm, etwa $4000^{\prime}$ hoch, unter der Rincle vou Baumstumpen, zugleich noch mit Scorpio germanus; ebenso habe ich sie anf der Seiser Alp in Gesellschatt des Cínyllus sibiricus augetrotfen; ferner beobachtete ich die Eidechse bei einer Excursion anf den Grünten, an sonnigen Stellen his nahe zum Gipfel $\left(5364^{\prime}\right)$. Gredter fand die ygutmüthige Bergeidechse" um den grossen 'l'eich von Lavace auf Joch Grim wohl ungefähr $6000^{\prime}$ hoch. ${ }^{5}$ ) Durch T'schUd erfahren wir, dass unsere Eidechse in dem Schweizer Hochgebirg bis zu einer Höhe von 7 bis 8000 F'uss anfsteigt; ja er erzahlt, dass Prof. HeER oberhalb Spada longa, in der Nähe des Unbrells in einer Höhe von 9134 Fuss ü. M. eine L. vivipara gefangen habe. „Wenn wir bedenken, dass bei 9000 Fuss Höhe mehr als nem Ifonate tiefer schnee liegt, und dass sich Mücken, Fliegen und Coleopteren, die ihre Nahrung ausmachen, nur selten hier herauf verirren, so ist es nicht leicht zn begreifen, wie diese 'Thiere ihr kümmerliches Dasein fristen können.“"

\section{Geschichtliches und Kritisches.}

Man bezeichnet herkönmlich ein mir unzugângliches Werk: MErreT's Pinax als dasjenige, welches zuerst unserer Eidechse gedenke, mit den Worten: Lacertus vulgaris ventre nigromaculato. Diese Diagnose

1) Quelques observations sur les reptiles du Gouvernement de Wologda, Bull. de Moscou, 1857, 2.

2) similens vulgo europaeae et plerumque rufescentem, fusco-maculatam in borealiore Rossia et citeriore Sibiria copiosam minusculame, Zoographia rosso-asiatica.

$\left.{ }^{3}\right)$ Fauna caspio-caucasica, 1841.

1) Troscues, Jahresh. iib. d. Leistungen in d. Herpetologie wilhrent des Jahres 1862.

j) Eine Excursion auf Joch Grim. 'Topograph-faunistische Skizze. Inusbruck 1867. 
kehrt darauf wiecler bei RAr. ${ }^{2}$ ) Da L. vivipara in England häufig ist, so wird wohl unter den von RAY aufgezahlten drei Lacertos terrestres auch die jetzige vivipara stecken; aber ich kann keinen Anhaltspunkt finden gerade für die mit dem "ventre nigro maculato" ausgestattete; denn $L$. agilis besitzt bekanntlich auch einen mit Schwarz besmenkelten Bauch.

Ulingegen lant ein Landsmamn von RaY, der englische Maler EdWards, wohl zuerst die L. viripara abgebildet in seinem bekannten Werke über die Vögel. ${ }^{2}$ ) Er nennt sie ndie kleine braune Eidechse", und bezüglich des Wolnnglatzes ist schr bezcichnend die Angabe: "sic halten sich an den Wurzela vun alten Bäumen auf unı sitzen auf der limde..... Das abgebildete Thier mag ein Weibchen vorstellen, daher der Bauch "keme Flecken" hatte; die übrigc braune Farbe des linekens "mit dunkeln Flecken besetzt" passt ebenfalls gut, mur nicht das ,bläulicht", wenn nicht beim Coloriren ein im Weingeist aufbewahrtes Exemplar gebraucht wurde, wo das Bliulichwerden sich gern cinstellt.

Als ter eigentliehc Ėutlecker. unserer Eidechse und zugleich der Eigenschaft, dass sie Iebendig gebärend sci, wird aber immer Jos. Franz v. Jacquin zu gelten haben. Er machte als Knabe ron elf Jahren im Jahre 1778 mit seinem Vater von Wien aus eine hotanische Excursion auf den Schnecberg, fieng da eine trächtige Lidechse, welche in die Kapsel gespert bei Wiedereröfinung nach zwei Tagen, ron sechs jungen, schwarzen Eidechsen umgeben war. Da lieine Spur von Eischaalen sich zugegen zeigte, so musste angenommen werden, dass die Mutter sic lebend zur Welt gebracht habe, wie diess Alles mit einigen näheren Umständen in gewähltem Latein durch die Baslel. Denlischriften veröffentlicht "wurde. ${ }^{\mathrm{s}}$ ) Auch die beigegebene Figur ist sauber gestochen; gibt nicht blos den Habitus gut wieder, sondern auch die Abstufungen der Farbe und der Fleckenbildung, in so weit diess durch den Kupferstich ausgedrückt werden kann; nu1 die Zehen sind missrathen und das Relief der Haut ist an ganzen Körper so ziemlich unberücksichtigt gelassen.

L's gibt abcr noch einen anderen Schriftsteller aus dem Ende des rorigen Jahrhunderts, welcher bereits wusste, dass sich bei uns eine lebendig gebärende Eidechse findet. Es ist Grasso, dessen Namen und Beobachtung. man in der bisherigen Literatur wenig begegnet.

Aus der Inauguralabhandlung tes Genannten ${ }^{4}$ ) und den hicbei rorgebrachten zoologischen Erörterungen ersehen wir in unzweifelhafter Weise, dass die bei Helmstadt ("nostris regionibus") vorkommende Lacerta agilis auch die $L$. vivipara mitbegreift; obschon der Autor nicht dazu gelangt, sie bestimmt von einander zu trennen. Zu L. agilis gehören die: „majores, non adeo frequentes, longitudino a capite ad candae finem sex ad septem digitorum, dimidii latitudine, ponderc ad unciam semis et ultra aequantes, erant per dorsum griseae, duabus lineis albidis maculis nigris punctisque albis notatae; ad latus griseum raro viridem habebant colorem, qui si aderat, interdum et per intervalla ad dorsum excurrebat; praeterea oculi iride aurantii coloris erant praediti." Auf die jetzige $L$. vivipara hingegen bezieht sich: "Aliae minores, longitudine quatuor digitorum, latitudine trium ad quatuor linearum, pondere sesquidrachmae al duas aequantes, iride albida, colore sorlide luteo vol griseo, lineis punctisque obsolete plerumque erant notatae." Ja unser" Verfasser hat bereits richtig herausgefunden, dass unter den kleineren diejenigen mit safranfurbigem, schwarz gesprenkelten Leib die Männchen seien: „Nonnullas harum (i. e. Lacertarum minorum) a collare ad principium caudae Havas punctisque nigris adspersas vidi, quas dissectas praecipue ob testiculos satis adparentes masculas inveni." In den Kiern aus dem Leibe eines Weibchens genommen fand er schon ziemlich grosse Foctus und cr wirft sich die Frage auf, ob sie nicht gar lebendig gebärend sein künnten. Dann kommt (Scite 6, An-

1) Synopsis methodica inimaliuin quadrupedum et serpentium generis. 1693.

2) Ich kenne nur die deutsche Ausgabe von Serrgsias, Nürnberg 1770, Siebenter 'Iheil, Tat. II. - Weder Th. Bex, noch Bnuos und Dusims citiren diese Figur zu vivipara; Merrem und Tscrupr beziehen sie irrig auf L. muralis, die gar nicht in England vorkomut.

$\left.{ }^{3}\right)$ Iacerta vivipara, Observatio Jos. Fraxcrscr de JAcQurs, Nic. Jos. filius. Nov. Acta Helvetica. Volum. I, Basilene 1787.

) Dissert. inaug. medica de Lacerta agili Liss. Helmstadi 1788. Unter dem als Polyhistor und merkwürdige Yersönlichkeit bekannten Hofrath Benks exschienen und ihm gewidmet. 
merkung) die uns am meisten interessirende Stelle: "Hisce jam scriptis, lacertam aliam etiam minorem revera lacertulas vivas partu edentem vidi, quod quantum scio, de hac specie nondum notatum est."

Gerade die Farbe der Männchen ist eine so aufiälige, dass sich unsere Eideclise auch ferner bereits unter den Varietäten, in welche LATRELLE im Jalı 1800 seine $L$. viridis zertheilt hat, befindet; es ist die aus der Umgegend von Paris beobachtete Varietät g. „D'un gris cendré en dessus. Dos plus foncé, avec des petits taches blanches, euvironnées de noir. Trois lignes de taclies semblable de chaque cóté du corps. Dessous du ventre d'un jaune souvent oraugé. Douze à treize tubercules calleux sur chaque cuisse postérieur." Von der FortpHanzung war dem französischen Zoologen wohl nichts bekannt, so wenig als dem Nürnbergischen Naturforscher WoLf, welcher 1805 das Thier als neu beschricb, unter dem Namen $L$. crocea oder gelbe Eidechse. Ihre vivipare Eigenschaft wurdedann später oftmals beobachtet und wiederholt für etwas Neues ausgegeben; loch scheint es, dass Manche immer noch nicht besagte Art mit Sicherheit von $L$. agilis zu unterscheiden vermochten, denu nur so erkläre ich mir die ganz unrichtige Angabe, dass unter Unständen, z. B. in Gefangenschaft, auch $L$. agilis Jebendig gebärend sein könne.

Unverständlich ist mir der Irrthum Tschupl's, welcher sich doch rühmt gegen bundert Exemplare genan untersucht zu haben, dass die Thiere mit dem satt gefürbten Bauch die Weibchen wären, was er mehr als einmal bemerkt und ihm auch von BıBON und DUMŕRIL nachgesprochen wird. Hingegen lässt sich leichter begreifen, wie T'schud dazu kommen konnte, die Varietät montana MikaN für eine besondere Art zu lalten. So lange man unter dem ersten Eindruck steht, den das lebende Thier auf den Beobachter macht, kann man den Fehler begehen.

Unter den mir bekannten Abbildungen möchte ich den Holzschnitt in dem Werke von THomas BeLL, ${ }^{1}$ ) allwo Männchen, Weibchen and drei Junge zu- einem Bilde gruppirt sind, obenanstellen; namentlich ist hier beim Weibchen das Feinere und Zartere in der Kopfbildung und den Extremitaten, bei sonstiger Grösse des Thieres, sehr gut getrofien.

Von der Varietät I. nigra sah ich nur zwei Abbildungen, jene erste von STurm und eine andere bei Tschudr. Da der ebengenannte Schriftsteller über die STurM'sche Figur streng zu Gericht sitzt — er nennt sie ein Phantasiegemälde nach einer gegebenen Beschreibung - so möchte ich mir die Bemerkung erlauben, dass zwar die von Tscuud veranlasste Figur die Tracht des Thieres weit besser versinnlicht als diess Stura gelungen; aber ein genau auf die Tschudische Abbildung blickendes Auge kann doch trotz der Versicherung, dass hier zum erstenmal das Thierchen treu abgebildet wird, etwas sehr störendes und unrichtiges finden. Die Zehen der hinteren Extremitäten sind ${ }^{2}$ ) scharf am unteren Rande gekämmt, so wie es etwa der Gattung Acanthodactylus zukommt. Nach meiner Meinung ist die Figur der L. nigra bei STurM nicht besser und nicht schlechter als alle seine Lacerten, die fast durchweg bezüglich der Zehen etwas zu dicklich gerathen sind und eine gewisse steife Haltung haben.

Kocr ${ }^{9}$ ) fieng die schwarze Eidechse in der Oberpfalz bei dem Städtchen Reding unweit Cham auf einer ziemlich hoch gelegenen Heide, und war, was sehr auffallend ist, im Stande das 'Thier ein ganzes Jahr am Leben zu crhalten; es nahm selbst während des Winters Mehlwürmer zu sich.

Bei GLückserig's böhmischen Reptilien lat sich L. nigra unter das Genus Podarcis verirrt!

Ich habe oben in Uebereinstimmung mit Andern unsere Art „Waldeidechse" genannt. Es mag an diesem Orte bemerkt sein, dass Scurank's "Waldeidechse" in der Fauna boica, I, S. 285, gar keine Lacerte ist, sondern unzweifelhaft das schon so manchfach verliannte Weibchen des Triton taeniatus und zwal in der Tracht des Landaufenthaltes.

In der Hof- und Staatsbibliothek in München, als ich die RösEL'schen Handzeichnungen ansehen durfte, fand ich auch cin Paquet mit der Aufschrift: OppeL's Aquarellzeichungen von Reptilien, 1815; ich

1) British Reptiles, second Edit. 1849.

2) Schweizerische Echsen, Fg. 3.

3) Sturse's Fauna. S. 7. 
verdanke es der Güte des Herrn Director IlaLM die Bläter nach Tübingen geschickt erhalten zu haben. Es sind 392 einzelne grossentheils Quartbogen, auf denen Schildkröten. Saurier, Schlangen und Batrachier abgebildet sind. Yon den Batrachiern sind Jie meisten blosse Bleistiftzeichnungen; die Schlangen als Aquarelle sind fast alle nur in den Grundfarben augelegt, und rom Kopf, mitunter auch vom Schwanz her, wurden eine Strecke weit die Einzelheiten aufgesetzt; die saurier erscheinen am meisten ausgeführt. Die Bilder stammen wie manchmal yon Oppen's Hand beigeschrieben ist, schon aus den Jahren 1807 und 1808. Der frühe Tod des Verfassers - er starb 1813 in München - und vielleicht auch die damaligen Kriegsläufte mochten die Herausgabe eines so kostspieligen Werkes verhinderı; was sehr zu bedauern ist. Man kommt beim Durchsehen dieser Aquarelle nicht aus dem Staunen heraus und weiss nicht, soll man mehr die Richtigkeit in der Zeichnung oder die ausserordentliche Feinheit der Ausführung bewunderu. Es ist, selbst bei den kleineren Arten, jedes Schüprehen und Körnchen über die ganze Kürperflïche weg mit genauester Surgfalt gemalt und bei der Kleinheit der Gegenstände muss oftmals der Pinsel unter dır Lupe geführt worden sein. Hätte das Werk auch in die Oeffentlichkeit gelangen können, es wäre nicht möglich gewesen, im Stich und Colorit die Feinheit und Genauigkeit der Originale wieder zu geben. Man kann sich eines wehmüthigen Gefüls kaum erwehren bei dem Gedanken, dass die Leistungen eines solchen T'alentes, die zwar einem Cuvier und ALExaxder Humbold ') bekannt waren, doch nur, gleich einem Manuscript, im Dunkel der Bibliothek ruhen. Warum ich nun gerade an dieser Stelle der OpPeL'schen Aquarelle gedenke, ist der Umstand, dass von den einheimischen Eidechsen $L$. vivipara auf Blatt 115 gemalt sich zeigt; die andern Arten muralis, agilis, viridis waren noch nicht an die Reihe gekommen, wohl aber $L$. ocellata auf Blatt 122.

4. Art. Lacerta muralis, LAur. Ma uereidechse. Seps muralis. LAURENTI, Synopsis reptilium, 1768. Seps muralis. KocH, in STURM's Deutschlands Fauna, 1828. Podarcis muralis. FitzINGer, Fauna des Erzherzogthums Oesterreich, 1832. Podarcis muralis. Plieninger, Verzeichniss der Reptilien Württembergs, in den Jahresheften für vaterländische Naturkunde, 1847.

Lacertu muralis. Kinschbaum, Reptilien und Fische des Herzogthums Nassau, 1865. Lacerta muralis. Medicus, 'Thierwelt der Rheinpfill. Bavaria, Landes- und Volkeskunde von Bayern, 1867.

\section{Kennzeichen. ${ }^{2}$ )}

Läge bis 7 Zoll. Tracht im Allgemeinen schlank und zierlich, Kopf von niedergedrückter Form, spitz-schnauziger als bei den andern Arten. Schwanz länger als Kopf und Rmmpt, sehr zugespitzt. Neist ohne Zühne am Gaumen. Drei Zügel-

1) Orper rühmt in seiner Schrift: die Ordnungen, Familien u. Gattungen der Reptilien, als Prodrom einer Naturgeschichte derselben, München, 1811, die sVatersorge«, welche Husinocd für iha hatte.

y) Vergl. Erste Tafel, Fg. 2, Fg. 7, Fg. 11.

Loydig, Saurier. 
schilder in einer Reihe. Aus der Mitte der Schläfengegend hebt sich ein grösseres Schild hier am schärfsten ab; die Schuppen des Rückens und der Seite weichen stark ab von jenen der vorausgegangenen Arten: sind klein, rundlich, daher Rücken und Seiten wie gekörnelt. Es gehen drei bis vier Reihen der Seitenschuppen auf einen Quergürtel der Bauchschilder. Letztere in sechs Reihen, das einzelne Schild mehr viereckig. Zahl der Schenkelporen bis zwanzig. Krallen der Vorderfüsse etwas über einmal länger als breit an der Basis; Krallen der Hinterfüsse nahezu zweimal so lang als breit an der Basis. Grundfarbe der Rückenseite ein Braun oder Grau, bei guter Beleuchtung, namentlich im Sonnenlicht, mit entschiedenem bronzegrünem Schiller; darauf ein dunklerer, schon vom Kopf beginnender Seitenstreifen, ausserdem mit fleckiger oder wolkiger Zeichnung. Am Uebergang von den Seitenflächen zum Bauch eine Längsreihe blauer Flecken. Bauch hell und weisslich oder mit gelblichen bis rothbraunen Tönen und Flecken.

Männchen. Kopf grösser (gestreckter, platter); Hinterbeine kräftiger, Schenkelporen stark kammartig sich abhebend; Schwanzwurzel verdickt. Rücken gern mit deutlichen dunkeln Flecken überzogen, und auch das Seitenband oftmals in Flecken aufgelöst. Die blanen Flecken an der Seite grösser und lebhafter. Der Bauch hăufig mit satteren Farbungen vom Citronengelben ins Rothgelbe; darauf zahlreiche braunrothe oder selbst schwärzliche Flecken.

Weibchen. Kopf kleiner (kürzer, schmäler, doch weniger niedergedrückt); Hinterbeine dünner. Schenkelporen sehr wenig sichtbar. Schwanzwurzel nicht verdickt. Die dunkeln Flecken der Rückenfarbe weniger zahlreich, auch kleiner; das Seitenband nicht selten ein zusammenhängender Streifen; die blauen Flecken klein und weniger lebhaft. Banch hell, weisslich, nur an der Kehle öfters etwas fleckig.

\section{Bemerkungen.}

\section{Farbe und Varietäten.}

Wie oftmals bei vielen anderen Thieren hat auch hier der Wohnort, namentlich das Vorkommen an Plätzen, welche den Sonnenstrahlen ausgesetzt sind, grossen Einfluss auf die Sättigung der Hautfarben. So habe ich z. B. an recht sonnigen Felsen auf der IIöhe des Küchelberges und auch sonst an sehr trockenen warmen Orten bei Meran, sowie bei Kaltern und Eppan Manereidechsen beobachtet, die nicht blos länger und stärker von Körper waren als die gewöhnlichen, sondern wo auch 
der grüne Schiller der Grundfarbe sehr in die Augen sprang und die Fleckenbildung iusserst scharf sich abhob; wăhrend andererseits die Exemplare an der Winterseite des Etschthals, sowie überhaupt an feuchten, höher gelegenen Stellen sich den Formen aus dem Württembergerlande mehr näherten.

An den Thieren, welche ich an Uferstellen des Gardasee's fing, schillert bei Sonnenlicht die branne Grundfarbe entschieden in Grau oder Graubläulich; überhaupt waren alle Thiere, die mir aus der Umgebung des genannten See's zu Gesichte kąmen, heller als die Thiere von Meran oder von Bozen. ${ }^{1}$ ) Auf solche örtliche Veranderungen beziehen sich wohl zum Theil die mancherlei Formen, welche nach der Farbe schon öfters ausführlich und mit Genanigkeit verzeichnet worden sind, so von Bibron und Duméril, von Prinz Bonaparte, sowie von de Betta.

Aber bei keinem dieser Autoren finde ich angegeben, dass sich denn doch gewisse Iauptzüge in der Färbung auch nach der Verschiedenheit des Geschlechts richten. Nur ein dentscher Beobachter, Kоch, ${ }^{2}$ ) hat bemerkt, dass Mäunchen und Weibchen ihr besonderes Farbenkleid haben, verwechselt aber beide mit einander. Was er von dem Weibchen sagt, ist das Männchen und ungekehrt. Ich habe eine ganze Anzahl theils frischer theils im Weingeist anfbewahrter Exemplare auf' die Anwesenheit von Hoden oder Eierstock geprüft und das Ergebniss erhalten, wie ich es oben unter den "Kennzeichen" aufstellte. Die lebhafter gefärbten Thiere sind die Männchen, und wie bei anderen Arten erreicht die Färbung den höchsten Grad der Sättigung und der Schärfe der Zeichnung, bei alten Männchen, wo namentlich die blanen Flecken der Seite, die gelben und braunen Tinten und Flecken des Bauches gar schön hervortreten.

- Die Angabe, dass die Männchen nach und nach, gegen die Geschlechtsreife hin, den rothbraunen Bauch bekommen, stützt sich meinerseits auf besonders dahinzielende Beobachtungen. Ich fing mir zur Herbstzeit in Südtyrol junge Thiere, mit noch gauz hellem Banch oder höchstens mit Spuren von Rothbraun am Rande. In der Gefangensehaft gut geptlegt firrbte sich im darauf kommenden Frühjahr bei den Irinnchen der Batuch über und über prächtig rothbraun, welche Firbe sich dann nicht nur auf die Bauchseite der Gliedmassen ansdehnte, sondern anch eine weite strecke am Sschwanz fort. Die Bunchfarbe der Weibchen erhob sich höchstens zu

1) PoLLix in der Schrift: Viaggio al lago di Garda e al monte Baldo, Verona 1816, gibt zwar bezüglich der Thierwelt jener (iegenden Interessantes und Neves, namentlich über die Fische und Krebse des See's, aber von den Eidechsen spricht er nicht. Ich bemerke diess für liejenigen, welche gleich mir sich abmühen sollten, in den Besitz des bei uns seltenen Buches zu kommen.

${ }^{3}$ ) In Sturs's Vauna. 
einem Anhauch von Schwefelgelb. Bei beiden Geschlechtern tritt von den satten Tinten der Bauchseite die Marmorirung der Kehlgegend zuerst auf.

Immerhin ist bezüglich der $L$. muralis ebenso richtig wie für $L$. viridis, dass man nach der Farbe allein nicht mit Sicherheit das Geschlecht bestimmen kaun. Aber unter den vielen untersuchten Thieren war z. B. kein einziges Thier mit stark rothem Bauch, woraus Prinz BoNAPARTE die Varietät L. mbriventris gemacht hat, weiblichen Geschlechts, sondern alle Männchen; ebenso wies sich ein schönes Exemplar der Varietät nigriventris der Fauna italica, welches ich der Güte de BETTA's verdankte, als ein Männchen aus. Bei letzterem sowohl, wie überhaupt bei allen erwachsenen Männchen verriethen schon, ehe man in die Bauchböhle blicken komnte, Kopfbildung, Hinterbeine, Schenkelporen und Schwanzwurzel das Geschlecht.

In STURM's Fauna wird eine „artige Abart" aus "sűdlichen Gegenden" abgebildet, an der hauptsächlich ein gewisser heller Grundton der Färbung auffällt. Ich habe bei Allgund im Etschthal, unter den prächtigen Castanienbäumen wie sie dort stehen, ein Thier beobachtet, aber nicht erbeuten können, welches mir beim ersten Blicke die angezogene Abbildung sofort ins Gedächtniss rief.

Während nun aber diese "Varietäten" als solche nicht fortbestehen können, so verhält es sich anders mit der Varietät campestris BETTA, welche sich von der Stammform nicht blos durch die Farbe, sondern auch durch die Lebensart sehr entfernt hat. Synonym mit ihr ist wohl $L$. albiventris BoNAPARTE. Das Thierchen lebt nicht an Mauern, Felsen oder Steinen, sondern lediglich unter dem Gebüsch des freien Feldes und wie es scheint gerne gegen den Saum sandiger Flussufer und gegen den ebenso beschaffenen Meeresstrand zu.

Ich wurde auf diese Eidechse aufmerksam gemacht durch das lehrreiche Buch G. v. MAartes's: Reise von Ulm nach Venedig, $1824,{ }^{1}$ ) wo erzählt wird, dass sich auf dem Lido, unmittelbar am Ufer des Meeres eine niedliche Eidechse besonderer Art aufhalte. Wegen des Wohnortes wäre v. Martens geneigt gewesen sie als $L$. arenicola DAUdin zu bezeichnen; allein da er bereits durch seinen Freund Roser davon unter-

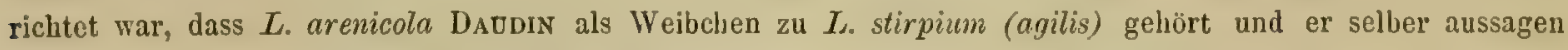
muss, dass er letztere Art um Venedig nicht geselien habe, so bezieht er sie auf $L$. velox Pallas, die allerdings in Grösse und theilweise in der Färbung Aehnlichkeit zu haben scheint, aber doch ein anderes Thier ist. Im Herbst 1868 fing ich mir selber cine Anzalı des hübschen Thieres auf dem Ufer ${ }^{2}$ ) bei Venedig,

1) Auch in dem Werke desselben Verfassers. Italien, 3 Bde, 1844-46, welches ich nicht selbst einsehen kann, soll Bd. II. S. 315 u. 316 von dieser Eidechse die leede sein.

2) Man gestatte, dieser Streiferei auf dem Lido, welche mir eine angenehme Erinnerung bleibt, mit einigen Worten zu gedenken. Noch steht dort in Menge, wie zu Görme's Zeit, der den 8. Oct. 1786 den Strand besuchte, das Eryngium maritimum; aber auch die schöne Golddistel (Scolymus hispanicus, $\boldsymbol{L}_{\text {. }}$ ) blühte, und war so wie die anderen durch v. MarTEss näher bezeichneten Strandpflanzen über und über bedeckt von der Helix pisana MïrL. 
wo es nahe am Meeresstrande in Menge herumsprang, sich aber nicht unter dem Auswurf des Meeres verbarg, sondern unter den Pflanzen und Sträuchern, namentlich gern im Wurzelwerk der Grasbüsche.

In der Gesammtfirloung, welche man als eine vielfach gestreifte bezeichnen könnte, hatte das rasch dahineilende 'Thier etwas helles, man möchte sagen, dem Sande auf dem es lebt, Aehnliches. Im Näheren angesehen, sind die Farben schön und lebhaft. Ueber die Mittellinie des Rückens zieht ein brauner Streifen mit dunkleren Flecken; zu beiden Seiten schliesst daran ein heller Streifen, der ins Grüne spielt ${ }^{1}$ ) dann kommt wieder ein brauner Streifen mit dentlichen Randflecken; hierauf folgen zwei helle Längsbinden, żum Theil in Flecken aufgelöst und zackig verlaufend. Diese Binde entspricht dem Augenstreifen und seiner Fortsetzung bei den anderen Reptilien. Jetzt kommt noch eimmal, gegen den Bauch zu, eine braune Zone, an welche das IVeiss des Bauches, am Rande mit kleinen schwarzen Flecken besetzt, selber anstösst. An den Kieferründern und der Wangengegend tritt bei einigen ein zartes lichtes Grün auf.

Das Verdienst diese Eidechse als eine wohlbegründete Varietät abgeschieden zu haben, gebührt de BETTA. ${ }^{2}$ ) Im Hinblick auf die so prächtig gerathene Figur der L. muralis var. albiventris in BONAPARTE'S Werk über die Thiere Italiens muss ich bemerken, dass keines der von mir am Lido bei Venedig erhaschten Thiere eine solche Grösse besass; auch die zwei grünen Rückenstreifen waren nie so satt, sondern alle Tinten neigten in die lichte Sandfarbe. Trotzdem möchte doch $L$. albiventris mit $L$. campestris einerlei sein und es ist nur zu bedauern, dass uns der 'Text obigen Werkes nichts über den Fundort sagt. Uebrigens sah ich in der Sammlung de BETTA's in Verona neben der gewöhnlichen kleinen und zarten Form der L. campestris auch Individuen, die jedenfalls ebenso gross, wenn nicht stärker sind, als die angezogene Abbildung zeigt. Sie stammten aus den Maremmen von Pisa.

An den erwachsenen Exemplaren der von mir eingefangenen 'I'hiere liess sich

Und damit gar nichts in dem schönen Bilde fehle, welches uns der ebengenannte Naturforscher gezeichnet hat, so kroch auch der Ateuchus semipunctatus FAB. auf dem Sande herum. Ein Searites laevigatus FABR, den wohl zuerst MEgerLe, (Entomologus acutissimus Viennensis, qui hunc in Lido Venetiis detexits) hier fand, liess sich überraschen, als er gerade in den feuchten Boden sich einbohren wollte. - Der bekannte Entomologe Toussainx von Curmpenter spricht in seinen Bemerkungen auf einer Reise durch Italien, im Jahre 1818, von den muntern Eidechsen die ihn auf dem Steincham, Murazzi, bei Palestrina belustigten. Es möchte sich dem nächsten Beobachter empfehlen, nachzusehen, ob es sich hiebei nu die Stammform muralis oder ebenfalls um die Var. campestris handelt.

1) Bei jüngeren Thieren sind diese grünen Streifen noch graubraun. Es scheint, dass v. Martexs nur solche jüngere Exemplare erbeutete, weil er die Streifen nirgends als grün bezeichnet. - Auch SELrs-Loxachamps bespricht, wie ich nachtrïglich in seiner Faune belge 1812, S. 174 sehe, die uns hier beschäftigende Eidechse; er fand sie zugleich mit der gewöhnlichen $\boldsymbol{L}$. muralis in der Umgegend von Turin und hebt ausdrücklich hervor, dass sie ein inderes Thier sei als dio bekannte L. muralis.

9) Erpetologia delle Provincie Venete e del Tirolo meridionale, 1857, und Materiali per una Fiuna Veronese, 1863. 
das Geschlecht nach den oben mehrmals wiederholten Merkmalen der Körperbildung schon äusserlich unterscheiden; was sich dann durch die innere Untersuchung bestätigte. In der Farbe bestand zwischen den beiden Geschlechtern kein erheblicher Unterschied; nur die Flecken der Rückenseite waren beim Männchen zahlreicher und umfänglicher. Die Bauchseite bleibt bei beiden Geschlechtern weiss.

Die ganz jungen Thierchen der gewöhnlichen L. muralis, wie man sie von der zweiten Hälfte des August an in Menge sieht, haben schon die spitzige Schnauze und einen ungemein langen Schwanz, der im Verhältniss zum Körper jetzt noch länger als später ist, denn er ist gut zweimal so lang als Kiopf und Leib zusammen. Die Farbe hat schon im Wesentlichen die Tinten und Flecken der Alten so weit angenommen, dass man die Art nach ihr allein zu erkennen vermöchte. Der Kopf zeichnet sich oben durch schwach metallischen Glanz aus. Noch erscheint mir bemerkenswerth, dass die kamm ausgekrochenen Thierchen, bei allem sonstigen grossen Unterschied zwischen ihnen und der Argusform der L. agilis, doch durch die Farbe insofern an die letztere erimnern kömnen, als die Seiten wie hellgetüpfelt sind. An Feinheit der Körperformen und Zierlichkeit der Bewegnngen haben übrigens diese kleinen Geschöpfe nicht ihres Gleichen!

Die L. strigata EICHWALD wäre ich, wie oben bereits bemerkt, geneigt hieher zu L. muralis zu stellen; anstatt wie es gewöhnlich geschieht, zu L. viridis. Die gestreckte niedergedrückte Form des Kopfes an der, allem Anschein nach sehr genauen Abbildung, der Aufenthalt und manches andere würde hiefür sprechen.

Von der Lacerta tiliguerta der Insel Sardinien wird weiter unten die Rede sein.

\section{Schilder, Schuppen.}

Die Schilder des Kopfes können abermals manchfache kleinere oder grössere Alänrlerungen zeigen, wodurch wir immer wieder daran erinnert werden, dass diese Theile zwar im Zusammenhalt mit anderen Formverhältnissen, gute Anhaltspuncte zur Bestimmung liefern können, aber für sich allein, weil nicht beständig, keinen allzuhohen Werth haben. So habe ich mir eine Anzahl von Fällen bezeichnet, wo das mittlere Hinterhauptschild bald in zwei, bald in drei Täfelehen zerfiel; ein andermal wil durch eine Querfurehe das Stirnschild in ein vorderes grösseres und hinteres kleineres aufgelöst und was dergleichen mehr ist.

Da die Beschuppung des Rückens von jener der anderen Arten so abrveicht, 
dass man der $L$. muralis einen "körnigen" Rücken beilegen konnte, darf man sich einigermassen wundern, warum Autoren, welche das Thier sonst ausführlich und gut beschreiben, z. B. Koch, dieses Merkmals mit keiner Silbe gedenken. Doch ist das bei dem Genannten wohl nur eine zufallige Auslassung, dem auf den Abbildungen hat STURM den Unterschied richtig und scharf hervorgehoben.

\section{Zähne; Schädel. ${ }^{1}$ )}

Die Zahl der Zăhne beträgt:

im Zwischenkiefer 6 bis 7 ;

im Oberkiefer, eine Seite, 17 bis 18 ;

im Unterkiefer, eine Seite, 20 bis 23.

Wollte ich bezüglich der Gaumenzühne nur nach meiner Erfahrung die Kennzeichen aufstellen, so hätte ich oben sagen müssen: „Keine Gaumenzähne“. Denn ich habe eine ziemliche Zahl von Schädeln durchmustert und nie etwas von Zăhnen an dieser Stelle wahrnehmen können. Ausser WAGLER möchte ich von jenen Zoologen welche in dieser Sache selber nachsuchten, noch DUGÉs und de BETTA sprechen lassen; wovon der erstere sagt: „il m'a été impossible de trouver les dents palatines ou mieux ptérygoidiennes chez le lézard des murailles." Und de BetTa:.... non che quelle ch'io stesso istituii su cinquanta e più individui della Podarcis muralis, in nessuno dei quali ebbi a trovare denti a palato." Allein Wiegmann ${ }^{2}$ ) bemerkt ausdrücklich: „dètes palatini parvi, obtuso-conici erectiusculi“, und auch BIBRoN und DumÉril erklären, dass manche Individuen wirklich Gaumenzähne besitzen.

Die Zweifel, welche ich früher an der Richtigkeit dieser Angaben hegte, musste ich aufgeben, durch das, was ich oben von Gaumenzähnen der $L$. vivipara mitzutheilen hatte. Es scheint eben, dass bei beiden Arten hin und wieder, in manchen Gegenden vielleicht häufiger, Gaumenzähne auftreten können; etwa sowie anch Fülle vom Vorkommen der Eckzähne bei solchen Arten von Wiederkäuern, welchen sie gewöhulich fehlen, bekannt geworden sind, z. B. beim Reb.

Die Zähne sind immer nur, gleichwie bei den übrigen Arten, zweispitzig und wenn der Anschein von drei Spitzen an den grösseren entsteht, so beruht er, wie anderwarts, auf der Drehung der Hauptspitze nach innen. Uebrigens scheinen mir die Zähne hier sehr glatt und wegen des Mangels der Streifen glinzender zu sein, als bei den andern Arten. Auch will es mir vorkommen als ob die Hauptspitze

j) Vergl. Zweite Tafel, Fg. 21, Fg. 22.

2) Herpetologia mexicana p. 9 . 
nicht nur länger und schärfer wäre als sonst, sondern anch der Zahn im Ganzen stärker nach einwärts gekrümmt.

Obschon bei den einheimischen Eidechsen durchweg die Unterschiede in der Schädelbildung nicht so weit vorgeschritten sind, als z. B. bei den Wassermolcken, so wird man doch immer im Stande sein den Schädel der $L$. muralis, ohne dass er besonders auffallende Kennzeichen darbietet, zu erkennen. Mit. den Schüdeln der $L$. viridis und $L$. agilis würde Niemand eine Verwechslung begehen können; nur L. vivipara wăre mit in Frage zu bringen. Doch ist der Schädel der $L$. muralis, wenn auch im Mangel der Gaumenzähne, in Bildung der Braunenplatte mit L. vivipara übereinstimmend, doch von gestreckterer Form. An jüngeren Thieren, wo sich die Haut vom Kopf leichter abziehen lässt, ist desshalb das Schädeldach glatter als später.

\section{Vorkommen.}

Die Mauereidechse ist als eine südliche Art anzusprechen, welche ihre eigentliche Heimath in den Ländern um das Mittelmeerbecken hat und von da in grösserer Ausdehnung oder nur in Strichen nordwärts vordrang.

Für Nordafrika wurde sie z. B. durch Ehrenbeng, Moritz Wagner ${ }^{1}$ ) und jüngst durch S'TRAUCH ${ }^{2}$ ) nachgewiesen; nach letzterem ist ihr Vorkommen in Algerien ein ebenso häufiges wie in Südemropa. Wie weit sie in Afrika südwärts geht, ist unbekannt. ${ }^{3}$ ) STRAUCH fand sie noch bei Tlemcen.

Auf der Insel Madeira scheint $L$. muralis in die Form L. Dugesii Miln. Edw. übergegangen zu sein.

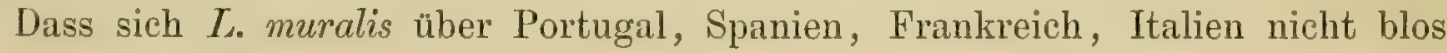
ausbreitet, sondern stellenweise geradezn in erstaunlicher Menge vorhanden sich zeigt, ist allbekannt. Und wegen ihrer grossen Zahl musste sie sich von Alters her dem Blicke aufdrängen; man sah sie gern nach dem Winter erscheinen als Boten der wiederauflebenden Natur. ALDrovand sagt: „lacertae a solo exemntes verni temporis nunciae esse feruntur", und lässt uns auch italienische Poeten uber die gleiche Sache vernelumen. Den vom Norden Kommenden, welcher sonst zu Hause nur hin

1) Reisen iu der Regentschaft Algier.

2) Erpétologie d'Algerie.

$\left.{ }^{3}\right)$ Doch mögen sich hierüber Angaben in mir vicht zugänglichen Schriften finden, so in Duverrier, Exploration du Sahara: les Ionareg du Nord, 1861, und in Aufsitzen von BArвozs de Bogsae über Reptilien des portugiesischen Afrika's. 1866. 
und wieder eine Eidechse erblickt, muss, sobald er die Mittagseite der Alpen erreicht hat, die Menge der Eidechsen an Mauern, Felsen und Wegen als etwas Neues anmuthen. ${ }^{1}$ ) Selbst auf Lavablöcken, welche noch nicht so weit zersetzt sind, um ein rechtes Pflanzen- und Thierleben gedeihen zu lassen, hat L. muralis schon Platz genommen. Besucher des Vesuv's, ${ }^{2}$ ) welche auch tür solche Dinge ein Auge haben, berichten ansdrücklich, dass nahe dem firater ,noch einige Insecten schwirren und Eidechsen über Lava und Schwefel hinwegschlüpfen." Auf deu Liparischen Inseln traf SpaldaAnzani einzig und allein unsere Eidechse an - die er nach dem Gebranch früherer italienischer Zoologen agilis nennt -, kein anderes keptil. ${ }^{3}$ ) Auch mitten in den Stitdten, z. B. in Amphitheater Veroni's ist das Thierchen häufig, selbst in Venedig, wo wenig Platz für Landthiere ist, sieht man da und dort $L$. muralis sich flüchten.

Bei dieser so allgemeinen Verbreitung des Thieres in Südeuropa durfte sich dann CetTI ${ }^{4}$ ) allerdings über den vermeintlichen IIangel auf der Insel Sardinien wundern: „Mi pare un spezie di fenomeno, che in Surdegna non si trovi la vera e propiamente detta Lucertula“. Unser Autor beschreibt dann die einzige Eidechse der Insel unter ihrem Volksnamen Caliscertula oder 'Tiliguerta, und sie wurde später

1) „Ueber Mauern wirft sich der Attig lebhaft herüber: Epheu wächst in starken Stämmen die Felsen hinauf und verbreitet sich weit über siẹ; die Eidechse schlüpft durch die Zwischenräume sind Eindrücke bei GürnE als er im September 1786, von Botzen auf Trient zufuhr. Ergötzlich spricht sich auch das Erstaunen des wackeren KEYssLex's welcher im Jahre 1730 in Italien war, in seiner $\$$ Reise durch Deutschland, Italien etc. aus. Nachdem er von den vielfältigen Schaden, den der Vesuvius in seiner Nachbarschaft verursacht, und der Noth durch Erdbeben gesprochen, lässt es sich folgendermassen vernehmen: „Eine andere Ungelegenheit, welche aber dieses Land (Neapolis) mit andern italienischen Gegenden gemein hat, verursacht clie Menge der Eydoxen, davon eine grủne Art in grosser Menge allenthalben anzutreften ist. Im Frühling findet man dieselben lundertweis auf den platten Dächern liegen, un sich daselbst an der Sonne zu wärmen. Sie kriechen die Mauern auf und ab, daher kein Zimmer, dessen Fenster oder Thüren offen stehen, vor ihnen sicher ist. Es ist mir selbst widerfahren, dass als ich in dem dritten Stockwerke eines steinernen Hauses einmals meine durch Regen nass gewordenen Handschuhe an das Fenster und in die Soune gelegt hatte, wenige Minuten hernach ein solcher Gast schon in den einen gekrochen war, welchen ich nicht eher vermerkte, als bis ich die Hand in den Handschuh gesteckt hatte. Jetzt gedachte gr rïne Art Eidechsen läuft seh. geschwind, hat eine schöne glïnzende Farbe, lebhafte Augen und thut keinen Schaden. Diese Angaben siud auch desshalb von Interesse, weil sie zeigen, dass Lacerta muralis - denn nur auf diese Art passt das Erzählte - bei Neapel in der Grundfarbe stark grün sein muss.

2) z. B. der hohe und unglückliche Verfasser des Buchs: Aus meinem Leben. Bd. I. Reiseskizzen, Leipzig, Dunker u. Humblot. S. 58.

3) Viaggi alle due Sicilie, Pavia 1792.

4) Anfibi e pesci di Sardegna. Sassari, 1777. Das ganze Verk, die Säugethiere und Vögel mit behandelnd, ist von hohem Werth und gewinnt den Leser auch durch die gefallige Form der Darstellung. Der Verfisser, ein Geistlicher ans Como in Oberitalien, lebte zehn Jahre auf der Insel und benützte diese lange Zeit zu naturhistorischen Studien. Auch das Aeussere des Buches, den Druck, die eingeschalteten Vignetten wird der Bücherfreund nicht ohne Interesse betrachten und es iv der Ordnuug finden, dass della Marsors in seinem Itineraire de l'ile de Sardaigne, Turin, 1860, zweimal (T. I, p. 73. и. T. II, p. 350) der Druckerei deg Gruseppe Pratrol gedenlt mit Hinweis auf die typographische Ausstattung des Cerrx'schen Buches. 
von den Zoologen des Festlandes, ohne dass sie das Thier selber gesehen hatten, bald für eine besondere Art ausgegeben, bald auch nur für eine Varietät der $L$. ocellate oder $L$. viridis erklärt. Es blieb GENE, welcher als Nachfolger BonelLr'S in der Turiner zoologischen Sammlung über hụndert Exemplare in Weingeist antraf, vorbehalten nachzuweisen, dass die CETTI'sche Eidechse nichts anderes sei, als Lacerta muralis; ${ }^{1}$ ) später hatte er bei seinen Reisen auf der Insel Gelegenheit, das Thier "ubique, sed praesertim in apricis atque ad parietes antiquas, frequentissima", im Leben zu beobachten. ${ }^{2}$ )

Da in jüngster Zeit de BETTA ${ }^{5}$ ) die Ansicht ausgesprochen hatte, dass $L$. muralis, var. campestris, und die sardinische L. muralis zusammengehören möchten, wofür der Umstand zu sprechen scheine, dass der Bauch auch bei der Tiliguerta nie rothgefärbt (nunquam rubriventris) und die Grundfarbe des Rückens grün sei, so suchte ich mir das lebende Thier zu verschaffen, was mir gelang, ${ }^{4}$ ) so dass ich geraume Zeit in einem und demselben Behälter die Var. campestris und die sardinische Tiliguerta lebend beisammen hatte. Es geht für mich aus dem Vergleich beider hervor, dass Tiliguerta der gewöhnlichen L. muralis, wenn wir wollen der Stammform, näher steht, als der Var. campestris. Die ausgewachsene sardinische Eidechse ist merklich grösser als L. muralis von gewöhnlichen Massverhältnissen; nur hin und wieder bin ich auf eine Manereidechse gestossen, welche in der Grösse der Tiliguerta gleichkommt. Die Grundfarbe des Rückens ist ein sattes Dunkelgrün, welches nach den Seiten sich abschwächt, gegen die Schwanzwurzel ganz aufhört und in Graubraun übergeht, von welcher Farbe auch die Rückenseite der hinteren Extremitäten ist, während die vordere ins Grünliche zieht. Auf der grünen Grundfarbe des Rückens verbreiten sich schwarze Flecken, derart, dass sie wie zu einem grobmaschigen Netz zusammenstossen. Die blauen Flecken der Seite sind nur spurweise zugegen und mehr perlnutterfarbig. ${ }^{5}$ )

Die sardinisthe Tiliguerta stellt somit eine $L$. muralis von besonderer Grösse und besonders langem Schwanze vor, deren Grundfarbe am Rücken stark ins Grüne geht, deren Bauch nie die rothe Tinte erhält, und deren blaue Seitenflecken

1) Osservazioni intorno alla tiliguerta di Cetti. Mem. della accademia delle scienze di Torino. 1832.

2) Synopsis reptilium Sardiniae indigenorum, ibid. 1838.

9) Erpetologia delle provincie venete, 1857.

4) Durch die Güte des Herrn Cav. Cara in Caghiari und des Herrn Dr. Eutrava, welcher phönicischer Inschriften halber die Insel besucht hatte.

3) Unter meinen lebenden Tiliguerten war ein ganz junges, wohl erst nur einige Monate altes Thierchen, dessen Grundfirbe am Rücken ein angenehmes Briungrau war. Im darauf folgenden Frühling setzte sich das Braun, mit den Wachsen des Thieres, in das Dunkelgrün der Alten um. 
fast völlig verschwunden sind. Zu all diesen Eigenthümlichkeiten lassen sich aber bei der gewöhnlichen Mauereidechse, z. B. von Südtyrol, Uebergänge finden. Die Geschlechtsverschiedenheit scheint, was schon CETT bemerkt, in dẹ Farbe dandurch ansgedrückt zu sein, dass beim Weibehen die Grundfarbe anstatt grün, braun ist, und das Schwarz Lăngsstreifen bildet.

Wie sehr L. muralis anf den Inseln des Mittelmeeres in der Farbe abändern kann, zeigt ferner die schöne Tafel, welche in der Famna italica der Podarcis muralis siculus gewidmet ist; das Thier besitzt dort ein wahrhaft prächtiges Farbenkleid.

Das dürre, sonnige Dalmatien wimmelt nach GERMAR ${ }^{1}$ ) von gegenwärtiger Art, die er übrigens $L$. velox PaLl. nennt. Und ein neuerer Reisender, welcher viel in Dalmatien gesummelt hat, ErBer ${ }^{2}$ ), hebt hervor, dass die Mauereidechse in endlosen Abänderungen dort vorkomme, fast in jeder Localität sei sie anders gezeichnet. Nicht minder ist Griechenland reich an diesen 'Thieren nach BorY de St. Vincent, ${ }^{3}$ ) ERhard, de Betta u. A.

Blicken wir jetzt von Südeuropa auf ihre Verbreitung in Mittel- und Nordeuropa, so wird sich zeigen, dass die Behauptung ${ }^{4}$ ) erfahrener Herpetologen: Lac. muralis komme in ganz Europa vor, keineswegs richtig ist.

Die Manereidechse noch so häufig auf dem warmen Boden Südtyrols, geht zwar weit in die Thäler hinauf, und selbst auf die Berge, aber sie überschreitet nicht die Alpen. Was ihre senkrechte Verbreitung in Südtyrol anbelangt, so hat schon GreDLen ${ }^{5}$ ) beobachtet, dass das Thier aus der Tiefe des Eisackthales am Frombach hinan ,beinahe die Ebene der Seiseralp“ erreicht. Ohne diese Mittheilung im Gedïchtnisse zu haben, war ich selber nicht wenig überraseht, im August 1868, unmittelbar an liande der Seisezralpe, bei etwa 5000 Fuss Meereshöhe, ein prächtiges Männchen mit lebhaft braunrothem Bauch unter einem Stein - es war trüber: Himmel - zu fangen. Bei einer zweiten Lxcursion, begünstigt von heiterem Wetter, zeigte sich $L$. muralis an allen mittägigen Stellen des Anstieges an Steinhaufen häutig. Ferner hat auch der Botaniker MrLDE ${ }^{6}$ ) bereits von gleichem Orte dieses

1) Reise nach Dalmatien, 1817.

2) Amphibien der österreich. Monarchie, 1864.

\$) Expedition scientifique de la Morée. Die colorirten Abbildungen der $\boldsymbol{L}$. murais in diesen Werk sind mit Rỉcksicht auf die obige Tiliguerta Sardiniens auch desshalb interessant, als ihre Grundfarbe ein deutliches Dunkelgrün, zeigt.

4) DLe lézard des murailles est répandu dans toute l'Europe«, Birros u. Dumérı; ; La Podarcis muralis, é sparsa in tutta l'Europa, in cui può dirsi non essere angolo di terra che non la possiedar, de BETrA.

3) Vierzehn Tage im Bad Ratzes, 1863.

${ }^{\circ)}$ Ein Sommer in Südtyrol, 1864. 
unerwartet hohé Vorkommen der Manereidechse angezeigt. ${ }^{1}$ ) Ebenso bemerkte ich wie nuser Thier und zum Theil in recht grossen Exemplaren am Kollernerberg an allen sonnigen Anstiegen und Wegen des Waldes herauf bis Obernkollern, und wahrscheinlich noch höher vorkommt; dessgleichen sah ich lebhaft gefürbte Thiere häufig bis zu den Dorfmauern von Oberbotzen (3995') und Lengmoos (3796'). Bei Besteigung der Mendel war das Thier bis nahe zur Passhöhe (4787') zu verfolgen, doch auf der spitze blickte ich mich vergebens darnach um. Nichts ungewöhnliches bietet es daher, wenn ich weiter anführe, dass ich $L$. muralis bei Völs $\left(2145^{\prime}\right)$ noch weit hinein in den Wald, am Wege der gegen Ratzes führt, gefangen habe; ebenso auch an den Mauen hinter Castelruth (3349'), gegen St. Nichele zu, und zwar iu Menge, während sie an sonnigen Maueru bei seis (2960') nur vereinzelt sich blicken liess.

In Deutschland kommt in Rede stehende Art nur an zwei Strichen vor, im Gebiet des Rheins und im Donauthal bei Wien.

Ins Rheinthal gelangte sie von der Schweiz her und Frankreich aus, wohin ihr (zugleich mit Lacerta viridis) durch die Gebirgslücke zwischen Juri und Vogesen, der Weg offen stand; demn wie schon T'schud über die "merkwürdige" geographische horizontale Verbreitung dieser Eidechse berichtet: sie findet sich, abgesehen von dem nicht mehr in Betracht kommenden Tessin, nur in der vestlichen und nördlichen Schweiz; der Jura besitze sie in Menge und sie fehle hingegen im Osten und in der ganzen mittleren Schweiz.

Wer sie im Rheinthal zuerst beobachtet und unterschieden hat, ist mir bis jetzt unbeliamnt geblieben; vielleicht war es Koch, der sie im Jahre 1828 in STuru's Fauma beschriel, und sagt: "Ihr Vaterland") ist die bayrische Rheinprovinz, wo sie häufiger als jedt andere Eidechse vorkommt". Begonders verdient aber hervorgehoben zu werden, dass schon mehrere Jahre zuvor die Manereidechse im Schwarzwahlgebiet bei Neuenbürg durch den bekannten würtembergischen Entomologen Roser entdeckt wurde. ${ }^{3}$ ) Doch scheint man anfaugs diesem Fund wenig 'Theilnahme

1) Auch die ausserordentliche Höhenverbreitung des Scorpio germanus, welche Greduer zuerst, dann MiLde aus dieser Gegend bekannt machten, kann ich, wie schon S. 222 angedeutet wurde, bestätigen. Ich fieng zahlreiche Exemplare bis zum Rinde der Seiseralp, sowie am Rande der Schlernklamm weit hinauf.

2) Medrcus, welcher sie (in der Bavaria 1867) ebenfalls für die Rheinpfalz erwïlut, meint der Verfasser der Fauna von Oberbayern in demselben Werke habe die Mauereidechse wohl für Südbayern. desshalb nicht aufgeführt, weil er sie für identisch mit der gemeinen Eidechse halte. Das ist aber wohl schwerlich der Fall gewesen; sondern die Art kounte für Süabayern desshalb nicht genannt werden, da sie in der That nirgends dort vorkommt. - Nach dem Verzeichniss Röser-Bicuser's zu urtheilen, welches ich mir erst spät verschaffen konnte, und wenn die Bestimmung richtig ist, hat dieser Beobachter vor Kocr, im Jabre 1827, die Mauereidechse bereits aus dem Rheingebiete angezeigt, und zwar ans der Gegend von Darmstadt.

$\left.{ }^{3}\right)$ Siehe Memsixoen, Beschreibung von Württemberg, 1820. Hier wird blos angegeben, diss $\gg$ vor Kurem 
geschenkt zu haben, denn mehr als zwanzig Jahre später (1847) berichtet erst wieder NördLinger, dass L. muralis bei Lauffen am Neckar vou ihm beobachtet worden sei. Unterdessen aber hatte der damalige Finanzassessor PAulus dem Thierchen und seiner Verbreitung in Württemberg grosse Aufmerksamkeit zugewendet. Er theilte') dem Verein für vaterländische Naturkunde eine Karte mit, auf welcher das Vorkommen farbig eingetragen war, woraus sich ergab, dass sich das Thier vom Rheinthal nur in die unmittelbar in dasselbe gehenden Thäler gezogen hat, während es, mit Ausnahme der Gegenden um Freudenstadt und Neuenbürg, anf dem Platean bis jetrt nicht beobachtet wurde. Ueberdiess beschränke es sich auf die Gebirgsformationen von dem Urgebirge aufwärts bis zum Muschelkalk, während es den Keuper und die über demselben lagernden Formationen nicht zu bewohnen scheine.

Nach Paulus verbreitet sich $L$. muralis aus dem ganzen Rheinthal durch das Neckargebiet bis oberhalb Hoheneck, lüngs dessen Zuflüssen aus dem Odenwald, längs der Elsenz bis Sinshein, der Jagst bis Möckmühl, des Kochers bis Neuenstadt, ferner längs der Enz bis zum Enzklösterle, der Glems bis nahe an Leonberg, der Würm bis über Döffingen hinaus, der Nagold bis nahe an Wildberg, längs einer liurzen Strecke an der Eyach und der kleinen Enz bis Faustberg, wo sie sich auch auf dem Plateau bis nach Neuenbürg ausbreitet, während sie an den bezeichneten Flussen -nur dem engeren Flusstlal folgt. Yon den übrigen in den Rhein sich ergiessenden Flüssen des badischen Schwarzwaldes folgt sie dem Schwetzinger Bach bis in die Nälte von Sinsheim, der Kraich, der Salza bis Bretten, der Pfinz, der Alb bis Herrenalb, der Murg mit deren Zuflüssen bis Freudenstadt und Umgebung, der Rench bis Oppenau, der Kinzig bis nahe an Lossburg, der Gutach bis Triberg und der Wutach und deren Zuflüsse bis über Waldhut hinaus.

Im Juni 1867 erhielt ich ${ }^{2}$ ) sechs lebende Exemplare aus dem Gebiete der Zaber von der Nordseite des Michelberges. Im Hërbst fieng ich am Wartberge bei Heilbronn selber vier Stück unserer Eidechse. Alle diese württembergischen Exemplare stimmteu mit den südtyrolischen in den Grundzügen der Fïrbung wohl überein; namentlich mit solchen, wie sie dort an weniger der Soune ausgesetzten Orten vorkommen. Dic braune Grundfarbe des Rückens und namentlich der Seiten hatte bei guter Beleuchtung einen grünlichen Ton. Der dunkle Seitenstrich war bei den einen sehr markirt, mit einer lichten Zone oben und unten; bei andern ersclien er aufgelöst in Flecken. Die Mittellinie des Rückens zeigte entweder einen Längsstreifen unterbrochener Flecken, oder bei andern zog über den ganzen Rücken eine verwischte oder schärfere Marmorirung. Bei keinem dieser Thiere war der Bauch roth oder gefleckt, sondern durchweg weisslich oder helgelblich, und die Reihe blaner Flecken an der Seite des Leibes zum Theil nur in schwachen Spuren vorhanden, selbst wenn sie deutlich da waren, zeigten sie sich klein auf einem etwas leiclit röthlichen Grunde, nach unten schloss sich daran ein schwarzer Strich.

Unser Thier erstreckt sich übrigens nicht gleichmässig durch das ganze Gebiet des Oberrheins; es gibt Stellen, wo es fehlt. Ich habe sie z. B. vergeblich in der Umgegend von Weinheim an der Bergstrasse gesucht; bei Freiburg soll sie, mündlicher Mittheilung zufolge, ebenfalls sehr selten sein.

die Mamereidechse bei Neuenbürg aufgefunden worden sei.\& Dass diess von Rosen geschah, erfahren wir durch G. v. Martess in Correspondenzblatt d. landwirthschaftl. Vereins, 1830.

1) Württemb, naturwiss. Jalireshefte, 1857.

2) Durch die Güte des Herrn KanRen, Forstreferendärs in Kleebronn. 
Ueber ihr Vorkommen rheinabwärts und in die Seitenthäler liegen noch Angaben vor von Kirschbaum, wornach sie an der unteren Lahn bei Hohenrhein und bei Ems gefunden wurde; ferner von NoLL, ${ }^{1}$ ) der das Thierchen bis Coblenz an Weinbergsmanern und Strassengeländern antraf, ebenso zwischen Coblenz und Winningen an der Mosel.

Sogar noch weiter nordwärts nach Holland, scheint sie vorzudringen; aus der Schrift SchlEgel's über die Reptilien der Niederlande erfährt mau, dass die Eidechse in der Provinz Gröningen, dann bei Nimwegen gefunden wurde; ja wollte man dem Colorit der Abbildung Werth beilegen, was mir aber gewagt scheint, so wären die holländischen Thiere mit lebhaft gelbrothem Bauch gefärbt. - In Belgien, wo Lacerta agilis selten vorkommt, ist Lacerta muralis die gemeinste Eidechse des Landes, mit Ansnahme einiger ebenen Strecken und der Ardennen, wie wir von SELYs-LoNGCHAMPS hören. ${ }^{2}$ )

Wie wenig leicht übrigens die Linien der Verbreitungsbezirke frei lebender Thiere sich durch Hinzuthun des Menschen verrücken lassen, leLrt der Fall, dass $L$. muralis von Heidelberg zweimal in grösserer Menge nach Giessen an passende Stellen von WeLKer ${ }^{3}$ ) verpflanzt, wieder eingieng; eine Erfahrung, welche an bekannte und ähnlich misslungene Versuche mit Verpflanzung von Schnecken erinnert.

Haben wir im Vorausgegangenen die Verbreitung im Westrande Deutschlands verfolgt, so ist jetzt noch des Vorkommens an der Ostgrenze zu gedenken. Die Art scheint in Niederösterreich allgemein heimisch zu sein; „in tota Austria, praesertim Viennae," sagt LAURENTI und ist nebenbei der Ansicht: „cum maxima habeatur quantitate, ut multis pauperibus nutriendis per totam aestatem sufficiat; caro caeterum nitida ac pura sit, posset nune ab illis conquiri (quod esset facile cum in morsu nullum sit periculum) et detracta cute instar pisciculis frixari, vel coqui: forte futurus olim magnatum cibus."

Es wäre wohl eine dankeswerthe Aufgabe nachzuweisen, wie weit die Donau herauf, gegen Bayern zu, das Thier sich erstreckt. Nordwärts scheint es vom eigentlichen Oesterreich nicht weiter vorzudringen, denn die Synopsis reptilium Bohemiae von GLÜcKSELIG enthält sie nicht, so wenig als die genaneren Verzeichnisse über die Wirbelthiere Schlesiens. Auch nach Heinnich (a. a. O.) kommt sie im k. k. Schlesien gar nicht vor, wohl aber im „südlichen Mähren, an den Grenzen von. Ungarn und Oesterreich“, und hier "nur selten“. Un so mehr mag erwähnt sein, dass nach einer neueren Zusammenstellung der Wirbelthiere der Oberlausitz, ") aller-

\footnotetext{
1) Zoologischer Garten, 1866, S. 313.

2) Faune Belge, 1842.

3) Zoologischer Garten. 1866, S. 210.

4) Mittheilungen d. naturforseb. Ges. in Görlitz, 1862.
} 
dings in fraglicher Weise, vom Vorkommen der $L$. muralis bei Görlitz die Rede ist und gesagt wird dass Lichtenstein sie in der Mark und in Schlesien gefunden habe. Auch dieser Punct möchte sich doch einer weiteren Nachforschung empfehlen.

In den Gegenden Württembergs, welche oben nicht namhaft gemacht wurden, dann im ganzen diesseitigen Bayern, sowie in Mittel-Dentschland und von da hinab zur norddeutschen Niederung bis zur Nordsee und Ostsee, wie im skandinavischen Norden fehlt die Mauereidechse. ${ }^{1}$ )

Da wo die Mittelmeerfauna sich östlich ausdehnt, treffen wir auch besagte Art, so in Südungarn, (Mehadia z. B.); in Oberungarn scheint sie seltener zu werden, JEITTELES wenigstens berichtet, dass er in Kaschan wăhrend eines dreijährigen Aufenthaltes blos in einem Sommer drei Exemplare erhalten habe. Nächst den Donaumündungen bei Tuldscha wurde sie beobachtet von Graf FERrari und ZELEBor; sie gehört ferner der pontischen Fauna an; kommt auch noch im Gouvernement Kiew vor (KEssler). Wie weit sie in Russland nordwärts geht, ist mir nicht bekannt geworden.

Nach Osten scheint sie sich ziemlich weit zu erstrecken, denn der verstorbene Turiner Zoolog de FiLipPI fand sie auf seiner Reise nach Persien noch daselbst, aber selten; schon für die Länder des Kaukasus wird sie von EIcHWaLd als "rarior“ bezeichnet, so dass es nicht gerade auffallen darf, wenn sie in dem Verzeichnisse der von MANN bei Brussa gesammelten Reptilien nicht aufgeführt wird. Auch fehlt sie unter den Eidechsen, welche Evensmans auf seiner Reise nach Bochara der Berliner Sammlung eingesendet hat.

\section{Geschichtliches und Kritisches.}

Es wurde oben die LaUrentr'sche Bezeichnung muralis als Speciesname beibehalten; wollte man aber strenger verfaliren, so müsste der ALDRovandi'sche Name Lacerta vulgaris hergestellt werden; denn es ist ausser Zweifel, dass der italienische Zoolog nur die jetzige muralis damit im Auge gehabt hat; ohne etwaige Beimischung der jetzigen agilis, da diese ja in Italien gar nicht vorkommt. Auch der von ihm gelieferte Holzschnitt trift, trotz aller sonstigen Mängel, doch den Charakter des Thieres.

Schon berührt wurde der Umstand, dass der Ausdruck Lacerta communis und L. vulgaris oder gemeine Eidechse, je nachdem der Beobachter im südlichen oder im mittleren und nördlichın Europa lebte, auf versehicdene Arten gieng und dadurch manche Verwirrung verursacht hat. Dem Italiener ist die gemeine Eidechse die Lacerta muralis, dem Deutschen aber die Lacerta agilis. In den anatomischen und physiologischen Schriften der Italiener bezieht sich Lucertola auf $L$. muralis, und Ramarro ist $L$. viridis.

1) Ueber Scandinavien vergl. Nrrssos's Scandinavisk Fauna, 1842. Nach dem, was mir, der ich das Buch nicht selber lesen kann, mein trefflicher College Hugo v. MoHr daraus übersetzt hat, ist $L$. muralis nirgends in Schweden oder Norwegen beobachtet worden. 
Unter den älteren Figuren verdient eine besondere Erwähnung die dreigeschwänzte Eidechse bei REDI. $\left.{ }^{2}\right)$ Sie ist in eigenthümlich schattenbafter Weise gehalten; in einer Art des Kupferstiches, wie er in Deutschland, wenigstens in naturhistorischen Werken, kaum je in Uebung war, in Italien aber, wenn auch in verbesserter Weise, sich lange erhalten hat. In der Zeichnung ist das Thierchen in vielen Stücken, z. B. was die Länge, Zartheit und Stellung der Zehen anbetrifft, bessẹ als manche Figur aus späterer Zeit. Sehr unbedeutend sind z. B. die Abbildungen in dem Werke Sonnini's und LaTreille's : Hist. nat. d. reptiles, Paris 1826. (Was dort, T. I, pl. 11. unterbalb des "Lezard gris" als "L. vert" dargestellt erscheint, ist wohl L. ocellata.)

Uuter allen mir bekannt gewordenen Abbildungen behalten die Figuren unserer Lidechse in der Fauna italica des Prinzen Boxaparte den ersten Rang. Sie würden aber in die zweite Liuie gerückt worden sein, wenn das oben (S. 224) erwähnte Werk OppeL's ans Licht gekommen wäre; denn die Aquarellblätter, welche die Gattung Lacerta umfassen, sind ausnehmend schön. Das Blatt, auf welchem die "Lacerta titiguerta L.", nach Haltung und Ausführung im Einzelnen vortrefilich, dargestellt ist; scheint die wirkliche sardinische $P_{0}$ darcis muralis zu sein; es spricht hiefür nicht bloss die Grösse, sondern auch das dunkle Grün der Grundfarbe. Nach der Fleckenbildung gehört sie zur gestreiften Form; die Dicke der Schenkel und der Schwanzwurzel lassen annehmen, dass ein männliches Thier vorgelegen.

A $n$ h a $n g$.

Die gegenseitige Verwandtschaft der einheimischen Eidechsen.

Unter dem Einfluss der Ideen über einen engeren Zusammenhang alles Lebencligen, wie sie gegenwärtig bei vielen Naturforschern Anklaug finden, wird auch ein Zoologe, nachdem er eine Thiergruppe der Jetztwelt näher ins Auge gefasst hat, selten melr es unterlassen, sich wenigstens versuchsweise die Formen unter dem Bilde eines Stammbaumes aufzureihen.

Wenn wir nun von diesem Gesichtspunct aus vor Allem fragen, "in welcher Zeit die Lacerten zuerst „aufgetreten“ sein mögen, so berichten die Paliiontologen, dass dieses in der Tertianzeit geschehen sei und machen dabei auf die merkwürdige Thatsache aufmerksam, dass die Sauriergeschlechter der vorhergehenden Weltalter oder der Primär- und Secundarzeit: die Teleosaurier, Mosasaurier, Megalosaurier, Ichthyosaurier u. s. w., damals so mächtig entwickelt, mit dem Ende der Kreidezeit erloschen sind und nur die Crocodile sich gleichsam als Reprïsentinten der grossen Eidechsen der Vorwelt durch die Tertiärzeit bis zur Gegenwart erstrecken.

Das Klima der Tertiärepoche wir in Mitteleuropa, wie besonders die fossilen Pflanzen der Miocenzeit lehren, anch in unseren Gegenden ein wärmeres, nahezu subtropisches; dabei von erhöhter Feuchtigkeit, da von ostwïrts breite Meeresarme in das Herz Europa's eindrangen. Dieses überlegend, werden wir uns denken dürfen, dass Lacerta viridis unter den lebenden Arten einen alteren Charakter haben möge,

$\left.{ }^{1}\right)$ Intorno agli animali viventi che si trovano negli animali viventi. Firenze, 1684. 


\section{1}

da sie neben grosser Wärme entschieden anch die Feuchtigkeit liebt. Eine solche Vorstellung wird denn auch begünstigt dadurch, dass von den spärlichen Resten, welche man bisher von Lacerta in Südfrankreich fand, LARTET eine Art in die Nähe der Lacerta viridis stellt, es ist Lacerta sansaniensis; eine andere Art, Lacerta ponsontiane war grösser als $L$. viridis; eine dritte Art wird auf $L$. ocellate bezogen. ${ }^{1}$ )

Vielleicht gleichzcitig oder etwas spüter, als sich in dem noch vorherrschend wasserreichen Land auch ganz sonnige, düre Gegenden gebildet hatten, mag sich eine der Lacerta murulis entsprechende Form abgezweigt haben; und da Trockenheit verkleinernd auf die Organismen wirkt, so liesse sich der Unterschied in der Grösse, gegenüber von den der Lacerta viridis entsprechenden Formen, in der angedenteten Weise begründet denken. Ob mam hiebei die Lrcerta pullı, welche r. MEYER ") aus der Bramkohle des siebengebirges beschrieben hat, in einen näheren Zusimmenhang mit L. murclis bringen darf, ist bei dem Dunkel, welches solche Fragen ungibt, weder zu hejahen noch zu verneinen; ebenso wenigg bezüglich des auf eine kleine Eidechse hiwweisenden Kiefer's, den Dr. DE LA HARPE in den Ligniten der Schweiz entdeckte und HEER ${ }^{3}$ ) erwåhnt.

Als nach der Tertiärzeit die Temperatur bedeutend sank und die Gletscherzeit folgte, mochte sich in den kilt gewordenen Gegenden die L. timilis zu $L$. argilis umwandeln und die $L$. muralis zu $L$. vicipara. Diese vier Arten stehen sich auch sonst, wenn wir gar nichts von derartigen Beziehungen wissen wollen, nach äusserem und innerem Bau in der angeführten Weise verwandtschaftlich näher.

Es wåre dann weiter in Betracht des auf wenige Puncte beschränkten Vorkommens von viridis und muralis in Deutschland anzunehmen, dass die beiden Arten, in wärmer gebliebenen Strichen erhalten, später bei uns einwanderten. Bei ihrer zärtlichen Körperbeschaffenheit komnte diess wicht durch Uebersteigen der Alpen geschehen, sondern e's erfolgte ost- und westwärts durch das Rhein- und Donanthal. ${ }^{4}$ ) Was oben über die horizontale und verticale Verbreitung, namentlich der vivipara

1) Vergl. Patr Gervars, Zoologie et palaeontologie françaises 1848-1852. Ich bedaure dieses WVerk nicht schon dazumal als ich über die Württembergischen Molche eine Abhandlung verötientlichte, besser gekannt zu haben; denn es enthält eine Tafel mit sehr guten Abbildungen über die Schädel der Gattung Triton, darunter auch den des Triton palmipes ( $T r$. helveticus, $\mathbf{R}_{\Lambda z_{3}}$ ).

3) Palaeontographica, Bd. 7. 2. Lief. 1860.

s) Urwelt der Schweiz. S. 405.

1) Es mag diess der Weg gewesen sein, auf dem manch anderes Thier und PAlanze rom Süden nach Norden gewandert ist; durch das Rheinthal herab z. B. die Geburtshelferkröte, Alyles obstetricans, die Aesculapschlange, Col. flavescens, die Würfelnatter, Trop. tessellatus, der Triton helveticus; von Schnecken: Helix carthusiana, Bulimus quadridens; von Arthropoden: Mantis religiosa, Oecanthus pellucens, Cermatia araneoiles etc. 


\section{2}

dargelegt wurde, möchte der Auffassung von einer Umwandlung der beiden Arten, wie sie eben bezeichnet wurde, zu einer gewissen Unterlage dienen.

Die Linien eines Schema's muthmasslicher Verwandtschaft liessen sich demnach so ziehen:

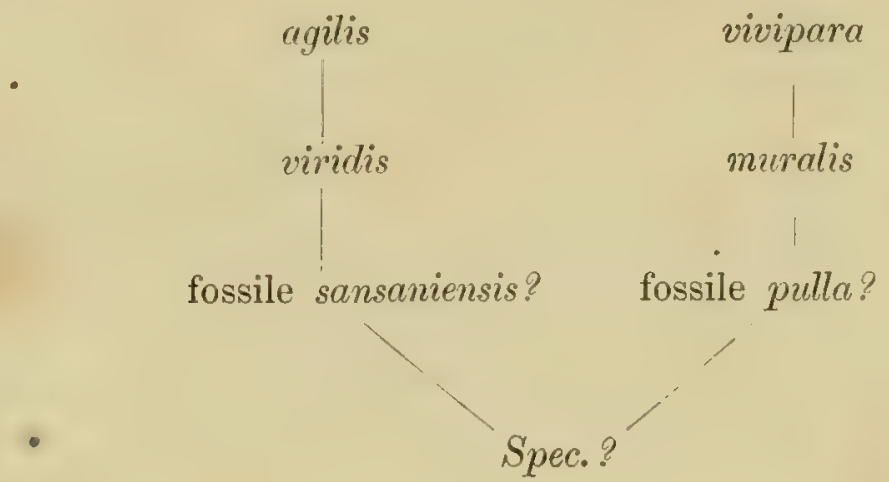

\section{Familie der Scinke.}

Körper walzig gestreckt, Kopf kaum abgesetzt vom Rumpfe; Schwanz (in vollkommenem Zustaude) so lang als der Körper, selbst noch länger, am Ende mit stumpfer Spitze. Ohne änssere Gliedmassen. Haut drüsenlos; Oberhaut zu Schuppen und Schildern verhornt; Lederhaut mit Kallitafeln. Zảhne in der Ober- und Unterkinnlarle, nicht am Gaumen; der inneren Seite, doch nahe am Rande angewachsen; Form des Zahns hackenförmig, von der Wurzel an stark rückwärts gekrümmt, Ende einspitzig; hinter der Hauptreihe noch eine lieihe kleinerer oder Ersatzzäline. Freie Augenlider; Ohr (Paukenfell) äusserlich nicht sichthar. Zunge ausehnlich, platt, an der stumpfen Spitze wenig ausgerandet, ausstreckbar, am Grunde ohne Scheide.

\section{Gattung: Anguis, LiNN.}

Kopf mit einigen Schildern; Beschuppung des Leibes gleichförmig, oben wie unten in Querringen, glänzend:

$$
\text { Art: Anguis fragilis. LinN. Blindschleiche. }
$$

Anguis fragilis, lineata. LAURENTI, Synopsis reptilium, 1768.

Gemeine Blindschleiche. Schrank, Fauna boica, 1798.

Anguis fragilis. SchNeIDER, Hist. natur. Amphibiorum, 1799.

Anguis fragilis, lineatus. Wolf bei Sturm, Deutschlands Fauna, 1802.

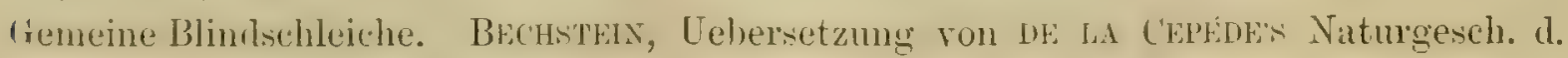

Amphibien, 1802. 
Anguis fragilis. RöMEr-Büchner, Verzeichniss der Steine und Thiere, welche in dem Gebiete der freien Stadt Frankfurt gefunden werden. 1827.

Anguis fragilis. GISTL, Bemerkungen über einige Lurche, Isis, 1829.

Anguis fragilis. SchëBlER, Thierreich in MEnmsger's Beschreibung von Württemberg, 1829.

Anguis fragilis. LENZ; Schlangenkunde, 1832.

Anguis fragilis. REIDER und HAHN, Fauna boica, 1832.

Anguis fragitis. GLUtCKSELIG, Synopsis reptilium Bohemiae, 1832.

Anguis fragilis. GLOGER, Schlesiens-Wirbelthierfauna, 1833.

Anguis fragilis. Martens, Thierreich in Meminger's Beschreibung von Württemberg, 1840 .

Anguis fragilis. Plieninger, Verzeichniss der Reptilien Württembergs in den Jahresheften für vaterländische Naturkunde, 1847.

Angris frugilis. Heınrich, Mährens u. k. k. Schlesiens Fische, Reptilien u. Vögel, 1856. Anguis fragilis. FAHRER, Thierwelt von Ober- und Niederbayern. Bavaria, Landesund Volkeskunde von Bayern, 1860.

Anguis fragitis. Kirschbatir, Reptilien und Fische des Herzogthums Nassau, 1865.

Anguis frorgilis. Medicus, Thierwelt der Rheinpfalz. Bavaria, Landes- und Volkeskunde von Bayern, 1867.

Anguis frapilis. Lerdit, Thierreich in der Beschreibung des Oberamtes Tübingen, herausgegeben vom statist. topogr. Bureau, 1867.

\section{Kennzeichen.}

Länge bis $1^{1 / 2}$ Fuss. Kopf nicht pyramidal, wie jener der Eidechsen, sondern von walziger Form; Schnanze stumpf abgerundet, breit und hoch, zum Wühlen eingerichtet. Von śchildern des liopfes ein Occipitale, zwei Parietalia, ein sehr grosses Interparietale und ein Frontale unterscheidbar; die übrige Beschuppung der Schuame und der Seitentheile des Schädels ist gleich der Beschuppung des Leibes. Grundfarbe ohen braun in verschiedenen Abschattungen, unten schwärzlich; hüufg mit feinen Lüngslinien. Mäunchen und Weibchen haben weder im änsseren Körperbau, noch in der Farbe unterscheidende Kennzeichen von einiger Beständigkeit. Hänfig ist beim Weibchen der Kopf verhaltnissmässig zarter und feiner und die Farbe des Bauches gerne schwarz. 


\section{Bemerkimgen.}

\section{Farbe.}

Das ganz junge 'Thier (lineatus der Autoren) ist bekanntlich von sehr hübscher Färbung. Die Oberseite zeigt ein eigenthümliches, fast einem lichten zarten Isabell ähnliches Weiss, über das in der Mitte eine feine schwarze Linie zieht, welche am Hinterkopf von dem schwarzen Fleck entsteht, der, wie oben schon berichtet wurde, dias hesondere Orgim im Interparietalschild umgreift. Seite und Banch sind tief schwarz.

Schon im ersten Jahre kann das satte Schwarz der Bauchseite in ein schwaches Blansthwarz übergehen, oder es sondert sich bei manchen Individuen in helle und dunkle Streifen sowie an der Kehle und Wange in Fleckenbildung. Bei anderen bleibt der Bauch gleichmässig schwarz; aber die Grundfarbe des Rückens setzt sich in ein sehr schönes ('astanienbraun um, und es heben sich mehrere dunkle Streifen davon ab.

Später zeigt sich in den Abschattungen der Grundfarbe sowohl, wie in dem Vor- und Zurücktreten der Lüngsstreifen eine grosse IIanchfaltigkeit, so dass beinahe kein Thier dem andern völlig gleicht; man trifft dahei auf fast ganz einfarbige Individuen, deren Rï̈lken hellgraubram, auch wohl hell liupferfarhig ist, die Bauchseite breit dunkel oder nur mit schmalem schwarzen Streif. Dann aber auch wieder kann das Streifensystem sehr hervortreten.

Nicht wenig überraschte mich ein Exemplar, welches ich an der Nordseite des epheuumranliten alten Schlosses Planta $\left.{ }^{1}\right)$ bei Meran, zugleich mit geröhnlich gefärbten Thieren, antraf. Nach Undrehen eines Steines lag eine grosse- Blindschleiche, dem ersten Anblick nach von nahezu ganz weisser Farbe da. Bei näherem Besehen zeigte sich als Grundfarbe des Rückens und Bauches ein helles Weissgrau, darübér hin zogen feine dunklere Lüngslinien: auf dem Rücken Tünf, eine mittlere und je zwei seitliche; dann folgten jederseits sehr dicht zusammenliegende Linien; eben solche umgaben in noch grösserer Zahl, doch schwächer im Ton, auch die Bauchthäche. Es war dieses das Thier, von dem oben mitgetheilt wurde, das es mir einen sehr deutlichen Farbenwechsel darbot. Dieser letztere Umstand möchte wohl immer in Auge zu behalten sein, da ganz offenbar ein und dasselbe Thier durch die 'Thätigkeit der contractilen Farbzellen der Haut sein Aussehen mehr oder weniger ändert; womit dam selbstverständlich auch die Grenzen in der bleibenden Verschiedeuheit der Farbe etwas enger gezogen werden.

Wie so häufig in der systematischen Zoologie vorkommt, waren auch hier die Farbenunterschiede für Diesen und Jenen hinreichend geung, um die gegen-

J) Unter den Steinen dieser Stelle batte sich ein merkwürdig reiches Thierleben augesiedelt: denn :usser zahlreichen Blindschleichen waren verschiedene Schneckenarten in einer Menge vorhanden, wie ich sie noch niemals beisammen sah, so z. B. Helix obvoluta, Helix strigella, Clausilien, Limax marginatus Dr., Scorpione, grosse Lithobien U. S. w. 
wïrtige Art in mehrere Formen aufzulösen; dahin gehören Anguis cryx, A. clivicus, A. bicolor, ete.

Ich kann es mir nicht versagen noch zweier Thiere zu gedenken, welche ich im Herbste 1869 in Südtyrol antraf, neben vielen anderen Exemplaren von gewöhnlicher Färbung. Das eine, ich fand es in der Nähe des Dorfes Kardaun unter einem Block, erinnerte in einem Puncte seiner Firbung beinahe an einen anderen Scincoiden, an Fongylus ocellatus: dadurch nämlich, dass der lüücken gir schön weissgetüpfelt war; die weissen Flecken waren klein, zahlreich und entweder ringsherum, oder wenigstens von einer Seite mit dunkler Einfassung, stellten somit Augenflecken vor. Im Uebrigen war der Grundton des Rückens eine lichte Erzfarbe, die nach den Seiten mehr ins Braune zog; Bauchflüche mit wenig Dunkel.

Das ziveite 'Thier wäre nach seiner Farbe an Lacerta nigra oder Vipera prester anzureihen. Bei Eppan konnte ich nach dem Umwenden eines am Rande eines Weiher's auf sehr feuchtem, torfigen Boden liegenden Steines, eine dem ersten Blick nach gamz schwarze Blindschleiche ergreifen. Nüher besehen zeigten sich Bauch und Seiten tief schwarz, am Riücken war ein braunes Mittelfeld, aber so dunkel, dass es dem Schwarz fist gleichkommt. Das Thier ist wohl ein neuer Beweis dafür, dass das Verfärben der lieptilien ins Schwarze auf dem Leben an sehr fenchten Orten beruht. Die schwarze Banchseite des Schwanzes hatte sehr zahlreiche, kleine blüliche llectien, deren Blau aber gewiss nicht wie in den von 'Tschus erwïhnten Fitlen durch Abreibung entstanden war; selhst mit der Lupe hesehen zeigt sich die Haut durchaus rein und ohne Verletzung. I)as Blau entstand hier, indem ein weissliches Pigment hinter dem Sehwarz durehschimmert.

Manche der neueren Autoren wollen Männchen und Weibchen nach der Farbe unterscheiden, so z. B. LENZ. Nach ihm ist beim Männehen der schwarze Streifen in der Mitte des Rüekens geschwunden; die Farbe des liückens gehe allmülig in die der Seite über; Bauchfläche und Seiten hätten wenig Schwarz. Beim Weibchen hingegen erhalte sich der schwarze Streifen üher die Mitte des lückens und Schwanzes. Die Furbe des Rückens sei von jener der Seite durch eine deutliche Linie geschieden; die Seiten seien stark mit Schwarz gemischt, der Bauch fast ganz schwarz. Nach meiner Lifahrung ist allerdings richtig, dass namentlich grosse, ausgewachsene Mämnchen gern ziemlich einforbig erzbraun anssehen, auch ohne liücken- und seitenstreifen sind, dabei nit hellem Bauch; während ein schwarzer Bauch hänfig anf das weibliche (ieschlecht dentet. Aber ich öfhnete auch Ifïnnchen, die nach der schwarzen Farbe des Bauches hatten Weibchen sein sollen. Es scheint eben, dass die Farbe 
in beiden Geschlechtern hin und her schwankt. Schon RaJUs ${ }^{1}$ ) sagt: „in foemina quam hac aestate observavi dorsum unicolor erat, nimirum e flavicante cinereum, latera lineis nigris et albicantibus varia, imus venter niger. Verum colores (ut puto) sexumm variant, forte etiam in eodem sexu". - Bei Weibchen mit schmalem mittlerem Zickzackstreifen des Rückens und tief schwarzer Bauchseite, erscheint die Bauchfläche des Schwanzes gern gesprenkelt, insbesondere hebt sich unmittelbar unter der Schwanzspitze öfters ein grösserer, weisslicher Fleck ab.

\section{Kopfschilder.}

Auf dem Interparietalschild, welches hier sehr gross ist, sieht man wie bei den Eidechsen eine markirte Stelle, ${ }^{2}$ ) in Form eines Grübchens mit wallartiger Umgebung und einer mittleren lichten Wölbung; das Ganze entweder von der Färbung der bräunlichen Umgebung, oder von letzterer durch weissliche Färbung sich abhebend. Der nähere Bau wurde oben dargelegt.

Dass die Kopfschilder anch hier manchfache Abånderungen zeigen, ja selbst an einem und demselben 'Thier von rechts und links nicht ganz gleich sind, schliesst an das an, was über diesen Punct bezüglich der Eidechsen mitgetheilt wurde. Eine Bildung, welche vielleicht herausgehoben zu werden verdient, ist die, dass zwischen das Interparietalschild und Stirnschild eine ganze Querreihe von Plätchen sich einschiebt, was man auch ungezwungen als eine Auflösung der vorderen Partie des grossen Interparietalschildes in eine Anzahl kleiner Schilder deuten kann.

\section{Schädel und Zähne.}

Es bedarf eigentlich kanm der Erwähnung, dass auf den ersten tlüchtigen Blick der. Schädel ${ }^{3}$ ) der Blindschleiche unter denen aller andern einheimischen Reptilien zu erkennen ist. Doch sei jetzt hier noch einmal auf einige der oben schon besprochenen Eigenthümlichkeiten zurückgewiesen.

Das Hinterhauptbein ist gestreckter, wesshalb bei Betrachtung des Schädels von oben das Occipitale superius und die Occipitalia lateralia freier liegen, und ebenso die beiden seitlichen Bogen der Parietalia. Wesentlich trïgt auch hier"zu bei, dass sie nicht mit Hautknochen verwachsen, also ohne krustigen Beleg sind. Das „Occipitalschild" ist reiner Hautknochen, dex mit keinem unterliegenden Knochen verwächst, daher auch am skeletirten Schädel fehlt.

1) Synopsis methodica animalium quadrup. et serpenti generis, 1693 .

2) Vergl. Erste Tafel, Fg. 14b.

3) Zweite Tafel, Fg。27 $\underline{\text { an }}$ Fg. 27 b. 


\section{7}

Die ursprünglich parrigen Stirnbeine erscheinen dureh Verwachsung mit Hautknochen als ein einziges grosses "Stirnschild“. Der Körper des Hinterhauptbeins und lieilbeins ist ursprünglich rein glatt und gewölbt; die zwei seitlichen Muskelhöcker, welche später auftreten, springen weniger vor. Der feine stachelförmige Ausläufer vorne am Körper des Kieilbeins, nach Rathke vorderer Keilbeinkürper, ist an seiner Wurzel von beiden Seiten her scharf abgesetzt. Gaumenbeine und Flügelbeine sind schmäler als bei den Eidechsen, daher die mittlere Spalte um vieles breiter als dort. Dagegen sind die Pflugscharbeine wenigstens nach vorne breiter und die Choanen, bei Eidechsen von einfach ovalem Umriss, sind hier buchtig und verengt. - Das Quadratbein ist niedriger, der Rand für's 'Trommelfell viel weniger geschweift und geräumig.

Im Hinblick anf die Zăhne, deren Ban ebenfalls bereits oben dargelegt wurde, sei hier erwähnt, dass das junge T'hier mehr Zähne hat, als das alte. Beim reifen Embryo zählte ich

im Zwischenkiefer $7-9$,

im Oberkiefer, eine Seite, 14,

im Unterkiefer, eine Seite 14-16.

Da sie aber, weil zum T'heil nur in der Schleimhant befestigt, leicht ausfallen, so bemerkt man bei alten Thieren in der einen Hälfte des Oberkiefer's meist nur 5 bis 6 , in der einen Halfte des Unterkiefers etwa 7, während am Zwischenkiefer sich die frühere Zahl vorwiegend erhält.

\section{Vorkommen.}

Die Blindschleiche gehört zu den Reptilien, welche eine sehr weite horizontale Verbreitung haben. Mitn hat früher wohl gesagt, ihr Verbreitungshezirk sei der nåmliche, wie jener von Lacerta agilis; allein er ist, wie sich mit Bestimmtheit behanpten lisst, $n$ vieles grösser. Lnser Thier findet sich in Ländern, welche die Lacerta agilis nicht hesitzen, was die folgenden näheren Angahen darthun sollen.

Angries fragilis wurde beobachtet "quoique assez rarement" in der Provinz Algier und der Sahara nach Gervals und STRAdCH; ${ }^{1}$ ) in Europa gehört sie nicht blus dem mittleren Theil an, sondern auch dem südlichen, nicht minder dem nördlichen.

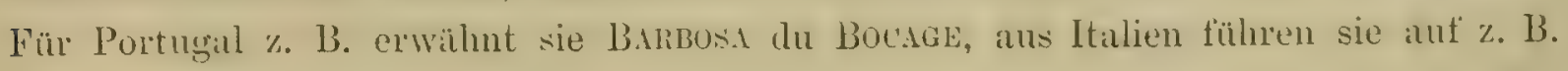

1) Erpétologrie d' l'Algrérie 1862. 
Risso, $\left.{ }^{2}\right)$ Bonaparte, ${ }^{2}$ ) SAssi, ${ }^{3}$ ) de BetTa ( $^{4}$ ) doch ist immerhin beachtenswerth, dass, während man aus Mitteleuropa kein Land kennt, dem die Blindschleiche fehlt, in Südeuropa es doch solche Gebiete gibt; so meldet z. B. GENk „Insula Sardinia caret Angue frigili“. Es scheint, dass auch manche der griechischen Inseln dieses Thier nicht besässen; es ist wenigstens auffalleud, dass EHrHard in seiner Fauna der Cycladen die Blindschleiche nicht aufführt; doch fand sie ERBER auf Tinos und nach de BETTA wäre sie durch ganz Griechenland verbreitet.

Was Frankreich, die Schweiz, Niederlande, England anbetrifft, so will ich unterlassen die Beobachter zu nemnen, da eben alle aufzuführen wären, welche die Reptilien dieser Länder ins Auge fissten; keiner ${ }^{5}$ ) vermisste die Blindschleiche, und mur hezüglich des skandinavischen Nordens sei ausdrücklich auf NiLsson ${ }^{6}$ ) hingewiesen, der sie arch für diese Länder erwähnt. In Deutschland ist die Blindschleiche an vielen Orten noch ein sehr häufiges Reptil, wie man erfährt, wenn man sich nicht blos an die uns zufällig begegnenden Exemplare hält, sondern ein Thal oder einen Bergabhang durch Umwälzen der Steine absucht. Man erstannt öfters über die Menge von Thieren aus allen Altersstufen, die sich da versteckt finden. Und ähnlich wie es bei den Eidechsen der Fall ist, halten sie fest an den Plätzen ihrer engeren Heimath, so lange die Bodenverhältnisse im gewohnten Zustande verbleiben.

Fül Osteuropa lautet schon die Angabe bei PaLLas ${ }^{7}$ ): In omni Rossia tam boreali, quam temporata, nec non per Caucasum, in Georgiam usque, satis frequens observatur, minime in Sibiria." Auch in Westasien soll die Blindsehleiche zu Hause sein; da mir aber die Beobachter unbekannt sind, so sei erwähnt, dass unter den

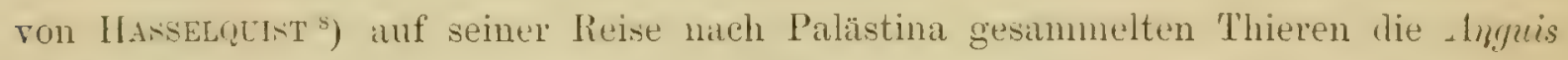

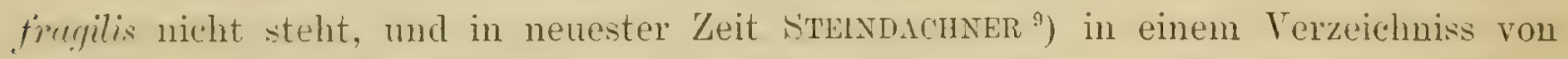
Reptilien, welche bei Brussa gefunden wurden, der Blindschleiche ebenfills nicht gedenkt.

Ueber ihre verticale Verbreitung gibt 'Ischud für die Schweiz an, dass sie

1) Hist. natur. d'Europe méridionale, Tom. 3.

$\left.{ }^{2}\right)$ Fauna italica.

3) Pesci, rettili e mammiferi della Liguria, 1846.

1) Erpetclogia delle provincie Venete, 1857, u. Materiali per una Fauna Veronese, 1863.

$\left.{ }^{5}\right)$ In dem Werke von Goldfoss und Biscroff über das Fichtelgebirge, Nürnberg 1817, wird die Blindschleiche nicht unter den Thieren aufgeführt, welche dort leben; allein ich möchte darius nicht schlieśsen, dass sie dieser Gegend wirklich fehlt.

6) Skandinarisk Fauna. T. 3. 1842.

7) Zoographia rossica.

8) Reise nach Palüstina, herausgeg. v. Carr Lixwaeus. Uebersetz. Rastock, 1762.

9) Zool. botan. Verein in Wien, 1863. 
von $2000^{\prime}$ an verschwindet, was mit meinen Beobachtungen in Tyrol nicht ganz stimmt. Ich fand z. B. im August 1868 drei Exemplare zwischen Castehuth und Ratzes, also höher als 2000'; dann noch ein Exemplar am Fusse des Schlern, an einem warmen Platze, mehr als $3000^{\prime}$ hoch. Anch gibt bereits Fitzintier, sehr wahrscheinlich nach eigener Beobachtung, au, dass die Blindschleiche ,selbst noch in der Irrummholzregion" vorkomme. ${ }^{1}$ ) Für die Umgehungen des Montblanc sagt VENANc'E PAYot: Naximum de la limite supérieur, 1200 it 1300 mètres. ${ }^{2}$ ) Poluini hebt ausdrücklich hervor, dass er die Blindschleiche am Monte Baldo höher als alle ührigen Schlangen angetroffen habe. ${ }^{3}$ )

\section{Geschichtliches und Kritisches.}

GESSNER's Liber de Serpentibus ist mir nicht zugänglich; aber bei ALDrovandr ${ }^{4}$ ) erfährt man, dass der erstere bereits die Eigenschaft des Lebendiggebärens kannte, ( $\ldots$. foetus vivos more viperarum ('nitantur'“), wälnend wir im Yerlaufe dieser Arbeit anf Schriftsteller der neueren und neuesten Zeit gestossen sind, welche die Blindschleiche Eier an sonnige Stellen u. s. w. legen lassen.

Obschon die älteren Zoologen sehr allgemein das Thier Coecilia nennen, so kannten sie doch die Augen, welche unmöglich übersehen werden konnten. („Caecilia dicitur non quod oculis careat, sed quod cos parros labeat." ") Die Meinung, dass dieses harmlose Geschöpf sehr giftig sei, ist alt und wurde selbst von Naturforschern vom Range eines VAldISNiERI ${ }^{5}$ ) getheilt. Mochte auch LAurests vor mehr als hundert Jahren (1768) seine Versuche anstellen und deren Ergebniss in den Worten zusammenfassen: „ergo innocentissima, licet hactenus rencni fama apud pleben infamis", so hat sich doch bis zur Stunde beim Volke die Ansicht von der ganz besondern Gefährlichkeit der Blindschleiche erhalten. Auch das Lirlebniss, welches der launige WULFF in seiner vor mehr als hundert Jahren erschienenen Ichthyologia cum amphibiis regni borussici von dem, ,jaculus, qui frondosos arborum ramos Theriotrophei Neodomus, vulgo Neuhäuser, pro hospitio suo elegit" zum besten gibt, wiederholt sich noch täglich.

Laurenti ist der erste Naturforscher, welcher das Thier nach seinen Aeusserlichkeiten genau und. richtig beschreibt. Er hebt unter Anderem auch bereits den silberglänzenden Iiand der Bauchschuppen hervor, welcher Silberglanz nach meiner Beobachtung ${ }^{6}$ ) von dem Luftgehalt der Hornschuppen herrührt. Dass cr das junge Thier für eine besondere Art hiclt, erscheint verzeihlich, wenn man sielit, dass er es nur aus einer Sammlung (in Museo Turriano) kannte; zur Aufstellung der Art clivica scheint ilım Gessser, den ich wie bemerkt, leider niclit einselien kann, verholfen zu liaben.

Besondere Verdienste um die Kenntniss der Anguis fragilis erwarb sich Schneider, ${ }^{7}$ ) welcher, indem er bei der anatomischen Untersuchmor die Rudimente eines Schulter- und Iieckengürtels entleclite, aus diesen

1) Landeskunde Oesterreichs unter der Ens, 1832.

2) Annal. d. scienc. phys. et natur. de Lyon, 1864.

9) Viaggio al lago di Garda e al monte Baldo. Verona 1817, pag. 34: „E l'unico che abiti anche sugli alti monti, avendolo più volte rinvenuto alla metì dell' altezza di monte Baldo.*

4) Hist. Serp. et Dracon. 1610 .

s) Operi T. III. in sua morsura e perieulosa.*

9) Organe eines sechsten Sinnes. Nov. Act. acad. Leop. Carol. 1863.

7 Hist. nat. Amphib. Fasc. IJ. 1799.

Leydig, Saurier. 
und anderen anatomischen Erfunden die Verwandtschaft des Thieres mit den Eidechseu, obschon es bis dahin unbedenklich als echte Schlange gegolten hatte, zuerst erkannte. "Cranium lacertino simillimum est" heisst es z. B. bei ihm; es sei ein wirkliches Trommelfell vorhanden, wenn auch bedeclit von Fleisch, ebenso eine Paukenhöhle und Eustachische Röhre. Er weist ferner auf die Columella (Trabecula perpendicularis) hin, was doch Alles eidechsenartig sei, sowie auch die Eingeweide dieselbe Aehnlichkeit aufzeigten. Er kennt ferner die so eigenthümliche Farbe der jungen Thiere: "Color dorsi margaritaceus, laterum et ventris nigricans; medium dorsum linea atra dividebat." Man darf fragen, warum er nicht sofort mit dieser Erfahrung die LaUnexti'sche Anguis lineata beseitigt hat:

WOLF in Nürnberg, welcher fast zu gleicher Zeit den Anguis linealus untersuchte, fügt seiner Beschreibung die Bemerkung bei: "Uebrigens hat sie viel Aehnlichkeit mit der Blindschleiche. Vielleicht lehren künftige genauere Untersuchungen, dass sie eine junge Blindschleiche ist.« Er batte nur zwei im Freien gefundene Exemplare vor sich; eine trächtige Blindschleiche mit reifen Früchten, die iln hätte sofort aufklären können, scheint er selbst nie geöffinet zu haben. Denn was er darüber sagt, ist Anderen entlehnt.

Es gibt eine ziemliche Menge von Originalabbildungen unseres Thieres. Eine der frühesten ist die in MeYeR's zu Nürnberg 1752 herausgekommenem Thierbuch, aber wenig gelungen. Der Kopi ist ganz verfehlt; die Mundspalte viel zu weit und dem Mundwinkel ist eine Falte gegeben, wie sie bei diesem Thier unter keinen Umstäuden sich bildet; die Schuppen des Körpers sind viel zu klein. Am beigezeichneten Skelet sieht man sich vergeblich nach den Knochen des Schulter- und Beckengürtels um.

Die neueste mir bekannt gewordene Figur ${ }^{1}$ ) kömte auf den ersten Blick durch Sauberkeit in der Zeichnung der Einzelnheiten, durch den reiuen lithographischen Druck und den richtigen Farbenton für sich einnehmen. Allein wenn der Verfasser der angezogenen Schrift diese Abbildung der Blindschleiche zu den -Bildern rechnet, welche an Naturtreue alle bekannten, selbst in den kostbarsten naturhistorischen Werken enthaltenen Abbildungen an Naturtreue entschieden übertreffen," so ist es exlaubt auf Etwas, ich will nicht sagen, fehlerhaftes, doch auch nicht lobenswerthes hinzudeuten, das die älteren Abbildungen mit richtigem Tact vermieden haben. Man vergleiche z. B. die Figur in Laurenti's Werk oder bei Sturm, oder die Darstellung bei Thomas BeLL. Während alle diese Autoren die Schlangen vielfach geringelt auftreten lassen, erhailt die Blindschleiche eine einzige Hauptlrümmung, höchstens dass sie in's S-förmige gebogen wird. Schon DAvdin nennt richtig "ses mouvemens presque sans oudulations et assez comparables it ceux des jules". Ebenso hat ЈоH. MüLuER ${ }^{2}$ ) auf den Unterschied in den Bewegungen der Blindschleiche von jener der Schlangen aufmerksam gemacht; letztere kröchen in horizontal wellenförmigen Bewegungen, crstere hingegen könnten sich nur sehr unbeholfen anfrollen und fortschicben. Sehr trefilich und mit genauestem Yerständniss ist hierin die Gruppe bei Tuomas BeLL, eine alte Blindschleiche umgeben vou funf Jungen, gezeichnet. Recht verschieden stellt sich uns nun das Stuttgarter Bild dar: dem Thier sind eine,ganze Reihe kurzer wellenförmiger Biegungen gegeben, die noch mehr herausgehoben werden sollen durch abrvechselndes Licht und Schatten nach den Wellenhöhen und Wellenthälern. Da aber naturhistorische Zeichnungen vorliegender Art sich an das Gewöhnliche oder Regelrechte und nicht an das Zufällige oder selten Eintretende zu halten haben, so hat für den Kenner besagte Abbildung etwas Störendes. Line Schlange mit durchweg weicher Lederhaut bewegt sich eben anders, als die Blindschleiche, deren Lederhaut in so grosser Ausdelmung zu Kalktafeln erstarrt, man darf sagen, gepanzert ist. ${ }^{9}$ )

Die Abbildung bei LENz, ${ }^{4}$ ) welche ihr Dasein, laut Vorrede, auch einem „Maler" rerdankt, weist eine bedenkliche schattige Partie an der Schwanzkrümmung auf, die den Anschein erweckt, als sei das Thier

1) Die Schlangen Deutschlands für landwirthschaftliche, Fortbildungs- u. Abendschulen, Realanstalten, lateinische und Volksschulen, Stuttgart 1862.

") In den Beiträgen zur Anatomie und Naturgeschichte der Amphibien.

3) Bereits oben im Abschnitt über die Lebenserscheinungen, (Seite 167) war hievon die Rede.

4) Schlangenkunde, 1832. 
clort nicht mehr walzenfürmig, soudern seitlich zusammengedrückt. Von dem nicht sonderlichen Colorit ist wenigstens zu rühmen, dass del' Iris das Gelbroth zuertheilt ist, was man häufig unterlassen findet, so z. B. auf der Figur in Bonaparte's Fauna italica. Auch in Sculegel's Amplibien der Niederlande ist nicht vergessen worden, die Farbe der Iris richtig einzutragen.

\section{Bemerkung uiber tossile Scinke.}

Wïlurend auf gegenwärtig deutschem Boden die Familie dei Scinke einzig und allein durch die Anguis fragitis vertreten ist, gab es am Niederrhein, als dort die tertiäre Braunkoble entstand, Formen von Scinken, welche sich denen wärmerer Gegenden des südlichen und südöstlichen Europa anschliessen.

MEYER gedenkt ${ }^{1}$ ) aus der Braunkohle des Siebengebirges der Reste eines schlangenartig geformten Sauriers, welche zu Pseudopus gehören und beschreibt unter dem Namen Lacerta rottensis aus gleichem Orte ein Thier, das unzweifelhaft keine Lacerta, sondern ein Scink mit entwickelten Extremititen war. Denn die wohlerhaltenen Hautknochen um den Schwanz herum lassen keine Einreihung in die Gattung Lacerta zu, welche letztere nur in der Nähe der Kopfschilder, sonst aber nirgends am Körper, mit Hautknochen versehen ist.

Gleichwie es aber scheint, dass, wenn wir uns an die Deutungen LARTET's halten, unsern Species der Gattung Lacerta grössere Formen in der Tertiärzeit vorausgegangen sỉda, so will sich das auch aus den IIttheilungen desselben Forschers ${ }^{2}$ ) bezüglich der Blindschleiche ergeben. Wenigstens fanden sich lieferreste mit Zähnen, die er auf grössere und stärkere Formen der Blindschleiche bezieht und z. B. Anguis aculidentatus nennt.

1) Herman v. Meyen, Palaeontographica, Bd. 7. Zweite Lieferg. 1860.

2) Mir uur bekannt aus Gervars' Zoologie et Palaeontologie francaises. p. 259. 


\section{N a chträge.}

Da das Erscheinen gegenwärtiger Schrift durch die Zeitereiguisse verzögert, die Untersuchung dieses und jenes Organes unterdessen aber fortgesetzt wurde, so nehme ich die Gelegenheit wahr, noch einige ergïnzende und zum Theil berichtigende Bemerkungen hier anzuschliessen.

\section{Die becherförmigen Sinnesorgane.}

a. Zum Vorkommen.

Es wurde oben (S. 108) einer Längsfalte der Schleimhaut gedacht, welche in der Mundhöhle, oben wie unten, die 'Zähne der Kiefer von innen her dergestalt begleitet und bedeckt, dass eine Art "Zahnfleisch" entsteht. Und dieser Vergleich er- . scheint noch mehr gerechtfertigt, wenn wir sehen, dass die Falte linten, am Aufhören der Zahmreihe, ebenfalls im Bogen endet, um in schwächerer Fortsetzung auch von aussen läugs der Zahnreihe herzugehen. Das Ganze erinnert durchaus an die Weise, wie bei einem menschlichen Fötus der änssere und der innere /ahmwall an den Kieferrändern herumzieht.

Eine andere Falte bei Lacerta, weiter nach einwarts am Gaumen, zeigt bereits an Anguis frugitis durch eine Furche, welche wenigstens in der vordern Hälfte sich eintieft, eine Annäherung zur Bildung bei den Schlangen. Denn hier - ich beziehe mich zunächst auf Tropidonotus natrix und Coronella lacvis - erscheinen auch die Gaumenzähne ringsum von einer Falte der Schleimhaut dicht unschlossen; die Zühme stecken wie in einem schmalen, nach der Länge aufgeschlitzten Sack. Und gleichwie bei genamnten Schlangen dieses "Zahnfleisch" schon um die Gimmenzïhne seln" entwickelt sich zeigt, so ist diess in noch fast höherem Grade der Fall mit den Zühnen der Kieferränder. Auch die Zähne der Kinnladen sind in einem Thal geborgen, dessen Waud von rechts und links, nachdem sie am vordern und hintern Ende der Zahmreihen angekommen ist, im Bogen abschliesst und auch auf solche Weise die nåhere Beziehung zu den Zahnveihen ausdrückt.

Die becherförmigen Simnesorgane haben nun ihren sitz eimmal auf diesen dem 
Zahnfleisch vergleichbaren Leisten der Schleimhaut, und bezüglich der şaurier erstrecken sich meine Kemntnisse auf die Gattungen Lacertu, Anguis und Pseudopus. Ueberall stehen hier die Organe dicht, ja gehüuft. Dann liommen sie auch am gleichen Orte vor bei den Schlangen, doch nicht gehäuft, sondern vereinzelt, in Abstinnden stehend; dies ist wenigstens der Fall bei der einheimischen bisher von mir untersuchten Ringehatter (Tr. natrix) und der glatten Natter (Cor. lavvis).

Eine zweite Stelle des Vorkommens unserer Organe ist bei genannten Saurieru die (iaumengegend: bei Lacerta die zäpfchenartige Bildung am Rachengewölbe, hei Anguis die Schleimhant unterhalb der Vomera und endlich bei Pseurlopus ein entsprechender paariger Wulst vor und zwischen den Choanen.

b. Z $n \mathrm{~m} \mathrm{Bau.}$

Meine Erfahrungen über die histologische Zusimmensetzung der becherförmigen simnesorgane haben sich nach zwei Seiten hin erweitert. An den bezeichneten Schlangenarten, welche frisch untersncht werden konnten, liess sich mit Sicherheit erkennen, dass die Faseru des starken, zum Becher herantretenden Nervenbündels, noch innerhalb der bindegewebigen Schicht der Schleimhant, aber genau unterhalb des Bechers, in Körper ausgehen oder enden, welche stattliche Terminalganglienkugeln vorstellen, oder vielleicht wegen gewisser Eigenschaften noch besser Endkolben genannt werden können. Ein Hinübertreten von Nervenfasern über die Kolben hinaus in den Becher findet nicht statt.

An diesen lediglich der epithelialen Schicht zugehörigen Organen unterscheide ich, wie früher, gewöhnliche Epithelial- oder Wandzellen und ferner zu innerst stehende Elemente, welche sich zusammen als besouderer Ballen oder Liegel abheben kömnen. Im Hinblick auf die Natur der letztern Zellen habe ich jetzt die Ueberzeugung gewomnen, dass sie jenen Theilen zu vergleichen sind, welche ich zuerst und ror langer Zeit in den Epitheliallagen verschiedener Wirbelthiere und Wirbellosen hemerkt und unter dem Namen Schleimzellen bekannt gemacht habe. Die oben (S. 101) vou Lacerta erwähnten feinen Spitzen der Zellen gehören, wie ich jetzt weiss, nicht den Wand- sondern den Schleimzellen an. Bei Anguis und Pseudopus sind diese, einzelligen Drüsen entsprechenden Ciebilde so entwickelt, dass die Becher, indem auch noch andere Eigenthümlichkeiten hinzukommen, nicht wenig an gewisse Drüsenformen erinnern und bei geringer Vergrösserung anch wohl für solche genommen werden künnen, wie ich denn in der That selber in diesen Fehler gefallen bin; dem die oben erwähnte Gammendrüse ist eine malssige Anhäufung rorgedachter simne-organe. Diss alle diese hier nur angedenteten Thatsiachen zur Be- 
kräftigung meiner früher (Nov. Act. Ac. Leop. Carol. Vol. XXXIV) ausgesprochenen Ansichten dienen kömnen, wird schon jetzt dem der Sache Kiundigen nicht entgehen.

\section{Zu den Jacobson'schen Organen.}

Anch die 0 phidier besitzen diese merkwürdigen Bildungen, wovon ich mich einstweilen an Tropidonotus natrix und Coronella laevis überzeugt habe.

Der Bau ist im Wesentlichen der gleiche wie bei den Sauriern: man sieht zwei Höhlen unterhalb des Nasenraumes und abgeschlossen von ihm; die knöcherne Umgebung liefern jederseits die sog. Concha und der Vomer, doch so, dass dem letztern der Hauptantheil zukommt. In jede der Höhlen springt ein knorpeliger Querwulst papillenartig vor. Die Mündung liegt am Gaumen, weit nach vorn. Der Geruchsnerv theilt sich wach seinem Abgang vom Gehirn in zwei Hauptbündel, wovon der eine zur Nase, der andere zum Jacobson'schen Orgau geht; die Entfaltung des letztern geschieht vom Dach der Höhle nach einwärts, ler Knorpelwulst trägt keine Nervenendigung. Das gerölbte Dach der Höhle erscheint von einer dicken, fürs freie Ange weissgranen Lage ansgekleidet, welche aus einem radiär stehenden System feiner und feinster Fäserchen, mit zahlreichen kleinen Zellen zwischen den Lücken, besteht und zu innerst mit dem Cylinderepithel aufhört.

Oben (S. 98) wurde diese Lage bei Lacerta einfach ein massiges Epithel genannt, dessen lange Zellen starre Härchen tragen. Auf Fig. 111 der achten Tafel ist jedoch die sonderung dieser Lage in das eigentliche (ylinderepithel und in die dickere aus kleinen Zellen und feinen Fäserchen zusammengesetzte Schicht ausgedrückt. Doch vermag ich auch jetzt noch nicht darüber ins Klare zu kommen, ob die unter den cylindrischen Grenzzellen sich hinziehende Lage - und sie ist die dickste Partie - in der That zum Epithel zu rechnen sei, oder ob man es nicht vielmehr mit einer eigenthümlichen Umbildung des bindegewebigen Theils der die Höhle anskleidenden Haut zu thun habe. Immerhin scheint mir das Meiste für die letztere Ansicht zu sprechen. Dann stellen sich aber die Fragen ein: Sind die Fäserchen blos bindegewebiger Natur oder verlanfen mit ihnen die Endtibrillen des Nervus olfactorius? Was bedeuten die Zellen zwischen den Fisserehen? Sind sie von nervöser Beschaffenheit?

Ich werde über alle diese hier zusatzweise und nur flüchtig berührten Puncte bald an einem andern Orte Ausführlicheres und cienaneres vorzulegen mir erlauben. 


\section{Erklärung der Abbildungen.}

Alle Figuren sind theils mit der Lupe, theils mit dem Mikroskop schwächer oder stärker vergrössert.

\section{Erste Tafel.}

Fig. 1. Kopf von Lacerta vivipara.

Fg. 2. Kopf von Lacerta muralis.

F. 3. Kopf ron Lacerta viridis.

Fg. 4. Kopf von Lacerta agilis.

Fg. 5. Seitentheil des Kopfes von einem anderen Individuum mit grösserem Schläfenschild.

Fg. 6. Schuppen der Seite und Schilder des Bauches ron Lacerta vivipara.

Fg. 7. Schuppen der Seite und Schilder des Bauches von Lacerta muralis.

Fu. \&. Schuppen der Seite und Schilder des Bauches von Lacerta vividis.

Fg. !. Schuppen der Seite und Schilder des Bauches ron Lacerta agilis.

Fg. 10. Krallen von Lacerta vivipara, a. Vorderfuss, b. Hinterfuss.

Fg. 11. Krallen von Lacerta muralis, a. Vorderfuss, b. Hinterfuss.

Fg. 12. Krallen von Lacerta viridis (mittelgrosses tyrolisches Exemplar), a. Vorderfuss (Mittelzehe), b. Hinterfuss (lïngste Zehe).

Fg. 13. Untere Seite einer Kralle derselben Art (kleinste Vorderzehe vou einem grösseren Dalmatinischen Thier).

Fg. 14 arallen von Lacerta agilis, a. Vorderfuss, b. Hinterfuss.

Fg. 14‥ Kopf ron Anguis fragilis.

Fg. 15. Schädel von Lacerta vivipara von oben.

F.g. 16. Derselbe von unten.

Fug. 17. Schädel ron Lacerta agitis von unten.

Fg. 18. Derselbe von oben, in leichter Wendung.

Fg. 1!. Schädel ron Lacerta viridis von unten; die farbigen Stellen sind Reste des PrimordialCraniums.

Fy. 20. Derselbe ron der Seite, im Umriss, um die Ausdehnung des bleibenden Primordialcraniums zu zeigen.

\section{Zweite Tafel.}

Fig. 21. Schädel von Lacerta muralis von oben.

F'g. 22. Derselbe von unten.

Fg. 23. Schaidel von Lacerta viridis von der Seite. 
Fg. 21. Schädel der Lacerta agilis von der Seite, um den Unterschied der Schläfengegend von der vorhergehenden Art hervortreten zu lassen.

Fg. 25. Hinterhauptsgegend eines Embryo von Anguis fragilis, bei durchgehendem Licht. a. Prooticum, b. Opiathoticum, e. Epioticum, d. Kalksäckehen, e. Atlas, f. Epistropheus.

Fg. 26. Hinterer Theil des Schädels und Anfang der Wirbelsäule vom Embryo der Anguis fragilis. a. Colunella, b. hinteres Horu des Zungenbeins, c. Clavicula.

Fg. 27. Schädel von Anguis fragitis von unten, in leichter Wendung. Das Farbige bezieht sich auf das Primordialcranium.

Fg. 28. Primordialcranium des Embryo von Anguis fragilis, von oben, a. Occipitalia lateralia, ק. Occipitale basilare und sphenoidale basilare, a. Zwischenkiefer, b. Abschnitt der Nase, c. Auge, d. Durchtrittsstelle für den Sehnerven, e. Ohrcapsel, f. Rückensaite, g. Frontale, h. Parietale, i. Temporale und Quadrato-jugale.

Fg. 29. Primordialcranium eines Embryo von Anguis fragilis, von unten. a. Intermaxillare, b. Vomer, c. Palatinum, d. Pterygoideum, e. Supramaxillare, f. Chorda dorsalis, c. Occipitale laterale, $\beta$. Occipitale basilare und Sphenoideum basilare, $\gamma$. Durchtrittsstelle fuir den Sehnerven, $\delta$. Ohrcapsel, $\varepsilon$. Columella.

Fg. 30. Grundtheil des Schüdels von Lacerta muralis, von oben und vorne. Erwachsenes Thiel. a. Occipitale, b. dessen Querbalken, c. vorderer Keilbeinkörper, d. grosse Flügel des hinteren Kieilbeins, e. Flügelfortsätze.

Fg. 31. Grundtheil des Schädels von Anguis fragitis von oben und hinten; erwachsenes Thier. a. Unpaarer Vorsprung am Hinterhauptsbein zur Verbindung mit Knorpel, b. ebensolche paarige Vorsprünge am Felsenbein, c. hinterer Keilbeinkörper, d. oberer flügelartiger Theil, e. untere Flügelfortsätze, f. vorderer Keilbeinkörper, g. Gelenktheil für das Quadratbein.

Fg. 32. Hinteres Stück des Schädels von Anguis fragilis, a. Gelenkkopf des Hinterhauptbeins, b. Vorsprung auf dem der Knorpelstreif c. sitzt, d. Lücke im Schädel, e. Theil des Scheitelbeines, f. Loch im Scheitelbein, als Rest der grossen Fontanelle, g. Ḱnochenkruste des Scheitelbeius.

\section{Dritte Tafel.}

Fg. 33. Grundtheil des Schädels von der Seite der Lacerta agilis; erwachsenes 'Thier. a. Gelenkkopf des Occipitale, b. Querbalken des Occipitale, c. medianer Hőcker der Hinterhauptschuppe, d. daraufsitzendes Knorpelstïck, e. hinteres Keilbein, f. grosse Flïgel, g. Flügelfortsïtze, h. Felsenbein, i. dessen schuppenartiger Vorsprung.

Fg. 34. Scheitelbein von Anguis fragilis, von innen, a. eigentliche Platte mit den rundlichen Grübchen b., dem Rest der frïheren Oeffnung, c. Vertiefung zur Aufnahme eines Knorpelstïcks, d. herabsteigende Schenkel.

For. 35. Scheitelbein von Lacerta muralis vou innen, a. Oeffuung in der eigentlichen Platte, b. Schenkel, c. Knoryelstab.

F.g. 36. Hinterer Theil des Schädels von einem Embryo der Anguis fragilis, von der Seite, a. Occipitale basilare, b. Lateralia, c. Prooticum, d. Opisthoticum, e. Epioticum, schou verwachsen mit der Schuppe des Hinterhauptbeins.

Fg. 37. Dieselbe Partie von nuten. a. Occipitale basilare, b. Sphenoideum basilare, c. hüutiger Verschluss des Śchäidels. 
Fg. 38. Hinterer Theil des Schädels eines Embryo vou Anguis fragilis, von oben. a. Occipitale basilare, b. Lateralia, c. Höcker für die Kalksäckchen, d. Parietale, e. noch häutiges Sichädeldach, später Sicheitelbein, f. Fontanelle. g. h. die beiden Stïcke des Frontale posterius.

Fg. 39. Oberkiefer a., 'Thrïnenbein b., Jochbein c, von Lacerta agilis.

Fg. 40. Pterygoideum a., und Transversum b., von Lacerta agilis, c. Zähne.

F.g. 41. Vomer a. und Palatinum b. von Lacerta agilis, von unten.

Fg. 42. Intermaxillare ron Anguis fragilis, von einwärts, a. Processus frontalis, b. Processus maxillaris, c. Processus palatinus.

Fg. 43. Intermaxillare von Lacerta agitis, von einwärts. a. b. c. wie vorher.

Fg. 44. Intermaxillare a. und Nasalia b. von Lacerta agilis, von aussen.

Fg. 45. Frontalia von Anguis fragilis, von innen. a. uach unten absteigendes Blatt.

Fg. 46. Schnitt durch die Stirngegend von Anguis fragilis, a. Lobi olfactorii, b. Absteigendes Blatt des Stirubeins, e. Knorpelleisten, d. Knorpelseptum, e. Schleimhant der Nasenhöhle.

\section{Vierte Tafel.}

Fg. 47. Zur Schläfengegend von Lacerta agilis, a. hinterer Schenkel des Scheitelbeins, b. Tympanicum, c. Temporale, d. Quadrato-jugale, e. Jugale.

Fy. 18. Zur Schläfengegend von Anguis fragilis, a. Tympanicum, b. Temporale, c. Quadratojugale, d. Stück des Frontale posterius.

Fg. 49. Erster Halswirbel (Atlas) von Lacerta agilis, a. oberer Bogen, b. unterer Dorn (unterer Bogen).

Fig. 50. Zweiter Halswirbel (Epistropheus) von Lacerta muralis, voul der Seite, a. Zahnfortsatz, b. unterer Dorn, c. Querfortsatz, d. Gelenkfortsatz, e.*oberer Dorn.

Frg. 51. Fünfter Halswirbel der Lacerta muralis, von oben, a. vorderer, b. hinterer Gelenkfortsatz, c. gegabelter Dorn.

Fg. 52. Achter Halswirbel des gleichen Thieres von der Seite.

Fg. 53. Halswirbel der Lacerta agilis von unten, a. untere Bogen, b. Halsrippen.

Fgr. 54. Letzter Lendenwirbel a., die zwei Heiligbeinwirbel b., erster Schwanzwirbel c. der Lacerta muralis, von unten.

Fr. 5j. Schwanzwirbel und Knorpelskelet des wiedererzeugten Schwanzes von Lacerta agilis. a. vordere, b. hintere Hälfte des Wirbels, c. oberer Dorn, d. Querfortsatz, e. secundärer oberer Dorn, f. untere Bogen, g. Knorpelstück.

Fg. 56. Zweiter Halswirbel (Epistropheus) von Anguis fragilis, vou der Seite. a. Zahnfortsatz, b. untere Dornen.

Fr. 5. Dritter und vierter Halswirbel desselben Thieres, von unten, a. untere Dornen, b. Querfortsatz, c. schiefer Fortsatz.

Fig. io. Brustwirbel desselben 'Thieres, vou der Seite, i. Gelenkkopf, b. Gelenkhöhle, c. Querfortsat\%, d. schiefer Fortsat\%.

F'g. 5!. Erster Schwanzwirbel desselben Thieres, von oben, a. gegabelter Querfortsatz, b. Gelenkfortsätze, c. untere Bogen.

k'g. 60. Wirbel aus der Mitte des Schwanzes des gleichen 'Thieres, a. vorderes Stïck, b. hinteres Stiick des Wirbelkörpers, c. Querfortsatz, d. untere Bogen.

Fg. 61. Ende der Wirbelsïnle desselben 'Thieres, a. untere Bogen. 


\section{Fünfte Tafel.}

Fg. 62. Beckeu von Anguis fragilis in seiner Lage, a. Beckenknochen, b. Harnblase, c. Mastdarm, d. Kloake, e. Muskel (Ischio-coccygeus).

Fg. 63. Mützenförmiger Kuochen der Schwanzspitze von Anguis fragilis.

Fg. 64. Hinterfuss eines Embryo von Lacerta agilis, an einen Flossenfuss erinnernd.

Fg. 65. Brustgegend von Anguis fragilis, um Brustbein und Schultergürtel in ihrer Lage zu zeigen. a. Sternum, b. Episternum, c. Seapula, d. Coracoideum, e. Procoracoideum, f. Clavicula.

Fg. 66. Becken der Lacerta muralis von oben. a. Os ilei, b. Os ileo-pectineum, c. Knorpel in der Symphyse, d. Os pubis, e. Os ischii, f. Foramen obturatorium, g. Knorpel in der Symphyse, h. Os cloacale, i. Foramen cordiforme.

Fg. 67. Becken von Anguis fragilis, rechte Hälfte, von aussen, altes Thier, a. Darmbein, b. Schambein, c. Sitzbein, d. Knorpelstück.

Fg. 68. Becken von Anguis fragitis, linke Hälfte, von einem reifen Embryo. Was daran dunkel erscheint, ist verkalkt. Die helleren Stellen sind reiner Knorpel.

$\left.\begin{array}{ll}\text { Fg. 69. Erster Beckenwirbel } \\ \text { Fg. 70. Zweiter Beckenwirbel }\end{array}\right\}$ von Anguis fragilis.

$\left.\begin{array}{ll}\text { Fg. 71. Oberes Ende } \\ \text { Fg. 72. Unteres Eide }\end{array}\right\}$ des Oberarmknochens von Lacerta agilis.

Fg. 73. Vorderarmkuochen, Radius r. und Ulna u. desselben Thieres.

Fig. T4. Tibia to und Fibula fo oberes Ende, rom gleichen Thier.

Fg. 75. Oberes Ende einer Rippe von Lacerta agilis.

Fg. 76. Oberes Ende einer Rippe von Anguis fragilis.

Fg. Ti. Ossificationen im Kniegelenk von Lacerta agilis.

\section{Sechste Tafel.}

Fg. $7 \&$. Brustbein und Schulter von Lacerta vivipara, a. Sternum, b. Episternum, c. Clavicula, d. Suprascapulare, e. Scapula, f. Coracoideum, g. Procoracoideum (beide zusammen Pars coracoidea).

Fg. 79. Brustbein und Schulter von Anguis fragilis. a. eigentliches Brustbein, b. Episternum, c. Schulterblatt, d. Coracoid, e. Procoracoid, f. Clavicula.

Fg. 80. Episteruum des Embryo von Anguis tragitis. a. bindegewebige Grundlage, b. die darin aufgetretenen Knochenstücke.

F.g. 81. Unterkieferstück von Lacerta vivipara.

Fg. 82. Unterkieferstück von Anguis fragilis, junges 'Thier.

Fg. 8:. Zïhne des Unterkiefers von Lacerta agilis.

Fg. 84. Zahn von Anguis fragilis.

Fg. 4.5. Senkrechter. Schnitt durch einen Schwanzwirbel von Anguis fragilis, um das den Wirbel umgebende Fettlager a. zu zeigen. Die Blutgefisse inverhalb der untern Dornen sind von einem Lymphraum umgeben.

Fin. 86. Lage und Grössenverhältnisse des Beckens zu den Rippen bei dem Embryo von Lacerta agilis, uach Aufquellung der Weichtheile, a. Becken. 


\section{Siebente Tafel.}

Fg. 87. Schnitt durch die Haut von Lacerta ocellata, a. Epidermis, b. Lederhat, c. Lymphdriisenmasse, d. Muskeln des Stammes.

Fg. 88. Ein Theil des vorangehenden Hautdurchschnittes stïrker vergrössert, a. Epidermis, b. Pigmentschicht der Lederhaut, c. eigentliche Lederhaut, d. Lỳmphdrüsenmasse.

Fg. 89. Schenkeldriisen von Lacerta agilis mit hervorstehendem Secret.

F'g. 90. Zwei Oeffnungen der Schenkeldrüsen mit nicht hervorstehendem Secret.

Fg. 91. Läppchen einer Schenkeldrüse nach seiner histologischen Zusammensetzung.

Fg. 92. Theil des vorstehenden Secretes (Crista) und seine zellige Beschaffenheit.

Fg. 93. Querschnitt durch die Unterkinnlade sammt Weichtheilen von Lacerta muralis, a. Knochen des Unterkiefers, b. Meckel'scher Knorpel, c. Zahm, d. Unterlippendriise, e. Unterzungendrüse, f. fester bindegervebiger strang.

Fg. 94. Rand der Schnauzenspitze, von innen, Embryo von Lacerta vivipara. a. Gewöhnliche Zähne des Zwischenkiefers, b. Eizahn.

Fg. 95. Schnauze von aussen eines Embryo von Anguis fragilis, a. Eizahn.

Fg. 96. Vorderer Theil des Bodens der Mundhöhle von Lacerta agilis, a. Zunge, vorderer Theil abgeschnitten, b. Unterzungendrüse. Man sieht auch die Leisten des "Zahnfleisches«.

Pg. 97a. Hautnerven und ihre Vertheilung von Lacerta agitis, A. das gröbere Endnetz, a. Büschel, welche weiter in die Höhe streben, B. Ein Theil des Netzes bei stärkerer Vergrösserung, a. ein nach oben gehender Büschel, b. eine einzelne Faser desselben, welche sich mit Pigmentzellen (Chromatophoren) verbindet.

Fg. 97․ Schnitt durch die Haut von Lacerta agilis. Geringe Vergr. Ist olyne Kalkschuppen.

Fg. 97․ Schnitt durch die Haut von Anguis fragilis. Geringe Vergr. Besitzt Kalkschuppen.

Fg. $97^{d}$. Eine der kleineren Kalk-Schuppen desselben Thieres, bei auffallendem Licht, um die Sculptur der Oberfläche zu zeigen.

\section{Achte Tafel.}

Fg. 98. Vom Zwölffingerdarm mit anliegenden und einmündenden Theilen von Anguis fragilis, a. Klappe am Anfang des Duodenum, b. Bauchspeicheldriise, c. Milz, d. Gallengangnetze.

Fg. 99. '/wölffingerdarm mit anliegenden 'Theilen von Lacerta agilis, b. Milz, c. Pancreas, d. Gallenblase; nebenan a. die Papille in dem geöffneten Duodenum.

Fg. 100. Zunge und Zungenbein von Lacerta agilis.

Fg. 101. Zunge und Zungenbein von Anguis fragitis.

Fg. 102. Rachengewölbe von Lacerta agilis. Man sieht die Choanen a., die Oeffunng der Jacobson'schen Organe b., den zäpfchenartigen Vorsprung, die Leisten des „'Lahnfleisches«.

Fg. 103. Zahn in seiner Entwicklung, vom Zwischenkiefer der Lacerta viridis, a. Epithel, b. das Zahmbein, e. bindegewebige Schicht.

Fg. 104. Senkrechter Schuitt durch die Zunge von Lacerta agilis.

Fg. 105. Einzelne Zungeupapille von der Seite und im optischen Längsschnitt ebendaher, a. Hornschicht, b. Schleimschicht, c. Blutgefïss, d. Muskeln.

Fg. 106. Mehrere Zungeupapillen von der Hiiche, im optischen Querschnitt, ebendaher. c., d. wie vorhin. 
Fg. 107. Haru- und Generationsorgane eines Embryo von Lacerta vivipara, a. Nieren, b. Wolffscher Körper, c. Eierstock.

Fg. 108. Seukrechter Längsschnitt der Schnauze von Lacerta viridis. a.. Nasenvorhöhle, b. eigentliche Nasenhöhle, c. Choane, d. Muschel, e. Jacobson'sches Organ.

Fg. 10\%. Senkrechter Längsschnitt durch die Schnanze von Anguis fragilis, a. Nasenvorhöhle, b. eigentliche Nasenhöhle, c. Muschel, d. Jacobson'sches Organ.

Fg. 110. Jacobson'sches Organ der Lacerta agilis, von obeu geöffnet, a. Gang zur Rachenhöhle, b. bindegewebige, pigmentirte Haut mit den durchschnittenen Nervenbündeln, c. Epithel.

Fg. 111. Schnitt durch das Jacobson'sche Organ von Lacerta viridis und sein histologischer Bau, a. Bündel des Riechnerven, b. Knorpel, c. Epithel mit starren Härchen, d. Wimperepithel, e. Knorpel des Wulstes (mit Pigment).

\section{Neunte Tafel.}

Fg. 1121. Eierstock von Anguis fragilis, a. eigentliches Ovarium, b. Parovarium, c. Epoophoron.

Fg. 1122. Reste des Wolff'schen Körpers etwas mehr vergrössert. Bezeichuung wie vorher.

Fg. 113. Oberes Ende des Eileiters von demselben Thier.

Fg. 114. Hinterer Abschnitt der weiblichen Generationsorgane eines trächtigen Thieres (A. fragilis), a. Harnblase, b. Mastdarm, c. Uterus, d. Embryo.

Fg. 115. Bildungsweise der faserigen Eischale von Anguis fragilis, a. Epithel des Uterus, b. homogene Cuticula, c. die auf letzterer als Verdickungen entstehenden Fasern.

Fg. 116. Freier Rand der Trompete von Lacerta vivipara.

Fo. 117. Innenfläche der Schleimbaut des Uterus von Lacerta vivipara, a. rosettenartige Erhebungen, b. Drüsen.

Fg. 118. Männlicher Harn- und Generationsapparat von Anguis fragilis, a. Niere, b. Harnblase, c. Mastdarm, d. Kloake, e. Penis, f. Hode, g. Nebenhode, h. Samenleiter, i. Paradidymis, k. Müller'scher Gang.

Fg. 119. Männlicher Embryo von Anguis fragilis um die beiden Ruthen in ihrer Anlage zu zeigen.

Fg. 120. Drüse des Penis vom erwachsenen Thier (Anguis fragitis).

Fg. 121. Knorpel des Kehlkopfes und des Anfangs der Luftröhre von Lacerta vivipara, junges Thier, a. Cartilago thyreoidea, b. Cartilago cricoidea (beide zusammen Cartilago laryngea), c. Cartilago arytenoidea.

Fg. 122. Kehlkopf mit seinen Muskeln, ebendaher, a. äusserer oder Längenmuskel, b. Quermuskel.

Fg. 123. Harnmasse von Pseudopus Pallasii; veranschaulicht die Aehnlichkeit mit den Koprolithen der Saurier.

\section{Zehnte Tafel.}

lig. 124. Harn- und Geschlechtsapparat des Mïmnchen von Lacerta agilis. Ḱloake geöffnet, die Prostatahälften etwas auseinander gezerrt. a. Niere, b. Harnblase, c. Kloake, d. Hoden, e. Paradidymis, f. Epididymis, g. Müller'scher Gang, h. Ruthe.

Fg. 125. Die beiden Ruthen in hervorgestülpten Zustande ron Lacerta agilis.

Fg. 126. Dieselben Organe von dem gleichen 'Thier mehr vergrössert und in anderer Ansicht. 
Fg. 127 ‥ Eingestülpter Penis im Querdurchschnitt, da wo er am dicksten ist, von Lacerta vivipara, a. Schwellkörper, b. Epithel, c. Muskeln, d. Nerv.

Fg. 1272. Epithel des Penis von Lacerta vivipara.

Fg. 1281. Stück des Schwellkörpers im Querschnitt und stärker rergrössert, von dem gleicheń 'Thier, a. Bluträume, b. Blutgefüsse, c. festere Balken des Bindegewebes.

Fg. 1282. Vom Nebenhoden im Längsschnitt, Lacerta agilis.

Fg. 1283. Zoospermien von Lacerta agilis.

Fg: 1284. Zoospermien von Anguis fragilis.

Fg. 129. Weiblicher Gesehlechtsapparat von Lacertı agilis, nach dem Eierlegen, a. Niere, b. Harnblase, c. Mastdarm, d. Eierstock, e. Parovarium, f. Nebeneierstock, g. Trichter, h. Eileiter, i. Uterus, k. Kloake.

Fg. 130. Kloake und Ende des trächtigen Uterus von Lacerta vivipara.

Fg. 131. Zur Entwicklung des Eierstockes a., und Umgebung des Wolft'schen Körpers b., aus dem neugeborenen Jungen von Lacerta vivipara.

\section{Elfte Tafel.}

Fg. 132. Weibliche Generationsorgane von Lacerta agilis in ersten Jahn (L. argus), a. Eierstock, b. Eileiter, c. Parovarium, d. Wolff'scher Körper, e. Niere.

Fg. 1331. Eierstock des ganz jungen Thieres von $L_{\text {. }}$ agilis, a. die zwei Zelleuwïlste, welche das eigentliche Keimlager bilden, b. Verdickung des Bauchfells, mit Lymphräumen.

Ig. 1332. Vom fertigen Eierstock der Lacerta ayilis, a. Rand eines Eifollikels, h. Lymphrïume.

Fg. 134. Angapfel von Lacerta viridis.

F'g. 1351 u. 135‥ Knochen des Skleroticalringes isolirt.

Fg. 136. Schnitt dureh den Augapfel von Lacerta agitis.

Fg. 137. Schnitt durch den Augapfel vou Anguis fragilis, um die Grössenverhältnisse des Kammes zwischen Eidechse und Blindschleiche zu zeigen.

Fg. 138. Kamm des Auges von Anguis fragilis für sich.

Fg. 139. Nickhaut von Lac. ayilis, a. a. zwei halbmondförmige Leisten, b. Knorpelstreifen. c. Drüse.

Fg. 140. Zum Muskelapparat der Nickhaut, a. lange Sehme, b. Muskel, am freien Rande einen Canal bildend, durch welchen die Sehne geht.

Fg. 141. Nasenhöhle von oben geöffnet, vou Lacerta viridis (grosses Exemplar von Dalmatien), auf der einen Seite ist die Muschel entfernt. a. Vorhöhle, b. in diese einmündender Drüsengang, c. innere oder eigentliche Nasenhöhle, d. Choane, e. Muschel, f. Nasendrüse.

Fg. 142. Skelet der Vorhöhle vom gleichen Thier. a. Zwischenkiefer, b. Oberhiefer, c. sog. Concha.

Fg. 143. Senkrechter Querschnitt durch die Schnauze von Lacerta agilis. Die blanen Partien bezeichnen den Nasenknorpel, die gelblichen die umliegenden Kínochen. a. Nasenvorhöhle, b. Jacobson'sches Organ, c. Lymphgang.

F'g. 144. Quersehnitt durch die eigentliche Nasenhöhle von Anguis fragilis. a. Drüse aussen an der Nasencapsel, b. Driise an der inmeren Fläche der Muschel, c. Driisen in der Schleimhaut des Gaumens. 


\section{Zwölfte Tafel.}

Fg. 145. Schnitt durch das untere Lid von Lacerta viridis, a. Epidermis, b. Lederhaut, c. glatte Musculatur, d. Lymphräume, e. Knorpel, f. Epithel.

Fg. 146a. Querschnitt durch den Kopf von Lacerta agilis in der Ohrgegend, a. Schädelraum, b. Höhle für das Ohrlabyrinth, c. Paukenhöhle, d. Rachenhöhle.

Fg. 146. Knochenring vom Auge der Anguis fragilis.

Fg. 147. Kopf desselben Thieres in der Ohrgegend nach der Länge gespalten.

Fg. 148. Ohrlabyrinth eines Embryo von Anguis fragilis, a. Vorhof, b. Bogengänge, c. Anhang des Vorhofs.

Fg. $149^{\text {a }}$ Gehörknöchelchen vou Lacerta ayitis. a. Operculum, b. Columella, c. erstes Knorpelstück, d. zweites Knorpelstïck des Hammers.

Fg. 149 b. Schnitt durch die Paukenhöhle von Lacerta agitis. a. Trommelfell, b. die Trommelhöhle auskleidende Schleimhaut, c. der Hörknochen im Durchschnitt und von der Schleimhaut umzogen, wie ausserhalb der Paukenhöhle liegend.

Fg. 150. Gehörknöchelchen von Anquis fragilis. Bezeichnung wie in vorhergehender Figur.

F'g. 151. Becherförmige Simnesorgane aus der Rachenhöhle der Lacerta agilis.

Fg. 152. Gehirn der Lacerta agilis von oben.

Fig. 153. Gehirn der Anguis fragilis von oben.

Fg. 154. Gehirn der Lacerta agilis, theilweise anseinandergelegt.

Fg. 155. Gehirn desselben Thieres im Längsschnitt.

Fg. 156. Qnersehnitt, a. durch das Mittelhirn, b. durch das Vorderhirn.

Fy. 157. Gehirn der Anguis fragilis von der Seite.

Fg. 15i. Schädel desselben Thieres nach der Länge gespalten.

Fog. 159. Sehnitt durch das Stirnorgan und die Schädeldecke der erwachsenen Lacerta agilis, a. Epidermis, b. Scheitelbein, c. Stirnorgan, d. pigmentirte harte Hirnhaut, e. Gefässhaut, f. Zirbel.

Fg. 160. Noch unreifer Embryo von Lacerta vivipara mit dem Stirnorgan a.

Fg. 161. Embryo von Anguis fragilis mit dem Stirnorgan.

Fg. 16:. Schädeloberfläche eines reifen Embryo von Anguis tragilis. Vergl. den 'T'ext.

Fg. 163. Stimorgan desselben Embryo für sich und stark vergrössert, a. der »schwarze Punkt« der vorigen Figur, b. der »schwarze Strich «, c. der »Hügel (Knorpelsubstanz), d. die Zirhel.

\section{Verbesserumgen.}

Seite 21 anstatt Rückenseite lies Rückensaite.

14 》Vomera "Ossa vomeris.

101 /eile 4 v. $\mathrm{u}$. ist sschon $\approx \mathrm{zn}$ streichen. 



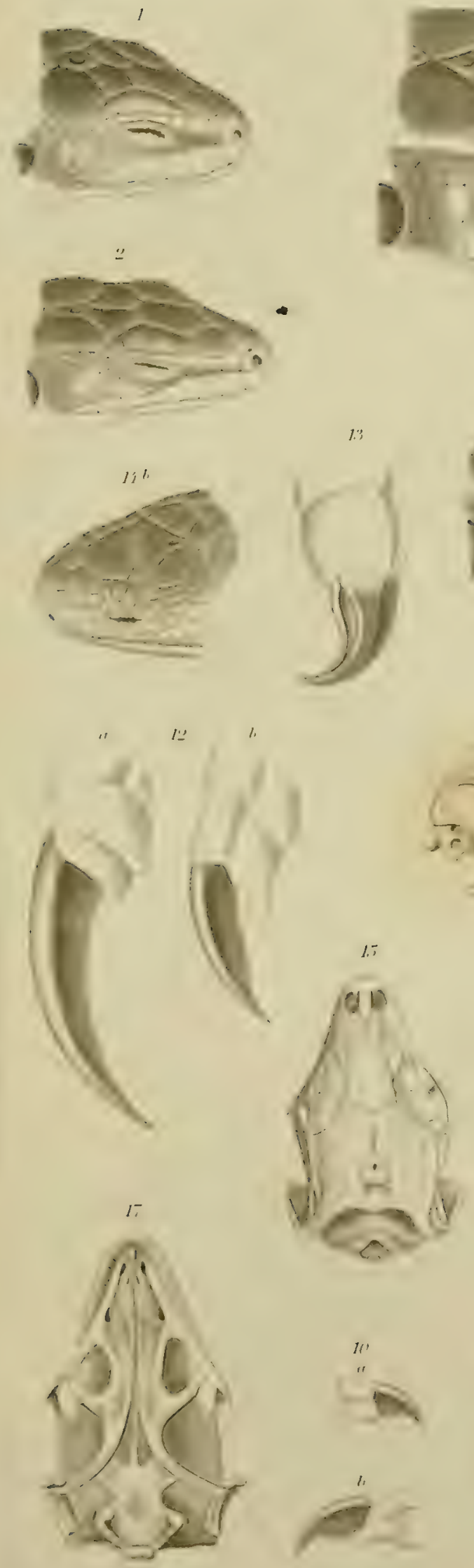
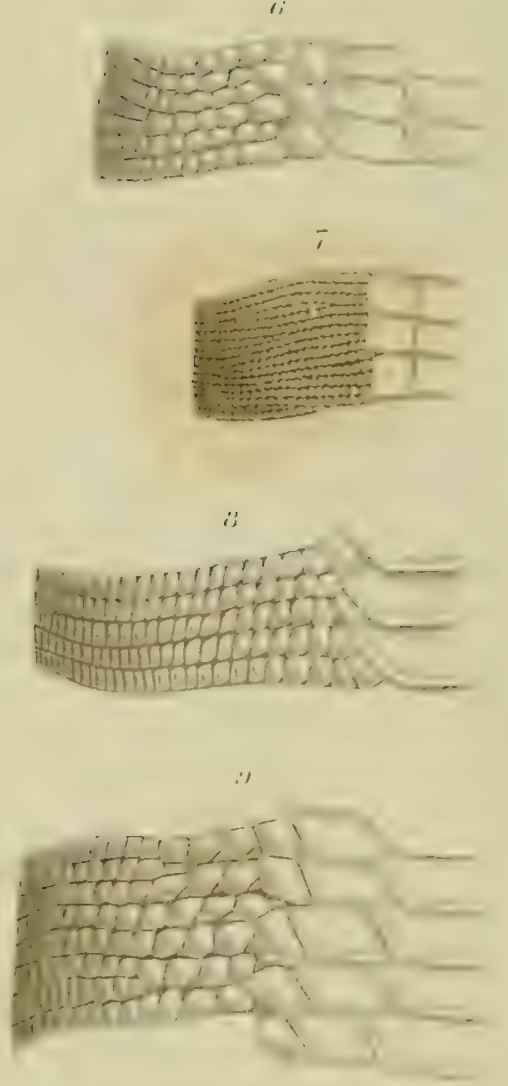

2"1
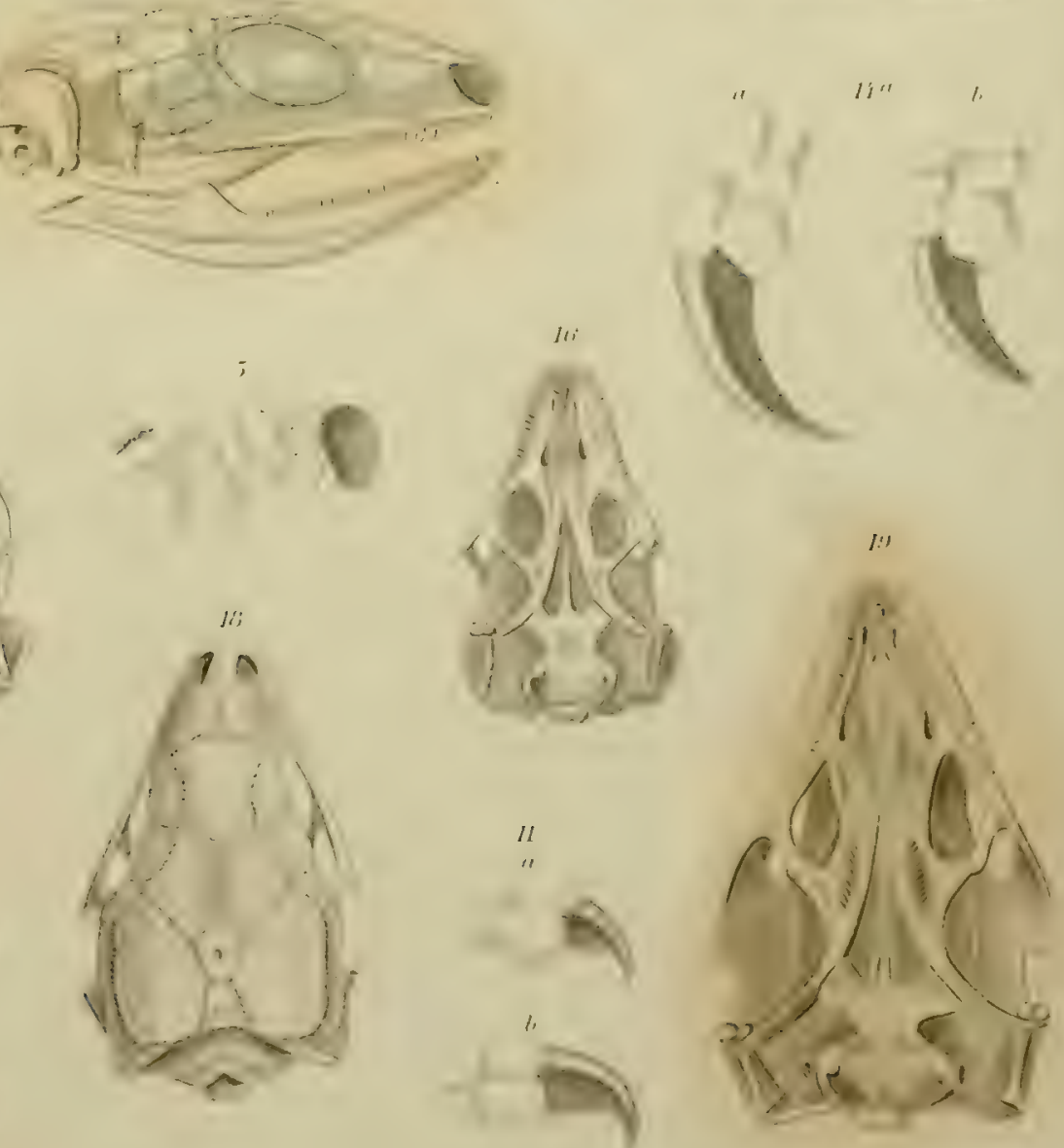



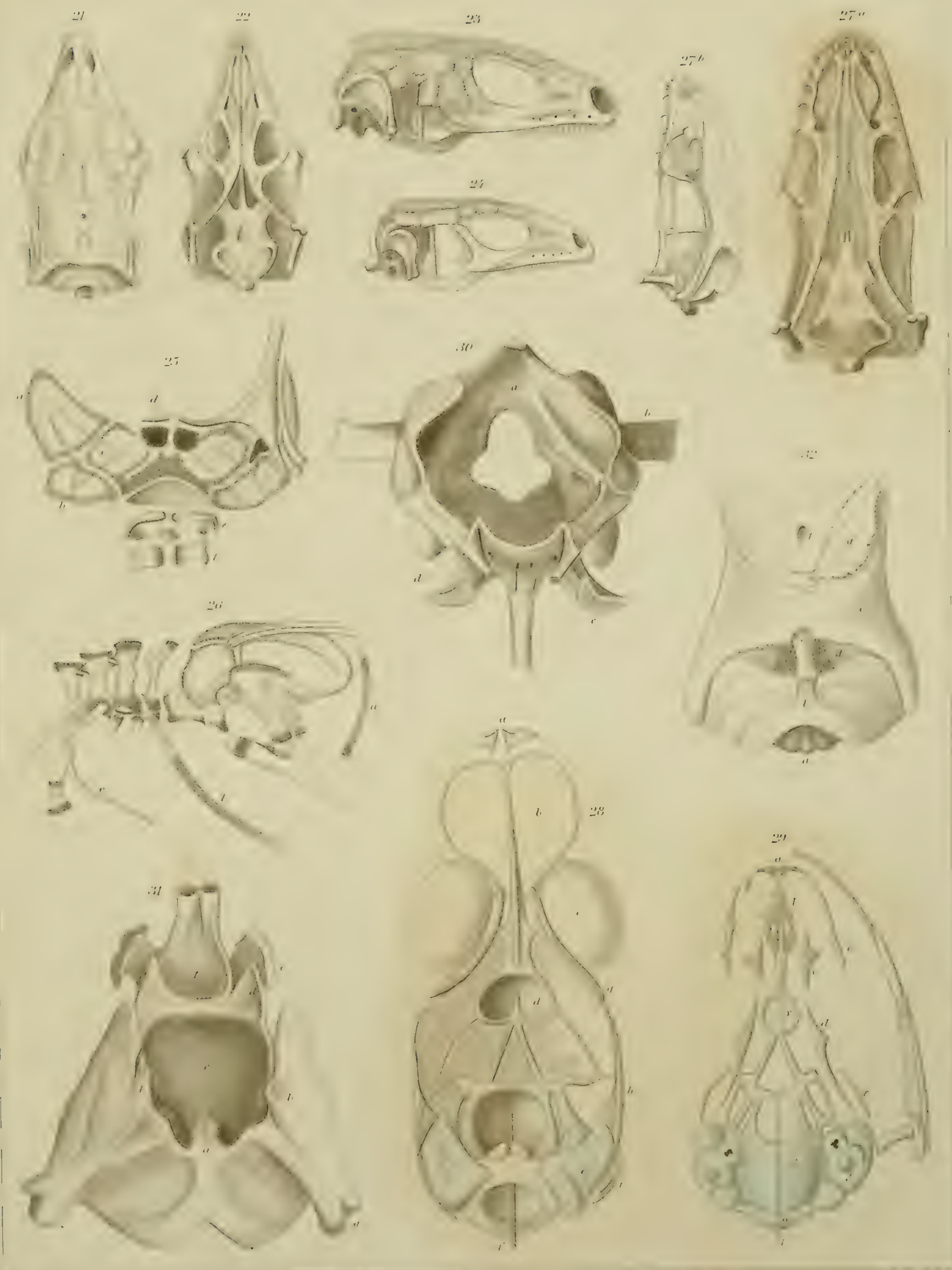


. 


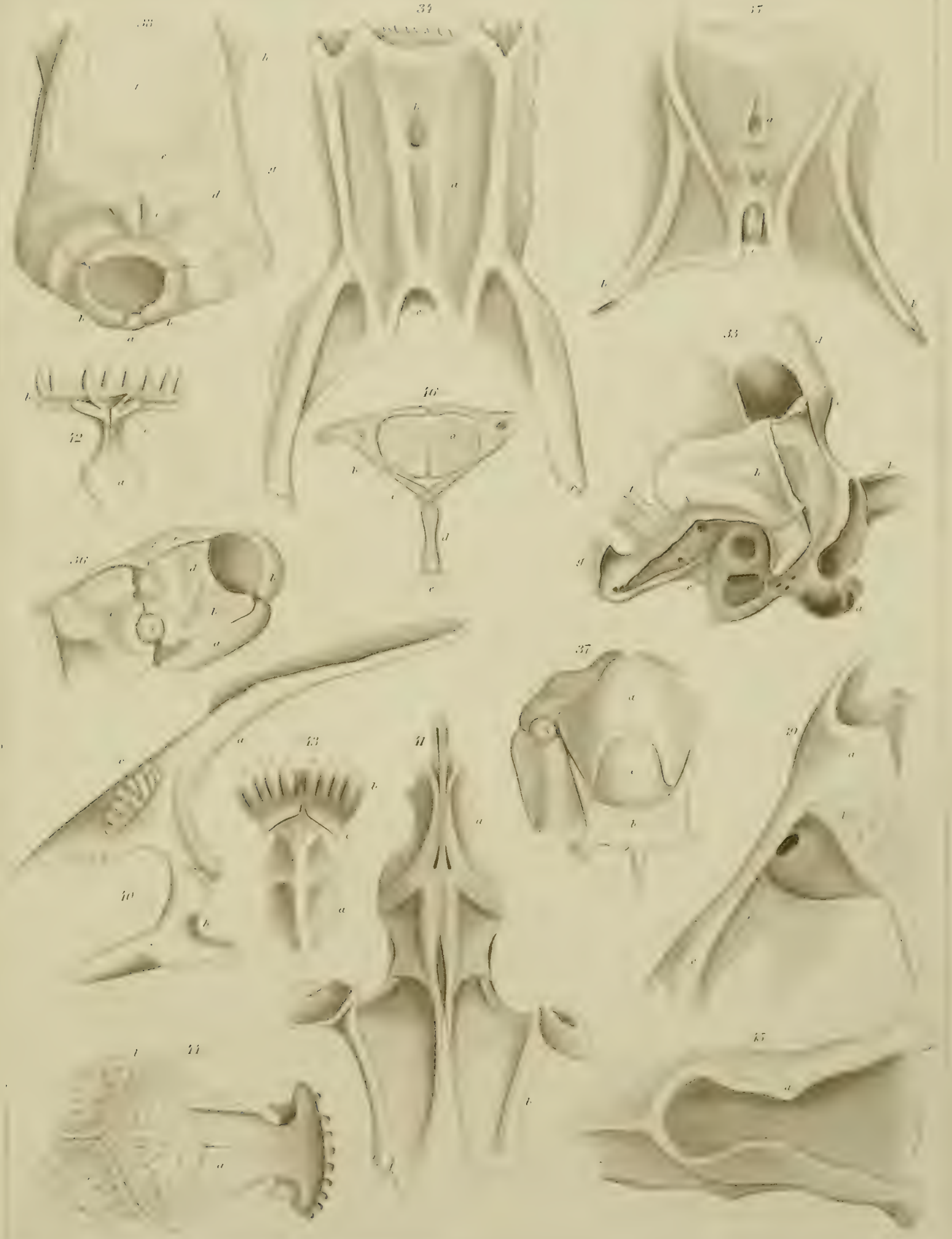




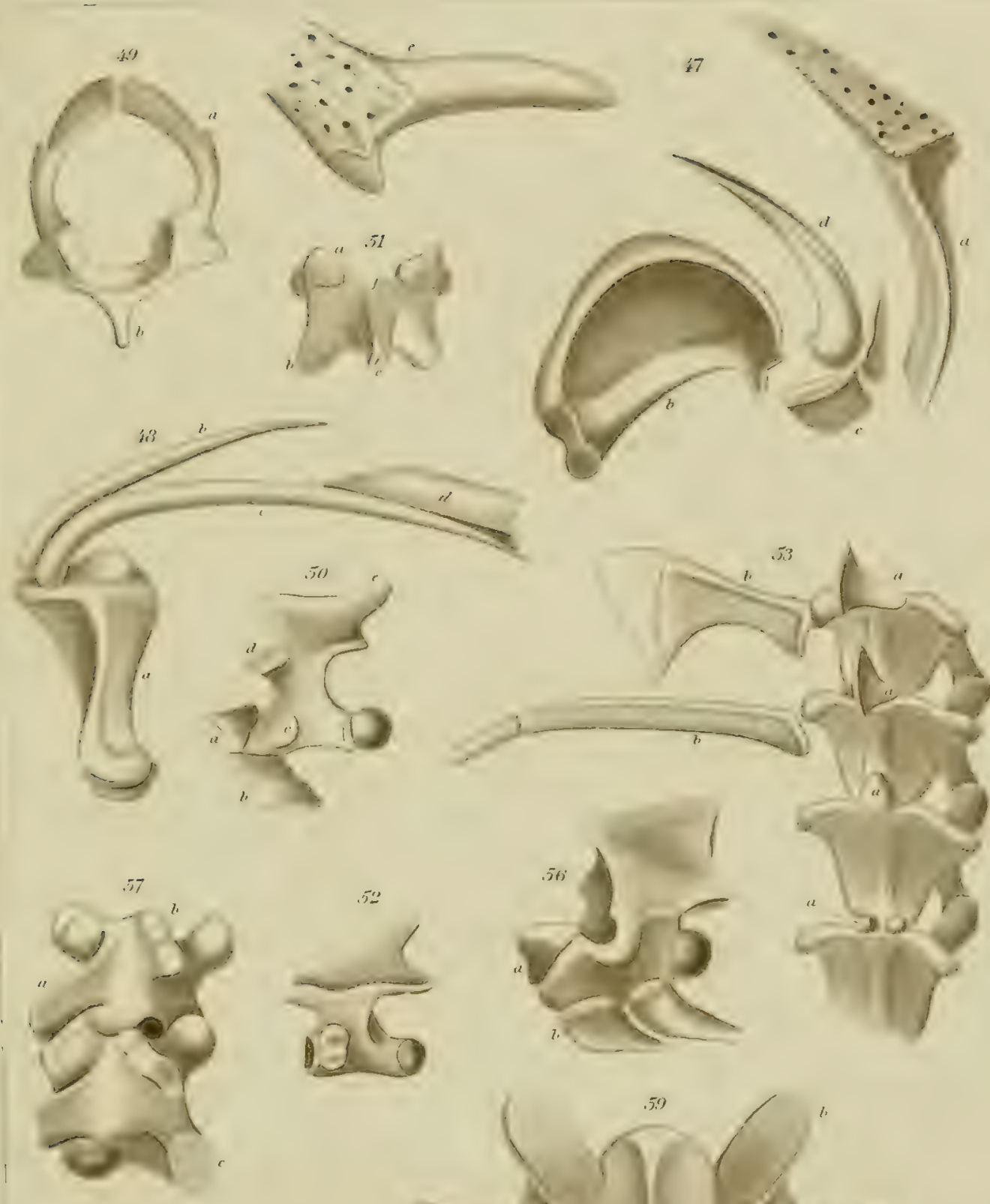


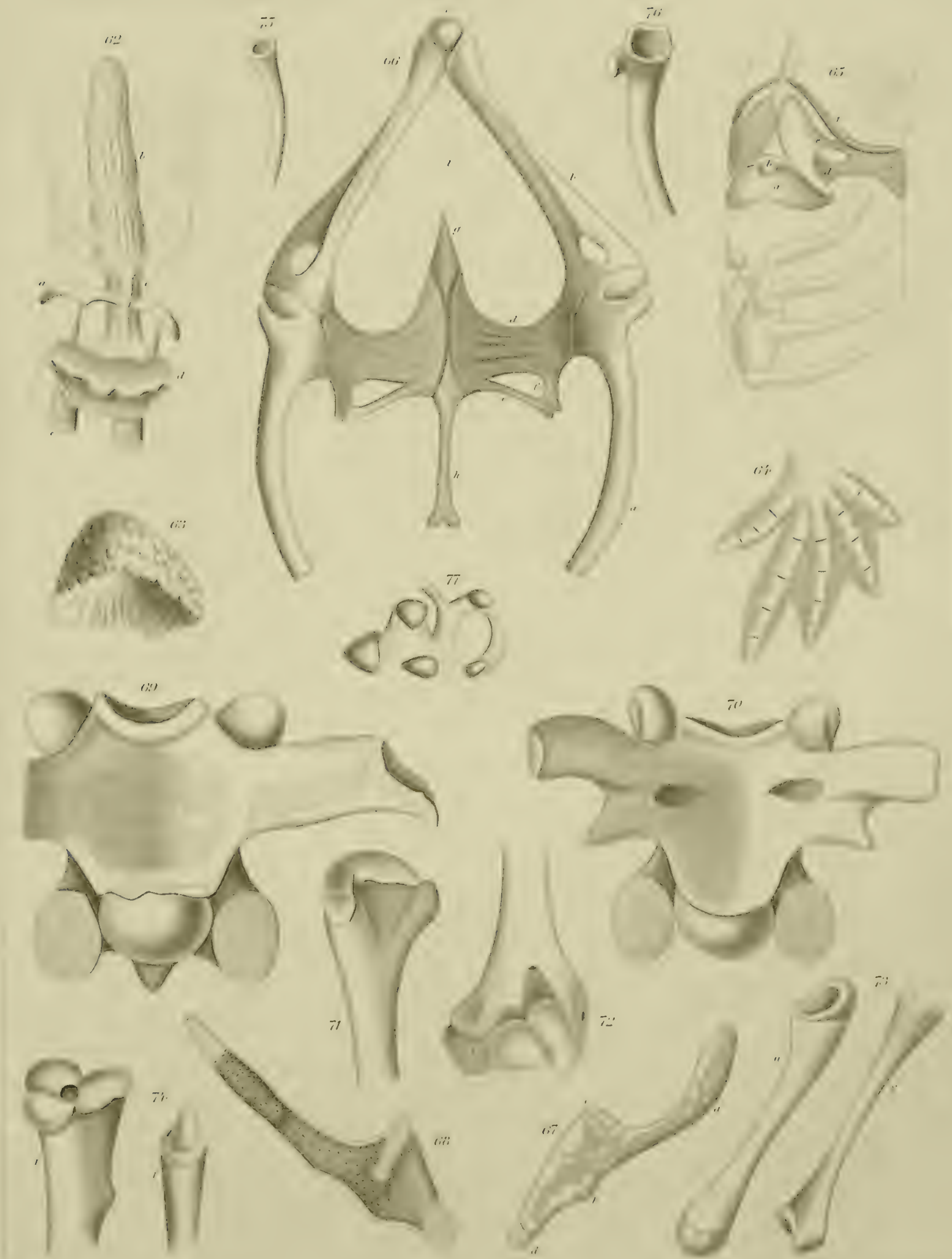


\section{.}



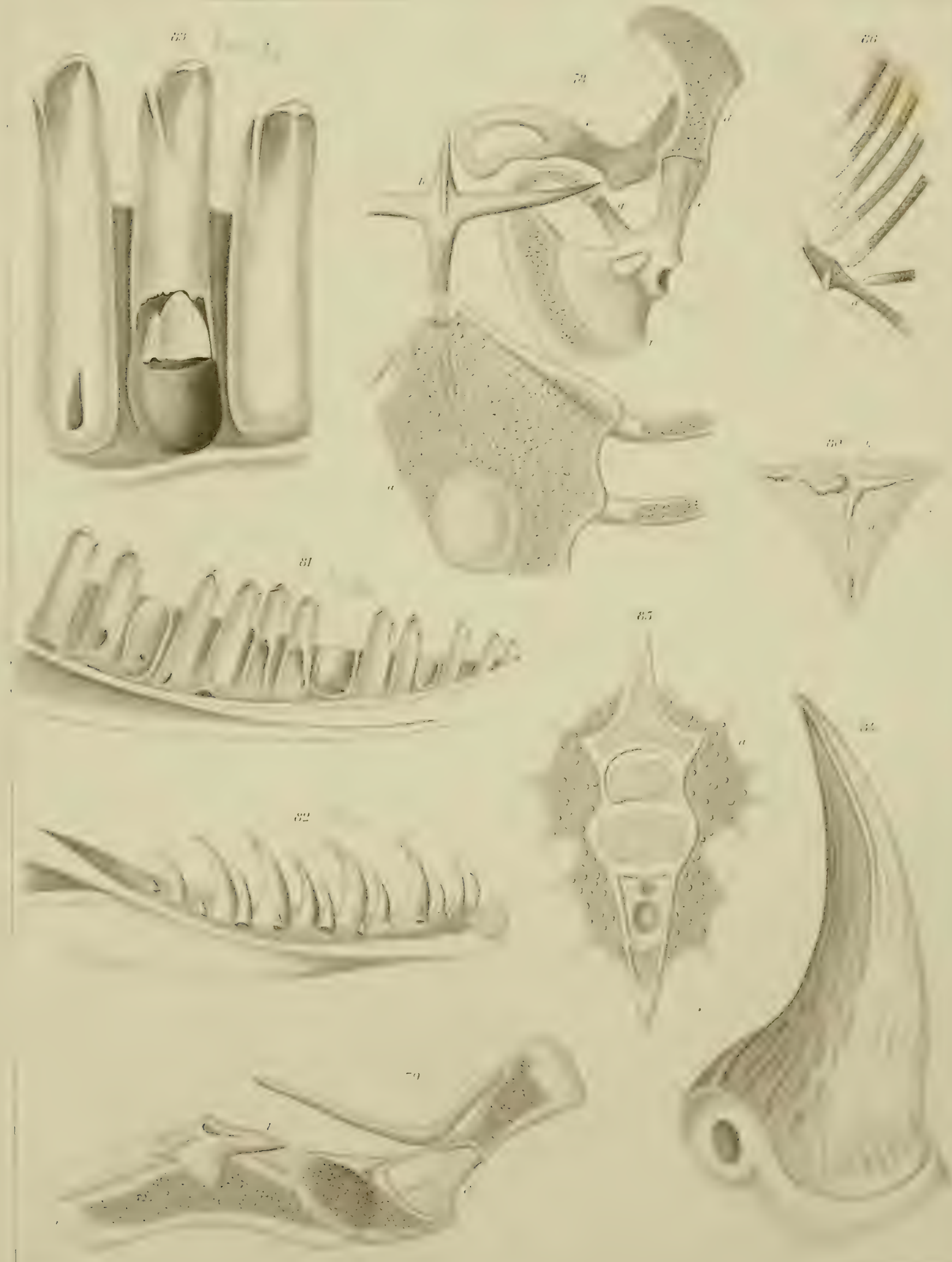
- 
(1911)
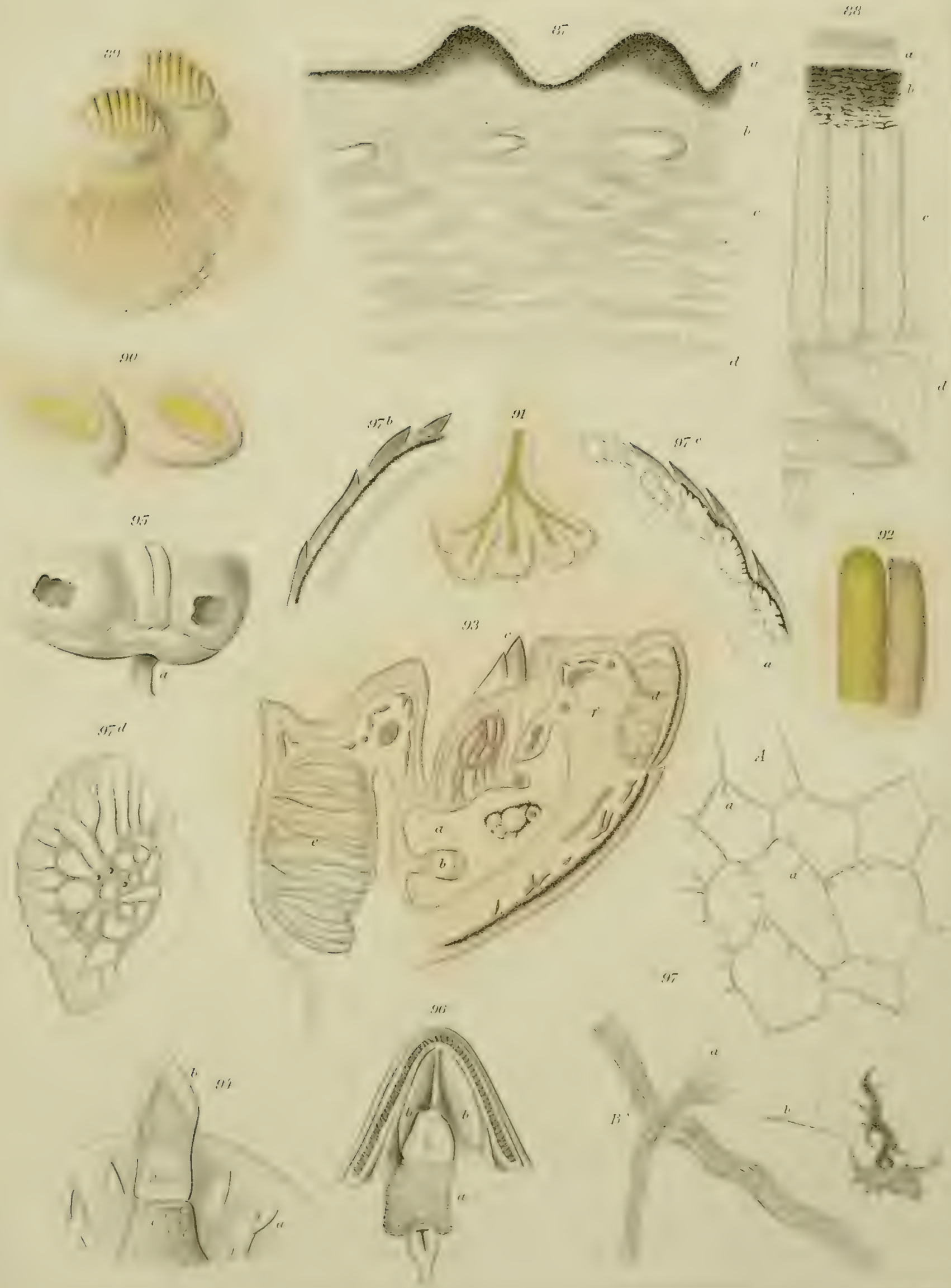



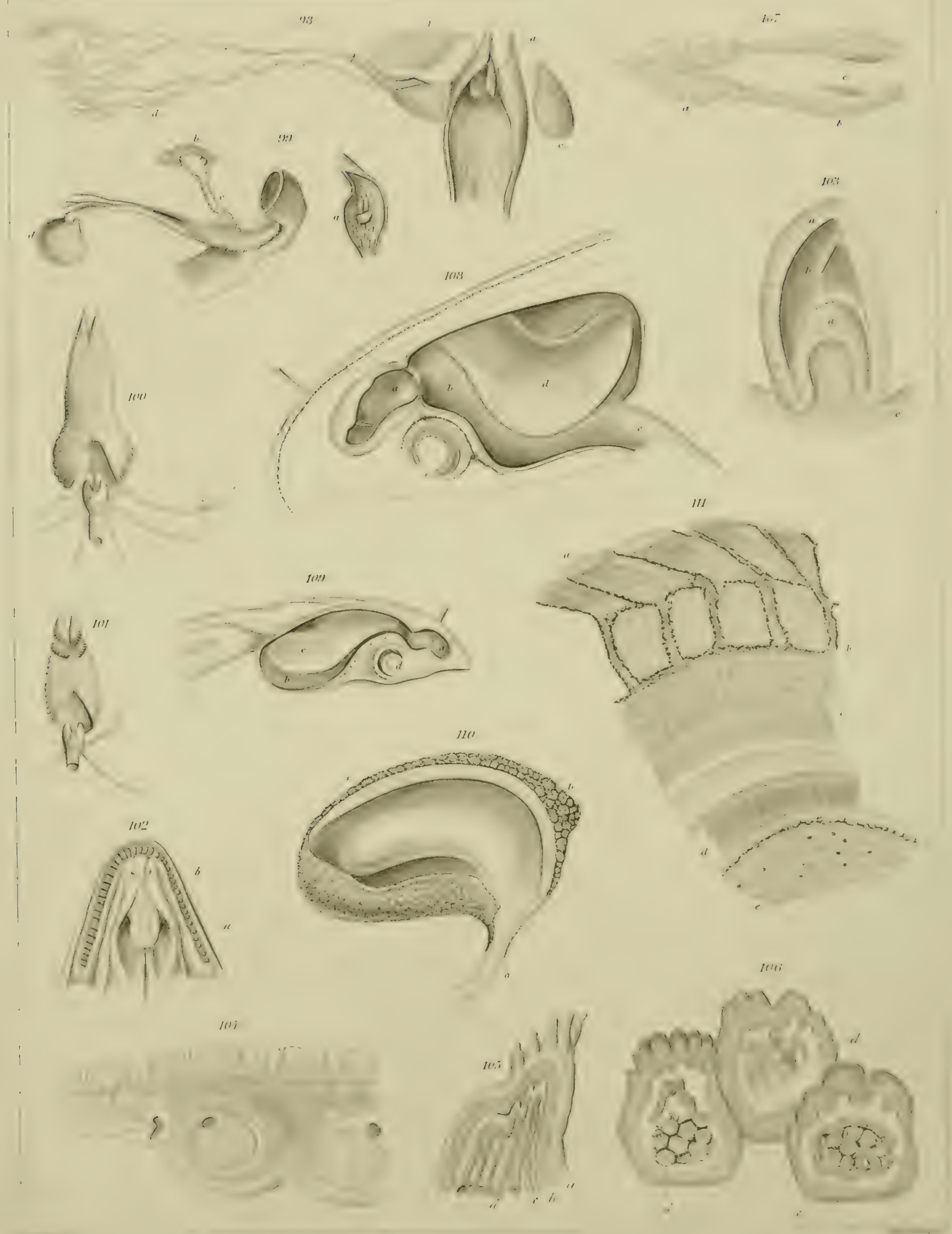





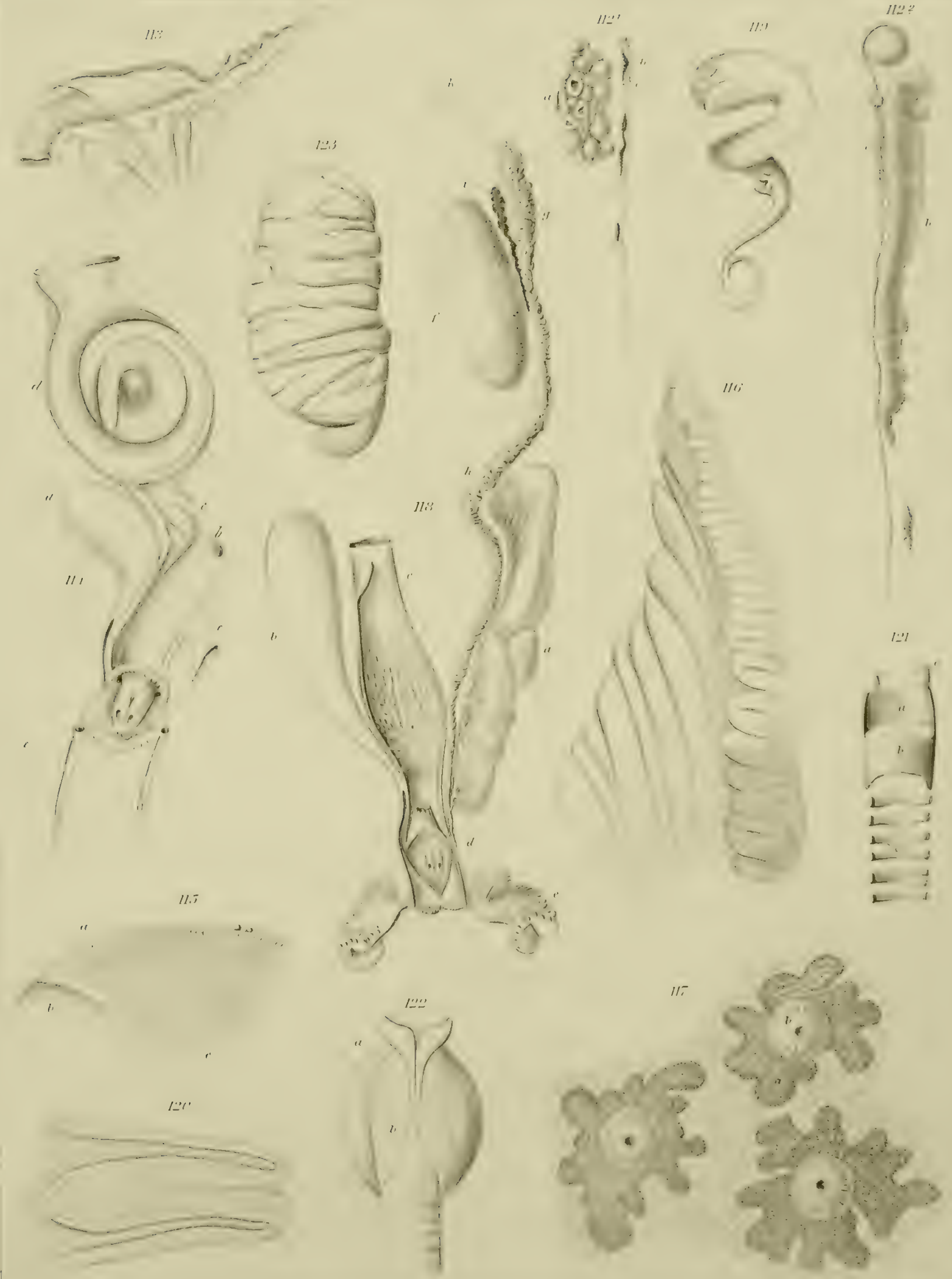




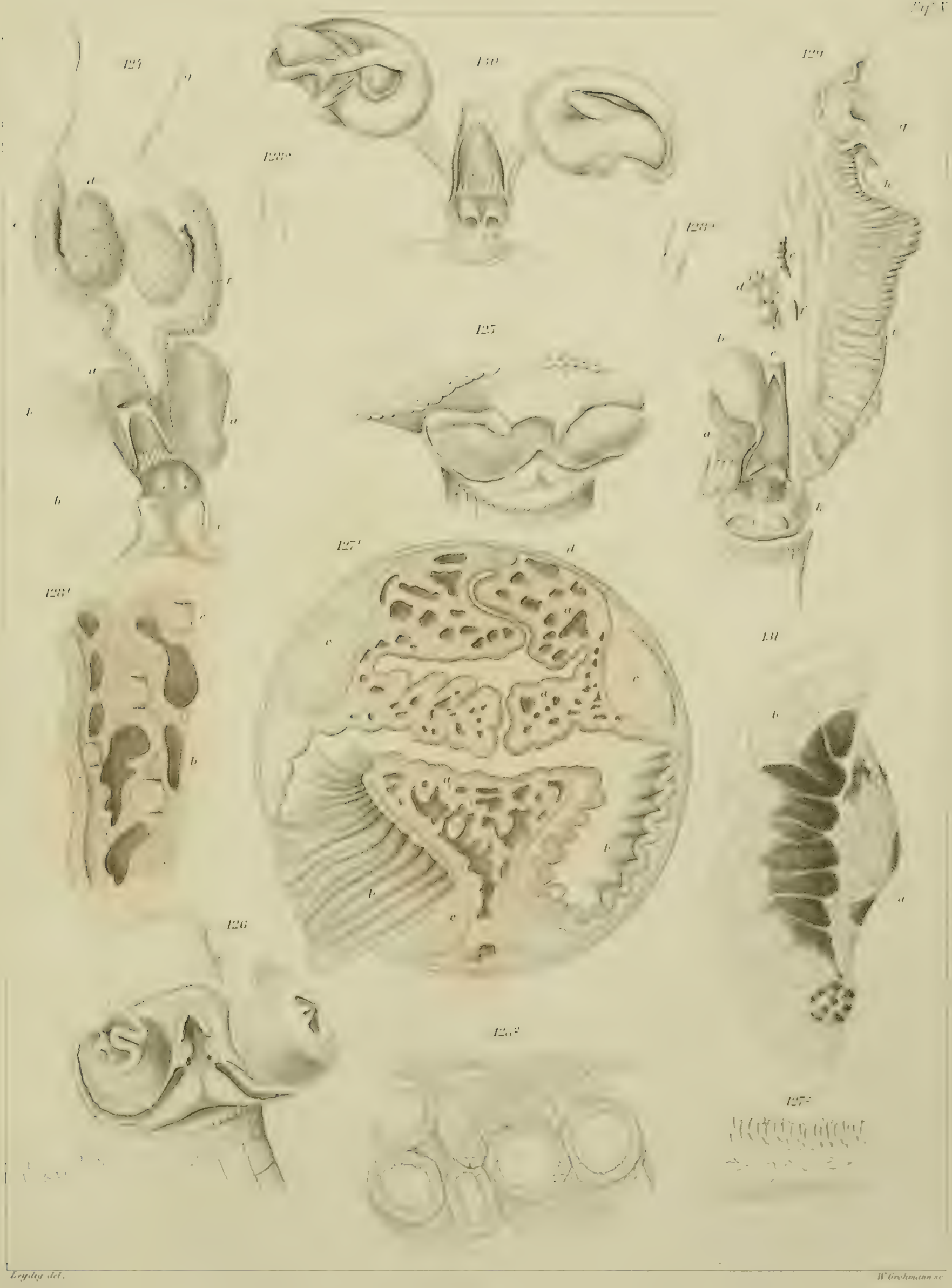




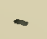




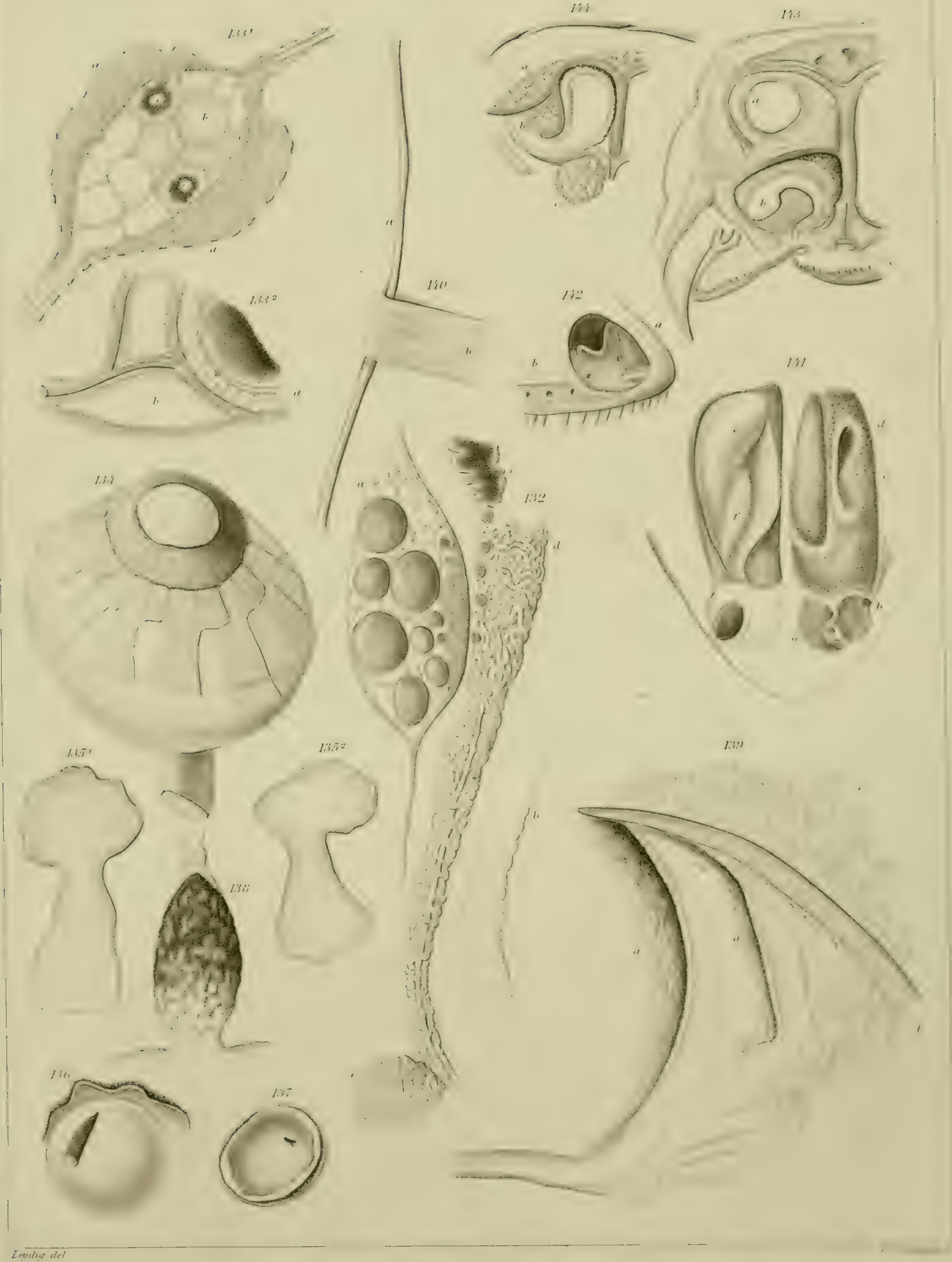



,

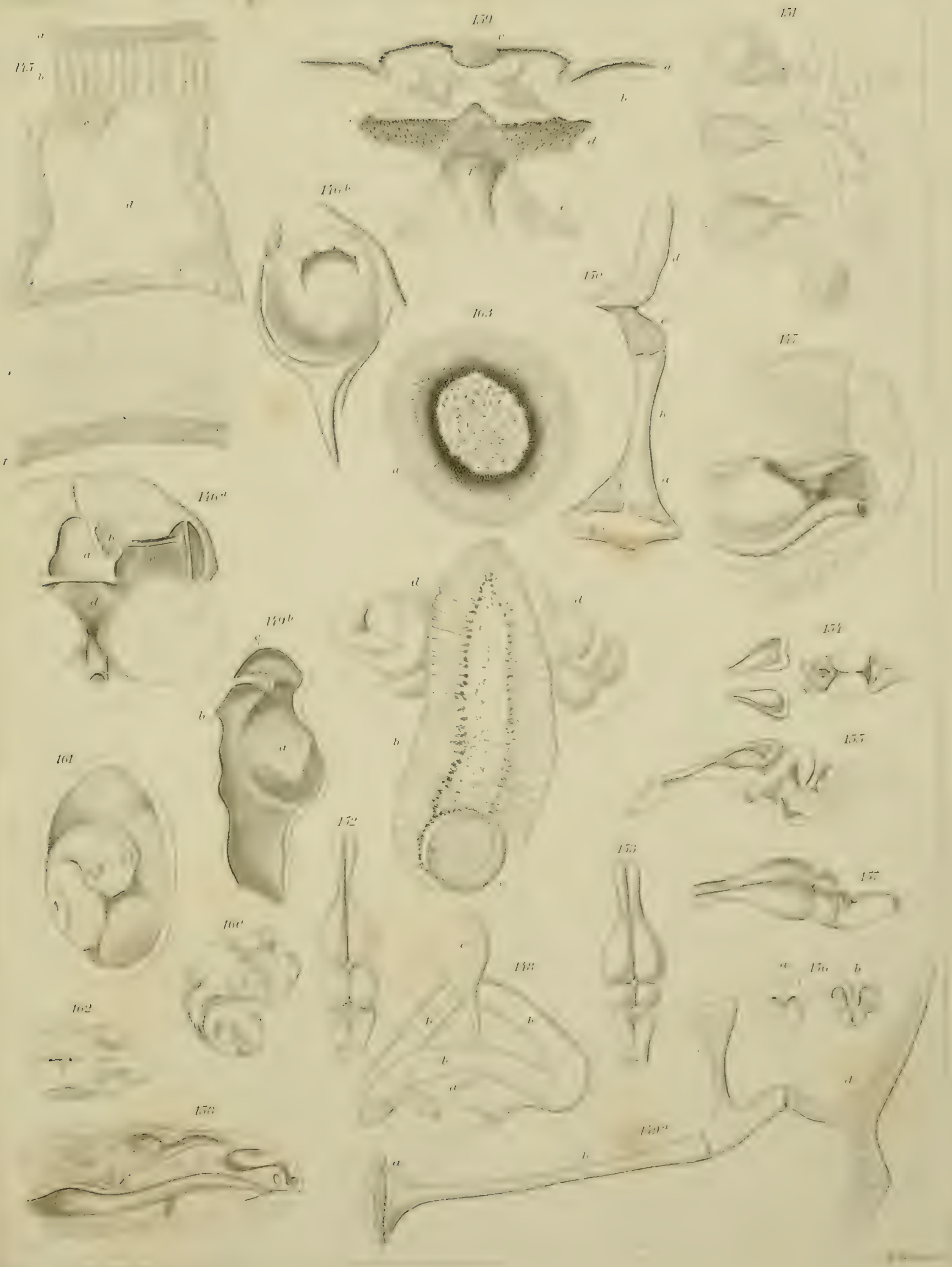



$-$

$+$ 


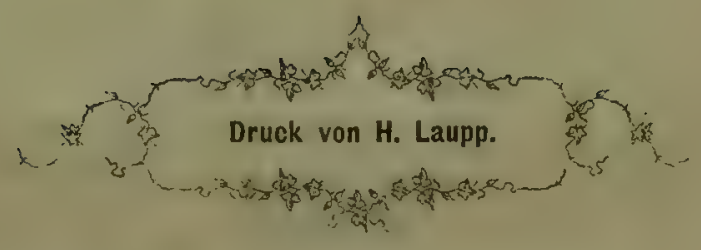





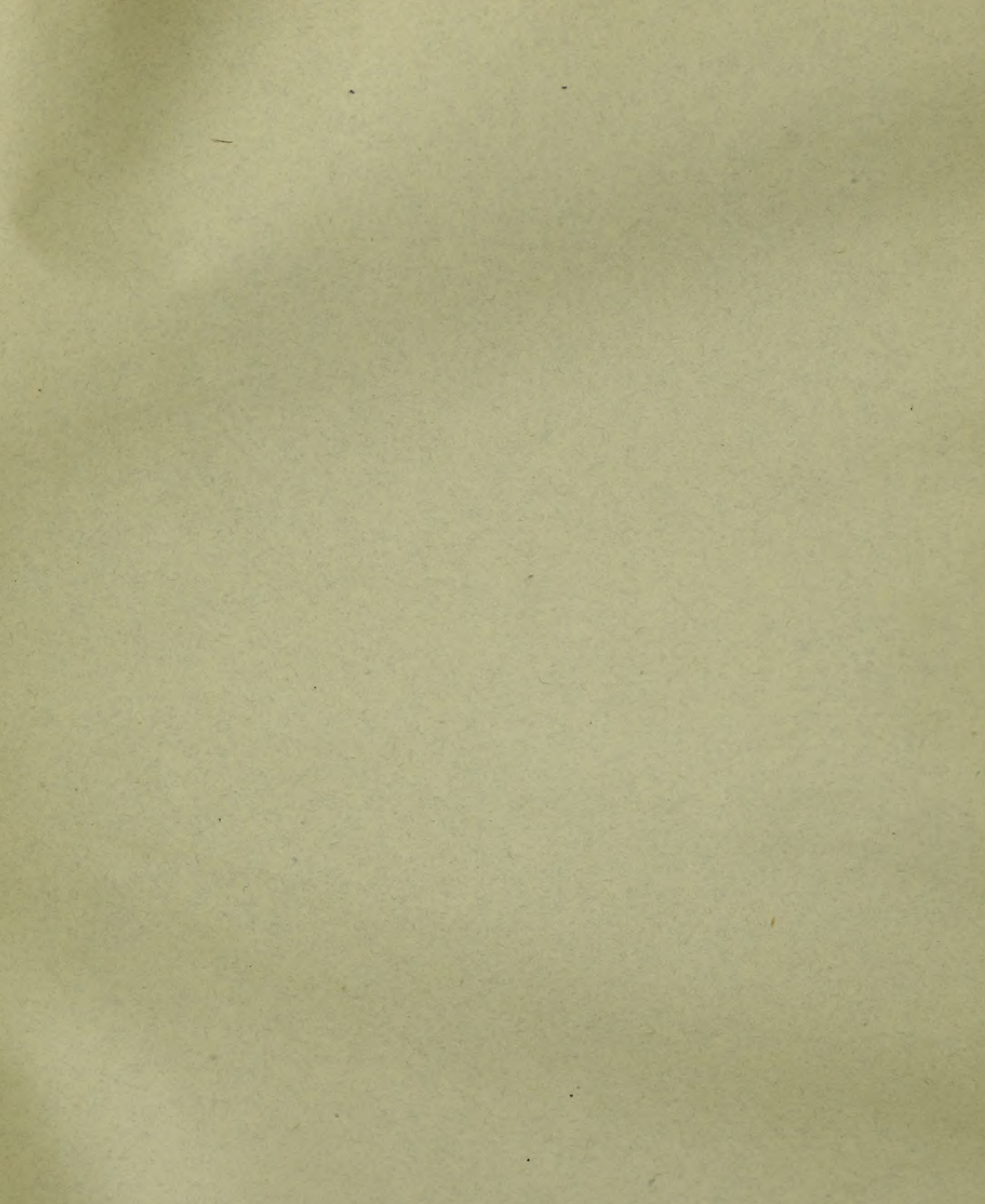





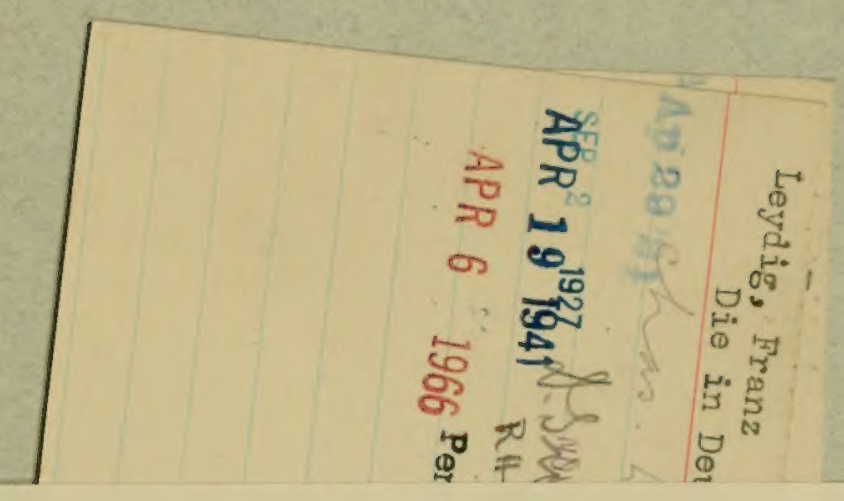


